57
677
.$M 3$ 
CD.

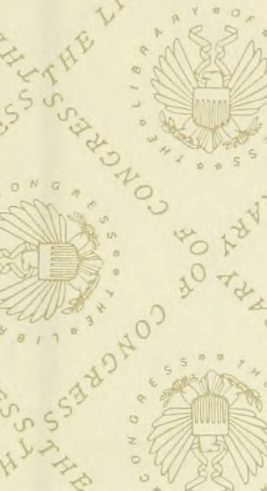

$(1)=$
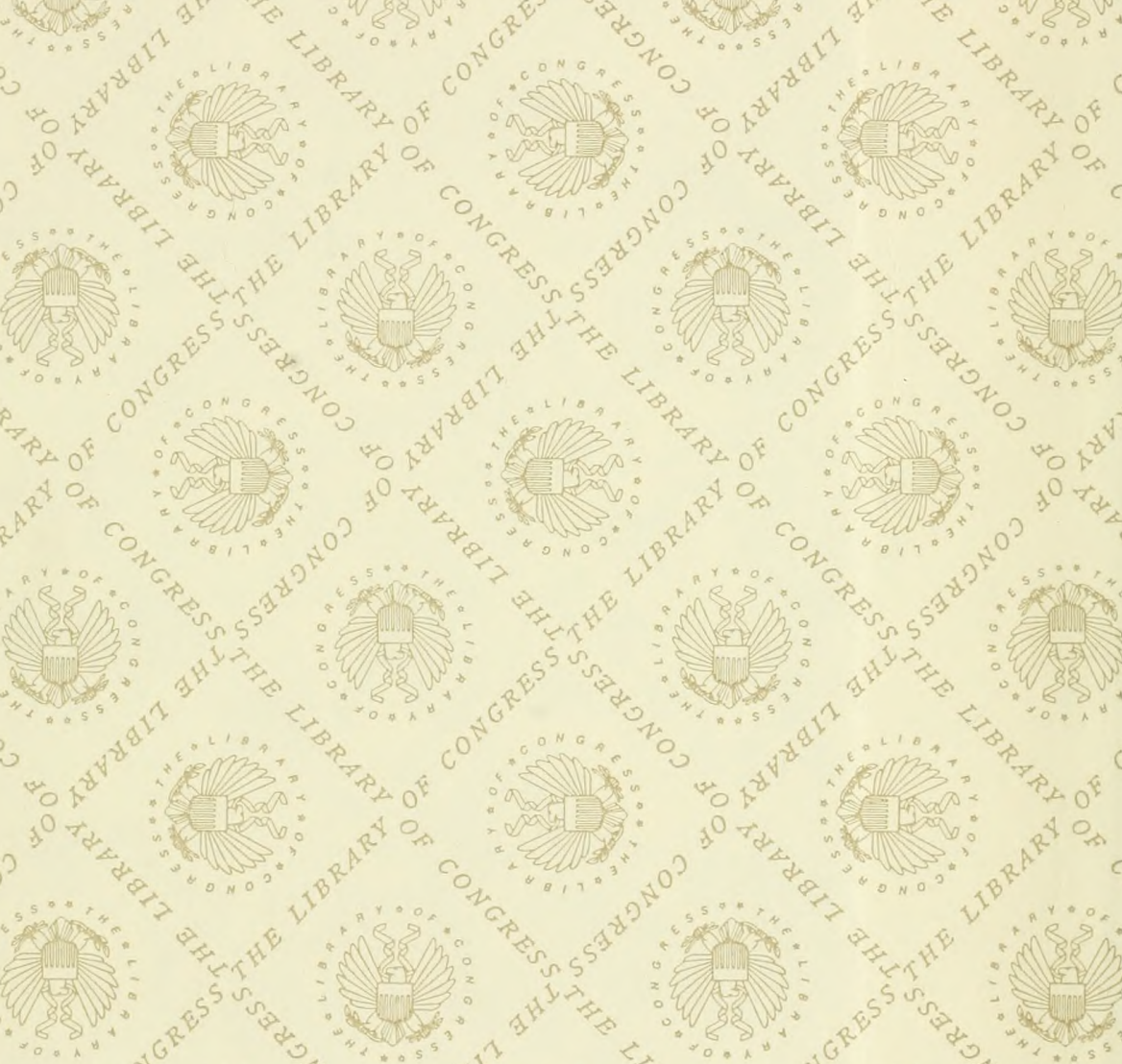

(a)

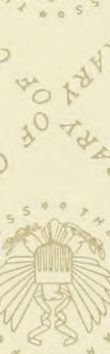

(1)

(1)
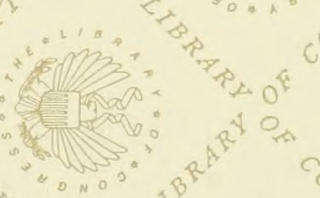
$a^{2}$

(15)

0

(4)

(1)

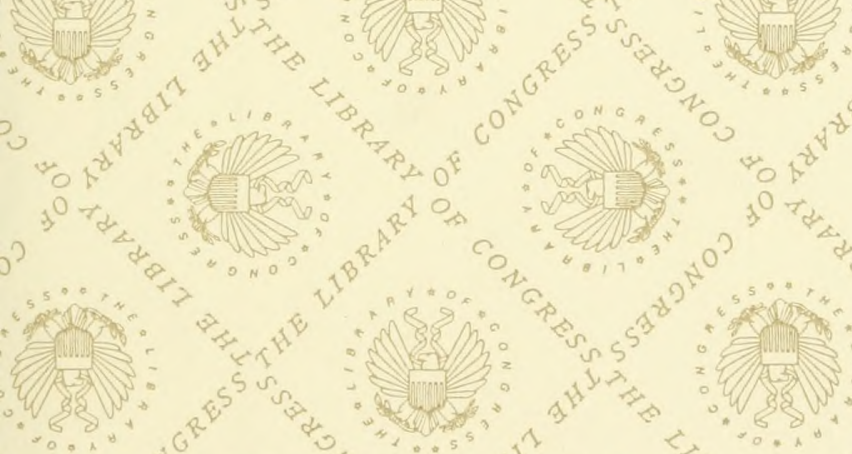

a
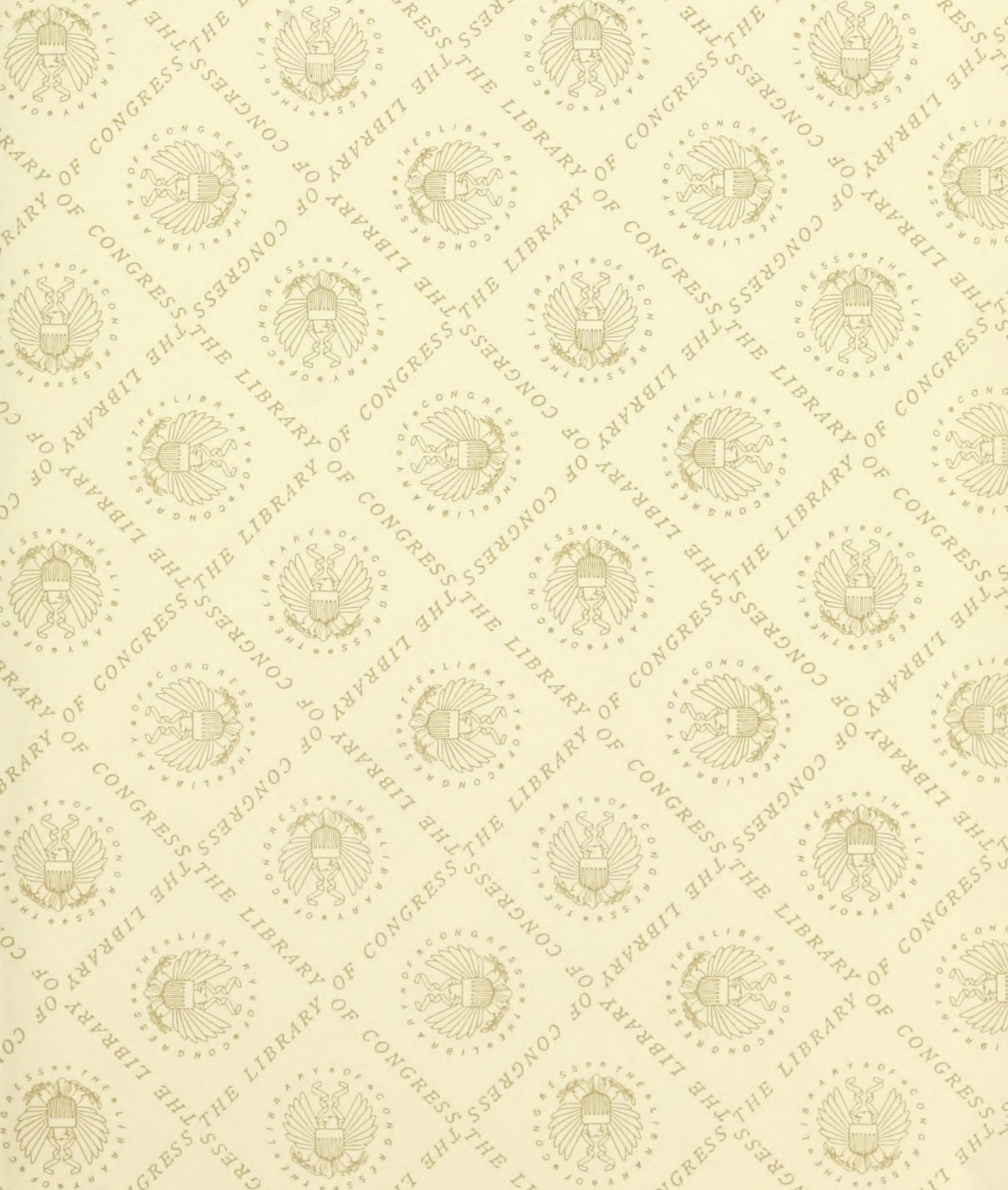




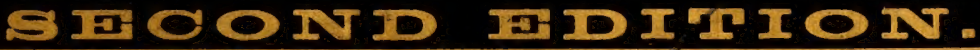

\section{CHARLES V. MAPES'}

(B. M. WhitLOCK, SPECIAL PARTNER) 35

(FOR 1861)

OF

\section{AGRIGULTURAL IMPLEMENTS.}

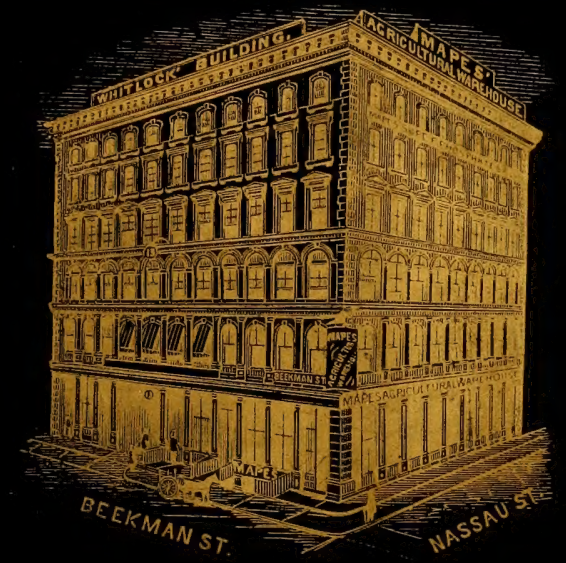

MAPES? AGRICULTURAL WAREHOUSE,

126 \& 123 NASSAU and 11 BEEKMAN STREDTS, NEW YORK.

Manufacturer and Dealer in every variety of improved Agricultural and Horticultural Implements and Machines, ete.

Garden, Field, and Flower Seeds, IN BULK AND IN PAPERS.

PES' NITROGENIZED SUPER.PHOSPHATTE OF LIME. Libiral Arrangements made with Dealers.

PERUVIAN GUANO, AND OTHER FERTILIZERS. 



$$
1902 \%
$$




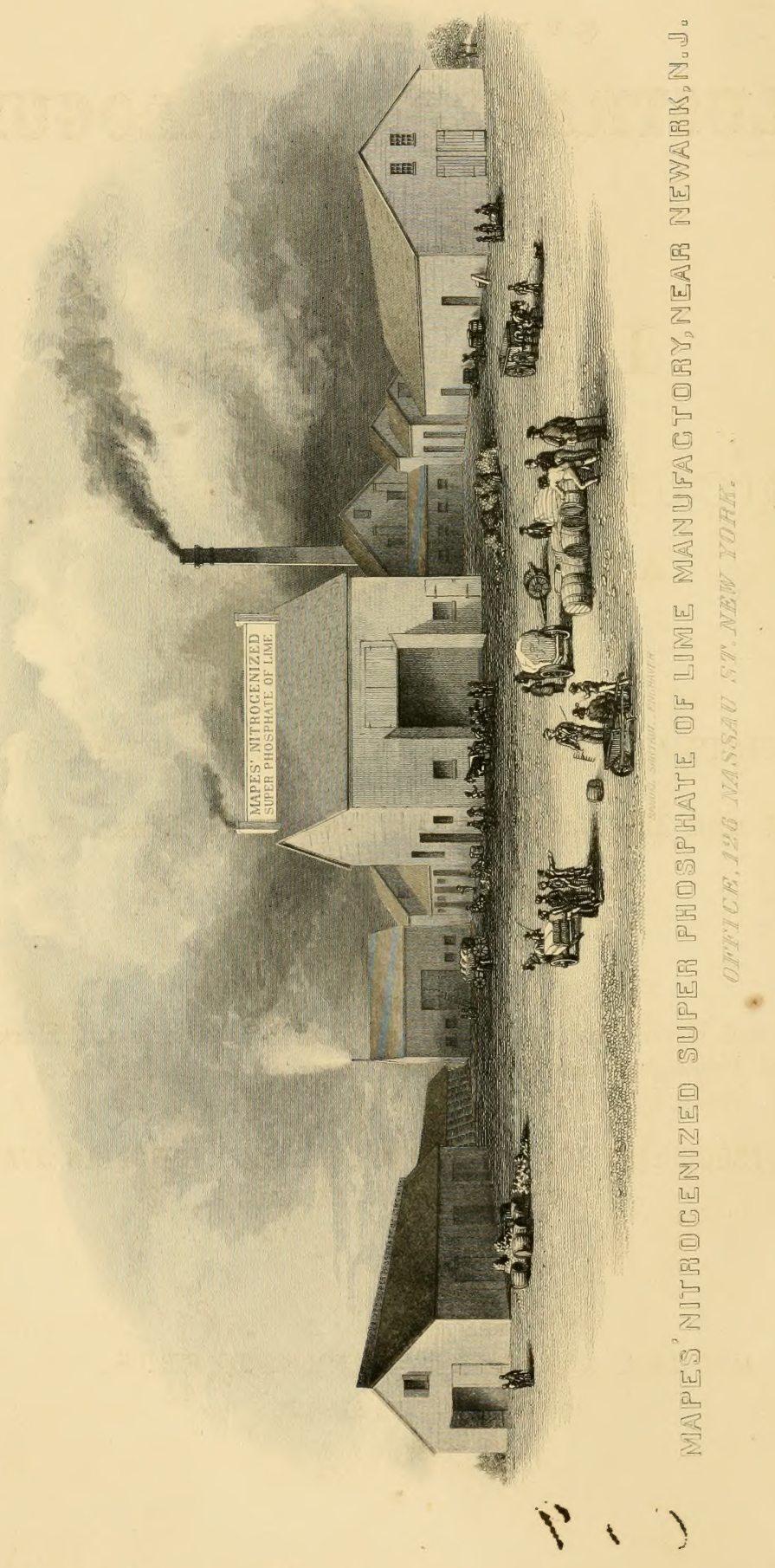




\section{CHARLES V. MAPES'}

(B. M. WHTLOCK, SPECIAL PARTNER)

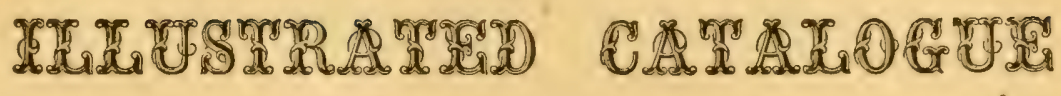

(FOR 1861)

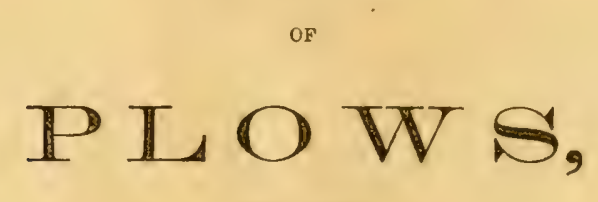

A.ND OTHER

AGRICULTURAL IMPLEMENTS

A N D M A CHINES,

FOR SALE AT

M A PES'

AGRICULTURAL IMPLEMENT AND SEED WAREHOUSE,

126 and 128 Nassau Street, and 11 Beekman St.,

NEW YORK, N. Y.

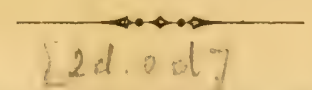

Wholesale and Retail Dealer in every variety of Agricultural and Horticultural Implements and Machines, Garden, Field, and Flower

Seeds, Fruit and Ornamental Trees, Vines, \&c., \&c.

MAPES' NITROGENIZED SUPERPHOSPHATE OF LIME, PERUVIAN GUANO, AND OTHER FERTLIZERS.

NEW YORK:

M'CREA \& MILLER, STEREOTYPERS, 15 VANDEWATER STREET, 1861. 


\section{COPIES OF THIS CAT̃ALOGUE WILL BE FURNISHED GRATIS, AT MY OFFICE.}

Entered according to Act of Congress, in the year 1861.

\section{AGRICULTURAT ADVICE.}

The proprietors have made an arrangement with Prof. J ${ }_{\triangle \mathrm{MrES}} \mathrm{J}$. MAPES, Consulting Agriculturist, to attend as their office each day, from 11 to 1 o'clock, for the purpose of advising farmers, without charge, as to all questions connected. with Agriculture, Horticulture, \&c. 


\section{ADVERTISEMENT.}

In offering this Price List to his friends and customers, th: proprietor begs to tender his thanks for past patronage, the increase of which has been so satisfactory as to command his earnest efforts to meet its requirements, and in consequence, he has extended his facilities, both as manufacturer, and as agent for manufacturing establishments, to a great extent. For several manufacturing houses in the East, and elsewhere, he has the exclusive agency; among these is the large establishment of Mr. H. WATERS, for the manufacture of Scythes, at Northbridge, Massachusetts; also, for Messrs. Bacheller \& Sons' Hay and Manure Forks; Whitney's Patent Plowaran; Lashes' Spring Beam Plow; Salsbury's Brick and Tile Machine, etc., etc.

In the Manure department, they have the sole agency of Mapes' SuperPhosphate of Lime, and are ready to supply all other Fertilizers of merit at the lowest prices.

The Seed department is superintended by an experienced Seedsman, and most of the Seeds sold in this establishment are raised on the farm of the editor of the Working Farmer. Those kinds which cannot be perfected in this country, are imported from the most responsible and reliable sources in Europe.

The Nursery and Plant department is supplied from a Nursery and Garden connected with this establishment, and under the surveillance of its proprietor.

Messrs. L. H. Gibbs, J. W. Parkinson, and others, have been engaged for the planning and improving of machinery connected with agriculture, and it is hoped soon to be able to present a variety of new machines, connected with the cultivation of cotton, tobacco, sugar, corn, and other crops.

Arrangements have been made with Messrs. Nourse, Mason \& Co., and other large manufacturers of agricultural implements, by which their goods can be furnished at the same prices at which they are sold at their establishments ; and in every department, the proprietor hopes to be able to meet the requirements of his customers.

During the year he has received from the American Institute, and other public institutions, twenty-one premiums for implements of superior qualities, all of which may be seen at his establishment.

Mlustrated and Descriptive Catalogues furnished gratis on application at my office, or by mail upon receipt of stamps sufficient to pre-pay postage, 10 cents. 


\section{A P E S}

AGRICULTURAL IMPLEMENT

A N D

\section{SEED WAREHOUSE,}

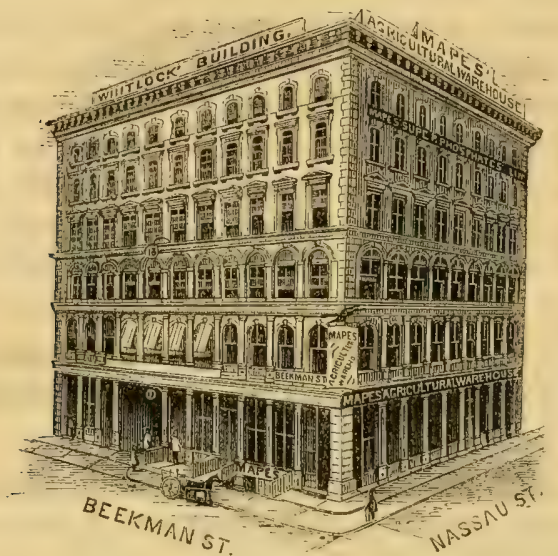

126 and 128 NASSAU, and 11 BEEKMAN STS.,

NEW YORK, N. Y.

EVERY VARIETY OF

AGRICULTURAL. IMPLEMENTS \& MACHINERT,

SEEDS AND FERTILIZERS,

G U A N O,

MAPES' NITROGENIZED--

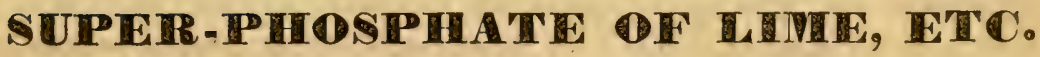




\section{NEW YORK, JAN'Y 1st, 1861.}

\section{EAGLE PLOWS.}

\begin{tabular}{|c|c|c|c|c|c|}
\hline KINDS. & NOS. & Plain. & Cutter & $\left|\begin{array}{c}\text { Wheel } \\
\text { and } \\
\text { Cutter }\end{array}\right|$ & $\begin{array}{l}\text { D. Rod } \\
\text { W. and } \\
\text { Cutter }\end{array}$ \\
\hline $\begin{array}{l}\text { Light Horse, } \\
\text { Light Horse, } \\
\text { Medium Horse, } \\
\text { Small Horse, } \\
\text { Medium Horse, } \\
\text { One Horse, } \\
\text { Two Horse, } \\
\text { Davis Cotton, } \\
\text { Davis Cotton, } \\
\text { Rice, Trenching } \\
\text { One Horse, } \\
\text { One Horse, } \\
\text { Two Horse, } \\
\text { Two Horse, }\end{array}$ & $\begin{array}{l}14, \\
14 \frac{1}{2}, \\
15 \\
\text { A } 1, \\
\text { A } 2, \\
1 \text { B, } \\
2 \text { B, } \\
6 \text { in. } \\
7 \text { in. } \\
\text { P. } 19, \\
\text { P. } 191 \\
\text { P. 20. } \\
\text { P. 21, }\end{array}$ & $\begin{array}{|ll|}3 & 25 \\
3 & 75 \\
4 & 50 \\
3 & 25 \\
4 & 50 \\
5 & 50 \\
7 & 00 \\
3 & 25 \\
3 & 50 \\
6 & 00 \\
5 & 00 \\
6 & 00 \\
7 & 00 \\
8 & 00\end{array}$ & \begin{tabular}{|l|l} 
\\
\\
6 & 50 \\
825 \\
\\
\\
\\
\\
850 \\
950
\end{tabular} & $\begin{array}{r}975 \\
1075\end{array}$ & \\
\hline
\end{tabular}

\section{IMPROVED EAGLE PLOWS.}

One Horse, . A

One Horse, : 0

Sod Plow, . 1,

Sod Plow,

Light Sod,

Light Sod,

Large Sod,

Large Sod,

Heavy,

Light Sod,

Medium Sward, B,

Medium Sward, C,

Medium Coult. D

Left Hand, . 46,

Left Hand, : 47,

Eagle, 20, with meadow fixturescomelete, 18

EACLE SELF-SHARPENERS.

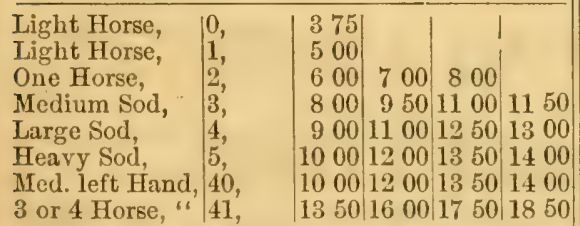

DOUBLE-MOULD PLOWS.

$\left.\begin{array}{l|l|r}\hline \text { Ridging, : } & 1 \frac{1}{4}, & 50 \\ \text { Ridging, : } & 500 \\ \text { Ridging, : } & 2, & 650 \\ \text { Ridging, : } & 4, & 800 \\ \text { Sugar Cane, } & 3, & 800 \\ \text { Sugar Cane, } & 4, & 1200 \\ \text { Sugar Cane, } & 16, & 00\end{array}\right\}$ Fluke, wro't. $\mid$

\section{MAPES' LIFTING SUB-SOIL PLOWS,}

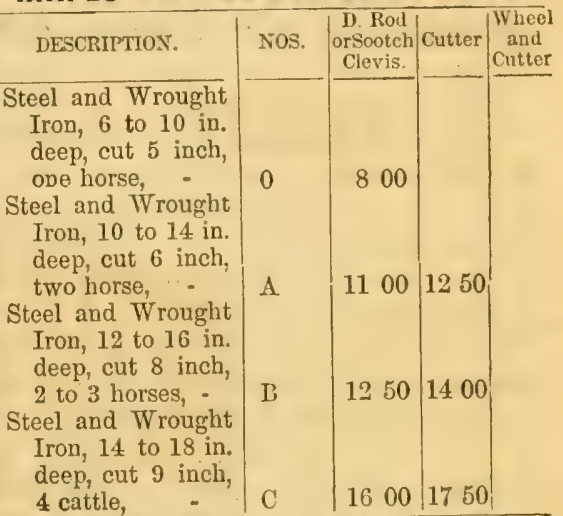

\section{CAST SUR-SOIL PLOWS.}

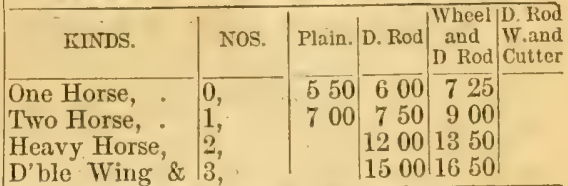

\section{SIDE-HILL PLOWS.}

\begin{tabular}{|c|c|c|c|c|c|}
\hline & & & Cutter & $\left|\begin{array}{c}\text { Wheel } \\
\text { and } \\
\text { Cutter }\end{array}\right|$ & \\
\hline $\begin{array}{l}\text { Light Horse, } \\
\text { One Horse, } \\
\text { Two Horse, } \\
\text { Sod, } \\
\text { Sod, } \\
\text { Large Sod, } \\
\text { Heavy Road, }\end{array}$ & $\begin{array}{l}0 \\
00 \\
\text { B } 1 \\
\text { A } 1 \frac{1}{2}, \\
\text { A } 2, \\
\text { A } 3, \\
\text { A } 4\end{array}$ & $\begin{array}{rl}5 & 00 \\
7 & 00 \\
800 \\
9 & 00 \\
10 & 00 \\
12 & 00 \\
14 & 00\end{array}$ & $\mid$\begin{tabular}{rr|} 
& \\
9 & 25 \\
10 & 50 \\
11 & 50 \\
13 & 50 \\
$D$. & Rod \\
15 & 00
\end{tabular} & 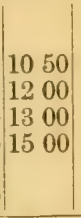 & $\begin{array}{ll}11 & 00 \\
13 & 00 \\
14 & 00 \\
16 & 00\end{array}$ \\
\hline
\end{tabular}

\section{SIDE-HILL PLOWS. (SIVIVEL.)}

\begin{tabular}{|c|c|c|c|c|}
\hline DESCRIPTION & Nos. & $\begin{array}{l}\text { 1). Roul } \\
\text { orScotch } \\
\text { Clevis. }\end{array}$ & Cutter & $\begin{array}{l}\text { Wheel } \\
\text { and } \\
\text { Cutter }\end{array}$ \\
\hline $\begin{array}{l}\text { Sod, Furrows } 6 \text { in., } \\
\text { deep, } 11 \text { to } 12 \text { in. } \\
\text { wide, } 2 \text { to } 3 \text { horses }\end{array}$ & No. 83 , & 1050 & 1200 & 1350 \\
\hline $\begin{array}{l}\text { Sod; li urrows } 7 \text { to } 9 \\
\text { in. deep, } 12 \text { to } 14 \\
\text { in. wide. } 3 \text { to } 4\end{array}$ & & & & 1000 \\
\hline $\begin{array}{l}\text { m. Wiae, } \\
\text { horses, - } \quad \text { - }\end{array}$ & No. 84, & 1100 & 1250 & 1400 \\
\hline $\begin{array}{l}\text { Stubble, Furrows } 6 \\
\text { to } 9 \text { in. deep, } 12 \\
\text { to } 14 \text { in. wide, } 2 \\
\text { horses, - }\end{array}$ & No. 82, & 900 & 1050 & 1200 \\
\hline $\begin{array}{l}\text { Stubble, Furrows } 8 \\
\text { to } 10 \text { in. deep, } 12 \\
\text { to } 14 \text { in. wide, } 3 \\
\text { to } 4 \text { horses, }\end{array}$ & No. 8 & 1100 & 1250 & 1300 \\
\hline
\end{tabular}




\section{IMPROVED DEEP-TILIING PLOWS-CAST IRON.}

\section{DESCRIPTION.}

Old Ground, Stuble, Furrows 4 to 6 inches deep, 8 to 10 in. wide, one horse,

old Ground, Stubble, Furrows 6 to 8 in. deep, 9 to 11

in. wide, small, two horse, - in. deep, 9 to 11 in. wide, Steel Share, two horse,
Ground, Stubble, Furrows, suitable for Western

old Ground, Stubble, Furrows, suitable for Western
and California soils, -

old Ground, Stubble, Furrows 6 to 9 in. deep, 9 to 12

in. wide, medium, two horse, 10 in. deep, 11 to 13 in. wide, large, two to three horses,

old Ground, Stubble, Furrows 9 to 11 in. deep, 12 to 14 in. wide, large, two to three horses,

old Ground, Stubble, Furrows 8 to $12 \mathrm{in}$. deep, 12 to $15 \mathrm{in}$. wide, large, three to four horses,

old Ground, Stubble, Furrows 8 to 12 in. deep, 14 to $18 \mathrm{in}$. wide, 3 to 4 horses, is adapted to burying of broom corn,

\section{GREENSWARD PLOWS.}

Lap Furrow, Sod Lap Furrows 6 to 7 in. deep, 11 to 12 in. wide, long handles, two horse,

Lap Furrow, Sod Lap Furrows 6 to 8 in. deep, 11 to $13 \mathrm{in}$. wide, long handles, two horse,

Lap Furrow, Sod, Furrows 6 to 7 in. deep, 11 to 12 in. wide, long handles, medium, two horse,

Lap Furrow, Sod, Furrows 7 in. deep, 12 in. wide, for stiff clay sod, two to three horses,

Lap Furrow, Sod, Furrows 8 to $10 \mathrm{in}$. deep, 12 to 14 in. wide, long handles, three to four horses,

Flat Furrow, Sod, Furrows 7 to 8 in. deep, 11 to 12 in. wide, medium, two horse,

Flat Furrow, Sod, Furrows 6 to 7 in. deep, 12 to 13 in. wide, medium, two horse,

Flat Furrow, Sod, Furrows 8 to $9 \mathrm{in}$. deep, 12 to 14 in. wide, large, three horse, - $\overline{10}$ in. deep, 13 to 15 in. wide, 3 to 4 horse, - - -

Flat Furrow, Sod, Furrows 9 to 10 in. deep, 13 to 15 in. wide, 3 to 4 horses,

Flat Furrows, Sod, Furrows 10 to 12 in. deep, 16 to 18 inches wide, extra heavy, four horses,

Flat Furrow, Sod, Furrows 10 to 12 in. deep, 16 to 18 inches wide, extra heavy, four horses,

Flat Furrow, Sod, Furrows 10 to 12 in. deep, 18 to 20 in. wide, Steel Share and Coulter, with Meadow Fixtures complete,

\section{DOUBLE PLOWS.}

Sod and Subsoil, Double Forrows, 7 to 9 in. deep, 10 to 14 in. wide, three to four cattle,

Sod and Subsoil, Double Furrows, 7 to 9 in. deep, 10 to $12 \mathrm{in}$. wide, three to four cattle, - -

Sod and Subsoil, Double Furrows, 10 to $12 \mathrm{in}$. deep, 12 to 13 in wide, four cattle,

Sod and Subsoil Swivel, Double Furrows, 10 to $12 \mathrm{in.}$ deep, 10 to 12 in. wide, four cattle, -

\begin{tabular}{|c|c|c|c|}
\hline NUMBERS. & \begin{tabular}{|c|} 
D. Rod \\
orScotch \\
Clevis.
\end{tabular} & Cutter. & \begin{tabular}{|l} 
Wheel \& \\
Cutter.
\end{tabular} \\
\hline No. 30 , & $\$ 675$ & $\$ 800$ & $\$ 925$ \\
\hline No. 31 , & 750 & 875 & 1000 \\
\hline No. $31 \frac{1}{2}$, & 850 & 975 & 1100 \\
\hline No. $31_{4}^{3}$, & Steel & Share, & $\$ 8.50$. \\
\hline
\end{tabular}

No. 32 ,

No. 33 ,

No. 34 .

No. 35 ,

No. 39 ,

\begin{tabular}{rrr|rr|rr}
8 & 00 & 9 & 25 & 10 & 50 \\
8 & 50 & 10 & 00 & 11 & 25 \\
9 & 00 & 10 & 50 & 11 & 75 \\
9 & 00 & 11 & 00 & 12 & 50 \\
10 & 00 & 11 & 50 & 13 & 00 \\
$\$ 9$ & 00 & $\$ 11$ & 00 & $\$ 12$ & 50
\end{tabular}

No. 1 ,

950

1100

1250

No. 2,

No. 72 ,

No. $72 \frac{1}{2}$,

No. 74 ,

No. $71 \frac{1}{2}$,

No. $73 \frac{1}{2}$,

No. 75 ,

No. 76 ,

No. 76. Coult.

950

1100

1250

\begin{tabular}{ll|ll|l}
9 & 50 & 11 & 00 & 12 \\
50
\end{tabular}

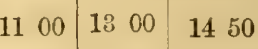

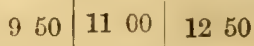

\begin{tabular}{ll|llll}
10 & 00 & 11 & 50 & 13 & 00
\end{tabular}

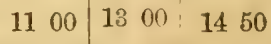

\begin{tabular}{ll|llll}
14 & 00 & 16 & 50 & 18 & 50
\end{tabular}

No. 77.

No. 77. Coult.

1600

1850 :

2050

\begin{tabular}{ll|l}
$18 \quad 50$ & $20 \quad 50$
\end{tabular}

2050

2250

No. 78,

$250 \mathrm{C}$

Wheel

$1200 \quad 1500$

No. 33,

No. 34 ,

No. 35 ,

No. 86.
1500

$\begin{array}{l:ll}15 & 00 & 1600\end{array}$

1700 


\section{PATENT IMPROVED STEEL PLOWS,}

DESCRIPTION.

\section{STUBBLE OR OLD GROUND PLOWS.}

Old Ground, Stubble, Furrows 4 to 6 in. deep, 7 to 9 in. wide'

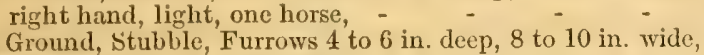

Old Ground, Stubble, Furrows 4 to $6 \mathrm{in}$. deep, 8 to $10 \mathrm{in}$. wide, right hand, light, one horse,
Ground, Stubble, Furrows 4 to 6 in. deep, 9 to $10 \mathrm{in}$. wide, right hand, one horse, 4 to 8 in. decp, 10 to $12 \mathrm{in}$. wide,

Old Ground, Stubble, Furrows 4 to $8 \mathrm{in}$. decp, 10 to $12 \mathrm{in}$. wide,
right hand, light, two horse, -

old Ground, Stubble,. Furrows 5 to $8 \mathrm{in}$. deep, 12 to $14 \mathrm{in.}$ wide, right hand, two to three horses,

old Ground, Stubble, Furrows 5 to $8 \mathrm{in}$. deep, 12 to $14 \mathrm{in}$. wide, right hand, two to three horses,

old Ground, Stubble, Furrows 6 to $9 \mathrm{in}$. deep, 12 to 14 in. wide, narrow cut, right hand, two to three horses, -

old Ground, Stubble, Furrows 6 to $9 \mathrm{in}$. deep, 12 to $14 \mathrm{in.}$ wide, left hand, narrow cut, two to three horses,
Ground, Stubble, Furrows 6 to 10 in. deep, 16 to 18 in. wide, right hand, wide cut, 4 horses, -

old Ground, Stubble, Furrows 6 to 10 in. deep, 16 to 18 in. wide, left hand, wide cut, 4 horses, - - -

old Ground, Stubble, Furrows 5 to $10 \mathrm{in}$. deep, 10 to $12 \mathrm{in.}$ wide, right hand, medium, two horse,

old Ground, Stubble, Furrows 5 to $10 \mathrm{in}$. deep, 12 to $14 \mathrm{in}$. wide, right hand, medium, two horse,

old Ground, Stubble, Furrows 5 to $10 \mathrm{in}$. deep, 10 to $12 \mathrm{in.}$ wide, left hand, medium, two horse, "

Sod, Furrows 6 to $10 \mathrm{in}$. deep, 16 to $18 \mathrm{in}$. wide, 4 horses

\begin{tabular}{|c|c|c|c|}
\hline Nos. & $\begin{array}{c}\text { 1. Rot } \\
\text { orScotch } \\
\text { Clevis. }\end{array}$ & Cutter. & $\begin{array}{c}\text { Whisel } \\
\text { and } \\
\text { Cutter. }\end{array}$ \\
\hline X 00 & $\$ 575$ & & \\
\hline X. 0 & 600 & & \\
\hline$\times 1$ & 800 & $\$ 925$ & $\$ 1050$ \\
\hline $\mathrm{X} 1_{2}^{1}$ & 950 & 1075 & 1200 \\
\hline $\mathrm{X} 4$ & 1300 & 1500 & 1650 \\
\hline$\times 4_{2}^{2}$ & 1300 & 1500 & 1650 \\
\hline$\times 6$ & 1300 & 1500 & 1650 \\
\hline$\times 7$ & 1300 & 1500 & 1650 \\
\hline X 6 & 1400 & 1600 & 1750 \\
\hline X 7 & If 00 & 1600 & 1750 \\
\hline X 8 & 1150 & 1300 & 1450 \\
\hline X 8 & 1200 & 1350 & 1500 \\
\hline $\begin{array}{l}\text { X } 9 \\
\text { X } 6 \frac{1}{3}\end{array}$ & 1150 & 1300 & $\begin{array}{ll}14 & 50 \\
22 & 50\end{array}$ \\
\hline U G 31 & 1500 & 1700 & 1850 \\
\hline $\mathrm{U} \mathrm{G} 4$ & 15 00 & 1700 & 1850 \\
\hline U G 5 & 1500 & 1700 & 1850 \\
\hline W B 2 & 1500 & 1700 & 1850 \\
\hline$x+4$ & & $\begin{array}{l}\text { Wheel } \\
18 \quad 50\end{array}$ & 1950 \\
\hline$\times 6$ & & 2000 & 2100 \\
\hline X 7 & & 1850 & 1050 \\
\hline
\end{tabular}

Prairie, Sod, Furrows 4 to 6 in. dcep, 12 to 14 in. wide, right hand, two to three horses, - - - -

Prairie, Sod, Furrows 4 to 6 in. deep, 14 to 16 in. wide, left hand, two to three horses,

Prairie, Sod, Furrows 4 to 6 in, deep, 14 to 16 in. wide, right hand, two to three horses, - - -

Lap Sod, Lap Furrows 7 in. decp, 10 in. wide, right hand, for stiff clay soil, two to three horses,

\section{DOUBLE PLOWS.}

Sod and Subsoil, Double Furrows, 7 to 9 in. deep, 10 to 12 in. wide, right hand, three to four horses,

Sod and Subsoil, Double Furrows, 8 to 10 in. deep, 12 to $14 \mathrm{in.}$ wide, right hand, four to six horses,

Sod and Subsoil, Double Furrows, 7 to $10 \mathrm{in}$. deep, 11 to $12 \mathrm{in}$. wide, left hand, three to four horses, Peacock Coulter or Circular Cutter, $\$ 2.50$ each.

\section{WESTERN PLOWS.}

Old Ground, Stubble, 4 to 8 in. deep, 12 in. wide, two horse, P 5 Old Ground, Stubhle, 4 to $8 \mathrm{in}$. deep, $14 \mathrm{in}$. wide, 2 to 3 horses, P 6 Old Ground, Stubble, 4 to $8 \mathrm{in}$. deep, 1:2 in. wicle, two horse, of 2 old Ground, Stubble, 4 to $8 \mathrm{in}$. deep, 14 in. wide, 2 to 3 horses, (1 3 old Ground, Stubble, 5 to $10 \mathrm{in}$. deep, $15 \mathrm{in}$. wide, 2 to 3 horses, \& 4 


\section{THE UNIVERSAL PLOW.}

This is a recent invention, for which measures have been taken to secure Letters Patent. The implement embraces various forms and sizes of mould-board, each nicely fitting one common standard and frame-work-thus adapting the plow to a wide variety of soils and modes of culture. Each mould-board is constructed to perform its respective work in a thorough and finished style.

The advantages of having the various mould-boards, needed for the different soils and modes of culture, combined in one general implement, rather than made up separately in several plows, the saving of expense thereby and of storage, are too apparent to need more than the bare mention.

The Universal Plow embraces the following kinds and sizes of mould-boards:

1. For plowing intervale and other smooth, grass-lands, five sizes of mould-board, of long or gentle spiral or twist, viz:

(Mark on Mould-board.)

"Intervale No. 120," flat furrows, 7 to 10 inches deep, 14 to 16 wide.

"Intervale No. 121," flat furrows, 5 to 9 inches deep, 13 to 15 wide.

"Intervale No. 122," flat furrows, 4 to 8 inches deep, 12 to 14 wide.

"Intervale No. 123," flat furrows, 4 to 7 inches deep, 11 to 13 wide.

"Intervale No. 124," flat furrows, 3 to 6 inches deep, 10 to 12 wide.

2. For plowing upland, stony land, old pastures and other grass lands of uneven or rough surface, four sizes of mould-board of short and powerful twist:

(Mark on Mould-board,)

"Upland No. 140," flat furrows, 5 to 9 inches deep, 13 to 15 wide.

"Upland No. 141," flat furrows, 4 to 8 inches deep, 12 to 14 wide.

"Upland No. 142," flat furrows, 4 to 7 inches deep, 11 to 13 wide.

"Upland No. 143," flat furrows, 3 to 6 inches deep, 10 to 12 wide.

3. For plowing clay and other stiff soil sod, two sizes lapping the furrow-slices one upon another at an inclination of 45 deg.

(Mark on Mould-board.)

"Lap Furrow No. 130," 5 to 7 inches deep, 9 to 11 wide.

"Lap Furrow No. 132," 6 to 8 inches deep, 11 to 12 wide.

4. For plowing stubble or old ground, two sizes of mould-board, throwing the soil over abruptly and breaking it fine:

(Mark on Mould-board.)

"Stubble No. 150," 6 to 12 inches deep, 12 to 16 wide.

"Stubble No. 152," 4 to 9 inches deep, 10 to 14 wide.

5. Also, by using the skim or little forward plow on the same beam with the stubble mould-board, two sizes of superior Double, or Sod or Subsoil plows :

Sod and Subsoil No. 150, 8 to 12 inches deep.

Sod and Subsoil No. 152, 7 to 10 inches deep. 


\section{UNIVERSAL PLOW-CAST IRON.}

\begin{tabular}{|c|c|c|c|c|c|}
\hline KINDS AND SIZES. & & DESCRIPTION. & 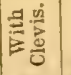 & 总 & 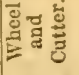 \\
\hline $\begin{array}{l}\text { Intervale, No. 120, - } \\
\text { Intervale, No. 121, : } \\
\text { Intervale, No. 122, : } \\
\text { Intervale, No. 123, - } \\
\text { Intervale, No. 124, : } \\
\text { Upland, No. 140, : } \\
\text { Upland, No. 141, : } \\
\text { Upland, No. 142, : } \\
\text { Upland, No. 143, } \\
\text { Lap Furrow, No 130, } \\
\text { Lap Furrow, No. 132, } \\
\text { Stubble, No 150, - } \\
\text { Stubble, No 152, - } \\
\text { Sod and Sulsoil, No. } 1 \\
\text { Sod and Subsoll, No. } 1\end{array}$ & & 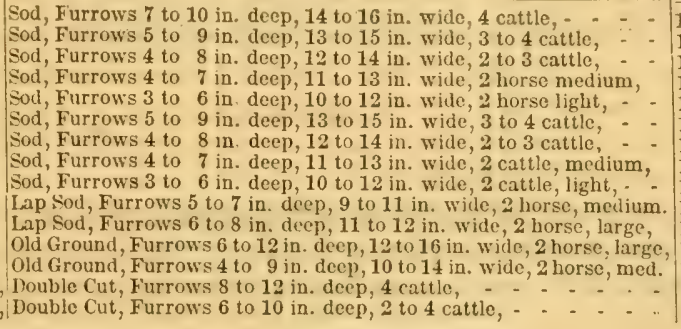 & $\begin{array}{ll}13 & 00 \\
12 & 50 \\
12 & 00 \\
11 & 50 \\
11 & 25 \\
12 & 50 \\
12 & 00 \\
11 & 50 \\
11 & 25 \\
11 & 50 \\
12 & 50 \\
12 & 50 \\
11 & 50 \\
15 & 50 \\
14 & 50\end{array}$ & $\begin{array}{ll}14 & 50 \\
14 & 00 \\
13 & 50 \\
13 & 00 \\
12 & 75 \\
14 & 00 \\
13 & 50 \\
13 & 00 \\
12 & 75 \\
13 & 00 \\
14 & 00 \\
& \\
17 & 00 \\
16 & 00\end{array}$ & $\begin{array}{ll}16 & 00 \\
15 & 50 \\
15 & 00 \\
14 & 50 \\
14 & 25 \\
15 & 50 \\
15 & 00 \\
14 & 50 \\
14 & 25 \\
14 & 50 \\
15 & 50\end{array}$ \\
\hline
\end{tabular}

Mould Board, Intervale, No. 120 ,

Mould Board, Intervale, No. 121,

Mould Board, Intervale, No. 122,

Mould Board, Intervale, No. 123,

Mould Board, Intervale, No. 124,

Mould Board, Lap Furrow, No. 130,

Mould Board, Lap Furrow, No. 132,

\section{$\$ 350$ \\ 300 \\ 250 \\ 200 \\ 175 \\ 200 \\ 300}

Mould Board, Upland, No. 140,

Mould Board, Upland, No. 141,

Mould Board, Upland, No. 142,

Mould Board, Upland, No. 143,

Mould Board, Stubble, No. 150,

Mould Board, Stubble, No. 152,
1\$3 00

250

200

175

300

200
Skim or Forward Plow for Sod and Subsoil, $\$ 300$ Shoe or Sole to Landside, "short," Shoe or Sole to Landside, "medium," Shoe or Sole to Landside, "long," Share, Universal,
Share, Universal, wide,

Share, "Lap Furrow,"

Share, - 50

Wtecl, wide cut, 150

87 Standard, alone, - _ - 250

\section{UNIVERSAI PLOW-STEEL.}

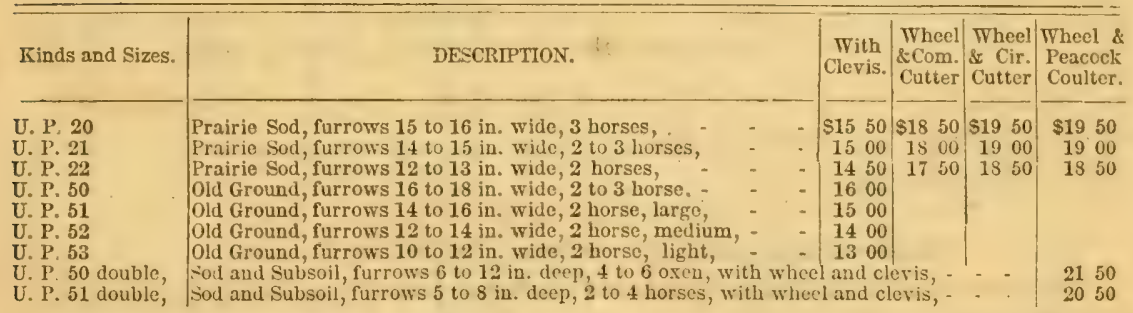

Mould Board No. U. P. 20, \$4 25 Skim Plow with Pencock Coulter, for Sod and Subsoil, $\$ 550$ Mould Board No. U. P. 21, 375 Sharefor lurealking Prairie, U. I'. 20 \& 21, 14 to 15 in. cut, 175 Mould Board No. U. P. 22, 350 Share for breaking Prairie, U. P. 22, 12 in. cut, 150 Mould Board No. U. P. 50, 425 Share for Old Ground, U. P. 50, 18 in: cut, - $\quad-225$ Mould Board No. U. P. 51, 375 Share for Old Ground, U. P. 51, 16 in. cut, - $\quad-\quad 175$ Mould Board No. U. P. 52, 300 Share for Old Ground, U. P. 52, 14 in. cut, - $\quad$ - 150 Mould Board No. U. P. 53, 250 Share for Old Ground, U. P. 53, 12 in. cut, - $\quad$ - 100 Share for Slim Plow, 12 in. cut, - _ - $\quad 100$

Landside, - _ _ _ _ _ 100 


\section{PROUTY \& MEARS'}

\section{CELEBRATED CENTRE-DRAFT PLOWS.}

These Plows are of easy draft, turn the sward most perfectly, and in a clear, free soil preserve the furrow without a holder; and if the ground is in good condition for plowing, nearly prepare it for seeding: by their peculiar shape and turn of mould-board. will pulverize and disintegrate the particles of the furrow slice, and consequently aid fermentation and decomposition, and the elaboration of food for plants, from the organic matter of the soil; all at much less expense, than the same point is outained by the harrow; and in perfection, perhaps nearly equal to "spade husbandry," which has been termed "the perfection of good culture."

\section{BETAIL PRICE LIST.}

\section{Prouty \& Mears' Patent Centre-Draft Plows.}

\begin{tabular}{|c|c|c|c|c|c|}
\hline LINDS. & NUMBERS. & Plain. & Cutter. & $\begin{array}{l}\text { Wheel } \\
\text { and } \\
\text { Cutter. }\end{array}$ & $\begin{array}{l}\text { Drast Rod, } \\
\text { Wheel and } \\
\text { Cutter. }\end{array}$ \\
\hline 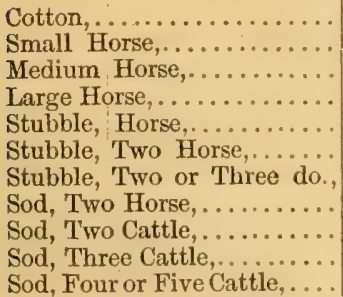 & 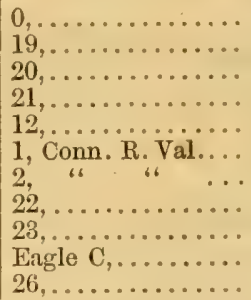 & $\begin{array}{rl}\$ 3 & 50 \\
4 & 00 \\
4 & 50 \\
5 & 50 \\
6 & 50 \\
7 & 50 \\
8 & 00 \\
7 & 50 \\
8 & 00 \\
8 & 50 \\
10 & 00\end{array}$ & $\begin{array}{r}\$ 650 \\
775 \\
900 \\
950 \\
875 \\
950 \\
1000 \\
1150\end{array}$ & $\begin{array}{rr}\$ 7 & 50 \\
9 & 00 \\
10 & 50 \\
11 & 00 \\
10 & 00 \\
10 & 75 \\
11 & 50 \\
13 & 00\end{array}$ & $\begin{array}{rr}\$ 1 C & 00 \\
11 & 50 \\
12 & 00 \\
11 & 00 \\
11 & 75 \\
12 & 50 \\
14 & 00\end{array}$ \\
\hline
\end{tabular}

New Series of Improved.Deep-Tiller Plows.

\begin{tabular}{|c|c|c|c|c|c|}
\hline $\begin{array}{l}\text { Sod, Two Cattle, } . . . \ldots \ldots \\
\text { Sod, 'Three Cattle,........... } \\
\text { Sod, Four Cattle,........ }\end{array}$ & $\begin{array}{l}25, \ldots \ldots \ldots \ldots \ldots \\
154, \ldots \ldots \cdots \cdots \\
155, \ldots \ldots \cdots \cdots\end{array}$ & $\begin{array}{rl}\$ 8 & 00 \\
9 & 50 \\
11 & 00\end{array}$ & $\begin{array}{ll}\$ 9 & 50 \\
11 & 00 \\
12 & 50\end{array}$ & $\begin{aligned} \$ 1100 \\
1250 \\
1400\end{aligned}$ & $\begin{aligned} \$ 1200 \\
1350 \\
1500\end{aligned}$ \\
\hline
\end{tabular}

Lock Coulter Plows for Rough Lands.

\begin{tabular}{|c|c|c|c|c|}
\hline $\begin{array}{l}\text { Two cr Three Cattle, ...... } \\
\text { Three Cuttle, ............ } \\
\text { Three or Four Cattle,...... } \\
\text { Heavy Roud,............ }\end{array}$ & $\left|\begin{array}{l}25, \mathrm{~L}, \ldots \ldots \ldots \ldots \\
\text { Eagle, } \mathrm{C} \mathrm{L}, \ldots \ldots \ldots \\
72, \mathrm{~L}, \ldots \ldots \ldots \ldots \\
8, \ldots \ldots \ldots \ldots\end{array}\right|$ & $\begin{array}{rl}\$ 10 & 00 \\
11 & 00 \\
13 & 00 \\
16 & 50\end{array}$ & $\begin{array}{rl}\$ 11 & 50 \\
12 & 50 \\
14 & 50 \\
18 & 50\end{array}$ & $\begin{array}{rl}\$ 12 & 50 \\
13 & 50 \\
16 & 00 \\
20 & 00\end{array}$ \\
\hline
\end{tabular}




\section{Improved Self-Sharpening Plows.}

\begin{tabular}{|c|c|c|c|c|c|}
\hline KINDS. & NUMBERS. & Plain. & Cutter. & $\begin{array}{l}\text { Wheel } \\
\text { and } \\
\text { Cutter. }\end{array}$ & $\begin{array}{l}\text { Draft Rod } \\
\text { Wheel and } \\
\text { Cutter. }\end{array}$ \\
\hline ight Horse, & & $\$ 500$ & $\$ 600$ & $\$ 700$ & \\
\hline & & & & 850 & $\$ 950$ \\
\hline & & & & 10 & 11 \\
\hline & & 80 & 9 & 1050 & 1150 \\
\hline & Stecl Poir & & 11 & & 13 \\
\hline & $5 \frac{1}{2}$. & 8 & 10 & 11 & 1250 \\
\hline & & 10 & & & 1400 \\
\hline Three Cat & & 900 & 10 & 1200 & 1300 \\
\hline Four & & 1000 & 1150 & 1300 & 1400 \\
\hline
\end{tabular}

\section{Meadow Plows.}

Two or Three Cattle.

Three Cattle.

Three or Four Cattle.

Four or Five Cattle.
25, L, Steel Share....

Eagle, C L, do.

do. $72 \mathrm{~L}$, cut edge.

do. $33 \mathrm{~L}$.
1400

1500

1700

1800

\section{Side-Hill or Swivel Plows.}

\begin{tabular}{|c|c|c|c|c|}
\hline One Horse.... & & 500 & & \\
\hline Two Horse . . . . . . & $00 \ldots \ldots \ldots \ldots$ & 700 & 825 & 950 \\
\hline Two Cattle................ & $1 \ldots \ldots \ldots \ldots \ldots$ & 800 & 925 & 1050 \\
\hline Three Cattle. .............. & $2 \ldots \ldots \ldots \ldots$ & 1000 & 1150 & 1300 \\
\hline Four Cattle.......... & $3 \ldots \ldots$ & 1100 & 1250 & 1400 \\
\hline Four Cattle, Heavy.. & 4 hoad. . & 1400 & 1550 & 1700 \\
\hline
\end{tabular}

\section{Michigan Sod and Subsoil Plows.}

\begin{tabular}{|c|c|c|c|c|}
\hline Two Cattle. & 8, old Series. & 1300 & 1400 & 1550 \\
\hline Three Cattle. & $9, \quad$ " & 1400 & 1500 & 1650 \\
\hline Four Cattle & 10 & 1500 & 1600 & 1750 \\
\hline c Cattle. & 9 , Left Hand...... & 1450 & 1550 & 1700 \\
\hline Three Cattle. . & 95 , Self Sharpening... & 1650 & 1750 & 1900 \\
\hline Two Cattle & 84 , New Series..... & 1350 & 1450 & 1600 \\
\hline Three Cattle. & & 1450 & 1550 & 1700 \\
\hline
\end{tabular}

\section{Sub-soil Plows.}

One Horse.

Two Horse ..............

Two Horsc................

Two Horse...............

Three or Four Horse. . . . . . . . .

Heavy Road.

\begin{tabular}{|c|c|c|c|}
\hline & & D. Fond. & I). Fod and Wheel \\
\hline $0 \ldots \ldots \ldots \ldots \ldots$ & 550 & 650 & \\
\hline $1 \ldots \ldots \ldots \ldots$ & 700 & 800 & 950 \\
\hline 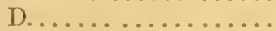 & 700 & 800 & 950 \\
\hline 2, G Left Hand. ...... & 750 & 850 & 1000 \\
\hline 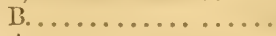 & 900 & 1000 & 1150 \\
\hline 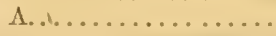 & 1100 & 1225 & 1400 \\
\hline
\end{tabular}

\section{Ridging Plows.}

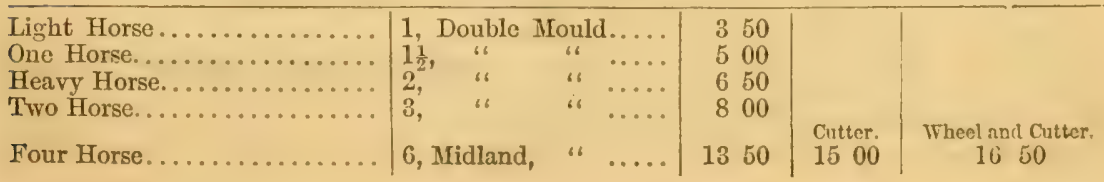




\section{HAY CUTTERS.}

Straight Knives.

\begin{tabular}{|c|c|c|c|c|}
\hline $\begin{array}{l}\text { No of } \\
\text { Cutter: }\end{array}$ & $\begin{array}{l}\text { No. of } \\
\text { Knives. }\end{array}$ & $\begin{array}{l}\text { Length of } \\
\text { Knives. }\end{array}$ & $\begin{array}{l}\text { Length of } \\
\text { Cut. }\end{array}$ & Price. \\
\hline 00 & 5 & $5 \frac{3}{4}$ inch. & $1 \frac{3}{4}$ inch. & $\$ 600$ \\
\hline 0 & 6 & $5 \frac{3}{4}$ inch. & $1 \frac{5}{8}$ inch. & 700 \\
\hline 1 & 7 & $5 \frac{3}{4}$ inch. & $1 \frac{3}{8}$ inch. & 860 \\
\hline 2 & 8 & $5 \frac{3}{4}$ inch. & 1 $\frac{1}{4}$ inch. & 900 \\
\hline $2 \frac{1}{2}$ & 10 & $5 \frac{3}{4}$ inch. & $1^{*}$ inch. & 1000 \\
\hline 3 & 6 & $6 \frac{3}{4}$ inch. & $1 \frac{1}{2}$ inch. & 1000 \\
\hline 4 & 8 & $6 \frac{3}{4}$ inch. & $1 \frac{1}{4}$ inch. & 1100 \\
\hline 5 & 10 & $6 \frac{3}{4}$ inch. & 1 inch. & 1200 \\
\hline $5 \frac{1}{2}$ & 12 & $6 \frac{3}{4}$ inch. & $\frac{3}{4}$ inch. & 1300 \\
\hline $5_{4}^{3}$ & 14 & $6 \frac{3}{4}$ inch. & $\frac{5}{8}$ inch. & 1400 \\
\hline $6^{2}$ & 6 & $7_{\frac{1}{2}}^{\frac{1}{2}}$ inch. & $1 \frac{3}{4}$ inch. & 1400 \\
\hline 7 & 8 & $7 \frac{1}{2}$ inch. & $1 \frac{1}{4}$ inch. & 1500 \\
\hline 8 & 10 & $7 \frac{1}{2}$ inch. & $1^{ \pm}$inch. & 1600 \\
\hline 9 & 6 & 81 inch. & $1 \frac{3}{4}$ inch. & 1700 \\
\hline 10 & 8 & $8 \frac{1}{2}$ inch. & $1 \frac{1}{2}$ inch. & $18 \cdot 00$ \\
\hline 11 & 10 & $8 \frac{1}{2}$ inch. & 1 inch. & 1900 \\
\hline 12 & 6 & $9 \frac{1}{2}$ inch. & $1 \frac{3}{4}$ inch. & 2200 \\
\hline 13 & 8 & $9 \frac{1}{2}$ inch. & $1 \frac{1}{2}$ inch. & 2400 \\
\hline 14 & 10 & $9 \frac{1}{2}$ inch. & $1 \frac{1}{8}$ inch. & 2600 \\
\hline
\end{tabular}

Nos. 12,13 , and 14 are fitted for horse power.

\begin{tabular}{|c|c|c|c|c|}
\hline $\begin{array}{l}\text { No of } \\
\text { Cutter. }\end{array}$ & $\begin{array}{l}\text { No of } \\
\text { Knives. }\end{array}$ & $\begin{array}{l}\text { Length of } \\
\text { Knives. }\end{array}$ & $\begin{array}{l}\text { Length of } \\
\text { Cut. }\end{array}$ & Price. \\
\hline 00 & 4 & 6 inch. & 2 inch. & $\$ 550$ \\
\hline 0 & 5 & $6 \mathrm{inch}$. & $1 \frac{3}{4}$ inch. & 600 \\
\hline 1 & 6 & 6 inch. & 1 incl. & 7.00 \\
\hline 2 & 7 & 6 inch. & $1 \frac{3}{8}$ inch. & 800 \\
\hline 3 & 8 & 6 inch. & 11 inch. & 900 \\
\hline 4 & 9 & 6 inch. & $1 \frac{1}{1} \mathrm{ch}$. & 950 \\
\hline $4 \frac{1}{2}$ & 10 & $6 \mathrm{inch}$. & 1 inch. & 1000 \\
\hline $5^{2}$ & 6 & 7 inch. & $1 \frac{3}{4}$ inch. & 1000 \\
\hline 6 & 8 & 7 inch. & I $\frac{1}{8}$ inch. & 1100 \\
\hline 7 & 10 & 7 inch. & $\frac{7}{8}$ inch. & 1200 \\
\hline $7 \frac{1}{2}$ & 12 & 7 inch. & $\frac{3}{4}$ inch. & 1300 \\
\hline $8^{2}$ & 6 & $8 \mathrm{inch}$. & $1^{\frac{4}{3}}$ inch. & 1300 \\
\hline 9 & 8 & 8 inch. & $1 \frac{1}{5}$ inch. & 1400 \\
\hline 10 & 10 & 8 inch. & $\frac{7}{8}$ inch. & 1600 \\
\hline $10 \frac{1}{2}$ & 12 & 8 inch. & $\frac{3}{4}$ inch. & 1700 \\
\hline $11^{2}$ & 6 & 9 inch. & $1 \frac{3}{4}$ inch. & 1700 \\
\hline 12 & 8 & 9 inch. & $1 \frac{1}{8}$ inch. & 1800 \\
\hline 13 & 10 & 9 inch. & $\frac{7}{8}$ inch. & 1900 \\
\hline
\end{tabular}

\section{IMPROVED FEED CUTTERS.}

Telegraph Hay and Stalk Cutter, No. 1, \$70 00 Telegraph Hay and Stalk Cutter, No. 2, 4500 Telegraph Hay and Stalk Cutter, No. 3, 3000 Telegraph Hay and Stalk Cutter, No.4. 2200 Daniel's Hay and Stalk Cutter, No. 1, 2500 Daniel's Hay and Stalk Cutter, No. 2, 5500 Cumming's Hay and Stalk Cutter, Cylindrical Hay and Stalk Cutter, Smith's Patent Lever Cutter, Common Lever Gate,

1600

1000

375
UNIVERSAL HAY CUTTER. Gale's Patent.

\begin{tabular}{|c|c|c|c|c|}
\hline No. & $\begin{array}{c}\text { No. } \\
\text { Knives. }\end{array}$ & $\begin{array}{l}\text { Length } \\
\text { Knives. }\end{array}$ & $\begin{array}{l}\text { Length } \\
\text { of Cut. }\end{array}$ & Price. \\
\hline 000 & 1 & 7 inches, & Coarse, & $\$ 800$ \\
\hline 00 & 2 & $6 \quad 4$ & Coarse, & 900 \\
\hline 0 & 2 & 6 & Coarse, & 1000 \\
\hline 1 & 3 & 6. 66 & Coarse, & 1100 \\
\hline 2 & 2 & 6 & Coarse, & 1200 \\
\hline 3 & 3 & 16 & Fine; & 1200 \\
\hline 4 & 4 & 66 & Fine, & 1300 \\
\hline 5 & 2 & 66 & Coarse, & 1300 \\
\hline 6 & 3 & 66 & Coarse, & 1400 \\
\hline 7 & 4 & 66 & Fine, & 1500 \\
\hline 8 & 2 & 66 & Coarse, & 1500 \\
\hline 9 & 3 & $" 6$ & Coarse, & 1600 \\
\hline 10 & 4 & 6 & Fine, & 1700 \\
\hline 11 & 2 & 10. & Coarse, & 1900 \\
\hline 12 & 3 & 10 & Coarse, & 2000 \\
\hline 13 & 4 & 10 & Fine, & 2000 \\
\hline 14 & 3 & 11 & Coarse, & 2500 \\
\hline 15 & 4 & 10 & Fine, & 2600 \\
\hline
\end{tabular}

EACLE HAY CUTTERS.

Gale's Patent.

No. 1, 7 in. long, - _ _ _ _ $\$ 1200$

No. 3, 9 in. long, - _ _ - 1400

No. 5, 11 in. long, _ _ _ 1600

No. 7, 13 in. long, - _ _ $\quad$ - 2000

\section{HAY CUTTERS.}

Self Sharpening.

\begin{tabular}{|c|c|c|c|c|}
\hline $\begin{array}{l}\text { No. of } \\
\text { Cutter. }\end{array}$ & $\begin{array}{l}\text { No. of } \\
\text { Flange. }\end{array}$ & $\begin{array}{l}\text { Length of } \\
\text { Knife. }\end{array}$ & $\begin{array}{l}\text { Length of } \\
\text { Cut. }\end{array}$ & Price. \\
\hline 0 & 6 & $6 \frac{1}{2}$ & $1 \frac{1}{2}$ inch. & $\$ 800$ \\
\hline 1 & 6 & $7 \frac{1}{4}$ & $1 \frac{1}{2}$ inch. & 900 \\
\hline 2 & 8 & 71 & $1^{2}$ inch. & 1000 \\
\hline 3 & 6 & $7 \frac{4}{4}$ & $1 \frac{1}{2}$ inch. & 1200 \\
\hline 4 & 8 & $7 \frac{7}{4}$ & $1^{2}$ inch. & 1300 \\
\hline 5 & 10 & $8 \frac{1}{2}$ & $\frac{3}{4}$ inch. & 1500 \\
\hline 6 & 12 & $8 \frac{1}{2}$ & $\frac{1}{2}$ inch. & 1600 \\
\hline 7 & 6 & $8 \frac{3}{4}$ & $1 \frac{1}{2}$ inch. & 1700 \\
\hline 8 & 8 & $8 \frac{3}{4}$ & $1^{3}$ inch. & 1800 \\
\hline 9 & 10 & $8 \frac{4}{4}$ & $\frac{3}{4}$ inch. & 1800 \\
\hline 10 & 12 & $8 \frac{4}{4}$ & $\frac{1}{2}$ inch. & 1900 \\
\hline 11 & 6 & $9 \frac{4}{2}$ & $1 \frac{1}{2}$ inch. & 2000 \\
\hline 12 & 8 & $9 \frac{1}{2}$ & 1 inch. & 2100 \\
\hline 20 & 6 & $11 \frac{1}{2}$ & 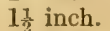 & 3500 \\
\hline 21 & 8 & $11 \frac{1}{2}$ & $1^{2}$ inch. & 3600 \\
\hline 22 & 10 & $11 \frac{1}{2}$ & $\frac{3}{4}$ inch. & 3700 \\
\hline
\end{tabular}

Nos. 20,21 , and 22 are fitted for horse power.

\section{VEGETABLE CUTTERS.}

Worcester, - - $\quad$ - $\quad$ - $\$ 1000$

Willard's Patent Root Cutter, _. 1000 


\section{STEEL HORSE HOES.}

Howe's No. 1, Expanding..........\$8 00 Howe's No. 2, Expanding............9900 Howe's No. 3, Expanding..........10 00

Armsby's No. 1, Expanding......... 700 Armsby's No. 2, Expanding..........8 800 Armsby's No. 3, Expanding......... 900

Knox's Patent, No. 1............ 700 Knox's Patent, No. 2.............8 800 Knox's Patent, No. 3............ 900

Centre Plow, or T'ooth,

No. 1. No.2. No. 3 .

for Horse Hoe. . . . . \$1 $50 \$ 175 \$ 200$ Two Side Plows, per pair,... 150 N $175 \quad 175$ Front Tooth........... $20 \quad 25 \quad 25$

\section{COTTON OR GARROT WEEDER.}

No. 1, Steel, 12 inch...............\$4 00

No. 2, Steel, 15 inch.............. 450

No. 3, Stcel, 18 inch.............. 500

\section{NEW PATTERN COTTON SCRAPER.}

Cotton Scraper, Wrought Iron.......\$4 50 Cotton Scraper, Cast Iron.......... 375

COTTON SWEEPS.

No. 1, Steel,

No. 2, Steel,

$\$ 485$

No. 3. Steel,

500

\section{CULTIVATORS.}

Common, 5 Teeth,

$\$ 400$

Common, 5 Teeth, Reversible,

450

Common, 5 Teeth, Steel, Reversible,

Improved, 5 Teeth,

Improved, 5 Teeth, Reversible,

575

450

Improved, 5 Teeth, Steel, Reversible,

500

625

Parallel Expanding, 3 Teeth, Reversible, 450

Parallel Expanding, 3 Teeth, Steel, Rev, 550

Parallel Expanding, 5 Teeth, Reversible, 600

Parallel Expanding, 5 Teeth, Steel, Rev. 775

Universal, Iron, 5 Teeth, broad, - 900

Universal, Iron, 3 Teeth, with Moulds, 1000

Hand Cultivator, - - - $\quad 225$

Cotton Sweep. No. 1, with Wheel, 800

Cotton Sweep, No. 2, with Wheel, 1000

1 Set Cast Cultivator Teeth, - - 125

1 Set Reversible Cast Cultivator Teeth, 150

1 Set Reversible Steel Teeth, - . - 275

1 Set Rogers' Patent Steel Teeth, _ - 275

\section{KNOK'S GANG GULTIVATOR.}

No. $1,-4$ Teeth, Steel, ............\$9 00

No. $2,-6$ Teeth, Steel, ............ 1050

\section{CORN PLANTERS.}

Batchelder's Improved........... \$14 00 Billings' Patent................. 1500

Wakefield Hand............... 500

Common Hand................. 200

\section{SEED DRILLS.}

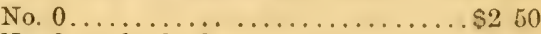

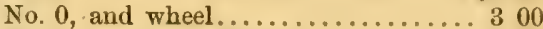

No. 1, Improved English..........6 600

No. 2, Improved English............10 00

No. 3, Improved English . ............. 1400

Wethersfield Seed Drill............6 600

Wells' Broadcast,................4 400

Cahoun's Patent Broadcast............. 1000

Cahoun's Patent Broadcast, Power,..... 3500

\section{ROAD SCRAPERS.}

No. 1, Cast Iron, - - - - $\$ 550$

$-10-10-5050$

No. 3, " - - - - 850

\section{HARROWS.}

\begin{tabular}{l|c|c|c}
\hline \hline \multicolumn{1}{c|}{ KINDS. } & $\begin{array}{c}\text { No. of } \\
\text { Teeth. }\end{array}$ & $\begin{array}{c}\text { Size of } \\
\text { Teeth. }\end{array}$ & Price. \\
\cline { 2 - 5 } Improved Hinge. & 30 & $\frac{7}{8}$ inch. & $\$ 1300$ \\
Improved Hinge. & 24 & $\frac{7}{8}$ inch. & 1100 \\
Geddes, & 14 & $\frac{3}{4}$ inch. & 800 \\
Geddes, & 18 & $\frac{3}{4}$ inch. & 1000 \\
Geddes, & 22 & $\frac{7}{8}$ inch. & 1200 \\
Geddes, & 26 & $\frac{7}{8}$ inch. & 1300 \\
Geddes, & 30 & $\frac{7}{8}$ inch. & 1400 \\
Geddes, & 30 & 1 inch. & 1500 \\
Expanding & 20 & $\frac{7}{8}$ inch. & 1000 \\
Reversible, & & & \\
Expanding & 20 & $\frac{3}{4}$ inch. & 900 \\
Reversible, & 32 & $\frac{3}{4}$ inch. & 1300 \\
Scotch, No. 1, & 32 & $\frac{7}{8}$ inch. & 1600
\end{tabular}

$\frac{3}{4}$ inch steel teeth, $\$ 200$ extra.

\begin{tabular}{l|l|r|rr} 
A & 11 & $\frac{3}{4}$ inch. & 5 & 00 \\
A & 13 & $\frac{3}{4}$ inch. & 600 \\
A & 15 & $\frac{7}{8}$ inch. & 800 \\
A heavy, & 15 & $1 \frac{1}{4}$ inch. & 10 & 00 \\
A & 17 & 1 inch. & 900
\end{tabular}

\section{Improved Hinge Steel Harrows.}

\begin{tabular}{l|r|r|rr}
1 Horse, & 24 & $\frac{1}{2}$ & $\$ 11$ & 50 \\
1 Horse, & 24 & $\frac{5}{8}$ & 12 & 25 \\
1 Horse, & 30 & $\frac{1}{2}$ & 13 & 50 \\
2 Horse, & 30 & $\frac{5}{8}$ & 14 & 50 \\
Sizer's Cotton Harrow, & - & - & 800
\end{tabular}

Mapes and Gibbs' Digging

Machine, - _ _ $\$ 12500$ 
CORN SHELLERS. Armsby's Patent.

Yankee.....................\$6 00

Yankee, extra Wheel.............7 00 Fitted with Pulley, $50 \mathrm{cts}$. extra.

Boston..................... 700

Boston, extra Wheel ............. 850

Boston, double.................9900

Boston, double, extra Wheel.........10 50

Southern.....................9900

Southern, extra Wheel...........10 50

Southern, double...............1200

Southern, double, extra Wheel.......13 50

Western, Extra Wheel and Pulley,......15 00

Western, Double Ex. Wheel and Pulley, 1700 With outside and inside balance wheels, and outside gearing.

Common, Wro't Shafts 1 Bal. Wheel.... 650

Common, Wro't Shafts 2 Bal. Wheels. ... 750

PREMIUM CORN SHELLERS

\begin{tabular}{|c|c|c|c|}
\hline KINDS, & Plain. & $\begin{array}{l}\text { With } \\
\text { Separa- } \\
\text { tor. }\end{array}$ & $\begin{array}{l}\text { With } \\
\text { Separator } \\
\& \text { Fan. }\end{array}$ \\
\hline No. 1, Northern... & $\$ 650$ & $\$ 800$ & \\
\hline No. $1, " 2$ bal whl & 750 & 900 & \\
\hline No. $2, \quad, \quad \ldots \ldots \ldots$ & 800 & 975 & $\$ 1150$ \\
\hline No. 3, "2 bal whl & 900 & 1175 & 1250 \\
\hline $\begin{array}{l}\text { Southern and Western. } \\
\text { No. } 4, \ldots \ldots \ldots . .\end{array}$ & 1050 & 1250 & 1450 \\
\hline No. 5,2 bal whls . & 1200 & 1400 & 1600 \\
\hline No. 6 , double ...... & 1400 & 1750 & 1950 \\
\hline No. 7 , sgl outside gr & 1300 & 1500 & 1750 \\
\hline "No. 8 ," " ", & 1450 & 1650 & 1900 \\
\hline No. 9 , double ... & 1600 & 2000 & 2250 \\
\hline $\begin{array}{l}\text { No. } 10, " \text {, } \\
\text { * Fitted with power. }\end{array}$ & 1750 & 2150 & 2400 \\
\hline
\end{tabular}

Smith's Patent Power, No. 1......\$45 00 Smith's Patent Power, No. 2........ 5500

Smith's Patent Power, No. 3....... 7500

Males' Hand .................. 3000

Burrell's Hand, Iron.............. 900

\section{H U R N S.}

\section{Improved CYLINDER. THERMOMETER.}

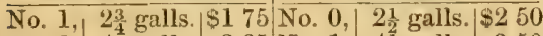

No. 2, 4 galls. 225 No. 1, $4 \frac{1}{2}$ galls. 350

No. 3, 7 galls. 275 No. 2, 6 galls. 400

No. 4, $10 \frac{1}{2}$ galls. 325 No. 3, 9 galls. 450

No. 5, 15 galls. 375 No. $4,10 \frac{1}{2}$ galls. 500

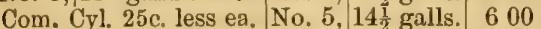

Dasher Churns, "' $5 \frac{1}{2}$,

75 cents to $\$ 5$ each. No. 6. 28 galls 1200 50c. extra fr Kobbins' c'ash

Patent Air Pressure, 10 gal.

Patent Air Pressure, 15 gal.

1000

Patent Air Pressure, 20 gal.

1200

1500

WINE AND LARD PRESSES.

No. 1 ,

No. 2,

No. 3 ,

No. 4,

700

1000

$\Sigma 000$

\section{GARDEN ROLLERS.}

2 Sections, ca. 7 t in. long by 15 in diam. $\$ 6$ 3 Sections, ea. $7 \frac{1}{2}$ in. long by 15 in diam. 9 1 Section, 12 in. long by 20 in diam.

2 Sections, ea. 12 in. long by 20 in diam. 14

1 Section, 12 in. long by 28 in diam. . 14

1 Section, $20 \mathrm{in}$. long by 20 in diam. 14

2 Sections, ea. 12 in. long by 24 in diam. 18

2 Sections, ea. $12 \mathrm{in.}$ long by 28 in diam. 20

\section{FIELD ROLLERS.}

3 Sections, ea. 12 in. long by 20 in. diam. $\$ 25$ 4 Sections, ea. 12 in. long by 20 in. diam. 30 4 Sections, ea. 12 in. long by 24 in. diam. 35 5 Sections, ea. 12 in. long by 20 in. diam. 35 4 Sections, ea. 12 in. long by 30 in. diam. 40 5 Sections, ea. $12 \mathrm{in.} \mathrm{long} \mathrm{by} 24 \mathrm{in}$. diam. 40 5 Sections, ea. 12 in. long by 30 in. diam. 45 6 Sections, ea. $12 \mathrm{in}$. long by $24 \mathrm{in}$. diam. 45 6 Sections, ea. 12 in. long by 30 in. diam. 50

WHEELBARROWS.

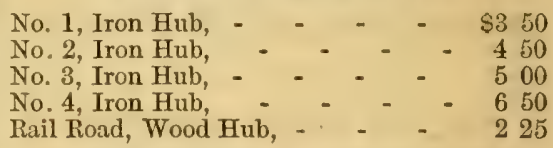

\section{OX YOKES-COMPLETE.}

No 1 , size 7 in. inside of Bow by 19 in. between Bows, $71 \frac{1}{2}$, size inside of Bow by $20 \mathrm{in}$, between Bows, -

No. 2 , size $\mathrm{S}$ is. inside of Bow by 21 in. between bows,

No. $3, \operatorname{siz} 81 / 2$ in. inside of Bow by 21 in. between Bows,

No. 4 , size 9 in, inside of Bow by 23 in. between Bows, $91 / 2$ in. inside of Bow by 24 in between Bows,

No, 6 , size $10 \mathrm{in}$. inside of Bow by 24 in. between Bows,

STORE TRUCKS.

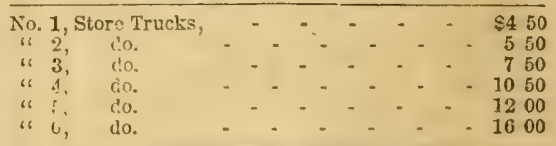

COTTON TRUCKS.

\begin{tabular}{l}
\hline 12 inch Wheels, \\
15 inch Whecls, - \\
18 inch Wheels,
\end{tabular}

\section{PLATFORM TRUCKS.}

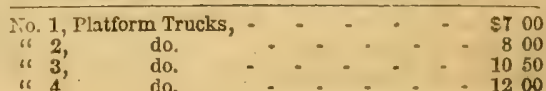


FAN MILLS.

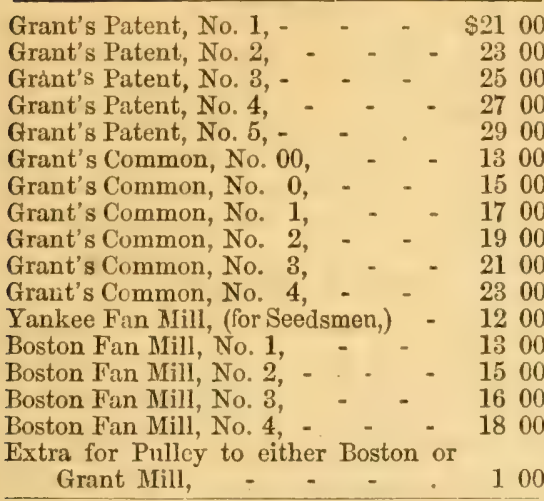

\section{SUGAR MILLS.}

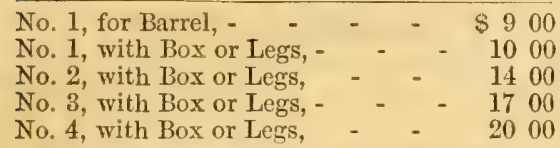

\section{SUCAR CANE CRUSHERS.}

Improved, 3 Rollers, No. 1, - $\quad$ - \$2600 Improved, 3 Rollers, No. 2, - - 6500

\section{GRINDSTONE FIXTURES.}

Sets Complete, No. 0 , Sets Complete, No. 1, Sets Complete, No. 2, Sets Complete, No. 3,

\section{SAUSAGE-MEAT CUTTERS.}

Family Iron, No. 1, - _ _ _ $\$ 200$ Family Iron, No. 2,

Family Iron, No. 3,

300

Butcher's Iron, No. 4,

600

Butcher's Geared, No. 4,

800

Butcher's Geared, No. 5 ,

No. 5 has pulley for power.

S. Stowe, No. 1,

$\$ 200$

S. Stowe, No. 2 ,

250

S. Stowe, No. 3

300

\section{SAUSAGE FILLERS.}

\begin{abstract}
No. 0, Plain, for Family Use, BUTCHER'S.

No. 1, Plain, - $\$ 300$, with 2 Tubes,
No. 2, Plain, - 350 , with 2 Tubes,

No. 3, Plain, - 400 , with 2 Tubes,

No. 4, Plain, Geared,

No. 4, Geared, 2 Tubes,
\end{abstract}

$\$ 200$

400

450

5.00

550
MU A L I D A Y'S

\section{WIND ENGINES OR MILLS.}

\begin{tabular}{r|r|r|r|r|r}
\hline No. & $\begin{array}{c}\text { No. } \\
\text { Sails. }\end{array}$ & Dia. & $\begin{array}{r}\text { Horse } \\
\text { Power. }\end{array}$ & Weight. & Price. \\
\hline 1 & 6 & $6 \mathrm{ft}$. & $\frac{1}{4}$ & $400 \mathrm{lbs}$. & $\$ 7500$ \\
\hline 2 & 6 & $8 \mathrm{ft}$. & $\frac{3}{8}$ & $425 \mathrm{lbs}$. & 8500 \\
3 & 6 & $12 \mathrm{ft}$. & $\frac{1}{2}$ & 800 lbs. & 13000 \\
4 & 8 & $12 \mathrm{ft}$. & $1 \frac{1}{4}$ & 900 lbs. & 16000 \\
5 & 6 & $16 \mathrm{ft}$. & 2 & 1700 lbs. & 22500 \\
6 & 8 & $16 \mathrm{ft}$. & 3 & 2000 lbs. & 30000 \\
7 & 8 & $18 \mathrm{ft}$. & 4 & 2200 lbs. & 32500 \\
8 & 8 & $21 \mathrm{ft}$. & 5 & 2500 lbs. & 35000 \\
\hline
\end{tabular}

\section{GRAIN MILLS.}

Magic, No. 1, Sweep Power, for Corn and Cobs,

$\$ 4000$

Magic, No. 2, Steam Power, for Corn and Cob,

7500

Little Giant C. \& C. Mills. \$25 \$35 \$45 \$55 Excelsior Flour Mill, - _ _ 10000 do. do. with Flour Bolt, 15000 Promium Flour Mill, - _ - 5000 do. do. with Flour Bolt, 7500 Horse and Hand Grain Mill, - _ 2000

\section{HAY \& COTTON PRESSES.}

Ingersoll's Improved Hay, No. 1, - \$5000 do. do. do. No. 2, - 7500 do. do. do. No. 3, - 12500 Cotton, Wool, Tobacco, Hop, Rag, \& MIoss Presses. Fay's Improved Hay, _ _ _ 11000

Horse Powers, Threshing Machines, \&c.

Patent Endless Chain, Changeable, one horse power, - - _ _ $\$ 9000$

Patent Endless Chain, Changeable, two horse power, - _ _ $\quad 12000$

Threshing Machine, with Separator and Fixtures, - - - - - 4000

Set Bands for Machine, with extras, \&c. 500 Portable Circular Saw Mill, with 24 in. Saw, filed and set, - - - 3700

Extra Table and Saw, for sliting boards and fence stuff, Improved Dog and Sheep Power, - 1500 Whitman's Sweep Power, - - 10000 Whitman's Combined Thresher and Cleaner,

11000 Planet Sweep Power, for 1 to 8 horses, 12000 Ficld' "Sweep "Power " 1 to 10 " 18000 Buckeye Portable Cider Mill \& Press, 4000 Male's Pat. "6 "6 "6 .6. 4500 Improved Boring Machine, with Auger, 650 " " " without " 450 Taft's Self-feeding Blacksmith Drill, $\quad 650$ 


\section{MA NURES, \&c.}

Mapes' Nitrogenized Super-Phosphate of Lime, - - - - - - $\quad$ - $\$ 5000$ per ton.

Peruvian Guano,

Land Plaster,

Bone Dust,

Poudrette,

125 per bbl.

$\$ 250$ to $3 \cdot 00$

150 to 200

\section{MOWING AND REAPING MACHINES.}

Ketchum's Patent One Horse Mowing Machine, $3 \frac{1}{2} \mathrm{ft}$. Bar, weight $450 \mathrm{lbs}$. - - $\quad \$ 7500$ Do. Light Two Horse " " $4 \mathrm{ft}$. " " 475 " - - 8000

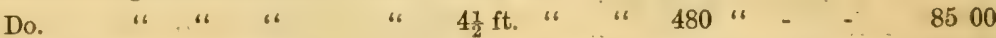

Do. Heavy " " " " 4 ft. " " 630 " - - 9000

Do. " " " " " 4 ft. 8 in. Bar, weight 650 lbs. - 9500

Do. " " " " " 6 ft. " " 660 " 610000

Reaper attachment extra.

Buckeye Mower, $4 \mathrm{ft} .8$ in. Bar, (Aultman \& Miller's Patent,) - - - - - 12000 Do. Jr. $4 \mathrm{ft}$. Bar, " " " - - - 10000 Little Buckeye Mower, $3 \frac{1}{2} \mathrm{ft}$. Bar, " . " " $\quad$ " $\quad \ldots \quad \ldots . . .850$

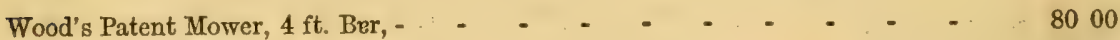

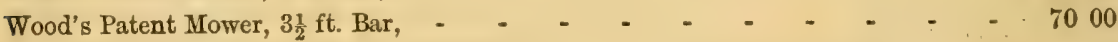

Wood's Manney's Mower, 5 ft. Bar, - - - - - _ _ _ - - 11000 Wood's Manney's Mower and Reaper, 5 ft. Bar, - - - - - - - $\quad-12500$ Wood's Manny's Large Mower and Reaper $5 \frac{1}{2} \mathrm{ft}$. Bar, - _ _ - - - - 13000

McCormiclz's Reaper and Mower, for 4 horses, - - - - - - - - 15500 M'Cormick's Reaper and Mower, for 2 horses, - - - - - - - 14000

\section{IMPROVED LAWN MACHINES.}

No. 1, Cutting 13 inches wide, drawn by one man, - _ _ _ $\quad$ - $\$ 4000$

" 2, Cutting 16 inches wide, drawn by one man, - _ - $\quad 4500$

"3, Cutting 20 inches wide, drawn by two men, _ _ _ $\quad$ - 5000

"4, Cutting 24 inches wide, drawn by two men, _ _ _ - 5500

“ 5, Cutting 24 inches wide, drawn by pony, - _ _ _ $\quad$ - 7000

" 6, Cutting 30 inches wide, drawn by one horse, _ _ $\quad$ - 11000

" 7 , Cutting 30 inches wide, drawn by one horse (extra), - _ $\quad$ - 13500

" 8, Cutting 36 inches wide, drawn by one horse, - - - 15000 


\section{PLOWS.}

UnTrL within a few years, the low price of land induced the early settlers to use short mould-boards, producing shallow plowing with wide furrows, and thus enabling them to disturb a large area of land very imperfectly. This gave rise to shallow plowing, rather as a habit, and the consequence has been the exhaustion of a large portion of the old estates. The early attempts to introduce root crops, in soil so badly prepared, were ineffective, and it remained for the present century to prove the advantages consequent upon deeper tillage, until twelve-inch depth of surface plowing has become, among the better class of agriculturists, rather the rule than the exception.

This necessity gave rise to the Eagle Plows, as the growing demand has been for such plows as had a capacity for deep and thorough work, with such a variety of mould-boards as have proved necessary for the working of the various soils. That kind of Eagle Plow known as deep tillers, have been made of such a variety as to embrace all the sizes and forms of mould-boards which may be demanded. The accurate scale of proportions, invented by Mr. Nourse and others, have added inaterially to the completion of this series of plows; the present mode of construction forms the mould board of a series of straight lines, in the direction of the movement of the furrow-slice, still admitting of all the variations necessary to produce longer or shorter mould-boards, of gentle or more abrupt curvature, with straight or more or less concave or convex lines laterally, as different soils or practical uses may require. Thus constructed, the mould-boards possess a combination of curved lines and planes, presenting so even a board against the furrow-slice that it insures an even polish to the entire face of the mould-board, insuring even wear, and causing the furrow-slice to undergo an equal and effective twist, being laid down with precision in the desired position, and yet being fairly disintegrated, leaving the soil admirably fitted for the reception of atmospheric influences, and the free travel of the roots of plants.

\section{THE UNIVERSAL PLOW,}

Described in our catalogue, embraces all the variety of mould-boards required by the agriculturist, and calling for a single beam and frame, to which either of these may be readily attached; thus securing great economy, and representing an entire series of plows in a single implement. 
These plows are manufactured for the subscriber, and always sold by him at moderate prices. The wood parts are of white oak, having great strength and compactness; all being worked by machinery, causing the fitting of the parts to be alike, so that any number of plows of a given mark are capable of having their parts changed from one to the other, always fitting as exactly as in any single plow. The mould-board, share, and land-side, if of steel, are of the best quality and highly polished; if of cast-iron, they are composed of an admixture of several kinds of iron, the result of many experiments, and having great hardness and durability, combining lightness with adequate strength; the castings are ground and smoothly polished, and then coated with a varnish to prevent rust, being thus fitted for immediate easy use in the soil. The point and entire edge of the shares, and sole of the land-sides and mould-boards, are hardened in casting by a process of chilling, causing them to last many times as long as when cast by the ordinary method. The extreme accuracy with which the parts of these plows are fitted, prevents them from being liable to become loose. Each part has a specific mark or number inscribed, which mark, being used only on that particular size, entircly distinguishes its parts from those of all other sizes.

The subscriber has always on hand any quantity of duplicates of each part of every pattern of plow, and can promptly supply the same to order, with the assurance that it will nicely fit the place for which it is wanted, and that an amended plow will work truly and efficiently again.

Hundreds of premiums have been awarded for these plows.

\section{MAPES' LIFTING SUBSOIL PLOW.}

This implement, invented by the editor of the Working Farmer, and fully described at pages 64 to 68 , is one of the greatest improvements of the day; the smaller sizes are used to disturb soil between row crops, while the larger sizes will disintegrate more soil, to a greater depth, and with less power than any other Implement. In underdraining, the lifting subsoil plow is used with great economy. 



\section{THE UNIVERSAL PLOW.}

The large engraving, opposite, is a view of the Universal Plow with its twelve mould-boards. This is a recent invention. The implement embraces various forms and sizes of mould-board, each nicely fitting one common standard and frame-work--thus adapting the plow to a wide variety of soils and modes of culture. Each mould-board is constructed to perform its respective work in a thorough and finished style.

The advantages of having the various mould-boards, needed for the different soils and modes of culture, combined in one general implement, rather than made up separately in several plows, the saving of expense thereby and of storage, are too apparent to need comment.

The Universal Plow embraces the following kinds and sizes of mould-boards:

1. For plowing intervale and other smooth grass lands, five sizes of mould-board, of long and gentle spiral or twist, viz.:

(Mark on Mould-board.)

"Intervale No. 120," flat furrows, 7 to 10 inches deep, 14 to 16 wide.

"Intervale No. 121," flat furrows, 5 to 9 inches deep, 13 to 15 wide.

"Intervale No. 122," flat furrows, 4 to 8 inches deep, 12 to 14 wide.

"Intervale No. 123," flat furrows, 4 to 7 inches deep, 11 to 13 wide.

"Intervale No. 124," flat furrows, 3 to 6 inches deep, 10 to 12 wide.

2. For plowing upland, stony land, old pastures, and other grass lands of uneven or rough surface, four sizes of mould-board of short and powerful twist:

(Mark on Mould-board.)

"Upland No. 140," flat furrows, 5 to 9 inches deep, 13 to 15 wide.

"Upland No. 141," flat furrows, 4 to 8 inches deep, 12 to 14 wide.

"Upland No. 142," flat furrows, 4 to 7 inches deep, 11 to 13 wide.

"Upland No. 143," flat furrows, 3 to 6 inches deep, 10 to 12 wide.

3. For plowing clay and other stiff soil sod, lapping the furrow-slices one upon another at an inclination of $45^{\circ}$.

(Mark on Mould-board.)

"Lap Furrow No. 132," 6 to 8 inches deep, 11 to 12 wide.

4. For plowing stubble or old ground, two sizes of mould-board, throwing the soil orer abruptly and breaking it finely:

(Mark on Mould-board.)

"Stubble No. 150," 6 to 12 inches deep, 12 to 16 wide.

"Stubble No. 152," 4 to 9 inches deep, 10 to 14 wide. 
5. Also by using the skim or little forward plow on the same beam with the stubble mould-board, two sizes of superior Double, or Sod and Subsoil plows:

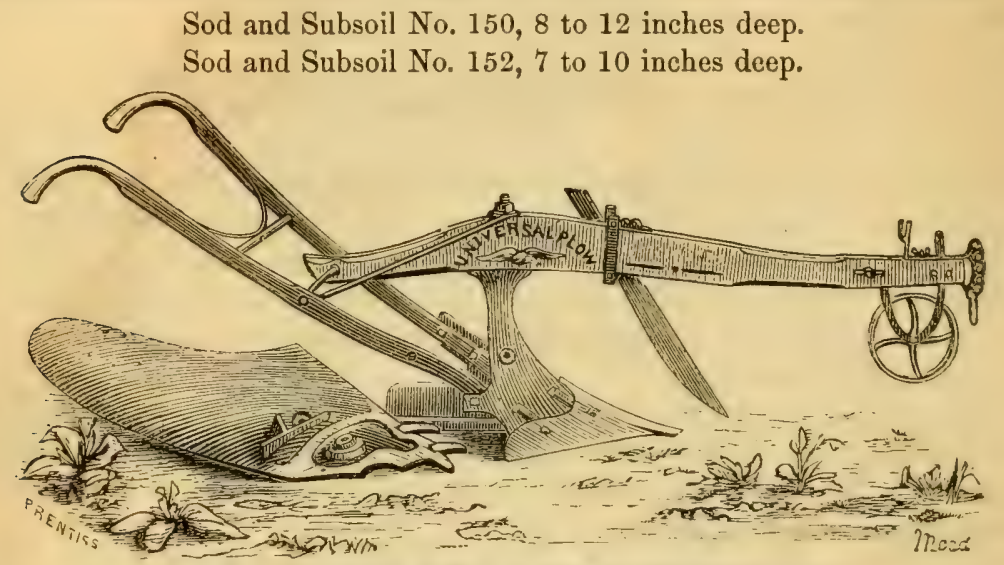

Fig. 2. Frame-work of Plow, with Mould-Boaru detached.

Fig. 2 is a view of the standard, share and frame-work of the Universal Plow, with one of the mould-boards lying in the rear. The slots in the standard, just back of the share, receive the locks on the forward end of the mould-board; the button on the mould-board, a little back of and above the locks, enters the socket back of and above the slots in the standard, and a bolt passing through the mouldboard and standard at this point, is made fast by a nut on the inner side; another bolt confines the mould-board to the right hand handle of the plow; and thus by means of the two locks and the two bolts the mould-board is held firmly and securely to its place. By loosening the bolts, any mould-board is taken off to give place to any other one of the series. The greatest attainable simplicity has been closely studied in adjusting the parts of this plow, so that the various changes are easily and quickly made.

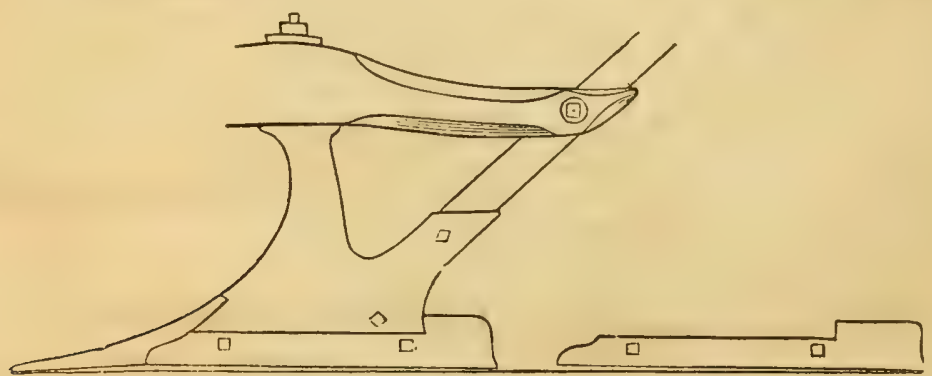

Fig. 3.

Fig. 3 is an outline of the land-side, showing how the sole or shoe piece is attached. It represents a long and short shoe-the former being used with the longest and largest of the Intervale mould-boards, and the latter with the Upland and Stubble. On all plows, the shoe of the land-side is exposed to great friction, 
and needs renewing long before the mould-board wears away. The shoe is very cheaply renewed on this plow.

Fig. 4 is a top view of one of the mould-boards for turning sod flat, showing the desirable form or twist for laying that kind of work in handsome style.

Fig. 4.
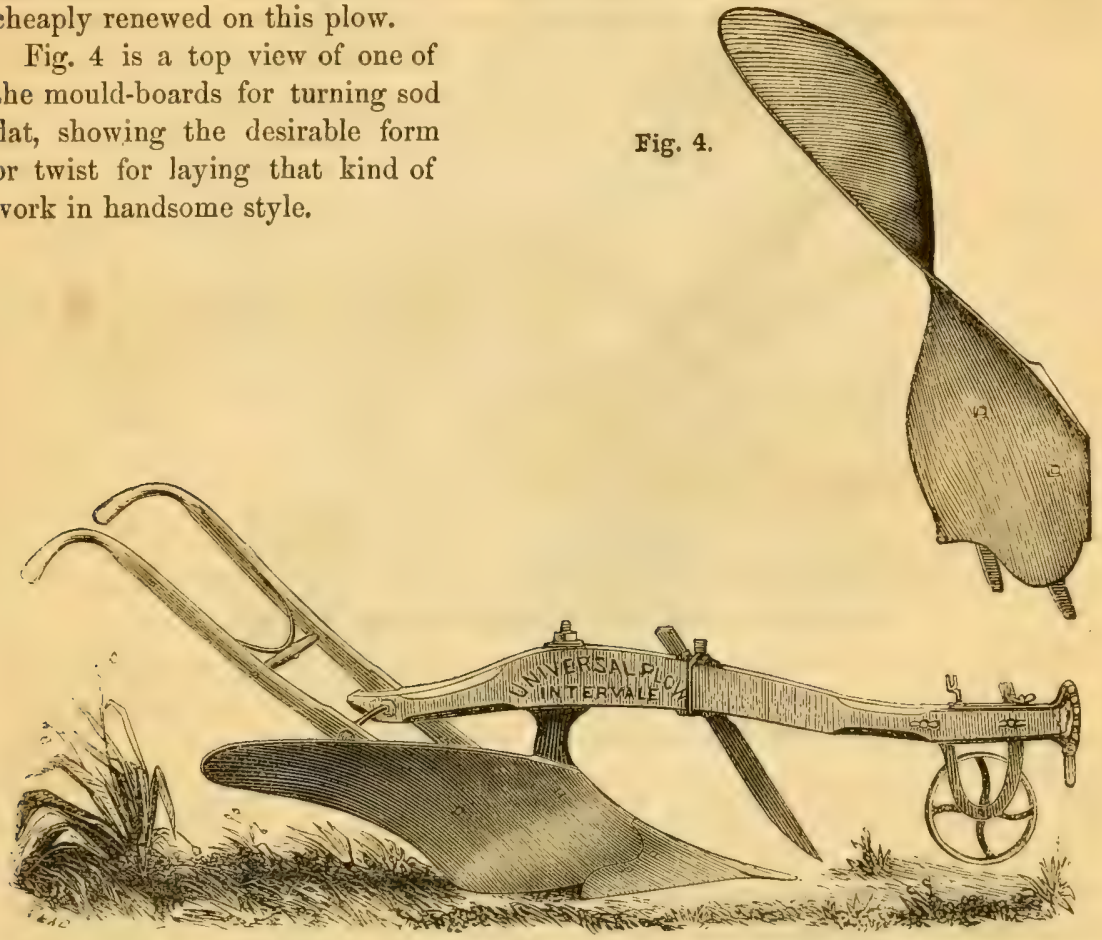

Fig. 5.

Fig. 5 is a side view of the plow rigged with one of the Intervale mould-boards. and wheel and cutter, for plowing flat furrows in smooth grass land.

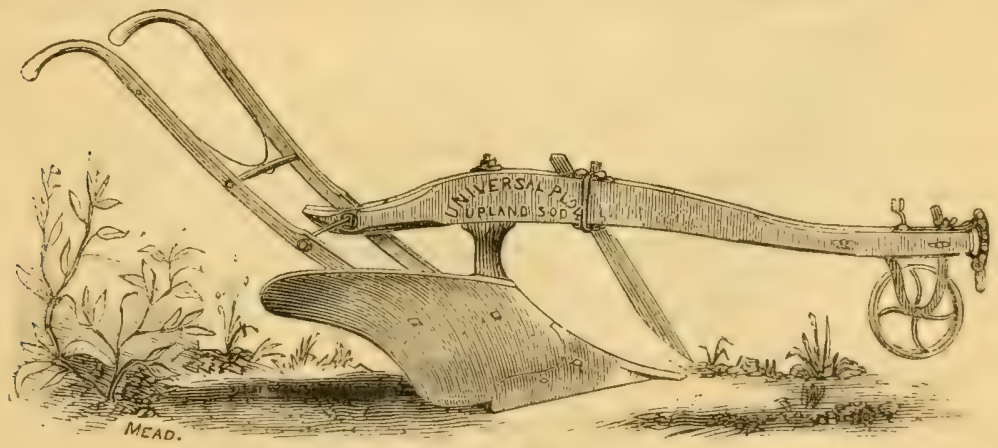

Fig, 6.

Fig. 6 is a side view of the plow rigged with one of the Upland mould-boards, for plowing flat furrows in stony or rough grass land.

Fig. 7 represents the movement of the sod as turned by an Intervale mouldboard. The long, easy flexure of the furrow-slice is noticeable; and the gentle and 


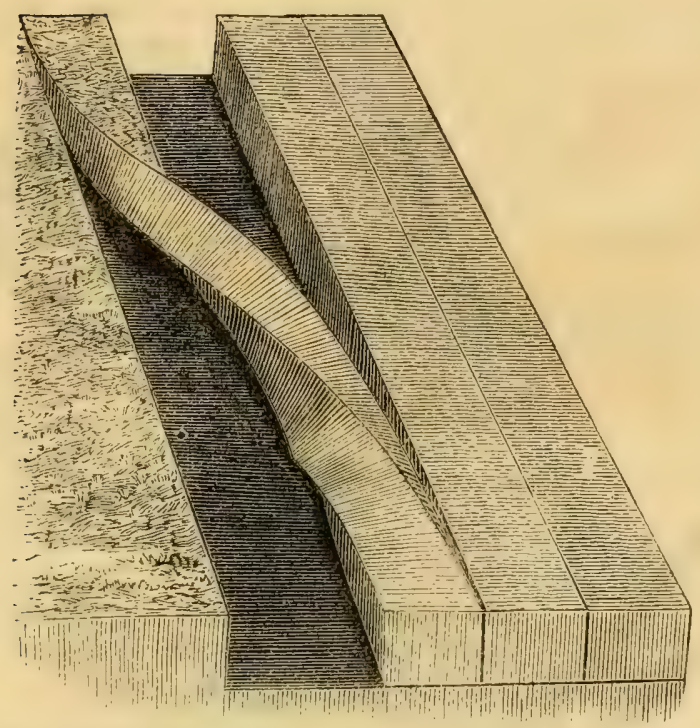

Fig. 7. View of the Movement of the Intervale Furrow-Slice.

gradual twist of the mould-board, which produces this result, also makes the plow of light dranght, and promotes highly-finished flat-furrow plowing in smooth land.

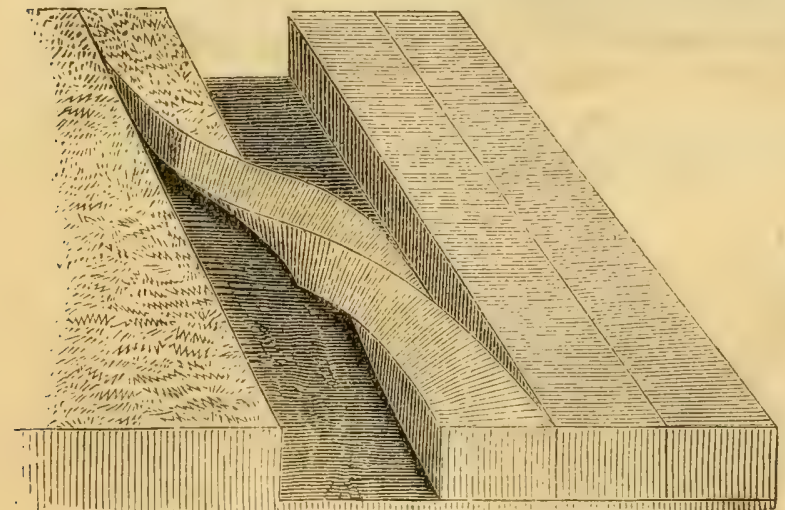

Fig. 8. View of the Movement of the Upland Furrow-Slice.

Fig. 8 shows the movement of the sod as turned by an $\mathrm{Up}$ land mould-board. The curvature of the sod is quicker than that represented in the preceding cut. The more abrupt twist of the Upland mould-board, though increasing the draught of the instrument somewhat, and not producing as handsome work as the Intervale mould-board in smooth land, is yet very valuable in plowing sod land that is quite stony or of a rough surface. It makes a short plow, which, when inter. rupted in its work by stones or stumps, or in passing ridges and hollows, readily catches its full depth of furrow again, and by its short and powerful curvature makes sure work of overturning the sod among these obstacles, where a longer plow could not produce so exact and desirable results. 


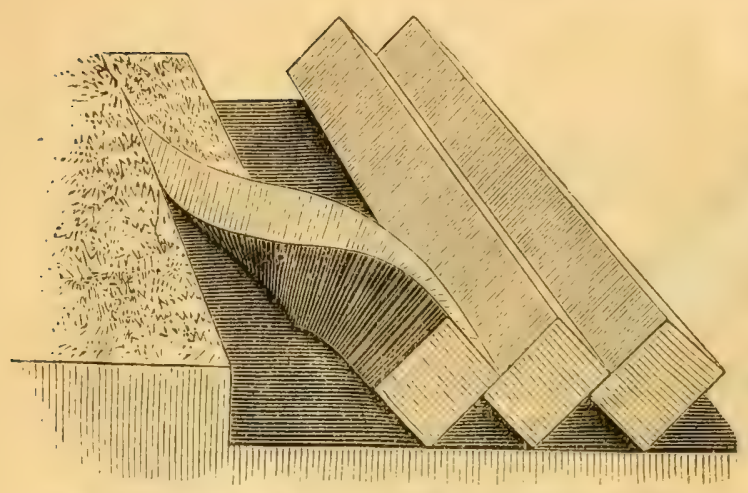

Fig. 9. View of the Movement of the Lapped Furrow-Slice.

Fig. 9 represents the movement of the sod as turned by the Lap Furrow mould-board. This mould. board is designed for turning stiff clay sod, lapping the slices one upon another at an inclination of $45^{\circ}$. The projecting angles of the furrow-slices present the greatest possible surface of soil to the atmospheric influences, and contain the greatest at-

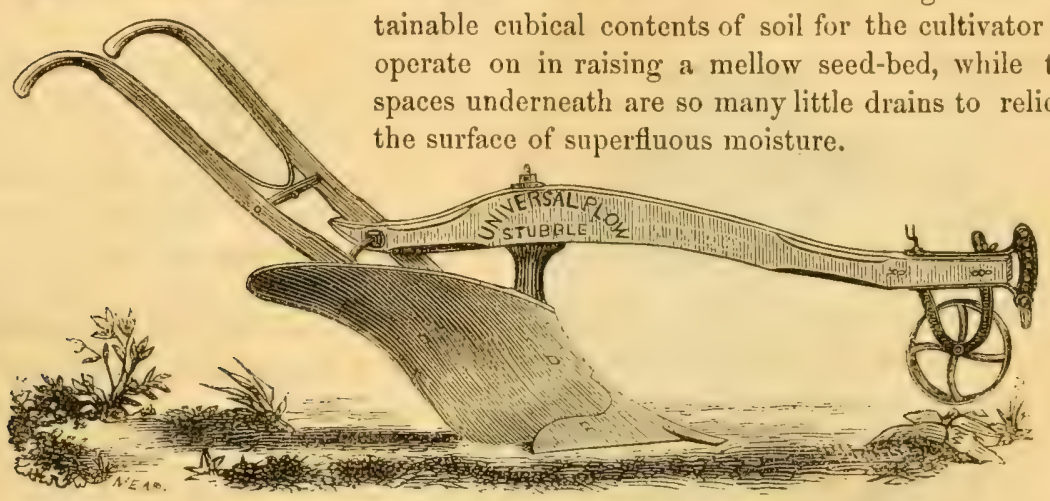

Fig. 10.

Fig. 10 is a side view of the plow rigged with one of the Stubble mould-boards' for plowing stubble or old ground.

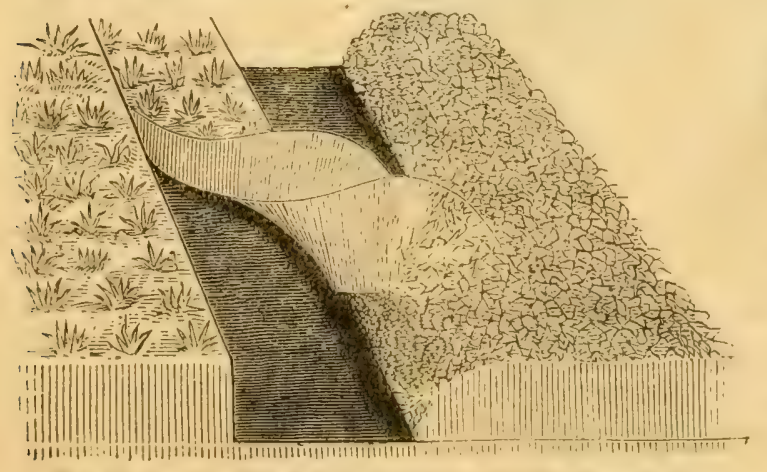

Fig. 11. View of the Movement of the Stubble Furrow-Slice.
Fig. 11 shows the morement of the old ground slice, as turned by one of the stubble mould-boards. The elevating and turning power of the mould-board is quite apparent in the sudden and high twist of the furrow-slice; and its capacity for breaking up and pulverizing ther soil is remarkable.

Fig. 12 is a side view of the plow rigged with one of the stubble mould-boards and the skim plow forward, for Double, or Sod and Subsoil plowing. 


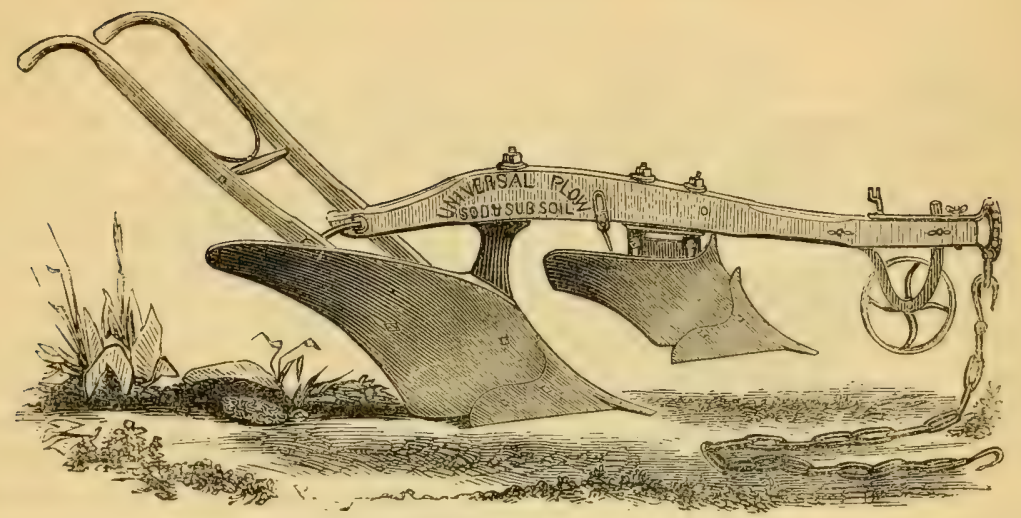

Fig. 12.

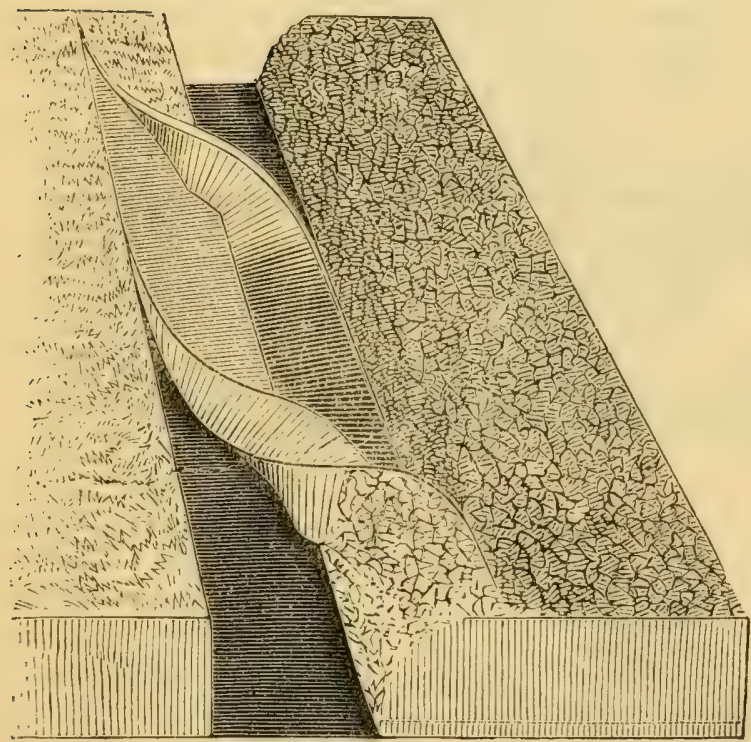

Fig. 13. View of the Movements of the Sod and Subsoil Furrow Slices.

Fig. 13 shows the movement of the two furrow-slices as turned by the Sod and Subsoil plow. The skim takes off the sod two to four inches deep, turning it into the furrow channel; and the rear mould-board lifts the under soil from the depth of six to eight or ten inches, scattering it over the sod-slice turned by the forward mouldboard, and filling the channel. The elevating and pulverizing power of the stubble mould-board, as seen in Fig. 11, is agair apparent in its work as the rear mould-board in Sod and Subsoil plowing.

The Universal Plow is sold by the proprietors, with one mould-board only, or with any number of mould-boards, as the purchaser may select. It is a desirable implement if but one mould-board is wanted, because that one will do thorough and finished work, and when worn away considerably, or if by accident broken-a contingency to which the mould-board of any plow is liable-its place can be cheaply supplied with a new one. Again, the purchaser, after obtaining one mould-board, and the standard, share and frame work to go with it, can at any time procure such other mould-boards of the series as he would like, at slight expense, as compared 



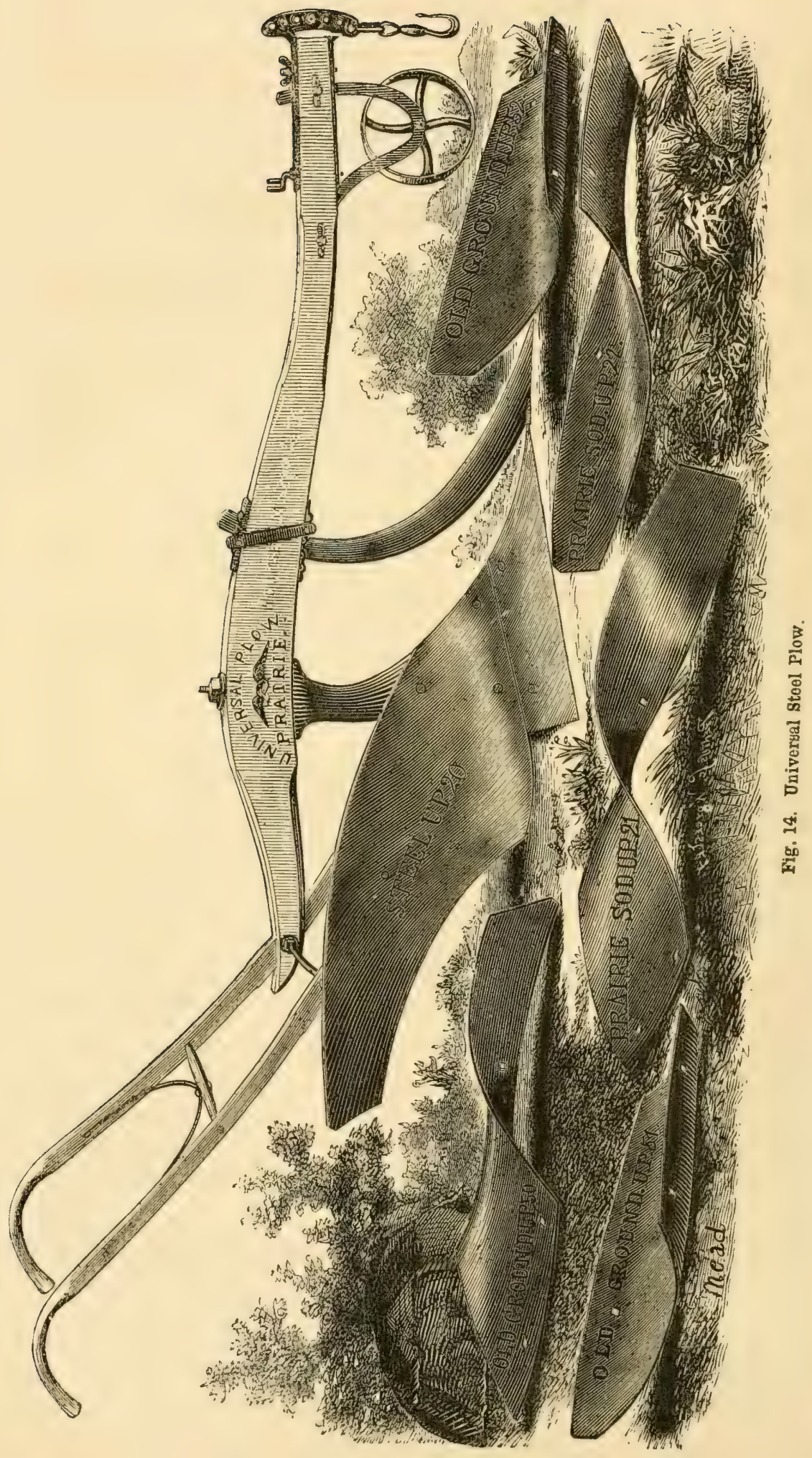


with buying new plows entire; and thus he may be induced to employ a larger and better assortment of plows, suited to his varions fields and modes of culture, than he otherwise wonld use.

\section{UNIVERSAL PLOW-STEEL.}

The Universal Plow is made with steel mould-boards, share and land-side, and an iron standard. The large engraving, opposite, represents the plow with its various steel mould-boards. Such other sizes or forms of mould-board as the wants of the public may call for, will be added to the present series.

The Share is put on with two bolts and nuts, so as to be handily changed and cheaply repaired, or replaced with a new one. The old ground monld-boards have a different share from the mould-boards for breaking sod. Shares of any width of cut desired are furnished with the plow, to order, as are also extra shares, to take the place of those worn out or needing repair.

The Land-side is bolted to the standard and beam handle, and fits up snugly to the share without being welded to it, and thus may be readily detached for repair or otherwise.

The Mould-boards each fit a common standard and frame, and are bolted to the mould-board handle, each one having the requisite backing to give it a bearing against the handle. The Mould-boards for old ground are set at a more or less abrupt angle to the furrow, as different soils or practical uses may require.

The Universal Plow in steel is sold with one of the mould-boards only, or with any number of them, as the purchaser may choose. It is a valuable plow to own with one mould-board only, as whichever of the series that one may happen to be, it will do its work thoroughly, with ease to the plowman and team. If a variety of sizes and forms are wanted, then, after purchasing the frame-work and one mouldboard, additional plows are in effect procured at the cost of mould-boards only; and little storage-room is required for a full assortment of plows, adapted to various kinds of ground and modes of culture.

The Universal Plow in steel enbraces the following linds and sizes of mouldboards :

1. For breaking Prairie, or for plowing any other grass lands shallow or deep, three sizes of mould-board, viz. :

(Stamp on mould-board.)

"U. P. 20 " furrows 14 to 16 inches wide, draught of three horses.

"U. P. 21" furrows 13 to 14 inches wide, draught of two to three horses.

"U. P. 22" furrows 12 to 13 inches wide, dranght of two horses.

2. For plowing old ground, overturning and pulverizing it thoroughly, four sizes of mould-board of abrupt curvature, viz. :

(Stamp on mould-board.)

"U.P. 50 " furrows 15 to 18 inches wide, two to three horses. 
"U. P. 51" furrows 14 to 16 inches wide, two horse, large.

"U. P. 52" furrows 12 to 14 inches wide, two horse, medium.

"U. P. 53" furrows 10 to 12 inches wide, two horse, small.

3. Also by using the skim plow forward on the same beam with the Old Ground mould-boards, two sizes of Double, or Sod and Subsoil plows, viz. :

"Sod and Subsoil, U.P. 50," 6 to 12 inches deep, draught of four to six horses or oxen.

"Sod and Subsoil U. P. 51," 5 to 9 inches deep, draught of three to four horses.

Mould-board No. U.P. 20, is represented on the plow in the large engraving, with the peacock coulter attachment, for breaking Prairie, furrows 14 to 16 inches wide, team three horses. The circular cutter is attached in lieu of the peacock coulter, where the purchaser so prefers.

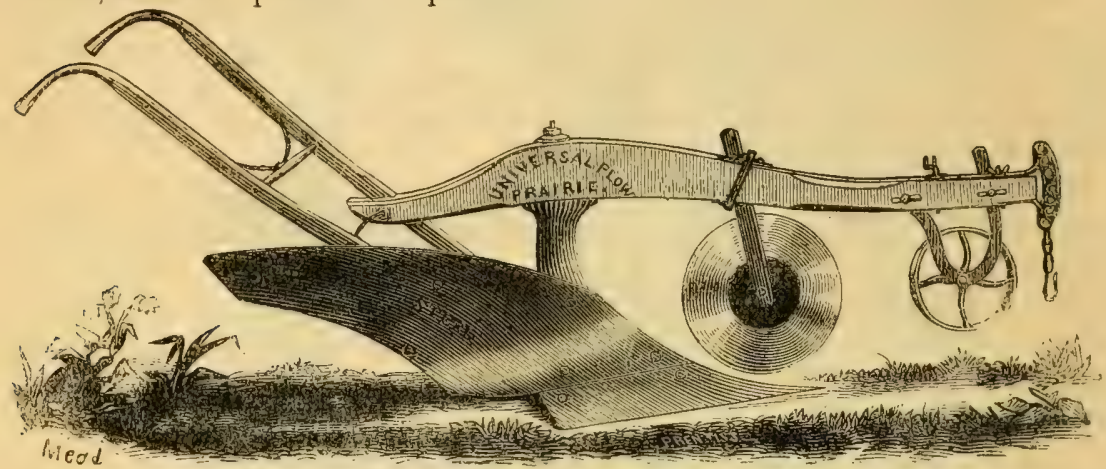

Fig, 15. Breaking Plow, U. P. 21.

Fig. 15 is a side view of the plow rigged with the mould-board No. U.P. 21, and the circular cutter, for breaking Prairic,-furrows 13 to 14 inches wide, team two to three horses. The peacock coulter is put on instead of the cutter, when preferred.

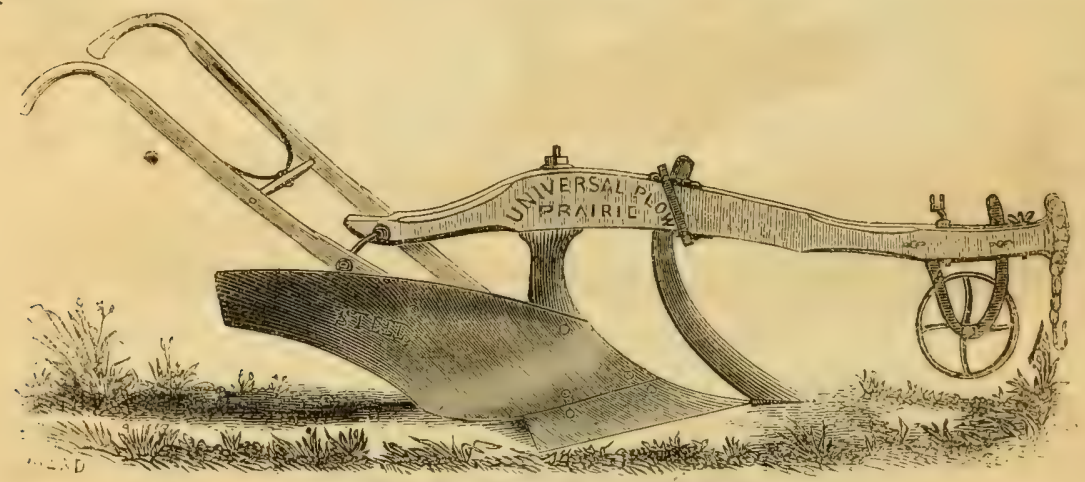

Fig. 16. Breaking Plow, U. P. 22.

Fig. 16 is a view of the plow rigged with the mould-board No. U.P. 22 and thr peacock coulter, for breaking Prairie,-furrows 12 to 13 inches wide, two horse team. It is trimmed with either cutter or coulter, as desired. 


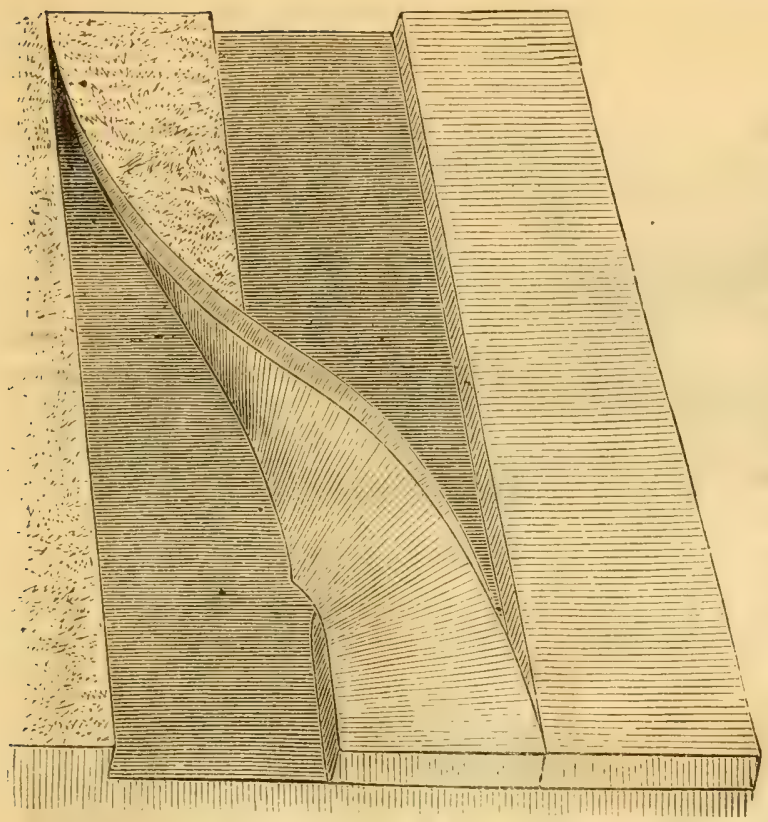

Fig. 17 is a view of the movement of the sod furrow-slice, as turned by one of the mould-boards, two to three inches decp by fifteen inches wide. The mould-boards have a broad cutting share and flat and gradual entrance under the sod, which, with their equal and easy curvature, or twist, adapts them to turn the furrow-slice over handsomely, giving the plow a true and level run and light draught.

\section{Fig. 17. View of the Movement of the Prairie Furmow-Slice.}

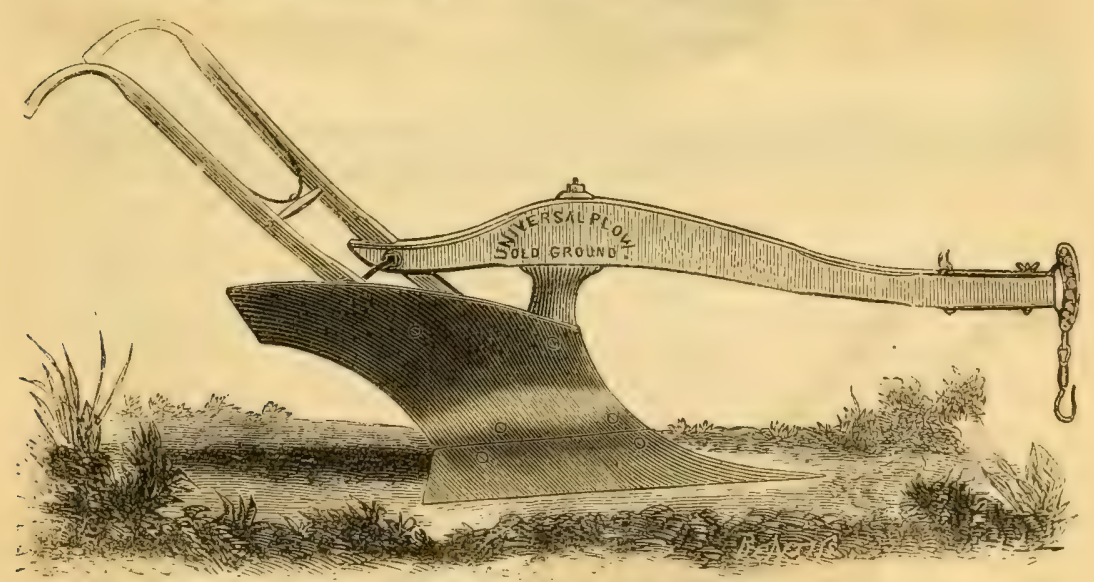

Fig. 18.-0ld Ground Plow, U. P. 50.

Fig. 18 is a view of the plow rigged with the mould-board No. U. P. 50, for plowing old ground,-furrows fifteen to eighteen inches wide.

The plow rigged with either of the old ground mould-boards will bury any amount of "trash," shallow or deep, as may be preferred. The mould-boards are high and of extra turning capacity, to fit them for turning under weeds and stubble of rank growth. 


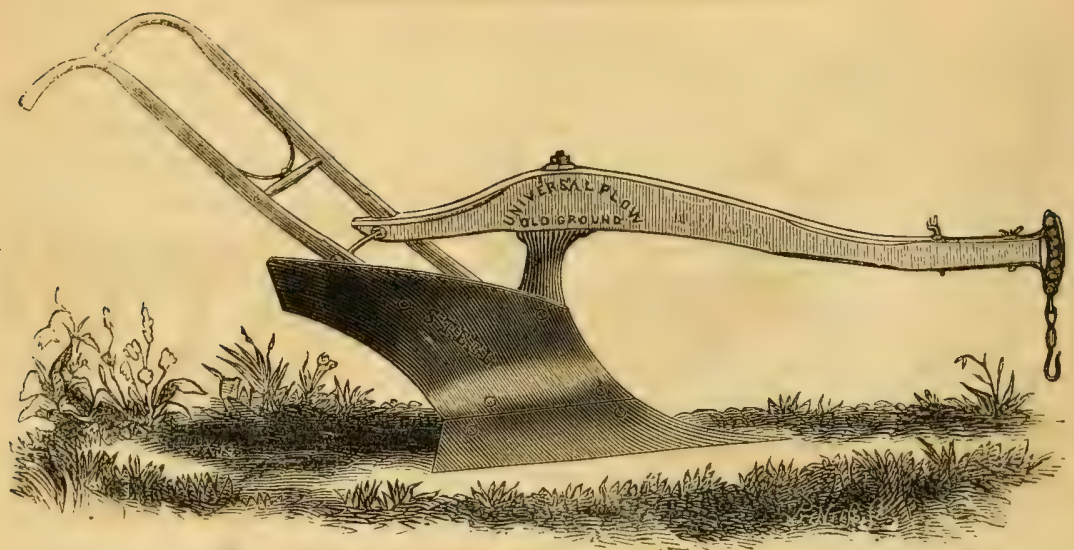

Fig. 19. Old Ground Plow, U. P. 51.

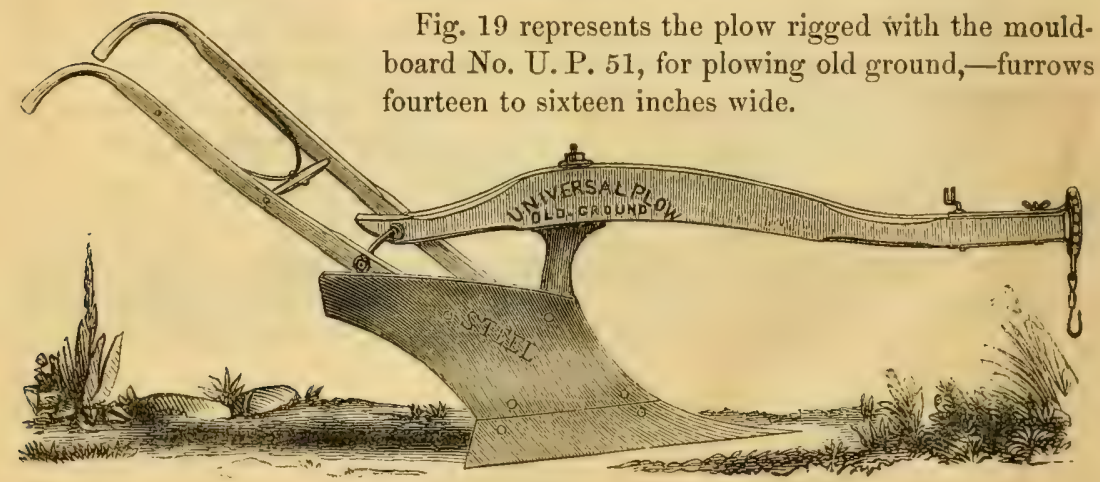

Fig. 20. Old Ground Plow, U. P. 52.

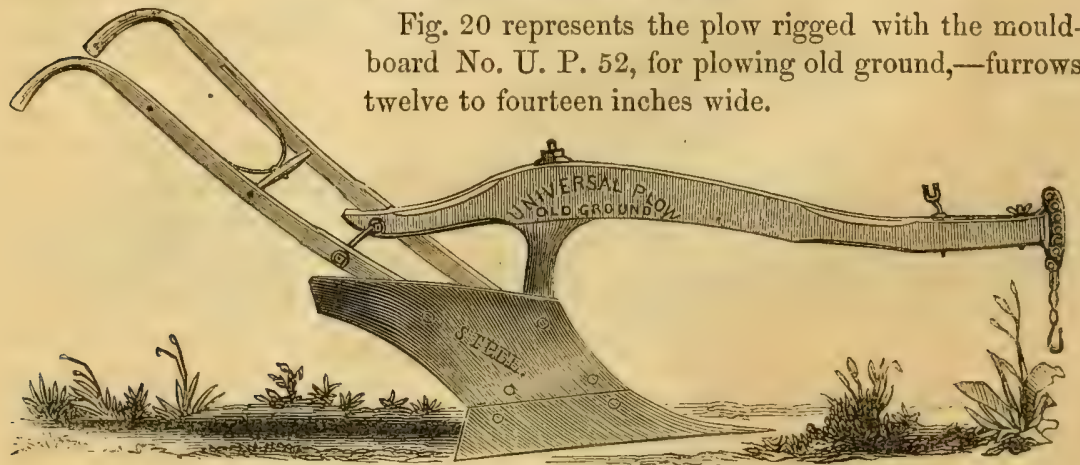

Fig. 21.-Old Ground Plow, O. P. 53.

Fig. 21 is a view of the plow rigged with the mould-board No. U. P 53, for plowing old ground, ten to twelve inch cut, light team. 


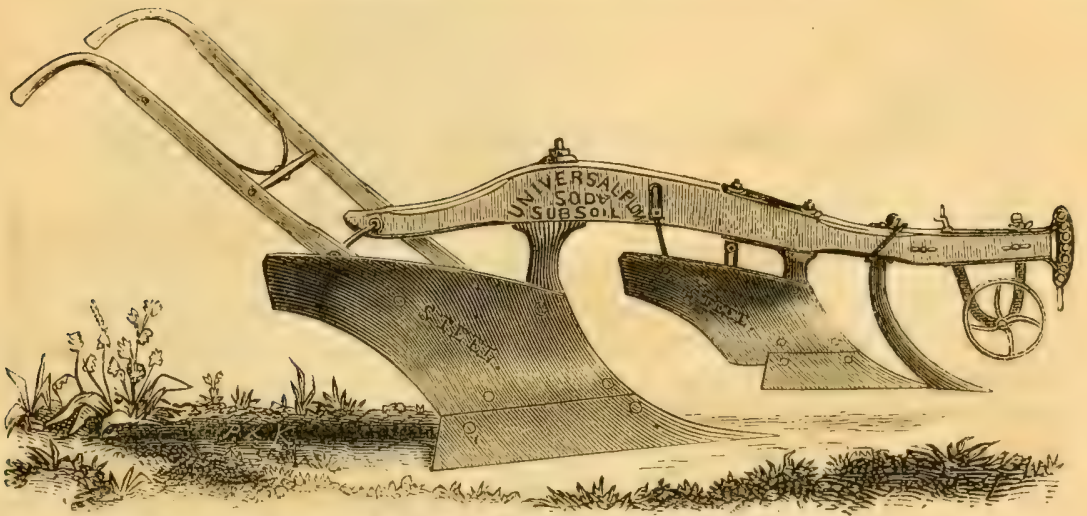

Fig. 22. Sod and Sub-Soil Plow, U. P. 50.

Fig. 22 is a side view of the plow rigged with the old ground mould-board No. U.P. 50, and the skim plow forward on the same beam, with the peacock coulter attached, for breaking Prairie, in the sod and subsoil style of plowing.

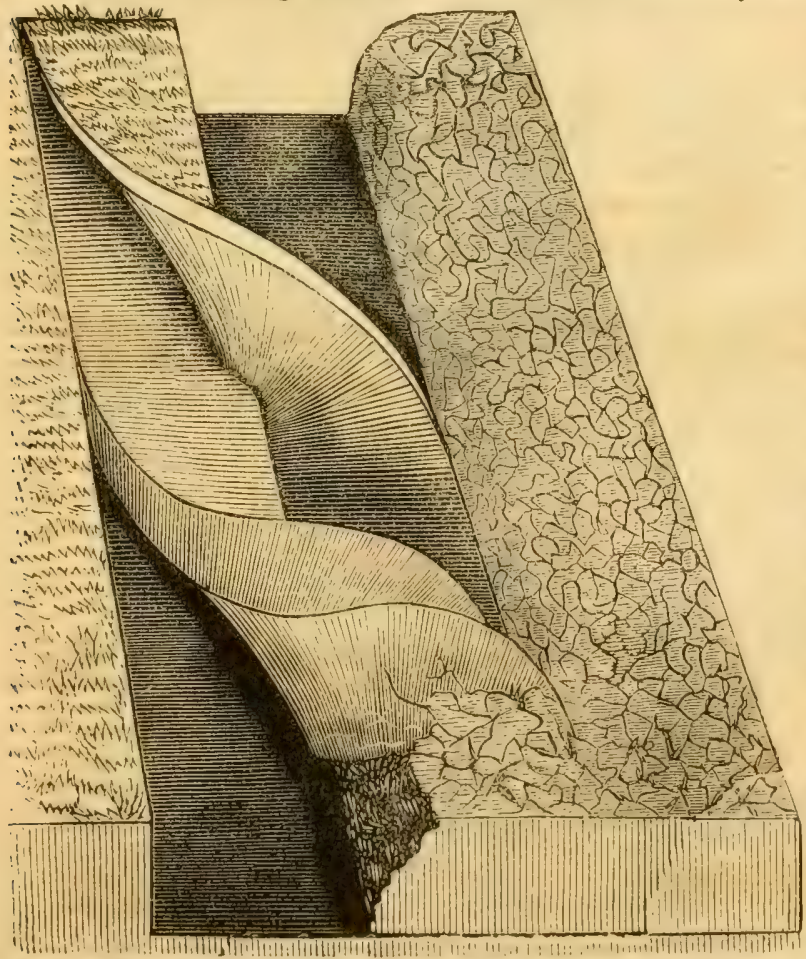

Fig. 23 represents the movement of the two furrow-slices in breaking Prairie with the Sod and Subsoil plow No. U. P. 50. The skim or forward plow cuts twelve or thirteen inches wide, and takes off a slice of sod from one to three inches thick, as may be desired, turning it into the furrow channel: the rear mould-board following, lifts the under soil in slices from thrce to eight or ten inches thick, at the option of the plowman, and deposits it on top of the sod slice, turned by the skim plow. With this plow the raw Prai-

Fig. 23. View of the Movement of the Sod and Subsoil Furrow-slices. rie, wherever tolerabiy feasible for plowing, can, at one operation, and the first time broken, be converted into the condition of mellow old ground. 


\section{New Series of Plows.-Deep Tillers.}

CAST IRON MOULD-BOARDS.

Plow No. 78, represented by the cut on the opposite page, is the largest of the series of the deep tillers. It is rigged with the lock coulter and broad steel share, to fit it for rugged work among stumps, roots, and stones, and for the making and repairing of highways. It is a very strong plow, and may be worked by six to eight oxen, turning furrows nine to fourteen inches deep, and sixteen to twenty inches wide. This plow is now being successfully used in clearing the scrub-oak lands of Long Island, New Jersey, and elsewhere, and when used in connection with the lifting subsoil plow of the larger size, materially lessens the expense of clearing new land.

Plow No. 77, which is represented by the cut on a following page, is next in size to No.78, and will carry a furrow-slice from eight to twelve inches deep, by fifteen to eighteen inches wide, and has great turning power. No. 77 is worked by six horses or oxen in easy soils, or by eight in very heavy soils.

This plow is well suited for burying the light surface of sand on new lands in Burlington and Nonmouth Counties, New Jersey, and other similar soils.

Plow No. 76 is of the same general construction, and performs in proportion to size; working seven to ten inches deep, by fourteen to sixteen wide. It is rigged with cutter for smooth lands, and with lock coulter for plowing among roots and stones.

Plow No. 75 is next in size, and is adequate to the turning of sod furrows six to nine inches deep, by thirteen to fifteen inches wide. It is easily drawn by two oxen and a horse, or three horses, at seven and eight inches, and by four oxen or horses at nine inches deep.

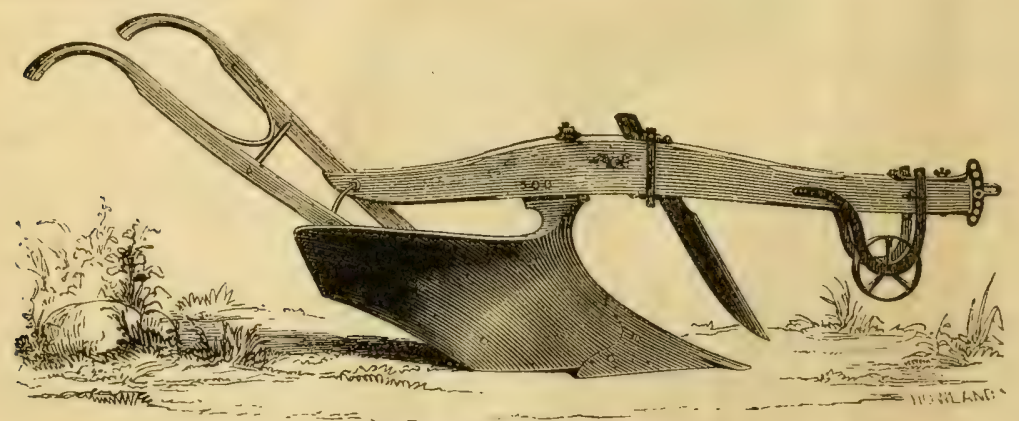

Fig. 24. Plow No. 73\%.

Plow No. $73 \frac{1}{2}$ is next in size to No. 75. It turns sod furrows five to eight inches deep, by eleven to fourteen inches wide, and may be drawn by two cattle or horses to the depth of seven inches; if worked deeper it is a threc-cattle plow. It is adapted to flat or lapped plowing, by the use of an inclined cutter for the first, 


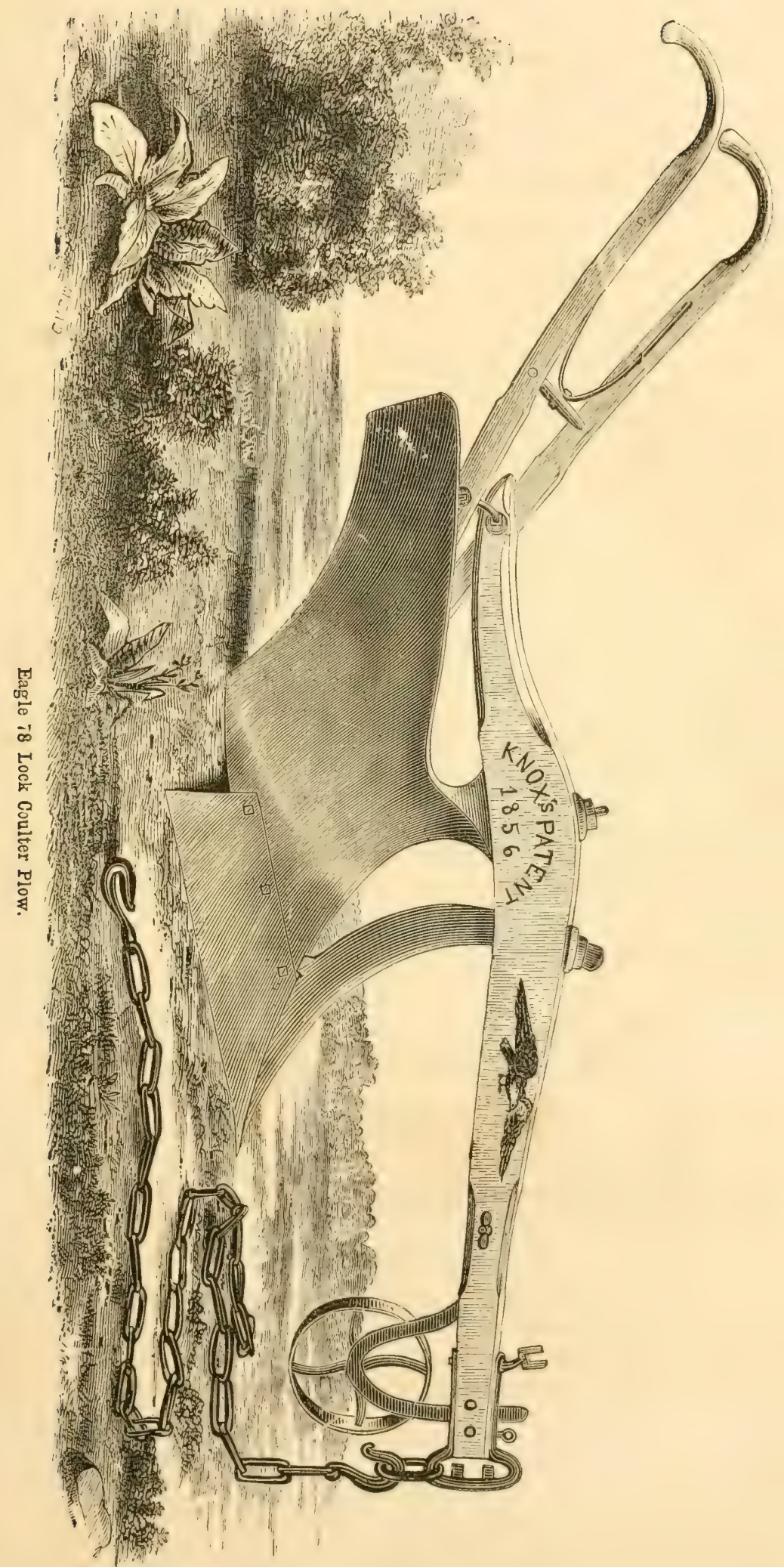



and a straight cutter for the latter mode of plowing. This change may be made at pleasure by the plowman.

At the Fair of the American Institute a few rears since, one plowran used this plow rigged for laying lap furrows, and took the first premium for the best lap plowing. Another plowman used the same plow for laying flat furrows, and took the first premium for the best flat plowing; each having many competitors.

Plow Yo. $71 \frac{1}{2}$ is next in size to To. $73 \frac{1}{2}$, and is especially designed for plowing loose, porous, sandr, and gravelly loams. It turns sod furrows five to seven inches deep, by eleven to thirteen inches wide, on a long and easy twist, so as to aroid unduly opening and disuniting its constituent parts; and, although this action would be detrimental in very heary soils, still, in those described, it is desirable, to enable their more perfect manipulation, as they require more compactness of parts; and hence the powerful pulverizing plow is not the best for working them. The best and most experienced cultivators of light, dry lands, have found that by thus plowing, and then compressing the furrows closely with a heary roller, they best insure the germination of seeds and an eren stand of crops.

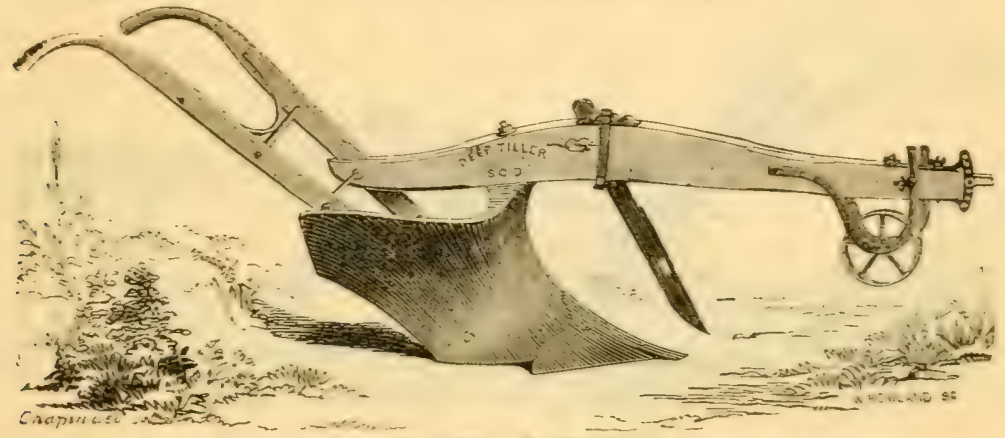

Fig. 25. Plow No. 33-Sod.

This cut represents the plow trimmed for sod plowing. It is well adapted to the plowing of grass lands that are stony and of uneven surface; its mould-board gives a short and powerful but equal twist to the furrow-slice, and leares the plowed land in a mellow condition susceptible of tilth. It may be moved by two or three cattle, rorking it fire to eight inches deep and eleven to thirteen inches wide.

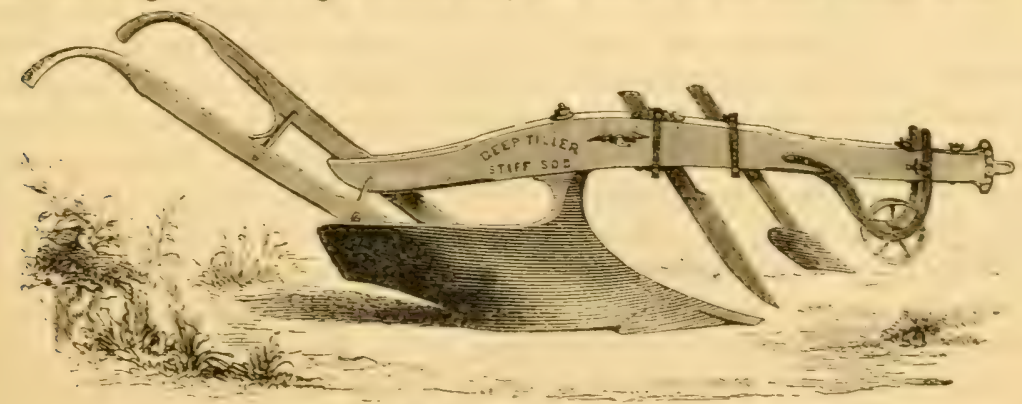

Fig. 26. Piow No. $72 \not 3$. 


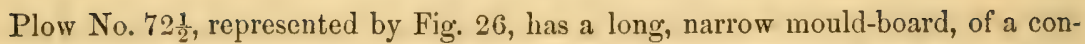
vex surface, and is specially designed for stiff soil, turning narrow furrow-slices, twothirds as deep as they are wide. No $72 \frac{1}{2}$ is adapted to turn furrow-slices 7 inches deep by 10 inches wide, in stiff clay sod, and set them at an inclination of $45^{\circ}$; and that is a position of furrow presenting the greatest attainable surface to the action of the atmosphere, and the greatest cubical contents of soil to the action of the cultivator in preparing a seed-bed. When the attempt is made to work clay sod with plows of short, wide, abruptly curved mould-boards, the furrows are too wide for their depth, and, turned abruptly, are broken in large pieces rather than disintegrated; they are laid over too flat, and in heavy clods, and a proper pulverization of the soil cannot be obtained. No. $72 \frac{1}{2}$, by its gentle convexity and curvature of mouldboard, is calculated to work bright and free in the most adhesive soil. The plow is rigged with or without the skim coulter; though this attachment is valuable because it disposes of the grass-edge of the slice, thus preventing the growth of grass between the lapped furrows, and its use is a convenience where finished lapped work is desired, acting in degree like a Michigan plow.

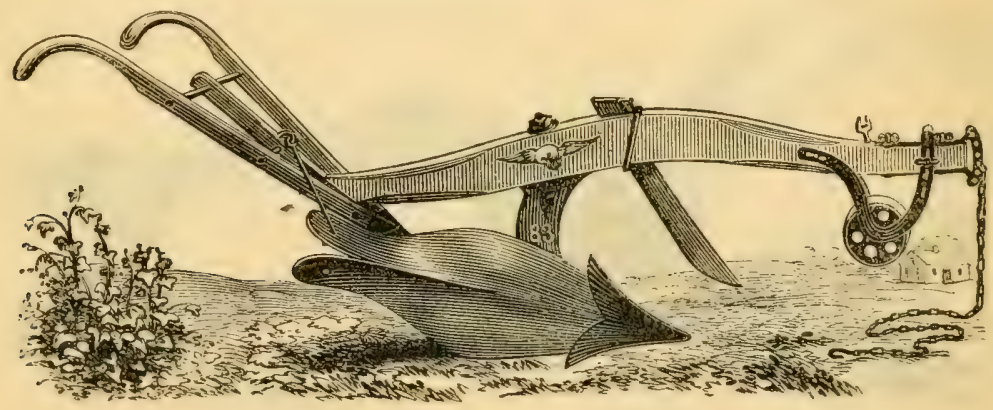

Fig. 27. Swivel Rlow, No. 83.

Plow No. 83, represented by Fig. 27, is a Swivel or Hill-Side plow. Its mouldboard, two in one, has the principles of construction of the other Deep Tillers. No. 83 is adapted to turn sod-slices 5 to 7 inches deep by 10 to 12 inches wide, whether the surface be hill-side or level land.

A hook, fastened by a staple to the center-piece of the handles, and changing to either side of the beam as may be desired, enters the back part of the mould-board, (as may be seen in the cut,) and holds it fast on either side of the standard as wanted. The mould-board is easily and instantly revolved from one side of the standard and beam to the other, making a right or left hand plow at pleasure, while the team is turning at the ends of the plow-field; indeed, if the hook is lifted, it naturally changes from one side to the other of itself, while the team is coming about at the ends of the field. With this plow, the plowman may commence on the lower edge of a hill-side, and turn his furrows all down the slope, changing his plow to a right or left hand one at each turning of the team at the ends of the field; or he may begin on one side of a level field, and lay his furrows all one way, thus avoiding the "dead" or cleansing furrow in the center, and the ridging on the sides; and at 


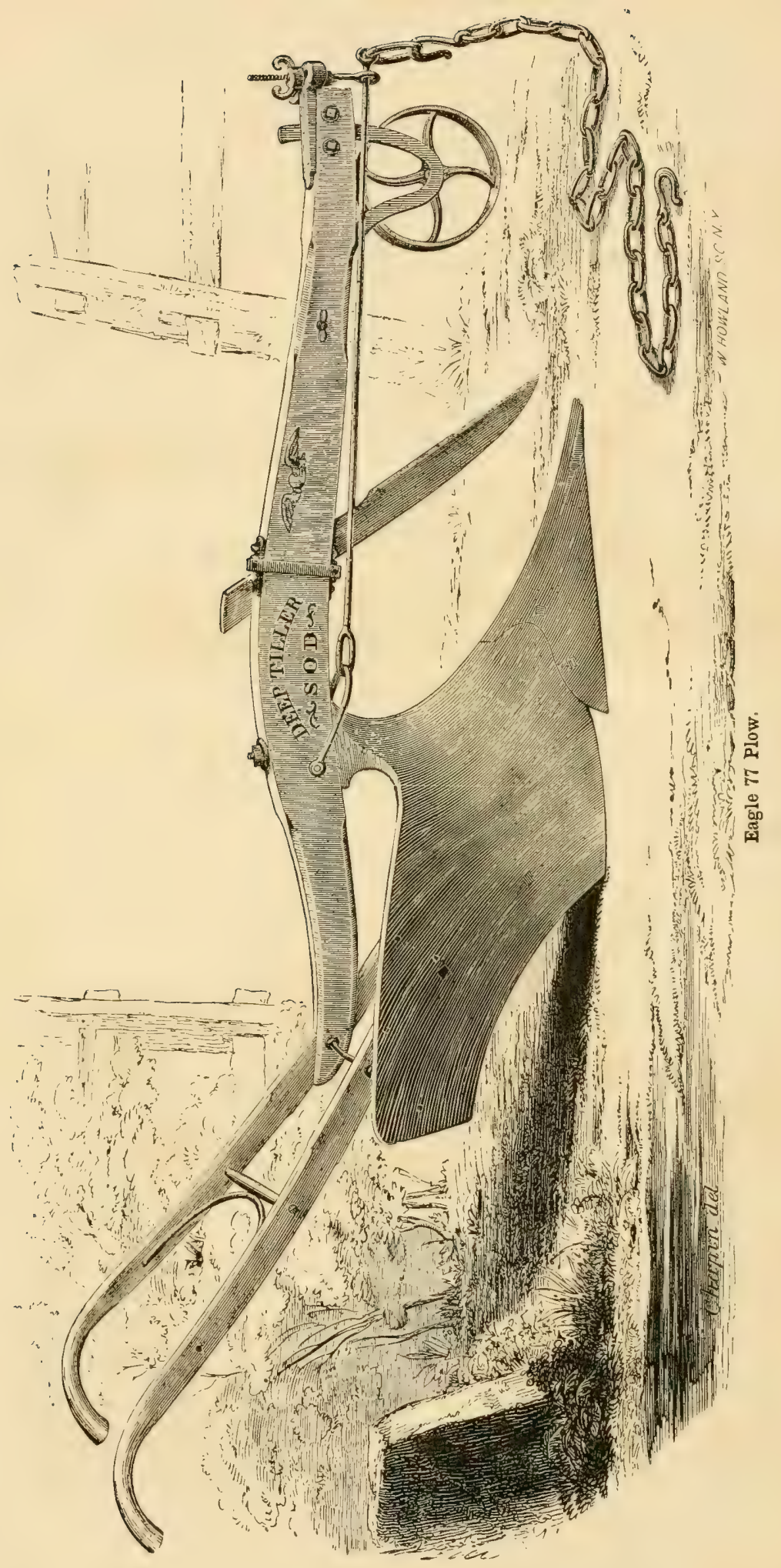


the next rotation of crops on the field, he may begin on the opposite side and turn them back again, thus keeping the soil equally distributed, and the surface level.

Swivel Plow, No. 84, is a size larger than No. 83, turning flat sod furrows, 6 to 9 inches deep. When worked to the greater depth, it is a four-horse or cattle plow.

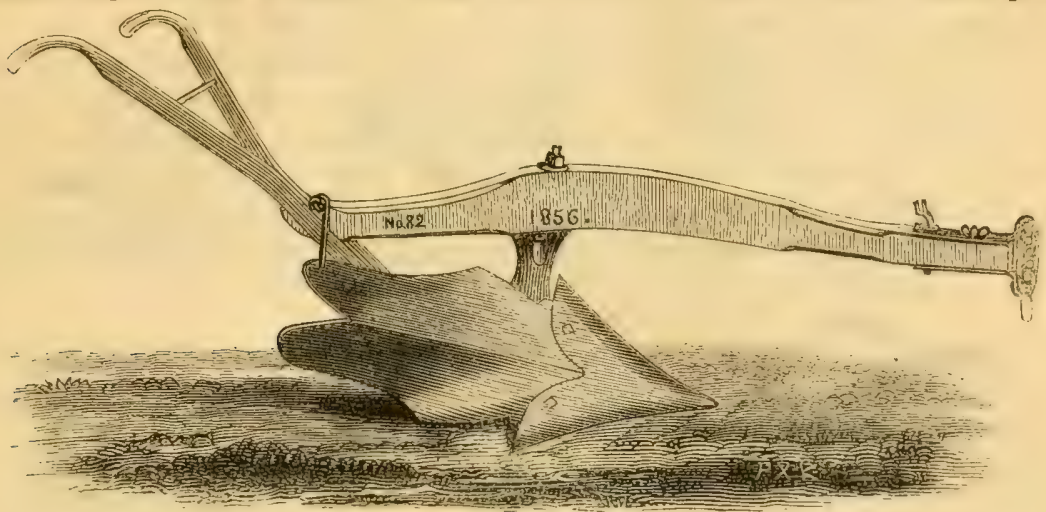

Fig. 27\%. Swivel Plow, No. 82.

Swivel Plow, No. 82, is like the two above named, in general construction, but has a quicker turned mould-board, to fit it for stubble or old ground plowing, turning furrows 4 to 8 inches deep, by 12 to 13 inches wide.

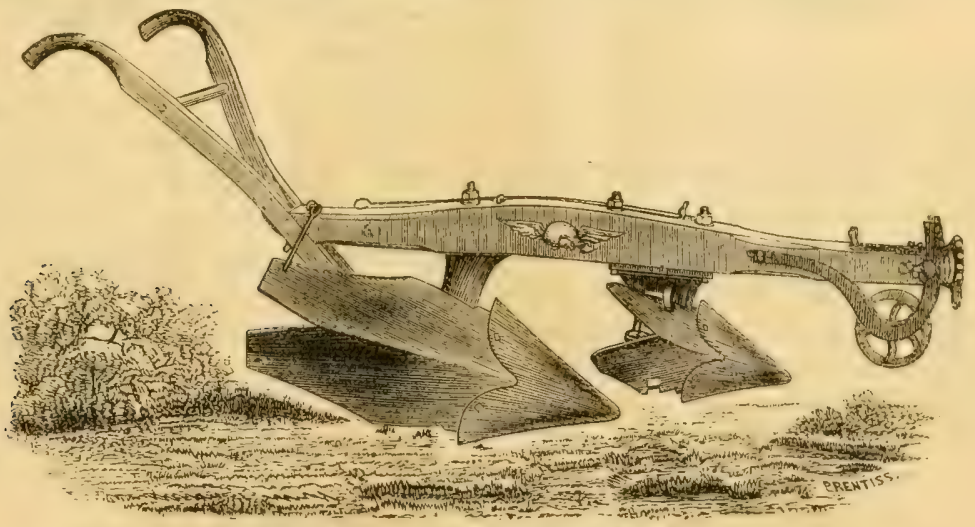

Fig. 28. Double Swivel Plow, No. 85.

No. 85, a Swivel Sod and Subsoil Plow, represented by Fig. 28, is a recent invention by Knox, and its mould-boards are formed on the principles discovered and perfected by him. The instrument is so constructed that two plows attached to one beam are readily changed from one side to the other, turning the furrow-slices either to the right or left, as desired. The forward plow turns the sod to the depth of about three inches, depositing it at the bottom of the channel; and the rear plow works to the depth of five to seven inches, raising and pulverizing the under or subsoil, and depositing it upon the forward furrow, burying the sod below the 
reach of the harrow or cultivator. This plow, combining the swivel with the sod and subsoil principle, enables the person using it to plow hill.sides in the sod and subsoil style; or to commence on one side of a level field, and passing forth and back turn the soil all one way, thus avoiding the center or dead furrow and ridges on the side.

To change the plows, on arriving at the end of each furrow, the plowman leans forward and raises the hooks or latches, retaining his hold on the handles, to keep the instrument in an upright position, while the team, in coming about, changes the plows to the opposite side of the beam. The beam is then tipped toward the side the plows are, the forward plow latches itself and becomes confined, and the plowman again stoops forward and latches the rear plow to its place-the whole being easily and quickly done.

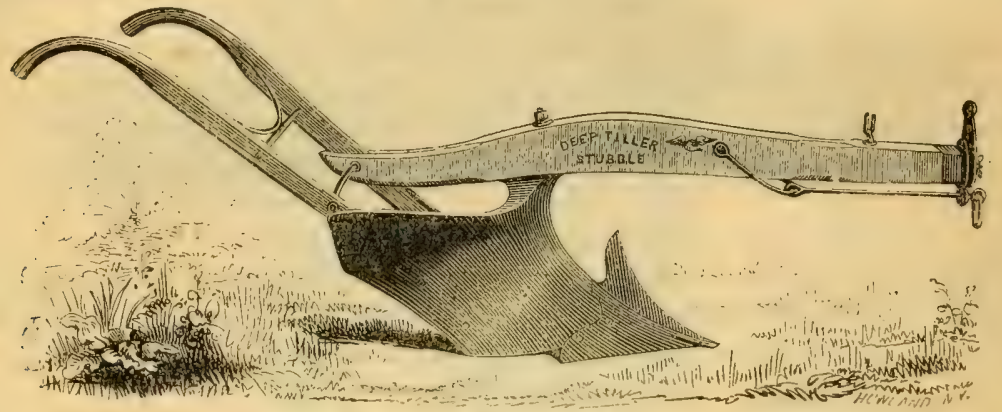

Fig. 29. Stubble Plow, No. 33.

Plow No. 33, for Stubble plowing, is represented by Fig. 29. It may be used as a swing plow, as represented in the cut, or with the addition of the wheel; or with the Fin Share, or the ordinary plain Share. For an explanation of the uses of the Fin Share, see cut and description of the same in this Catalogue. No. 33 is very high in the standard, which enables it to keep its course and depth in the ground without clogging. Its mould-board is short and high, of a capacity for deep work, of great turning power, and a thorough disintegrater and pulverizer of the soil. It works from 5 to 9 inches deep by 10 to 13 inches wide.

Stubble Plows Nos. 30, 31 and 32, smaller sizes, and No. 35, a larger size than No. 33 above described, are of the same principles of construction as No. 33, and their work is proportionately the same.

Plow No. 39 is specially adapted to the burying of broom-corn stubble. Through the Valley of the Connecticut river, where it has been much used, it is highly commended for its capacity to put the hills and stalks of the broom-corn crop cntirely beneath the surface.

Double Plow No. 33, for Sod and Subsoil plowing, is represented by Fig. 30. The forward mould-board is connected with the beam, and its depth of furrow is adjusted as follows: A substantial iron flange is fastened to the under side of the plow-beam by two bolts passing up through the flange and the beam and made tight $\mathrm{c} \Omega$ top by nuts and screws; the flange has two rows of slots in it to receive the bolts frem the land-side of the former plow, and the plow is made fast to the 


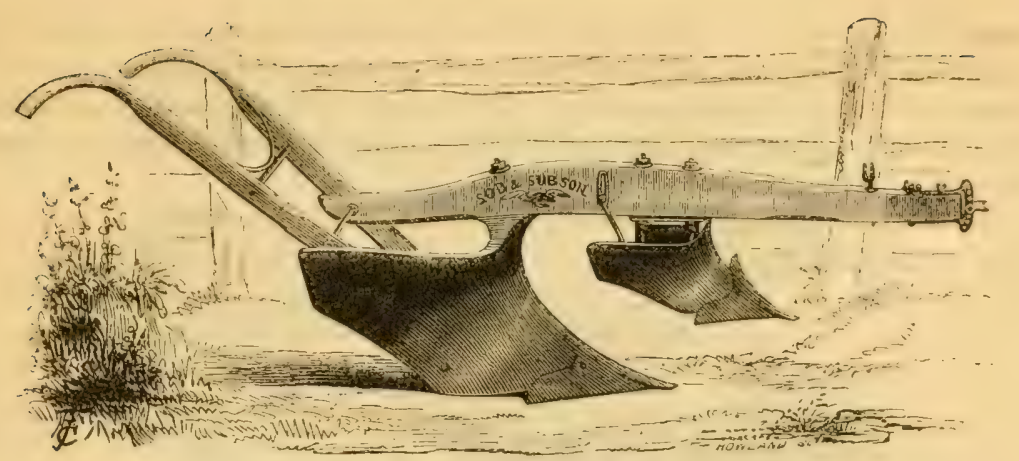

Fig. 30; Double Plow, No. 33.

flange by bolts and nuts. By means of the slots in the flange, the forward plow may be raised or lowered, according to the depth of plowing desired, and made fast at the requisite point to give the depth desired. The forward mould-board turns the sod-furrow as wide as the working of the whole plow, and the earth on top assuming an arch-like shape, is naturally opened, while the effort of the rear monldboard brings up the deeper soil, placing it upon the sod and filling the channel, so that the sod-furrow is in no case liable to be brought to the surface by after-cultivation, the cohesion of the soil is broken, and the plowed land lies light and mellow, and almost as fine as if worked by the cultivator-indeed, in some free soils it renders the use of the cultivator unnecessary.

TVe here subjoin cuts of a portion of the older patterns of Eagle Plows. They are very strongly made and especially well adapted to the plowing of stony lands, and lands of a rough and uneven surface. Plows of these patterns are spread abroad widely in the United States and in foreign countries, having been critically tested in various conditions of soil and cultivation; and for perfection of form, durability of material, and excellence of working properties, are regarded with much favor. The greatest commendation which can be paid to them is, that they have received over four hundred premiums, and have been initated in degree by many plow makers, who have sold them as genuine Eagle Plows.

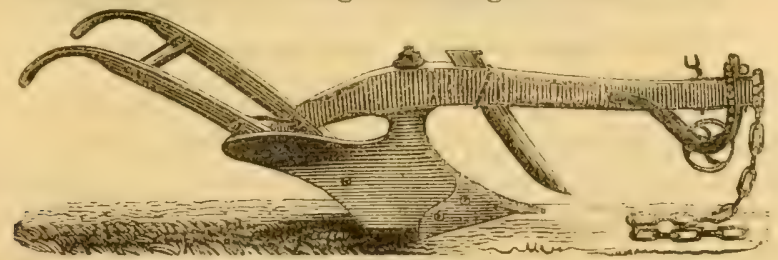

Fig. 31. Eagle No. 1. With Wheel and Cutter.

Eagle No. 1 is called at the North a small sized sod or stubble plow, and is quite light of draught for two horses or oxen. At the South it would be considered a larger size, requiring three mules in turning a furrow six inches deep and eleven 
inches wide, though this amount of work has often been accomplished with a pair of mules. It is a light, pretty sod or stubble plow, working to the depth of six inches. It is rigged as represented by Fig. 31 ; or with lock coulter, wheel, draftrod, and dial clevis, as is Eagle No.2, represented by Fig. 32 ; or with fin share, as is sward $\mathrm{C}$, represented by Fig. 33 .

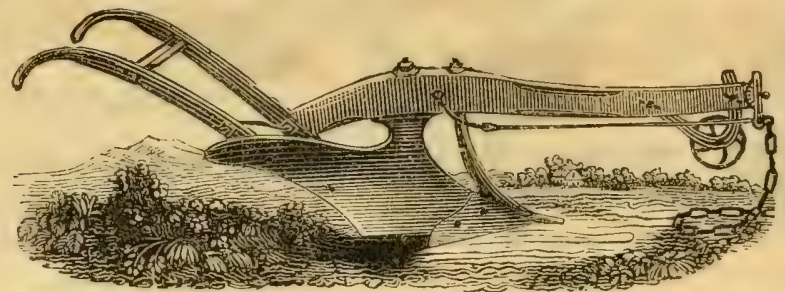

Fig. 32. Eagle No. 2. With Lock Coulter, Wheel, Draft-Rod and Dial Clevis.

Eagle No. 2 is a size larger than Eagle No. 1, and is a medium-sized two-horse or cattle sod or stubble plow. It is adapted to turn sod furrows four to seven inches deep by twelve to fourteen inches wide, and will work somewhat deeper in stubble plowing. It is rigged with the lock coulter, wheel, draft-rod, and dial clevis, as represented by Fig. 32 ; and, with these fixtures, is a very strong and at the same time light plow for two cattle or horses, in plowing stony, stumpy, or rough uneven land. Or it is rigged with wheel and cutter, for flat furrows in smooth land, as is Eagle No. 1, represented by Fig. 31; and thus rigged it has competed triumphantly with the flat furrow sod plows of the country, carrying off the highest premiums at a great many plowing matches. It is also rigged with wheel and fin share, like sward C, represented by Fig. 33, which adapts it in the best manner for stubble plowing.

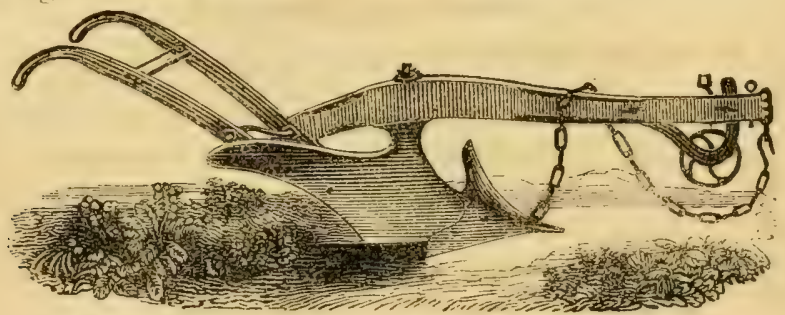

Fig. 33. Bagle or 8ward C. With Wheel and Fin Share.

Sward C is larger than Eagle No. 2, and is a two or three cattle or horse plow, working from 4 to 7 inches deep by 12 to 15 inches wide. Sward C is rigged with the fin share and wheel, and thus rigged is well adapted to stubble plowing, or the plowing of rough or stony sod land. Or it is rigged with the wheel and inclined cutter, like Eagle No. 1, represented in Fig. 31 ; and thus rigged for flat sod furrows, and turning them six inches deep by twelve to thirteen inches wide, it has won numerous premiums at plowing matches in different States.

Eagle No. 20 is a very strong four cattle or horse plow, adapted to deep, heavy work, having a mould-board of great turning power. It is rigged with wheel, cut- 


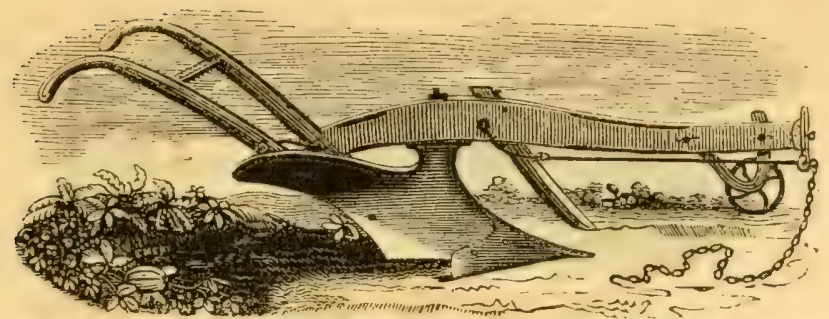

Fig. 34. Eagle No. 20. With Wheel, Cutter, Draft-Rod and Dial Clevis.

ter, draft-rod, and dial clevis, as represented by Fig. 34, and has thus been repeatedly used at plowing matches, and won the highest premiums for plowing sod nine and ten inches deep, with double teams. Or it is rigged with the lock coulter, wheel, draft-rod, and dial or quadrant clevis, like Eagle No. 2, represented by Fig. 32 , and thus trimmed is equal to the deep plowing of rough, stony, or stumpy and rooty land. Or it is trimmed with the meadow fixtures, consisting of the lock coulter, the broad wide-cutting steel-edged share, the reversed or drag cutter, wheel, draft-rod, and dial or quadrant clevis, as represented by Fig. 35 . Thus trimmed, Eagle No. 20 possesses excellence for turning over the spongy sod of recently ditched peat meadows, or muck swamps, and is extensively used for the purpose.

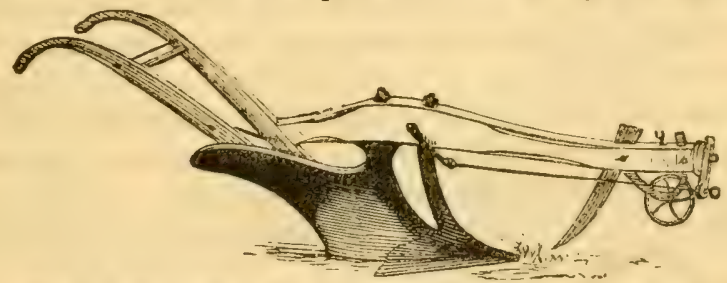

Fig. 35. Eagle Plow No. 20, Trimmed with Neadow Fixtures.

Eagle Plow No. 20, when denuded of its drag cutter, is one of the best clearing plows for new land with which we are acquainted, and its late use in the Martha tract in Burlington County, New Jersey, has given it a high reputation. The wide steel-edged share cuts off the vertical roots, while the stecl-fronted lock coulter removes those in a horizontal direction. It is nearly or quite as effective as the large Eagle 78 coulter plow, and requiring much less team.

\section{Plows with Self-Sharpening and Adjustable Steel Points.}

These plows are of the same superior form and general construction as the other celebrated Eagle Plows, with the exception that the point and share are in two pieces, which are made on an improved self-sharpening principle.

The point, as shown detached at No. 1, Fig. 36 , is simply a bar of iron sharp- 


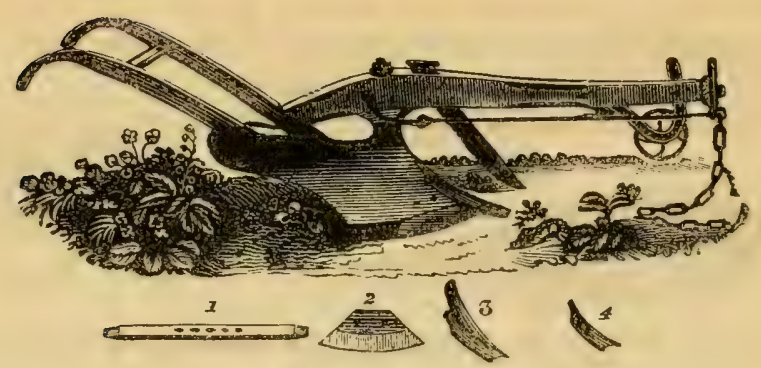

Fig. 36. Eagle Self-Sharpener.

ened at each end, about twenty inches long, and which passes upward into the body of the plow, where it is confined with one bolt. As it becomes shorter and worn on the under side, it is readily moved forward and turned the other side up, thus always presenting a sharp point of full length, and proper shape; when one end is worn off five inches, the other end is placed forward and performs a like service. The wing or share, as shown detached at No. 2 , is made of either wrought iron with steel edge, or of cast iron, and is also reversible, being used either end forward or either side up.

Both point and share are so very simply constructed, that any blacksmith can replace them at trifling expense, or perpetuate the use of the original by new-laying with steel, as they become worn.

There is a coulter of cast iron a little back and above the point, as in Fig. 33, and shown detached at No. 3, Fig. 36, forming part of a cap, shown detached at No. 4. which cap protects the shin or forward part of the mould-board; it is confined in its place by the same bolt that confines the point, and is cheaply replaced when worn.

This is much less expensive, and in many kinds of soils quite as serviceable as a wrought coulter or cutter, as shown by the cut above. They are sold with one or both, or with simply the cap.

These plows are particularly commended for the southern plantations, for any blacksmith can easily repair them.

Self-sharpening points and shares have been considered objectionable, inasmuch as they have not possessed sufficient strength, owing to their complicated construction of cast metal: but a single glance at these plows will convince any person, by the simple construction of the point and share of wrought iron and stecl, that they combine strength and durability unequalled by any other form or construction, and that they are kept in repair at much less trouble and expense.

The point can be used projecting more or less forward, causing the plow to incline more or less into the ground, as different soils may requure.

Eagle Self-Sharpener, No. 1.

A light one-horse or mule plow.

Eagle Self-Sharpener, No. 2.

A medium-sized one-horse plow, useful at South or North. 
Eagle Self-Sharpener, No. 3.

A medium-sized two-horse or cattle plow, for sod or stubble land.

\section{Eagle Self-Silarpener, No. 4.}

A large-sized two-horse or cattle plow.

Eagle Self-Sharpener, No. 5.

A strong breaking-up plow. It is an admirable implement for breaking up deep stony soils.

\section{Eagle Left-Hand Plows.}

These are made to turn the furrow-slice to the left instead of the right hand, and are constructed with the self-sharpening and adjustable steel point, as described above. They are used principally by the German and Dutch farmers, and are trimmed with the various fixtures used on the right-hand plows.

\section{Eagle Self-Sharpener. Left-Hand, No. 40.}

Is a size suitable to be drawn by two strong horses.

Eagle Self-Sharpener. Left-Hand, No. 41.

Is a heavy, large size, and designed to be drawn by three or more horses.

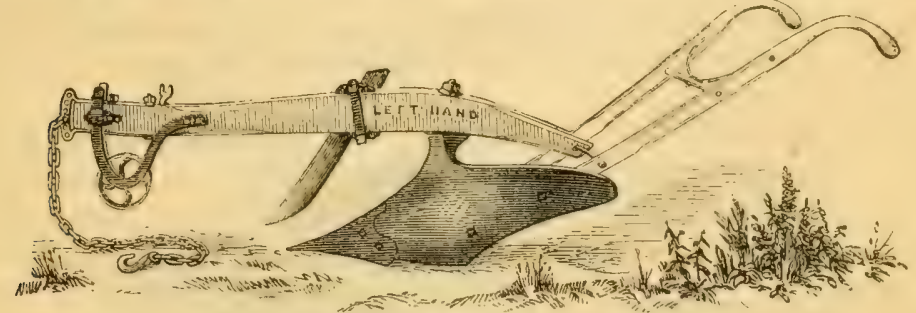

Fig. 37. Eagle Left Hand. Nos, 46 and 47.

These are strong, powerful plows, for two or more horses, according to amount of work wanted. They are made with the common plain cast shares, and are trimmed with the same fixtures as other plows.

\section{Small Plows, of different Forms and Sizes,}

USED FOR VARIOUS PURPOSES, VIZ:

No. 14. - A light, single one-horse or mule plow, calculated to carry a wide furrow in a light or sandy soil, and well adapted to Northern and Southern culture.

No. $14 \frac{1}{2}$ - The same size as No. 14, but has extra strong heavy castings, for rough, rugged or stiff soils.

No.15.-A single-horse or mule plow, of same construction as above, but one size larger.

No. A 1.-A light one-horse or mule plow, but better calculated for a clay soil. It is much used among cotton or corn, as well as for furrowing-out or drilling. 
No. A 2.-A single-horse or nule plow, same construction as the above, but one size larger.

No. 1 B.-A large one-horse plow; frequently used with two horses.

No. 2 B.-A small two-horse plow, same as the above, but one size larger. It is much liked at the North and South.

Eagle No. 0, is a size suitable for two horses at the South or one at the North, is sometimes used with two horses at the North. It is of very easy draft.

\section{Ridging or Double Mould-Board Plows.}

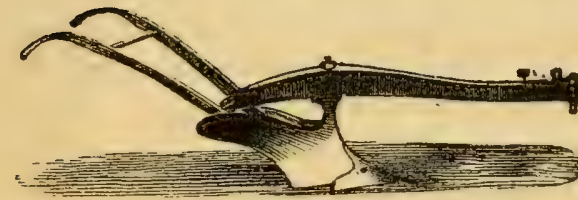

Fig. 39. Side View.

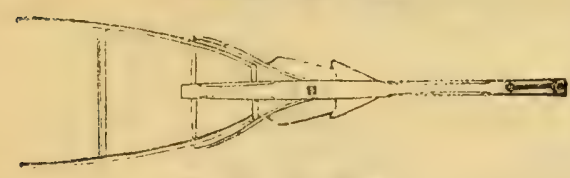

Fig. 40. Top View.

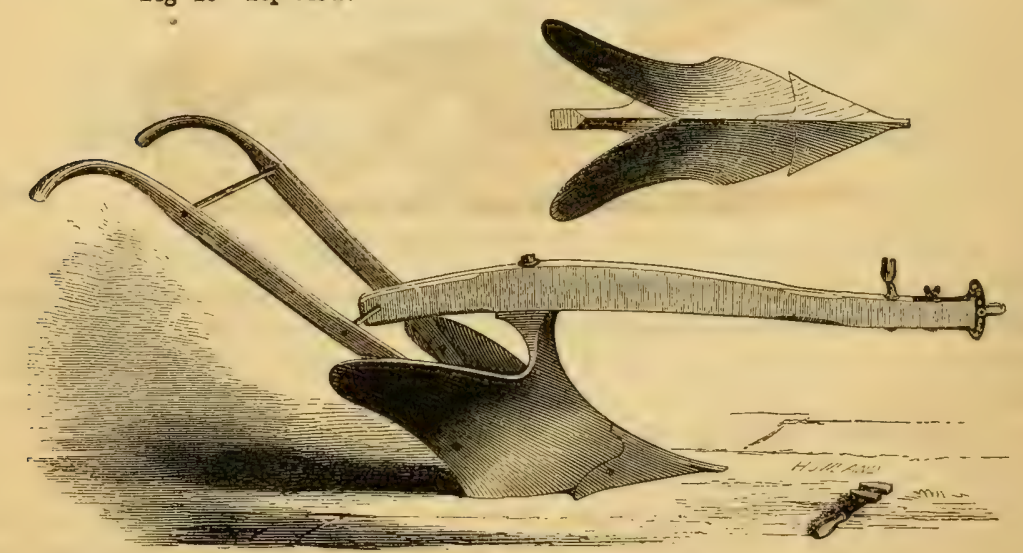

Fig. 41. Double Mould-Board Plow No. 1\%2.

No $1 \frac{1}{2}$ is similar in construction to No. $1 \frac{1}{4}$, but of a size larger.

No. 2. Double Mould-Board.-Of same construction and use as the above, but one size larger. This is also used in furrowing for planting cane, and making light ditches. No. 2 has an extra point, made wide, for the purpose of digging potatoes.

No. 3 Fluke-or Double expanding Mould-Board Plow, for Planting 
Sugar-Cane. - This is a plow recently made, expressly for the use of sugarplanters, by which a furrow is made ten to twelve inches wide, and four to five inches deep. The mould-boards are of wrought iron, and may be longer or wider, or otherwise, to order.

\section{Cotton Plows.}

Davis 6 INCH.-A light one-horse or mule plow, particularly designed for the South.

Davis 7 Inch.—Of nearly same construction, but a size larger than the above.

\section{Rice Trenching Plow.}

This plow is made from a pattern furnished by an eminent Southern planter. It will do the work of many hoes, in trenehing a field for the rice crop, and will be found a great labor-saving implement for the South. It is an excellent implement, also, for opening drills for corn or cotton, and for various root crops at the North.

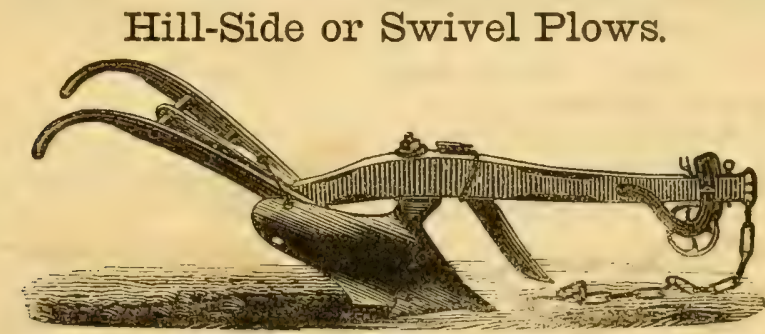

Fig, 42. Hill-Side or Swivel Plow.

Of the above plows the manufacturers make seven different sizes. They are so constructed that the mould-board is easily and instantly changed from one side to the other, which enables the operator to perform the work horizontally upon sidebills, going back and forth on the same side, and turning all the furrow slices downward. This prevents the washing of the soil by heavy rains, to which all side-hills are more or less liable when plowed up and down the slope. They are much liked at the South for horizontal plowing; for by this system of turning and laying the soil, it is prevented from being washed in those deep gullies so destructive to the general face of the country. They are likewise useful in enabling the plowman to turn the furrow from his walls and fences.

\section{No. 0. Side-Hill, or Swivel.}

A large one-horse or mule plow, more particularly for horizontal plowing at the South.

No. 00. Side-Hill, or Swivel.

A large one-horse plow for the North, or suitable for two mules at the South. 
No. B 1. Side-Hill or Swivel.

A light two-cattle sod or stubble plow.

No. A $1 \frac{1}{2}$ Side-Hill, or Swivel.

A medium size two-horse or cattle plow.

No. A 2. Side-Hill, or Swivel.

A large two-cattle plow-is sometimes used with three or four horses, according to the nature of the soil.

No. A 3. Side-Hrul, or Swrvel.

A large four or six-cattle plow, made very strong. It is suitable for heavy farm or road work.

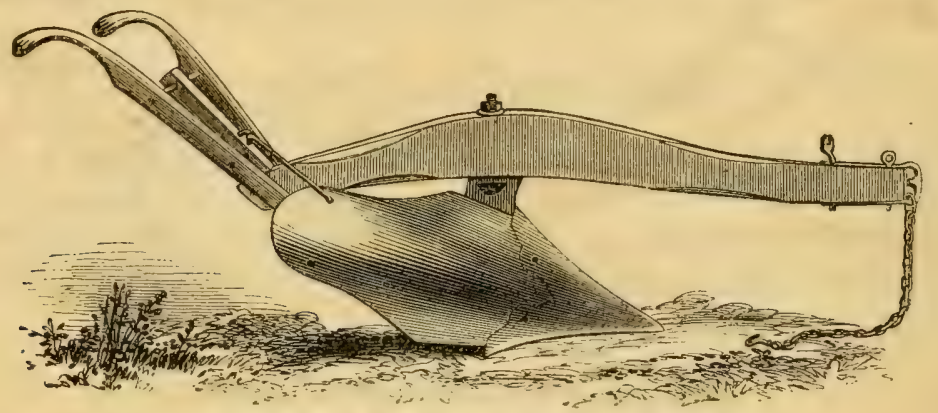

Fig. 43. No, A 4. Swivel, or Heavy Road Plow.

Fig. 43 represents Swivel or Heavy Road Plow, No. A 4. It is made very strong, and is especially designed for the roughest road work, being of a size and capacity to do work requiring the dranght of four to eight cattle. It is extensively used by road-makers, being considered by them as a great labor-saving implement. It will break the ground and give the general shape to a road in the newest or most difficult soils, plowing among roots, stumps, aud stones without breaking, and making a very imposing appearance with six or eight oxen hitched to it. For the annual repair of the roads, it is most valuable, as it will speedily and with great facility open the ditches at the sides, and furnish earth with which to shape up the road-track.

Swivel-Plow No. 4 is often purchased by towns and districts for the purpose of making and repairing roads; and such purchase will always prove a very econom. ical investment.

\section{Prouty \& Mears' celebrated Centre Draft Plows.}

These plows are of easy draft, turning the sod most perfectly, and in a clear free soil preserve the furrow without a holder; and if the ground is in good condition for plowing, will nearly prepare it for seed. By their peculiar shape and turn of mould-board, they will pulverize and disintegrate the particles of the furrowslice, and consequently aid in the proper aeration of the soil and decomposition of organic matter, and thus liberate food for plants from the inorganic matter of the 
soil. In perfection perhaps they are nearly equal to spade husbandry, which has been termed the perfection of good culture.

These plows have justly gained a high reputation in many parts of Pennsylvania and New Jersey, and are fairly entitled to the encomiums passed upon them by the different State Agricultural Societies.

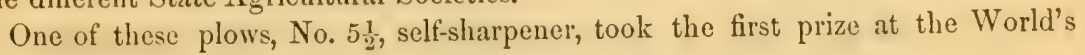
Fair in London.

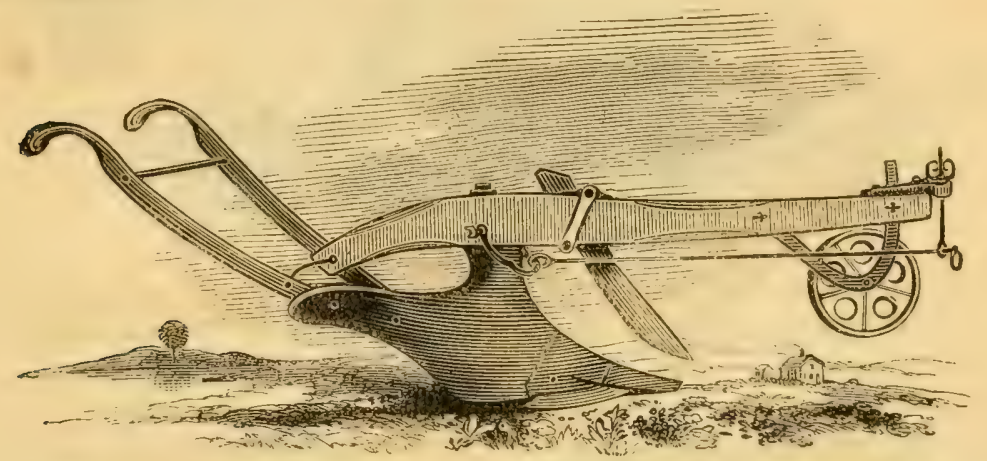

Fig. 44. No. 5\%, Self-Sharpening Plow.

This plow is self-sharpening, and requires two or three cattle, cutting a furrow seven inches in depth and thirteen inches in width. It should not be held on its bar-share while at work, but permitted to lean toward the furrow, which will cause the vegetable surface matter to be completely turned and buried. It is admirable for breaking up old sward land, the pulverization of which will produce a fine condition for corn.

The use of the wheel is strongly recommended, although withont it the plow is perfect as a swing plow.

The coulter should be kept in a direct line with the breast of the plow; the point and share may be repeatedly turned, by which treatment they will last during the plowing of 80 to 100 acres of land for each set.

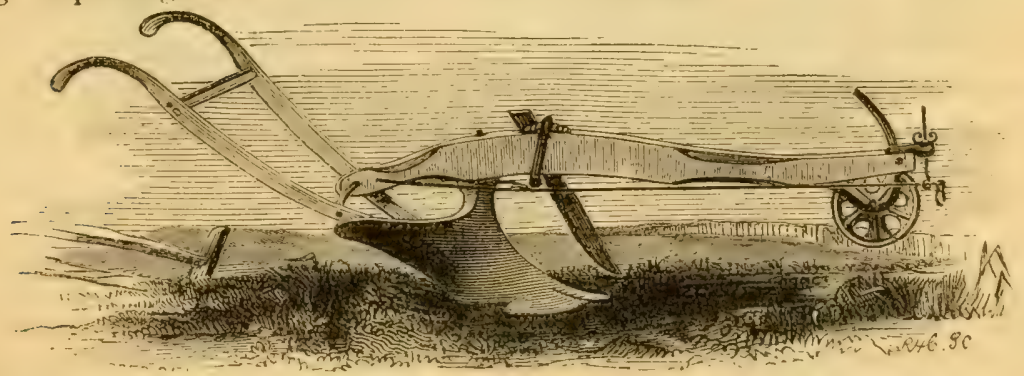

Fig. 45. No. 40. Self-Sharpening Plow.

This new pattern is constructed with special reference to deep and narrow furrows, for plowing very stiff soils. It is designed to work a furrow ten inches wide and seven inches deep, cutting them with remarkable exactness. and requiring com- 
paratively little aid from the plowman, leaving the soil in an open and friable condition, effectually burying all surface plants.

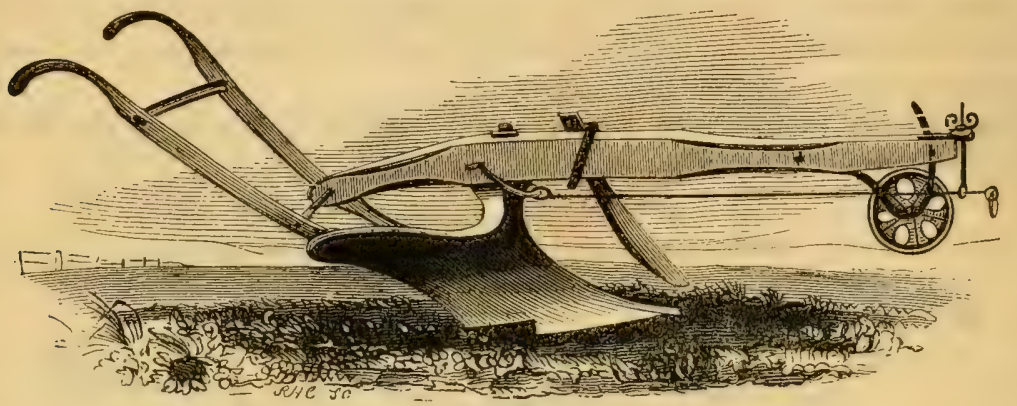

Fig. 46 .

This, in common with Nos. 22, 23, and 26, are the sward or grass plows of the series of the centre draft, [Nos. 20 and 21 being the light one-horse and seedplows of this variety]. These, from their peculiar shape, lift the soil, disintegrating it and altering the relation of the particles, producing a result resembling spade husbandry, instead of wasting the resolution of force in horizontal pressure to compress the furrow-slice; leaving the soil in a light and friable condition, inverted and laid off by the side of the last furrow, completely covering all surface matter.

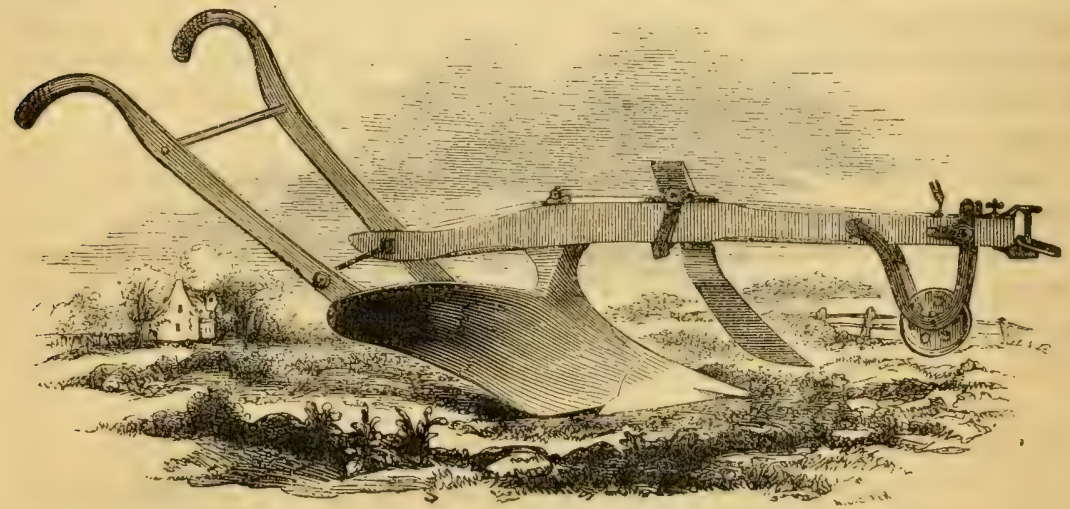

Fig. 47. No. 155. Sod Plow.

This is a four-cattle piow, complete in all its appurtenances, and capable of turning sod to a depth of from six to ten inches, and in width from fourteen to eighteen inches; producing results proportioned to the amount of force applied.

Fig. 48 is of the kind usually known as the double mould-board plow.

Its greater length and easy rise cause the resolution of force to elevate the soil, leaving an open furrow without compressing the portions removed. It may be used as a potato digger, but it is especially calculated for the opening of furrows for the planting of crops, or for the ridging and back-furrowing of clayey soil, to enable it 


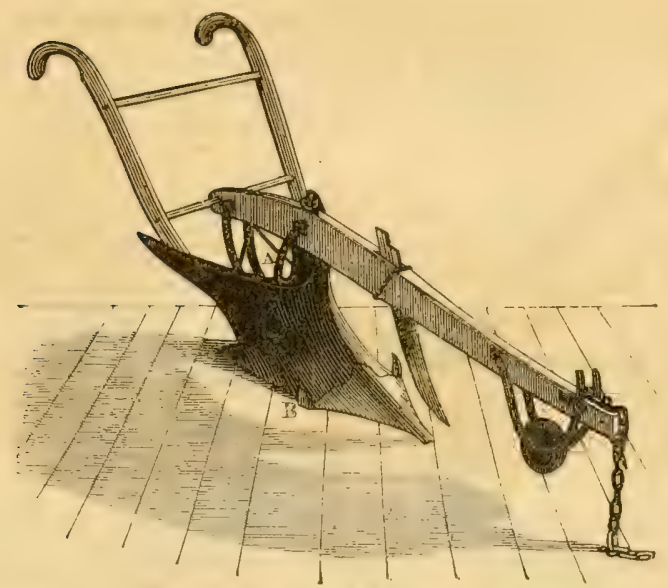

Fig 48. Improved Midland Plow.

to avail of the freezings and thawings of winter, for more perfect disintegration. When used on the sward land where manures have been spread upon the surface, it encloses the manure within each ridge so as to form a seed-bed for crops to grow upon; a system now being rapidly adopted in the growth of many crops. It is also used in the spring for the splitting and distribution of ridges.

This plow is furnished with a wheel at the fore end of the beam; it has, also, a larger wheel under the after end of the beam, as seen at $A$, which serves as a landside, on which it is supported while in action, and by means of which it is with ease carried around the ends of the land, and from place to place. The cutter, suspended from the beam, divides the furrow-slice from the surface downward into two parts. The fins, seen at BB, near the top of each wing of the share and extending upward some three inches, separate the divided and ascending furrowslices from the solid land on either side, and enable the plow, by the peculiar form of its mould-board, to place the furrow-slice thereon with ease and regularity. The width of the work carried may be varied or adjusted by the cutters, from eighteen to twenty-four inches, viz.:-two furrows may be laid off from nine to twelve inches each, and from five to seven in depth.

The other Prouty \& Mears' Plows, the names of which will be found in our price list at pages 6 and 7 , are of superior quality, and we are prepared to furnisb them from the genuine patterns made by the inventors.

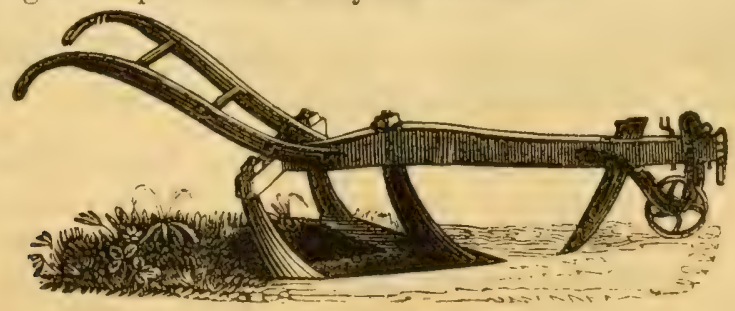

Fig. 49. Paring Plow. 
The preceding plow is used for paring turf lands preparatory to burning. The share is thin and flat, made of wrought iron, steel-edged. It has a lock-coulter in the centre, and short coulters on the outward edge of each wing of the share, cutting the turf as it moves along into two strips, about one foot wide, and as deep as required.

After the turf is pared off in strips, men follow with sharp spades, and cut it into suitable lengths, say of two or three fect. These pieces are then thrown into heaps, and after drying they are burned, and the ashes spread broad-cast on the land. Paring and burning is a very ameliorating process for stiff clay soils; it changes their mechanical texture, and renders them friable and suitable for cultivation.

\section{Steel Plows.}

The Soils of the Western and some of the Southern States being composed largely of vegetable substance, with little perceptible sand intermixed, and lying loosely, after the sod has been once broken and subdued, do not present friction or scouring-quality enough to the cast iron mould-board to give it a suitable polish. Steel being a finer and less porous metal than cast iron, and less affected by rust, and requiring much less friction to give it a high polish, is considered the more desirable material for the construction of the mould-board, share and land-side of plows for working such soils.

Duplicates of the varions parts of each pattern of these Steel Plows are always kept on hand; so that customers, in any section, can obtain any such parts as may be needed for purposes of repair or otherwise, and may be certain that the parts ordered by them will fit the proper place, and cause the instrument needing repair to work truly again. The Shares of these Steel Plows are put on with bolts so as to be replaced at any time with new shares.

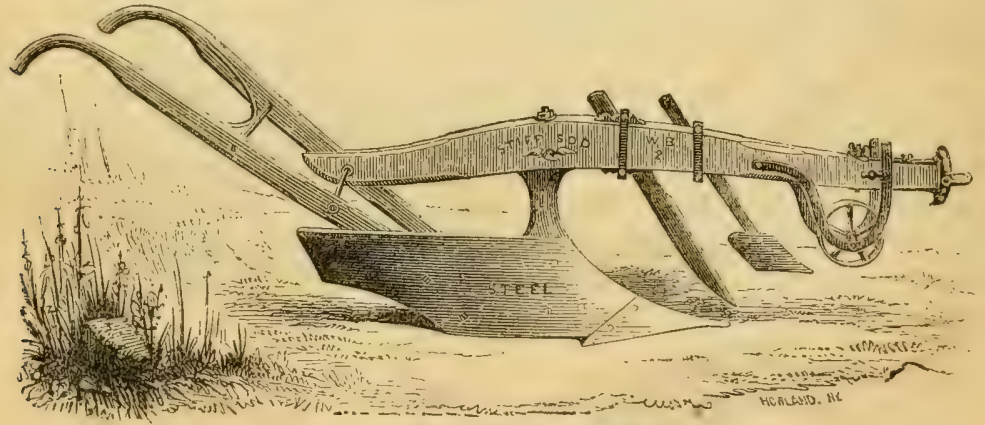

Fig. 75. Steel Plow No. W B 2.

Stecl Plow No. W B 2, is represented by Fig. 75. The mould-board and share are a duplicate of those parts of Plow No. $72 \frac{1}{2}$ in cast iron; but the standard is higher than that of No. $72 \%$, to enable the plow to keep its course through the extra amount of stubble and vegetable matter usually encumbering the surface of rich new lands. Its mould-board, like that of No. $72 \frac{1}{2}$, is fincly adapted to the 
working of stiff clay sod land, in deep narrow furrows. It will plow $\tau$ inches deep by 10 inches wide, in the most adhesive clay soil. It will take less depth or more width of furrow, as may be desired. It is of easy draught for two oxen or a span of horses.

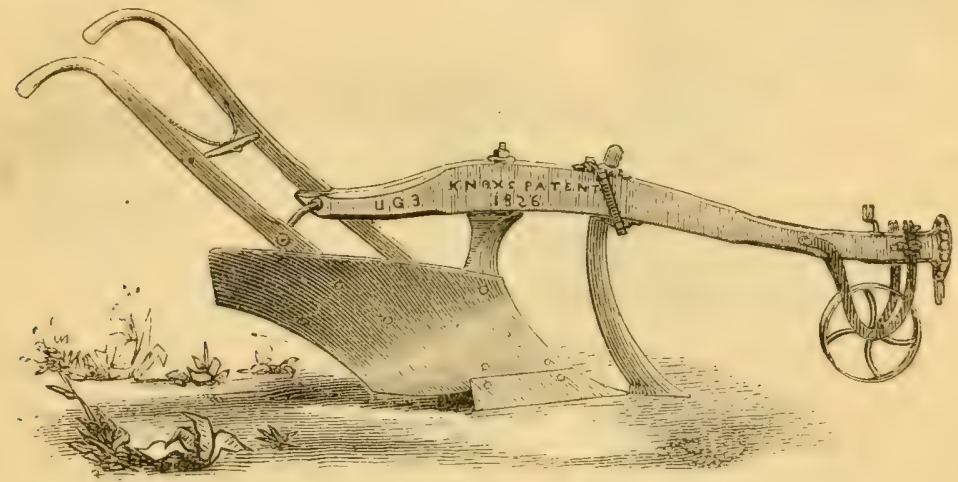

Fig. 76. Steel Plow No. U G $3 \%$.

Steel Plow No. U G $3 \frac{1}{2}$, represented by Fig. 76 , is a duplicate in the body parts of Plow No. 73\%, in cast iron. The standard, however, is higher, and the land-side lower than those of No. 73\%, to suit the wants of customers in the Western States, This plow is rigged with the "Peacock Coulter," for breaking prairie, or with the Circular Cutter, for the same purpose. It is a light plow, of easy draught for two to three horses. The mould-board is of that equal curvature which will canse it to polish brightly in any soil. This plow received the medal at the World's Fair, in Now York, and has won many premiums at the Agricultural Fairs.

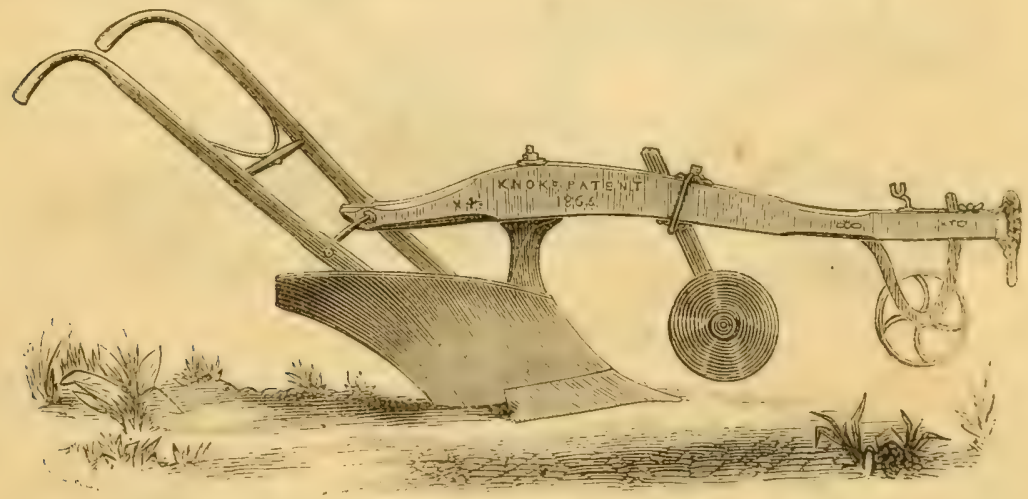

Fig. 77. Steel Plow No. X 4\%.

Steel Plow No. X 4 4 , represented by Fig. 57 , is trimmed with the Circnlar Cutter, for breaking prairie. It is also trimmed with the "Pcacock Conlter," where that arrangement is preferred to the Cirenlar Cutter. Remove the Cutter 
or Coulter, and the plow is well adapted to old ground work. It is a light twohorse plow.

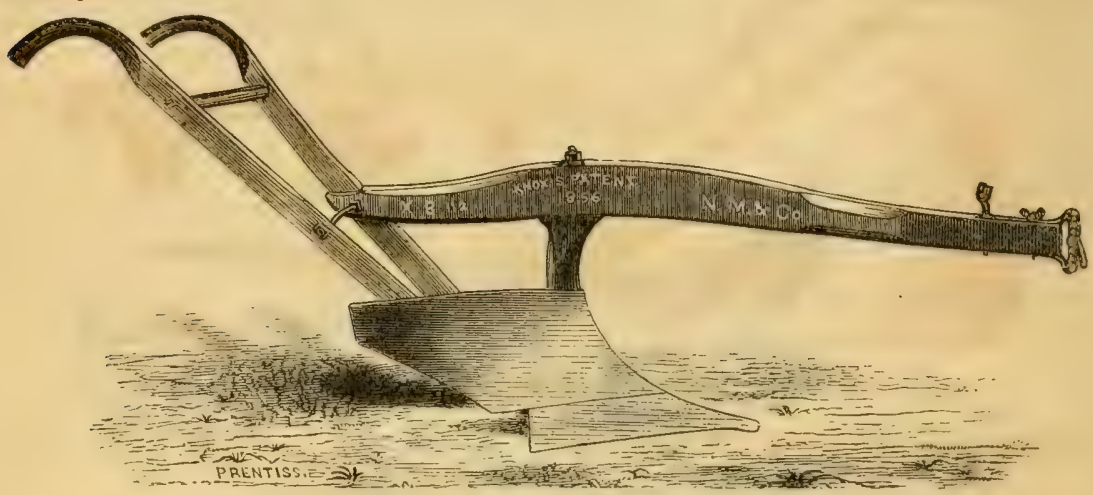

Fig. 78, Steel Plow No, X 8\%.

Steel Plow No. X 8⿱亠䒑 2 , represented by Fig. 78, is a duplicate of Stubble Plow No. 32 , of cast iron monld-board and other body parts. It is rigged as a swing plow, as represented by the cut, or with a wheel, as may be desired. It is extra high in the standard, as it is specially designed for prairie or old land plowing. It has a short mould-board, is a thorough pulverizer, and a decp worker, carrying furrowslices from 5 to 10 inches deep and 12 to 14 inches wide, and will brightly polish and work free and clear in all soils. It is of easy draught for two cattle or horses.

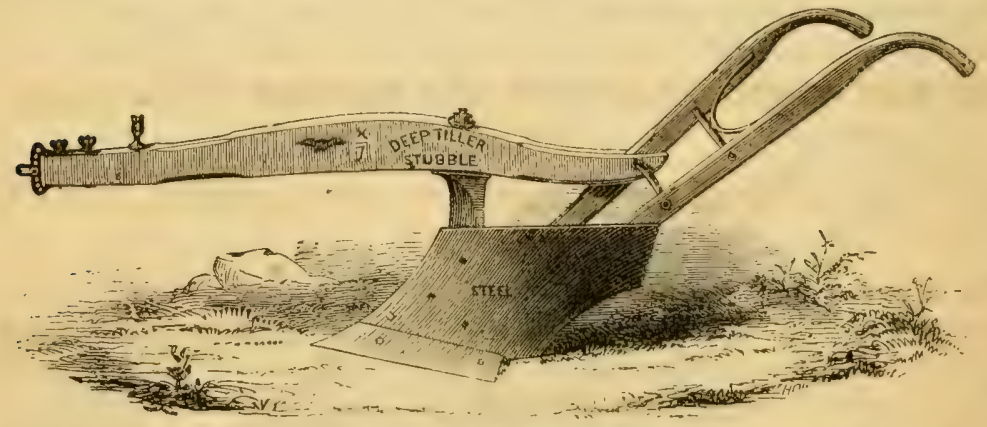

Fig. 79. Steel Plow No. X7.

Fig. 79 represents X 7-a left-hand steel plow, of corresponding size with $\mathrm{X} 4 \frac{1}{2}$ right-hand, and adapted to the same purposes.

Steel Double Plow No. X 4, represented by Fig. 80 , is a right-hand plow, and a duplicate in the body parts of Double Plow No. 33, of iron mould-boards, \&c. For a more particular description of the working properties of the Steel Double Plow, sce the cut and description of Double Plow No. 33, Fig. 30.

Steel Double Plow No. X 7, a left-hand plow, is of corresponding size with the $\mathrm{X}$, represented by Fig. 80 . 


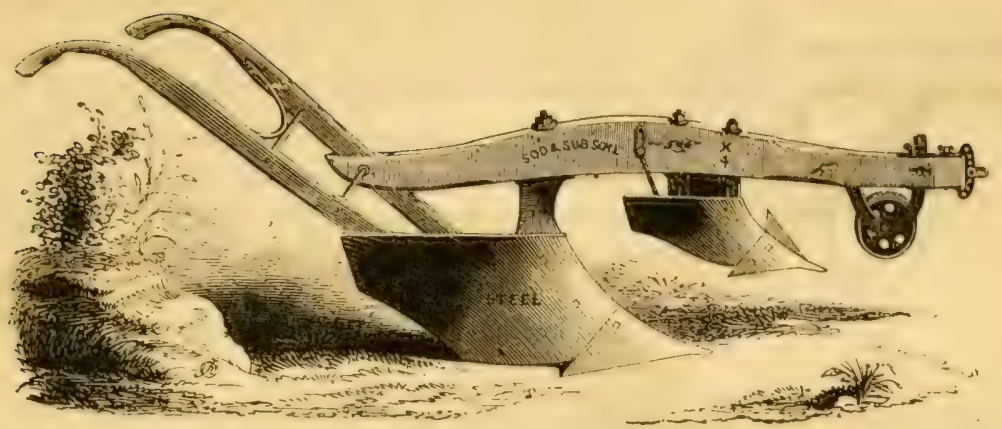

Fig. 80. Steel Double Plow No. X 4 .

Other sizes of Steel Plows, as follows :

$\mathrm{X}$ 00, a right hand, old ground plow, one horse, small.

$\mathrm{X} 0$, a right hand, old ground plow, one horse, light.

$\mathrm{X} 1$, a right hand, old ground plow, one horse, large.

$X$ 8, a right hand, old ground plow, two horse, light.

$\mathrm{X} 8 \frac{1}{2}$, a right hand, old ground plow, two horse, light.

$\mathrm{X} 9$, a left hand, old ground plow, two horse, light.

$\mathrm{X} 6$, a right hand, old ground plow, two horse, large.

\section{Cuts and Explanations of the various 'Trimmings of the Plow.}

It may perhaps be well here to speak of the various appendages to the Plow; and first-

The Wheec. Several advantages are realized by the use of the wheel attached to the plow, particularly in turning sod: the plow is drawn at a convenient distance from the team; its movements are steady and regular, and of uniform depth, promoting the ease of both plowman and team.

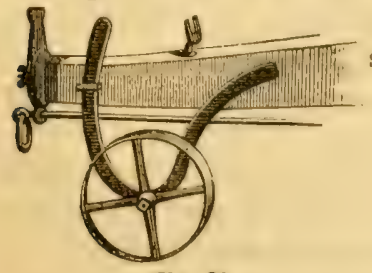

Fig. 81.

The wheel is placed on the side of the plow-beam, as shown by the annexed cut,-(Fig. 81).

Or under the beam, as shown by the annexed cut,-(Fig. 82).

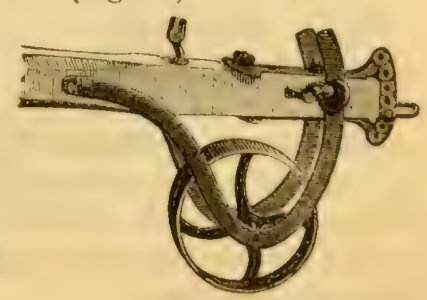

Fig. $8 \%$. 


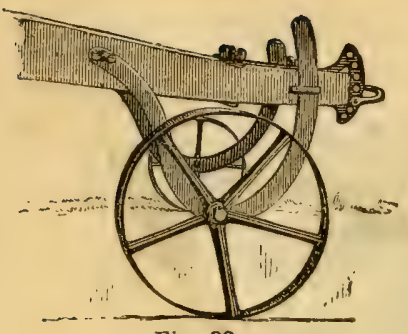

Fig. 83.

Or two wheels are used, one running on the upland, and the other in the furrow-channel, as shown by the annexed cut,-(Fig. 83).

In either case, the wheel-frame is clasped to the beam in a manner that readily admits of raising or lowering the wheel to give the plow any desired depth of work; and, when adjusted to a given point, and there made fast by tightening the clasp, the plowing will be of uniform depth throughout.

The Cutter. This is an important appendage to the plow in turning sod. It suparates the furrow-slice from the main land by an easy, smooth cut, securing a true edge and uniform width to the slice, and a highly-finished style of plowing, with a saving of draft to the team. Without the cutter the furrow-slice would be torn off the land by the breast of the plow, its edges would be bristling and ragged, its width irregular, and its inversion by the mould-board wonld not be at all times so sure. A vessel is directed and controlled by its rudder, and so is a sod plow by its cutter; and hence the importance of the correct adjustment of the cutter; for very much in proportion as it is wrongly set, will the plow work wrongly, notwithstanding its capacity in other respects to do nice and finished work. When a particular style of plowing is desired, such, for instance, as lapped or flat, the set of the cutter must be governed by a consideration of that kind of plowing, or the desired work will not be realized. The following cuts will assist to illustrate this point:

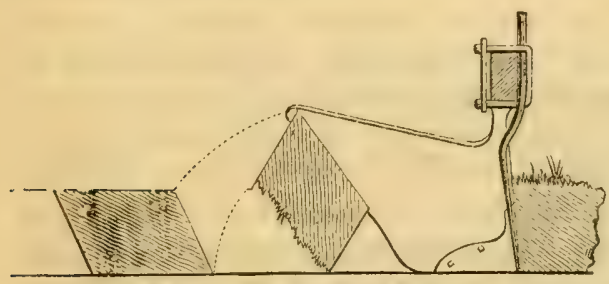

Fig. 84. The Inclined Cutter.

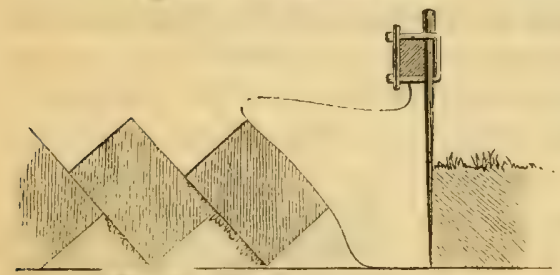

Fig. 85. The Straight Cutter.

Fig. 84 represents a cutter set for plowing flat furrows. It should stand as much inclined toward the mouldboard side as the land-side of the plow does, and it is generally best to set it even a little more so, in order to obtain that bevelled edge of the furrow-slices so essential to their sure and finished matching-in side by side as they come over from the plow, and to do perfectly flat work, as shown by Fig. 84 .

Fig. 85 represents a cutter set for plowing lapped furrows. It should be set to cut rectangular furrow-slices and a perpendicular edge of the unplowed land, thus insuring high-crested lapped work, as seen in the Figure.

The cuttex is made either of a flat or of a round bar of wrought iron, steel-edged, or of a thin ircular plate of steel, and is variously adjusted to the plow-beam as follows : 


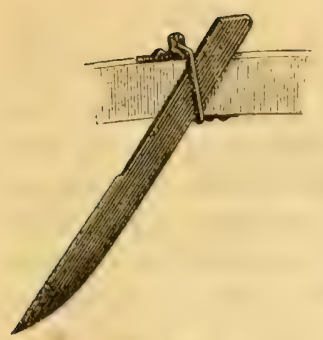

Fig. 86.

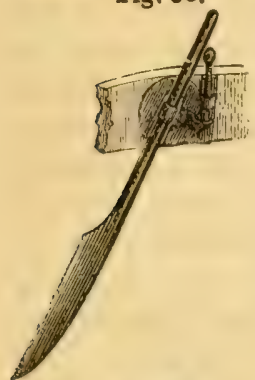

Fig. 88.

It is made of a flat bar, and clasped to the side of the beam, as shown by the annexed cut,-(Fig. 86).

Or passes through the beam and is fastened by a gripe and key, as shown by the annexed cut,-(Fig. 87).

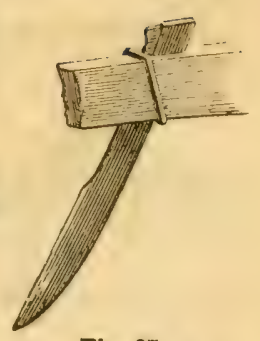

Fig, 87.

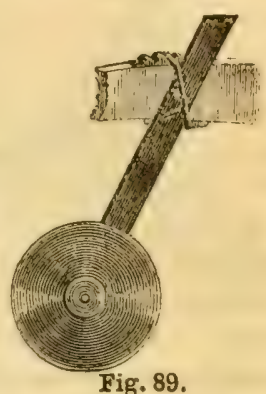

The rake of the cutter forward may be greater or less at pleasure; though in some conditions of the soil and the sod it is best set raking, for the edge will thereby the better free itself of the loose roots and stems that may incline to double over and remain upon it. The adjustment of the cutter to the beam is such as readily to admit of its being raised or lowered, set more or less raking forward, or its edge turned to or from land at pleasure.

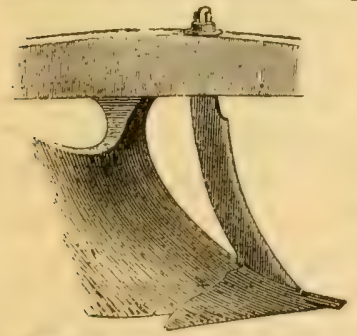

Fig. 90. The Lock Coulter.

Fig. 90 represents the Lock Coulter. The lock coulter is made of wrought iron, steel-edged. It passes through the plow-beam and is made fast on top with a key, and locks through the share and mould-board where they join together. The adjustment is a very strong one, both for the coulter and plow, and fits the implement for working among stones, stumps, and roots, as the coulter cannot be turned out of place or broken by such obstacles.

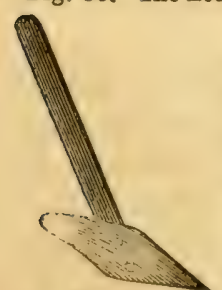

Fig. 91.

The Skim Coulter, Fig. 91, is usually placed a few inches forward of the cutter, and the stem or shank is attached to the beam by an iron clasp with nuts and screws to make it fast. The skim coulter promotes highly finished plowing, particularly that of lapped sod. It shaves off the grass edge of the furrow-slice, and the turf thus taken off is carried over on the turning slice, till it drops into the furrow-channel and is buried. The edges of the lapped slices being thus freed of the sod, no grass springs up between

The Skim Coulter. them, and being jointed to an equal thickness, they are laid with great precision. 
The Share is made of cast iron, or wrought iron steel-edged, or wholly of steel.

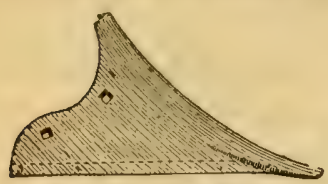

Fig. 92. The Share.

If of cast iron, the entire cutting edge and the point, is hardened in casting, by a process of chilling, which forms a very hard surface, the effect of which is constantly to produce a sharp thin cutting edge, of great advantage in plcwing; and to insure three times the service in the share that would otherwise be obtained. The extent of the case-hardening is indicated in Fig. 92, by the dotted line back of the edge of the share.

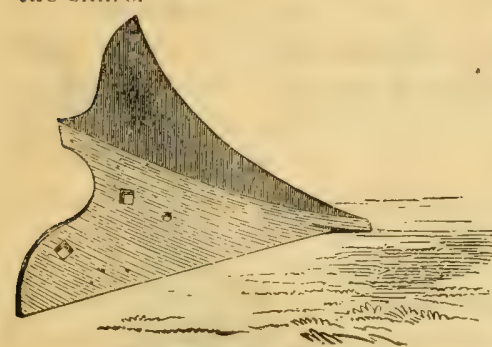

Fig, 93. The Fin Share.

Fig. 93 represents the Fin Share. A share like that represented in Fig. 92 is cast with the addition of the fin, and is termed the Fin Share. It is a useful addition for plowing sod lands infested with roots and stumps or stones, where the sward cutter cannot be used without danger of getting bent or misplaced. It is also useful when plowing-in stubble or coarse manure, serving to keep the plow from clogging at the standard. It separates the furrow-slice from the unplowed land more smoothly and easily than it could be done by the breast of the plow.

The Dial Clevis. In order to obtain the same steady, easy and uniform motion of the plow, running at different depths of furrow, the point of attaching the chain, or motive power, must be varied. For instance, if properly attached to work six inches deep, the chain at the end of the beam must be raised considerably to work well at twelve inches deep, and carried to the right in order to acquire more width of furrow-slice, and in proportion for the intermediate depths; with the common clevis sufficient variations cannot be had. The manufacturers of the Eagle Plows use for the purpose the Scotch clevis, or the patent dial clevis; the latter is represented by the cuts below in detached parts, and is seen attached on the preceding cuts. It is strong and instantly adjusted to any degree of nicety, and capable of greater variation than any other kind, without the least endangering the strength of itself or the other parts of the plow.

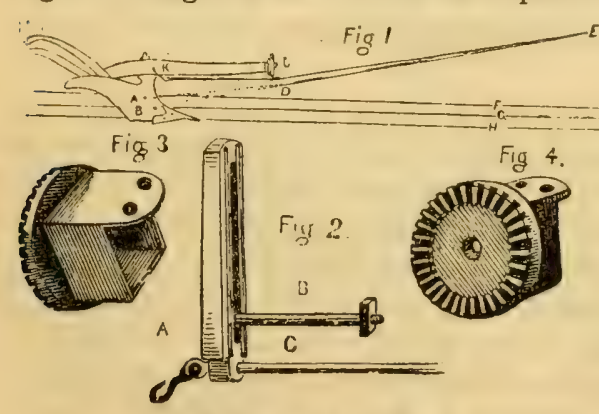

Fig. 94. The Dial Clevis.

$\mathrm{C}$ and $\mathrm{K}$, Fig. 1, shows plow with dial clevis with rod attached, and a position with plow in operation, line of draft, \&c., \&c.

A, Fig. 2. The guide or movable plate, which is confined across the end of the beam. B, Fig. 2. The joint bolt and nut, which confines the guide to the end of the beam.

C, Fig. 2. A section of the draftrod passing through the guide, and to which the power is applied. Figs. 
3 and 4. The cast iron cap, fitting the end of the beam, and through which the bolt passes and to which the guard is confined by means of a bolt, and cogs or teeth on it fitting into ribs upon the guide.

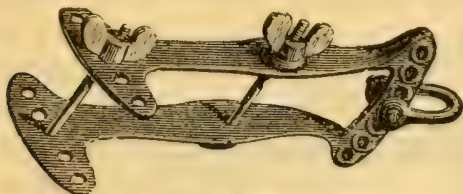

Fig. 95. The Scotch Clevis.

The Scotcr Chevis, made of malleable iron, is a strong and convenient attachment to the plow. 'Through the head of the clevis there are a number of holes for the reception of the bolt of the smaller clevis, to which the evener or chain is attached; and thus a level gauge is obtained for the plow at any required depth. The rear of the clevis terminates in a $\mathrm{T}$ form, with various holes for the reception of the back bolt. There are three holes in the plow-bean through which the back bolt may pass; and the changes which they aftord, together with thoste obtained by the various holes in the terminus of the clevis, give to or take from the plow any amount of land desired. Eleven changes are attainable by the use of this clevis. The means of making them may be readily seen by a reference to Fig. 95 .

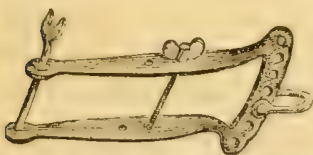

The Half Scotch Clevis, also of malleable iron, is represented by Fig. 96.

Fig. 96. Half Scotch Clevis.

And the Common Clevis, of wrought iron, by Fig. 97 .

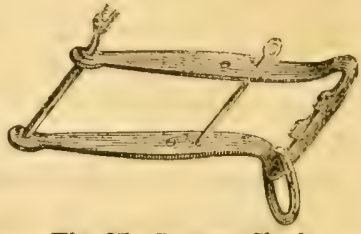

Fig. 97. Common Clevis.

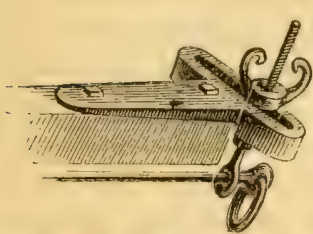

Fig. 98. The Quadrant Clevis and Draft-Rod.

The Quadrant Clevis, Fig. 98, affords a wide range to the earthing or landing of the plow, and is generally used in connection with the draft-rod on subsoil and other plows where extra deep heavy work is to be done. $\mathrm{By}$ loosening the nuts of the screw bolt of the clevis, through which the draft-rod passes, the line of draft may be raised or lowered, turned on or off the land, and more or less depth or width of furrow may be given the plow, to any desirable extent.

\section{Lash's Spring-beam Plows.}

This new invention will be understood in part from Fig. 99. A spring of wood is attached to the front of the plow on the top of the beam; from its rear end descends a connecting rod, which couples with a toggle joint inserted within the beam, and at the lower end of which toggle, beneath the beam, is attached the draft-rod of the plow. Under all ordinary circumstances the plow may be pro. pelled through the soil without the spring being at all moved, the toggle being so configured as not to put the spring in motion with the mere pull of the draft-rod while plowing; but if the point come in contact with a stump, stone, or other immovable body, then the momentum consequent upon such interference resolves 


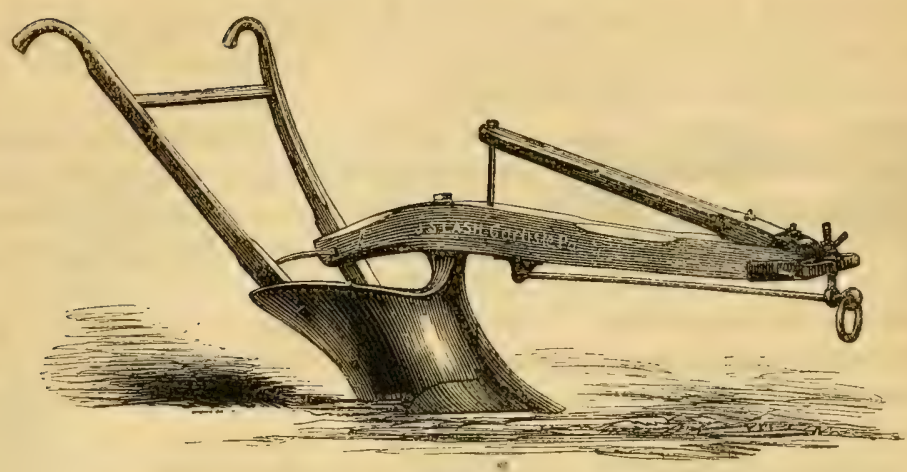

Fig. 99.

itself through the draft-rod toggle to the spring, causing it to be depressed, and thus dividing the momentum, and taking the jar off the plow, the plowman, and the team.

We quote the following from the report of a committee of the American Institute, who experimented with this contrivance on the farm of the editor of the Working Farmer :

"Your committee witnessed the operation of this machine and fairly tested its usefulness. A stake four inches in diameter was driven two feet into the ground; and when the plow to which Mr. Lash's contrivance was attached was moving at full speed, with a heavy team, the point of the plow was brought to bear on the stake, and although the progress of the team was arrested, neither the member who held the plow nor the team seemed to recognize the least shock; the whole force was resolved upon the relief-spring, and there expended itself gradually and not impulsively.

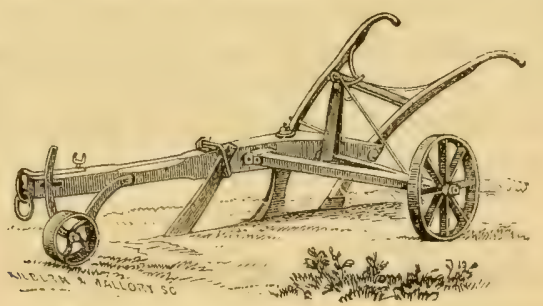

Fig. 100. Whitney's Iron Plowman.

This contrivance may be attached to any plow, and really takes the place of a plowman, so far as regulating the position of the plow, depth of insertion, etc. If the team be driven the handles of the plow need not be held by the plowman. Its form and operation may be thus understood. A V-shaped casting of iron, as above, its extremities attached to the beam by hinged joints; at the point of the $\mathrm{V}$ is a wheel intended to rest on the unplowed ground, and from the point near the wheel runs a rod with a slot at its further end held to the plow by a thumb-screw ; while this screw is loose the plow is entered into the soil in the usual way, and when at 
the desired depth, the thumb-screw is turned so that the wheel on the unplowed ground cannot alter its relation to the plow in an upward direction, and thus secures not only the vertical position of the handles but regulates the depth of travel of the mould-board. The weight of this wheel on the end of a lever, equal in length to its distance from the plow-beam, is fully equal to a man's strength at the plow handles. The whecl will follow the sinuosities of the surface of the ground, thus causing the plow to make the depth of its furrows parallel with the surface.

"This utensil is a great leveller of excellence among plowmen, for by its assistance the veriest novice becomes an expert."

\section{General Remarks on Plowing.}

There are a few general principles connected with plowing which may be thus understood. The effect of plowing in the year 1858 is in degree neutralized in the year 1860 by rains and dews lubricating the surface of the particles, and thus enabling them to settle back to their previous condition. This particularly applies to rains, or to soils containing a redundant amount of water from an absence of underdrains. No amount of ramming by mechanical force will compact a soil as heavily as will the effect of water when soil is suffered to subside through it. Thus in a barrel filled with water and soil sieved in it, each particle, from the thorough lubrication while sinking, will compact itself to a closer fit than if rammed in a dry state; and when the water is all displaced from the barrel by the soil, and the portion between the particles suffered to run out at the bottom, and the whole mass then dried, it will be found to contain more sand than can be rammed intc the same space when in a dry state. This, then, accounts for the necessity of plowing the land every year to overcome the effect of rains, local water, etc. Sand on a sea beach settles so tightly, from its continued lubrication by water, that the wheels of a heavily laden carriage scarcely make an impression on its wet surface.

It must be evident that plowing should be as deep as the effect produced in recompacting the soil by rains. This depth varies in different soils from ten to fifteen inches; as few soils can be readily plowed to a depth of fifteen inches at one operation, the sub-soil plow, represented by our figures 101,102 , and 103 , is called in. This plow disintegrates the soil to any required depth without elevating it or mixing it with the surface soil, as will be more fully described uncter the head of sub-soil plows.

It is a common mistake to use such plows as will turn soils most smoothly and with least disturbance. The oliect of plowing is not to move large masses of earth for a great distance but rather to aiter the relation of particles to cach other so that new points of contact with each may occur and new portions may be subjected to atmospheric influences and the consequent chemical clanges.

The progression in the soil, or rather of its integrants, is in part a consequence of its disturbance, while its liability to suffer from drouth is materially lessened by thorough change of relation among the particles. 
In sod-plowing the regularity of turning becomes necessary to insure the decay of organic matter in the soil, and in such practice our remarks as above do not apply.

\section{Sub-soiling and Sub-soil Plows.}

The following, from The Working Farmer, of May, 1860, fully describes both the process and implements above referred to:

The deeper disintegration of the soil has long been admitted as a desirable mode for general adoption, and some experimenters have concluded that no depth is too great which can be practically attained. In particular districts, however, where the surface-loam was shallow, and the sub-soil too heavily charged with clay, it was found not beneficial to reverse the position of the soil, placing the clay on top, but that the disturbance of the clay in place, without elevating it, was advantageous; thus the digging of a trench and afterward filling it up, first with the clay and then replacing the surface-soil, caused the crops to be much greater, not only immediately over the trench, but for a considerable distance on each side. We remember an experiment of this kind made on Long Island, by William Cobbett, and shall never forget the pride with which he showed the result to his neighbor farmers, foretelling, at the same time, that a tool would be invented for disturbing sub-soils without elevating them. The use of a sub-soil plow at all is of very recent

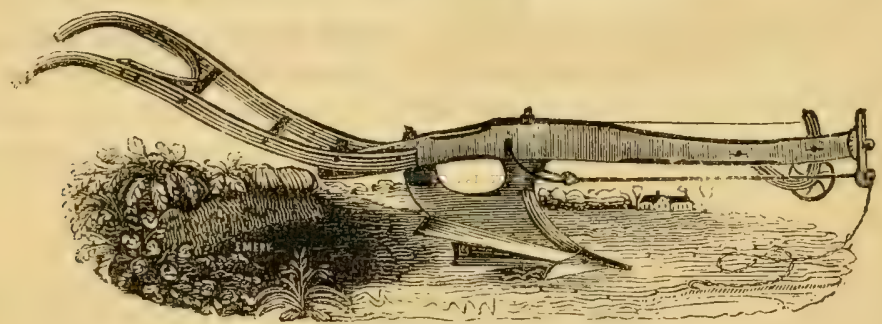

Fig. 101.

date. The first one imported in the United States by Messrs. Ruggles, Nourse \& Mason, in the year 1840 , was of a kind not unlike that represented in the engraving; it has a wing on one side only, running from the point back, elevated at the rear five inches; and we are sorry to say that many such plows are still sold, and attempted to be used. They are suited neither to sub-soiling nor even to the economical admixture of the surface with the sub-soil. The wing being only on one side, performs but half the service required of the sub-soil plows, while the great elevation of the wing demands an amount of force, which renders it impossible to sink this plow in the bottom of the furrow left by the surface-plows; for in this way the sub-soil plow should be always used.

Let us suppose that the surface-loam has a well defined depth of eight inches, and beneath this either a clay or red kellis hard-pan soil, or any other differing 
from the surface-soil. The surface-plowing should not exceed at first the depth of the loam; the sub-soil plow should then follow in the bottom with the lower side of its beam actually resting in the bottom of the furrow, so that the sub-soil should be slightly elevated and fall back again in its place, so disintegrated as to admit the after action of the atmosphere, moisture, etc., improving its condition, and changing it gradually to a character more resembling the surface-soil. This cannot be done with the plow represented above, for when inserted to full depth, say fifteen inches below the bottom of the surface-furrow, four yoke of oxen cannot move it with ease in moist sub-soils, and if they could, it would simply raise this sub-soil five inches, mixing it with the surface soil in the lower portion of the furrow.

In this condition we found the sub-soil plow and the art of sub-soiling many years ago. Our first suggestion to our friends, the plow-makers, was to lower the wing to three inches, they insisting that sufficient strength of parts could not be had with the wing below that point, as the point would be rendered too thin to sustain itself. We then suggested the plow represented by Fig. 102.

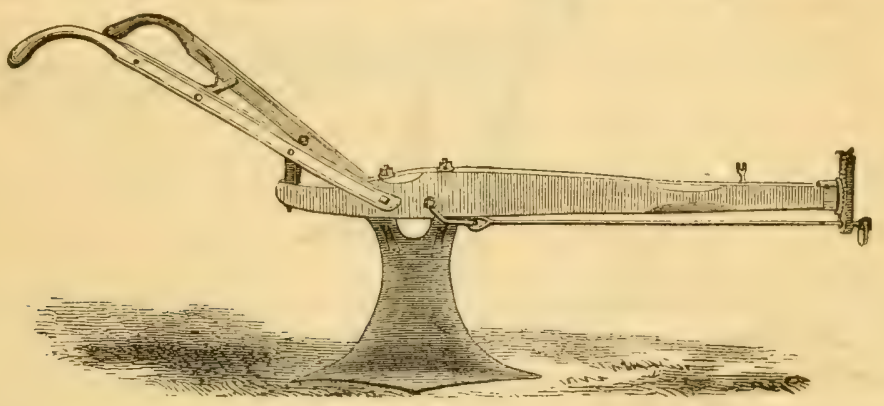

Fig. 102.

This was called the reversible sub-soil plow, and was a modificution of our views' which are more fairly represented in Fig. 103 by the manufacturers. It will be seen that this reversible sub-soil plow has a lozenge-shaped bottom, alike on both sides of the standard, and is but an inch and a half higher at the middle of its sole, than at the point; this elevation of the sub-soil being entirely sufficient to cause the most thorough disintegration from the line of its travel at the bottom of the surface of its action, under-cutting both the land-side and the furrow-slice, lifting each, and affecting the mass very much as the mole does when traveling beneath the surface of the soil, cansing a much greater pulverization of the portion of soil above his track, than would one hundred surface-plowings turning furrow-slices. This plow, when worn out at the point, could be reversed, presenting a new point.

Although this plow was far superior to the old sub-soil plow, even with the wing depressed, still it required a large amount of power to foree the cast-iron standard through the soil ; this difficulty gave rise to the lifting sub-soil plow, now so generally passing into use. This is made of steel, and may be understood by Fig. 103.

The sole of this plow is not unlike a spear placed flat on the ground, pointed forward, with its lower side changed in figure so as to be slightly concave. The upper side of this plow, from its point, and from each of its sides toward its heel 
and bridge, is a gradual inclined plane, attached to the beam by a scimeter-lockcoulter in front and the standard in its rear; the front standard being made of wrought iron and steel. This plow, even when of a large size, may be propelled in most soils by a single pair of oxen, and when used as a sub-soil plow, it should always be with such a team; for if horses are used, the whiffletrees will prevent the beam from sinking into the bottom of the furrow, as they will rest upon the furrow-slice. When oxen are used, the chain is attached to the draft-rod, and this latter difficulty is obviated.

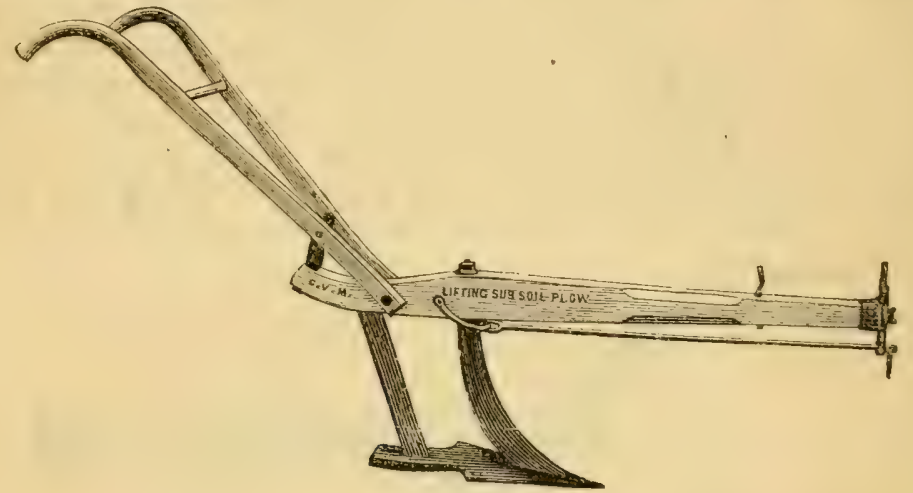

Fig. 103.

Now let us compare the disintegrating power of this plow with any surface-plow. With the latter we lift a portion of the soil, carry it through the are of a circle of twenty-three inches or thereabonts, and let it down again with but slight disturbance, and at every foot of travel, we thus lift, when plowing deeply, one hundred pounds or more of soil through this long line, and must have the requisite power. The lifting sub-soil plow, however, lifts the soil but one inch in height, itself being a wedge of but one inch in thickness, but of four or five in width. In thus lifting the soil, the resolution of its forces is upward and outward, causing the soil to be disintegrated at the surface to a width of twenty-four or more inches, and when following in the bottom of the furrow, it not only under-cuts the land-side, adding no useless friction on this side, as does the surface-plow, but it elevates it, disintegrating all the way to the surface, and rendering the next surface-plow furrow-slice peculiarly easy of disintegration on the furrow side. It elevates the furrow-slice itself with the sub-soil beneath it for one inch, and in so doing causes the furrowslice to move, as if an immense serpent or tortoise were beneath it, securing a thorough disintegration of the whole.

When the soil is thus prepared, the roots can readily travel in the sub-soil and ramify themselves to greater depths than before. On the removal of the crops, these roots, by their decay, deposit both organic and inorganic matter of a progressed kind through the sub-soil, and prepare it gradually for forming part of the surface-soil in the course of future cultivation.

All who have thoroughly sub-soiled their land, have been made aware of the following facts, viz. : 
That a sub-soiled meadow never runs out.

That thin seeding, by a greater amount of tillering, will give as large crops as thick seeding without sub-soiling.

That less manure is required to fertilize sub-soiled land.

That a larger amount of crops can be produced.

That no land thoroughly sub-soiled can ever suffer from drouth; for the atmosphere, in which all moisture must be resident when it is alsent from the soil, will continually deposit, by condensation, in the cold, well disintegrated sub-soil, sufficient moisture to supply, by capillary attraction, the wants of the surface-soil.

It is true that wet soils requiring under-draining as a means of getting rid of water, soon settle back to their original hardness after sub-soiling, and therefore in such soils the sub-soiling requires to be renewed more frequently than in underdrained soils; but in all soils the cut of the sub-soil plow may be viewed as a partial underdrain, at least sufficient to secure at times the upper soil from containing an excessive amount of water.

The use of this implement does not end here. We have known many a wornout pasture to be renewed by its use without taking the field out of grass. It may be run through with a suitable team to its full depth, at distances of three feet apart, so as to elevate the old sod, with eighteen inches of earth beneath it, one inch high, rendering the whole soil free, permitting old roots to decay, and new ones to establish themselves, and this without turning over the sod, the sub-soil cut closing itself behind the plow, as it passes along, but still leaving a free opening for atmosphere, moisture, etc. A slight top-dressing in early spring of a field so manipulated, will renew the grass ; a slight seeding, if necessary, may occur at the same time. By such treatment many ficlds have been restored so as to give a full burden of hay without reversing the sod, and carrying the field through the usual system of hoe crops, before putting it down again to grass.

The real object of plowing is not to turn immense masses of soil without disintegrating them, but rather to change the relative position of every particle of soil ; the movement of one millionth of an inch of each particle in its relation to surrounding ones, is just as thorough cultivation as lifting it a foot high and placing it back again on the surface. This is attained by the use of a lifting sub-soil plow, particularly when used following the surface-plow and propelled by a separate team. With the surface-plow, the force of the team is resolved in all directions; in the lifting and turning the furrow-slice, and in useless friction on the land-side; the whole being an endeavor to burst the surface of the globe asunder, in degree pressing horizontally, and to that extent producing a compression of soil and a useless loss of power. Not so with the lifting sub-soil plow; it is free, and the whole resolution of force applied is upward and outward, and therefore only requires sufficient power to overcome the compactness of the soil and its weight; no part of the force being expended in useless horizontal pressure; and although the sub-soil is very much harder and more compact than the surface-soil, still no nore team is required to propel the lifting sub-soil plow through this compact sub-soil, than for surfaceplowing to an equal depth.

When the surface-plow is run at a depth of twelve inches, and a sub-soil plow 
capable of disintegrating to a depth of fifteen inches bencath the bottom of the surface-furrow, then we have a total disintegrated depth of twenty-seven inches, and those who so practice will find that they have discovered another farm beneath that represented on their map.

A smaller size of this plow, still thinner in the sole and more dart-like in its figure, capable of being drawn by one horse or a small mule, is an admirable implement for cultivating crops, and will do the work of more than forty men with digging forks, spades or hoes. With the corn crop this tool may be run close alongside the corn, and to the full depth of ten or twelve inches when the corn is but three inches high, and before its roots occupy the space between the rows; this will lift the soil, move every corn plant with the soil, and for so slight a distance as not to separate the particles from the roots, yet so completely loosening the mass that the plant may be picked up with the fingers. This is more thorough cultivation than could be achieved by one hundred hoeings, leaving the soil in better tilth and cutting off no roots. The whole distance between the rows may then be made clean by Howe's Horse Hoe, and thus the certain cultivation of the corn be accomplished by these two implements.

Row crops, such as beets, carrots, parsnips, onions, etc., may be cultivated in part by this No. 0 lifting sub-soil plow. When these plants are just out of the ground, and when any other implement would cover them with soil, this may be run half way between the rows to the depth of ten or twelve inches, lifting and disturbing the soil, and moving both rows of plants slightly as it passes along, doing the work of more than forty hand-hoes. It is true that it removes no weeds, but it leaves the soil in such admirable tilth that a carrot weeder may be passed between the rows a few days after; finding the soil in such perfect condition, it will shave two inches of the surface, separate every weed and leave it exposed to the sun to be wilted. In the cultivation of cabbages, and indeed all other crops requiring a thorough disintegration of the soil in the early stages of their growth, and before their roots have ramified themselves materially, this little soil-lifter is superior to all other implements. After a field has been prepared for a crop, and has rested a few days, perhaps slightly settled by a drenching rain, this tool may be used for striking out rows previous to planting, leaving the soil in admirable condition for receiving the seed.

For the gathering or digging up of many crops, the lifting sub-soil plow answers a good purpose. Thus the largest size, standing nineteen inches from the beam to the point, may be run alongside of a row of carrots, with the team straddling the row and lifting the soil and carrots one inch, thus loosening them so thoroughly that they may readily be pulled out by hand, leaving the soil in admirable tilth to be improved by culture.

If the steam plow is ever to succeed for general purposes, we believe it will be by adopting in degree the principles of this plow, and not by applying an undue amount of power to pressing a furrow-slice, as is often the case with clayey soils if plowed when in too moist a state, even with the power of a single team. 

C. V. mapes' illustrated catalogue.
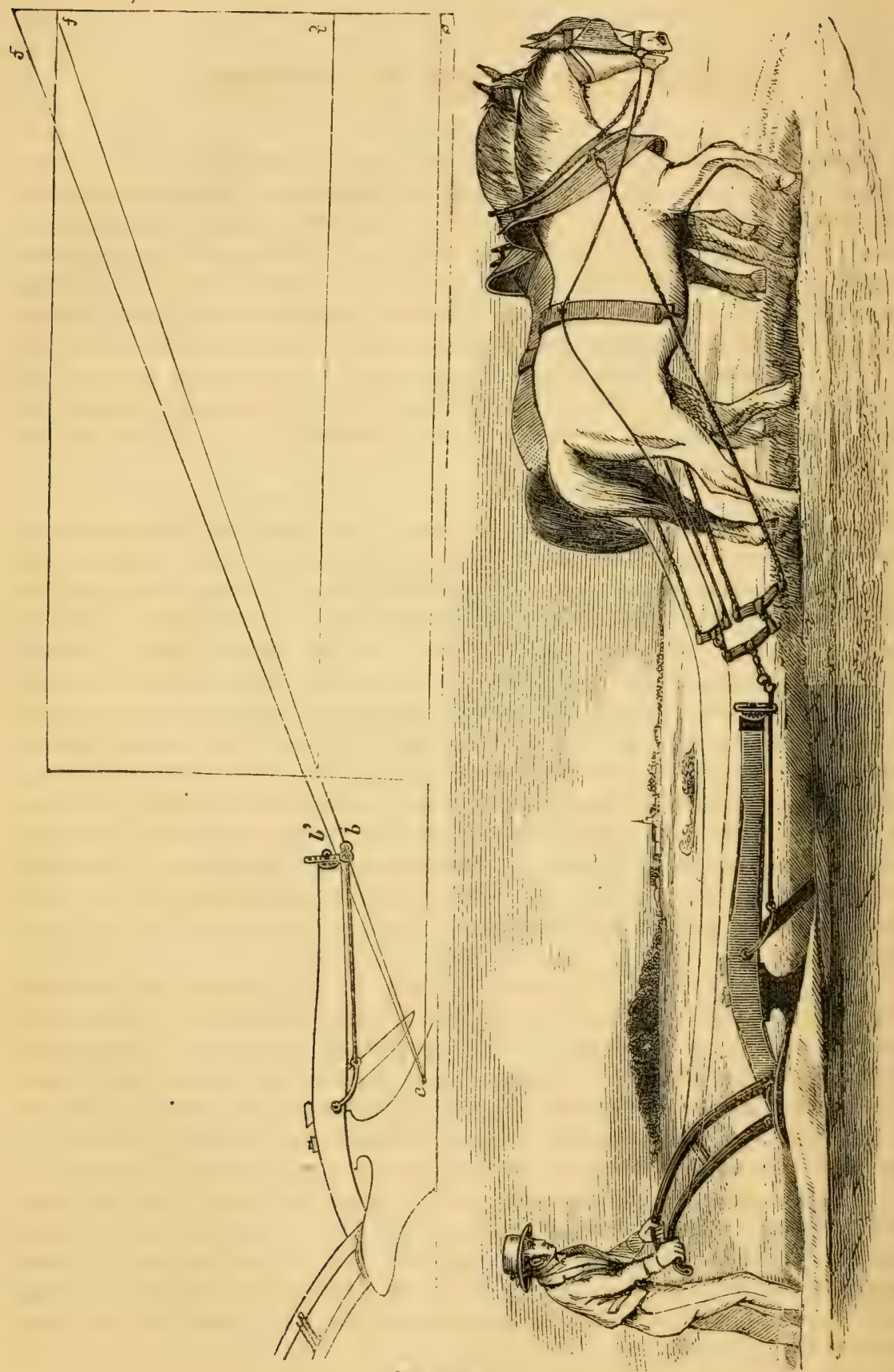

Fig. 104. 


\section{REMARKS ON PLOWING.}

From the complicated structure of the plow, and the manner in which circumstances oblige us to apply the draft to the implement, some misconceptions have arisen as to the true operation of the draft, and the proper manner of its application. Too little is understood of the true principles of draft, to enable the plowman to attach his team and arrange the elevis so that the plow will do its work properly, and with the least force or power. To render this subject intelligible to every mind, the following remarks are made in connection with the plate annexed, Fig. 104

Let $b$ represent the forward end of the beam, and $c$ the centre of resistance on the plow, which may be assumed at two inches above the plane of the base of the plow, $d e$, though it is liable to constant changes, from the depth of the furrows, and constant inequalities in the soil.

We have first to consider the particular form of those parts through which the motive power is brought to bear upon the plow. It is evident that the motive force acts in a direct line from the hook or ring at the shoulder of the animal, to the centre of resistance, and were it not for considerations of convenience, a straight bar or beam lying in the direction $c b$, and attached firmly to the body at $c$, would answer all the purposes of draft perhaps better than the present beam. But the draft not being the end in view, but merely the means by which the end is accomplished, the former is made to subserve the latter; and as the beam, if placed in the direct line $c$ to $b$, would obstruct the proper working of the plow, we are constrained to resort to an indirect action to arrive at the desired effect. 'This indirect action is accomplished through the medium of an angular frame-work, consisting of the beam and the body of the plow, so strongly connected together as to form an unyielding structure. The effect of the motive force applied to the frane-work at the point $b$, and in the line of $b$ to $f$, produces the same results as if $c b$ were firmly connected by a bar in the position of the line $c$ to $b$, or as if that bar alone were employed.

The average length of the trace-chains being 10 feet, including all that intervenes between the clevis of the plow at $b$, and the horse's shoulders, let that distance be set off in the direction of $b$ to $f$; and the average height at the horse's shoulders where the chains are attached, being about 4 feet 2 inches, let the point $f$ be fixed at that height abovethe base line $d e$. Draw the line from $f$ to $c$, which is the direction of the line of draft acting upon the assumed centre of resistance, $c$; and if the plow be in proper trim it will coincide also with the ring of the clevis; $e$ c $f$ being the angle of draft, and equal to $20^{\circ}$. It will be readily perceived, that with the same length of hames, the angle $e c f$ is invariable; and if the plow has a tendency to rise at the heel, or run on the point, under this arrangement, it indicates that the ring at $b$ is too high in the clevis. Sbifting the ring one or more holes downward, will bring the plow to work evenly upon the base of the land-side, or work flat. 
If the plow has a tendency to rise at the point of the share, the ring $b$ is too low, and must be moved by raising it one or more holes in the clevis. If a pair of taller horses be harnessed to the plow, the draft chains, depth of furrow, and soil (and, by consequence, the point of resistance $c$,) remaining the same, we should have the point $f$ raised, suppose to $f^{\prime}$; by drawing the line $f^{\prime}$ to $c$, we have $e c f^{\prime}$ as the angle of draft, which will now be $22^{\circ}$, and the ring will be found to be below the line of draft $f^{\prime} c$; and if the draft chains were applied at $b$, in the direction at $f^{\prime} b$, the plow would have a tendency to rise at the point of the share, by the action of that law of forces which obliges the line of draft to coincide with the line which passes through or to the centre of resistance; hence the ring $b$ would be found to rise to $b$, which would raise the point of the share out of its proper direction. To rectify this, the ring must be raised in the clevis by a space equalling that between $b$ and $b$, causing it to coincide with the true line of draft, which would again bring the plow to work evenly on the base of the land-side, and run fiat.

The foregoing principles are substantially such as are adopted by the most experienced plowmen, and, if properly applied, will not only do the best work, but accomplish it with the greatest ease to themselves and their team. If the power (or team) is not rightly applicd, good work cannot easily be done; for if the plow inclines in or out of the ground too much, or takes too wide or too narrow a furrowslice, the plowman must exert force to direct it properly, in addition to that required to overcome the obstacles and inequalities in the soil, but if the power be rightly applied, the plow will move so accurately as not only to perform good work with more ease to both plowman and team, but, in soils free from obstruction, even without being guided.

To effect a proper horizontal movement, the clevis at $b$ or draft-rod (if one be used instead of a clevis) must be adjusted and confined at that point, moving it to the right or left, if necessary. This will canse the plow to take the proper width of furrow-slice, which, in sod, should be wider or narrower, according to the depth of furrow, or rather the thickness of the furrow-slice required; for as the thickness is increased, so also must be the width, in order to turn it easily and perfectly over, particularly when the furrow-slices are required to be laid over level and side by side. The proportion in ordinary sod should be 6 by 11,7 by 12 , or 8 by 14 inches. In determining the width of furrow-slice, some regard must be had to the strength of the particular sod to be turned; for the plow will turn over a wider slice in a strong or stiff sod, than when running in one more easily broken, or it will cripple and double when raised to a perpendicular position, thus only doing the work called "cut and cover." When the slices are required to be laid at an angle, and lapped each one upon the preceding, the proportion of width should be less, or about 6 by 9 and 10 , or 7 by 10 and 11 inches; for the narrower the slice in proportion to the depth, the greater will be the inclination of the slice as it is lapped upon the preceding one. 


\section{THE HARROW.}

WE find the agricultural press all engaged in publishing articles on the Harrow ; we have them circular, square, triangular, and of every other form, but they all contain one principle in common, namely, a conical tooth, point downward.

Every farmer knows that land may be harrowed until it is rendered so hard that it cannot be plowed. If this be true, as a substantial result from excessive harrowing, then it is true in degree at each application of the harrow ; for the same reason that ducks, geese, etc., notwithstanding their bodies are light, can render land too compact to remain fertile, the weight of a harrow when resolved upon a cone, point downward, will compress and compact the soil. The snuff manufacturers use a single harrow tooth for compacting bladders of Scotch snuff, which are nearly as hard as a cannon-ball; at each incision of this tool the snuff is forced downward and outward, and the cavity is immediately filled with new quantities, until eventmally the blow of a hammer ceases to dent it. This is but a miniature illustration of the effect, of which a harrow is the full-length portrait. Harrows have but one use, and that use is not to thoroughly pulverize the soil, as some suppose; this can only be done by cultivators, the teeth of which are an exaggerated representative of a harrow tooth, reversed in its position, namely, point upward. The cultivator, if properly formed, will pulverize the soil. Its teeth should be flattened out like the foot of a duck, with a gradual and not a sudden inclined plane, so that its action in traveling through the soil is upward and outward, like the back of a mole, or like the lifting sub-soil plow; such an implement will indeed pulverize the soil. The only use for a harrow is to comb from the surface those things which may lie upon it. Weeds already brought up by the cultivator, may be combed off by the harrow; but for such purposes the harrow should be light, not heary; its teeth indeed may be of wood; in other words, it may be an enlarged rake; it should not. be a heavy framed implement, armed with cones, point downward, so well calculated to compact the soil.

With the above remarks as a caution against the improper use of "the harrow," the following are offered as the best for the use of those who choose to continue this instrument in their practice.

This harrow, Fig. 105, is usually made to take a breadth of five feet. It is composed of two pieces of frame-work, connected to each other by iron hinges coming together like common barn-door hinges, and which, extending across the pieces widthwise, are bolted to each bar, thus greatly strengthening the harrow. The ends of the 


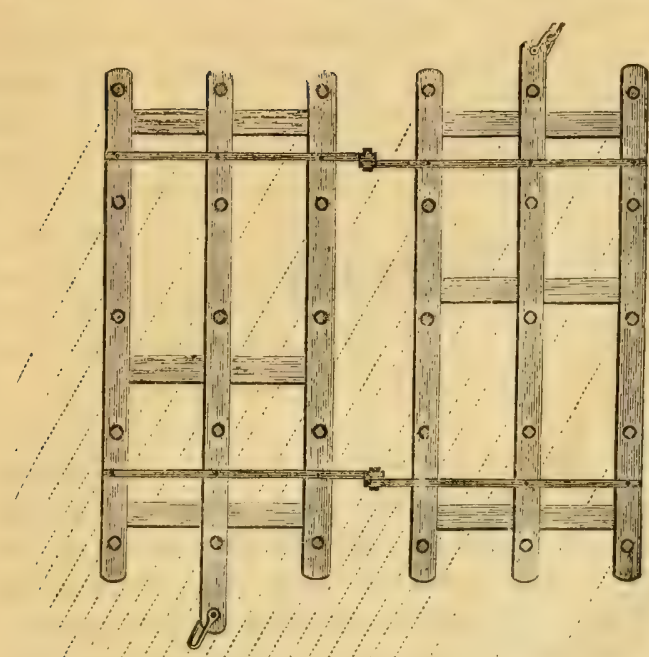

Fig. 105. Improved Hinge-Harrow. Two-Horse.

bars are secured from splitting by iron rivets. The harrow may be folded double, or separated into two parts, for the convenience of transportation or other purpose. Either half may be lifted for any purpose while the implement is in motion; and the easy and independent play of the parts up and down upon the hinges, enables the instrument to adapt itself to the surface of the ground in all places, so that wheth. er going through hollows, or over knolls and ridges, it is always at work, and every tooth has an operation upon the soil. There are thirty teeth in the harrow, and yet they stand equi-distant and wide apart each way, so that while from their number and arrangement the ground is worked fine, they are not liable to clog. This harrow is made heavy or of white oak bars three inches square, with teeth three-quarters or seven-eighth inch square, to fit it for rough land and the pulverizing of sod furrows. It is made to draw either end forward; and when the teeth become dull by working in one direction, the team may be hitched to the other end, and they are sharp again.

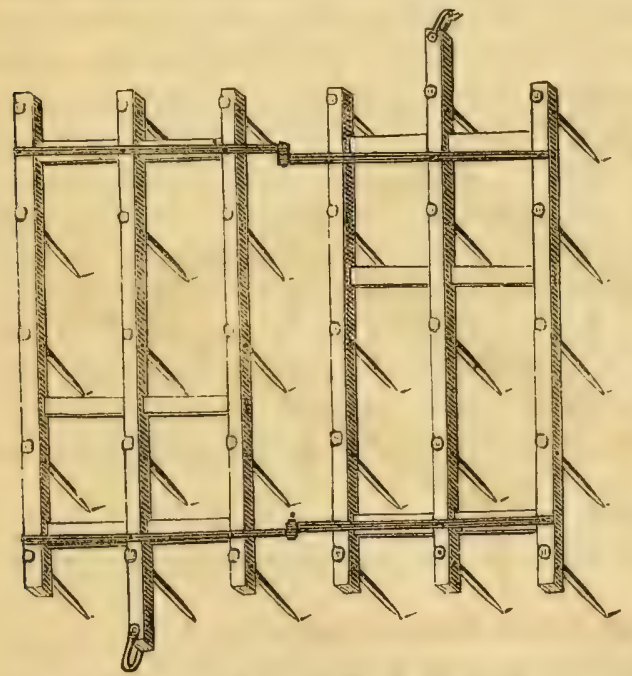

Fig. 106. Improved Hinge Steel Harrow. One-Horse.

Fig. 106 is of the same length and breadth and construction as the one represented in the preceding cut. But it is made quite light, of white ash bars, 2 to $2 \frac{1}{2}$ inches square, with teeth of one-half or five-eighth inch steel. It is adapted to the draught of one horse, or two small mules. The teeth standing a foot apart each way, are not liable to clog, and yet their number and arrangement are such as to work the ground into a fine tilth. With this harrow, one horse will go over as great a breadth of land in a day as is usually accomplished by two horses. The instrument may be drawn either end forward. 


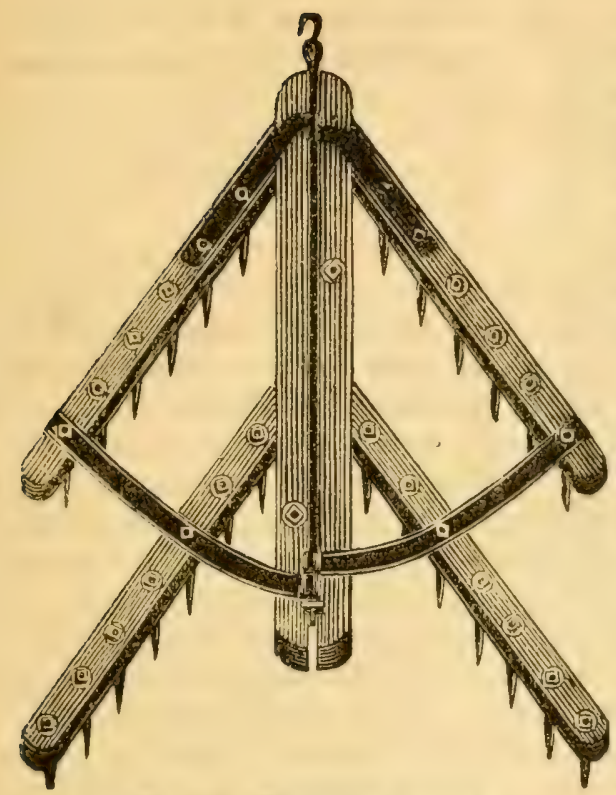

Fig. 107. The Geddes Harrow,

The Geddes Harrow is made of two pieces of frame-work, joined by hinges in the center, so that it adapts itself to an uneven surface, and either side may be conveniently elevated to free it from stones, sods, \&c., while the harrow is moving along, without disturbing the operation of the other half; and one part may be folded upon the other in passing stones, between stumps, fruit-trees, \&c. The arrangement of the teeth in the frame-work is such, that each one opcrates distinctly from others, and the number of impressions made on the soil will be equal to the number of teeth, and at equal distances. The tecth are made of the best Swedes' iron, steel pointed. The harrows are of various sizes and weights, containing $14,18,22,26$, and 30 teeth.

The Expanding and Reversible Harrow is so constructed as to admit of being widened or narrowed, to do coarser or finer work, as circumstances may require. The two bars on the top of the frame-work are connected with the four under bars by the outside teeth, the upper parts of which are rounded and shouldered, with nuts and screws on the top, and on which the entire frame swivels or turns in ex-

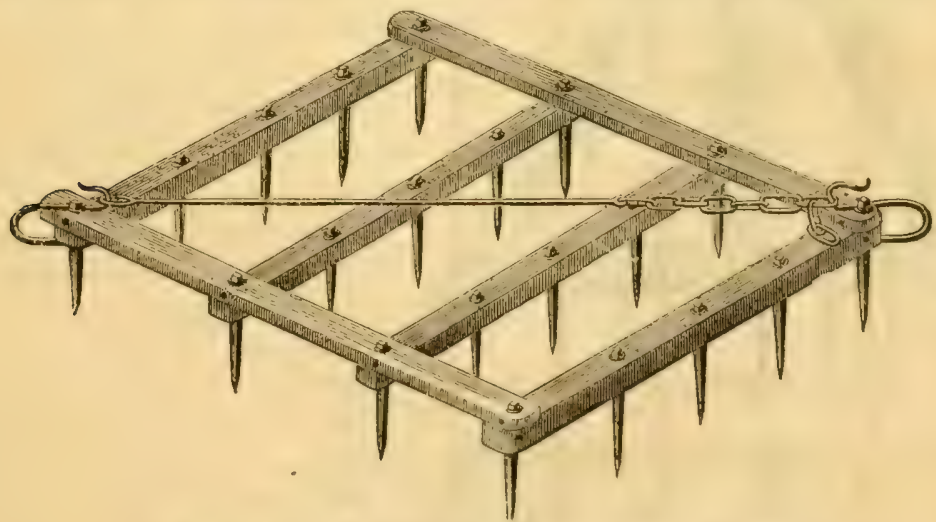

Fig, 108. The Expanding and Reversible Harrow.

panding and contracting, which is simply done by shortening or lengthening the chain on the top. Thus the harrow is made any desirable width, and any degree of fineness, while the teeth in every position operate independently of each other 
The harrow is constructed to be drawn either end forward, so as to secure sharp teeth, and is folded completely together for transportation. Various sizes, made heavier or lighter, are supplied to order.

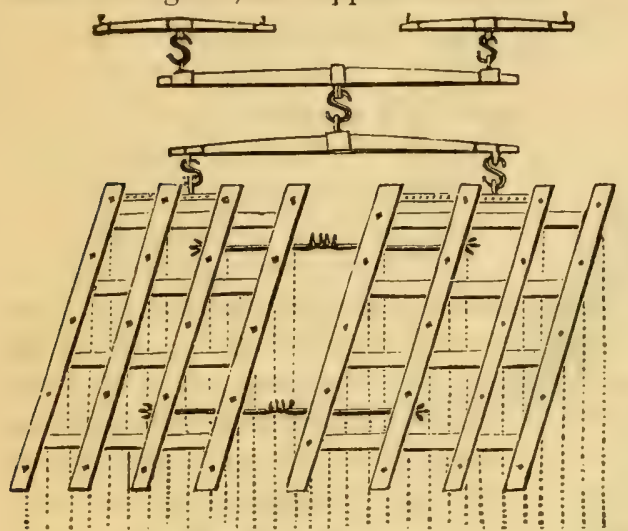

Fig. 109. Scotch Harrow

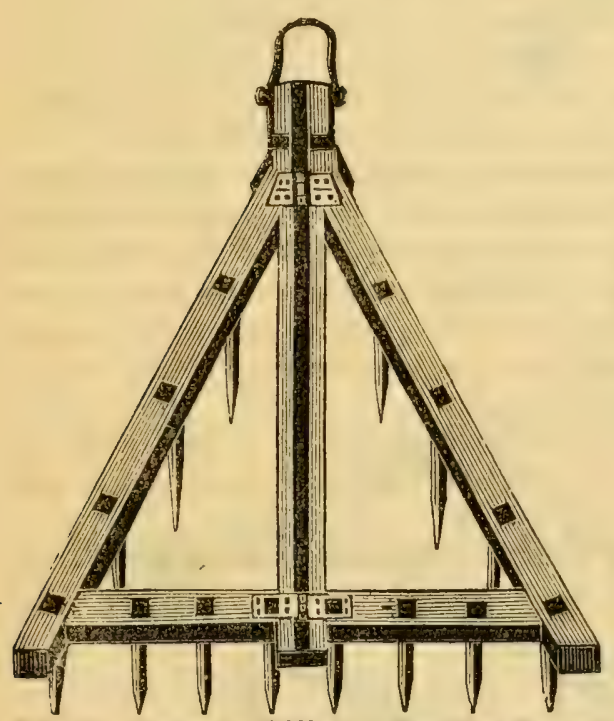

Eig. 110. Triangular Folding, or Chandler's Harrow.
This is a hinge larrow, and may be used single or double. It xs made of several sizes.

This is also a hinge harrow, very strong and heavy, for rough, difficult work, and made to order. 


\section{CULTIV ATORS.}

These are of various kinds, but all partaking of the same general principles, being intended to be drawn by one horse and to be used between the rows of cultivated crops, such as corn, potatoes, root-crops, cotton, etc., though it is frequently employed to pulverize the ground preparatory to seeding, and for this purpose is every, way superior to the harrow as to the result. The force is expended upward and oxtward instead of downward and outward, and therefore renders the soil light instead of compact. It is also used for covering the seeds of grain, and in such cases is sometimes made larger, to be drawn by two horses or oxen. When intended to work between rows of corn, cotton, etc., it is constructed so as to expand or contract according to the width between the rows. It stirs the surface of the soil most thoroughly, and working as near the plants as may be desired, while it can be set so as not to run deep enough to injure the roots of the crop.

In its various modifications the cultivator exterminates grass and weeds much more effectually than the hand-hoe, leaving them on the surface to be wilted by the sun, at the same time pulverizing the surface-soil, and rendering it light and friable, so as to admit dews, and rains, and atmospheric influences, giving to the water in the soil the power to dissolve much larger proportions of the inorganic elements of plants, thus promoting the growth and product of the crop while it saves hand labor.

When the wheel is attached, it causes the implement to move steadily and at an even depth, facilitating its turning at the end of rows, passing stones, other obstructions, etc.

The more recent and better class of cultivators are those known as Horse-Hoes, of which the following are the best kinds:

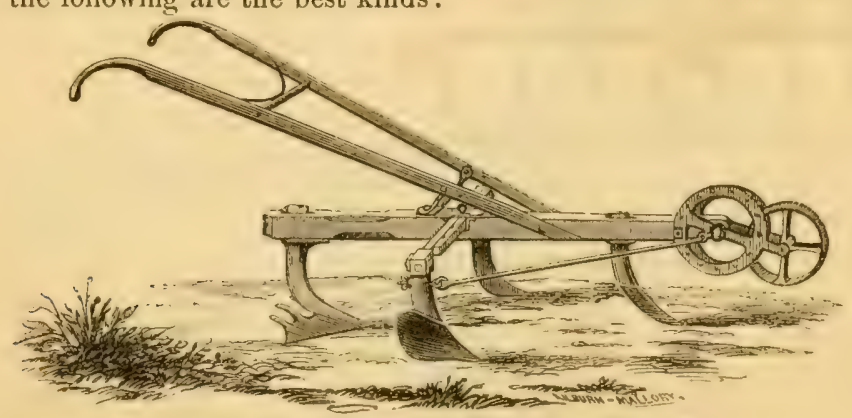

Fig. 111. Howe's Improved Expanding Horse-Hoe. 
Fig. 111 represents an improvement recently invented by J. A. Howe, which is designed for the hoeing or cultivation of corn, the various root crops, cotton, hops, nurseries, and all crops that require a frequent stirring of the soil. It is light, easily managed, turns, pulverizes and mixes the surface, and is consequently highly destructive to the weeds and grass. The side teeth are miniature single monldboard plows, and may be changed from one side of the implement to the other, so as to turn the soil from the rows when the plants are small and tender, or toward them at a later period, as may be desired; the broad rear tooth penetrates but two or three inches, cutting off the roots of weeds, and sifting the soil through its elevated prongs above. The improvement consists in adding parallel expanding bars, so that it may be worked as wide or as narrow as is desired. The side teeth are also supported by a rod connected with the front part of the hoe, thereby giving them permanency, and without any wearing of the socket that holds the tooth to the bar. This power of controlling the width of work will enable the cultivator to adapt it to any crop where a horse can be used. In light lands that have been well plowed the preceding year, it does excellent work without being preceded by the plow. It lifts, changes, and pulverizes the soil in a manner that is not effected by any other implement. It is made of the best materials, and with proper care will last for many years.

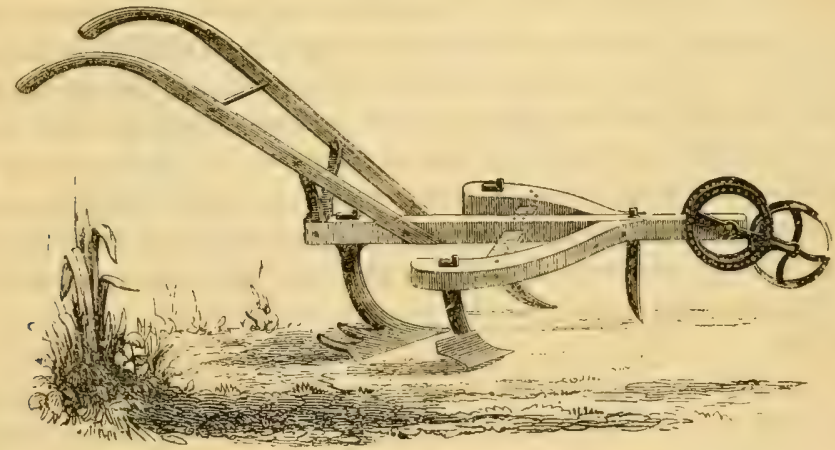

Fig. 112. The Horse Hoe. Knox's Patent.

Fig. 112 represents Knox's Horse Hoe. It is designed for the hoeing or cultivation of corn, the various root crops, cotton, hops, young nurseries, and hoed crops generally, is quite light, easily managed, and of very easy draft for one horse or mule; a thorough pulverizer of the surface-soil, and exterminator of weeds and grass. The forward tooth is simply a coulter, to keep the implement steady and in a straightforward direction; the two side or middle teeth are miniature plows, which may be changed from one side to the other, so as to turn the earth from the rows at first weeding, when the plants are small and tender, or toward them in later cultivation-at the option of the operator; the broad rear tooth effectually disposes of grasses and weeds, cutting off or rooting up all that come in its way, is a thorough pulverizer of the surface, sifting the earth and weeds through its iron prongs or fingers in the rear, leaving the weeds on the surface to wilt and die, 
and the ground level and mellow. For hoeing carrots, turnips, etc., where the rows are narrow, the side teeth are taken ont, and the rear tooth with the forward one as a director to guide the instrument, hoes and mellows the ground between the rows very perfectly.

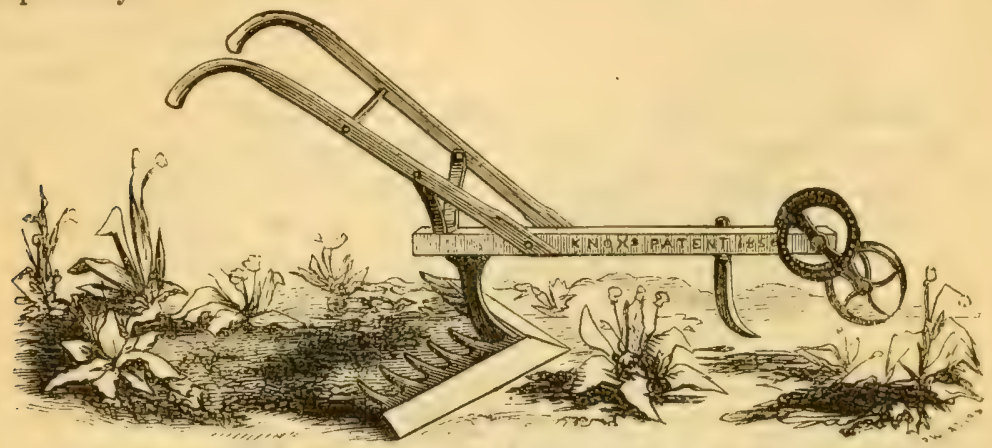

Fig. 113. Horse Hoe for Cotton or Carrots.

Fig. 113 represents Knox's Horse Hoe, adapted to the cultivation of cotton, or of carrots, and other root crops. The forward tooth is simply a coulter to balance the Hoe and keep it in a straight course. The rear tooth has a broad steel share, spreading in all to the width of twenty inches, or ten inches each way from the center-the cutting edge being on an easy angle backward and outward from the point, adapted to make a clean and easy cut. The tooth has also five prongs or fingers on each side, above and back of the steel share, which are of iron, formed on a gentle upward curve, so that the soil lifted by the broad share is combed or harrowed on the under side by the fingers-the weeds being sifted out and left on the surface to wilt and die, and the earth reduced to a mellow tilth. A broader or narrower rear tooth may be used on this instrument, according to the width of rows of the crop to be hoed.

Figs. 103, 111, and 113, are invaluable for the use of the market gardener-full descriptions of their use may be found in "The Working Farmer" for April and May, 1860.

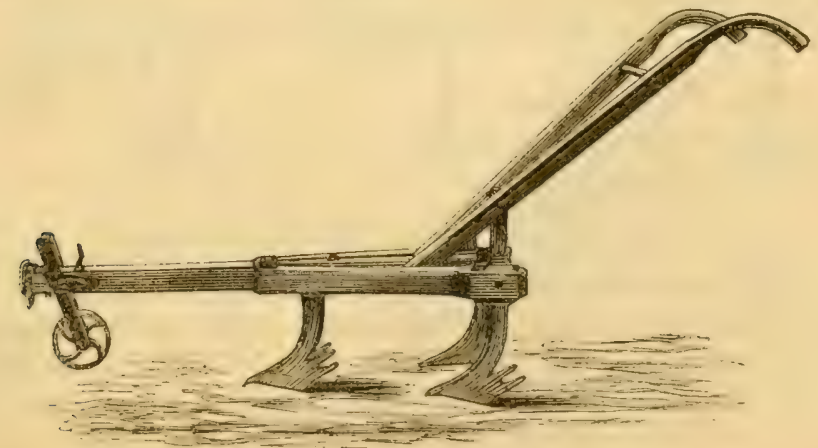

Fig. 113\%. Armsby's Expanding Horse Hoe.

This implement resembles, in effect, the Howe's Horse Hoc, being expanding 
and differs only in the form of the side teeth, which are easily changed from right to left, and may be used profitably in the flat cultivation of cotton, corn, tobacco, and many other crops. This machine is lighter than Howe's, and may sometimes be substituted for it with profit. The form of the outside disintegrators may be seen in the engraving.

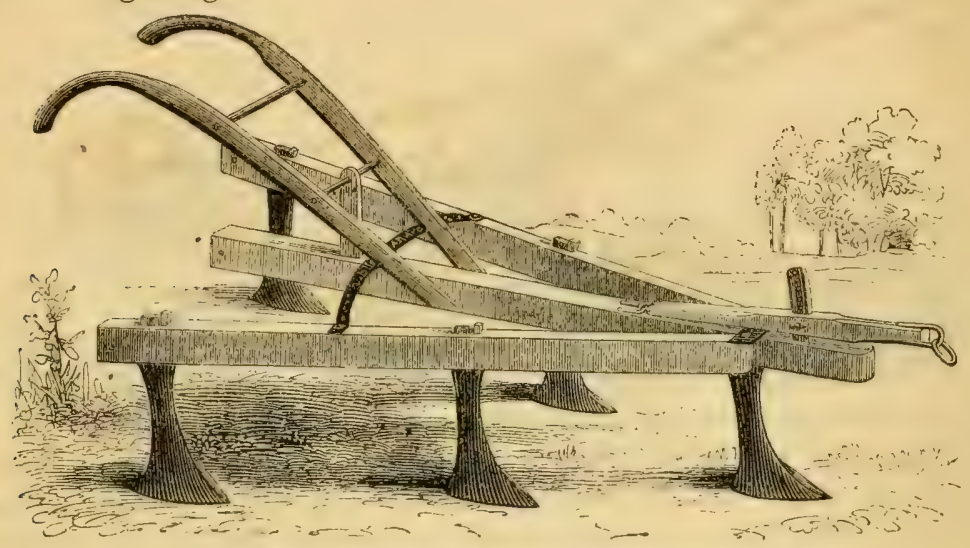

Fig. 114. Common Expanding Cultivator.

This is a low-priced instrument, when it is sold with cast iron teeth, though different teeth, hereafter described, and made of part or all steel, may be used.

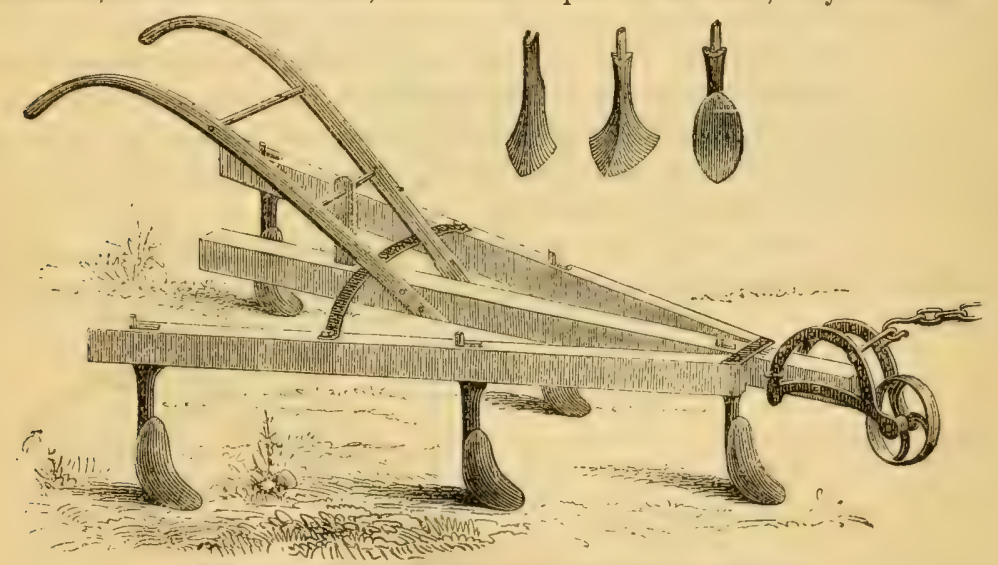

Fig. 115. Expanding and Reversible-Tooth Cultivator.

This is a highly approved cultivator. The points or shares of the teeth are made of steel or cast iron, and are fastened to the shank or standard by bolts or nuts, so that either kind of shares may be used on the same standard, cheaply replaced when worn, and one substituted for the other. The shares being also reversible, are thereby very enduring, as, when one end is too much worn to be effective, they may be changed to the other end down, and a double amount of service obtained.

The tooth represented at the left, in the Fig., of teeth detached, is made of all 
steel, and known as "Roger's Patent," and may be used, but requires a differentformed mortise; the center tooth is cast iron, and fits the same mortise as the steel-pointed reversible tooth above described. The various teeth are furnished separately.

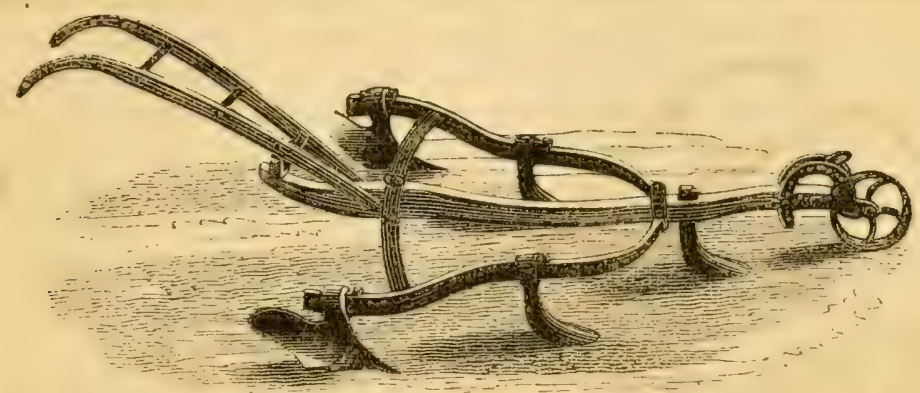

Fig. 116. Oniversal Cultivator.

Fig. 116 represents the Universal Cultivator, recently invented by the manufacturers. It is made long and all of iron except the center beam and handles; the side beams, of wrought iron, are so curved, that as they are expanded or contracted, each tooth, by loosening the iron key which confines it in its place, may be moved forward or back to a point that will again cause it to work parallel with the center beam, and at proper distance from the others. To the beams are fitted several sets of different-formed teeth and scarifiers, of wrought and cast iron, and one or more sets are supplied to order.

There is also one pair of teeth calculated to work in the rear, represented by the Figure, which may be used instead of the common teeth; they are in form like small plows, turning the furrows in opposite directions, and fitting alike both side beams; they may be placed to turn the furrows to or from the center, or rows of vegetables. If the forward teeth are used at the same time, they finely pulverize the soil, and if the plows are set to turn inwardly, a beautiful light bed is formed in which to plant any kind of seed. The farmer or planter using this cultivator

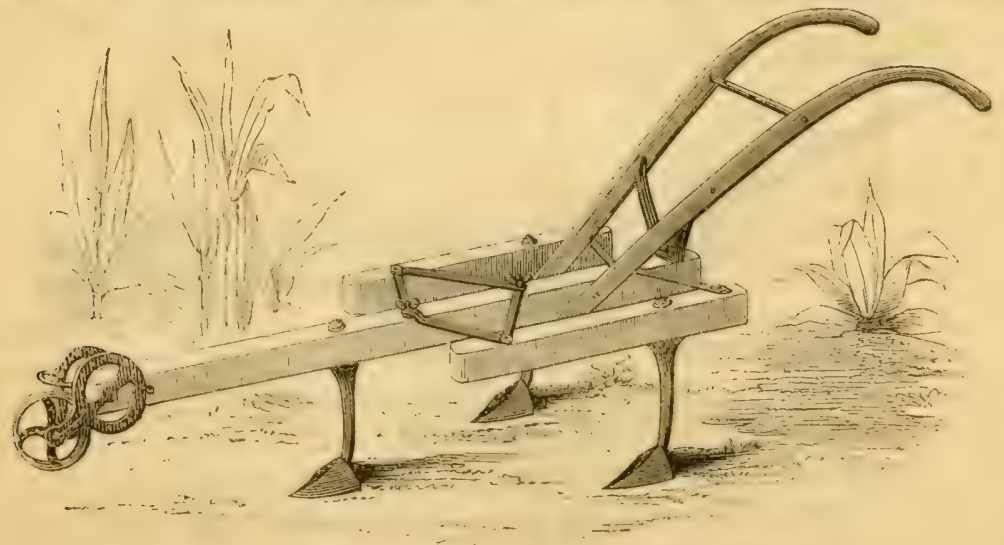

Fig. 117. Parallel Expanding Cultivator. Three Teeth. 
can have any form of wrought teeth he may desire, attached to the frame, by his blacksmith, as the manner of fitting them to the beams is very simple and easy.

Fig. 117 Parallel Expanding Cultivator, the teeth stand in the same relative position to the line of draft, whether the frame be expanded or contracted, and always work in a direct line forward. Both steel and cast iron shares are made to fit the tecth. These shares being fastened to the upright standard by bolts and nuts, may be slifted to use steel or iron ones at pleasure, or new ones may be substituted for those worn out,-an economical arrangement, as this part of the tooth is subject to the greatest wear, and is used up long before the remaining portion begins to fail. The teeth have high standards, which elevates the frame-work so far from the ground as to prevent the instrument from clogging with sods, \&c.

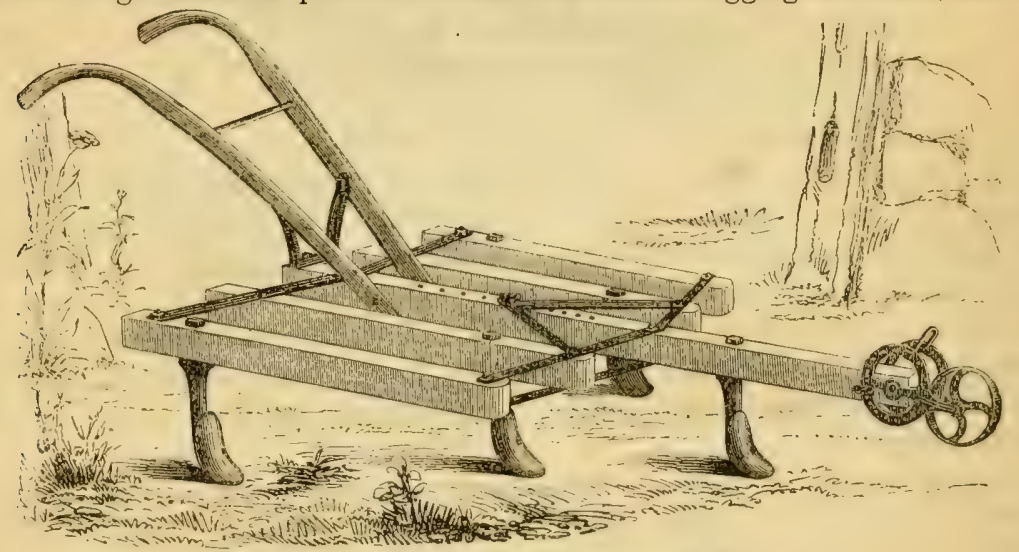

Fig. 118. Parallel Expanding Cultivator. Five Teeth.

This cultivator is of construction similar to the preceding one, except that the frame is made longer and wider, so as to receive five teeth, and take a greater breadth of surface in working. It is rigged with teeth either like those in the three-tooth cultivator, Fig. 117, or with the reversible teeth, as represented in Fig. 118.

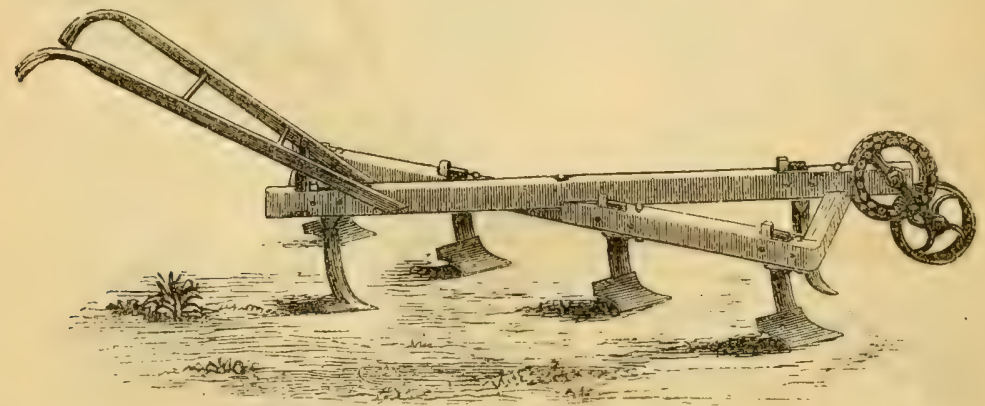

Fig. 119. Knox's Patent Gang Cultivator.

This is a combination of the Horse Hoe and Gang Plow. The beam, to which the team and the handles are attached, is placed in the line of draft of the 
instrument, and has the coulter or curved tooth of the Horse Hoe forward, and a tooth with a double share in the rear, for the purpose of balancing the cultivator. Another beam, placed diagonally to the draft, or to the first-named beam, contains a row of small steel plows, ench cutting and covering a breadth of earth of about seven inches, inverting and pulverizing the soil to the depth of one, two, three, or four inches, as may be desired, and raising a fine tilth. The instrument is perfectly balanced, so as to run straightly and steadily, and is easily managed in passing trees and stumps, and over rocks or large stones. For covering grain, or for preparing the surface soil for crops of any kind, and covering compost manure, it is preferable to the harrow. The Gang Cultivator, when designed for one horse, is constructed with four small plows, and carries a breadth of work of two and a half to three feet; and for two horses, it is made with six teeth, and a corresponding increase in length of beams, and carries one-third more breadtl of work.

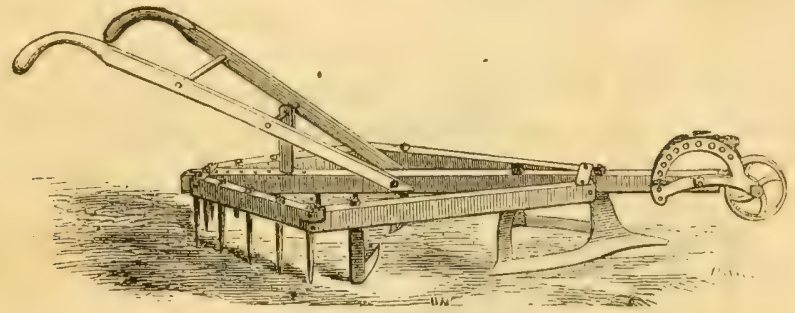

Fig. 120. Cotton Sweep.

Fig. 120 represents an implement much approved for the cultivation of cotton, in sections where it has been introduced. There are two sizes.

The forward or triangular share or sweep works the ground 14 or 18 inches wide; the next succeeding teeth are made of flat bars of iron, with the forward edge sharpened and turned inward at the bottom, and level with the share or . sweep in such a manner as to cut to the point marked by the sweep, thus making

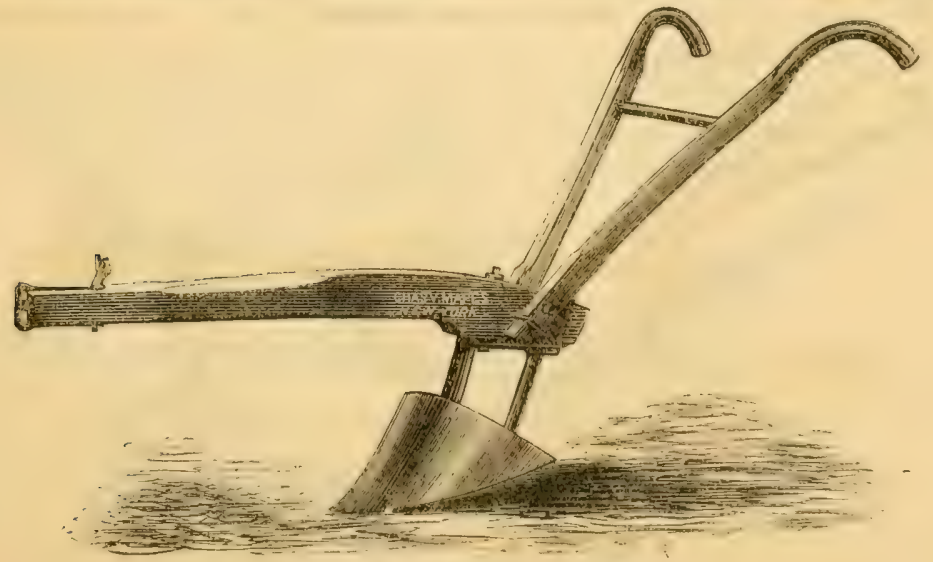

Fig. 121. Steel Mould Cotton Sweep. 
a clean cut of 24 to 32 inches, more or less deep; and the small pointed harrow teeth follow and more perfectly pulverize the soil, and work the weeds to the top in such a condition that they are killed by the sun. The implement is readily expanded and contracted at pleasure.

Fig. 121 is made of steel and at small cost; its lightness and peculiar adaptability render it popular in many parts of the country.

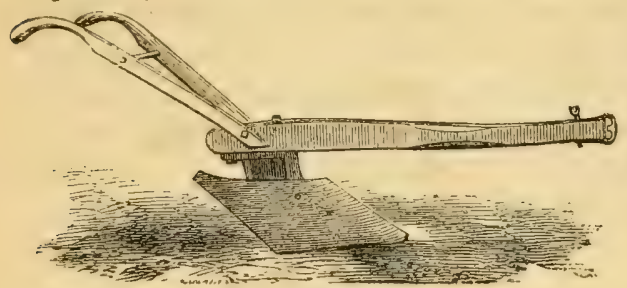

Fig. 122. Cotton Scraper.

Fig. 122 represents an improved Cotton Scraper, the importance of which every cotton-planter understands, and appreciates its advantages for the first working of the cotton.

The implement as here shown possesses important improvements, suggested by George W. Sizer, Esq., of New Orleans, and by whom it has been introduced to a large number of planters, who have expressed their entire satisfaction and given liberal orders. The Scraper is made either of wrought or cast iron, and is strong, durable, and very cheap.

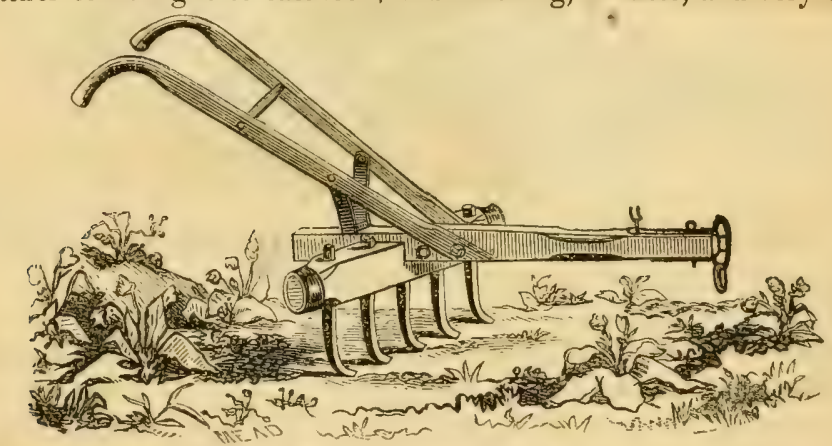

Fig. 123. Cotton Harrow.

Fig. 123 represents the new Cotton Harruw, recently improved by George W. Sizer, Esq., of New Orleans. It is very effective in destroying weeds and pulverizing the soil between rows of cotton. The teeth are very strong, and so shaped and set as to avoid the liability of clogging or of becoming loaded with earth.

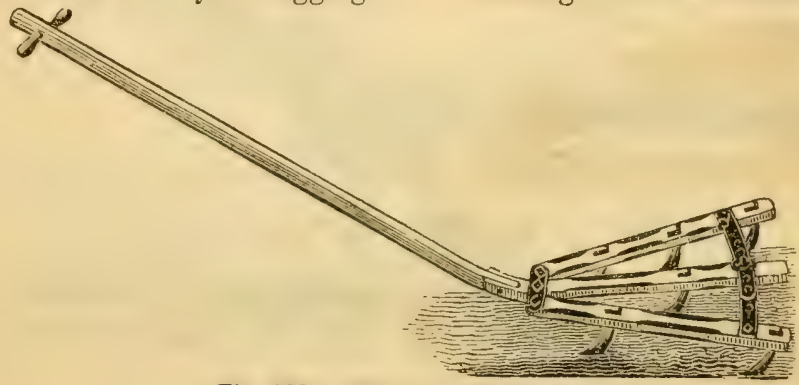

Fig. 123\%. The Hand Cultivator. 


\section{V. MAPES' ILlustrated CATAlogue.}

Fig $123 \frac{1}{2}$ represents the Hand Cultivator, which is made entirely of iron, excepting the handle, and expands from 10 to 18 inches. It is a very useful implement in garden culture, and is often used in fields, among rows of carrots, beets, onions, etc., where there is not sufficient width to use a horse.

We cannot but advise our customers to put their rows wider apart, and use the small lifting Sub-soil Plow and Carrot Weeder with a horse instead of the above implement-it may be used, however, in small gartens, where it is nearly or quite equal to a scuffle hoe.

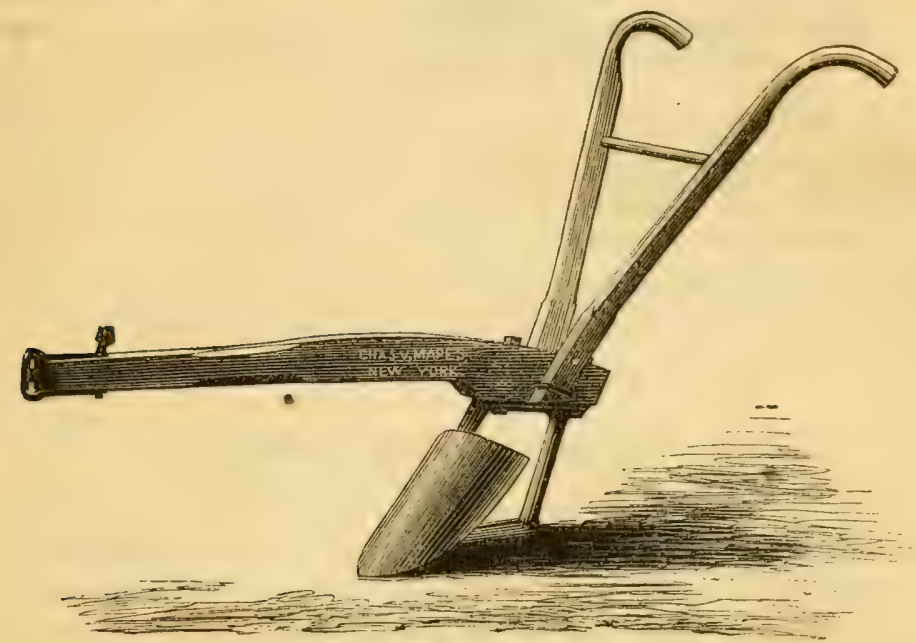

Fig. 124. Shovel Plow.

This implement is used in the South and West in cultivating corn and potatoesthe mould-board is of steel.

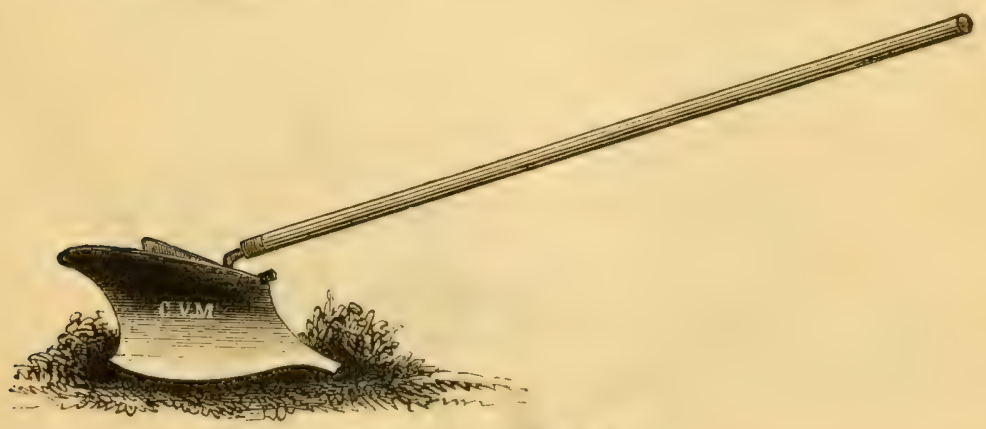

Fig. 1243/2, Hand Plow.

This implement is very useful in small gardens and for the hand cultivation, when preferred, for onions and other row crops. The implement is fully described by the engraving. 


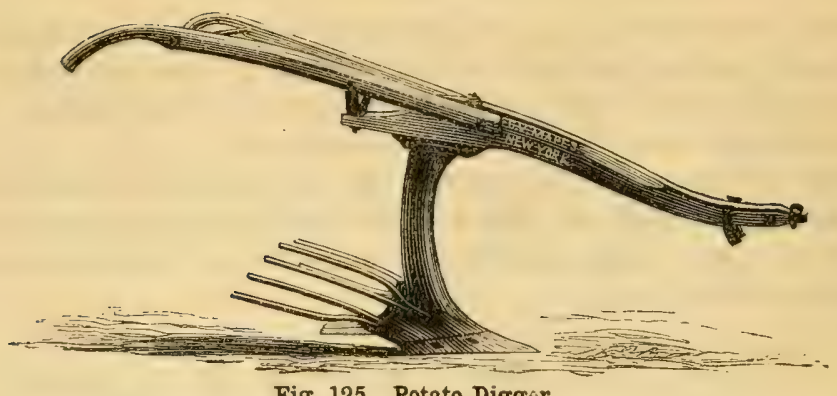

Fig. 125. Potato Digger.

The above cut represents one of the forms of the Potato Digger, of which we have several, all embracing the same principles, with formal differences, but substantially alike in their effects and mode of operation. They are worked by a team straddling the potato row, the point entering the end of the row beneath the potatoes, raising them with the dirt up the front inclined plane, which is gradual, the earth falling through between the rods or bars, and the potatoes rolling off on either side free from soil.

\section{Potato Planters and Coverers.}

Of these there are a variety of patterns. But since the improved method by flat cultivation, the use of the Double Mould-board Plow assisted by the soil-lifter, to make and open furrows for planting, and the $V$ of plank with the open end moved forward for covering, is quite equal to any of the implements now in use for these purposes. The rear of the $\mathrm{V}$ coverer may be rendered expansible so as to be left partially opened if required.

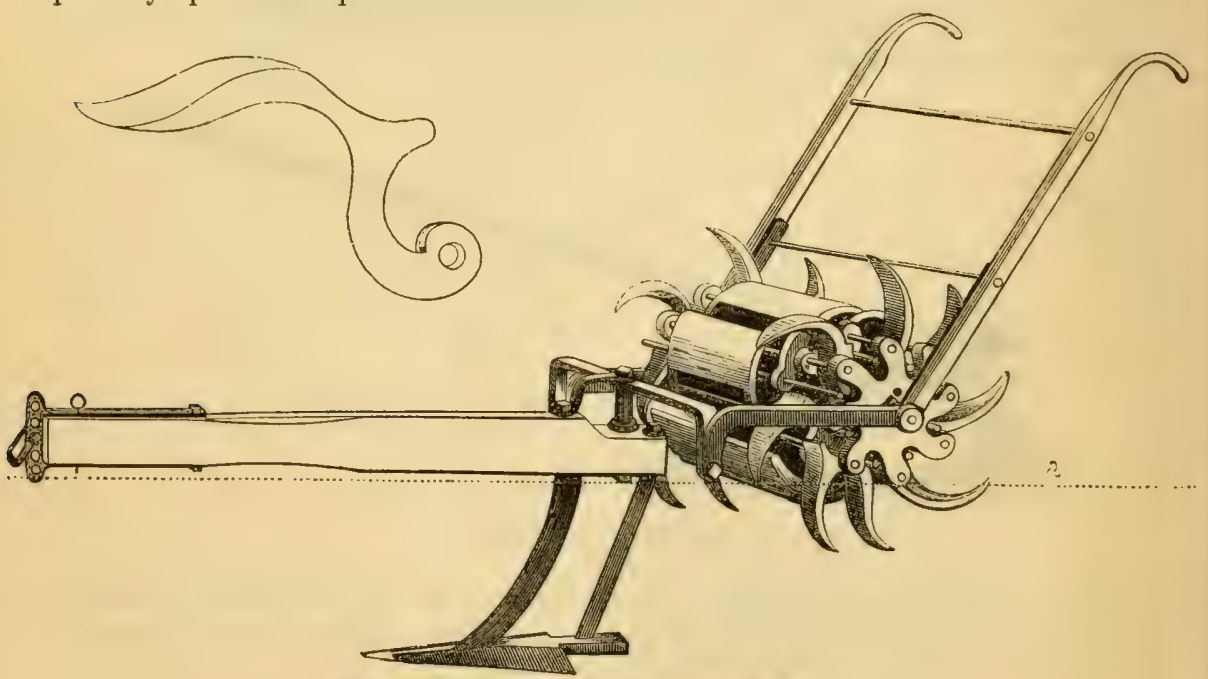

Fig, 126. Mispes and Gibbs' Digging Machine. 
Fig. 126 is intended to produce the same results upon soils as spading or forking, and to a much greater depth, and without reversing the position of the soil ; such as would be the result of well sub-soiled land, forked at the surface. With this machine nine acres may be dug and thoroughly disintegrated to the depth of twelve inches, in the same time and with the same team which would plow four acres eight inches deep. The sub-soil lifter disintegrates from the depth of its line of travel upward and outward to a width of twenty-four or more inches at the surface, while the digger appended to it pulverizes and thoroughly mixes the immediate surface to a depth of five or more inches, thus rendering it peculiarly adaptable to the inixture of manures in the surface-soil. It requires no attendant at the handles, but maintains its position, fitting itself to the sinuosities of the surface of the ground. When either of the spades strikes a stone which is too large to slip, the machine is lifted over such stone, and the next spade entering the ground beyond it throws it out at the rear.

Weeds may be thrown on the machine by armsful, upon its top and amoug its parts while in motion, without impeding its progress. Its tendencies being all outward, it clcanses itself thoroughly at every revolution.

In sod ground it is ineffectual, as it merely tears the sod finely apart, replanting the parts and permitting future growth.

Three sizes are now completed. They all disturb the soil to the same depth, the only variation being in the proportion of the top soil, which may be reversed or mixed.

For disintegrating corn or grain stubbles it has no equal, leaving the ground in better tilth than with twenty surface plowings. In putting land down to grass or grain, the operation is quite perfect, it answering all the purposes of surface and sub-soil plow, clod-crusher, harrow, and roller, leaving the surface in fine garden tilth and perfectly level-all of which is attained at a single operation. 


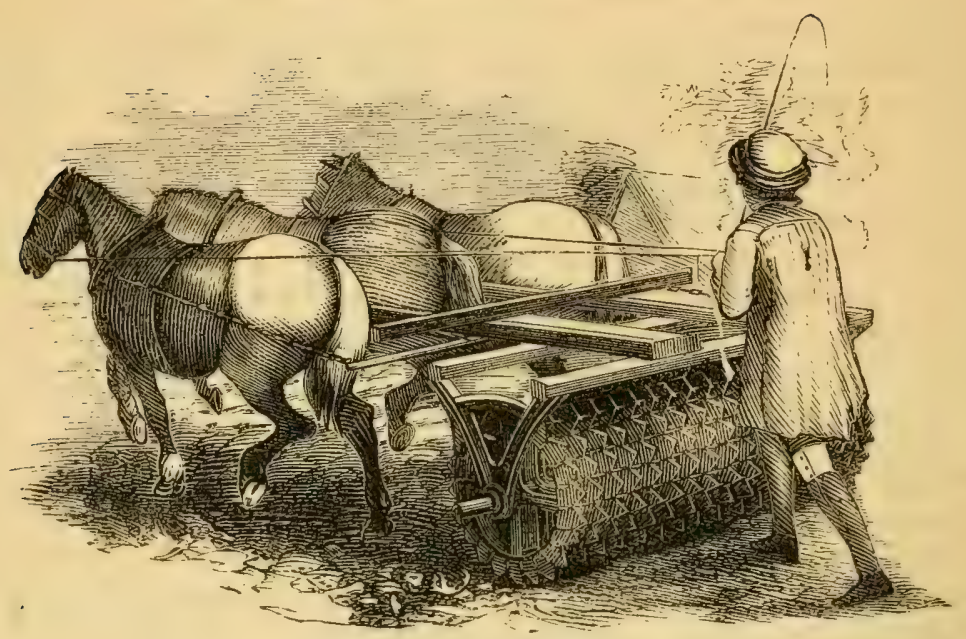

Fig 127. Crosskill's Clod Crusher.

Many attempts have been made to manufacture this implement in this country, but generally the makers have been guided by wood-cuts found in English Catalogues, and from which the true construction of the implement could not be gathered. If the objectwere to crush clods alone, then on a rough soil a smooth roller would answer the purpose; but the clod-crusher, as it is called, compacts the immediate surface, after seeding the grain, without compacting the lower soil.

It is made like an ordinary roller, in sections, with the following differences: Each section is but three inches wide, and they are kept from touching each other by a washer on the main shaft; each alternate section has an opening or hole in the centre fitting the shaft, while those between are of increased diameter, and have openings an inch larger than the shaft; these latter revolve eccentrically, instead of concentrically, as compared with the former, and any lumps or clods received between the rollers are sure to be rubbed to pieces, for the rollers are not only toothed on their face but at their sides. It may be called a pulverizer and surface presser with propriety.

In England, it is claimed that by its use larger crops of wheat are obtained; that the ruffled edges of these wheels compress the earth in vertical masses toward the seed, and at the same time divide all lumps so as to prepare the soil for the free circulation of the atmosphere, as well as compressing it in vertical portions against the seed.

The English also claim the propriety of its use in rolling grain as soon as sown, upon high lands; also upon strong lands that are cloddy.

Rolling wheats upon light lands in the spring, after frosts and winds have left the plants bare. Stopping the ravages of the wire worm and grub.

Crushing clods after turnip crops to sow barley.

Rolling barley, oats, etc., when the plants are three inches out of the ground, before sowing clover, etc. Rolling grass lands and moss lands after compost.

They may be had of any required length. 


\section{FIELD ROLLERS.}

Among the advantages attained by the use of the Field Roller, are the following; it levels and smooths plowed land, when being sowed down to grass, and unlike the Crosskill, forces the sods and lumps into the soft ground without pulverizing them, and in this particular is its inferior; indeed its only superiority or use on plowed ground is to produce a dead level surface, such as is required for lawns, to render their after treatment or frequent mowing more easy, and to mend surfaces that have been hove by the frost. The roller, however, is beneficial when applied to very light soils, known as blowing sand, for when thus compacted in the fall they are rendered more valuable for spring use. For all other purposes the Crosskill is entirely superior to the field roller.

In road-making the roller is sometimes used with advantage. When made in sections, like the following, it can be turned very suddenly, for while the advancing sections roll forward, those at the opposite end roll backward, enabling the turning to occur within its own length.

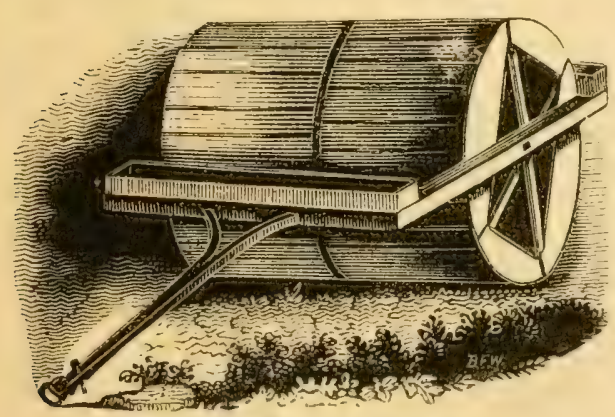

Fig. 128. Wooden Field Roller.

Field Rollers are made of wood or iron.

Fig. 128 represents a wooden field roller, made in two sections of about $2 \frac{1}{2}$ feet long, and larger in diameter than those made of iron.

Those of iron are more durable, and not subject to decay like those of wood, and are made of the following sizes, viz. :

3 Sections, each 12 inches long, by 20 inches in diameter.

\begin{tabular}{|c|c|c|c|c|c|c|c|c|}
\hline 16 & 66 & 12 & 66 & 66 & 66 & 20 & 66 & 66 \\
\hline 66 & 66 & 12 & 66 & 66 & 66 & 20 & 6 & 66 \\
\hline 66 & 66 & 12 & 66 & 66 & 16 & 30 & 66 & 66 \\
\hline 66 & 66 & 12 & 66 & 66 & 66 & 30 & "4 & 66 \\
\hline 66 & 66 & 12 & 66 & 66 & 66 & 30 & 66 & 66 \\
\hline
\end{tabular}

and other sizes given in our price list. 


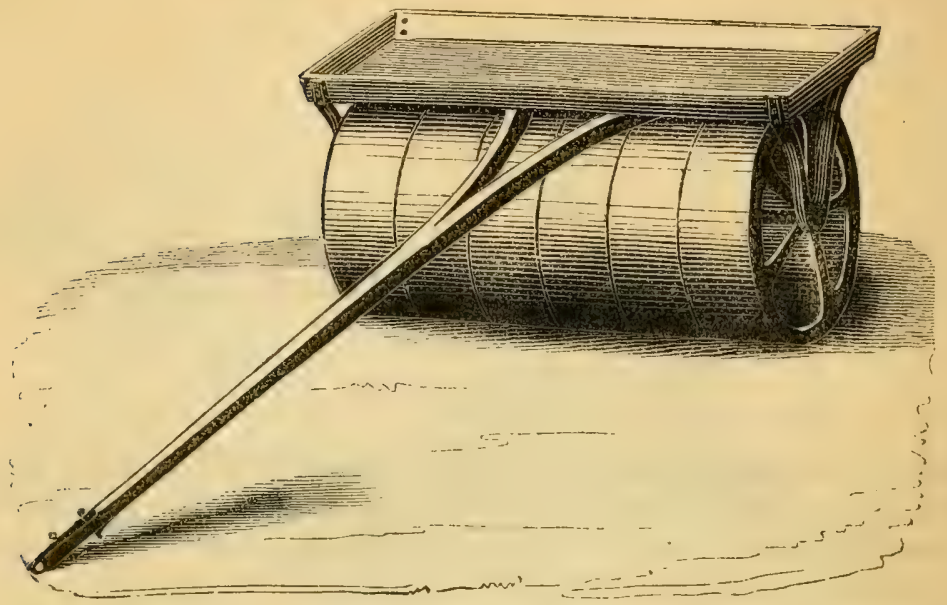

Fig, 129. Iron Field Roller.

Fig. 129 represents the iron field roller. It is a very strong, durable instrument, being constructed wholly of iron, excepting the tongue and box, which are of wood. It is made in sections, each one foot long, and embracing any number from three to six, as may be desired. The sections are placed on a wrought iron arbor or axletree, on which they each revolve independently, so that in turning the roller at the ends of the field, the ground is not left uneven. If not more than four sections are required, thills or shafts may be substituted for the tongue, and the implement may be easily drawn by one horse; or both tongue and shafts may be had. and one or two horses used, as occasion may require. The box is attached to receive stones, \&c., picked up on the ficld rolled, and for giving, extra weight to the roller when the same may be needed. For distant transportation, the iron sections, and standards to which the wood-work is attached, are furnished to order, either with or without wrought iron arbor, by weight, and the wood parts can be furnished and attached by any wheelwright or carpenter.

Fig. 130 represents an iron Garden Roller. The cylinder is cast in parts, $15,20,24$, and 28 inches in diameter, and $7 \frac{1}{2}$ to 20 inches long. To the arbor is attached, inside of the cast cylinder, a comnter balance, which adds weight to the instrument, and causes the handle to stand perpendicular when not in use.

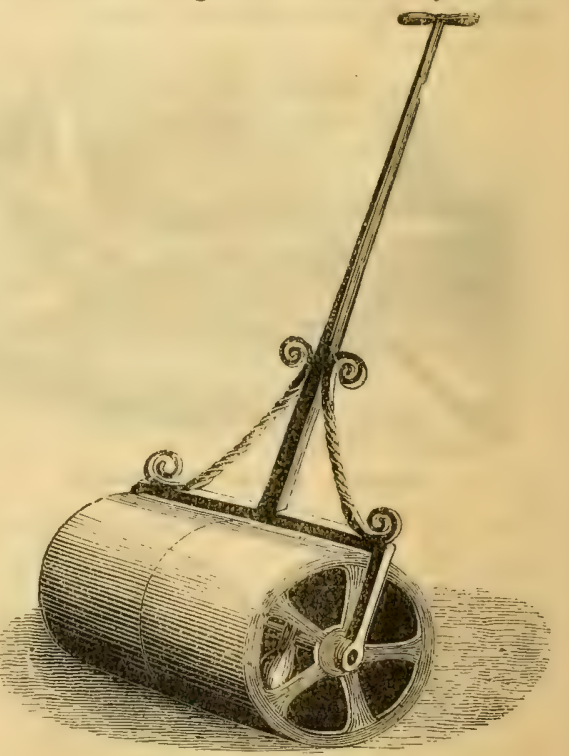

Fig. 130. Garden Roller. 


\section{SEED SOWERS.}

The importance of proper implements for this purpose should not be undervalued. When we consider the great labor of sowing seeds in drills by hand, together with the unsatisfactory result or irregularity in line and in depth, the Seed-Sower is, indeed, a time and labor saving machine. Its economy is not dependent upon these alone; for, as every seed would be planted at the proper depth and in the proper place, less seed is required than for hand sowing, while the labor and expense of their after-culture is materially lessened.

The sowers here described claim to be sure and accurate in distributing the various kinds of seeds. Printed directions for using accompany each machine.

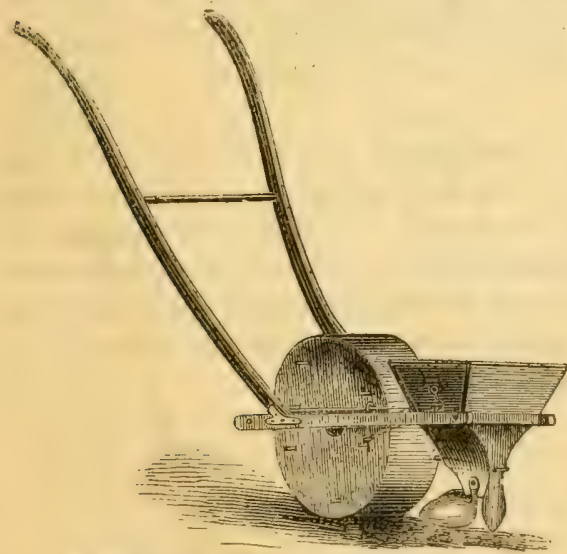

Fig. 131. The Wethersfield Seed Sower.

In structure Fig. 131 is simple, compact, strong, durable, portable, and perfectly efficient. It adapts itself to every form and size of seed, makes its own drill, distributes with perfect evenness, screens the seed from dispersion by the wind and clogging by the rain, covers promptly, and gently presses down to secure that close contact of soil essential to quick germination. The perfect precision and certainty of every part of the process, enables the cultivator to sow his land in exactly the variety and proportions of crop be wishes, without the excess or deficiency of a seed; and secures a uniformity throughout alike beautiful to the eye and auspicious to the harvest.

There are eight reeds furnished with each machine, gauged respectively for different seeds, according to the following table, with driver and screws for interchanging. It must be observed, however, that the table is graduated to the average size of each species of seed, and extreme cases may sometimes require the variation of a number in the reed:

No. 1. Corn, beans, and marrowfat peas.

No. 2. Beets, early peas, and white field beans.

No. 3. Parsnips.

No. 4. Onions, asparagus, and lecks. 
No. 5. Radish, peppers, and mustard.

No. 6. Sage, carrot, cabbage, cauliflower, broccoli, spinach.

No. 7. Pepper-grass, lettuce, summer savory.

No. 8. Turnips, celery, parsley.

The patentee begs leave to guard against disappointment, by suggesting a few cautions in the use of this utensil. It is very important that the soil be well prepared, level, pulverized, and dry enough not to pack upon the wheel. Of course, a judicious seedsman will select a favorable time for every thing to work well. The instrument is well guarded against ary sudden unterruption by the weather, and the hopper perfectly excludes wind and rain from the seed within it.

Carefully used, the sower operates with such uniformity that the quantity of seed required for any given area, can be accurately ascertained from the proportion taken by any aliquot part.

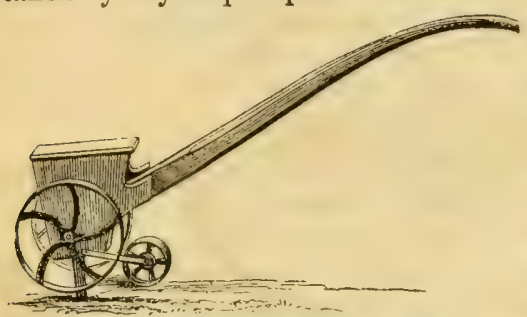

Fig. 132. Seed Sower No, 0.

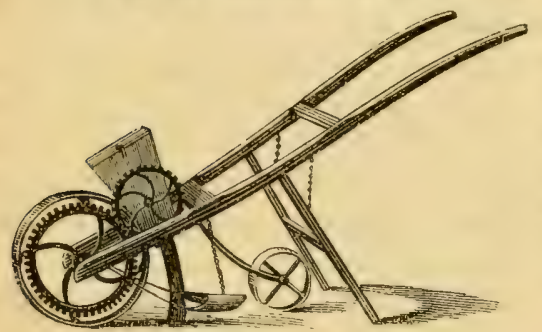

This is a small hand-drill, designed for the garden. It is a cheap, light sower, well adapted to the wants of those who cultivate root and vegetable crops on a limited scale, and will sow all such crops, excepting peas and beans. It opens the ground, sows the seed, covers and rolls it at one operation or passing.

Seed Sower No. 1, is adapted to garden or field sowing, is a size larger than No. 0 , and is designed for sowing the same kinds of seeds. The cylinder and brush within the hopper go by gearing, and thus are always sure to operate.

Fig. 133. Seed sower No. 1.

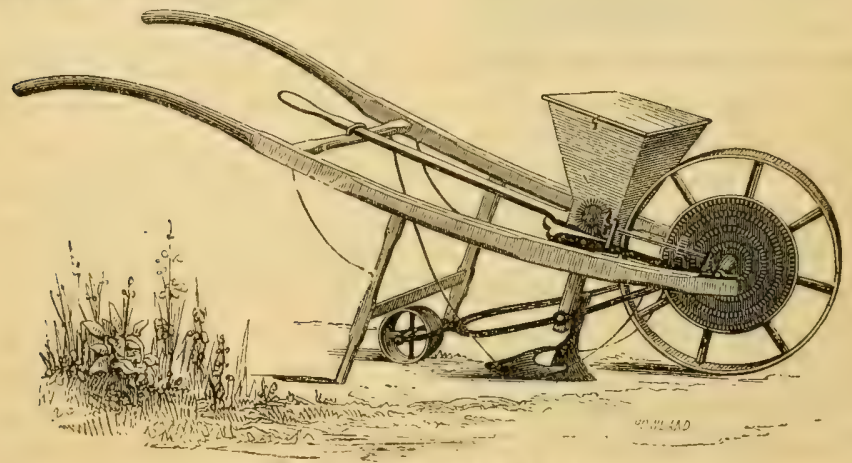

Fig. 134. Seed sower No. 2. 
Seed Sower No. 2 combines several important improvements upon the English Drill, particularly in those additions which fit it for sowing large seeds. The brush and cylinder of No. 2, which distributes the seeds, go by graduated rows of iron cogs or gearings, which operate simply and uniformly, are durabie, not likely to get out of order, and by which the speed of the dropping may be increased or lessened, large or small seeds sown, in all their varieties, at any desirable distances, in hills or drills, and the several necessary changes for the purpose are made with ease and expedition. The brush is used for small seeds, as turnips, carrots, etc., and the cylinder for corn, peas, beans, etc. Six tins, with different sized holes through them, accompany each machine, to be used in connection with the brush, as circumstances may require.

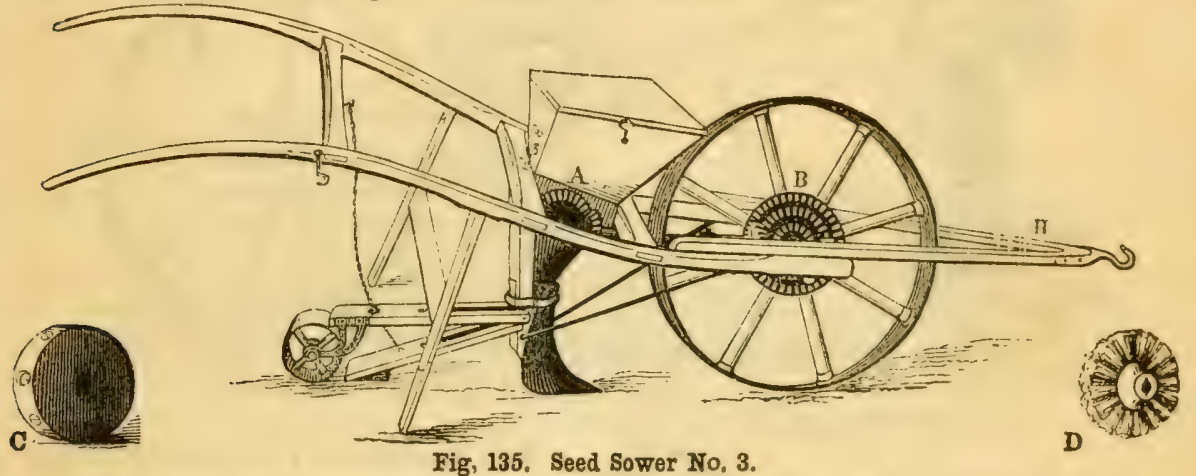

Fig. 135 is substantially like Sower No. 2, is adapted to hand or horse power; to sowing seeds continuously in drills, or planting them in hills. By change of eylinders, it sows or plants large or small seeds. The gearings for the purpose of producing a rapid or slow motion, in order to adapt the machine to different kinds of seed, are simple yet excellent. They are made of iron, are durable, and work with regularity and precision.

Fig. 136. One great advantage in this sower is the ease with which the hopper which contains the seed may be taken off and the seed changed. To do this, nothing is required but to move a hasp, when the hopper may be taken off and the brush removed.

In this machine we have the advantage of an adjustable plow, by its being hinged to the arbor of the driving-wheel forward, and holding the roller in the rear of the plow by the same arms, thereby giving a uniform depth to the seed independent of the operator. There is also attached to the plow an iron rod, which passes through the cross-bar of the handles, by which the operator is enabled, by dropping the handles, to raise the plow, and at the same time the seed is cut off, and the whole thing is thrown upon the forward wheel; then the machine may be run from one row to another, or from field to field, in the easiest manner possible. The plow is selfcovering. The whole machine is light, the spokes of the wheel being wood and the rim iron, but broad and thin. When in motion, the plow, hopper, and roller are independent of the handles, so that the machine is as properly adapted to one person as another, whether be be short or tall. 


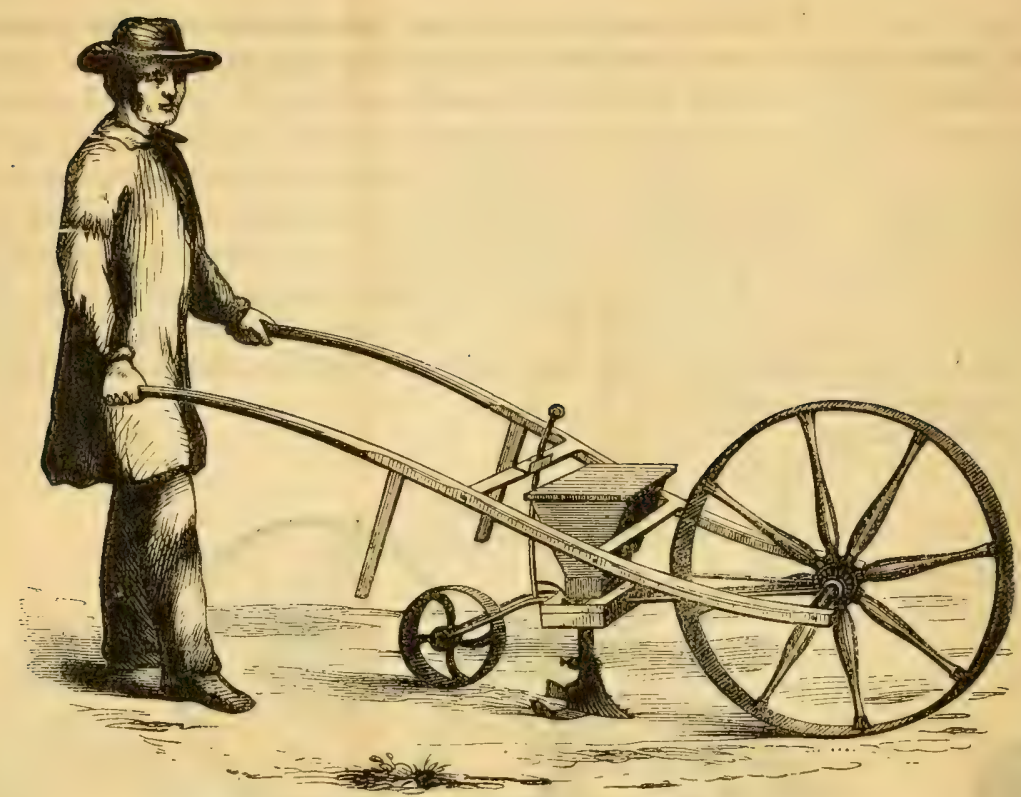

Fig. 136. Howe's Eagle Seed Sower.

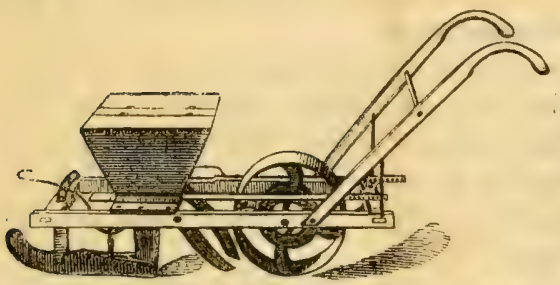

Fig. 137. Billing's Improved Planter and Fertil. izer. low intervale or other smooth land. The hopper above the beams is made with two apartments, one for the seed and the other for the fertilizer. By a very simple but sure and unerring arrangement of the working parts of the machine, it may be gauged to drop any desired quantity of seed, and of fertilizer with it, at any distance apart, in hills or in drills, of equal depth-the seed being dropped in the furrow opened by the share below, falling through the rear or hollow standard of the share to the bottom of the furrow, and the fertilizer at the same instant being dropped through the same hollow standard and deposited with the seed; the curved iron blades, directly in rear of the share, cover the seed and fertilizer to the desired and a uniform depth; and the broad wheel, by which the machine is moved, rolls or presses the soil down upon the seed much more uniformly than is ever done by the hand boe. Thus, with this machine, the operator is not only enabled to plant his seeds rapidly, at any desired distance and depth, but also at the same time 
to cheaply and expeditiously deposit any fertilizer with the seed-as superphosphate of lime, bone dust, plaster, etc.-for promoting a quick germination and rapid growth of crop.

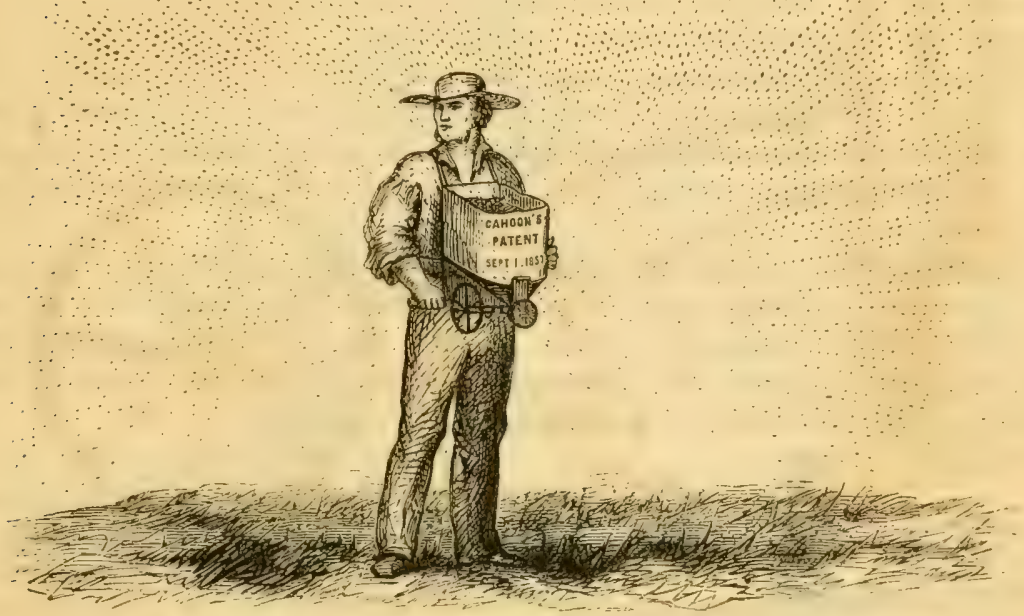

Fig. 138. Cahoon's Patent Hand Broalcast Sower, for Seeds and Fertilizers.

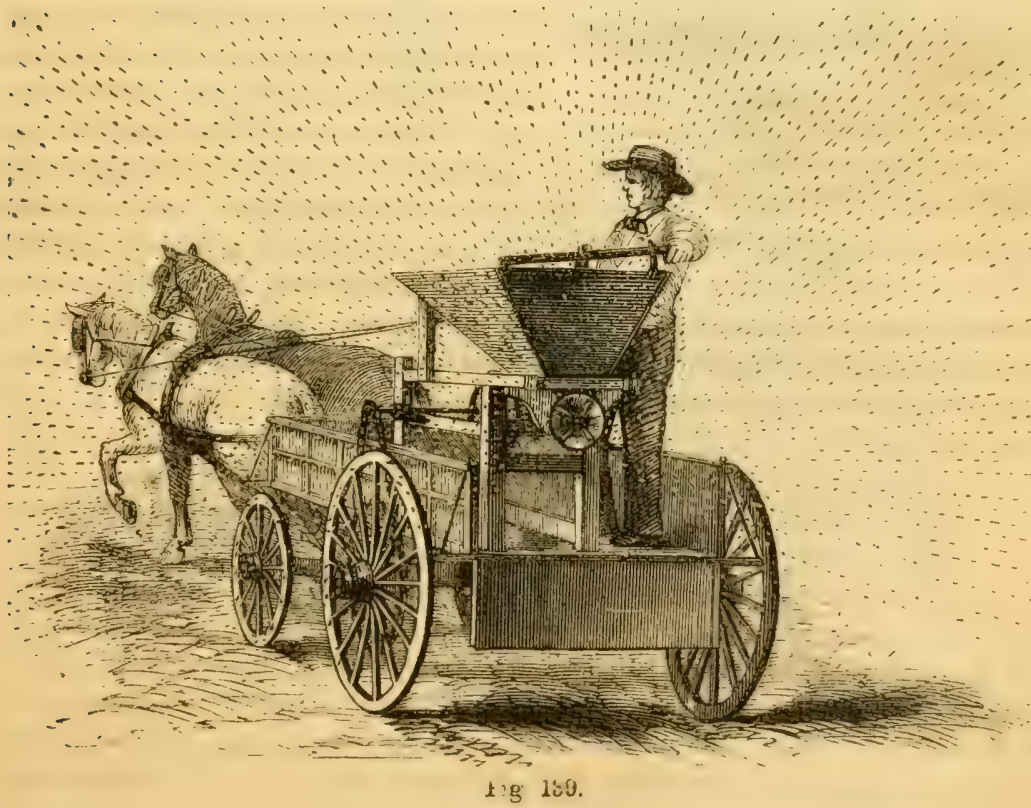


Figure, 138. is intended for sowing wheat, oats, hemp, barley, rye, buckwheat, grass seed, fertilizers, etc., made in a substantial and durable manner. It saves four- . fifths of the labor and time-cnables any one, with a little experience, to sow with regularity-and in consequence of the evenness with which it distributes the seed, causes a saving of from one quarter to one-third of the grain ordinarily required. Farmers who have used this machine for two seasons, say that they would not be without one for three times its cost.

The best crop of wheat raised in the State of Illinois, and which took the first premium at the Illinois State Fair for 1859, was sown with this machine. This machine, at a common walking gait, distributes by centrifugal force over the surface of four to eight acres per hour. Full directions for use furnished with the machine.

Fig. 139 may be attached to a wagon or cart, and at the ordinary walking gait of a horse, will sow from ten to fifteen acres per hour. It is particularly well calculated for the distribution of superphosphates, Peruvian guano, plaster, ashes, salt, lime, liquid manures, etc. Motion is given to the machine by a belt chain moved by the wagon wheel, as represented in the engraving.

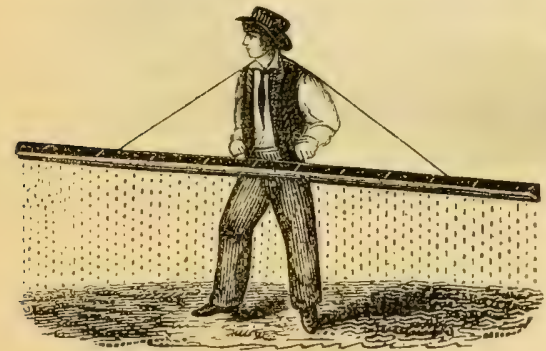

Fig. 140. Wells' Grass-Seed Sower.

This little hand Sower is of so simple construction, that any person of ordinary tact can at once operate it perfectly, sowing any desirable quantity of seed to the acre, and distributing the seed very much more evenly and rapidly than it is possible to do by hand in the common way. In early spring, when one's land is all prepared and waiting for grass-seeds, it often happens that more or less wind will rise with the sun, and so interfere with the proper broadcast sowing of seeds, that the work, to be done well, must be done at early dawn or in the evening, perhaps causing considerable delay and inconvenience; but by using this Sower, and carrying it low on the body, the seed may be put on the ground quite evenly, though there be a moderate wind, as the seed will reach the ground so directly as not to be diverted much, if any, from its proper resting-place. The seeding of land to grass can be done with so much dispatch with this machine, that one Sower may serve a neighborhood of five or six farmers. 


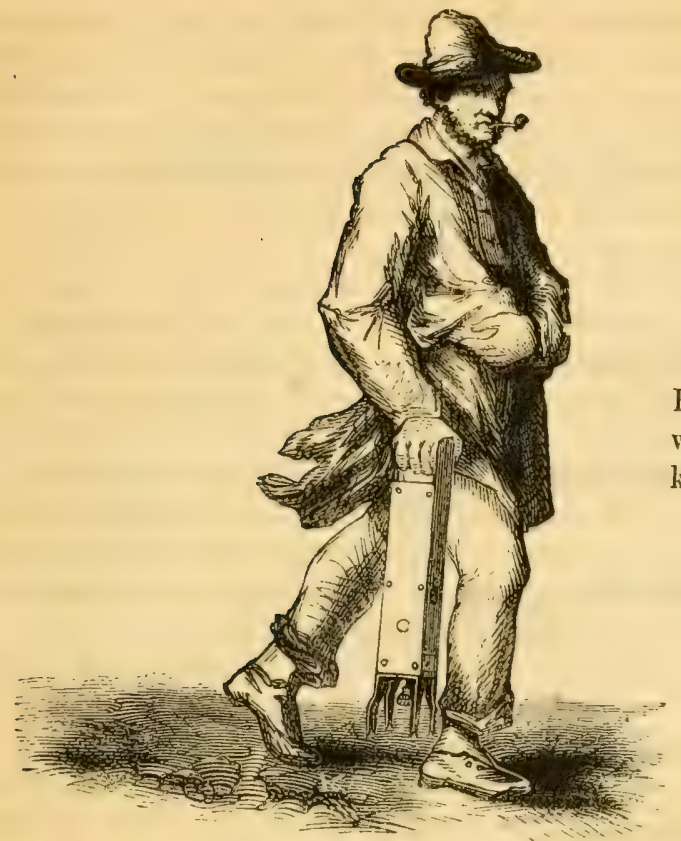

Fig. $140 \frac{1}{2}$ represents "The Hand Corn Planter." Of these we have many patterns and kinds.

Fig. 140\%

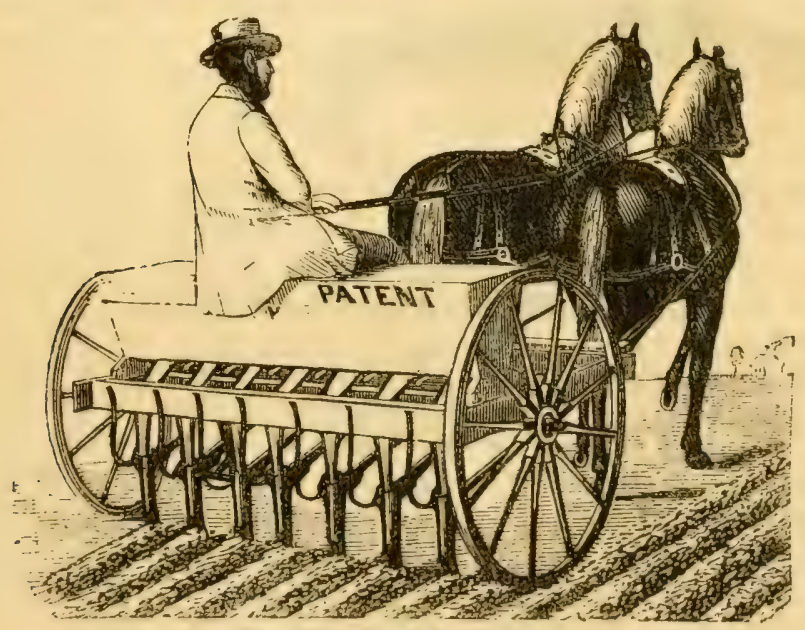

Fig. 141. Horse Grain Drill.

Fig. 141 represents the Horse Grain Drill, for drilling the various kinds of grain There are several modifications of the Grain Drill, varying in price, and which can be furnished to order. $\Lambda$ man and team, with the Horse Drill can sow from 10 to 12 acres per day. Drills furnished with Fertilizer attachments if desired. 


\section{HAYING AND HARVESTING TOOLS.}

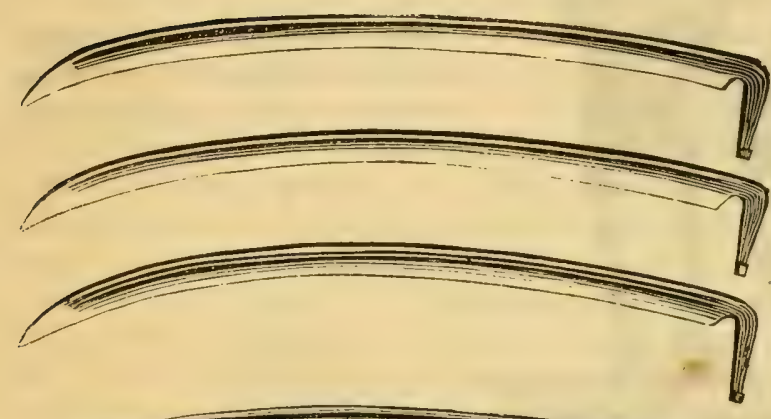

A large assortment of Scythes, selected from the most celebrated makers throughout the country, for which the proprietors are agents, furnishing them at manufacturers' prices.

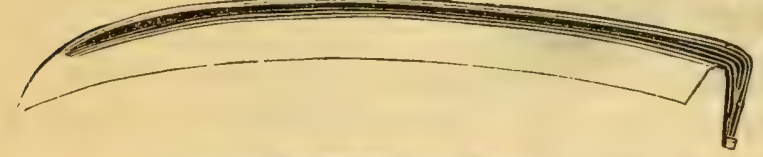

Fig. 142. Grass, Lawn, Grain, and Bramble or Bush Scythes, of Cast,

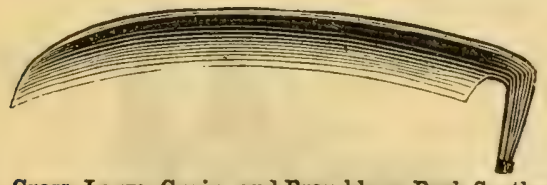
Shear, and German Steel.

\section{H. Waters' Patent Scythe.}

This scythe excels all others yet manufactured. Before the invention of Mr. Waters, scythes were made of German steel, running in on the web, and no steel on the back, and many of those stamped "cast steel" are of the kind noted above. For the purpose of making a sightly scythe, the web is lined from one side of the back so as to present a broad polished surface, and in so doing the grinding of the two sides of the scythe or web, are unlike each other, the one being flat and the other beveled, leaving the steel nearly on one side, and thus of a figure not calculated to stand the blows of salt grass, accidental interferences, etc.

Not so with the Waters scythe. This is rolled by machinery, and differs essentially, in its construction, from all scythes which have preceded it. The web is precisely in the middle of the back, and both edges are ground to the same bevel; the web is thin and of regular thickness, with steel of the best quality in its center. 
In the early part of the process the scythe is made straight, like a sword; the edge is then crimped, causing the whole to bend, and, being held in this position, the crimp is forced into a solid, while the back is clamped in a die; the particles are pressed and thus forced forward, rendering the edge of that peculiar quality so essential to cutting grass easily, wherein a seythe should differ from a razor, for with a smooth edge, however keen, it will not cut; nor can an edge otherwise made than by the plan of Mr. Waters, so well retain its cutting power. The stecl being in the center of the plate or web of the scythe, having on cach side an equal thickness of iron, as the web is thinned the steel is also thinned, and when ground on both sides equally, the steel must, of necessity, occupy the edge. The webs are wide in the bosom of the scythe, toward the point, and the backs there are quite low, therefore they should not be ground on too small a stone and the necessary thickness of the edge will be fully maintained. When new they may be obtuse, and as they become narrower by wear, they may be ground to a more acute edge. The peculiar construction and art of producing this edge, renders this scythe preferable to all others for the mowing of salt and other silicious coated grasses, maintaining their edge far better than any other scythe.

In the tempering, Mr. Waters has introduced a novel and exact method. The scythe being moved automateally must receive the same degree of heat, in the same time, in all its parts, and when the precise temper has once been obtained in a single scythe, all others must be exactly like it; producing uniformity in quality and temper. No such evenness has ever been obtained by any other method.

We would call the attention of the trade particularly to this scythe, for which we have the exclusive agency at New York.

\section{Hay Forks.}

Premium Cast Steel Elastic Forks.

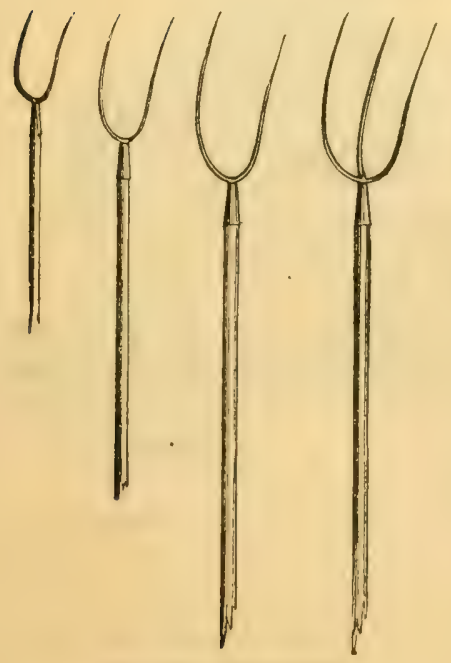

The proprietor is agent for Batcheller \& Son's celebrated elastic oval-tine hay and other forks, and is now prepared to supply the trade at manufacturers' prices.

Partridge's Premium Cast Steel Elastic Hay Forks; also a full assortment of forks from other makers.

Fig. 143. Hay Forks. 


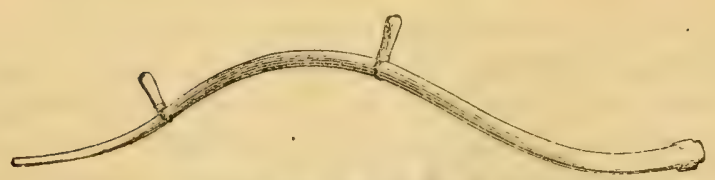

Fig. 144. Scythe Snath.

A great variety of improved Snaths, patent and others, constantly on hand; these include the various plans for fastening, bush snaths, etc.

\section{Grain Cradles.}

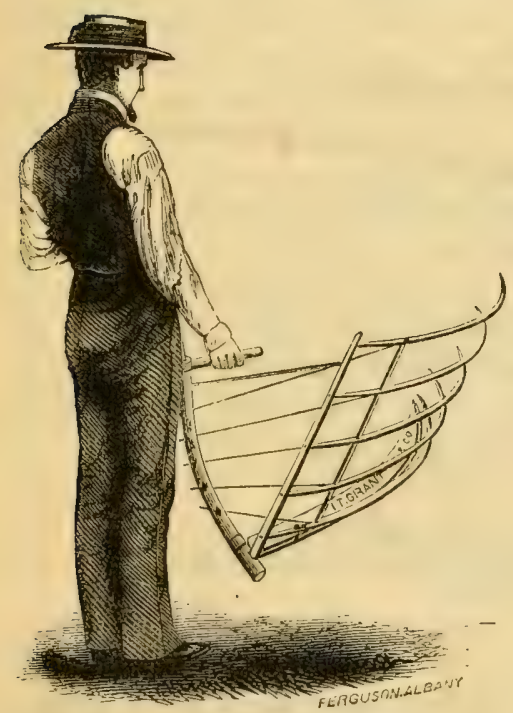

Fig. 145 represents Grant's Patent Grain Cradle. This is made of the best white ash timber, with wood or wire braces. The heel of the snath is bent forward in order to get the whole cut of the scythe, and the fingers are set back of the scythe, to make them work equally easy in large or small grain. The cradle is easily taken apart to pack and ship to any distance; and only a hammer is required to put it together again. It is made with four or five fingers, and the patent nib.

Fig. 145. Grant's Grain Cradle

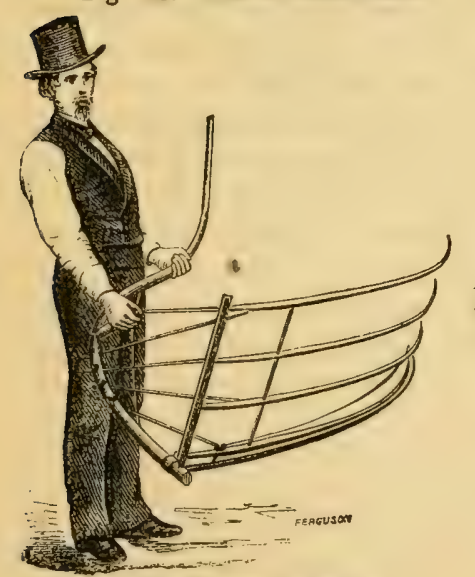

Fig. 146 is a superior article, and from the peculiar form of its snath, is preferred by many.

Fig. 146. Grapevine Cradle. 


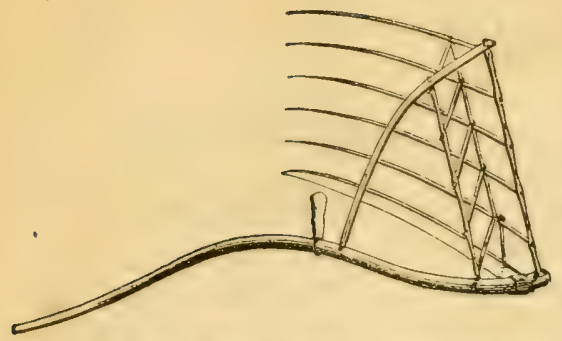

Wilcox's Grain Cradle is well known in the South, and has been long in use. The fingers are adjusted by screws, in the most simple manner. It is made of the best white ash timber. It is taken apart to pack for transportation, and put together with the greatest facility.

Fig. 147. Wilcox's Grain Cradle.

Also a variety of Cradles, made by Blanchard and others.

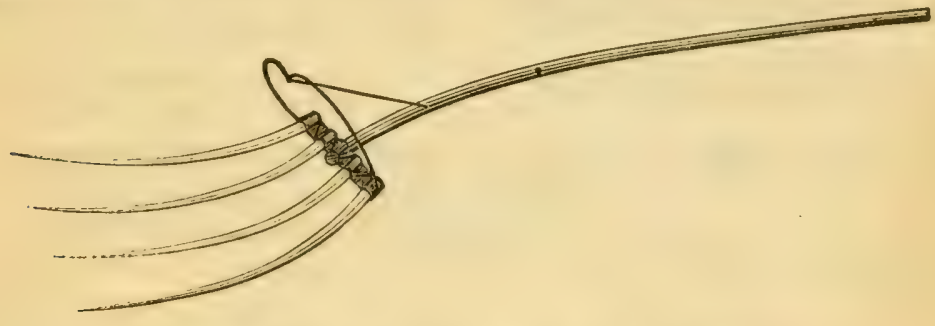

Fig. 148. Clowes' Patent Straw and Barley Fork.

Clowes' Patent Straw and Barley Fork, with malleable iron head and wood or steel tines, fastened in the head independent of each other, so that if one is accidentally broken it may be easily replaced.

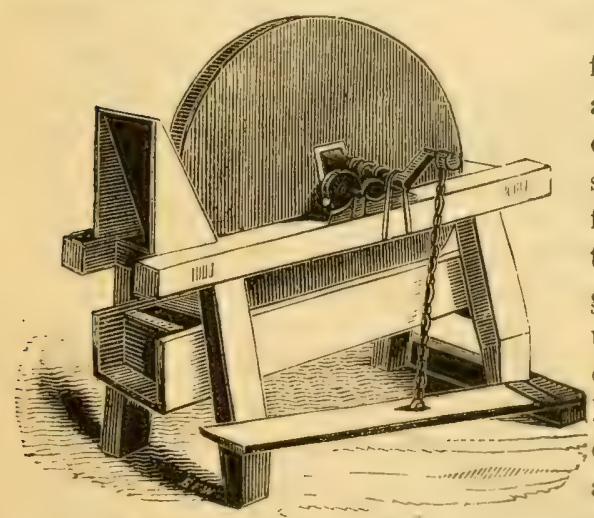

Fig. 149. Grindstone, Mounted.

Fig. 149 represents a Grindstone in full rig, hung on rollers, and turned by a crank on one side and a treadle on the other. The treadle arrangement is designed more particularly for mechanics, for the sharpening of small tools without the aid of a second person to turn, the grinder operating the stone by his foot upon the treadle. The fixtures are very durable, and save much friction and labor in turning the stone. Stones variously hung, of various sizes and prices, and of the best quality, are sold by the proprietor. 


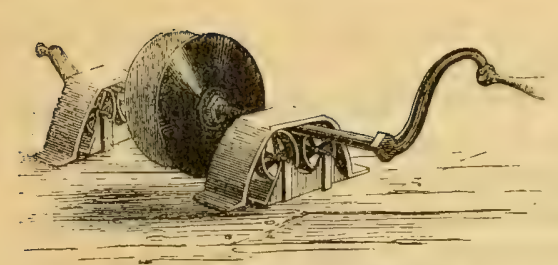

Fig. 150. Grindstone Fixtures.

Fig. 150 represents a Grindstone Arbor, Crank, Rollers and Roller Covers. To the arbor is attached a fixed and loose flange; the stone is placed against the fixed flange and held firmly between the two by a large screw nut, which works on a screw cut round the arbor, forcing the stone and loose flange against the tight one. In this way the stone is not liable to get out of place, and the liability to split, by the force of wedges used to confine the stone hung on the common arbor, is entirely avoided. There are four different sizes and lengths, adapted to the use of both the mechanic and farmer.

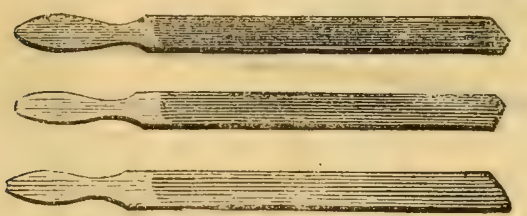

Fig. 151. Scythe Rifles.
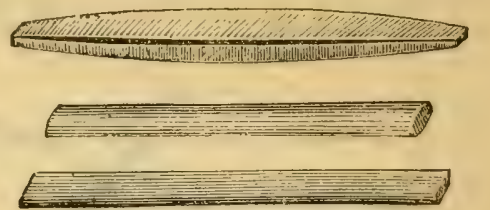

Fig. 152. Scythe Stones.

Fig. 151 represents the most approved forms of Scythe Rifles, of which we have a large variety.

Fig. 152. The first in the cut represents the English Talacre, which took the first premium at the World's Fair. It is a very superior stone, having a coarse, soft, sharp grit. The others represent the stones quarried in this country, of which we have a full assortment.

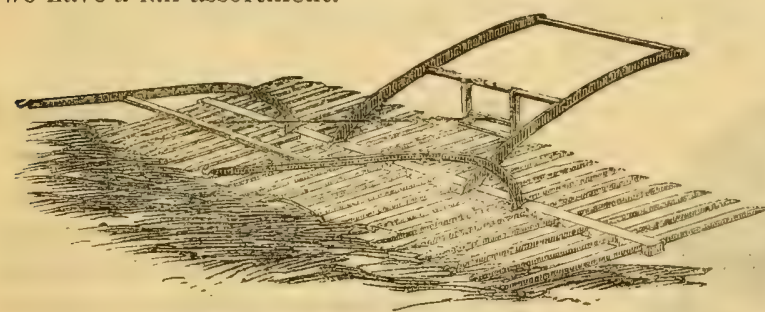

Fig. 153. This implement is now in extensive use, and to be appreciated needs only to be used. It is not exaggerating to say that a man, boy, and horse will perform in the most perfect manner,

Fig. 153. Revolving Horse Hay Rake. with this implement, as much work as from eight to ten men with common hand rakes.

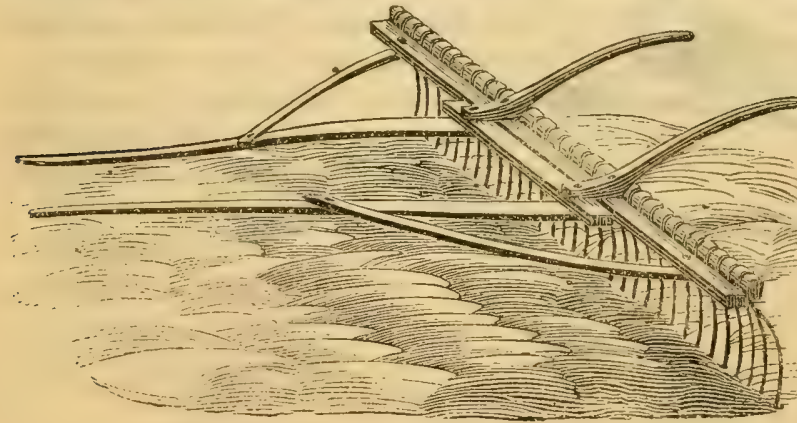

Fig. 154. Wire Spring-Tooth Horse Hake.

Fig. 154 represents a Wire Spring-Tooth Horse Rake, a desirable kind for new, rough grounds, where it has some advantages over those with wooden teeth. This rake requires more strength to be applied by the holder, ana does not leave the hay 
in a condition so free from dust, etc., as other kinds; but by some farmers, in particular locations, it is prefered to any other rake.

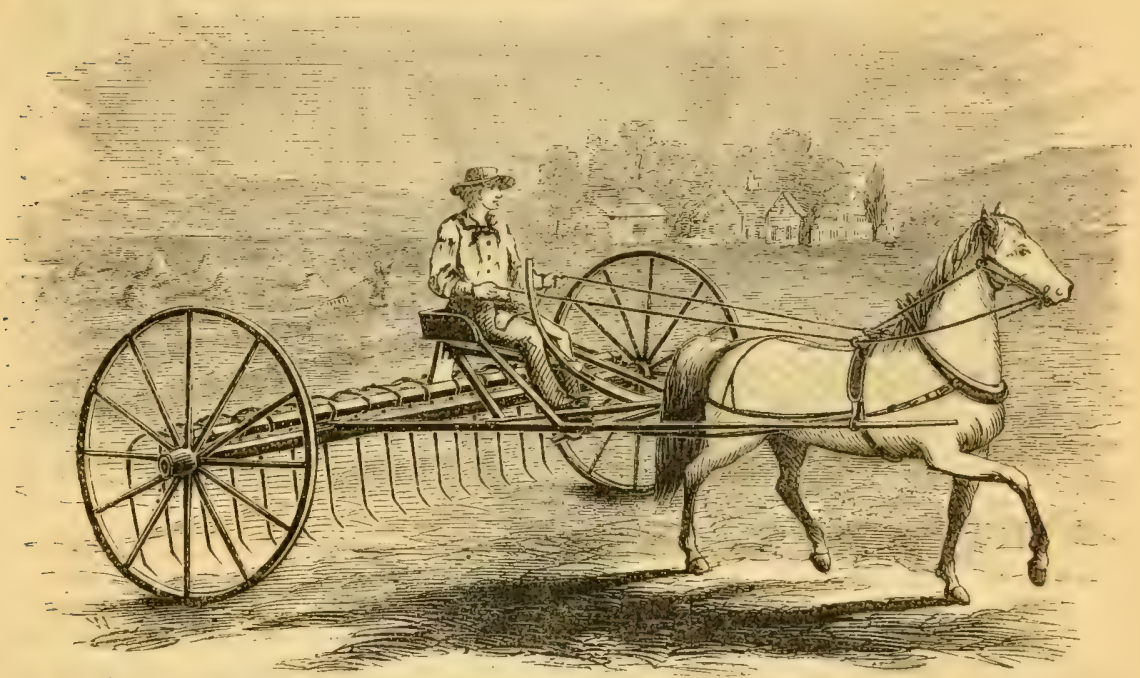

Fig. 155. Whitcomb's Patent Metallic Spring-Tooth Horse Hay Rake.

The above rake is intended for hay raking and gleaning grain-fields. As a gleaner after the cradle it will soon pay its cost.

By means of several holes in the arms the rake-head may be elevated so that the teeth will pass lightly over the surface of the ground.

Having been thoroughly tested for hay raking in all kinds of grasses, it is offered with confidence, may be readily operated by a lad, and is very simple in its construction, and will rake 20 acres per day.

The Rake.Head is attached in such a manner as to act as a partial counterpoise, and assist in elevating the teeth as the hay is discharged, and also serves to prevent the casual rising of the teeth from the ground, at the same time allowing them to conform to the irregularities of the ground; this, with the elasticity of the teeth, enables it to pass over stones and other obstacles. Horse Rakes, with metallic spring teeth, without wheels, have been long in use, and have answered a good purpose; but to use them is hard work, and they plow into light porous ground, as the weight rests upon the teeth, and colleet dirt, dust, and stones. But the Whitcomb Rake passes lightly over and places the hay in winrows, without compressing, like the Revolver-in good condition for curing and pitching; it works equally well in rough, uneven, as on smooth ground.

This Rake, Delano's, Fig. 156, is usually fitted to the hind wheels of a single-horse wagon. Each tooth acts separately, its head being suspended by a rod. The operator cleans the rake, when filled with hay, ly pressing with his foot npon the triangle, without stopping the horse. The instrument operates well on land either rough or 


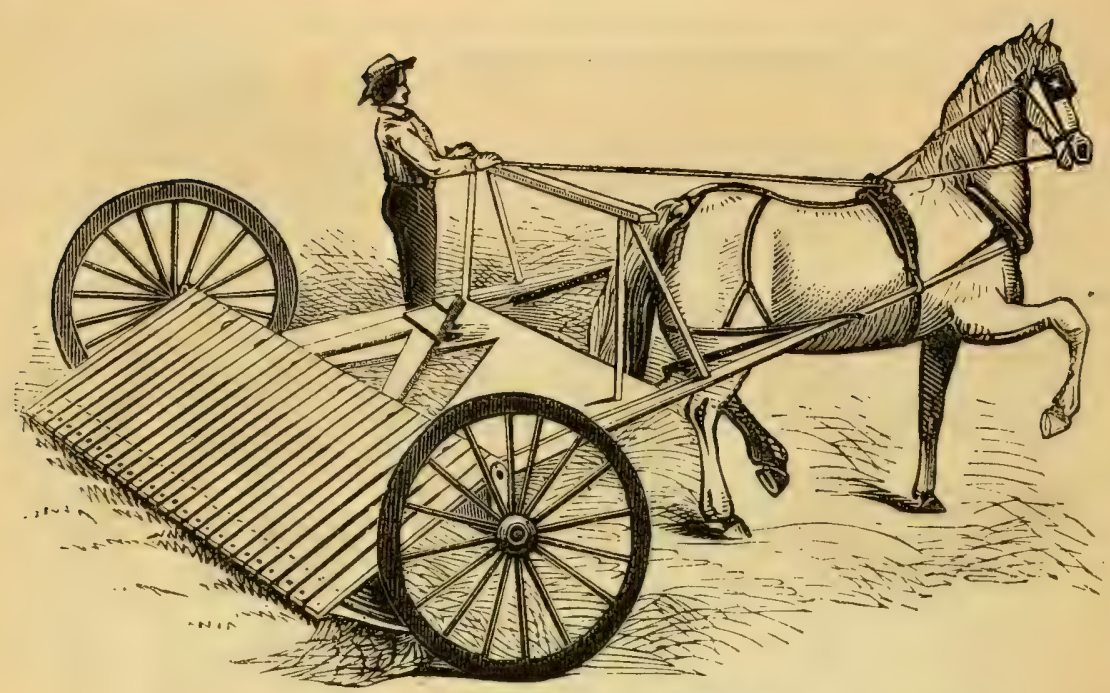

Fig. 156. Delano's Independent Horse Rake.

smooth, and lightly for both man or beast, and requires but one person to work it, who can ride comfortably while at work.

A variety of other rakes on wheels will be found in our assortment, of which the above are some of the best types.

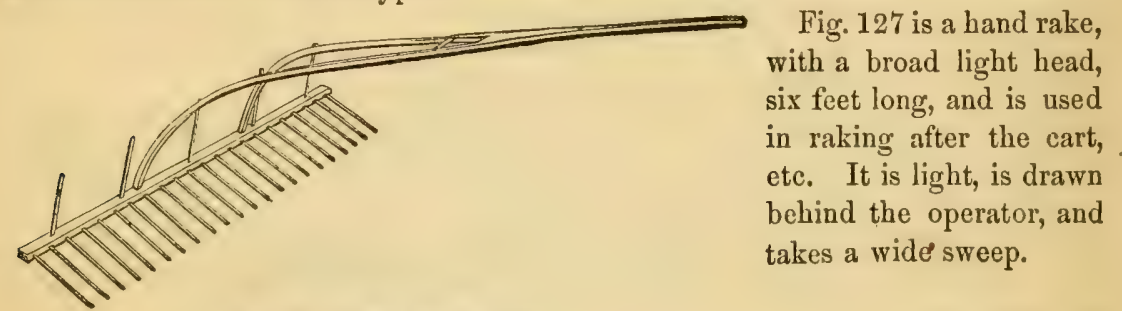

Fig. 157. Broad Hand Rake.

Hand Hay Rakes, from many different makers, of various qualities and sizes, two and three bowed, and made of the best white ash.

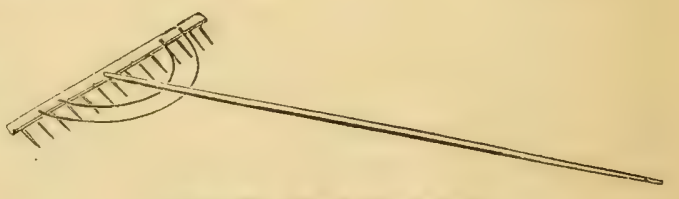

Fig. 158. Hand Hay Rakes. 


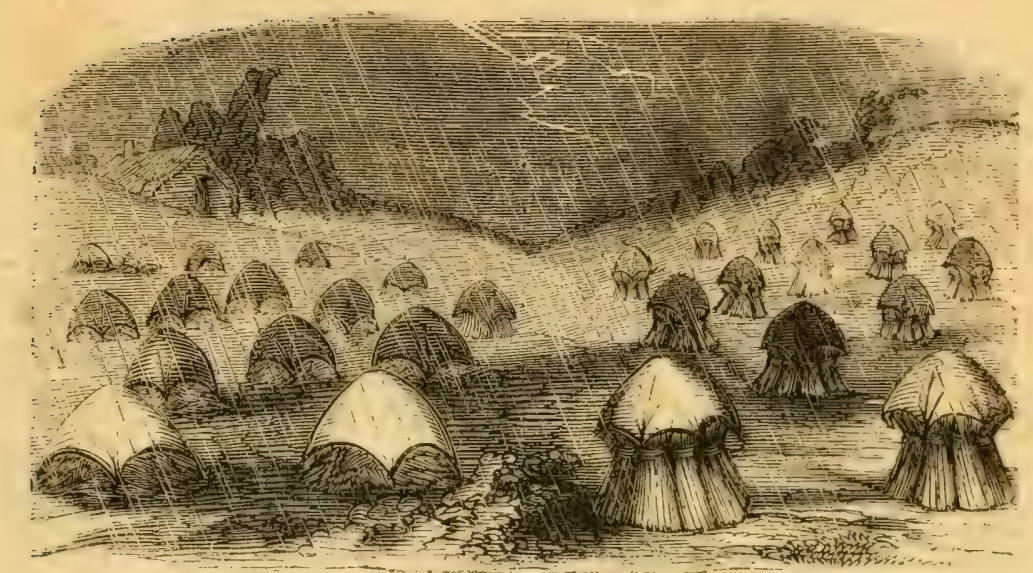

Fig. 159. Hay and Grain Protectors.

The Hay Protectors, Fig. 159, are made from cloth expressly prepared for the purpose, whereby they are rendered unsusceptible to mildew and better adapted to withstand the rain. Superior hard-wood skewers, neatly manufactured, and used for the purpose of securing the caps to the hay, furnished if desired.

There can be no doubt of the practical utility of Hay Caps, and no farmer can afford to be without them; they secure to the hay both brightness and sweetness, and can be used to equal advantage in protecting grain. 


\section{Mowing Machines and Reapers.}

Of these we have all the approved kinds, both for one and two horses. The usefulness of these machines is too well known to require comment, and they have justly become a source of national pride, those of American invention being used in all countries.

The following cuts represent some of the best machines.

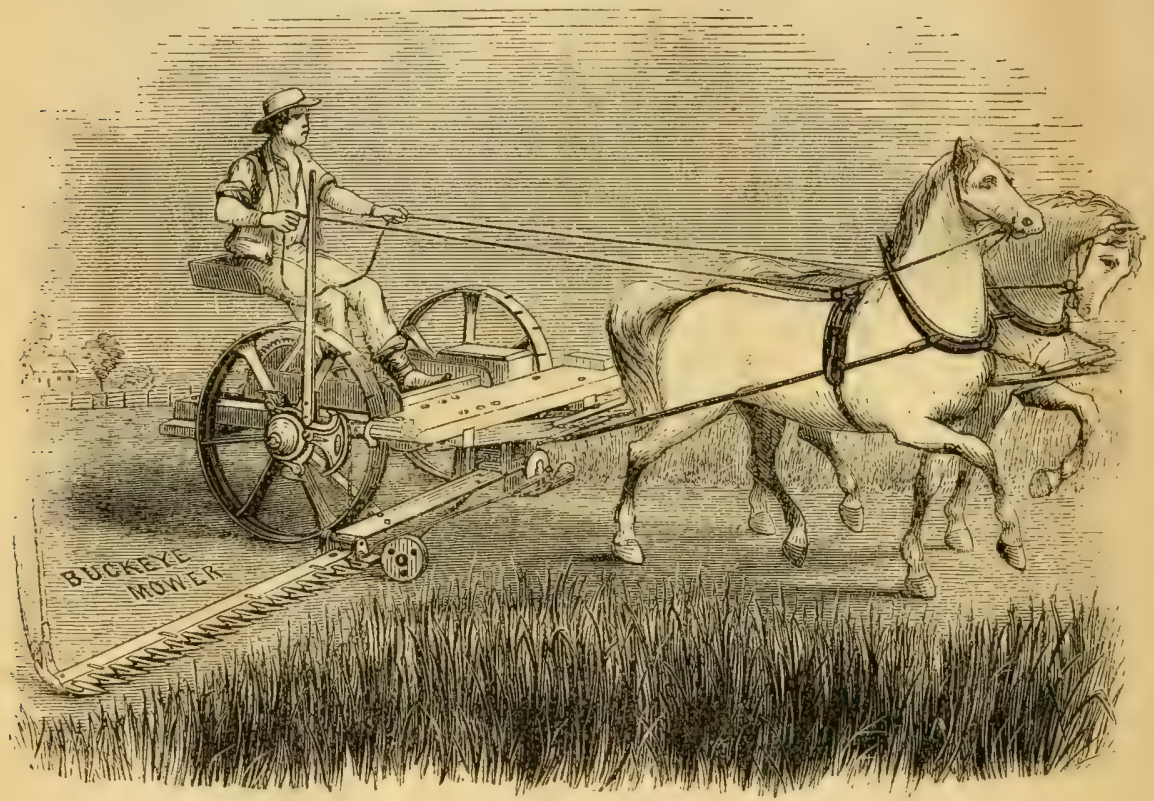

Fig. 160. Buckeya Mower.

Fig. 160. Buckeye Mowing Machine. This machine is so constructed that the knife, or cutting-bar, may be folded up, so that when the machine is on the road or moring from place to place, the cutting-bar is not subject to accident. It is furnished of three sizes, as follows, viz.:

Buckeye Mower, - - 4 feet 8 inches length of bar.

Do. do Junior, 4 " 0 " " "

See Price List, page 12.

Ketchum's Improved, Mower, Fig. 162, can be furnished with either or all the following lengths of cutting-bars, so that it may be used for one or two horses:- 


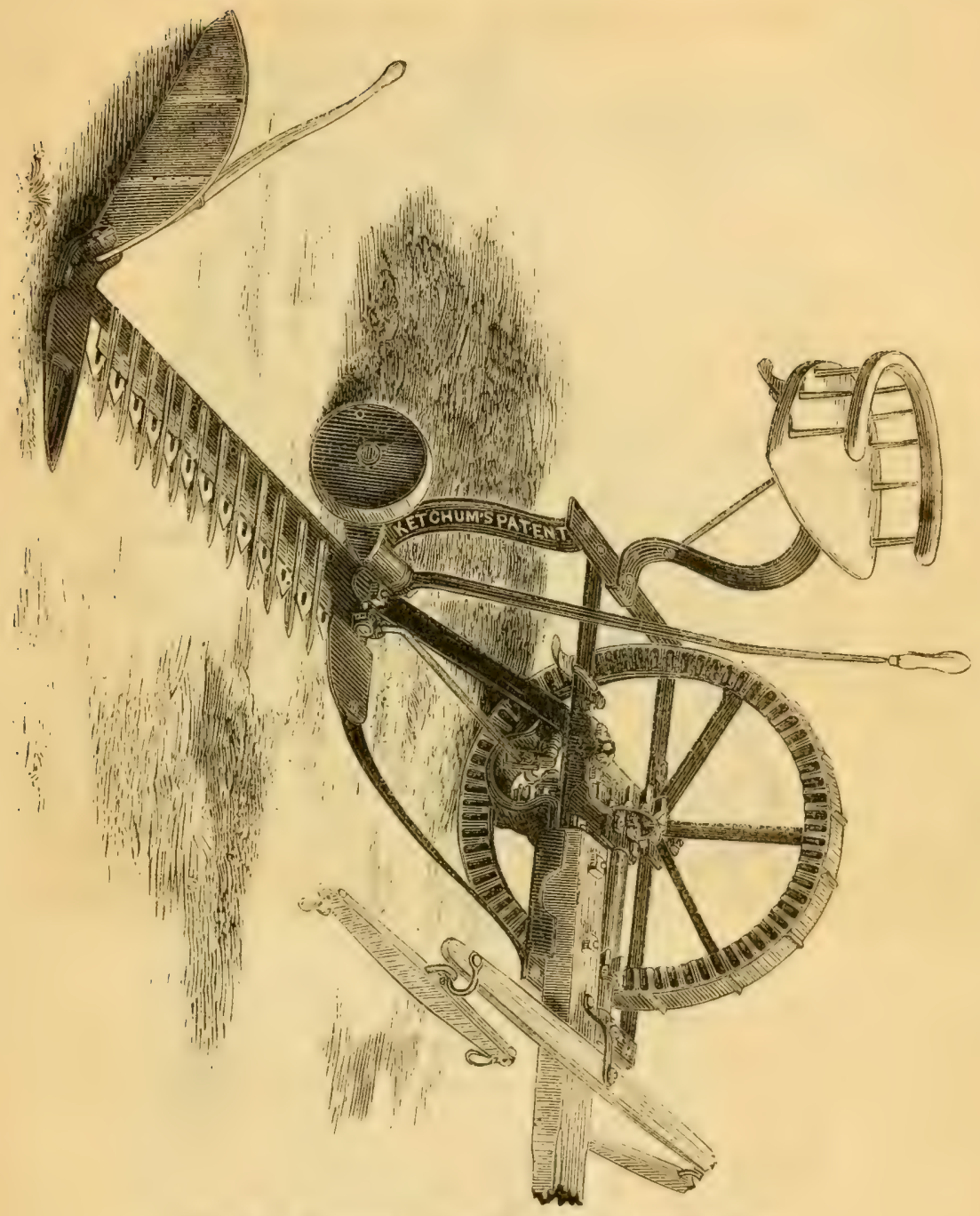

Fig. 162. Ketchum's Patent Improved Mowing Machine.

One-horse Mowing Machine, 3 feet bar, weight 450 lbs.

\begin{tabular}{cccccccc} 
Light two-horse & " & 4 & " & " & 475 & " \\
Heavy " & " & $4 \frac{1}{2}$ & " & " & 4 & 480 & " \\
" " & 4 & 4 & " & " & 630 & " \\
\hline
\end{tabular}

See Price List, page 12. 


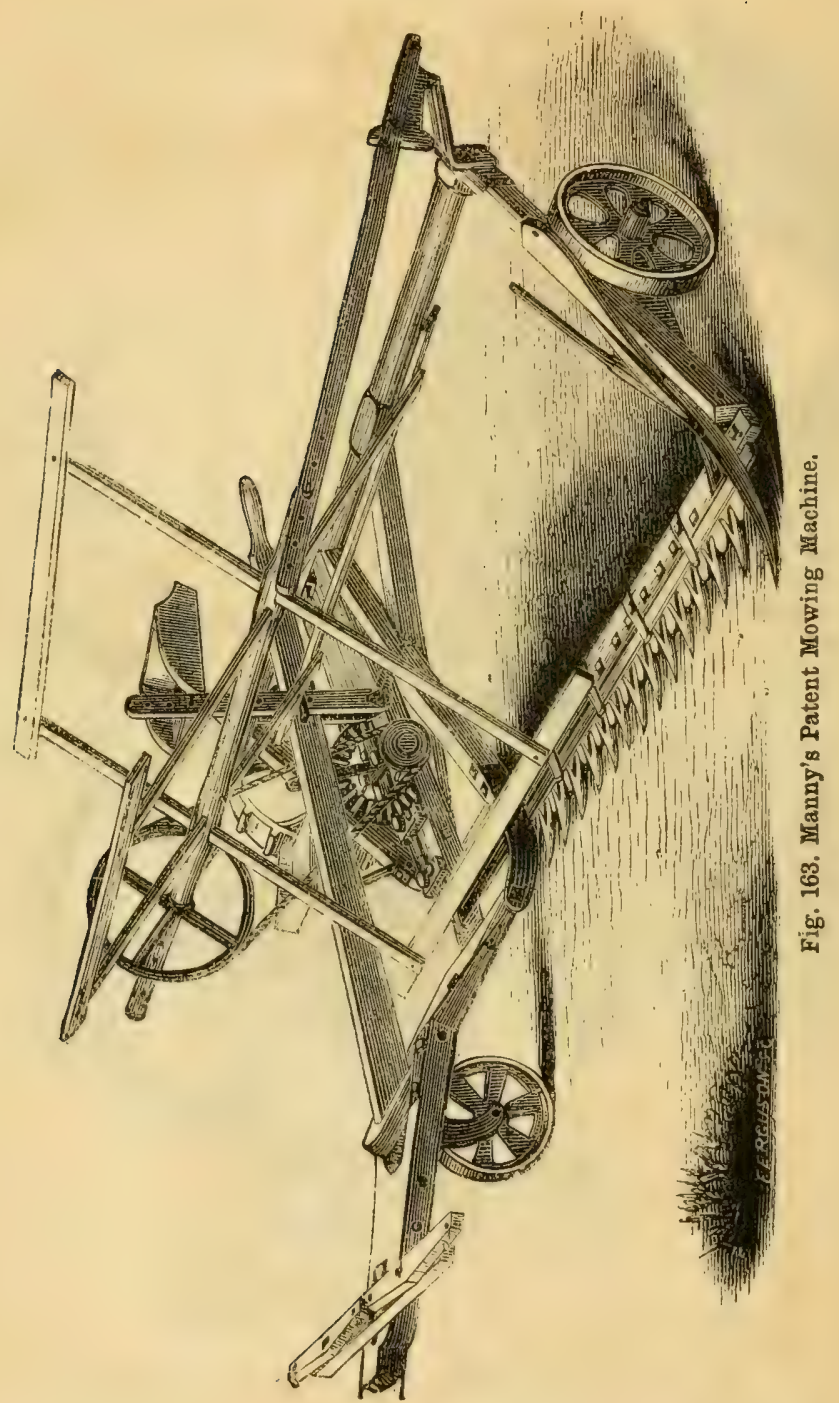

The cutting-bar for the above is 5 feet long. See Price List, page 12 , 


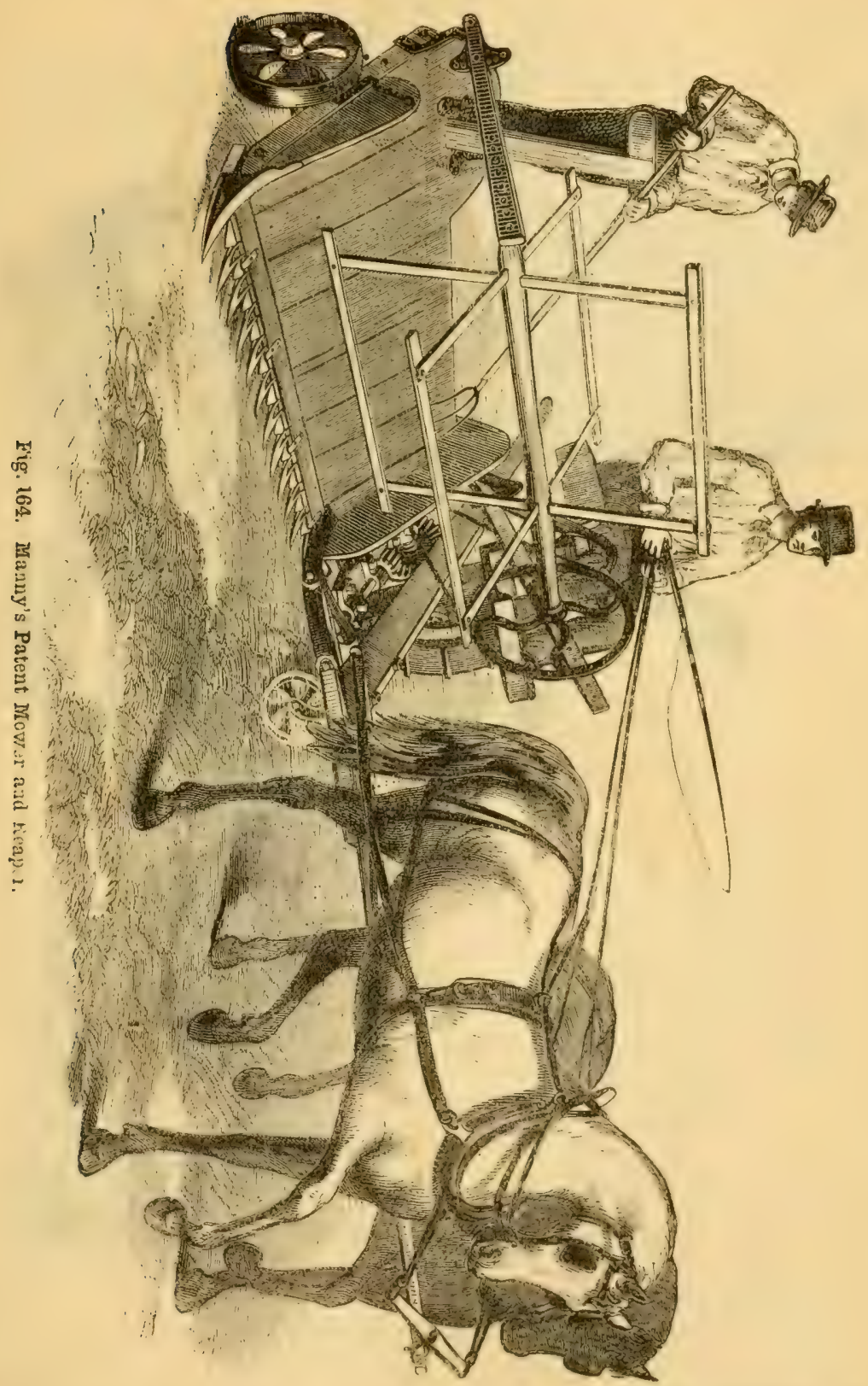

The above machine is of two sizes, as per our price list, with cutting-bars $5 \mathrm{amrl}$ 5t feet long. See Price List, page 12. 


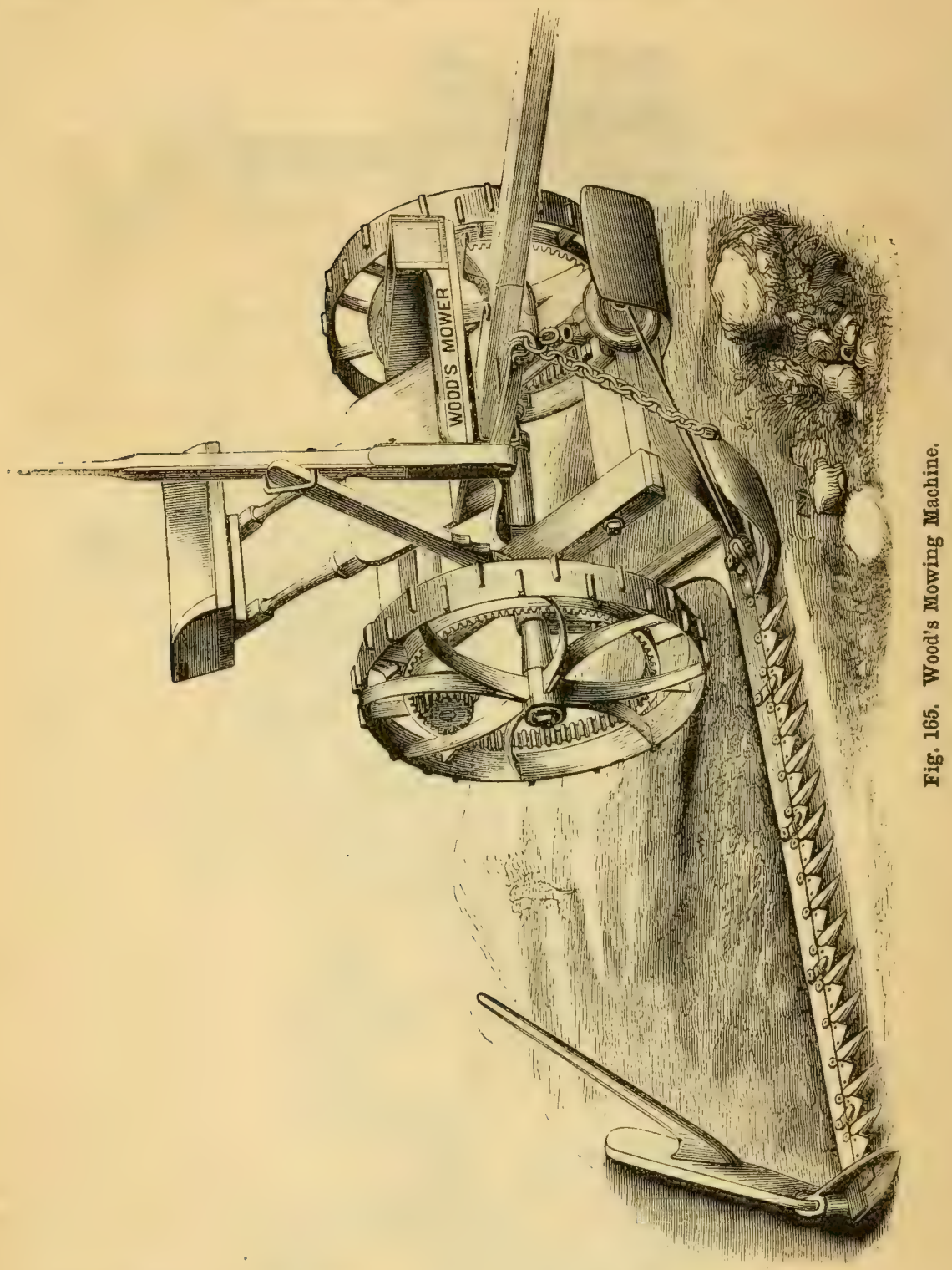

This Machine is of two sizes.

One-horse machine, $3 \frac{1}{2}$ feet cutting bar, weighs $464 \mathrm{lbs}$.

Two-horse " 4 " " " 6514 "

See Price Jist, page 12. 


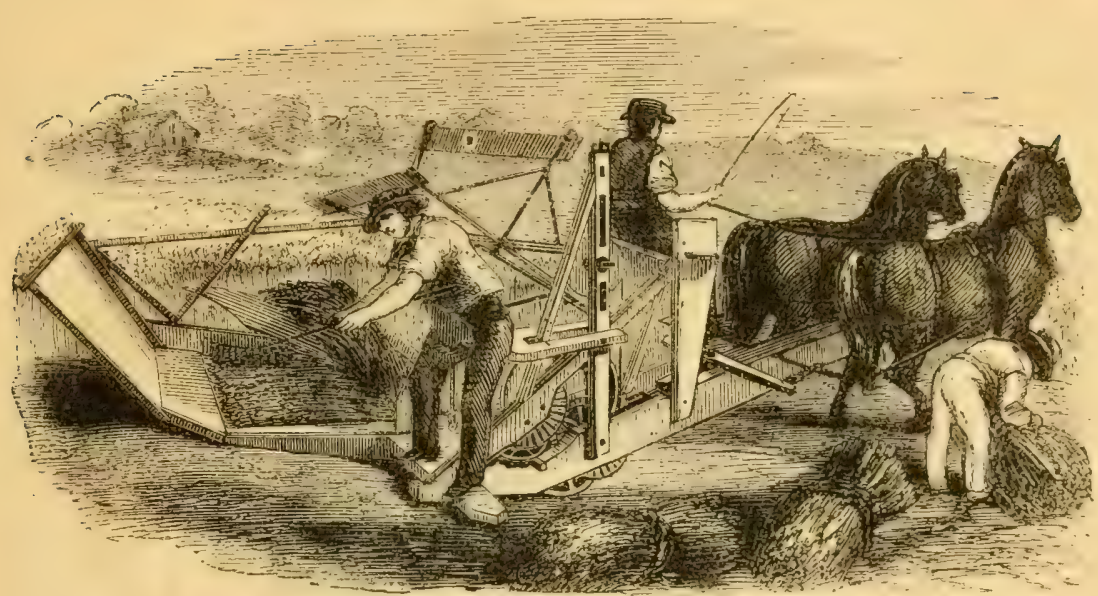

Fig. 166. McCormick's Reaper

Large machine, 4 horses, 6 feet cut.

Small " 2 " $5 \frac{1}{4}$ " " 


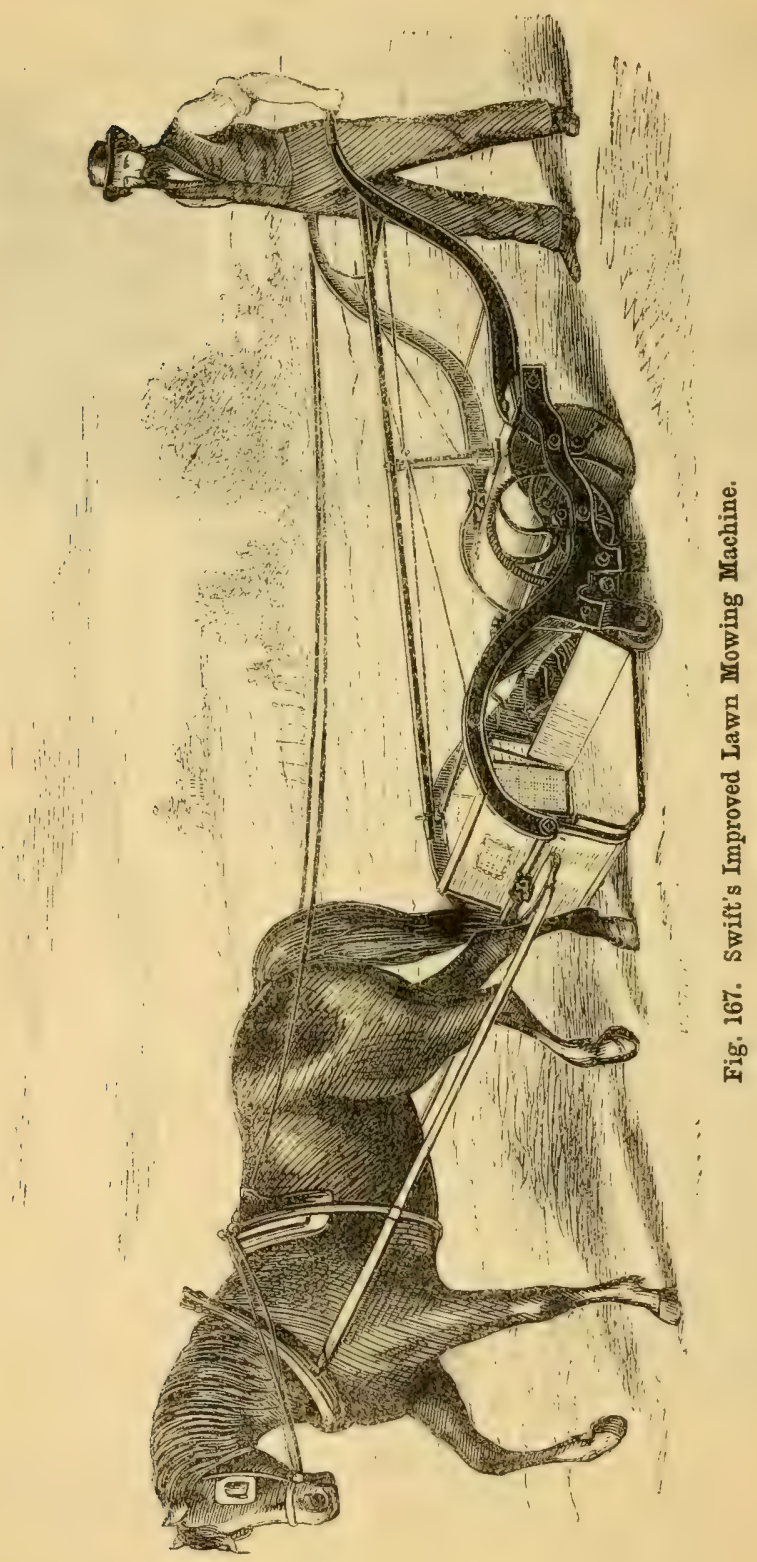




\section{Lawn Mowing Machine.}

The manufacturer has made some very important improvements in the English Lawn Mower, and he gruarantees them to be well and firmly built, and if properly used, not likely to get out of order, but to be superior to any other now in use.

The improvement consists mainly in making the knife so adjustable as to allow it to be ground and worn three-fumths of an inch; and also in so altering the form and construction, that small stones will do no material injury, where the English knife would be rendered entirely useless.

The superiority of this machine over the English Lawn Scythe consists in the even and rapid manner in which the lawn can be cut, with the advantage of rolling, and gathering up the grass at the same time. With the large machine, and an experienced horse and man, a continuous acre, withont trees or turns, can be cut, rolled, and the grass gathered in an hour. Lawns cut with this machine likewise acquire an even, firm sod, like that produced by. sheep grazing.

These machines have been in operation five seasons, and have given umwersal satisfaction. The increased demand enables the manufacturer to increase his variety, which now comprises an assortment that cannot fail to satisfy every requirement. The machines for this season will embrace all the important improvements brought out in Europe, with many valuable improvements founded upon experience. The patterns have all been remodelled, adding greatly to their lightness of draft, strength, utility, and simplicity. They are all front balance, with compound swivel rolls, which enables them to be turned short around with the greatest ease, without the least liability of marking the lawn. The front balance renders the motions of the machine more steady, and prevents the grazing of the sod in uneven places. It also renders the hand machines suitable for cutting broad surfaces in an even and uniform manner. A great improvement has also been made in the manner of attaching the knife-bar to the machine, and in adjusting the knife, simplifying its operation and rendering it more permanent.

\section{DESCRIPTION.}

Nos. 1, 2, 3, and 4, are hand machines, with which the grass should be cut close, and never allowed to grow so as to take off more than $1 \frac{1}{2}$ inches at one cutting. Nos. 3 and 4 may be drawn by one man on level ground, provided that not more than one inch of grass is taken off at a cutting. No. 7 is an extra thirty-inch macline, calculaterl to cut off four or five inches of grass at a cutting. It will also work equally well in cutting off one inch of grass. It is huilt much heaviur and stronger that it may be enabled to do the work properly. It may be here remarked that the longer the grass the more power is required in entting. No. \& can be used by one horse, only when the ground is nearly level aud the grass cut frequently.

It should be di-tinctly understood, in using these machines, that the smoother the lawn the closer and evener it may be cut; and to work to the best alvantage, and do GOOD work, the grass should be cut once in six or eight dars, during most of the season.

Every machine is guaranteed to be well built, of good materials, and to work well on ground properly prepared. Sce Price List, page 12. 


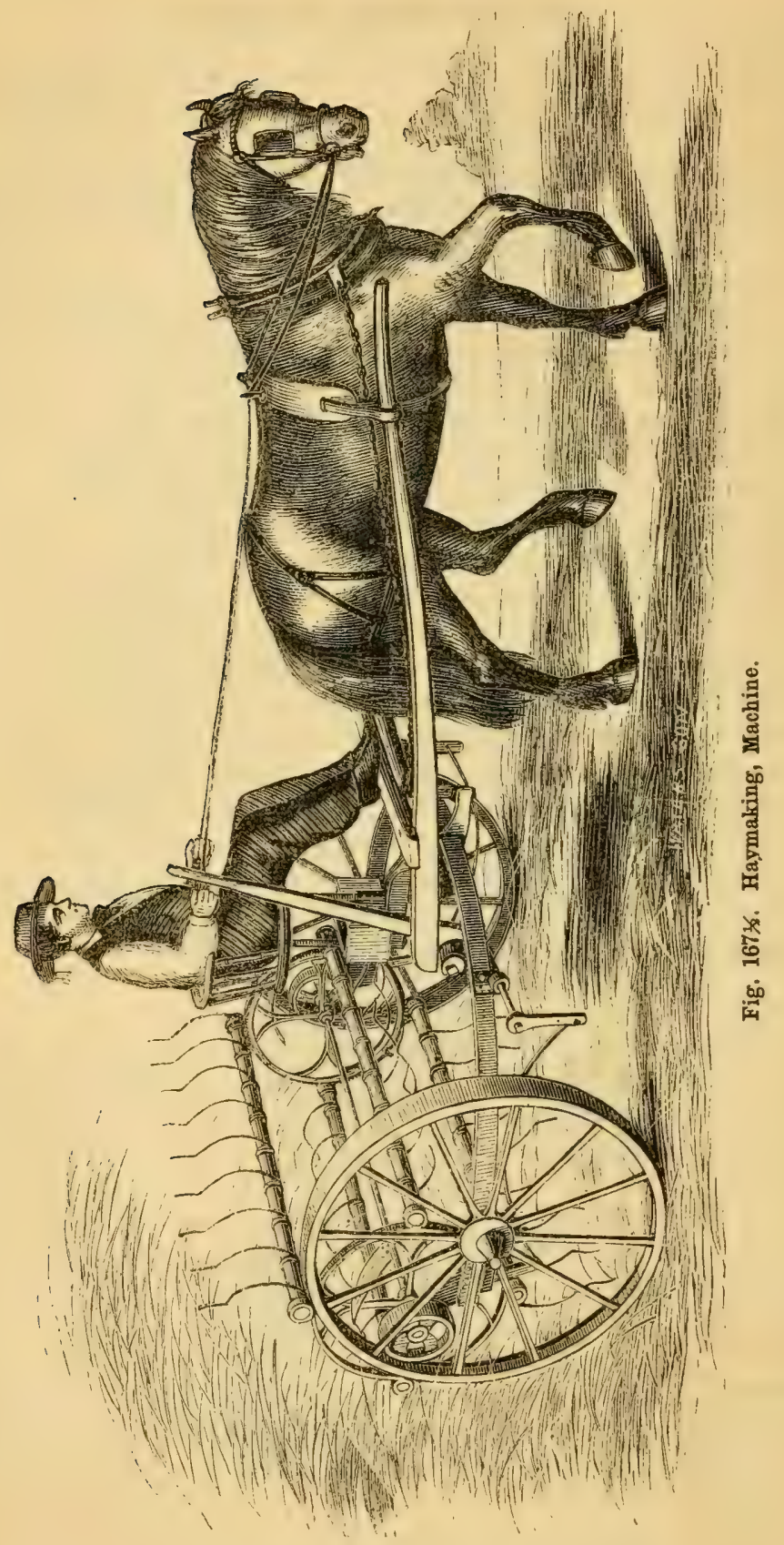




\section{Haymaking Machine.}

This machine has been long used in England, but its cost, as there made, is very large. An improvement made here is now under experiment, and will doubtles, be ready in time for next season's crops.

Fig. $167 \frac{1}{2}$ represents the machine recently patented by Mr. Stodari, and has many improvements as compared with those which have preceded it. The teeth may be turned to any required angle, for heavier or lighter grasses, or may be turned in so as to be entirely protected when passing over common roads, or when not in use. Its promise is very great, and we anticipate receiving favorable reports from its use the present season.

A series of rotating forks are moved by the axle of a two-wheeled frame, drawn by one horse, throwing the cut hay high into the air, and permitting it to fall in so open and divided a condition as to insure the full action of the sun and air.

There is perhaps no implement the value of which has been so little understood, until very recently. The labor usually employed on a hay crop is of a casual and most expensive kind, whilst the above machine, when properly constructed, not only suffices to make the owner independent of extraneous aid, but enables him to do his work more quickly and efficiently, and thus to be more independent of the weather. Those already manufactured do the work of from 6 to 20 men. It is quite impossible to shake out and separate the hay so well by hand as by this machine, and the drying is so much quicker as to frequently save a day in the securing of the hay crop. With this machine and the mowing machine, in connection with the improved horse-rakes, a farmer is no longer confined to a small area of mowing land.

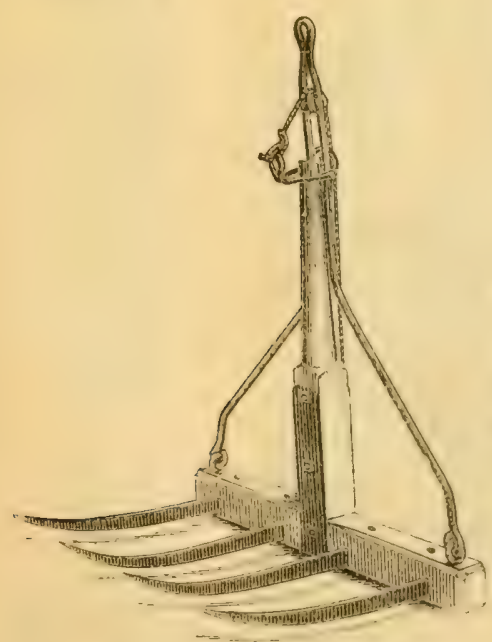

Fig, 168. Horse Unloading Fork.
This is a new invention, and labor-saving in its use. Hay may be carried by this implement, assisted by a tackle and sheaves, from the wagon to the highest mow, and there discharged of its load by the wagoner, and again lowered for re-use. 


\section{HAY AND COTTON PRESSES.}

OF these we have a variety hoth for power and hand use.

The production of Cotton is confined to the Southern states, while IIay, of some quality, is grown in all the states.

The entire cotton crop amounts to abont $4,500,000$ bales, and this must, from necessity, be properly packed for market.

According to the census of 1850 , there were produced of hay in the

$\begin{array}{lllllll}\text { Northern States, } & - & - & - & - & - & 9,473,605 \text { tons. } \\ \text { Western States, } & - & - & - & - & - & 3,227,253 \text { " } \\ \text { Southern States, } & - & - & - & - & - & 1,137,754 \\ \text { Making in the aggregate, } & - & - & - & - & 13,838,592 & \text { " }\end{array}$
averaging in value $\$ 10$ per ton.

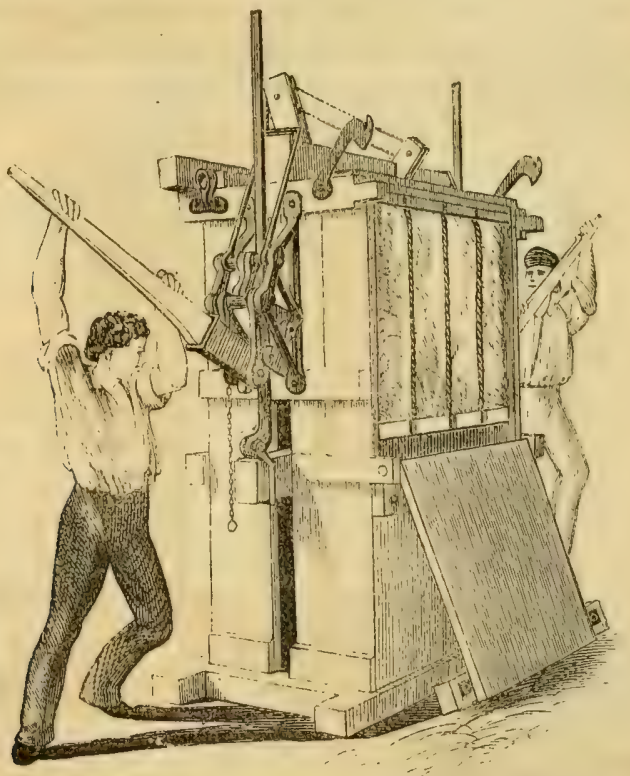

Fig. 169. Ingersoll's Patent Hand-Power Hay and Cotton Press.

This press is extremely effective, and has passed the ordeal of use satisfactorily. It combines simplicity, occupying the least possible space, durability, portability, 


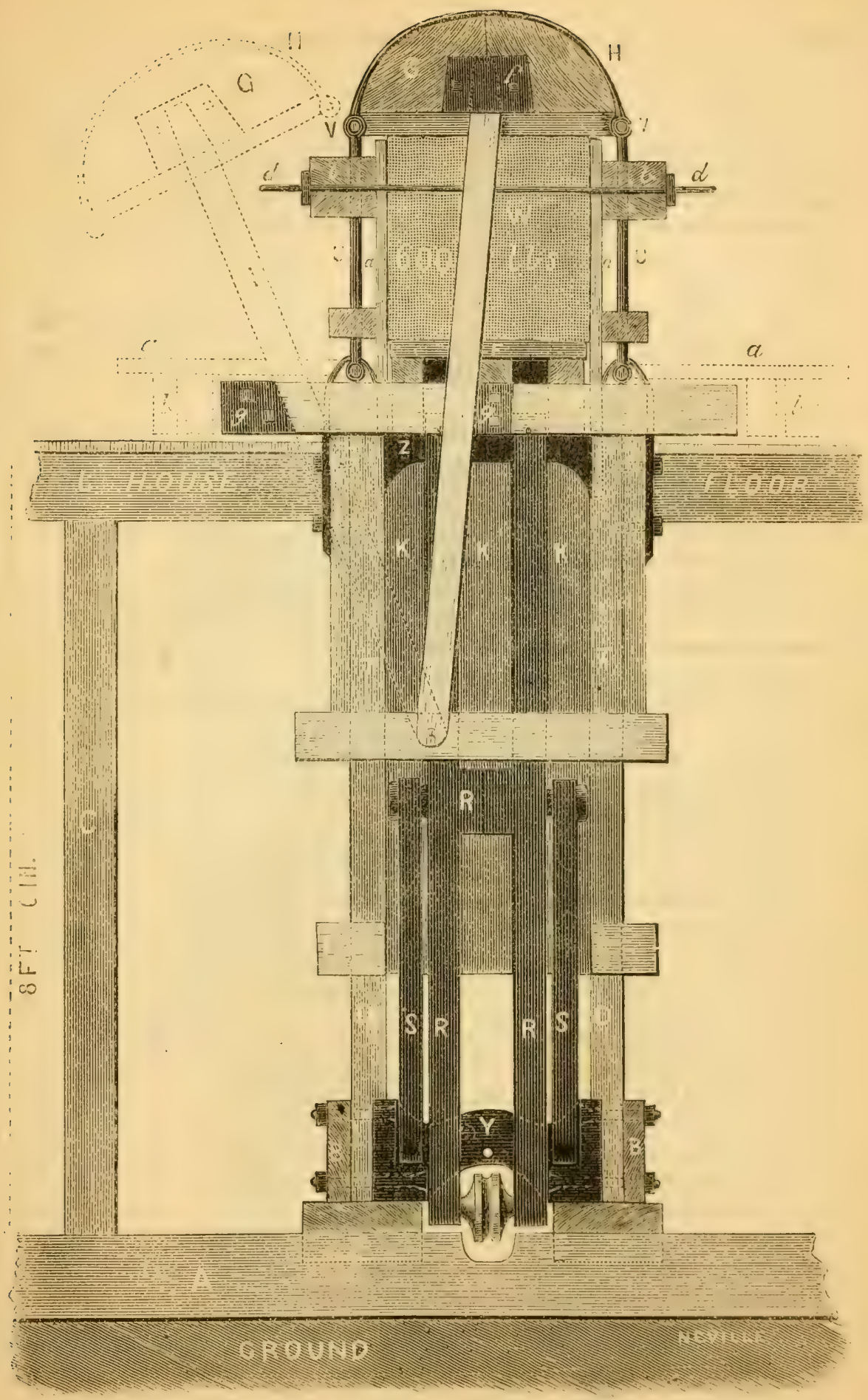

Fig. 170. Bullock's Progressive Power Improved Cotton Press. 
and economy. In addition to packing cotton, hay, straw, rice-straw, etc., they are used for packing numerous other articles, such as rags, wool, hemp, hides, hair, hasks, broom-corn, paper, hops, moss, etc.; are readily taken apart and packed, occupying but little space, and as readily put together again for use. They vary in size, strength, and cost.

Weight of cotton bales, 250 to 500 lbs. ; wool, 300 to $800 \mathrm{lbs}$; rags, hides, hair, etc., the usual market weight required. Weight of hay bales, 150 to $300 \mathrm{lbs}$. ; hop bales, $200 \mathrm{lbs}$.

Bullock's Press has been long and successfully used for the pressing of cotton. Fig. 170 is an end view and Fig. 171 a side view of this powerful press. It may be worked by hand power, but is usually preferred as a power press.

\section{LETTERS OF REFERENCE.}

A A A are Foundation Stones, or Blocks.

B B are String Pieces to which the Windlass is attached.

$\mathrm{C} \mathrm{C} \mathrm{C} \mathrm{are} \mathrm{posts} \mathrm{to} \mathrm{support} \mathrm{the} \mathrm{Press} \mathrm{and} \mathrm{the} \mathrm{Gin-House} \mathrm{Hoor.}$

D D are pieces which serve as guides to the Follower.

E E E are Clamp Girts, which hold the Press-box together.

$\mathrm{F}$ is the Follower Block, or under platen, attached to the upper end of the Lever Beam by means of the Journal or Crosshead Z.

$\mathrm{G}$ is the Cap, against which the bale is pressed.

$\mathrm{H} \mathrm{H}$ are wrought-iron Straps attached to the Cap to form a connection with the rods $\mathrm{U}$.

I I are Sway Bars attached, to carry the Cap off' one side.

J J J are Floor Timbers, or beams, of the Gin-House.

$\mathrm{K} \mathrm{K}$ are Planks forming sides of the Cotton-box.

$\mathrm{L}$ is a Lever, or sweep, to which the horse is attached.

M is a cast-iron Frame to support the Iron Capstan, or Windlass.

$\mathrm{N}$ is the Windlass, or Capstan, around which the chain is wound.

$O O$ are parts of the chain, one end of which is attached to the cast-iron Step Block $\mathrm{Y}$, and the other end to the Windlass.

$\mathrm{P}$ is a Pulley in the lower end of the Lever Beam.

$\mathrm{Q}$ is a connecting rod in the chain.

$\mathrm{R}$ is the Lever Beam attached to the Crosshead.

S S are arms, or supports, for the fulcrum of the Lever Beam.

$\mathrm{T} \mathrm{T}$ are Rods which receive the Step Block at the lower end, and connect with the Rod $U$ at the upper end.

$\mathrm{U} U$ are Rods connecting the Straps $H$ H and the Rods T T.

$\mathrm{V} \cdot \mathrm{V}$ are Pins by which the Rods and straps are connected.

W, Bale of Cotton.

$\mathrm{X}$, Pall or Drag-pike, to hold the Sweep from flying back.

$\mathrm{Y}$, cast-iron Step-Block on which the arms rest.

Z, cast-iron Journal or Crosshead attached to the Follower.

a $a$ are Side-doors, or top parts of the Press-box. 


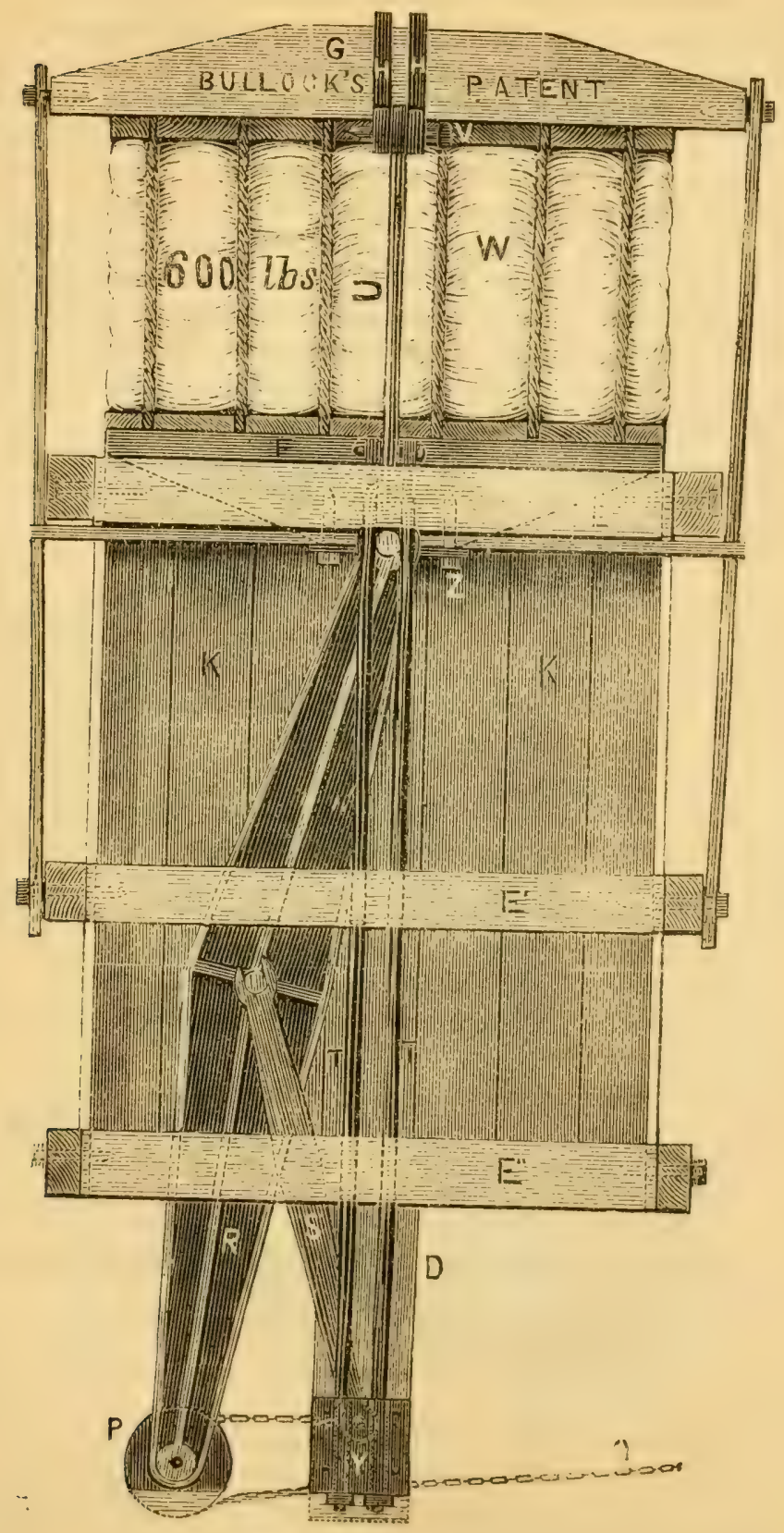

Fig. 171. End view, 


\section{$b b$ are Door-Battens.}

$d d$ are wrought-iron bars, or clamps, to hold up the doois.

$f$, cast-iron Socket to receive end of Sivay-Bars.

$g g$ are cast-iron Stops for the Sway-Bars to rest against.

The dotted lines in Figures 170 and 171 show the position of doors when let down, and also of the cap when swung off one side.

The convenience claimed is as follows:

1st. It can be put under cover in a corner of the gin-house, convenient to the lint-cotton, which enables two men to fill the box in a few minutes.

2 d. It occupies but a small space-about six by three feet, exclusive of the horsepower, which may be put outside of the building in the most convenient place.

$3 \mathrm{~d}$. The top of the box is left open, unobstructed by beams or follower-blocks, while the men are filling and treading the cotton into the box.

4 th. The whole amount of cotton for each bale is put into the box at once.

5th. The doors around the bale may all be moved out of the way, and allow free access on all sides for roping and sewing up the bagging after the bale is pressed.

The power used in this press is the Progressive Lever, operating upon a movable fulcrum - a feature peculiar to the Bullock Press, and one most admirably calculated for, and adapted to, the pressing of cotton. It allows a long range of the follower, and the progressive power just meets the increasing resistance of the bale as it becomes more and more compact, and this, $\mathrm{tm}$, without any increase of power applied to the lever. The last turn of the horse in running up a bale, requires no more power than the first turn, and the power is only limited by the strength of the material the press is made of, which, of course, can be made all that may be required for any purpose, and yet work rapidly.

The box is sufficiently large to allow six hundred pounds of lint cotton to be putinto it at once. And as the strain comes entirely on iron, it can be pressed up safely.

The weight of the Improved Press is about two thousand pounds. But when taken apart and packed for transportation, two men can handle easily every package, and load and unload it.

Every thing about it is perfectly plain and simple.

Bullock's Improved Press is complete and ready for use when it comes on the plantation, and gives the planter no trouble. No time is spent in getting timber; no hands to furnish; no carpenter to pay; no iron to buy; no blacksmith's bill to pay.

This Press requires one mule to run it up in two minutes, or two mules in one minute. The Screw, a strong team, a long time.

In roping the bale and sewing up the bagrging in the Bullock Press, it will be found impossible to place the bale in a position more convenient to work atnot a post or a beam in the way. The rods are jointed so as to fall down and allow the bale to roll out of the press when desired, and also to allow the cap to swing off one side out of the way when filling the box. Not so with the Screw Press; the posts and beams render it difficult to sew up the bagging at all in the press; and when the bale is finished it is usually left in a pit, where it requires 
half-a-dozen hands, with a tackle-block, to get it out. And again, in filling the box of a Screw Press, the follower-block is always in the way of the workmen.

The Press can be put up and operated by any body. It is not one hour's work, after the place is prepared for it, for two men to move it from the wagon and put it up ready for work. These presses are made in the most substantial and workman-like manner, under the immediate direction of the Inventor, who has had eighteen years' experience in making and using these Presses upon the Cotton Plantations, and consequently knows well what is required.

Every press is put together and thoroughly tested, numbered, marked, and painted before leaving the manufactory.

Printed instructions, giving full particulars how to set it up, and how to work it, will always accompany each press.

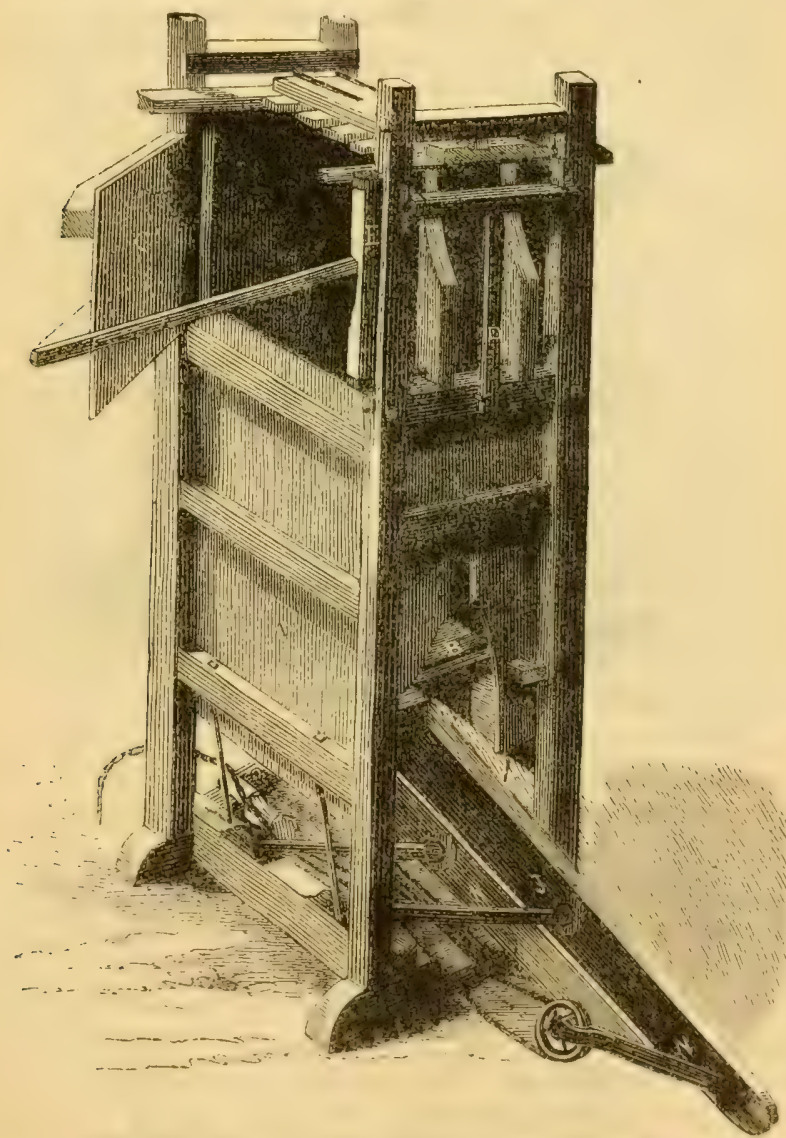

Fig. 172. Dederick's Patent Parallel Lever Hay Presses.

The engraving above is so plain, that it requires searely any explauation. When the door, $\mathrm{C}$, is closed, the head, $\mathrm{U}$, is moved over to cither side at pleasure. The 
hay is then thrown in, and when the box is full the head is moved back again to the centre of the press. The power being then applied to the parallel levers, $J \mathbf{K}$, through the block and tackle system of ropes and pulleys, $N R R$, the follower, $B$, is pressed upward against the hay with a power which is not interfered with by the least particle of friction against the sides of the press, and which is as simple as it is evidently great. The door, $\mathrm{C}$, and also a similar door on the other side, is then opened; the bale is then bound, and the ends of it being relieved ly releasing the end of the bar or handle, $D$, it is taken out from either side at pleasure; and it is worthy of special remark, that the side door of these presses can be opened quite easily with one hand. They are operated by a horse upon a capstan,- - the horse going round only five times to make a bale. In one of them two men and a boy will bale from five to nine tons of hay per day, according to the size of the press. These presses are inade in six sizes, and to bale from 100 to $500 \mathrm{lbs}$. each, according to size. They are taken apart for long transportation, and are accompanied with full printed directions for putting up and operating.

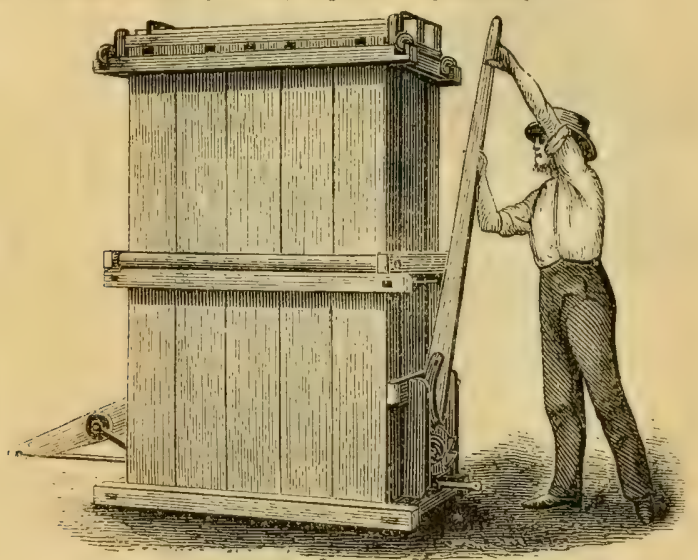

Fig. 172\%2. Dederick's Patent Hand Hay Press.

Fig. $172 \frac{1}{2}$ represents the press as being filled and closed, and ready for operation. The power consists, as in the horse-press, of "two toggle joints" (one only can be seen) so arranged that they operate parallel, and one being placed underneath each end of the follower, and the two being confined together by a connection rod, (as seen in cut,) both sides of the follower must movo simultaneously and even. This press, thus constructed and arrangerl, has a power which increases as fast as the resistance of the hay.increases, is durable, and in no way liable to get out of order even in careless hands, and operates more quickly and presses bales compactly.

\begin{tabular}{|c|c|c|c|c|c|}
\hline $\begin{array}{l}\text { No. } \\
\text { No. } 1 .\end{array}$ & $\begin{array}{l}\text { Bales from } \\
375 \text { to } 425 \text {, }\end{array}$ & $\begin{array}{c}\text { Size of Bale. } \\
4 \mathrm{ft} \text {. by } 24 \mathrm{x} 30 \text {, }\end{array}$ & $\begin{array}{l}\text { Height of Press. } \\
14 \text { feet, }\end{array}$ & $\begin{array}{c}\text { Weight. } \\
2,800 \text { lbs., }\end{array}$ & $\begin{array}{l}\text { Price. } \\
\$ 16500 .\end{array}$ \\
\hline No. 2. & 275 to 325 , & 4 ft. by $22 \times 28$, & 12 feet, & $2,400 \mathrm{lbs}$. & 15000. \\
\hline No. 3. & 250 to 300 , & $4 \mathrm{ft}$. by $24 \times 30$ & 9 feet, & 1,300 lbs., & 12000. \\
\hline No. 4. & 200 to 250 , & $4 \mathrm{ft}$. by $24 \times 28$, & $8 \mathrm{ft} .6$ in., & 1,200 Ibs., & 10000. \\
\hline No. 5. & 275 to 300 , & $4 \mathrm{ft}$. by $26 \times 30$, & 8 feet, & 1,200 lbs., & 00. \\
\hline & 150 to 2 & 4 ft. by $24 \times 26$ & $6 \mathrm{in}$., & 800 lbs., & \\
\hline
\end{tabular}


Nos. 3 and 4 as hand-presses, same style and prices as horse-presses,-combined as hand and horse-press, $\$ 10$ extra. Nos. 5 and 6 are the hand-presses.

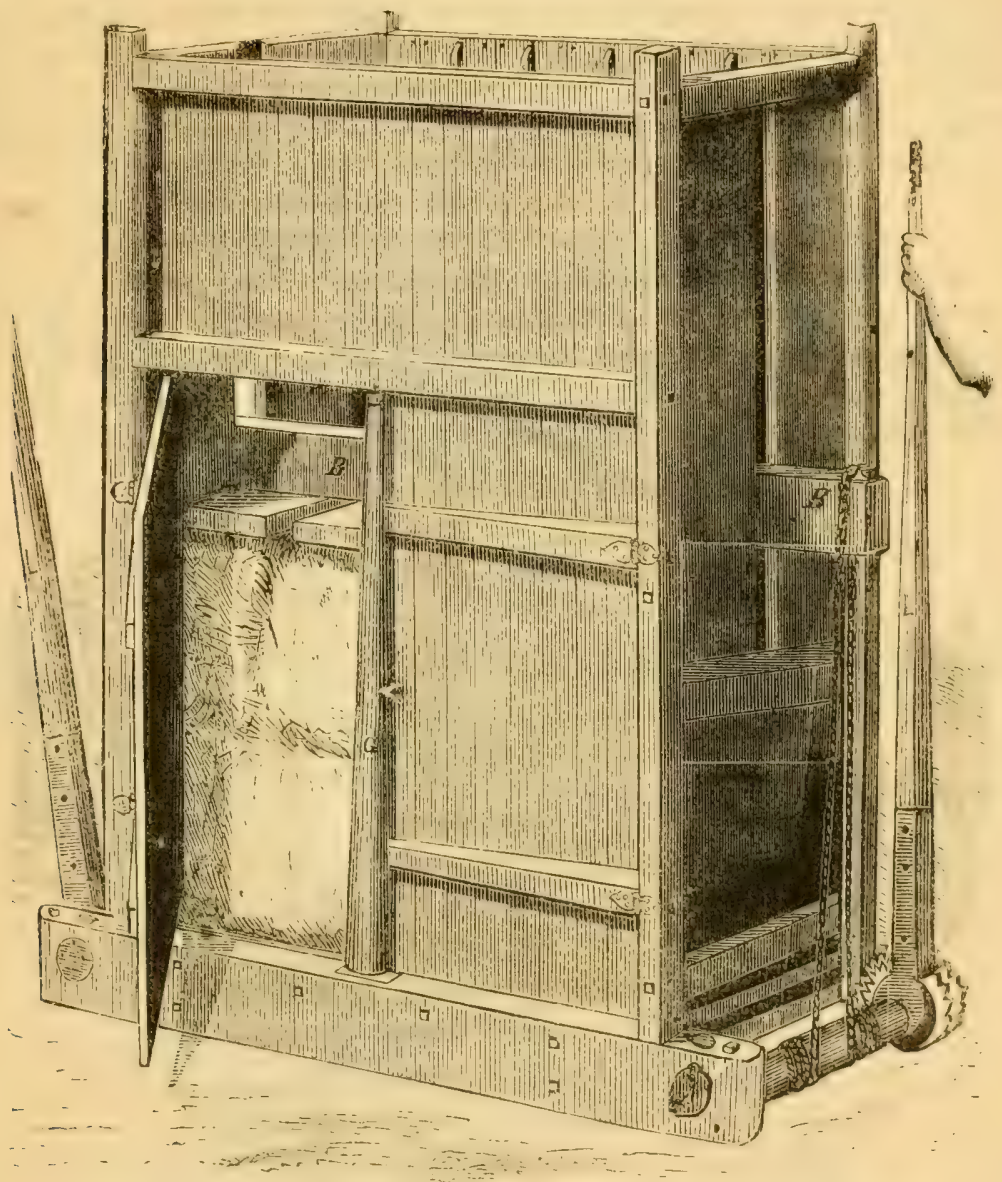

Fig. 173. Fay's Portable Hand Power Hay, Straw, and Cotton Press.

This machine is simple in construction, and is well alapted for pressing eotton, hay, straw, hemp, broon-corn, flax, hops, wool, rice-straw, rags, pmice, linsecel-oil, etc. It is strong and effectual, and, from its simplicity, may be readily used by a common hamd. It is readily taken apart and re-established in working order: may be packed in small space for shipment.

No. A will weigh $1,100 \mathrm{lbs}$, and will press five or six tons of hay per day, in

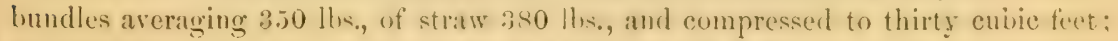
the proportion of une bale being 29 ly 31 inches and of feet long; it ocenpies i by 3 feet. 
This press is worked by hand-power, with a downward line of travel, giving: great facility in tying of bales, adjustment of covering cloth, etc.

No. B occupies 6 by 3 feet, and with proportionably less results. It forms bales 26 by 29 inches and 4 feet long, compressed to twenty cubic feet, averaging about $265 \mathrm{lbs}$, of straw $285 \mathrm{lbs}$. The index plate attached to the end of the press denotes the number of cubic feet of the bale.

Broom-corn and flax press No. C is upon the same principles, but differently proportioned; dimensions of bale 24 by 29 inches and 4 feet long.

\section{HAY, STRAW AND STALK CUTTERS.}

THis class of implement is in general use. It is now established beyond a doubt that a less amount of cut hay will sustain an animal, than when fed, as it now frequently is, in the long state. And if this be true when cut as at present from half an inch to an inch in length, it is true in degree all the way down to a chaff. The proprietors have now a variety of machines in addition to those in general use, for cutting hay much finer than has been heretofore done.

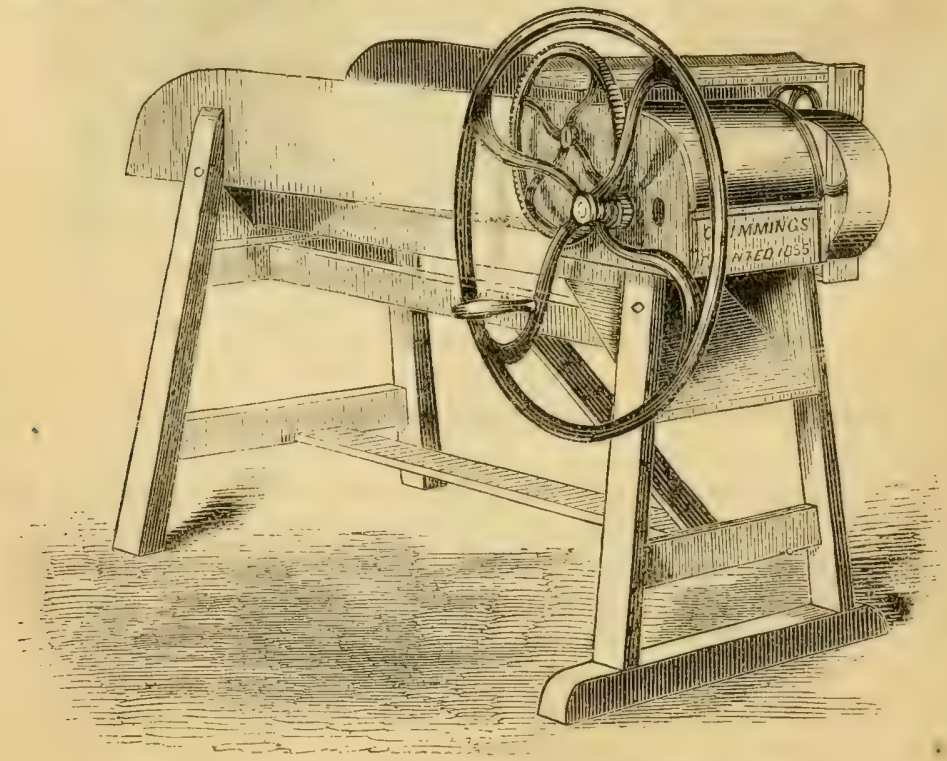

Fig. 174. Cumming's Patent Hay, Straw, and Stalk Cutter. 
Fig. 174 is a recent invention. It is of simple construction, easily operated or repaired, and cuts all varieties of forage very rapidly, whatever may be the condition of the forage to be cut. It may be operated by hand or horse power.

By change of gears furnished with the machine, it is rendered capable of cutting extremely fine, or of ordinary length, as may be preferred; and the proprietor is now experimenting, with a fair hope of success, for rendering it truly a chaffing machine.

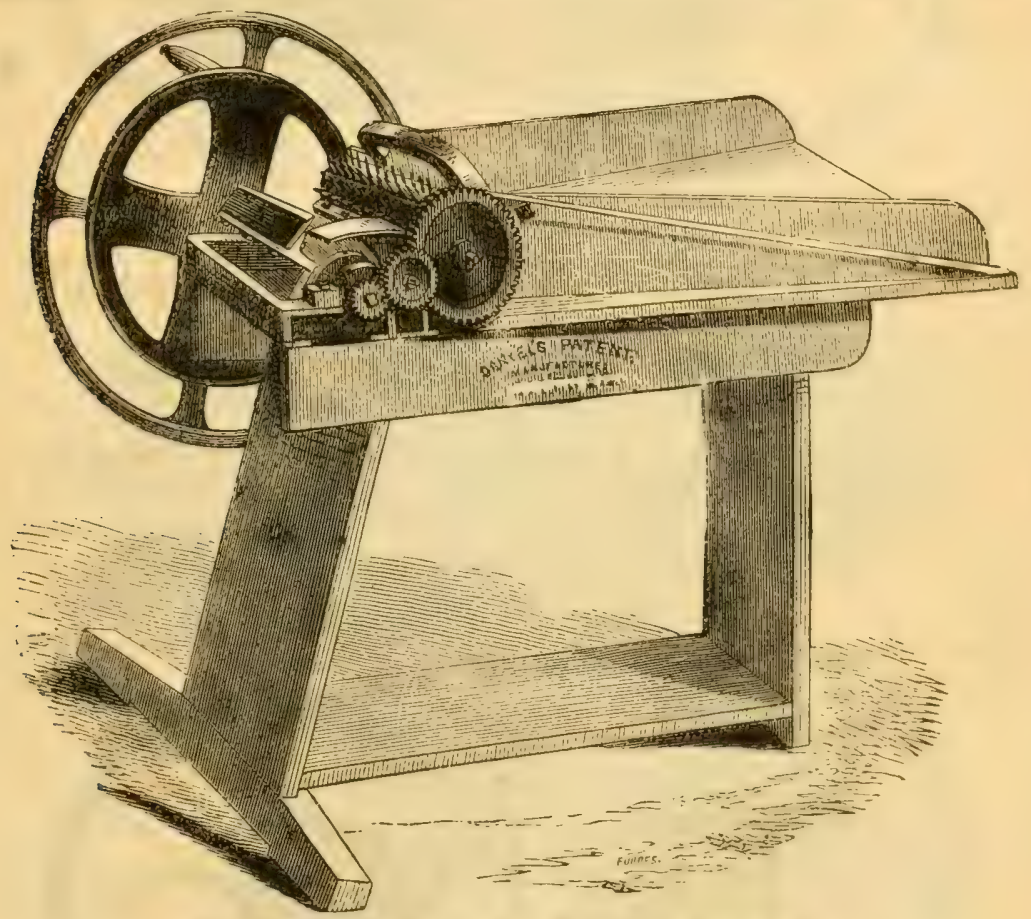

Fig. 175. Daniel's Patent Hay Straw, and Stalk Cutter.

Fig. 175 is of two sizes, and very efficient in practice. No. 1 has knives 10 inches in length, and is intended for a hand machine-may, however, be moved l,y horse power-cuts one inch long, and when well attended will cut half a ton per hour. No. 2 is calculated for horse power, but may be run by hand; length of knife 16 inches, cuts one inch long, and capable of cutting one ton per hour, of hay, stalks, or straw. This machine is well known in the South.

Fig. 176 represents a new machine for Cutting Stalks, Straw, and other coarse forage-a modification of the best Cylindrical Chaff Cutter, and is strongly made. 


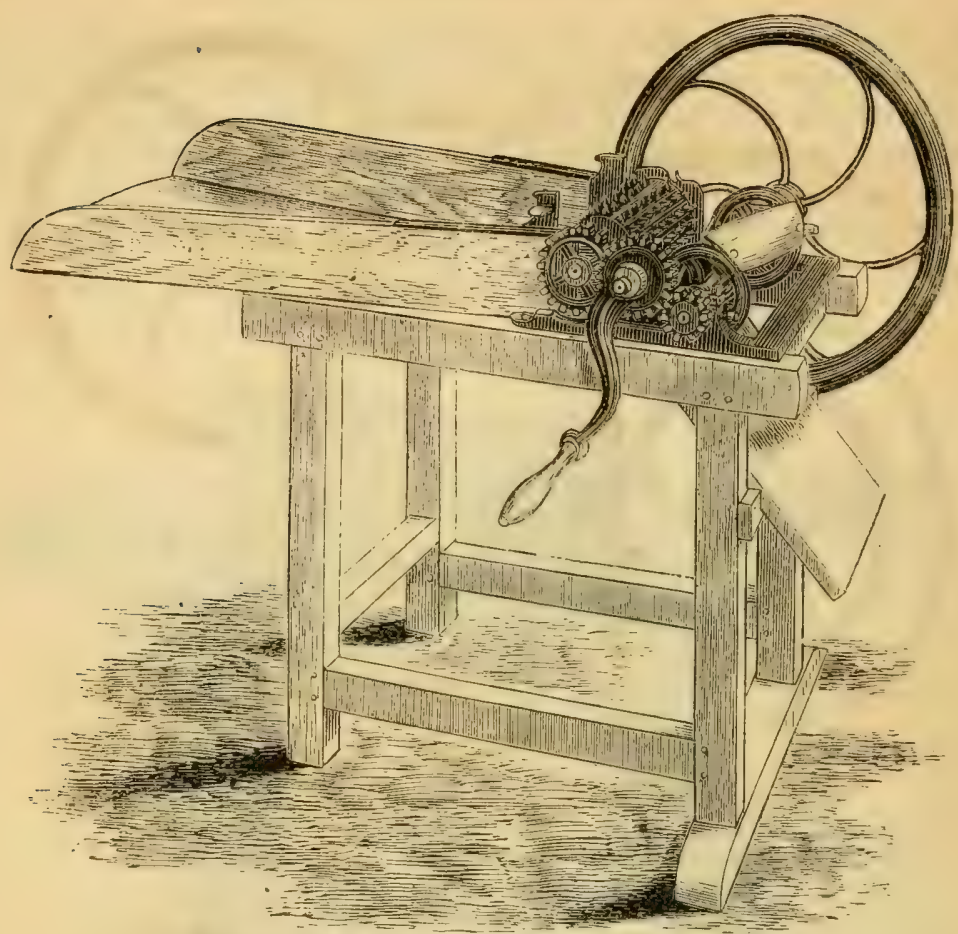

Fig. 176. New Cylindrical Straw and Stalk Cutter.

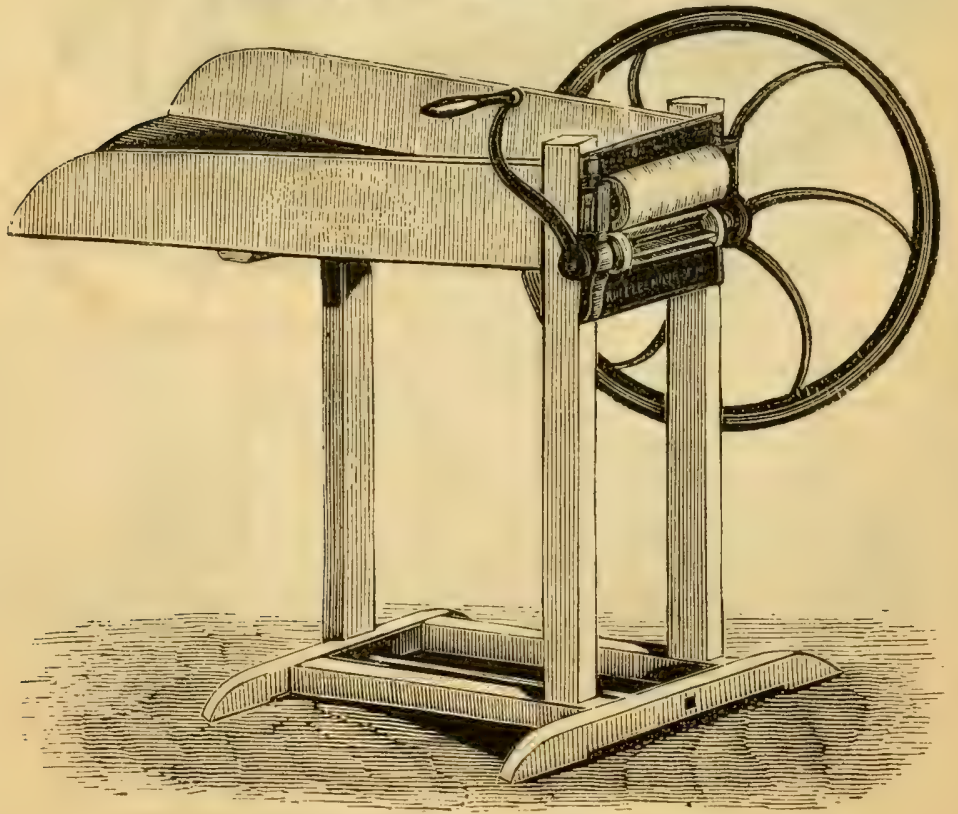

Fig. 177. Cylindrical Hay and straw Cutter,-Straight Knives. 


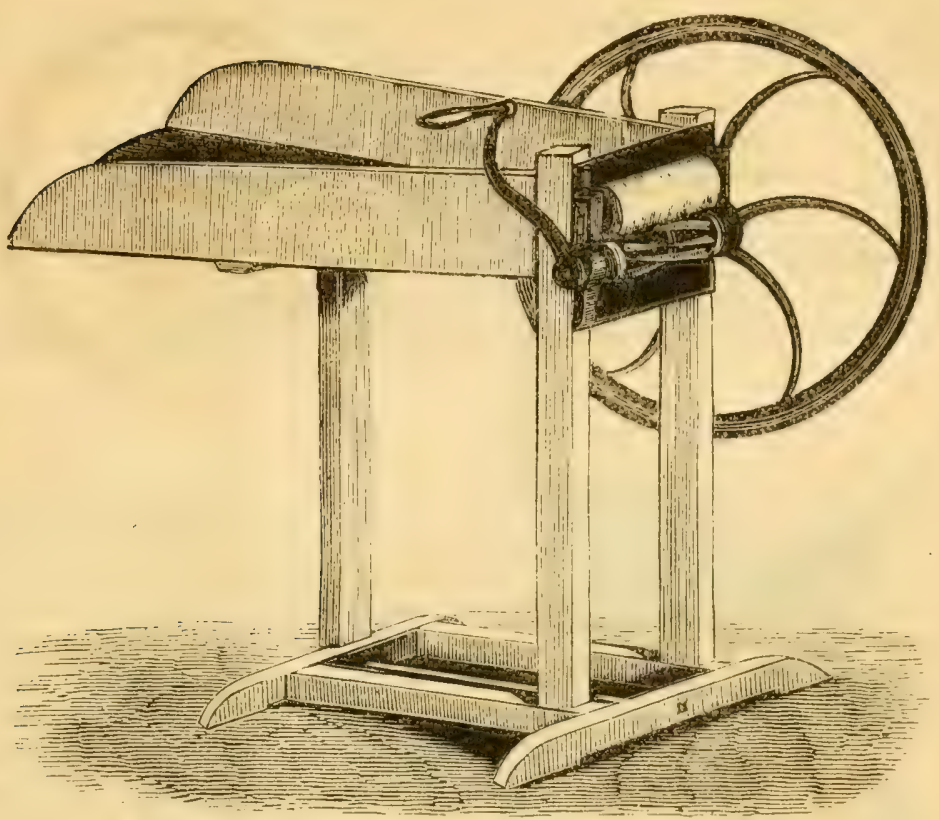

Fig. 178. Cylindrical Hay and Straw Cutter-Spiral Knives.

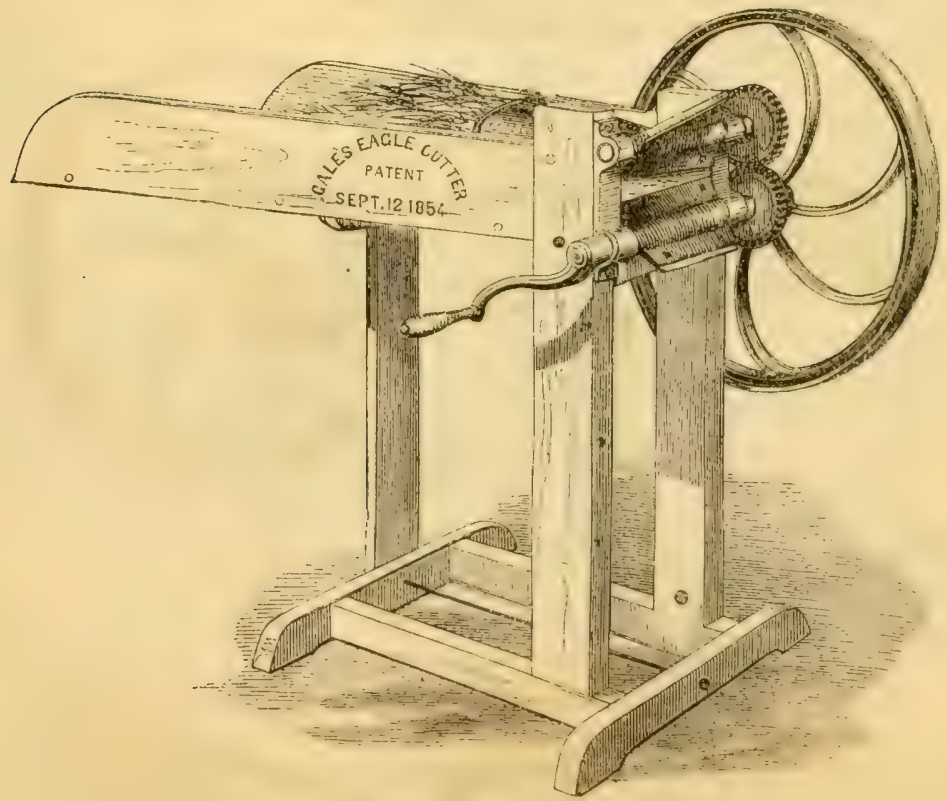

Fig. 179. Gale's Patent Eagle Cutter. 
Figs. 177 and 178 represent the hide-roller, straight and spiral knife hay-cutters; in either machine, the knives being set in the circumference of a cylinder, or arbor, and cutting against the hide-roller.

The various kinds and sizes of these cutters are so put together, with joint-bolts and serews, as to be taken apart and boxed for transportation, and are readily set up again.

We have many sizes as per price list.

Fig. 179. Gale's Patent Hay, Straw, and Stalk Cutters.

Of these we have various sizes, known as Universal and Eagle Hay Cutters in the price list.

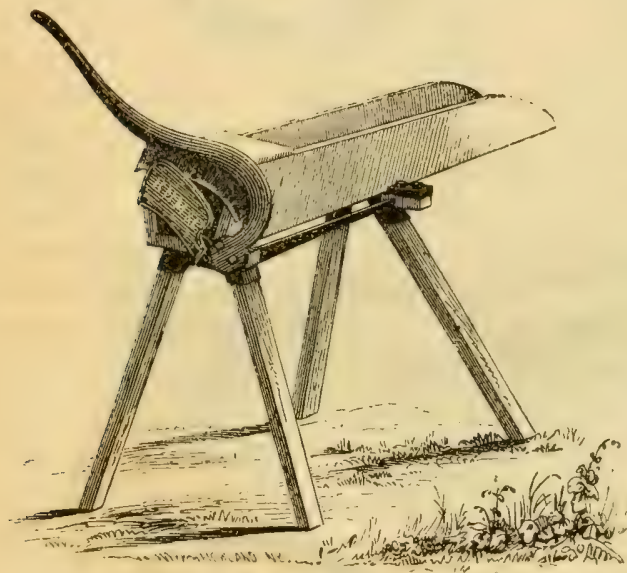

Fig. 180. Smith's Patent Lever Cutter.

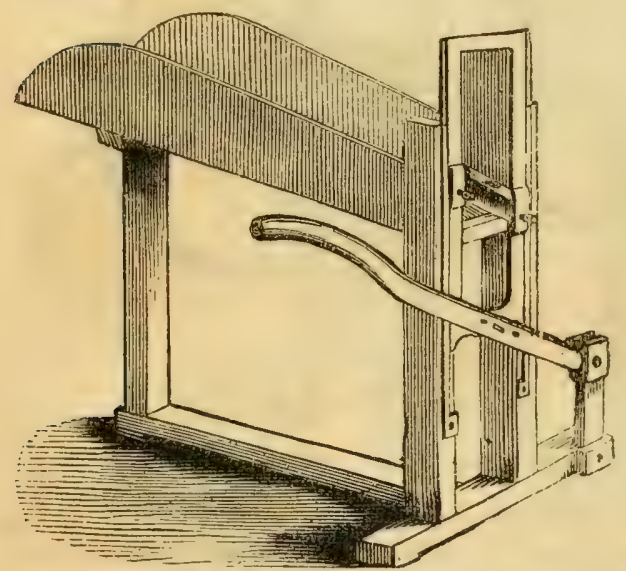

Fig. 181. Lever Hay Cutter.
Fig. 180. A strong, effectual cutter, well calculated for the Southern states, and adapted to cutting corn stalks. It is less liable to be injured by inexperienced hands, exposure to the weather, etc., than most machines. The parts are easily separated and packed into the box or hopper for transportation, and readily put together again.

Fig. 181. This is one of the ear liest forms of the Cutter, and can be furnished at a very low prime 


\section{HORSE POWERS.}

Mucn of the labor of the farm, now performed by hand, should be done by horse power; and indeed, for all purposes requiring less than the power of five 'horses, steam power cannot be economically used : repairs, cost of attendaut engineer, etc., rendering horse power more economical than steam for small purposes.

Horse powers are divided into two classes, viz., those known as railway powers, where the floor is caused to move by the tread of the horse acting as an endless belt; and a number of forms of static powers which are rendered active by a horse placed at the end of a lever, or its equivalent, walking on the ground.

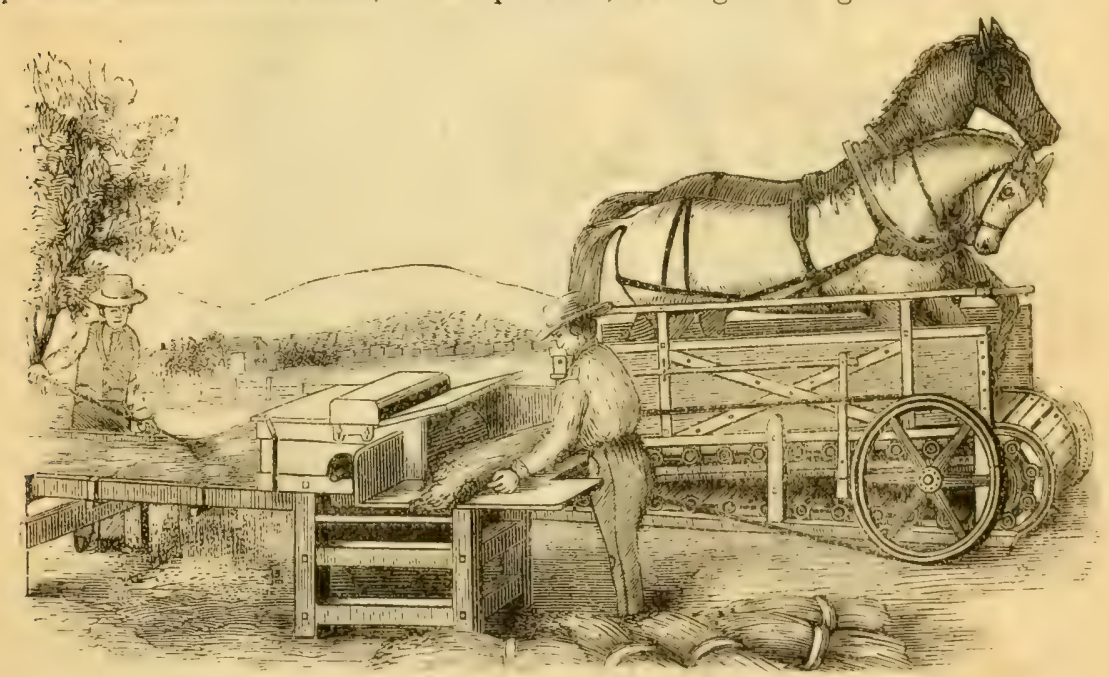

Fig. 182. Patenit Endless Chain Changeable Horse-Power.

Fig. 182. Patent Endless Chain Changeable Horse Power, arranged to be worked by one or two horses. This railway power is a material improvement on those which have preceded it, as it is capable of several changes for increasing and diminishing the speed so as to adapt it for threshing grain, ginning cotton, sawing wood, grinding feerl, and in fact for all purposes to which power can be applied, and without any adidional expense of gearing. All the moving points of this 
machine are upon the outside, where they may be protected from dust, requiring little time or oil to keep them in the best possible runuing order.

The arrangement for tightening the endless platform permits it to be instantly done by a common wrench, without stopping the machine.

The Overshot Thresher (represented in the cut), Fig. 182, and Vibrating Separators, with improvements, have been used with like success as the Powers. They admit of a level feeding table, thus avoiding accidents (which often occur with the inclined feeding board), by preventing hard substances, sticks and stones from getting into the machine and breaking the spikes, endangering those engaged with them. The grain, by this motion, is thrown on the floor within three feet of the machine, and admits a separator to be attached sufficiently high to allow the grain and fine chaff to fall through it, while the straw is thrown off without being cut, and in fit condition for binding.

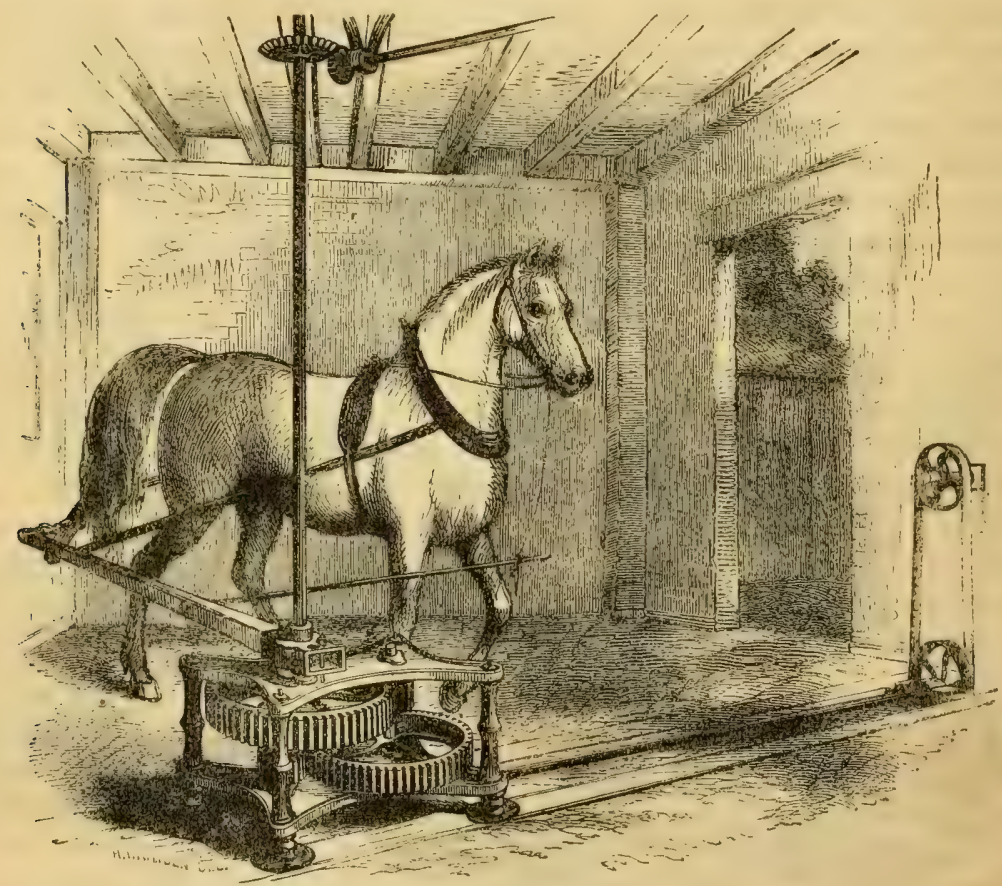

Fig. 183. Field's Patent Horse Power.

This machine can be operated by one to four horses, and is a very compact, simple, durable, and cheap Sweep Power. For two horses, it is made three feet two inches long, two feet two inches wide, and two feet high. The power, of whatever size, is geared either upright or horizontal, as may be preferred, the expense being the same.

The Planet Sweep Power, Fig. 184, is built entirely of iron, and is so equilibriated in all its parts, that whether used for one or more horses, the resolution of 


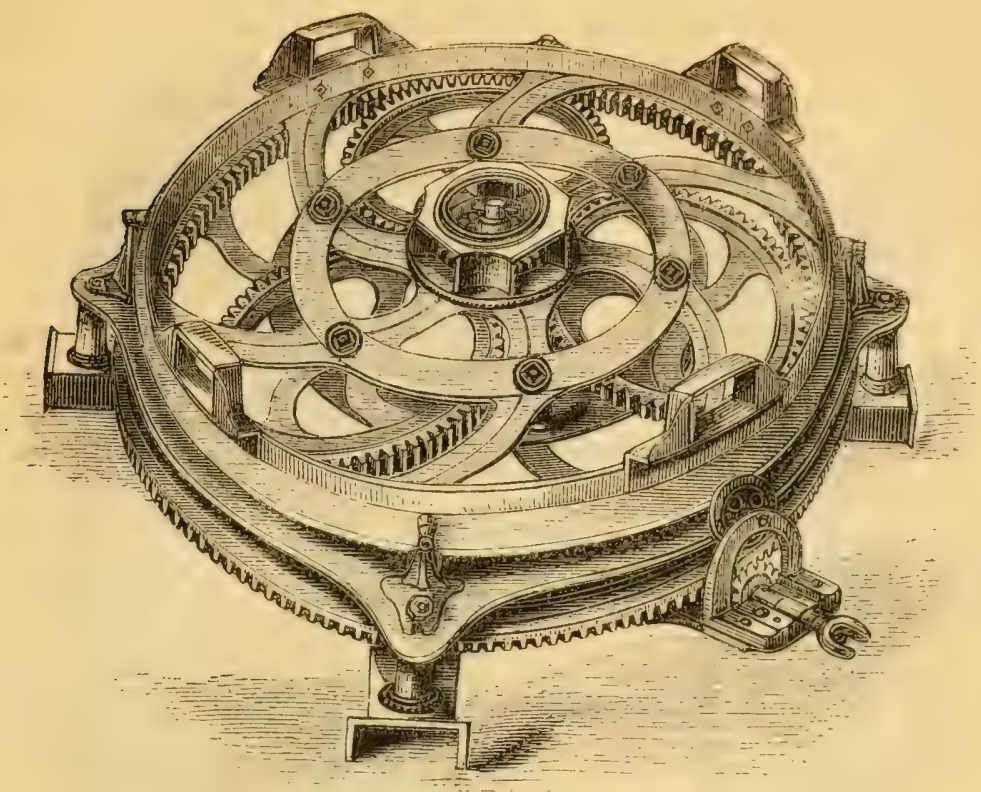

Fig. 184. Planet Sweep Power.

forces is felt on all parts alike, so that it is not liable to derangement, change of figure by strain, or other casualty; and in every instance has given the most perfect satisfaction.

There are two sizes; and levers are furnished with these powers adapted to any number of horses, from one to ten. Compactness renders it desirable for shipping, occupying but little space. It may be put up without the assistance of mechanies, being all ready for use as sold.

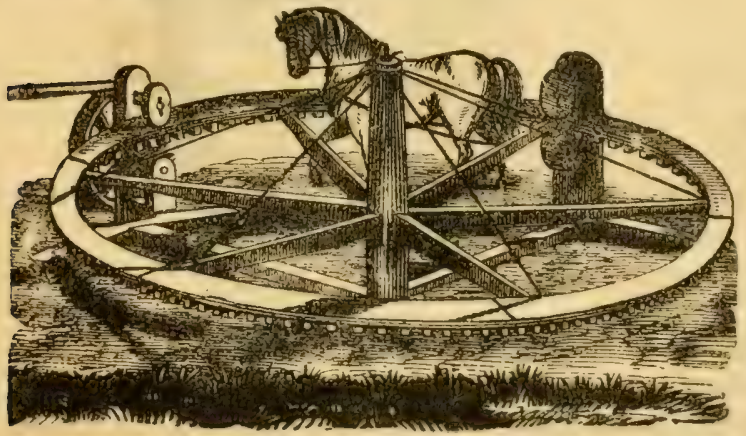

Fig. 185. 'Laplin's Horse Power.

Fig. 185. This is a circular or level Power, with a wooden rim about twenty feet in diameter, with wrought-iron gearing bolted in seginents on the under side of the rim, which works into a cast pinion, and on the pinion-shaft a pulley or gear is attached, as may be required, to drive different kinds of machinery.

It is worked with from one to six horses, walking inside the rim, one between each pair of arms. It is readily taken apart and packed in a very small compass for transportation. 


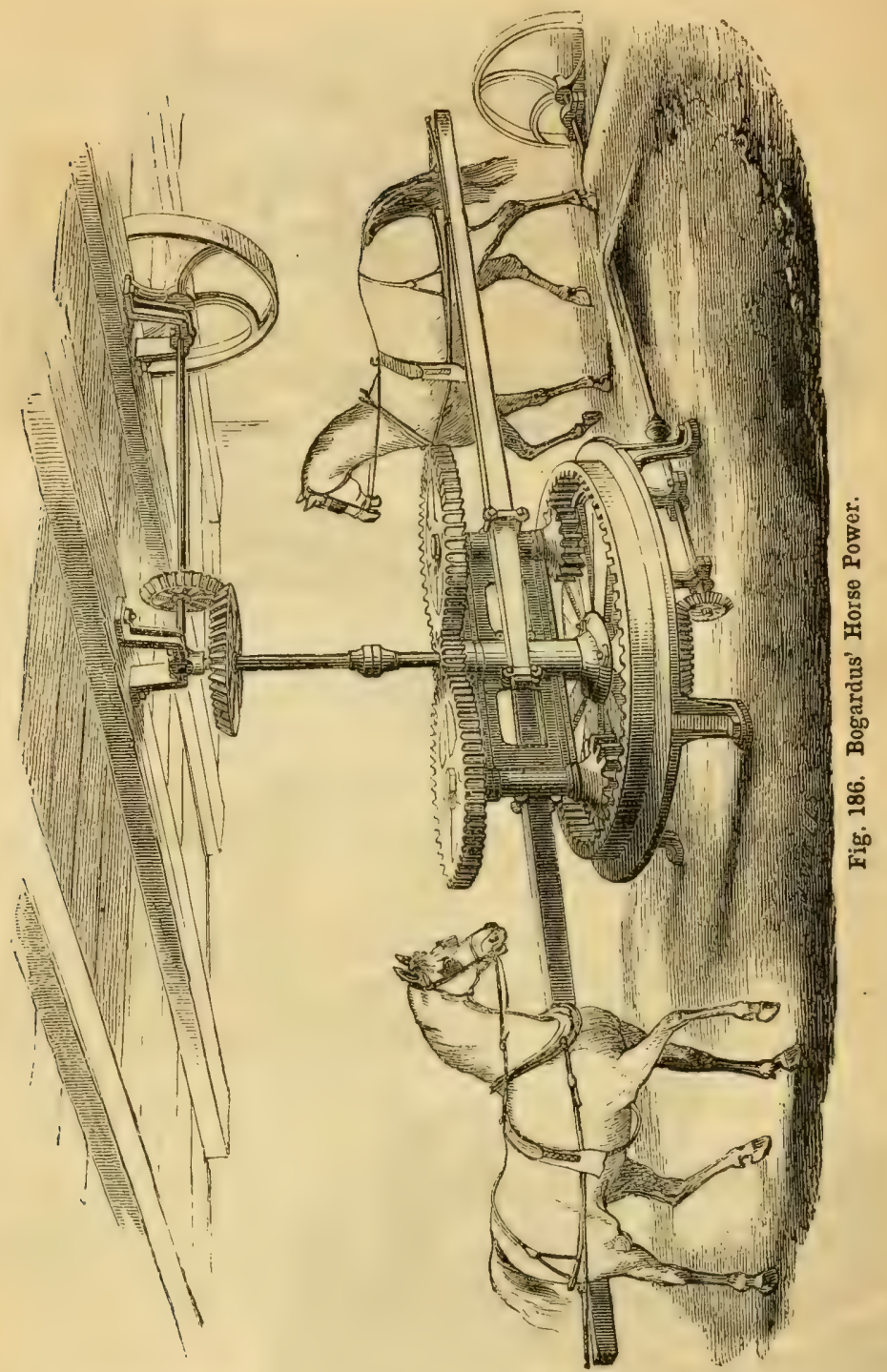

This is a strong and well-constructed machine, fairly equilibrated so as to avoid local strains, and so arranged as to be worked by one, two, or four horses.

The following, cut Fig. 187, illustrates our most approved Dog Power. It is a simple endless platform, formed upon two India-rubber straps, with strips of light wood firmly riveted to it. This endless platform is supported by a drum about twelve inches in diameter at each end, and the whole so arranged that it can be elevated to any angle required by the weight of the dog or work to be done by it. 


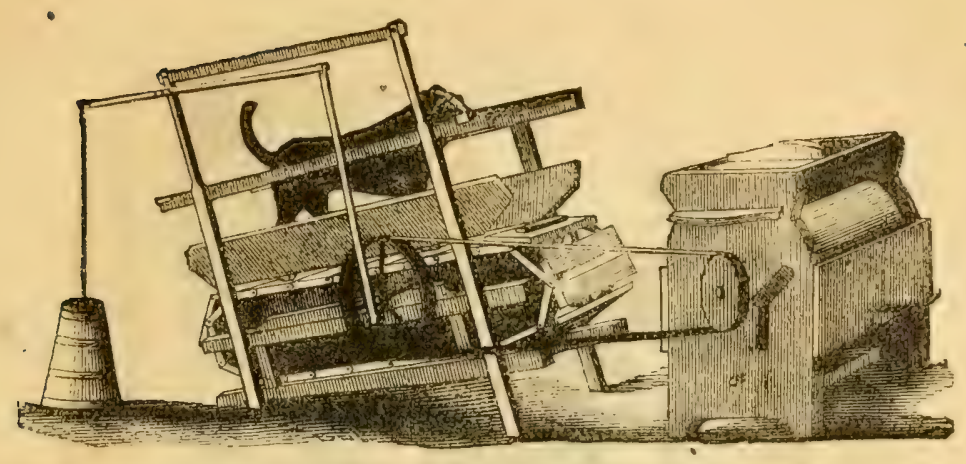

Fig. 187. Dog Power, for Churning.

It is also equally adapted to a sheep, which is sometimes employed instead of a dog. The cut represents it producing both the vertical and rotary motion.

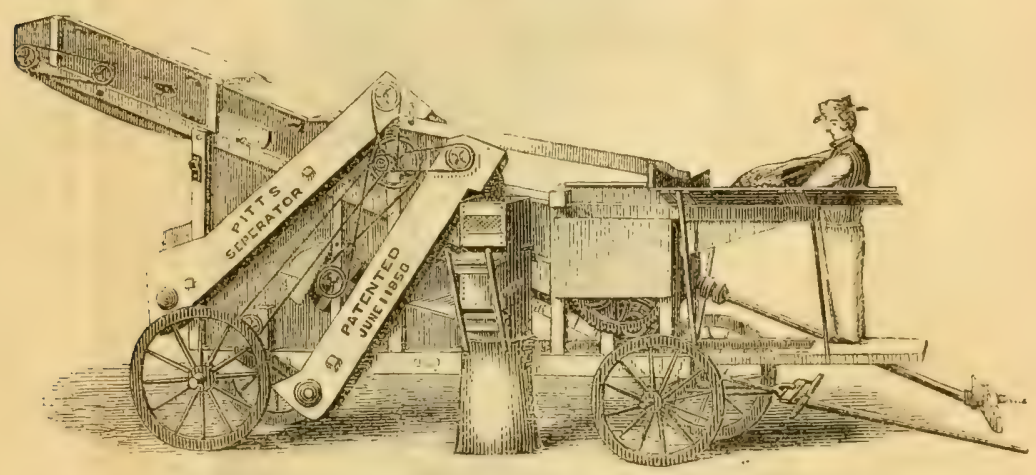

Fig. 188. Pitt's Improved Threshing Machine, Separator, and Cleaner.

A Gold Medal of Honor was awarded at the World's Fair in France for this machine. Also at every exhibition when brought into competition with other machines, its superiority has been universally acknowledged, and, in nearly every instance the first premium has been awarded it. The Separator, for the future, will be superior in every respect to those before made. We have determined to spare nothing that will add to its durability, effective operation, or style of finish. This machine cannot be surpassed in the genuine qualities of durability, ease of draft, and the thorough and effective manner of its operation. None but the very best selected materials are used in their construction; the joints are all well fistened with bolts, cast-steel shafts in cylinders, babbitt metal in boxes where necessary, and every thing is got up in the best manner throughout, and furnished with belts, platform for feeder to stand on, run-boards for convenience of oiling, feed-tables, a tool-box, and sieve for wheat, barley, and oats; screen, etc. 


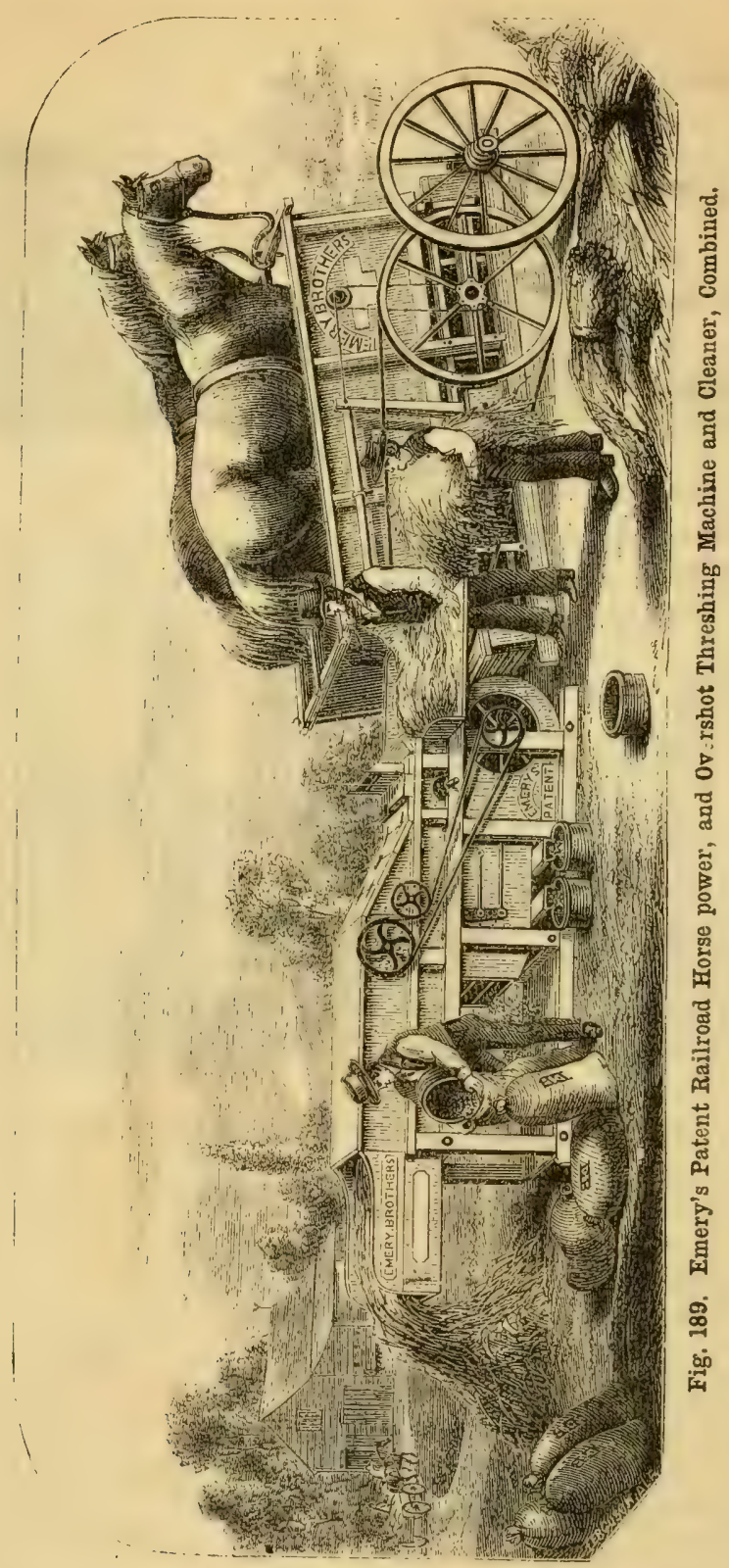

This threshing machine and cleaner combined has been popularly received during the last three harrests; the journals of its cylinder are hung in universal boxes, thereby avoiding binding and unnecessary friction; the fan beneath the feeder's 
table is driven by an outside pulley; the length of the frame-work is from 6 to 8 feet beyond the center of the cylinder, and contains a light wood riddle with a close wood bottom connected with it; these have an endwise vibratory motion in contrary direction to each other, causing the grain and straw to be carried off in opposite directions. The endless apron with slat, forms cells for recciving, holding, and conveying the grain, while the straw occupies the upper surfice of the slats; indeed the whole separation of grain from straw is nearly perfected by this contrivance alone; the straw is afterwards caught by a revolving beater with strong iron teeth, which completes the separation of the grain.

The series of wood fingers acts with each vibration of the riddle, consuming but little force, and perfectly agitating the straw to secure the entire result. In extension is furnished tor the manipulation of light grain. The discharge is by two spouts, delivering separately the clean grain and the tailings; and when ordered, an elevator is supplied for returning the tailings for further manipulation.

For a full and entire description of this machine, see the "Working Farmer," for August, 1860.

Price of these Improved Machines, in sets complete, . . . . . \$ \$25000

Price of Horse-Power, endless-chain or lever principle,...... 12000

Price of Threshing Machine and Cleaner, combined,....... 13000

Price of set of bands and extras, ..................... 500

Price of Elevator for tailings, (always an extra charge)...... 1000

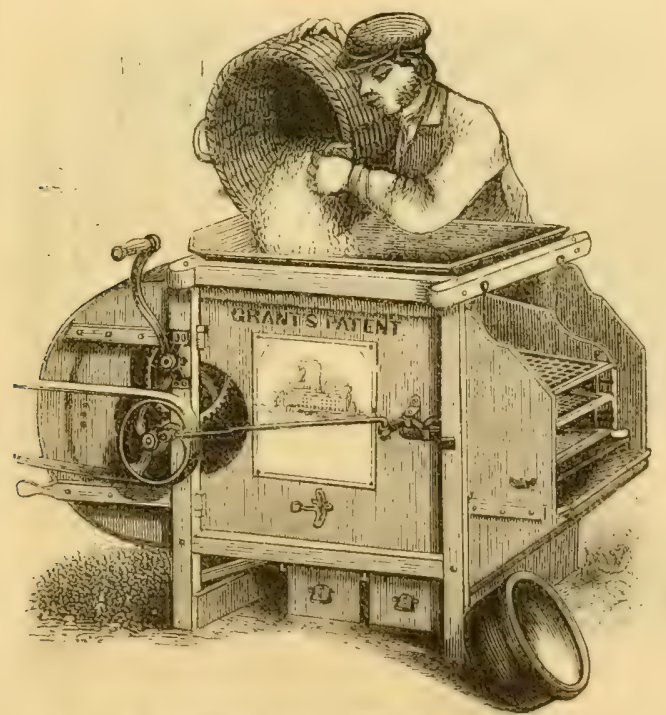

Fig, 190. Grant's Patent Double Blast Fan-Mill.

The above mill, invented by Messrs. I. T. Grant \& Co, is believed to be the most effective for cleaning every kind of grain, rice, grass am other seeds, which it does perfectly at one operation. They are of six sizes, built in the most sul- 
stantial manner and of the best materials ; seven sieves accompany each mill, with printed directions for placing the sieves, slides, etc., for the cleaning of the different kinds of seeds.

The following statement is from the inventors:- "Our Fan-Mills have taken the first premiums at the New York State Agricultural Fairs, at the State Fairs of Pennsylvania and Maryland, at the Mechanics' Institute of the city of New York, and at many county fairs. They received the highest consideration at the National Fair at Washington, and have uniformly taken premiums wherever presented for competition. When thoronghly timed they have chaffed and screened one bushel per minute. This may easily be done with the larger sizes, taking out all the chess, cockle, or smut, at the same time."

These and other fan-mills are constructed so that they may be taken apart for transportation, they being put together with joint bolts and screws. Three mills, measuring 52 cubic feet each, can be packed in one box measuring only 27 feet, and in that proportion for larger or smaller mills, thus making a material saving of freight. They may be set up without difficulty or fear of want of adjustment.

\section{Grant's Common Fan-Mill.}

This is an admirable machine, and is only surpassed by Grant's Patent Mill, described above. It is furnished with four sieves, and can be afforded at a less price than Fig. 190. See Price List.

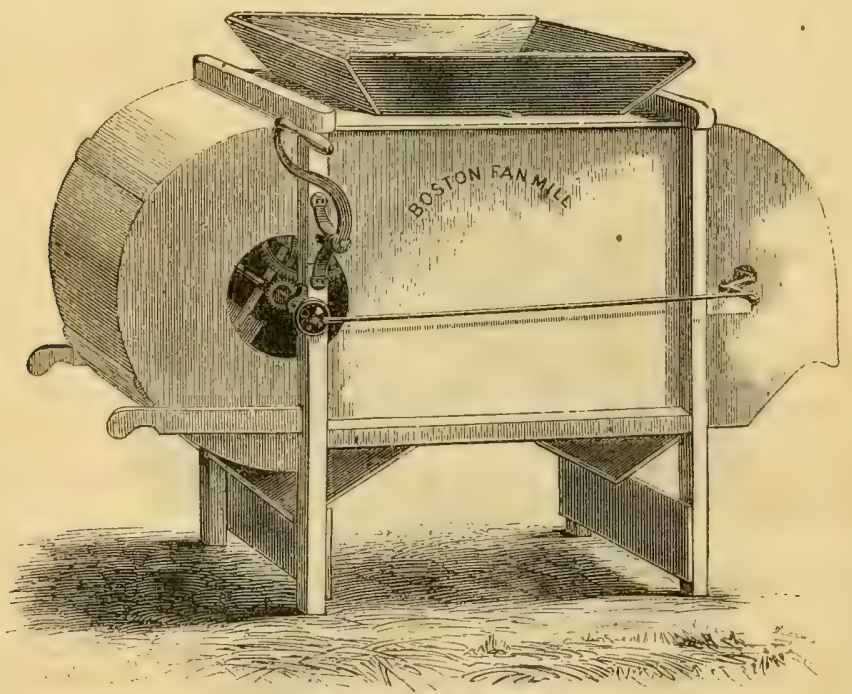

Fig, 191. Boston Fan-Mill.

Fig. 191. This is a cheap Mill, light and portable, strong, and durable, for cleaning grain and small seeds at a single operation. Four sizes of this Mill are made, See Price List. 


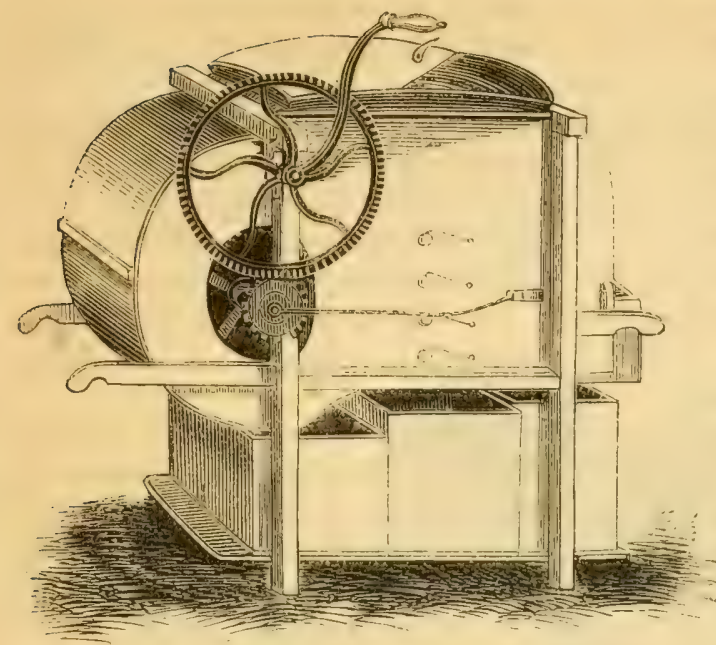

itig. 192. Fan-Mill for Coffee, Spices, Grass-Ŝeeds, etc.

Fig. 192. This is a very convenient little Mill for the merchant and grocer. It is designed for cleansing coffee, the various spices, rice, grassseeds, seed-grain, etc., having a variety of sieves, slides, and boxes to adapt it to these various articles. it is so adjusted, that in operating, more or less wind may be let on the sieves, to exactly suit the wants of the occasion, or the particular article to be winnowed. It occupies very little space, is light and portable, and a perfect Fan-Mill for the purposes designed.

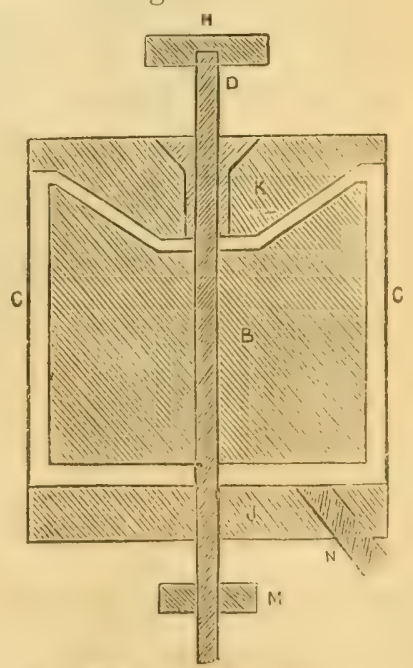

Figs. 193 and 194. Harris \& Son's Patent Smut Machine and Fan.

This machine, invented to hull and pearl rice, coffee, ete., as also for smuttinu. polishing wheat and other grain, has proved itself valuable and popular, being now in successful operation at the raligo Mills, Richmond, Va.; Croton Mills, New York; Revere Mills, Rochester; Etowah Mills, Ga., and over one hundred others.

The grain passes in the machine, as seen in the section above, at the center of the top bed-stone around the spindle, thence by the centrifugal force is thrown out of the convex surface to the periphery of the center or ruming stone, passes down 
between it and the case, and so out of the spont near the center of the lower bedstone, a distance, on the 30-inch machine, of over eight fect. This machine cleans from 10 to 150 bushels per hour, according to size. It is readily set to suit all kinds of grain. The following are among the advantages of this machine: being constructed of stones, it is very durable; the stones can be dressed by any miller once a season, which makes them do the work as well as when first put up; the stones can be set or changed, similar to a mill-stone, to suit any lind or quality of grain; a powerful fan is attached, such as no other machines possess.

Varions sizes supplied to order.

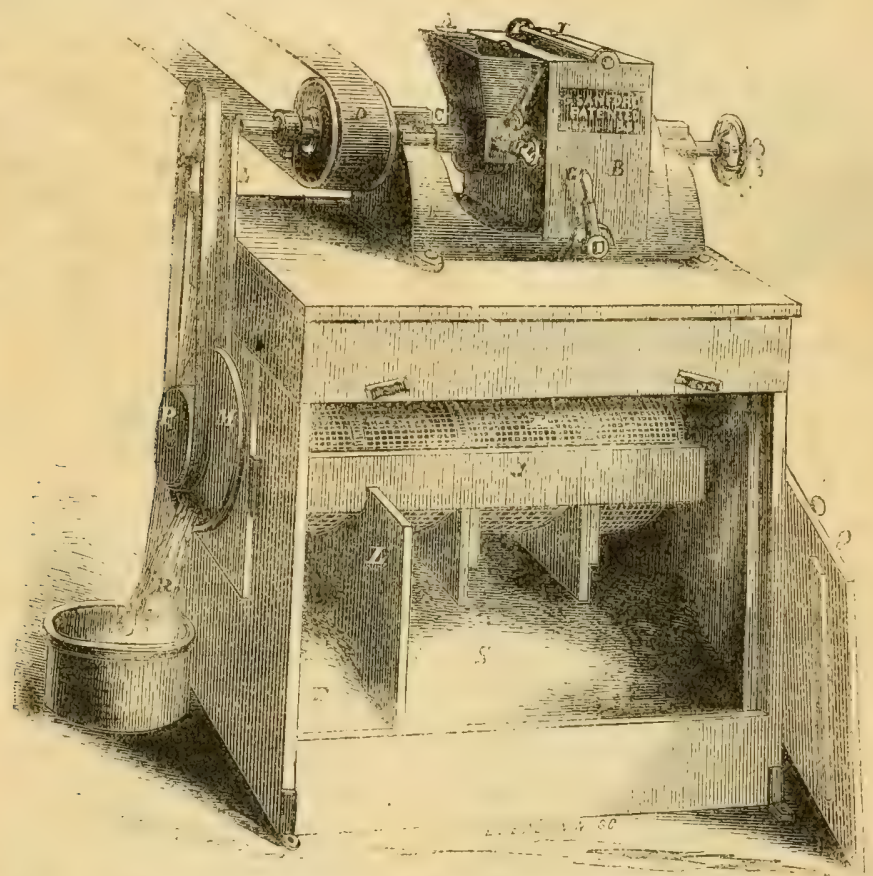

Fig. 195. Sandford's Excelsior Mill, for PIanters, Farmers, and Millers.

This Mill, invented and patented by Mr. G. S:undford, is now on exhibition and in actual operation in this city.

It is a Conical Burr Stone, of new and greatly improved construction. It is superior to any known Mill in compactness, in simplicity, in the amount of power required to operate it, in rapidity of operation, in facilities for keeping it in perfect grinding order, in not heating the grain; in being adapted to grind, on the same Mill, the coarsest feed and finest flour; and in the perfect manner in which it does its work. For domestic, farm, or plantation purposes, will last a lifetime.

It is almost an axiom that, "by grinding fecd, 20 to 25 per cent. is saved. This item of savings alone would in a short time repay the cost of a Mill; and the ordinary horse power used by farmers. planters and others, applied to it, would 
grind their flour, meal or feed in less arerage time than would lie reguired to carry their grain to mill.

Sandford's Excelsior Mill was tested in Philadelphia by the side of a 36-inch flat Burr Stone Mill. It ground 40 bushels of feed in three hours, and the Flat Stone Mill ground in the same time but 36 breshels, using to do that, one-third more power. Two Excelsior Mills were ordered by the establishment making the trial.

The "Eriesson Caloric Engine" has been found an admirable power for driving these mills, and at an expense of 25 cents per day.

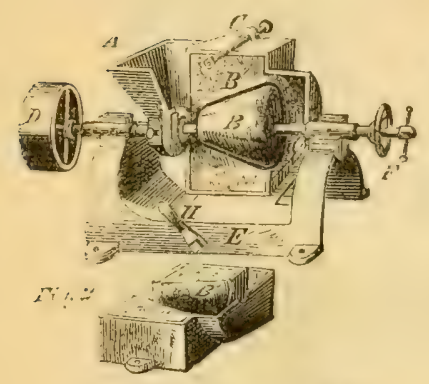

Fig. 196. Interior of Mill.

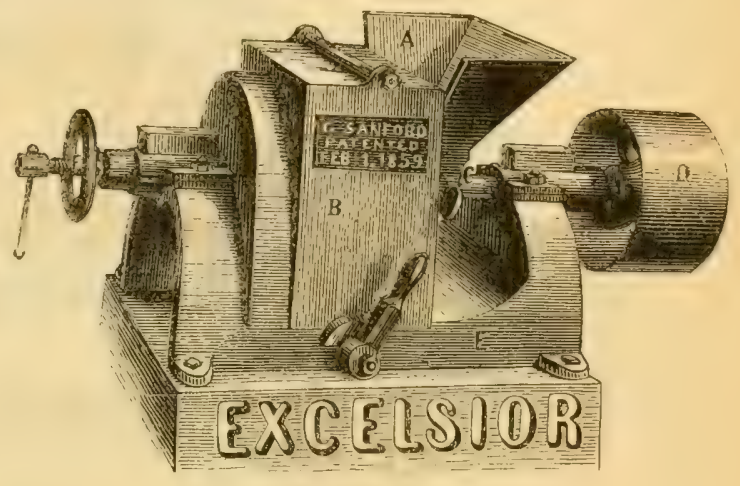

Fig. 197.

The above cuts, and the following description, are thought to be all that is necessary by way of explanation and illustration, to enable any one to form a correct idea of our Excelsior Mill.

$A$, is the hopper in which the material to be ground is placed. B, a Conical French Burr Stone, immovably secured upon the shaft-see the open mill above. $\mathrm{BB}$, the concave stones in two solid pieces, encased in iron, are placed over the cone, fitting it perfectly; these are the grinding or milling surfaces. F, the adjusting screw by which the grinding cone is forced toward the shell to make the mill grind finer or coarser, as mąy be desired. D, a pulley upon the end of the shaft to which the grinding cone B is attached, and by which it is operated. K. is a bolt into which the ground material is passed to separate the ground product into the various grades required-the middlings falling into the bin $T$, and the fine flour into the bin S, while the bran is passed out of the end of the bolt into a receptacle placed to receive it. The bolt is stationary, but brushes are oprerated on the insire, to drive the flour through, by a belt passed orer the pulley $\mathrm{O}$ on the main shaft, and over the pulley $\mathrm{P}$ on the bolt shaft.

We claim no superiority for this bolt oyer the ordinary one in use in this country; it is the English plan of bolting flour, and as it is ery compect is better adapted to farmers' and planters' use than the American bolt; the flour male by it is of the best quality.

Corn and Feed Mill ........................ \$100 00

Mill with Improved Flour Bolt, complete.......... 15000 


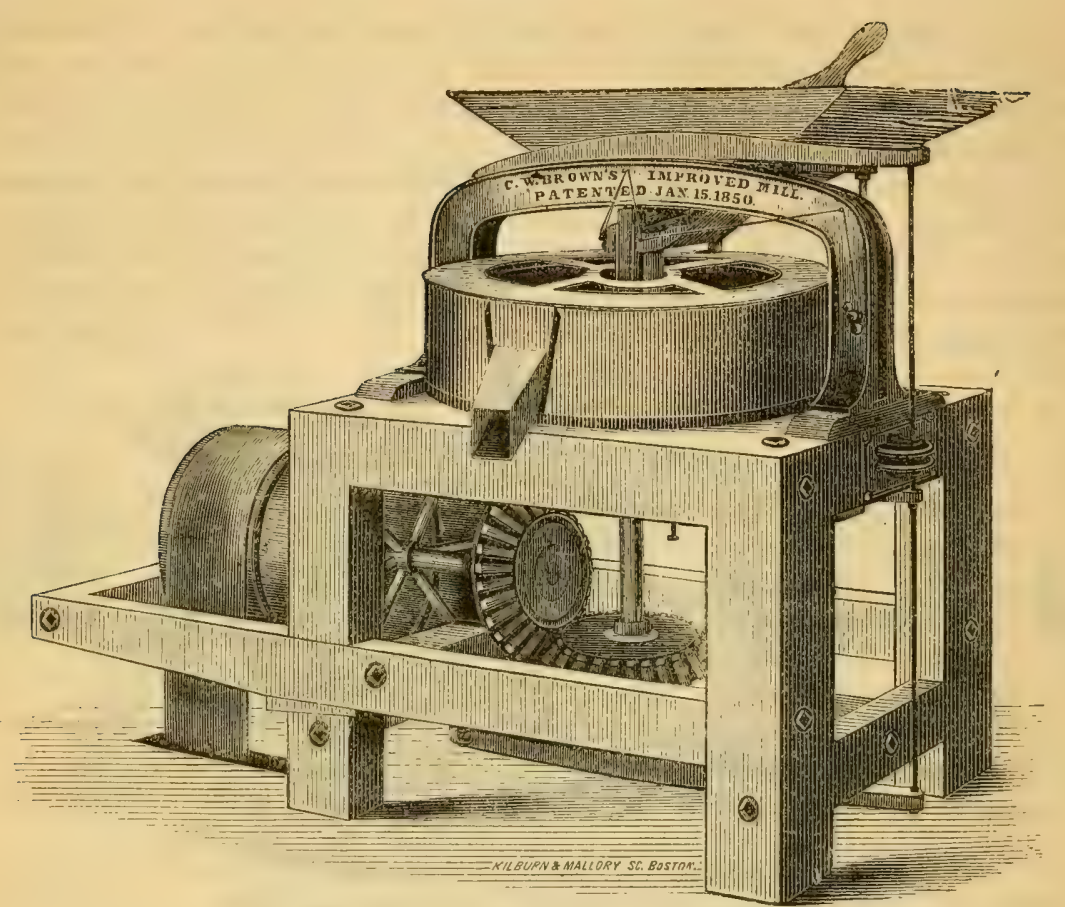

Fig, 198. Brown's Improved Patent Grist Mill.

These Mills are nade of seven sizes, the largest size being represented by Fig. 198, and the smallest by Fig. 199. They have been before the public a sufficient length of time to test their utility, and the proprietors can recommend them for grinding Corn, Grain Feed, Floming Wheat; they are also adapted to grinding Plaster, Coal, Salt, Coffee, Spice, \&c., equal to any other mills. They are made from one entire piece, from the choicest of French Burr Stones.

The superiority of these Mills consists in-

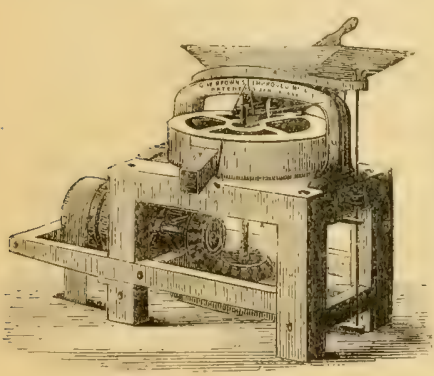

Fig. 199.

1st. Dispensing entirely with the bush used in all large mills, and in most of the small ones, thereby making a great saving of power and oil, avoiding a very great difficulty that has always existed in mills, bringing the care of these mills within the skill of an ordinary mechanic or farmer.

2d. The mode of attaching the Runner Stone to the Spindle, by means of an universal joint (similar to the Mariner's Compass), so that the Runner will keep level or parallel with the Bed Stone, if the Spindle is out of a perpendicular line with its face.

3d. The efficient mode of attaching the Runner Stone to the Spindle, the 
Spindle to the top and bottom Bridge-tree, in connection with the intermediate one upon which rests the adjustable tube, all connected by mears of the side rod, adjusted by and confined in their relative places by means of the hand or check wheels at the side of the Mill.

The capacity of these Mills can be increased to almost any extent, by an increase of speed and power, or can be worked with light power by diminishing the speed and quantity of work. The 30,33, or 36-inch Mills are considered the best for water or steam power. The 16,18, and 20-inch Mills are designed for horse or other light power, for domestic or plantation use. The 24-inch Mill, either for a light steam, water, or a heavy animal power.

It is found, from use, that the following is the best speed to run the Mills:

Dismeter of Stone.

42 inch, 200 to 300 revolutions per minute,

36 "6

$33 \quad 66$

3266

$30 \quad 6$

$24 \quad 66$

$20 \quad 66$

$18 \quad 66$

16 66

$$
250 \text { to } 350
$$$$
275 \text { to } 375
$$

$$
275 \text { to } 375
$$

$$
275 \text { to } 375
$$

$$
300 \text { to } 400
$$$$
360 \text { to } 450
$$

$$
300 \text { to } 400
$$

300 to 400

6
6
6
6
6
6
6
6
66 $66 \quad 66$ $66 \quad 66$ $66 \quad 66$ $66 \quad 66$ $66 \quad 66$ $66 \quad 66$

$66 \quad 66$

\begin{tabular}{llcc}
\multicolumn{3}{c}{ Steam or Water. } & Animal. \\
250 & best speed, & - \\
300 & 66 & 66 & 200 \\
325 & 66 & 66 & 200 \\
340 & 66 & 66 & 200 \\
350 & 66 & 66 & 200 \\
350 & 66 & 66 & 200 \\
350 & 66 & 66 & 175 \\
350 & 66 & 66 & 175 \\
350 & 66 & 66 & 175
\end{tabular}

Power required. Horse Power.

$\begin{array}{cccccc}\text { Bushels Fine. } & \text { Bushels Coarse. } & \text { Bushels Cracked. } & \text { Horse Power. } & \text { Inches. } & \text { Inches Fs. } \\ 18 & 25 & 150 & 15 & 24 & 10 \\ 15 & 22 & 150 & 10 & 24 & 8 \\ 12 & 18 & 150 & 8 & 20 & 8 \\ 11 & 17 & 150 & 7 & 20 & 8 \\ 10 & 16 & 150 & 6 & 20 & 8 \\ 6 & 12 & 100 & 4 & 16 & 6 \\ 5 & 10 & 40 & 3 & 14 & 5 \\ 4 & 8 & 40 & 3 & 12 & 5 \\ 3 & 7 & 40 & 2 & 12 & 5\end{array}$

\section{HARRISON'S PATENT GRIST MILT, FOR FARM AND PLANTATION USE}

This is a burr-stone mill, is made of various sizes, and the one represented by Fig. 200 is called the light geared mill, and may be moved at a speed of two hundred revolutions per ininute, with the power of one horse; and with a well adjusted feed, such as will not clog the mill, a fine flour of good quality will be produced. When set coarse it may be used for grinding feed and other materials. By the use of two or more horses' power, this mill may be made to run at much higher speed and with increased amount of results.

The 20 inch mill represented above, when run with one horse will turn out $2 \frac{1}{2}$ bushels of fine flour, and with two to five horses, will grind 5 to 8 bushcls of corn, and 4 to 6 bushels of wheat, per hour. 


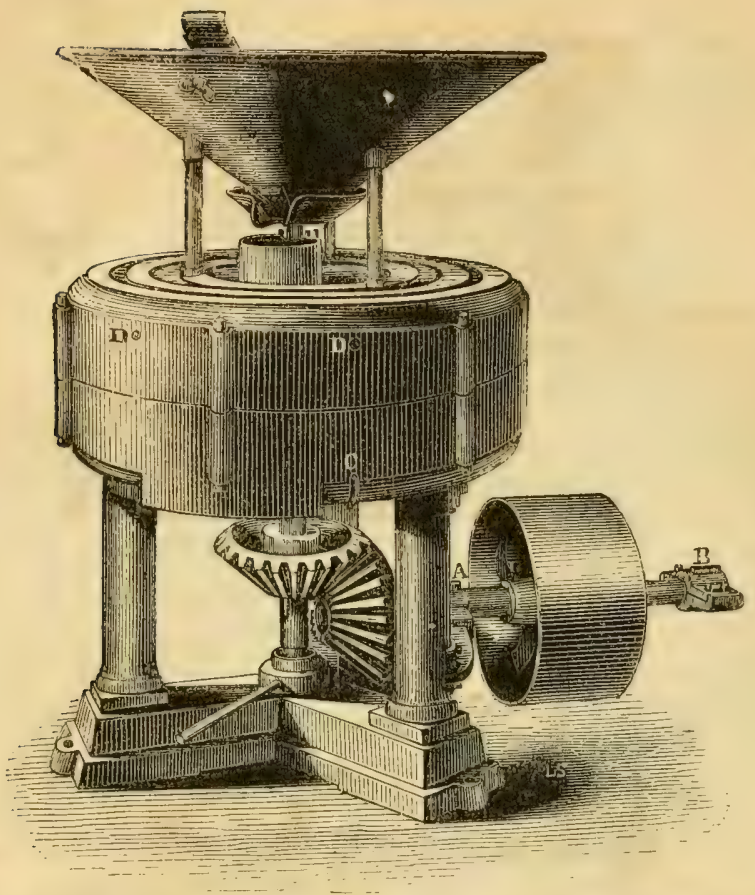

Fig. 200. Harrison's Patent Grist Mul for Farm and Plantation use.

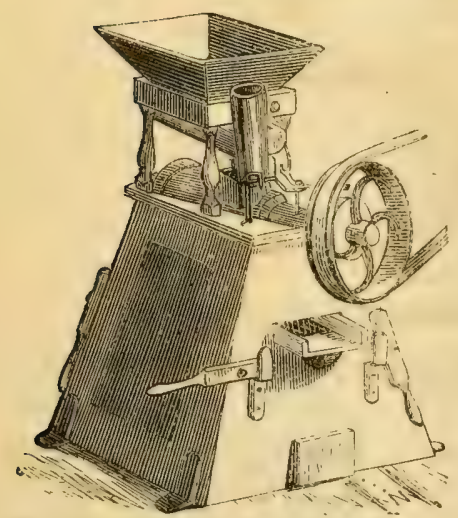

Fig 201. This is an iron mill, and may be run by one, two or four horses' power, and will grind coru, rye, oats, or wheat, from 6 to 12 bushels per hour, according to the fineness required, and is also arranged with steel cutters to grind corn with the cob.

The grinding parts of the mill may be replaced at small expense if ever worn out. Occupies a space of three feet square, and weighs 275 pounds.

Fig. 201. Premium Farm Grist Mill, an Improvement of the Coleman Mill. 


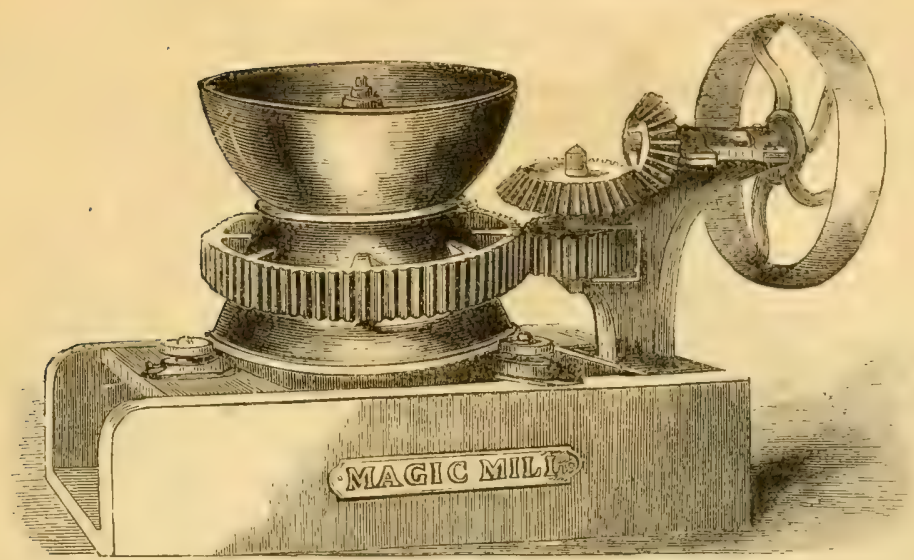

Fig. 202. Patent Magic Corn, Cob, and Meal Mill.

Fig. 202 represents this mill arranged for the direct application of power by a belt.

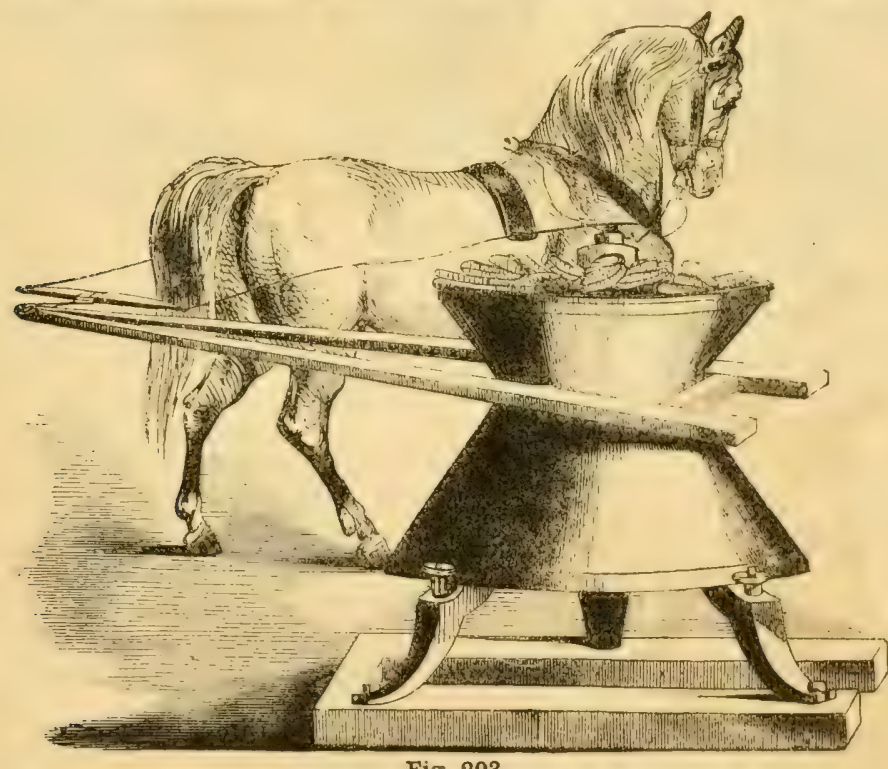

Fig. 203.

Fig. 203 represents the same mill arranged for the direct action of the horse by a sweep.

Either of the above mills, with ten to fifteen revolutions per minute, will grind from 15 to 25 bushels per hour. Extra grinding teeth may be had at three to five dollars per set, thus renewing the mill at small cost.

The peculiar excellence of this mill consists in the following, viz.:-

The cone is in a state of rest while the shell revolves. The arrangement of rollers prevents any alteration in figure of the meal space between the cone and the shell. 
The change of feed is regulated by a single nut.

While the number of feet of grinding surface, active per minute, is as great as in any other mill, the number of revolutions and chance of breakage or accident, is materially lessened.

The cob is ground finer than the corn, although ground together. .

From slow action at any one point, heating cannot occur.

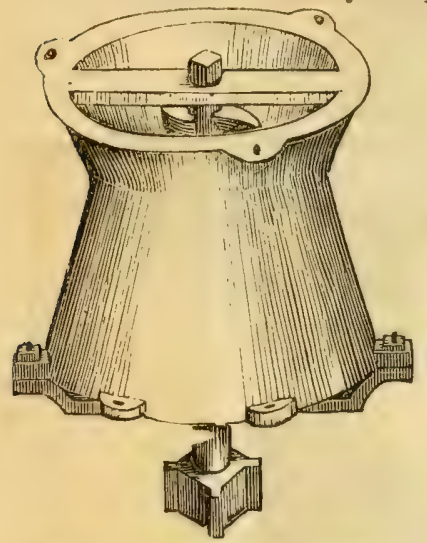

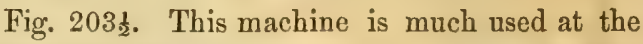
North and West in connection with the common grist-mill, for the purpose of cracking or crushing the corn and cob together, preparatory to grinding between mill-stones. It is made to run either way, (right or left), to conform to the power by which it is driven. It is strong, cheap and durable.

Fig. 203\%, Corn and Cob Crusher. 


\section{Rice and Coffee Hullers.}

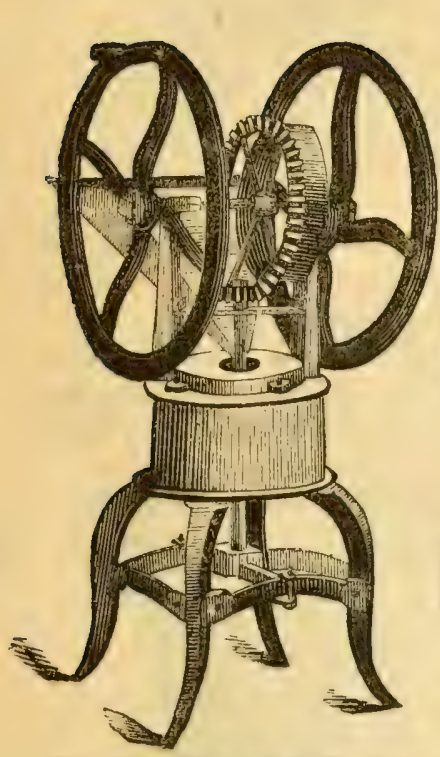

Fig. 204. Rice and Coffee Huller.

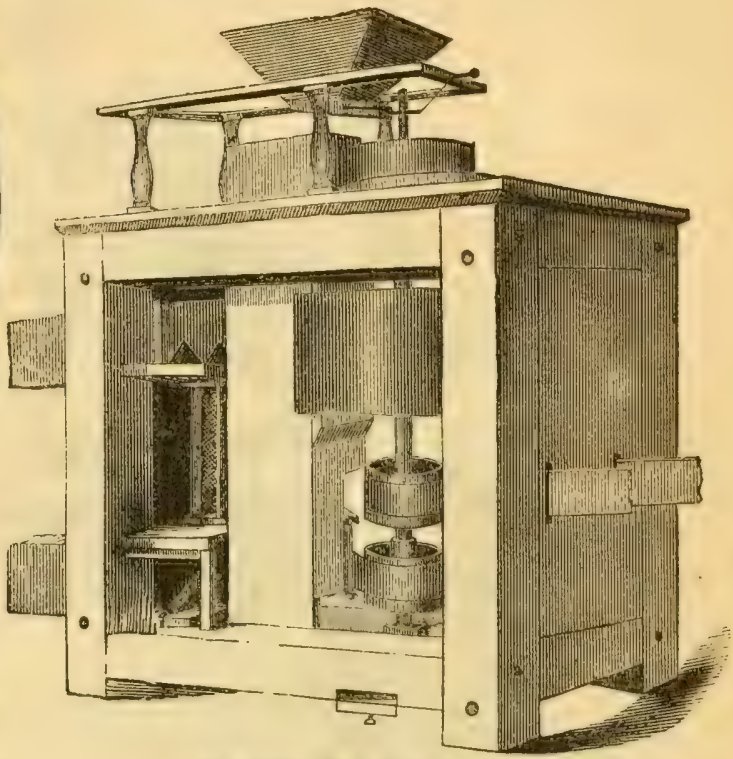

Fig. 205. Rice Huller and Polisher.

The attention of all those who are engaged in the culture of Rice and Coffee, or who are in the business of hulling and preparing rice for market, is invited to the above-mentioned machines.

We have three sizes of the Rice and Coffee Huller. No. 1 is intended to operate by hand, and will hull 30 to $50 \mathrm{lbs}$. of rice per hour, and a much larger quantity of coffec. Nos. 2 and 3 are for horse or steam power, and will hull 50 and $100 \mathrm{lbs}$. respectively per hour.

The Rice Huller and Polisher can be worked with four-horse power or steam. It hulls the rice perfectly, and afterward polishes and thoroughly cleanses it at the rate of 200 lbs. per hour.

The peculiar advantages of this machine orer the old-fashioned way of pounding the rice, are, that it will produce two or three pounds more rice in every bushel, and all the rice obtained is No. 1 or head rice, none being broken except what is broken by threshing.

Both this machine and the huller are constructed with stones and india rubber attachments, with all the recent improvements.

These machines have been in use for several years, have been fully tested, and wherever tried have given perfect satisfaction. 


\section{Cutler's Patent Quartz Crusher.}

This is a powerful and efficient pulverizer, and is well suited to the disintegration of hard substances, either in a wet or dry state; it may be seen in operation at our factory, where it is used for grinding burnt bones, and is capable of pulverizing 40 tons per day to a dust, requiring 5 to 10 horses' power. Price $\$ 350$.

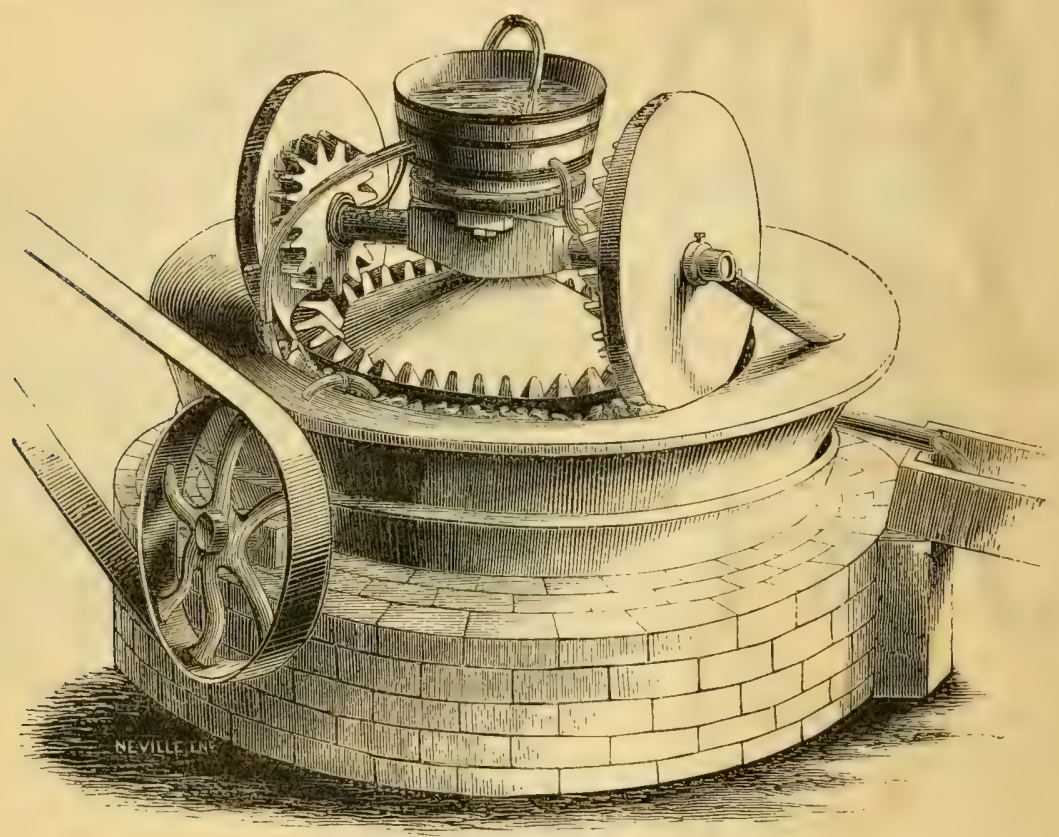

Fig. 205\%. Bullock's Quartz Crusher.

Fig. $205 \frac{1}{2}$ represents Bullock's Quartz-Crusher, the general principles of which can be understood from the engraving. They are made of many sizes, varying in price from $\$ 500$ to $\$ 6,000$, and capable of performing duty, varying from 2 to 40 tons per day of hard quartz-grinding, and from 10 to 100 tons per day of soft ore, requiring from 2 to 20 horse power.

The engraving fully represents the machine, which is intended to crush quartz by the continued rotation of large wheels passing around a circle, exercising not only their weight, but also, in addition to their crushing in line, a twisting motion which secures the finest results. The syphon arrangement for passing the water through the mass and washing out the more finely divided portion is fully illustrated in the cut. See description of Howell's Quartz Crusher. Fig. 430,pg 231. 


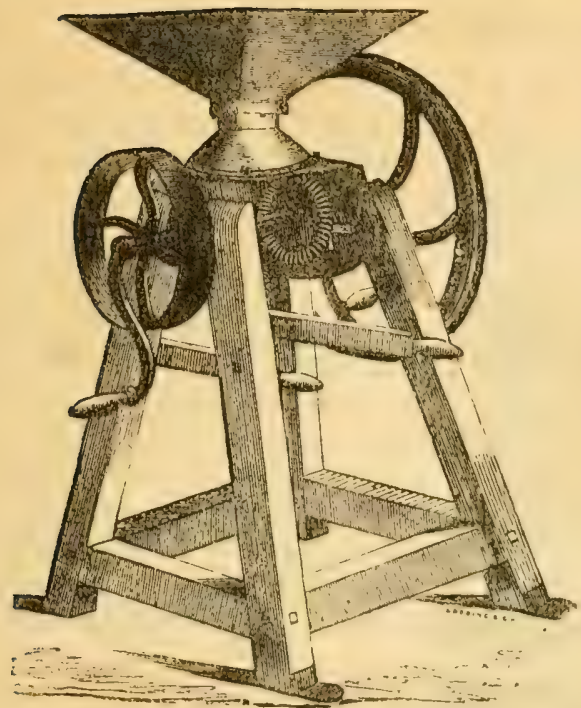

Fig. '20s'. Hand and Hos sa Grain Mull.

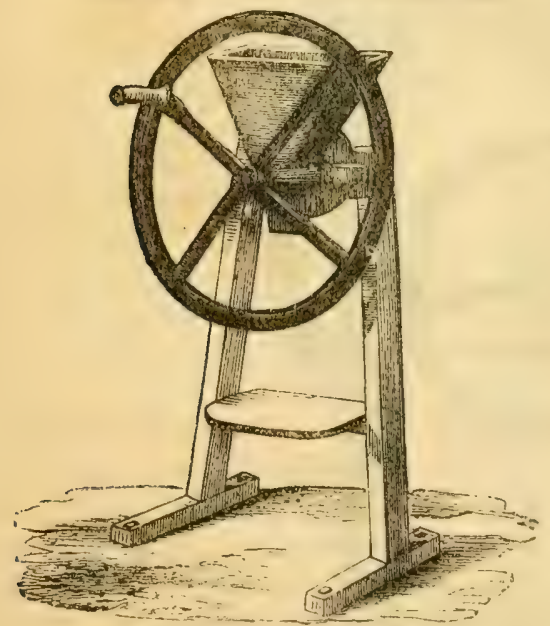

Fig. 207. Hand Grain Mill.

Fig. 208. This is properly a coffec or spicemill, but will grind grain of any kind. It is sold without a frame, and is so constructed as to be fastened to a post or board in any part of the housc; or it can be attached to a simple frame. It grinds from cight to sixteen quarts per hour, depending mainly on the speed at which it is run. It may be had with or without extra plates. There are several sizes of this Mill.

Fig. 206 represents a valuable iron mill, very efficient and durable. It runs either by hand or horse power. With the latter it can be made to grind four bushels of grain fine, per hour, and a greater quantity if coarse. It is simple, and not liable to get out of repair; and when the plates or grinding surfaces are worn out, they can be replaced at a small cost.

Extra plates can always be had with the machine.

Fig. 207. This Mill is used for grinding grain, coffee, spices, and drugs. It is usually operated by hand, though it ean be constructed to run by other power. It grinds from one to two bushels per hour. When the plates or grinding surfaces are worn out, they can be replaced as in the foregoing machine.

There are several sizes of this Mill.

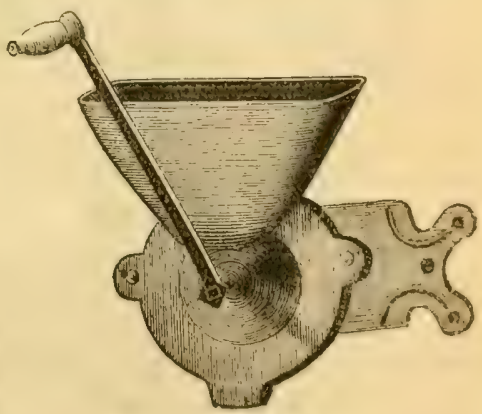

Fig, 208. Coffee Mill. 


\section{CORN SHELLERS.}

Thrs labor-saving machine is among the valuable improvements of the day, as $800,000,000$ of bushels of corn are annually shelled in the United States, and when performed by machinery saves, in many districts, the waste consequent upon feed ing corn on the cob.

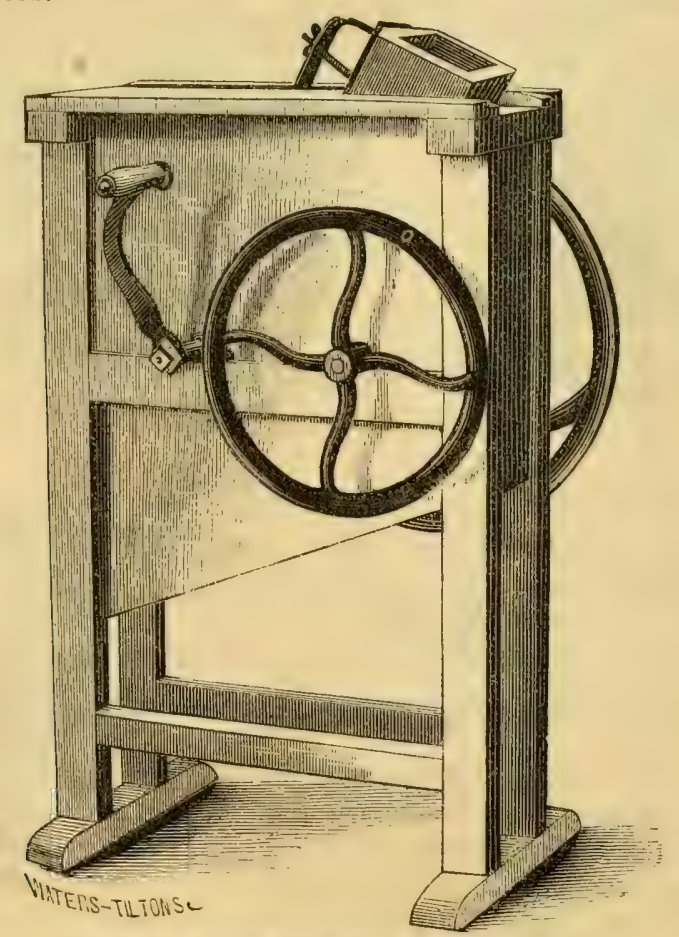

Fig. 209. Clinton or Common Southern Sheller,

These shellers, Fig. 209, are made with one and two balance-wheels, and are adapted to shelling the smaller varieties of corn. They can be furnished at low prices. 
Fig. 210 represents the Southern sheller, a size adapted for shelling the large corn of the Southern and Western states; the wood work and machinery are designed especially for large farms and plantation use. It is made single or double, to shell one or two ears at the same time.

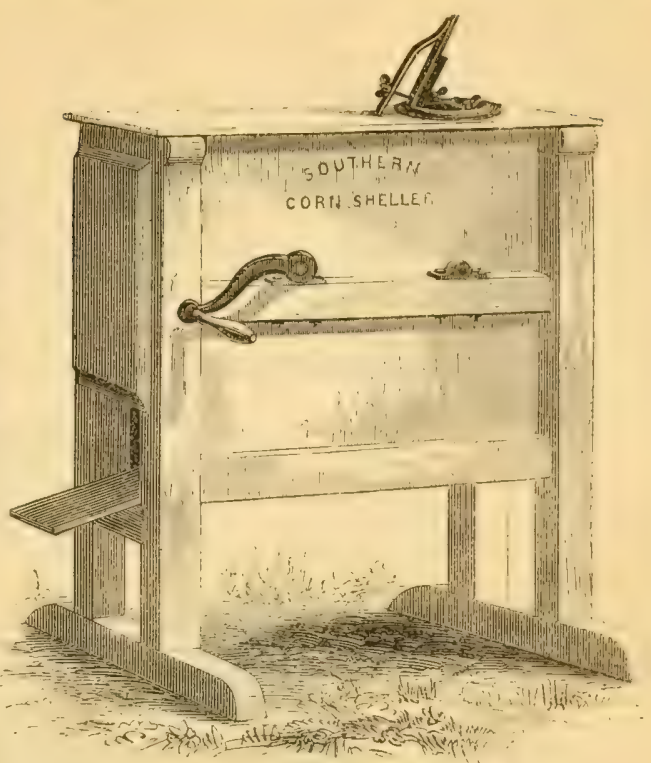

Fig. 210, Southern Sheller.

Fig. 211 represents the Southern Sheller, with a pulley and extra balance-wheel on the outside, which is also made single and double. It is operated by hand or horse power.

The Western Sheller is of the same form and general construction as those above represented, but is of still larger size and stronger make, to fit it for shelling the largest kinds of Western and Southern corn. It is made single or double, for hand or horse power.

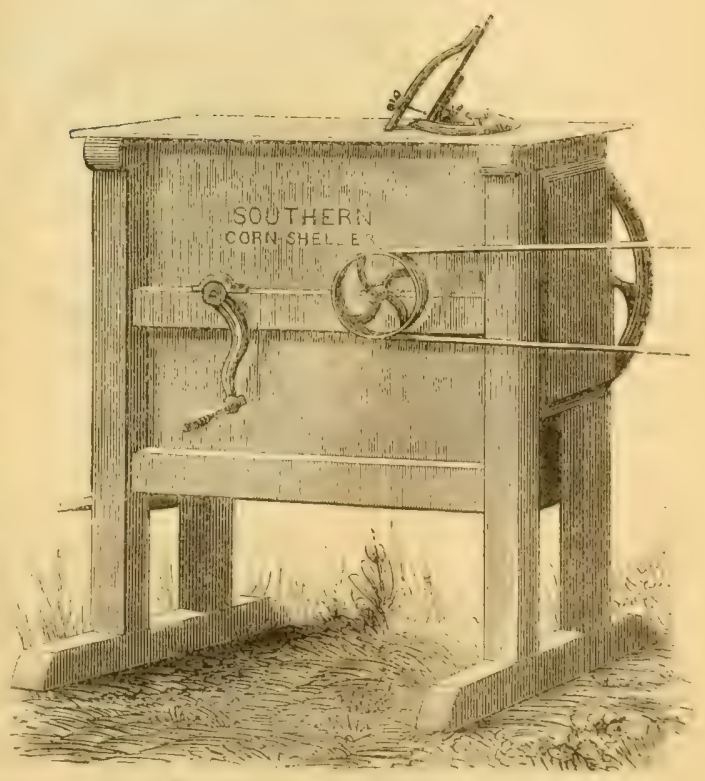

Fig. 211. Southern Sheller. 
Fig. 212 represents both the Yankee and Boston shellers, which are different only in size, the former being the smallest, and adapted to the smaller corn grown in the New England States, while the latter is a size larger, and adapted to the larger corn of the Northern States. It is made single or double, to shell one or two ears at the same time.

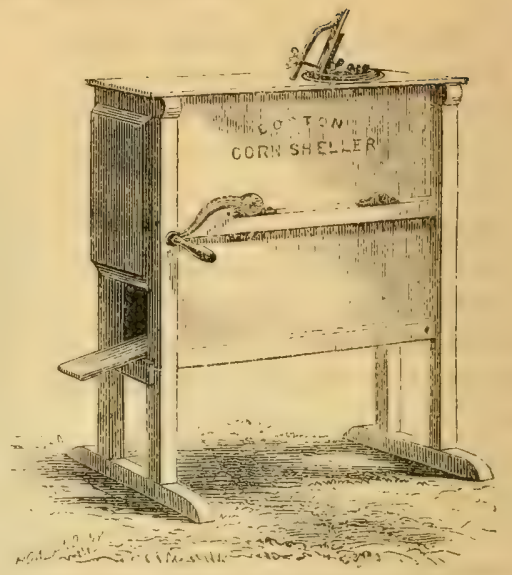

Fig. 212. Yarkee and Boston Sheller.

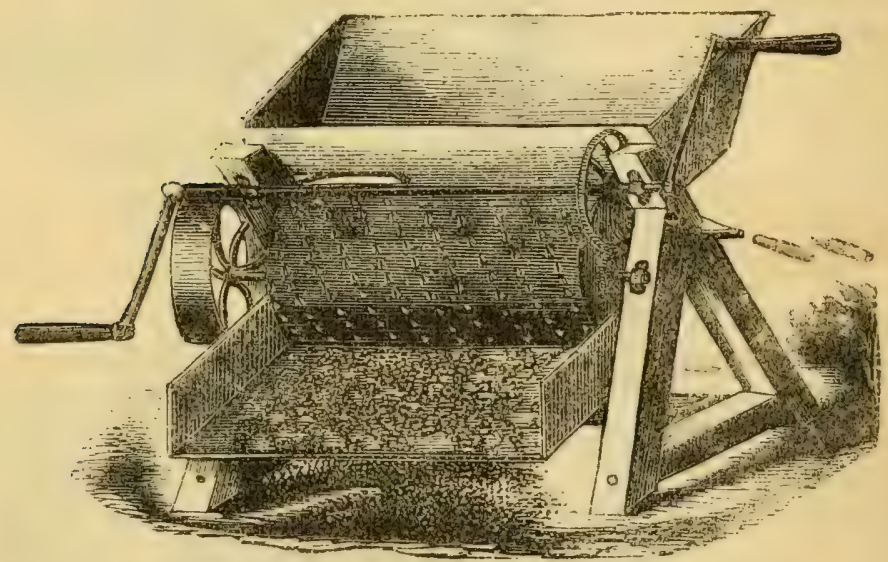

Fig. 212\%. Virginia Corn Sheller.

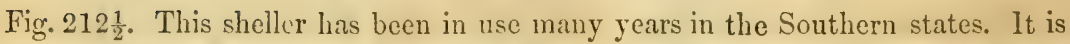
a strong machine, and may be operated by two men or by horse power. Shells well and rapidly. Price, \$25.

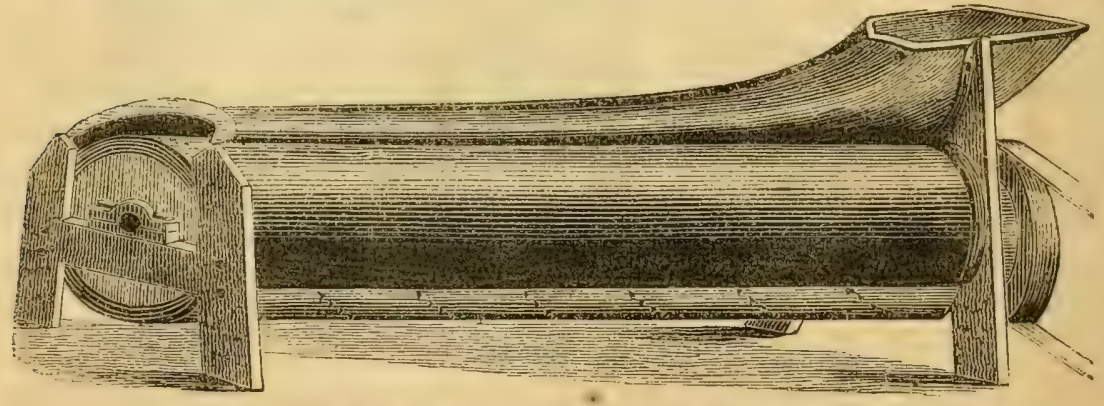

Fig. 213. Smith's Corn sheller and Separatsr. 
Fig. 213. This machine consists of a horizontal toothed eylinder, and is made of several sizes. The ears of corn, in the operation, are confined to a part of the upper and rising side of this cylinder, by means of a concave extending the whole length of the machine, and being shovelled or let into the machine at one end, they are driven through, and the cobs discharged at the opposite end, while the grain falls below, being admitted on either side of the cylinder. The operation is governed by elevating or depressing the discharge end, which causes the machine to discharge the cobs fast or slow, and of course operates more or less upon them. This inachine is capable of shelling two hundred bushels of ears per hour.

We have several other hand and power corn shellers not enumerated above.

\section{Corn Huskers.}

This implement is much needed, but those already before the public require material amendment before they will deserve general adoption.

We have several under consideration, and hope to be able to supply a sunerior article to any now on the market.

\section{Root Cutters.}

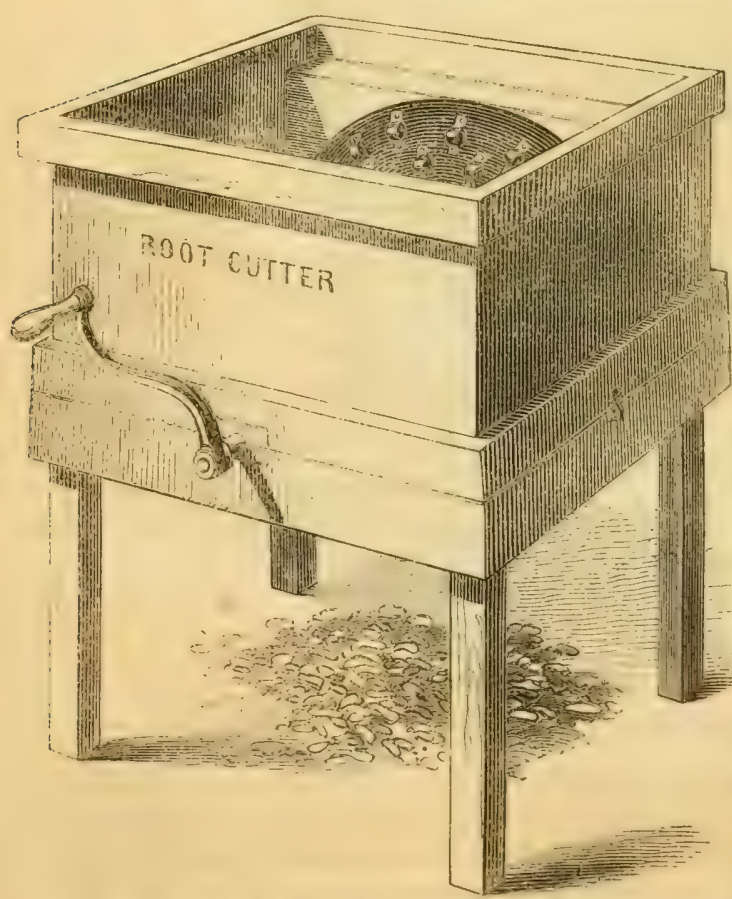

Fig. 214. This Cutter is a recent invention. It euts vegetables very rapidly, and in slicesthin and fine enough for sheep, lambs, or calves. It is so very easily operated, that a boy can turn the crank rapidly. The inside arrangement is such as to prevent all liability of clogging the cutter while working it, and the knives are easily repaired. The vege- ' tables, after being passed through the Cutter, may be mixed with straw, coarse hay, or other cheap forage which one would like to dispose of economically, and the mixture, after lying a little time, so that the forage may become impregnated with the juices and scent of the sliced roots, will be greedily and

Fig. 214. Willard's Patent Root Cutter. wholly consumed by the stock. Pumplins are easily cut with this machine, so as to be conveniently and quickly cooked for swine. 


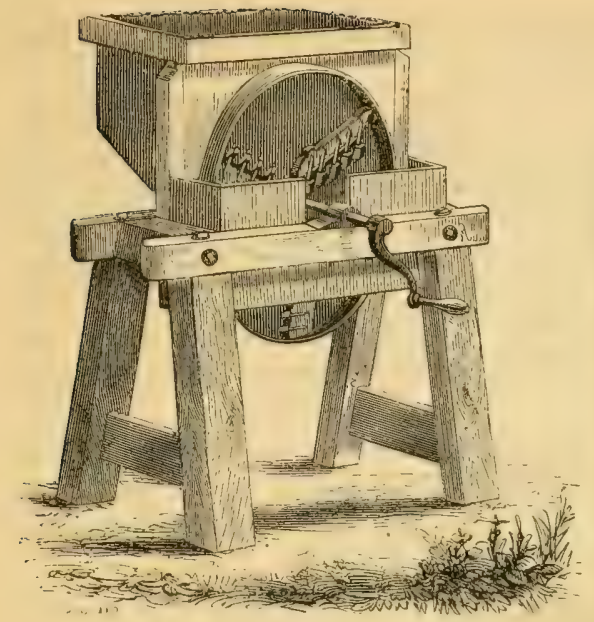

Fig. 215. The cutting-wheel is made of cast-iron, faced on one side, through which are inserted three knives similar to plane-irons. These cut the vegetables into thin slices with great rapidity, and then cross-knives operate to cut and break them into irregular pieces, of convenient form and size for cattle or sheep to eat, without danger of choking. This machine is put together in the most permanent and manner.

Fig. 215. Vegetable Cutter.

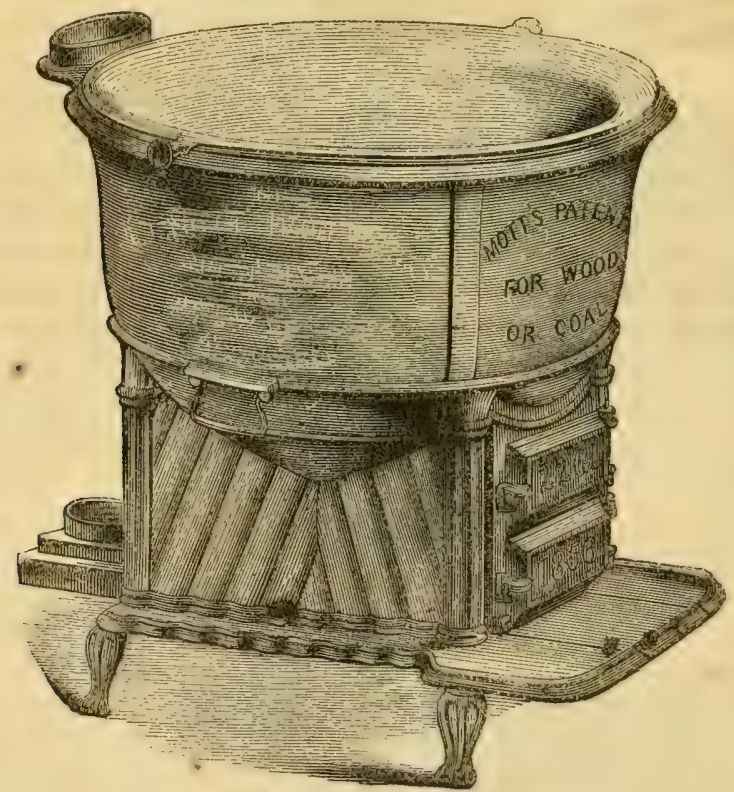

Fig. 216. Mott's Agricultural Furnaces.

These are well adapted for cooking vegetables and other food for stock, and as a portable furnace if required. They are made double: the inner hemisphere being the boiling-kettle, and the onter shell attached to the fire-room below, supplying a concentric space as a fire-passage, permitting the whole surface of the inner kettle to be enveloped by flame. There are several sizes, varying from 10 to 120 gallons each, and are sufficiently light and portable to be easily moved; they may be 
used for burning either wood or coal; when used for coal, the fire-chamber is lined with brick.

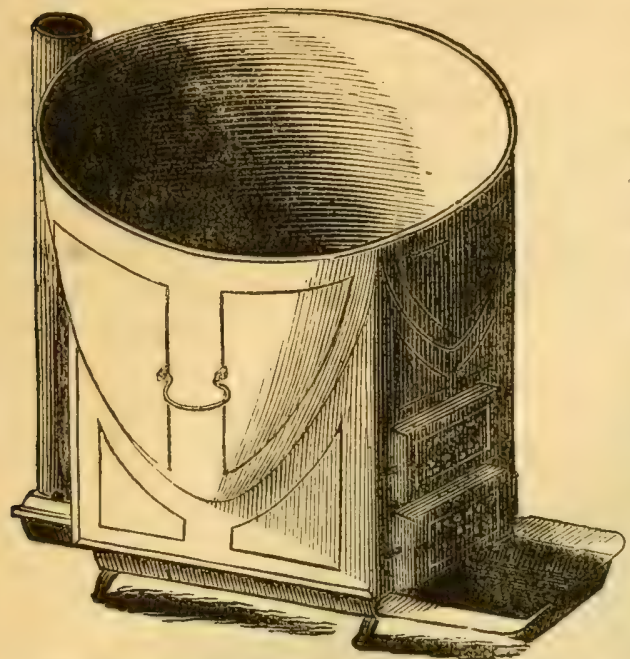

Fig. 217. MacGregor's Patent Portable Caldron Furnace, or Agricultural Boiler.

Fig. 217. These furnaces are marle with and without covers, and are arranged for wood or fitted with grates and fire-brick lining for coal. With the lining they are ever durable by replacing the bricks occasionally, at an expense of only $\$ 1.25$, and can be used with wood with equal facility as if not lined.

They heat equally as quick at the front as at the back part, the fire and draft being entirely under the control of the operator by simply moving one damper at the back part; consequently they are well adapted for manufacturing and mechanical purposes, and for farmers' use, where an equal and governable heat is required. For the boiling of oil, the rendering of tallow, lard, and such like articles, the boiling of food for stock, and the scalding of hogs, they are unequalled by any furnace or boiler in the market. They are of different sizes, holding from a half-barrel to foul barrels.

Small Steaming Apparatus of various kinds supplied for steaming or cooking food. See description of Prindle's Agricultural and General Steamer, fi.7. 431, page 235. 


\section{CIDER MILLS.}

The following is a material improvement on the old style Cider Mill, where the press impinged on so large a surface as to render the exudation of the juice but partial ; indeed the very time and labor bestowed in the preparation of the pumice was greater than is now required for the entire manufacture of cider.

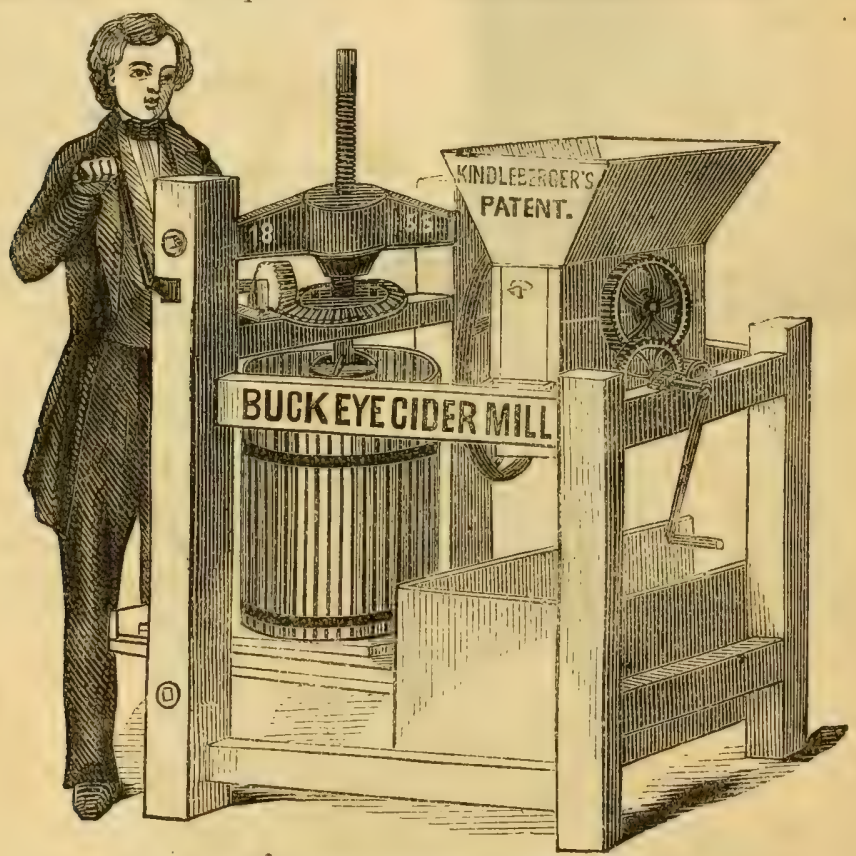

Fig. 218. Kindleberger's Patent Buckeye Cider Mill.

Fig. 218. A very effective Cider Mill, compact, light, and portable, easily operated, and of low price.

They may be worked by steam, water, horse, or hand power. The apples are first ground in the mill attached to the machine, which is capable of being varied so as to prepare the pumice nore or less fincly; it is then shovelled from the box under the mill into the press-frame, where the juice is readily expressed by the running down of a heavy screw, armed with a pinion, working on a larger cogwheel, so as to multiply the power, as in Fig. 218. When apples are pressed immecliately after being ground, the cider is of much better quality than when pressed from pumice which has lain exposed to the atmosphere until the surfaces have turned brown. 
These portable mills enable small quantities to be worked at a time and early in the season; when dropped apples are unfit for making cider, they may be expressed for vinegar without its having the foul flavor consequent upon the long keeping of unripe apples.

In the making of currant, rhubarb, blackberry, raspberry, cherry, and otlier fruit wines, it is necessary to grind the fruit before the juice can be expressed from it, and this must be done immediately after the grinding, all of which can be realily brought about by these mills. The same facts apply in the making of wine from grapes. The press portion of these machiries may also be used for the pressing of lard, tallow, etc. Te have a variety of sizes of smaller presses varying in price from $\$ 1$, to $\$ 20$.

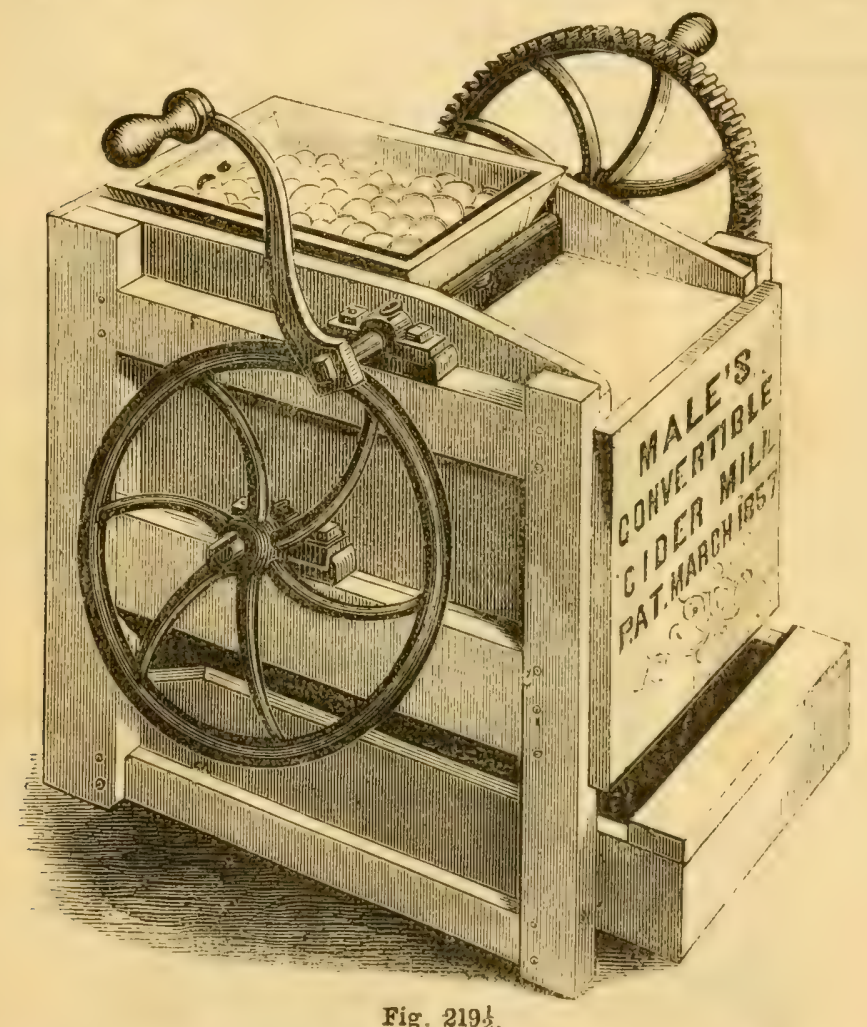

This machine presents more surface and is better arranged for a linge amount of work than the grinding portion of any other cirler mill, while its applicability to pulping roots, now so desirable for mixing with chaffel hay and other fodlder, renders it peculiarly valuable. By a slight change it becomes an effective corn sheller, equal to any other hand sheller in market; it is accompanied by a press simin to that in Fig. 218. 


\section{CHURNS.}

A theory has been long advocated that the ultimate spheroids of milk or cream were hollow and contained butter, and this of late has given rise to a variety of churning implements under the name of "Milk-Grinders" the inventors claiming that, by their peculiar mode of manipulation, these molecules or spheroids were more perfectly broken, and therefore that they could liberate the butter in five minutes, or even less time. They, however, churn with the milk or cream at very high temperatures, producing less butter, without grain, being homogeneous in its character, and not possessing good keeping properties. By close microscopic investigation we have failed to find these spheroids, and therefore do not believe in their existence.

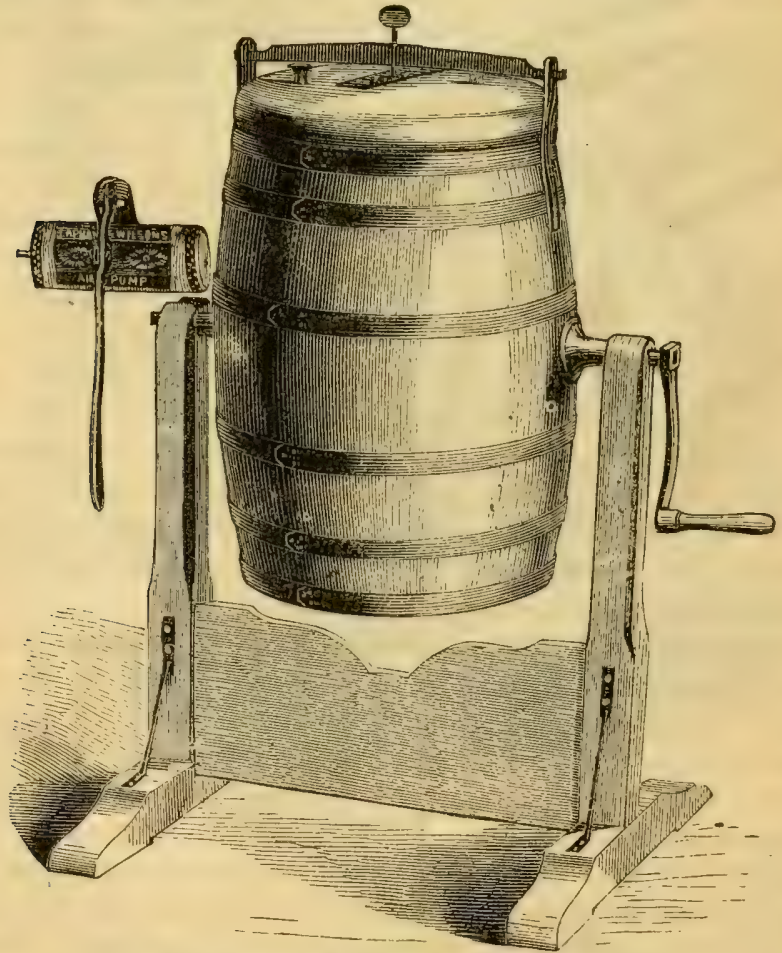

Fig. 220. Lapham \& Wilson's Air Pressure Churn.

The requirements for a good churn are the ability to produce butter from sweet milk or cream, at a low temperature, possessing perfect grain and good keeping properties; ten minutes is as short a time for the production of such, as has been 
attained. A good churn should produce all the butter the milk or cream is capable of furnishing, and nearly at the same instant of time, so that the portion first formed should not be overchurned before the completion of the process.

This, as will be seen by the fiig. 220 is a barrel mounted on two trumnions, one of which is armed with a handle, by which the barrel may be revolved in the direction of its length. The cover is fastened on by a thumb-screw bearing upon a bar and making a tight joint at the chime; near the quarter is a small faucet, which is connected by an India-rubber tube, with a movable air-pump; after placing the milk or cream within the barrel the air-pump is attached, the small faucet opened and air is foreed into the vessel until the necessary pressure is attained; the faucet is thus closed and the air-pump removed, the barrel is then revolved by the handle from five to ten minutes, when the butter will be found to have formed; it may then be removed from the churn and worked in the usual way. The result is of excellent quality, good grain, and good keeping properties, and eight to nine per cent. greater in quantity than when made in those churns requiring the contents to be warmer than sixty-two degrees.

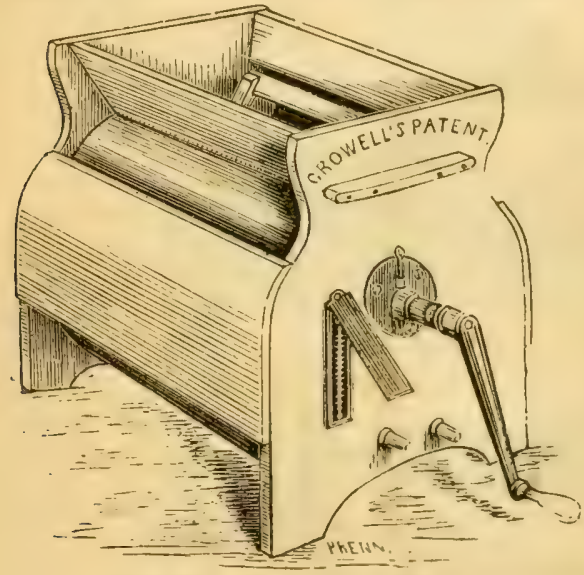

Fig. 221. Thermometer Churn.

Fig. 221. This Churn is so constructed that the cream or milk is readily brought to the desired temperature without mixing water or other substances, and the temperature certainly and definitely determined, which proves invaluable in the art of making butter.

One improvement consists in the construction of a double bottom, made in the form of a semicircle, of two sheets of zinc, or other metal, placed one above the other, the cream to rest on the uppermost; between the two sheets is a space or chamber, into which may be introduced cold or warm water, as may be required to increase or diminish the temperature of the cream or milk.

Another improvement is a Thermometer permanently and securely placed in one end of the Churn, marked at 62 degrees, and which comes in contact with the milk or cream, to indicate its temperature, so that the operator may know and determine with certainty when it is brought to the proper state. If the cream is too warm, the mercury in the thermometer will rise above the mark of 62 degrees and cold water should be applied in the chanber described; if too cold, the mercury will fall below the mark, when warm water must be used instead of cold. The cream or milk should be stirred by turning the crank while the water is being introduced, to give the contents an equal temperature throughout. When the thermometer indicates that the cream or milk is of the proper temperature, the water may be drawn out through the tube placed for the purpose, when the churning should be performed by giving the crank about forty revolutions to the minute. 
This Churn is simple in its construction-is light, portable, durable, very easily operated, and readily cleansed. The crank and dash are easily taken out to facilitate cleansing.

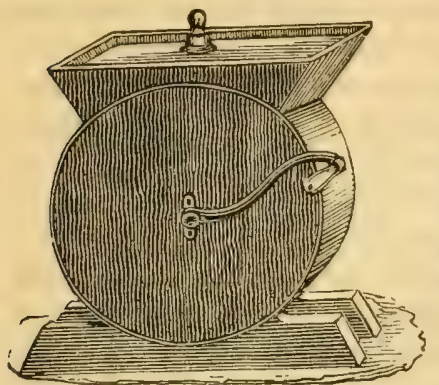

Fig. 222. This is one of the simplest rotary Churns, and combines many of the good qualities of other cylindrical Churns; the dasher can be taken out in a moment when it requires cleaning, which should be done at the end of each churning. It is light and portable, and may be operated by a child. There are five sizes varying from two and threequarters to fifteen gallons.

Fig. zaz. Cylinder Churn.

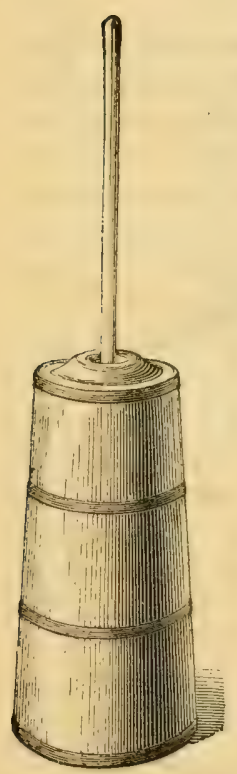

Fig. 223. Dash Churn.

Fig. 223 represents the Common Dash Churn, of which we have a great variety of sizes, made of cedar or pine, and with iron or brass hoops as may be preferred.

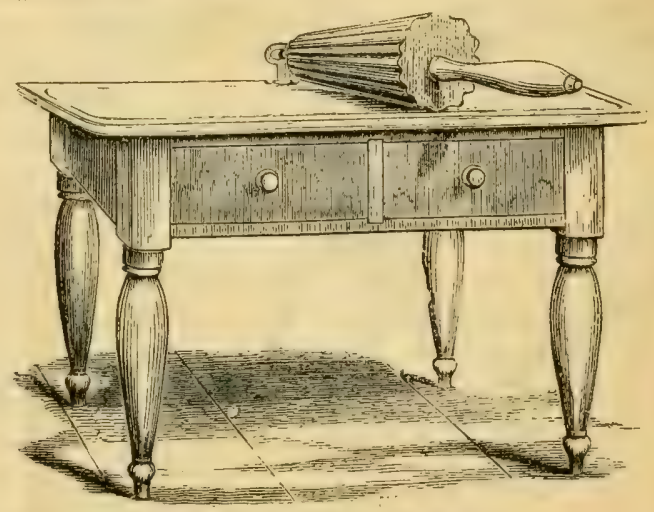

Fig. 224. Cylindrical Butter Worker.

Fig. 224 represents the Cylindrical Butter Worker, a machine which should be more generally used in butter-making. Its advantages are, that the butter can be kept cool in working, and the necessity of using the hands avoided; the butter-milk may be more thoroughly worked from the butter, and the salt worked in more evenly. Marble tops when ordered.

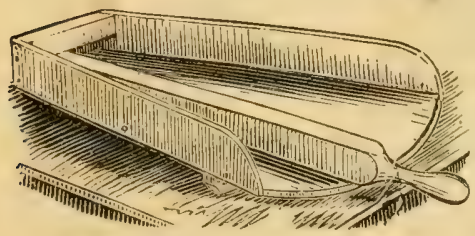

Fig, 2\%5. Lever ॐutter Worker.
Fig. 225 represents a very simple machine for working butter. It is easily cleansed, and takes but little room. It may be made with square or round fluted lever, as may be required.

There are three sizes, capable of working from 5 to $20 \mathrm{lbs}$. to each operation. 

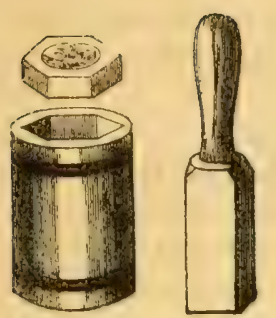

Lig. 226. Butter Moulds.

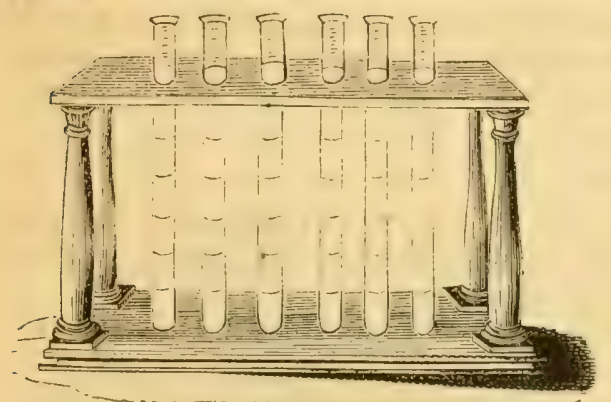

Fig. 227. Lactometer.

difference determined by the marks.

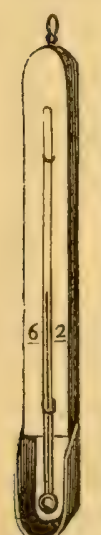

Fig. 228. Thermometer for testing the temperature of milk.

As milk should never be churned at a temperature above $62^{\circ}$ Fahrenheit, the thermometer becomes a necessary appendage to the dairy.

Fig. 229. This is a light and portable cheese press, and a great convenience to the dairy-woman. The cheese is placed in the machine, and its own weight presses it-the pressure at first being quite moderate, as it should be, but gradually increasing as Fig. 228, the inside frame moves down, until the cheese is perfectly pressed. Light or heavy pressure may be applied to cheese of the same weight, by simply raising or lowering the inside frame by sliding blocks between the two followers-indeed, the Press may be regulated to any degree of pressure that may be desired. The cheese is not removed until the pressing is completed.
Fig. 227. The only proper instrument for testing the qualities of milk drawn from different cows. It consists of glass tubes placed perpendicularly in a wood frame: these tubes are divided and subdivided by marks into equal spaces; they are filled to equal height, each with the milk of a particular cow, when, after remaining a proper time, the quantity of cream in each is readily seen through the glass, and the exact

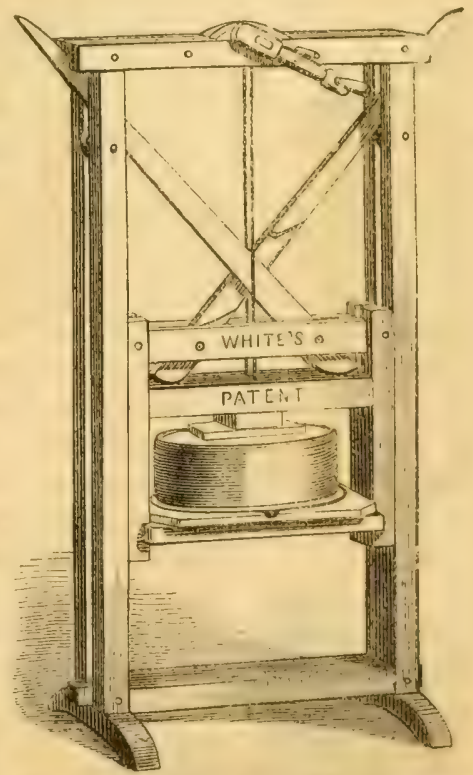

Fig. 229. White's Patent Self-Acting Choese Press. 


\section{IRON MEAT CUTTERS.}

These are of various patterns, and differ materially in the quality of the cutting some tear the meat more than others, and some cut without tearing-some present a greater amount of knife-surface than others, and therefore may remain longest in use without requiring sharpening-some are readily cleaned by all the parts being separable, even the knives being movable for sharpening, washing, etc.some are arranged with sausage-stuffers attached, and others are without them. The larger sizes are for butchers' use for the cutting of sausage-meat, and are arranged for hand or other power-the smallest sizes for family use, for making sausage-meat, meat-balls, fish-balls, hashes, etc.

Directions for using.-Fasten the machine firmly on a level form or table, by screws through the feet-cut the meat into pieces, the size of an egg, free from bone, and feed it in the hopper, at the same time turning the crank as fast as the machine will clear itself of meat. If the meat delivers too coarsely, set the slide, so as to partly cover the exit opening, and feed more slowly-if the meat be frozen, dip it in warm water, before cutting. The larger sizes when driven by power, are capable of cutting $1,000 \mathrm{lbs}$. per hour.

The sausage stuffers are cylinders of tin, armed with a piston, worked by a rack and pinion, some of the smaller sizes of meat cutters have stuffers of a different construction.

Figs. 230 and 231 represent Perry's Patent Revolving Knife, meat cutters, geared; of which there are four sizes,-Nos. 20, 30, 40 and 50 , the latter is large for steam power-the object in gearing these cutters has been; not simply to make them work easier, but to make them cut the meat better. It will be noticed that

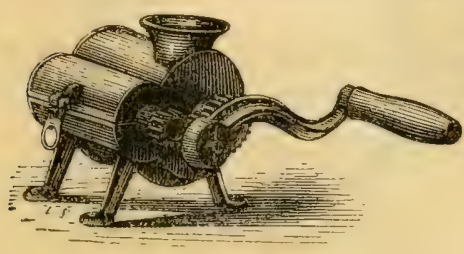

Fig. 230.

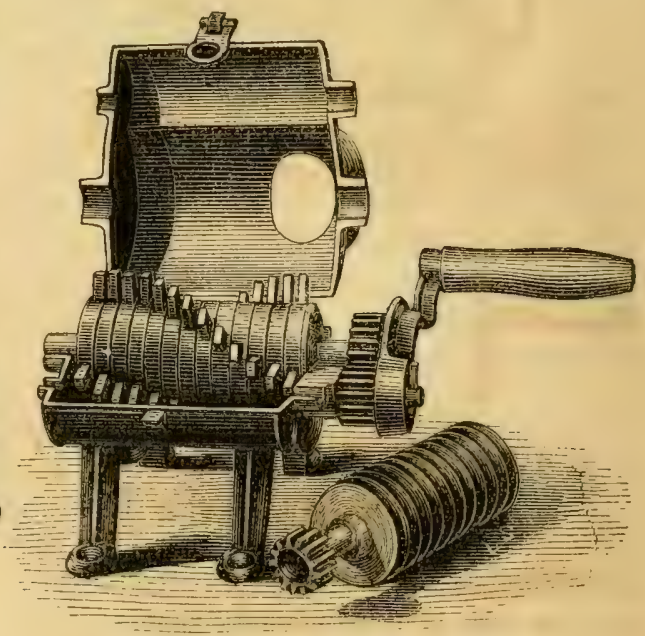

Fig. 231. Perry's Patent Meat Cutters. 
they are so geared, that the cutters and driving studs run in opposite directions, causing a continual drawing stroke by the knife, as the meat is pressed on it by the driver. In fact these Geared Cutters are the only ones in market that completely cut the meat without mashing or grinding it in some degree.

We have the same kind of cutters not geared, at a lower price-of these, there are two sizes, Nos, 2 and 3.

Nos. 00 and 000 are simple and cheaper machines, with straight knives.

\section{The Older Patterns of Meat Cutters.}

Of these, we have five sizes, as per price list.

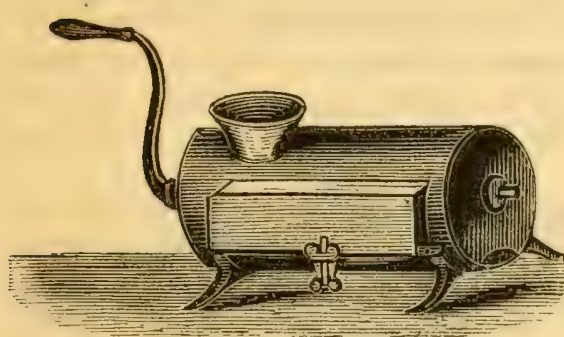

Fig. 232 represents the Iron Meat Cutter Shut.

Fig. 232. Iron Meat Cutter. Shut.

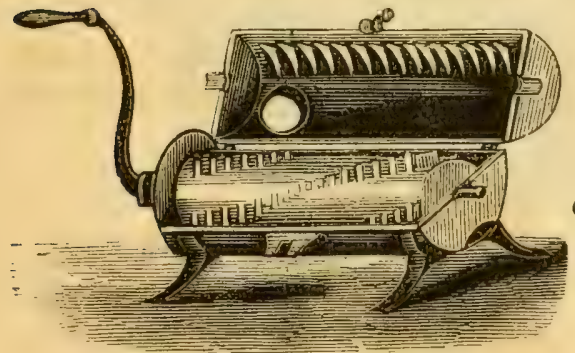

Fig. 233 represents the Iron Meat Cutter Open.

Fig. 23?. Iron Meat Cutter, Open.

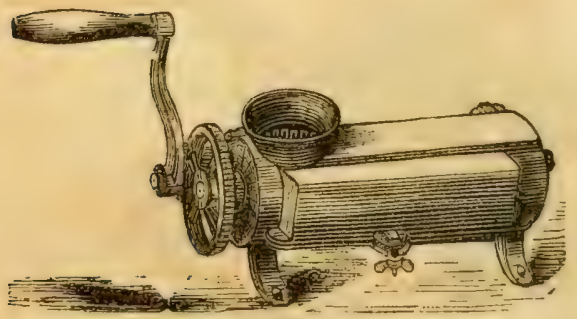

Fig. 234 represents No. 4 Meat Cutter,

Fig. 234. No. 4 Meat Cutter, Geared. Geared. 


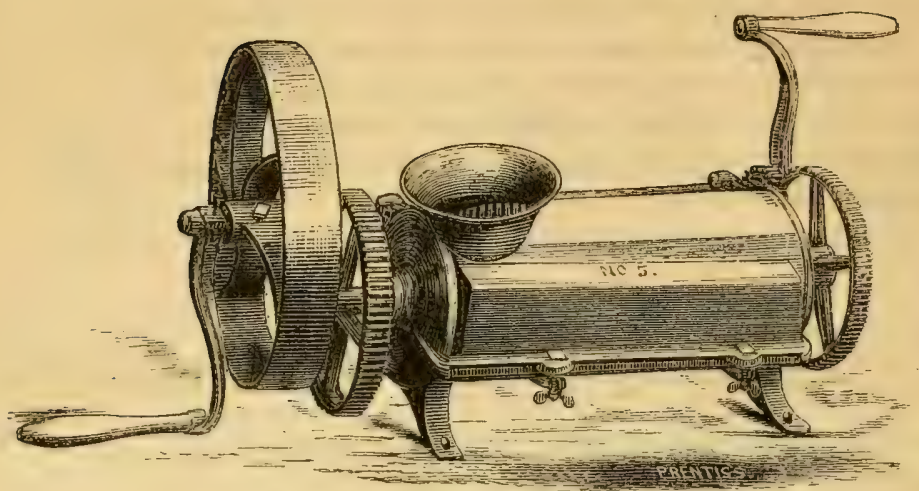

Fig. 235. Double Geared Meat Cutter.

Fig. 235 represents a large size Meat Cutter, for horse or steam power.

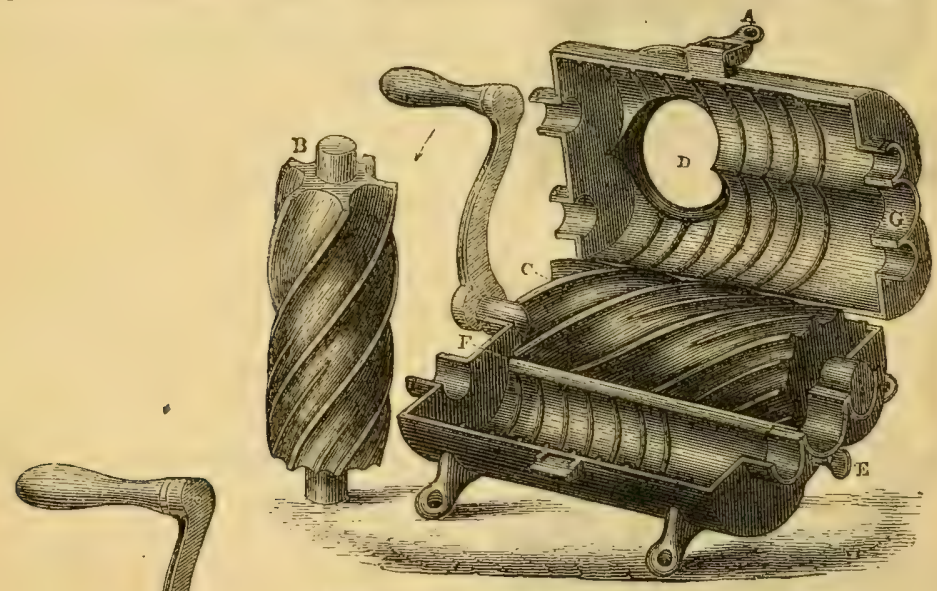

Fig. 23€. Hale's Meat Cutter and Stuffer, open.

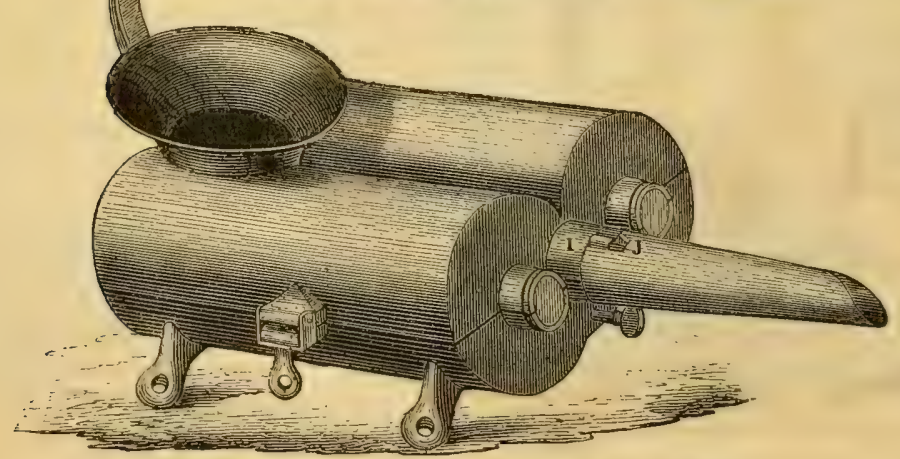

Fig. 237. Hale's Meat Cutier and Stuffer, closed. 
Figs. 236 and 237 represent Hale's new meat eutter composed of edged rollers, acting as continuous shears on a central knife placed between them: the machine is continuously self-sharpening, and has the sausage-stuffer attached when required, as in Fig. 237. The cutting and stuffing are automatic to the action of the machine, and therefore both are performed at onee; the easy removal of the shearcylinders and knife from the case facilitates the cleansing of it.

\section{SAUSAGE FILLERS OR STUFFERS.}

Of these we have a variety, as represented by the following illustrations:

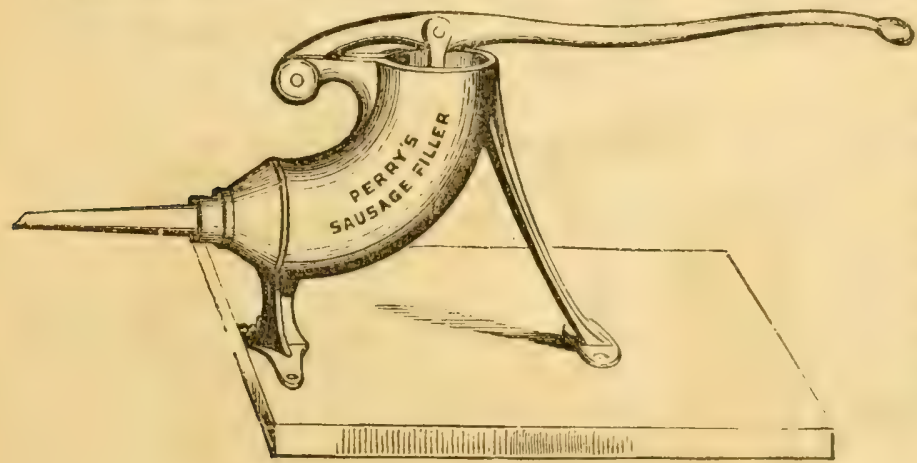

Fig. 238. This Filler is simple and effective, substituting lever-power for the ordinary rack and pinion.

Fig. 238. Patent Sausage Filler.

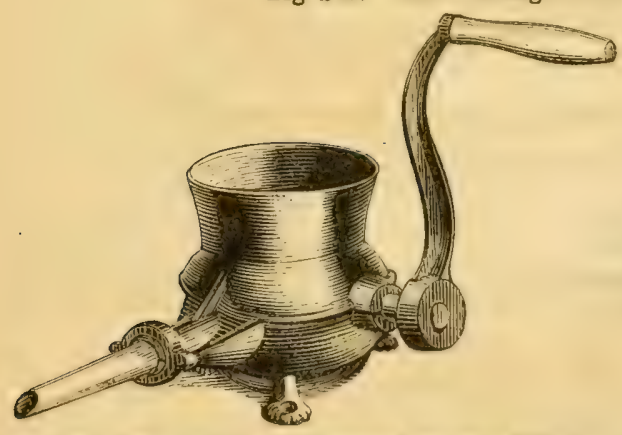

Fig. 239. Shepard's Improved Sausage Filler.

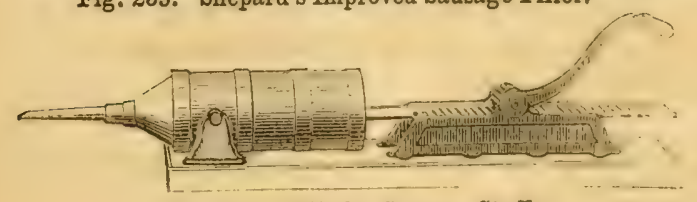

Fig. 240. Cylinder Sausage Stuffer.
Fig. 239 is the newest Filler, and is continuous in its action; its capacity may be increased by the addition of a tin hopper holding a greater quantity. It is capable of filling 300 pounds of sausages per hour.

Fig. 240. Of these we have 5 sizes-four sizes with one or two tubes, which screw on to the nozzle, differing in size, to fit large or small skins. 


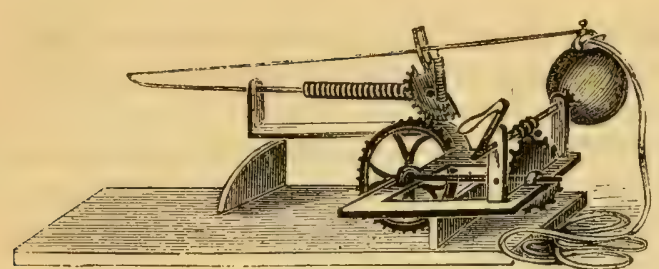

Fig. 241. Apple Parer.

Fig. 241 represents the automatic Apple Parer, one of the first and still the best in use. We have a variety of kinds, some of which pare, core, and slice the fruit at one time. The fruit is simply placed on the fork, and, by turning the crank, the knife will adjust itself to the surface, removing the entire skin.

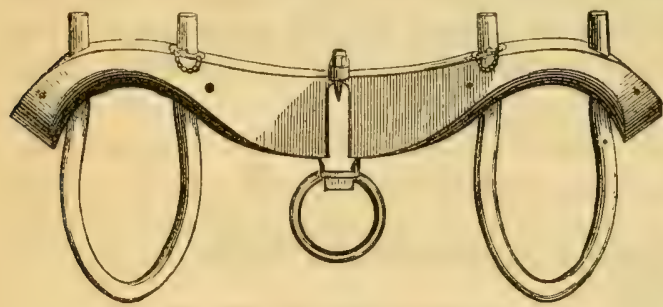

Fig. 242. Ox Yokes and Bows.

Fig. 242. These Yokes and Bows are of superior quality, both as to timber and workmanship. The Yokes are of birch, beech, and elm; the bows of the best hickory, and bent by steam by the most approved methods, so as to prevent the striating of the wood on the outer side; the use of screw-rivets in these Yokes materially increases their strength, thus permitting a proper degree of lightness; the iron portions are of superior quality and workmanship, and the bows are well fitted, of common or egg shape, and fastened with patent spring Bow-pins.

We have a variety of sizes of these Yokes, as per Price List, page 10 ; other sizes will be furnished to order. Also have on hand a large stock of finished and unfinished Ox-hows of all sizes; also Yoke-irons and plain Yoke-shapes.

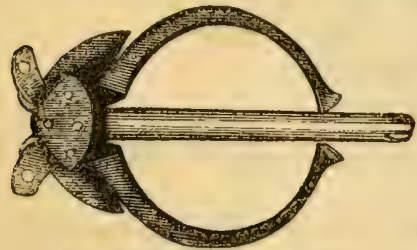

Fig. 243. Patent Bow Pin.

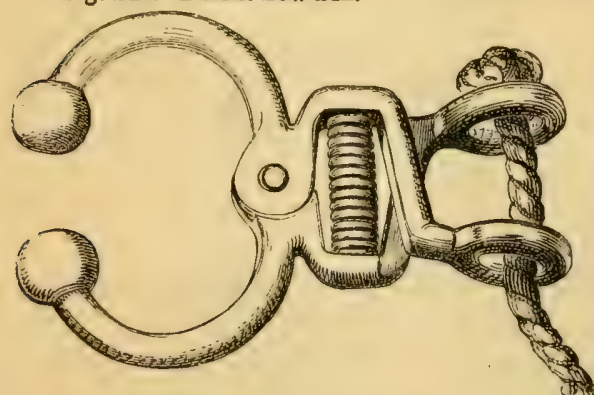

Fig 244. Howe's Adjustable Cattle Leader.

Fig. 243 represents the Bow-Pin used above for confining the bow in the ox-yoke. The outside circular parts are opened from the center or body part by a spring, when the center part is put through a hole in the bow, and the spring closes the circular parts again, clasping the bow on both sides, and preventing all possibility of its dropping out.

Fig. 244. This is an excellent instrument for leading bulls or other cattle. The thumb and finger being pressed immediately over the ends of the spring of the Leader, open the balls, and it is then slipped on the cartilage of the nose, and the spring gently closes it. The cartilage being thinner on the inside of the nose than it is near the end, prevents the balls from slipping off ; and the harder the strain is on the cord, the tighter the balls hug to the cartilage. The instrument can be applied or removed in a moment. 
The superiority of this instrument over the use of a cord around the horns, particularly for young cattle, cannot be doubted, while for the unruly bull it gives more perfect control.

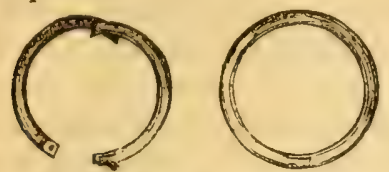

Fig. 245. Bull Ring.

Fig. 245. Every bull should be rung after attaining the age of one year. It is easily done by punching the cartilage between the nostrils, and then inserting the ring and screwing it together. With a ring in his nose, the most fractious animal is easily managed. The left hand figure shews the ring open ready to insert. A serew-driver accompanies each ring. These rings are of copper and steel, and of various sizes; also plated with silver.
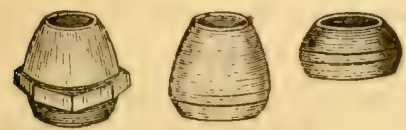

Fig. 246. These are of brass or composition. They are screwed to the ends of the horns, and thus prevent cattle from injuring each other by hooking. They are also very ornamental.

Fig 246. Ox Balls.
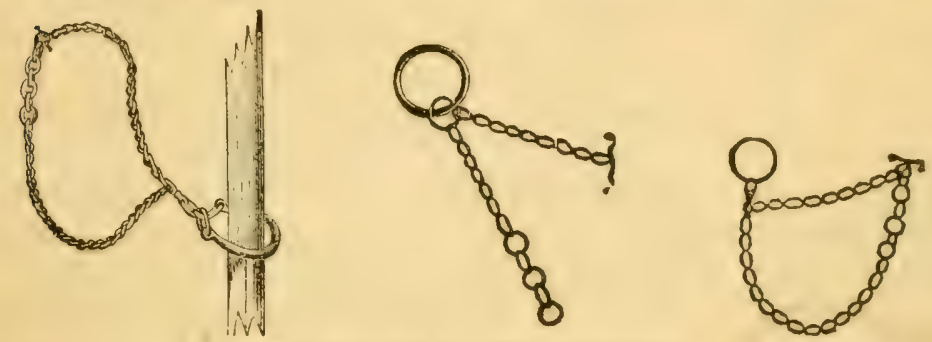

Figs. 247, 248 and 249. Cattle-Ties.

The above cuts represent Chains for confining cattle in their stables. The large ring works up and down upon a round post or stanchion at the side of the manger.

It is the neatest and most secure fastening known, and at the same time the most comfortable, as the animal slips the chain up and down the stationary post, by the large ring, when it wishes to move its head in feeding, or getting up and lying down; it can also turn and lick itself thus fastened. Such a chain will last an age. The kind at the left hand can be attached to posts already up.

\section{Chains.}

Chains of all kinds, of superior quality, including tethering chains for feeding off lawns and grass-fields; halter chains; trace chains, from light to heavy, suitable for plowing and heavy draft, and varying from $6 \frac{1}{2}$ to 11 feet; back chains of all linds; draft chains, from 6 to 11 feet in length, with a hook at each end, and of various sizes; whiffle-tree, fence, log, and other chains. 


\section{HARNESS, CARTS, \&C. \&C.}

Double and single harness for plow, wagon, and cart use; cart saddles, breeching collars, bridles, bands, reins, etc., and every article required, for cart, wagon and plow.

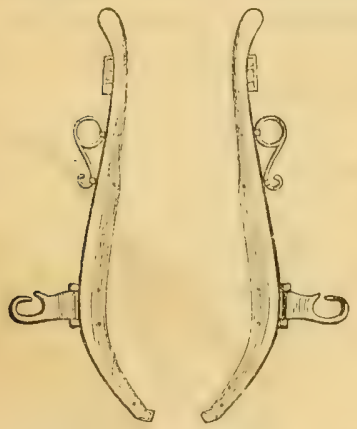

Fig. 250.

Fig. 250 represents a strong light hame for a cart horse. Of these, we have a great variety of light and heavy, variously mounted.

Fig. 251 represents a pair of truss whiffle-trees, with an evener, forming a full set: of these, we have two sizes. Their construction resolves all the force of the team on the wood in the direction of its length, thus causing strength to be combined with lightness. We

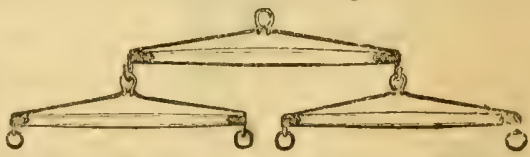

Fig. 251. Plow and Cart Harness.

have also a variety of wooden whiffle-trees of different sizes, with hooks, spring hooks and rings, as may be preferred.

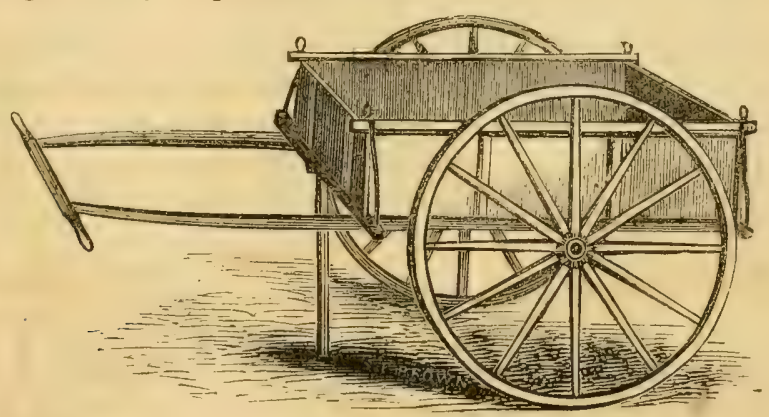

Fig. 252. Hand Cart.

This is a light, useful Cart, and is very serviceable for plantation farm, garden and city use. They have iron hubs, and are not subject to derangement by exposure to whe weather. Price, $\$ 18$. 


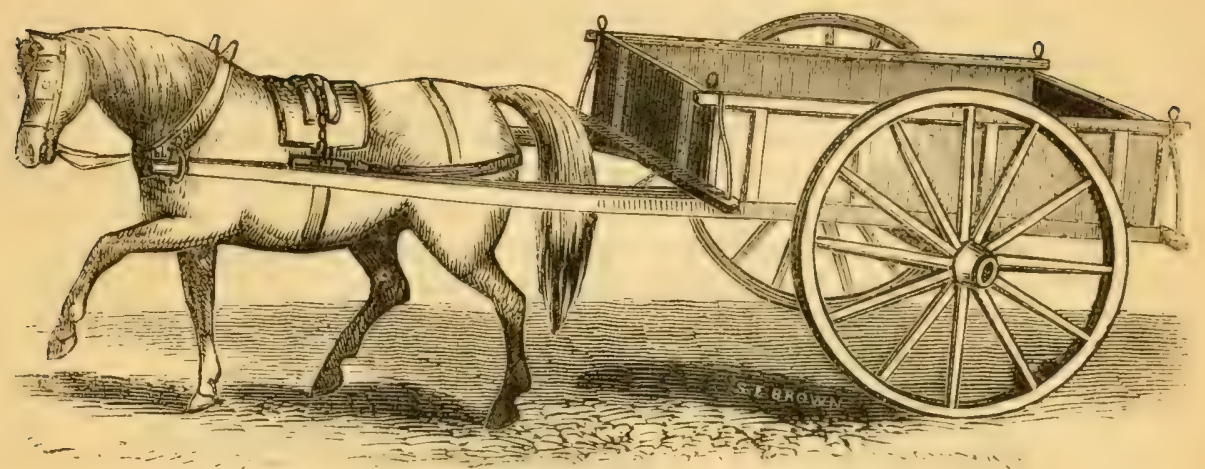

Fig. 253. Horse Cart.

These Carts are manufactured expressly for plantation and farm use, and are made strong for hard service; may be used with one or two horses, and are so arranged as to discharge the load by upsetting it. When supplied with a tongue, they may be used with a yoke of oxen. Piice, $\$ 40$ to $\$ 50$.

Farm Wagons. Of all kinds furnished to order.

Fig. 254. This is the simplest and cheapest form of road scraper. We can also furnish the improved road scraper with wheels. This scraper is elevated by a rack and pinion, and is capable of transporting with a single horse a cubic yard of dirt. Fig. 25t, however, is a much cheaper implement and in more general use, being better adapted to the ordinary repair of roads and the removal of earth for short distances. It is also sometimes used as a stone boat, and answers the purpose quite as well as the long tim-

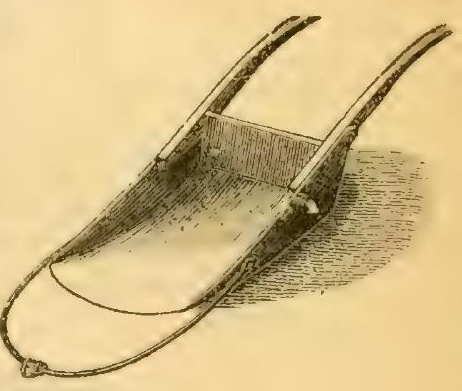
ber stone boat, being much cheaper and more durable.

Fig. 254. Cast Iron Road Scraper or 0x Shovel.

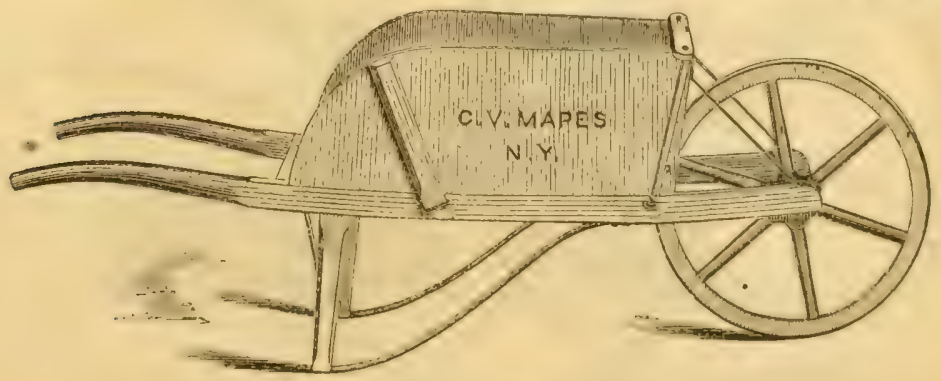

Fig. 255. Improved Wheelbarrow.

Fig. 255 represents the Improved Wheelbarrow, being much stronger than 
any before made, and extremely light. The hub of the wheel is of iron, containing pockets to receive the spokes, and these being attached to an iron axle, cannot become deranged from change of figure. An iron shoe attached to the side rails passes under the standing legs, thus bracing the frame work thoroughly. Joint bolts enter the top of the leg, giving permanency and strength to the mortice. All parts are put together with similar joint bolts, enabling the barrow to be readily taken apart and packed in a small space for shipment. Of these, we have four sizes, as per price list, the smallest size suited for boys' use.

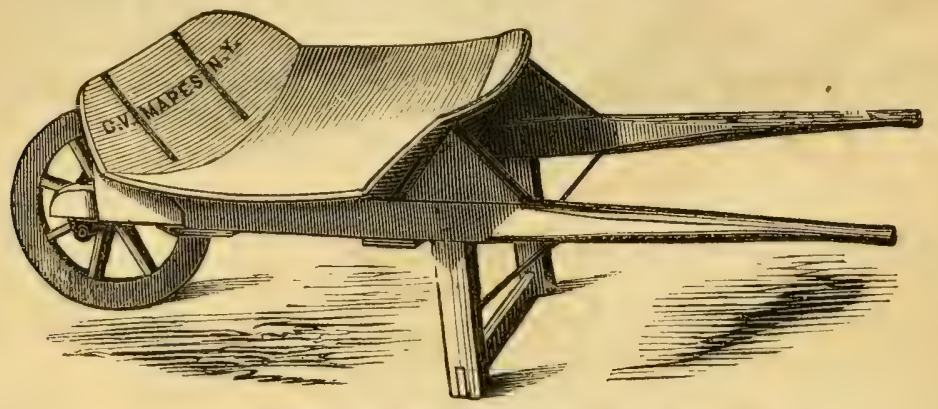

Fig. 256. Railroad or Canal Barrow.

Fig. 256 is a cheap barrow, and calculated for use in the building of railroads and canals. In the removal of stones, and other rough uses, this barrow will be found useful. Its body or pan is of bent timber, and the whole so thoronghly braced by hoop iron judiciously strapped upon it, as to produce the greatest amount of strength and the least cost and weight. The bowls may be packed in nests of six each, the handles strapped in a bundle, and the wheels and small pieces boxed.

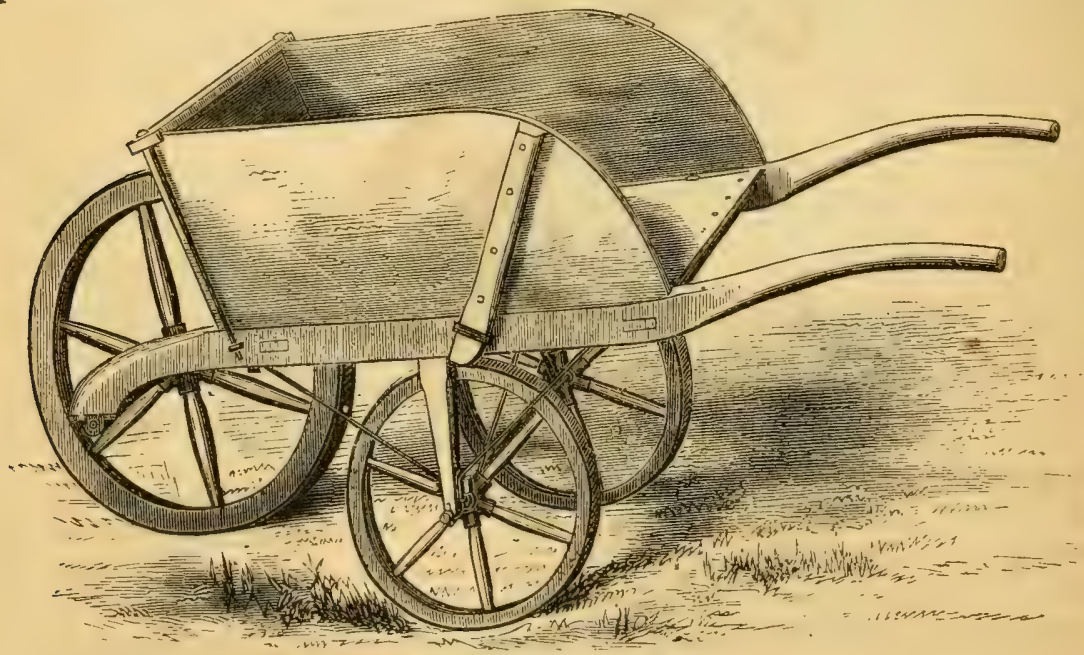

Fig. 257. French Pattern Barrow. 
Fig. 257 represents the French pattern barrow, with three wheels. By this arrangement the barrow, when heavily loaded, may be moved without the operator suspending the weight by the handles. In meeting an impediment, the handles become levers, by which the single wheel may be lifted as in mounting a curb-stone. For store use this barrow is peculiarly adapted.

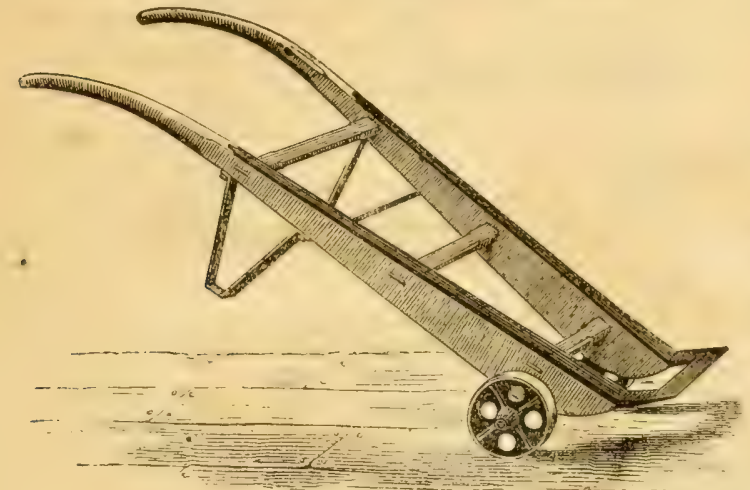

Fig. 258. These are fully described by the engraving, the darker portions representing iron. These trucks are used in stores and warehouses for moving boxes, bales, etc. Of these we have six sizes, varying from very light to very strong and heavy, as per price list.

Fig. 358. Store Trucks.

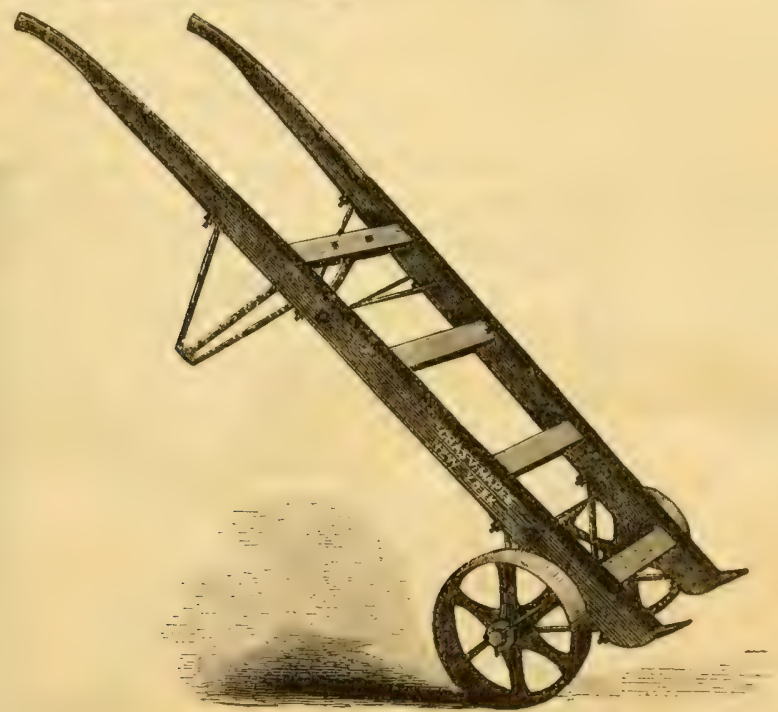

Fig. 259. Southern Cotton Truck.

Fig. 259 represents the Southern Cotton Truck. These are of three sizes, with wheels of increased size, as compared with those of 258 , and terminating at the lower or fulcrum end with flattened points instead of a bar, as in the store truck, entering these flattened points beneath the bale of cotton, enables the handles to be used as a long lever to raise it with ease. This is a new article and well suited for use at cotton presses, etc. 


\section{Platform Trucks.}

We also have four sizes of these trucks, with four wheels each and a hinged tongue; the wheels, axles, and tongue being of iron, platform of wood bolted to rear axle and front transit bar.

\section{Wheel-Jacks.}

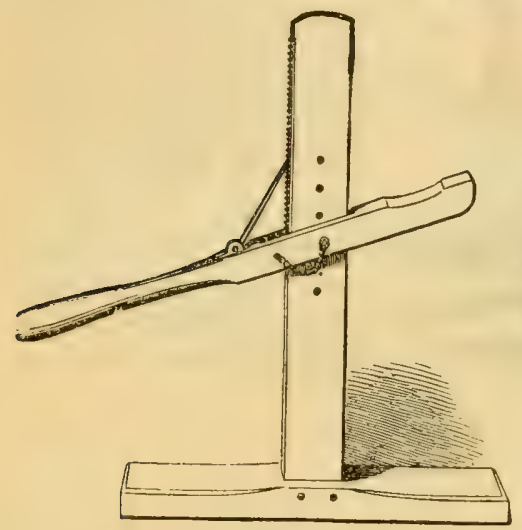

Fig. 260 is a simply-constructed jack, which explains itself as given in the engraving.

Fig. 260.

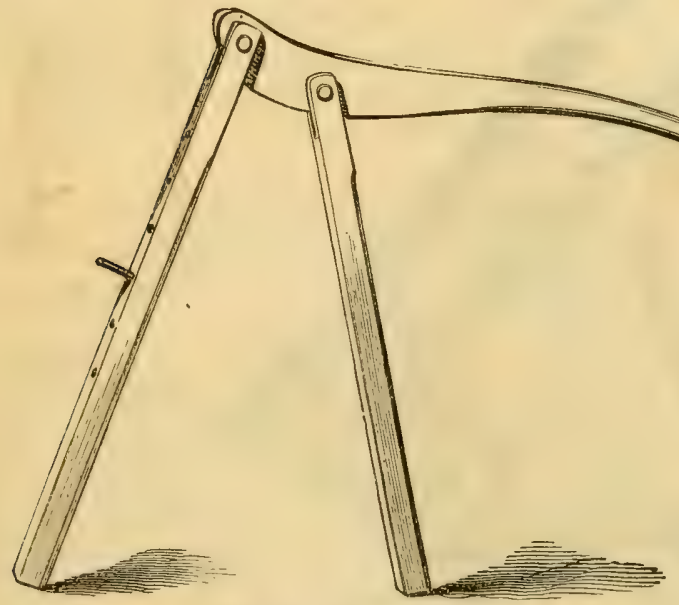

Fig. 261. Wheel Jack.

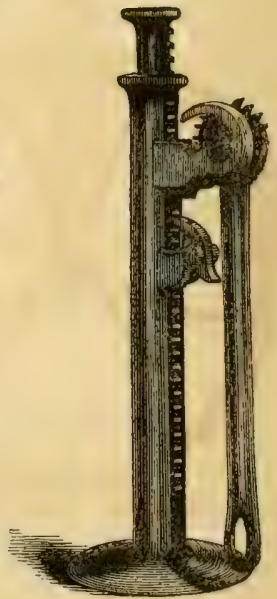

Fig. 262. Cylinder Wagon Jacks.

Fig. 261. This represents a wheel-jack of a larger size, capable of sustaining heavier weights. For still heavier purposes sec Jack-Screw.

Fig. 262 is a wheel-jack entirely of iron, and of sufficient strength for all the uses to which it is likely to be applied.

The above are very useful articles for greasing wagons, etc. 


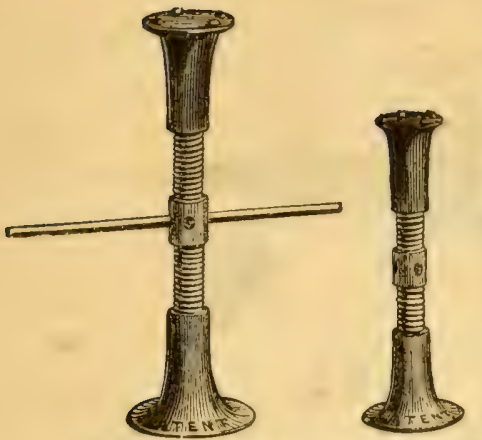

Fig. 263. Reed's Patent Jack-Screws.
Fig. 263. Used for raising buildings or heavy work, and consisting of two screws, one above the other, and moving in opposite directions, so that the gain is double at each revolution of the lever which turns them. They are made of various sizes $-1 \frac{1}{2}, 1 \frac{3}{4}, 2$, and $2 \frac{1}{2}$ inch, and of various lengths. Another size, $1 \frac{1}{4} \mathrm{inch}$, is made quite light, and used principally as a wagon jack. Also single screw Jacks.

\section{Ballard's Patent Jack-Screw.}

These are a superior article, and have met the approbation of the government, being now in general use in the United States navy; indeed they have displacel jack-screws of most other makers. We have 25 kinds of these screws, varying in price from $\$ 12$ to $\$ 50$, including the large size clawed jack-screws, railroad, cotton, timber, sugar, planking, iron-clamp, and other jack-screws.

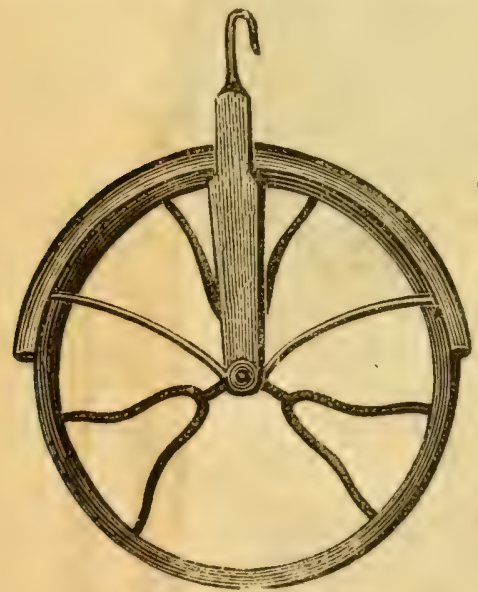

Fig. 264. Well Wheel.
Fig. 264 represents a cheap fixture, with a rope, to raise water from wells, and is admirably adapted for raising and lowering light weights, as it works with despatch. Several sizes.

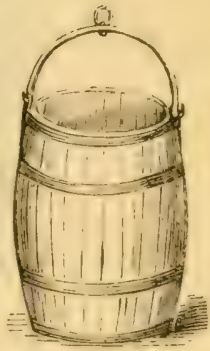

Fig. 265. Bucket.

Fig. 265. Well-Bucket, used in connection with the Wheel, or any apparatus for drawing water from wells. Three sizes. 


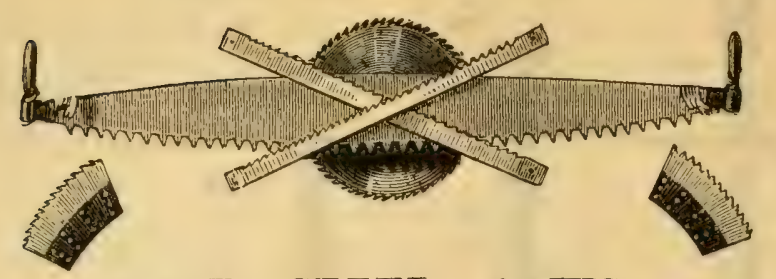

CAST STEEL SAWS.

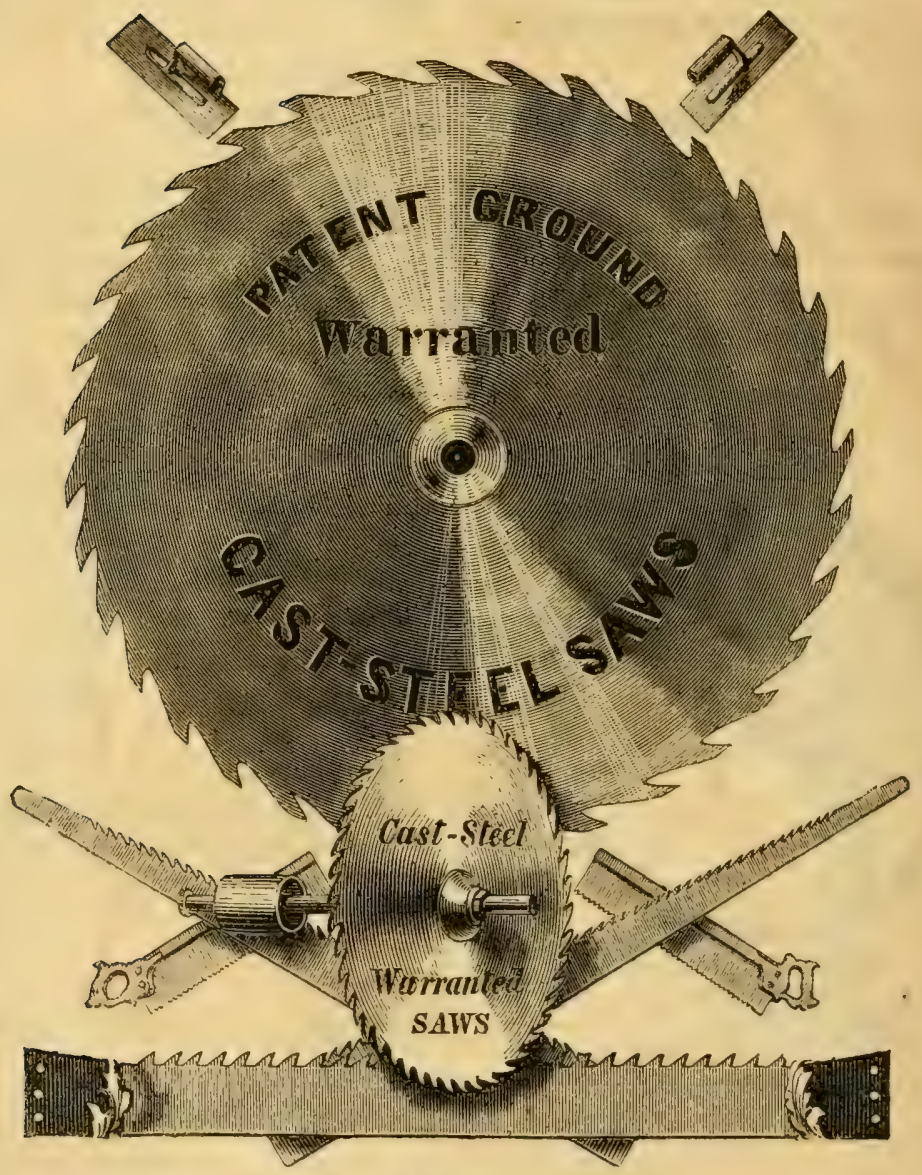

Fig. 266.

Of these we have every variety, including Hoe \& Co.'s warranted cast-steel and extra cast-steel saws. These saws are carefully hardened and tempered, and are 
groun. and finished by machinery designed expressly for the purpose, and are much superior in truth and uniformity of surface to those ground in the usual manner; they require less set, are less likely to become heated, and produce a saving in timber.

We have also extra cast steel gang-mill, cross-cut pit saws, and billett-webbs of superior quality, manufactured by R. Hoe \& Co. and others.

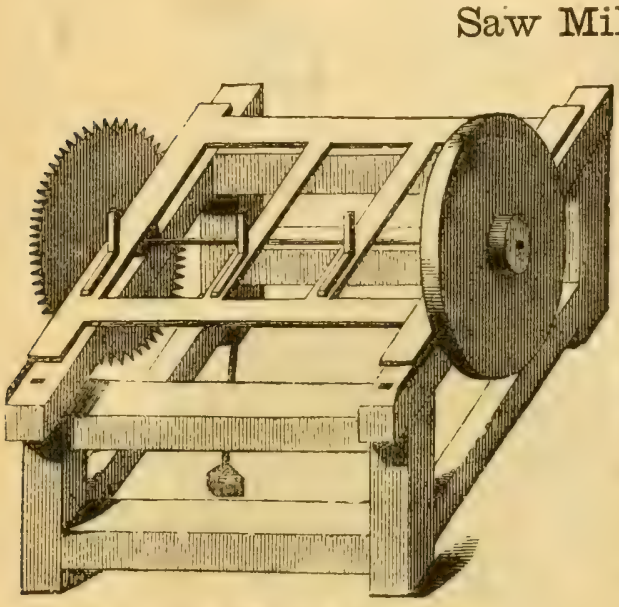

Fig. 267. Saw Mill.
Fig. 267. This Mill is made strong, with joint-bolts, patent metallic boxes, large and long shaft, and heavy flywheel, and may be used with the single or double horse-power. A 24-inch saw is used; and with the one-horse power and two men, from ten to fifteen cords of hard wood may be cut twice in two per day, or as much soft wood as can be handled.

The same mill, by changing saws, can be used for slitting boards and planks for fencing, etc.

\section{Cotton Gin.}

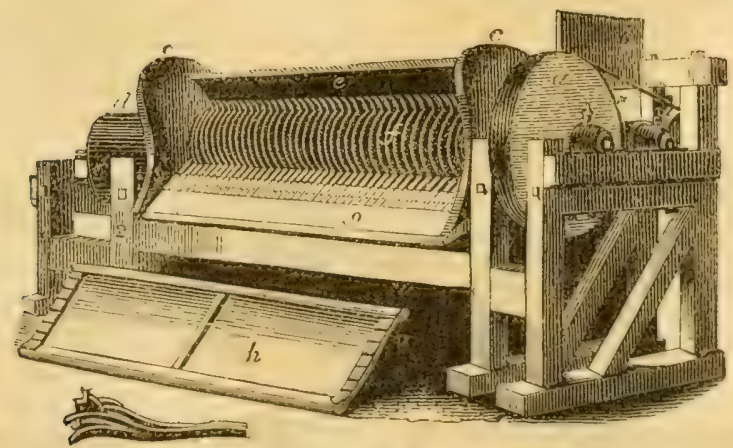

Fig. 268. Improved Eagle Cotton Gin.

Of these we have every variety, large and small, or power and hand gins, and are ready to supply to order, manufactured by several approved makers. 


\section{Cane Mills.}

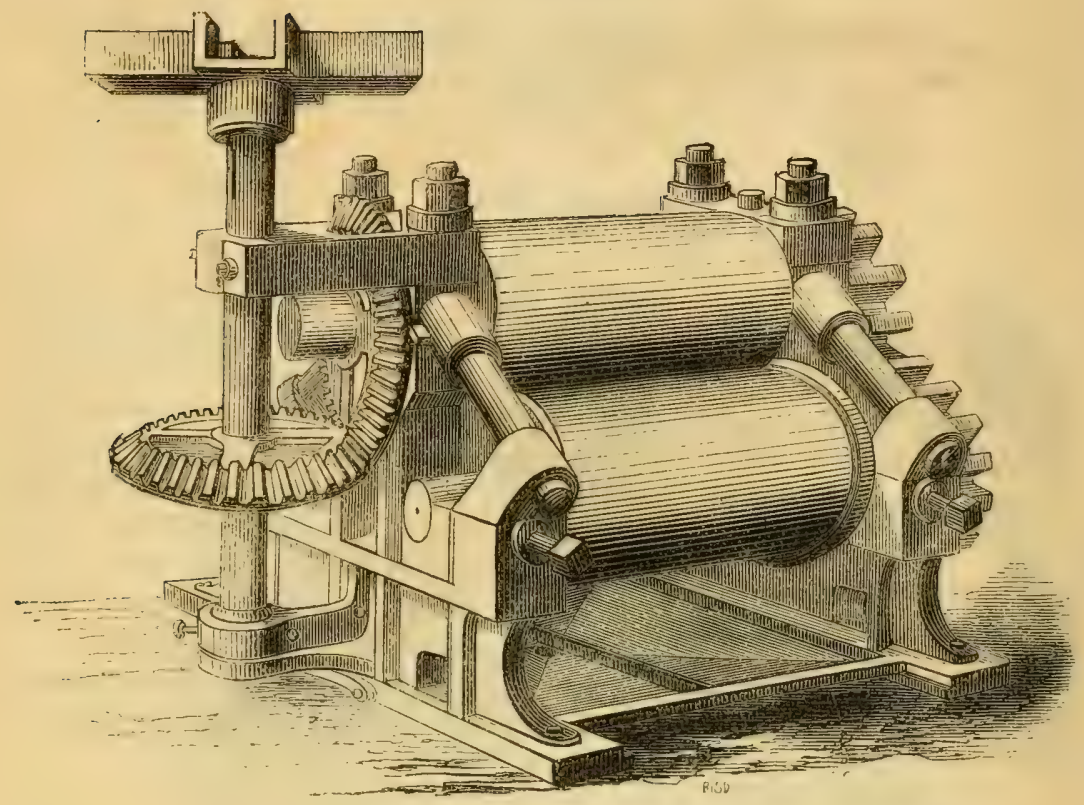

Fig. 269. Horizontal Cane Mill.

Fig. 269 represents the horizontal power Cane Mill, now in general use in Louisiana, Texas, Cuba, and elsewhere.

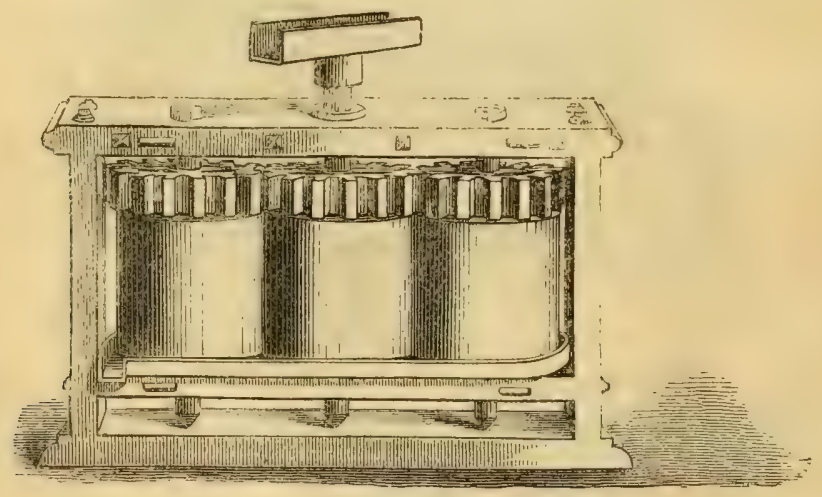

Fig. 270. Vertical Cane Mill.

Fig. 270. A similar mill, with the rollers in a vertical position. Of these we re prepared to furnish every size, with or without steam engines, etc. 


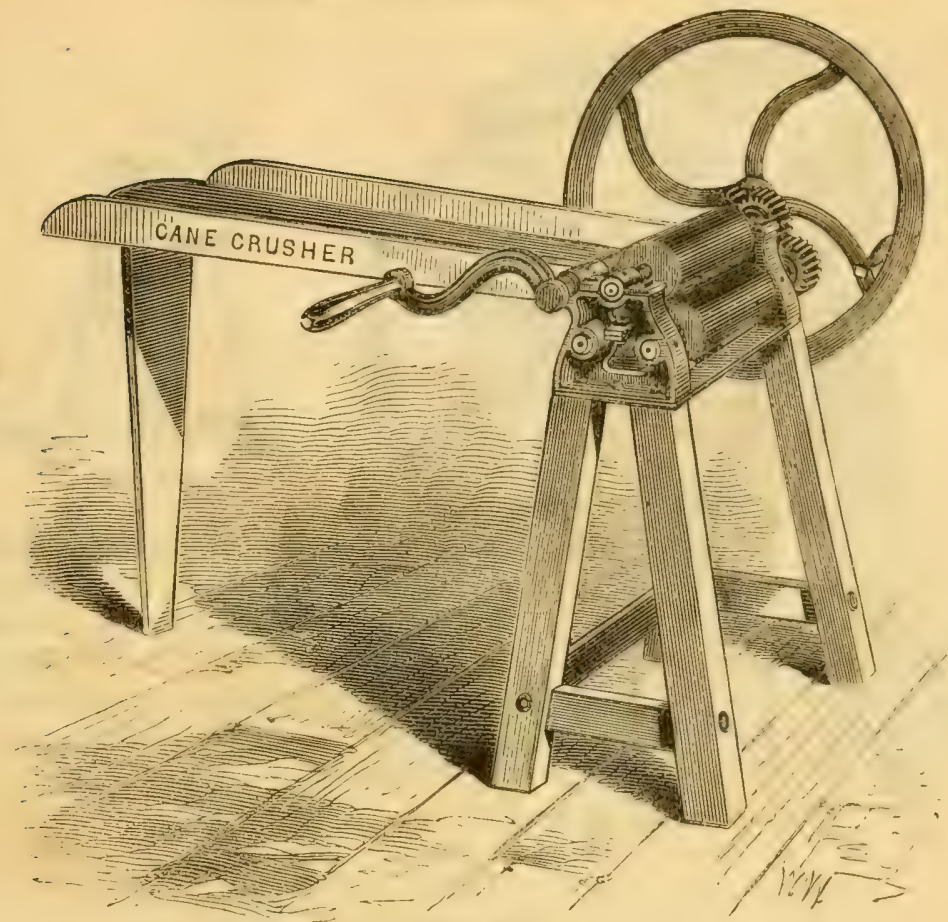

Fig, 271.

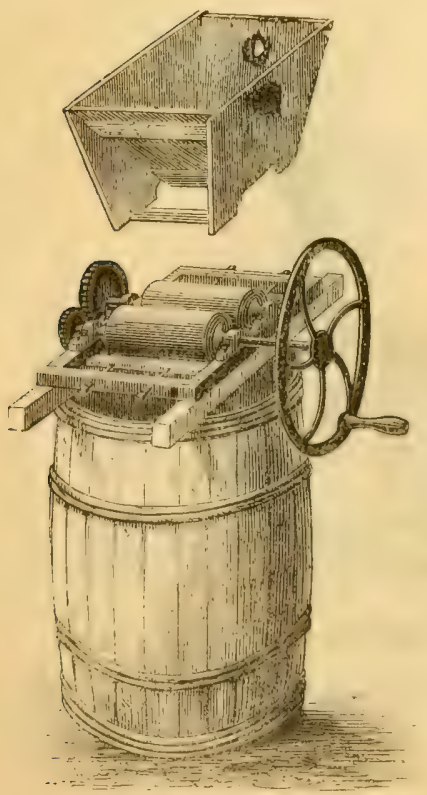

Fig. 271 represents the usual hand mill for crushing sorgham and imphee, and other juiceyiclding stalks. They are of two sizes, Nos. 1 and 2 , as per price list, page 11 ; the largest is designed for power.

Figs. 272 and 273. These mills are used by grocers for grinding aud preparing sugars for use when taken from the original packages, by which process the damp and hard portions are crushed and disintegrated, and made to look light and of uniform appearance.

Five sizes of these mills are made, the smallest one, for placing on a barrel, as represented by Fig. 272, and the larger sizes adjusted to a frame or box, and standing on the floor, as represented by Fig. 273 , from which box the sugar is removed by the use of a shovel. For sizes and prices, see price list, page 11.

Fig. 272. Sugar Mill. 


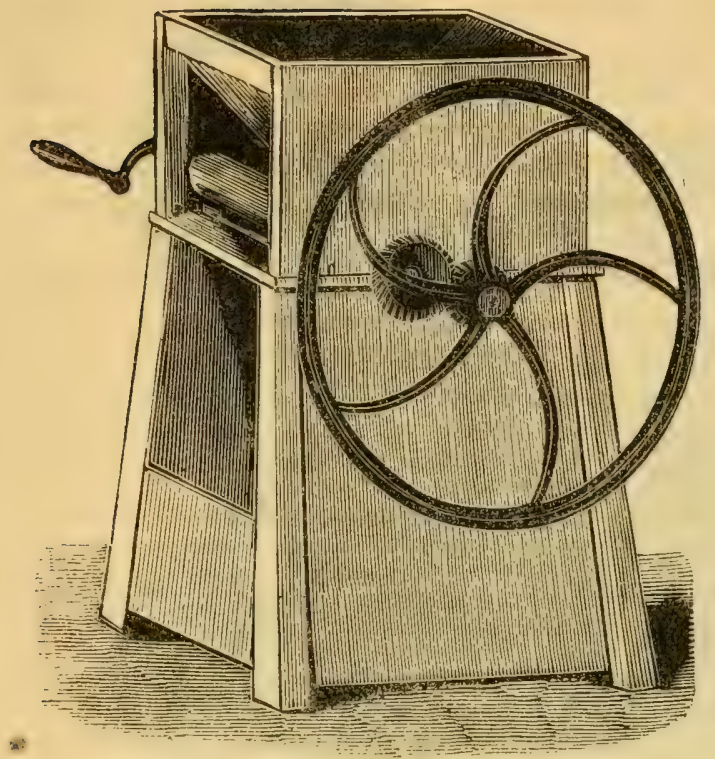

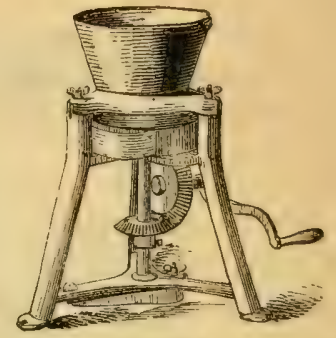

Fig. 274.

Fig. 274 represents Harris' Patent Paint Mill, for grinding and mixing paints. It is easily worked by hand. We have three sizes of these mills; the largest is geared for power.

Fig. 273. Sugar Mill on Box.

\section{Brainard's Improved Paint Mills.}

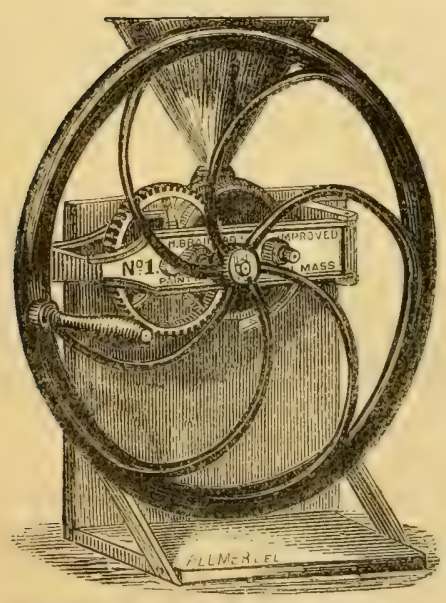

Fig. 275. No, 1. with Fly Wheel。

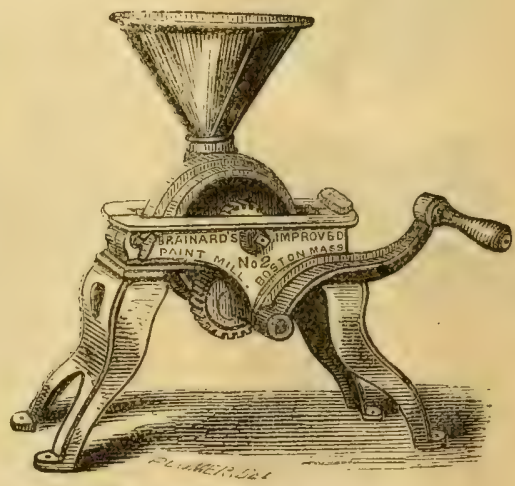

Fig. 276. No. 2. with Crank.

These mills are the invention of a practical painter of long experience, and combine many excellencies, a few of which may be named: 1st. No color, however coarse, needs grinding through them more than once to render it fine enough for 
any purpose whatever. 2d. They will grind from two to four times the amount of paint which can be ground in any other mills in the same time, thereby paying for themselves in a very short time. 3d. They do not "throw" when run rapidly. 4th. The coarse and heary colors do not settle in them. 5th. The grinding surfaces wear perfectly even, and the mills therefore work well until entirely worn out. 6th. The principal bearings are of hardened steel, and every part is finished with care and accuracy.

Four sizes are now made, each differing from the others in the details, and adapted for different kinds of work; the general principles, however, are the same in all.

No. 1, is a mill of medium size, intended for grinding thin colors for coachpainters' use, etc. The "runner" is geared to revolve rapidly, and will grind as fast as No. 2 when turned by hand. For grinding small quantities of costly colors it is donbtless better than a larger mill, but is not so well arlapted for grinding the thick colors used by honse-painters as No. 2. A fly-wheel is furnished when desired, and also a spare tunnel of small size.

No. 2, is about double the size of No. 1, and is equally adapted for grinding thick or thin colors. It turns as easily as No. 1, and as it does the same work with about half the number of revolutions, is of course more durable. Fly-wheels of two sizes are made for this mill, and a large tunnel, holding three gallons, when desired. Where a small power mill is wanted, this has no equal, and great numbers of them are now running by steam, water, and horse power. The pulley can be unserewed and the crank substituted in a moment whenever necessary.

When paint is ground by hand, the use of a fly-wheel renders the process much easier. This remark applies to all paint mills.

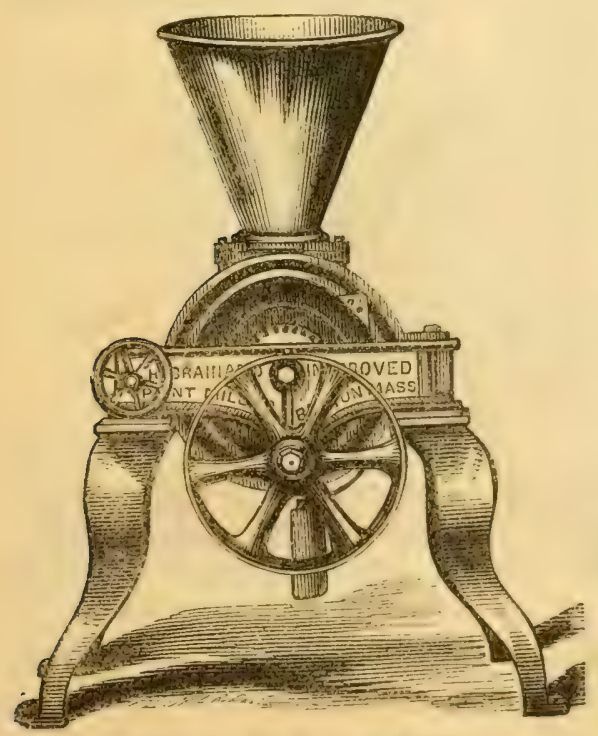

No. 3. This mill is as large as No. 4 , and like that, is intended only as a power mill. It will grind as much paint as No. 4, provided it is not too stiff to feed through a four-inch circular aperture. There are knives upon the inside of the rumner, which stir and beat up the color between the grinding-plates, and by an original contrivance both plates in this and No. 4 are scraped at every turn, making the mill very cleanly in its operation, and allowing it to run at any rate of speed required.

Fig. 277. Ko. 3, with Pulley. 
No. 4, like No. 3, is intended for paint dealers, painted carpet and color manufacturers, etc. Though the grinding-plates are no larger than those of No. 3, yet it is a much more elaborate affair, and will mix as well as grind the stiffest colors. The tunnel will contain $125 \mathrm{lbs}$. of lead and the oil necessary to mix it. Within the tunnel is a mixing : apparatus running independently of the grinding part, and ending in a worm which crowds the paint down between the grinding plates, keeping them constantly fed, however stiff the paint may be. The dry paint and oil, therefore, being thrown into the tunnel, is mixed, fed to the grinding plates, and ground, at one operation. It will grind any color, stiff or thin, in oil or water, and may be used as a mixer for otber mills. One horse power is amply sufficient to drive it at a speed of 200 revolutions a minute, and usually not half that power is required after the plates become warm. It will mix and grind $3,000 \mathrm{lbs}$. of white lead per diem, as stiff and fine as the average lead of commerce. If ground very fine, this quantity will

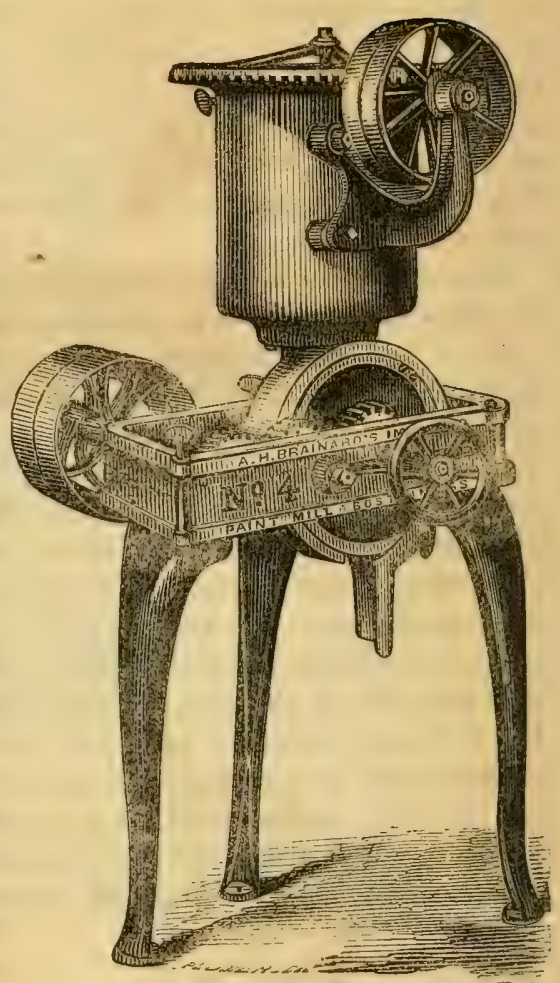

Fig. 278. No. 4 .

of course be proportionally reduced. When a clange of color is to be made, the mill can be taken apart, cleaned, and put together again in a very few minutes. For such parties as have but a limited amount of power, or do not wish to invest much in grinding apparatus, this mill is peculiarly adapted; while in very large establishments, where stone mills are in use, it will be found a useful auxiliary.

\section{Pig Troughs.}

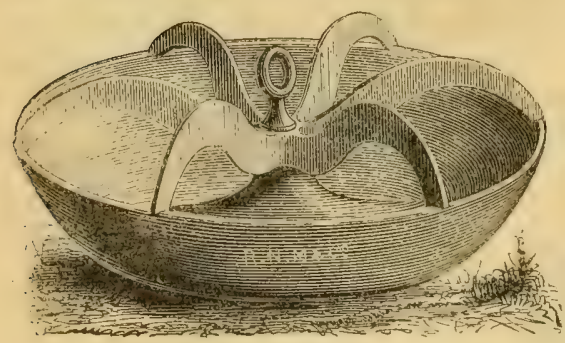

Fig. 279. A good article, durable, convenient, and cheap; arranged to prevent the swine from getting their feet into the trough, or hindering weaker ones among them from obtaining their portion of food. as one cannot drive another out.

Eig. 279. Iron Pig Trough 


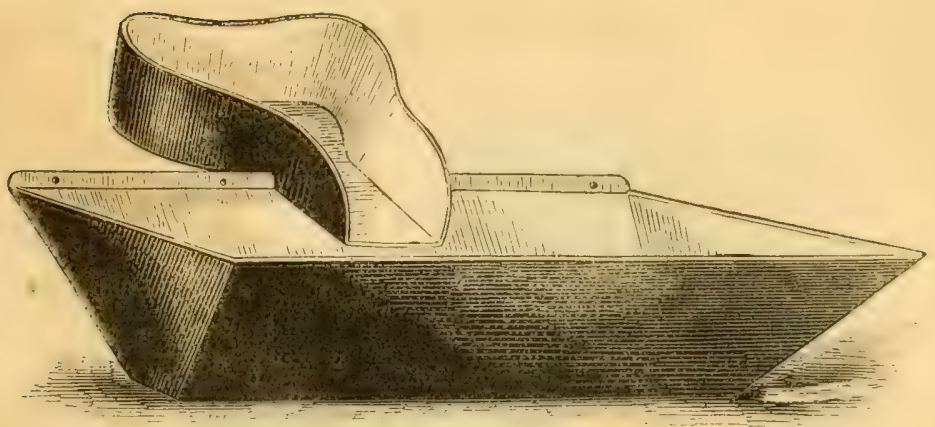

Fig. 280. Cast Iron Pig Troughs.

Fig. 280 represents another form of pig-troughs, of which we have 3 sizes; the lower or main trough may be fastened to the pen by bolts and nuts, leaving the conducting tronghs to protrude through the siding.

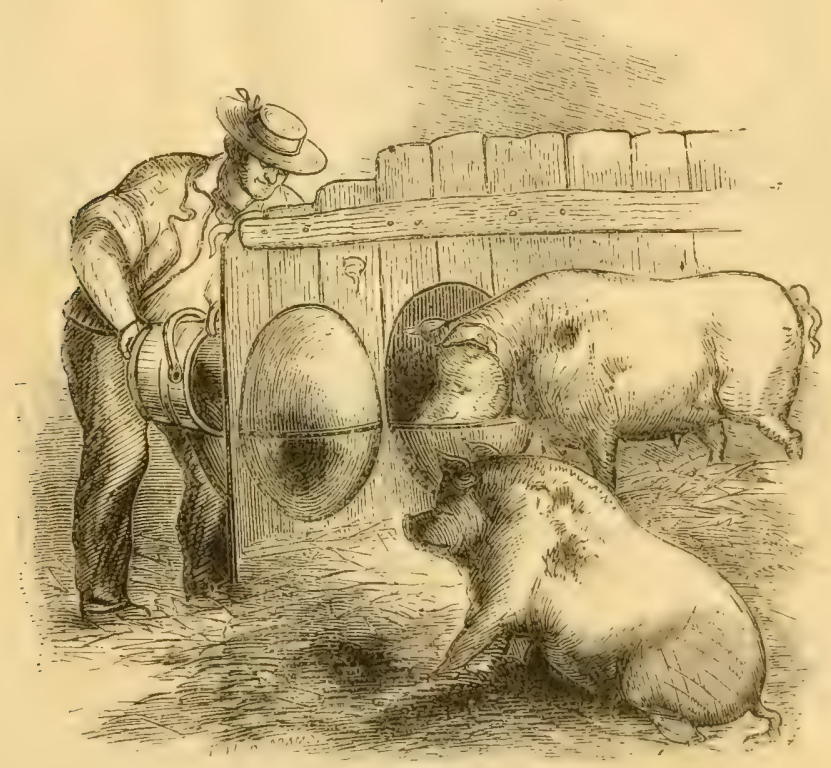

Fig. 231. Metallic Hog Troughs.

Fig. 281 is a reversible hog-trough, which, while being filled from the mutsite of the pen, is shut on the inside, thus preventing annovance from the rumateity of the inmates. Price $\$ 150$ each. 


\section{Iron Horse Manger.}

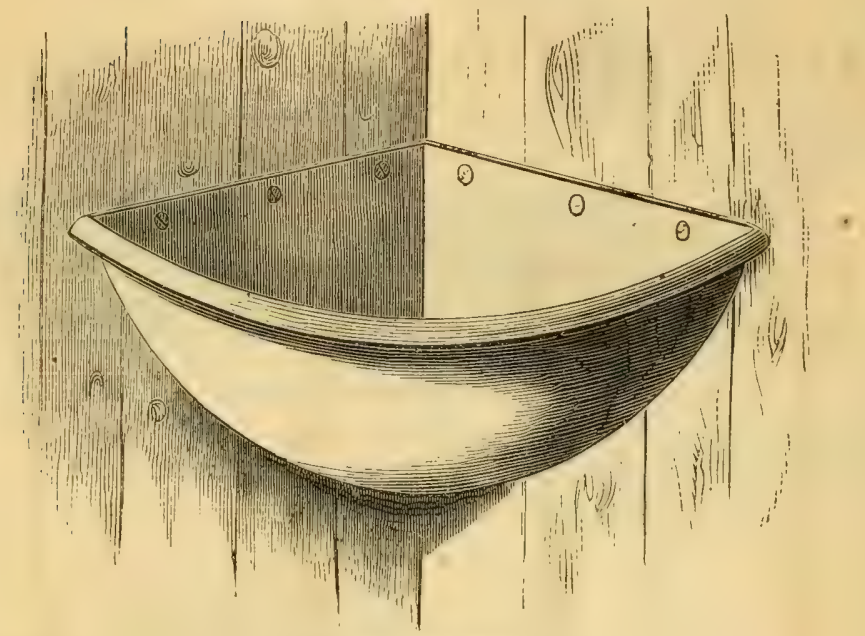

Fig. 282. Manger.

Fig. 282 is so formed as to contain no corners, thus permitting the contents to be easily removed and cleansed, preventing souring, accumulation of dust, etc. Price $\$ 300$.

\section{Iron Horse Rack.}

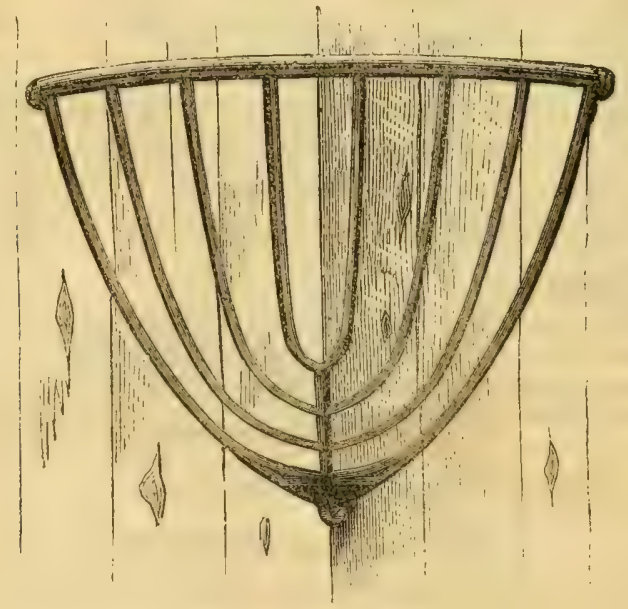

Fig. 283. Hay Rack.

Fig. 283. This rack, like Fig. 282, being made of iron, cannot absorb the virus from distemper and other diseases, and therefore is worthy of general use. Price $\$ 300$. 


\section{AMES' SHOVELS \& SPADES.}

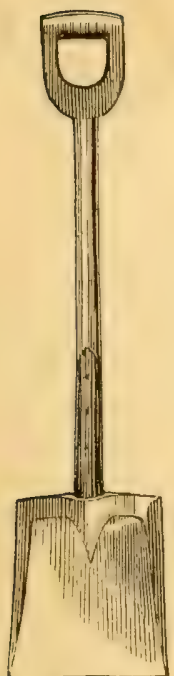

Fig. 284.

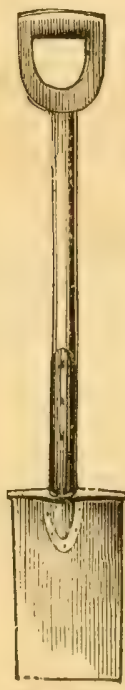

Fig. 285.

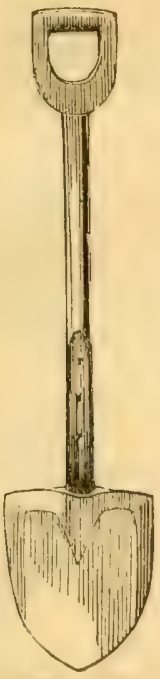

Fig. 286.

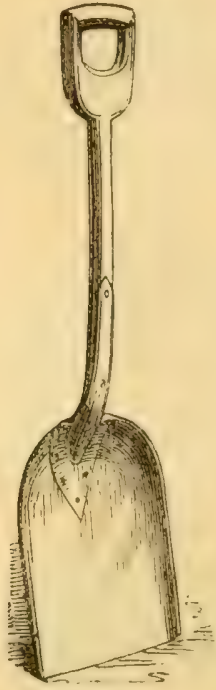

Fig. 287.

The above Shovels and Spades have a world-wide reputation, and we are ready to furnish them at manufacturers' prices. Shovels and Spades of various other manufacturers will be found in our assortment. Grain Scoops of all sizes.

Draining Spades will be found under the head of Drainage.

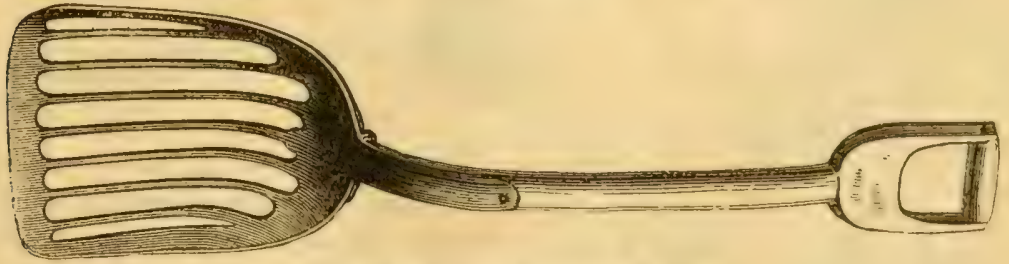

Fig. 288. Patent Screening Shovel.

Fig. 288. This peculiar Shovel is well suited for the use of Gas Worlis, Coal Dealers, Miners, etc., etc.

The advantage of this Shovel to Gas Works, Machinists, and all others who require to feed a furnace, is, that by allowing the braize and dirt to be separated from the coke or coal, the heat of the fire is better maintained, and clinkers are avoided, thus obtaining more heat, and saving labor and the cost of repairs. 


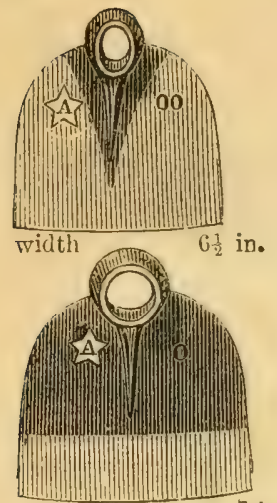

\section{$\mathrm{H} O \mathrm{E} \mathrm{S}$.}

Fig. 289 represents Six Planters' Hoes of the most approved patterns, and of various styles of finish. They are made of the best Norway Iron, and English Cast Steel. See description at Fig. 291.

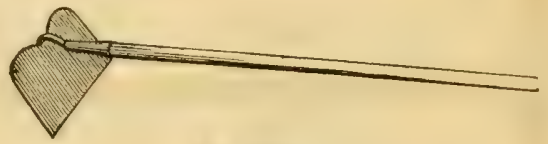

Fig. 290.
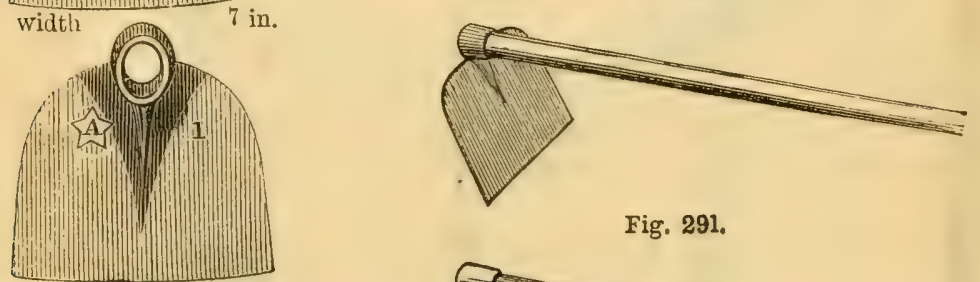

Fig. 291,
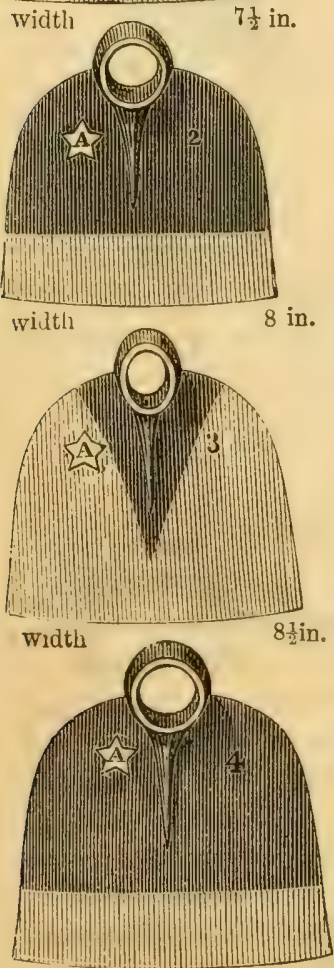

$8 \frac{1}{2}$ in.

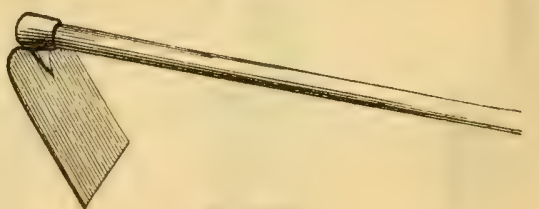

Fig. 292.

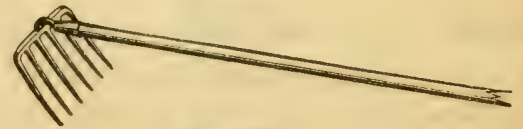

Fig. 293.

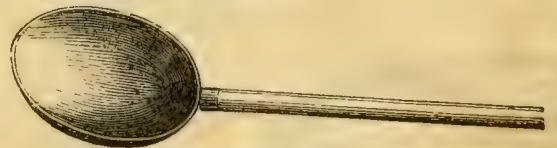

Fig. 294.

Fig. 290 represents the Field Hoe, of which we have a large assortment of various patterns. The most approved are the concave, cast steel, with either solid shank or socket, drawn out under the hammer and tempered like a brick trowel; also, a cheaper variety of hoes, plated, and riveted shanks.

Fig. 291 represents the Planters' Hoe, handled-these are very highly finished-full or half polished, either solid steel or plated, with the eye round or oval in form width rig. 28 . - from various approved makers. 
Fig. 292 represents the Bog or Rice Hoc, used for heary work on the farm and plantation, digging unsubdued places, grubbing brambles, etc., etc.

The above Hoes can be furnished at manufacturers' prices.

Fig. 293. The Hand Potatoe Digger, and equally applicable to many other purposes-of these, we have a variety of patterns-square, flat, and oval prongs.

Fig. 294 represents the Post Spoon, for removing dirt from post holesthey are made of iron or steel.

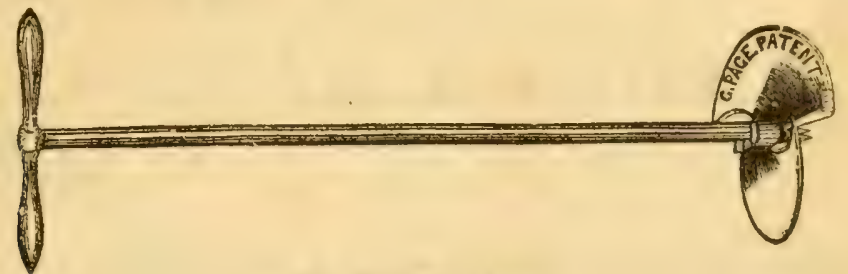

Fig. 295. Post Anger.

Fig. 295 represents a Post Auger, used in a way similar to the common auger for boring timber, with which post holes are readily made in sand, loam, clay, or alluvial soils.

We have two qualities of Post Augers-malleable Iron, and with steel lips -riveted, varying in diameter from 6 to 12 inches.

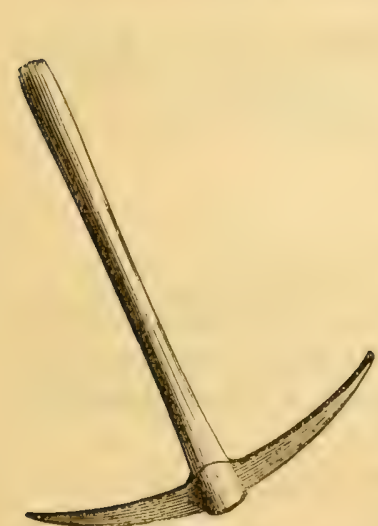

Fig. 296. Pick.

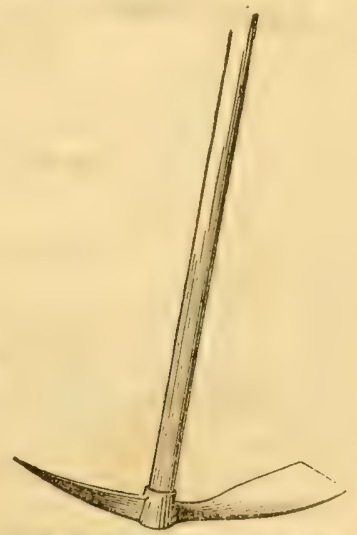

Fig. 297. Pick Bog Hoe.

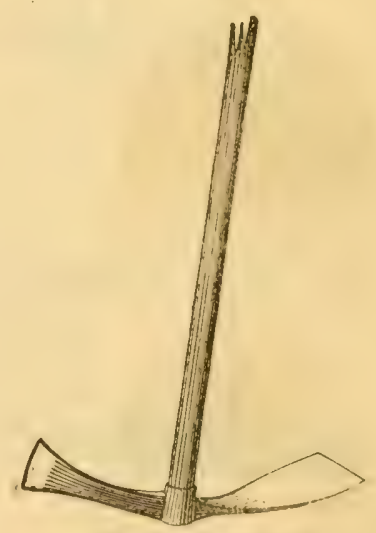

Fig. 298. Mattock.

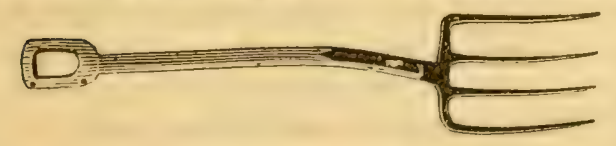

Fig.299. These are celebrated Forks, and considering durability, the cheapest, whether used by the farmer himself or by those employed; they have $4,6,8$, or 10 tines, and are drawn from a solid bar of cast steel, without a weld orlap, are so perfectly uniform, and of such tempor, as to possess the most perfect elasticity. Fig. 299. Patridge's Premium Manure Forks.

In addition to the above, we have 
a great variety of Forks, of various kinds and qualities, by other makers of reputation; also, a peculiarly strong kind of digging or spading forks, with square or flat tines, and particularly adapted to the use of market gardeners.

\section{- GARDEN RAKES.}

Of these, there are various kinds and sizes, made of cast or German steel, highly finished, having 6 to 18 teeth; also, a fine article of Malleable Iron Rake, at lower prices; some of these are of iron, the teeth rivetted into the heads, and sold with or without handles; some with wooden heads and iron teeth, sold only with handles; some with Hoe Blades on the opposite side as garden tools for general work.

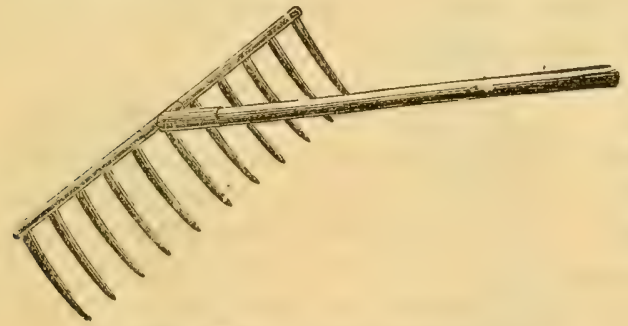

Fig. 300 represents the Malleable Iron Garden Rake, of which we have various sizes, of coarse and fine teeth.

Fig. 300. Malleable Iron Garden Rake.

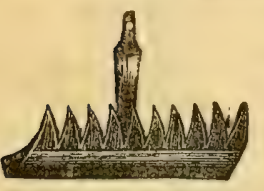

Fig. 301. Lawn Rake.

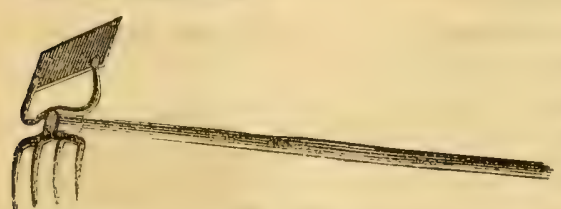

Fig. 302.

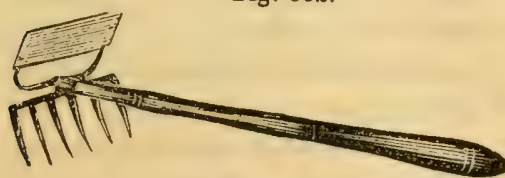

Fig. 303.

Fig. 301. This Rake has teeth sharpened on both edges, from the lower side, and it is used for raking grass lawns, etc., etc., tearing off the flower-heads or buds of daisies, dandelions, and other plants in grass lawns.

Fig. 302 represents the Hoe Rake, with 4 or 6 teeth, having a steel hoe blade on one side, and a malleable iron rake on the other. We have also a superior article made of steel entire.

Fig. 303. This is a six-toothed Garden Rake, very light, with a 15-inch handle, with a steel hoe blade, used for weeding flower beds, etc., etc. A pretty implement for ladies' use. 

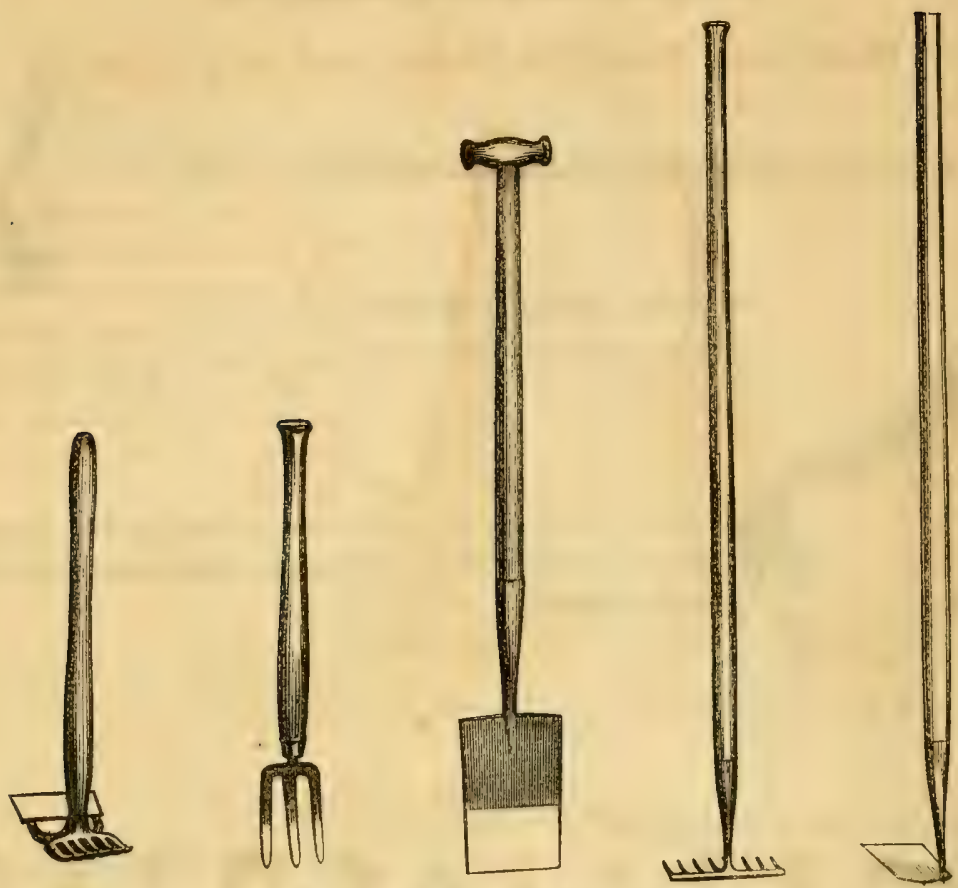

Fig. 310. Garden Tools for Ladies.

Fig. 310 represents our set of Garden Tools for ladies, such as is generally used by ladies in gardening and the cultivation of flowers and shrubs.

Garden Tools for Children.-This is a smaller set than those represented by Fig. 310, and are suited for the use of boys and misses.

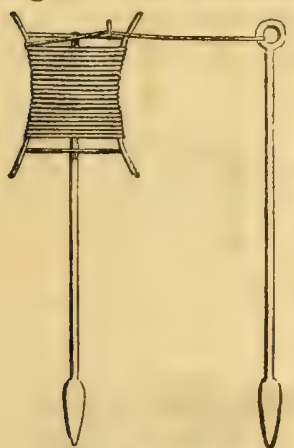

311. Garden Reel.

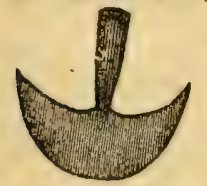

Fig. 311 represents the Garden Reel and Line, a convenient article for laying out gardens, walks, etc. We have two sizes.

Fig. 312 is a cut of a Grass Hook, used for cutting grass on borders and banks. It is readily ground and sharpened like the scythe. Of these we have 4 sizes. They are an excellent corn cutter.

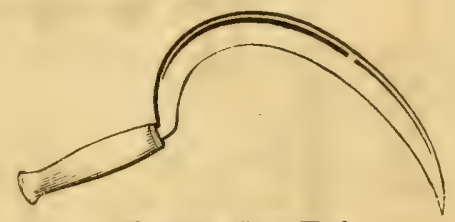

Fig. 312. Grass Hook.

Fig. 313. Fitted to a straight handle, and used for paring the edges of grass bordering walks, \&c.; also for cutting the outlines of sods, which may then be readily raised by the spade.

Fig. 313. Grass Edging Knife. 


\section{Bush and Bramble Hook, and Bill Hooks.}

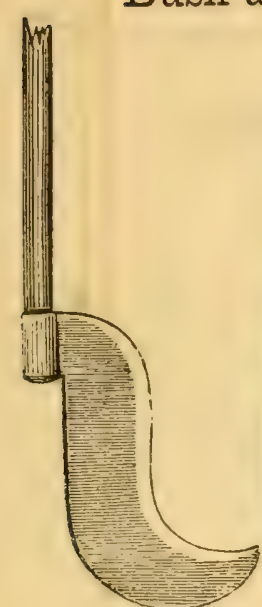

Fig. 314.

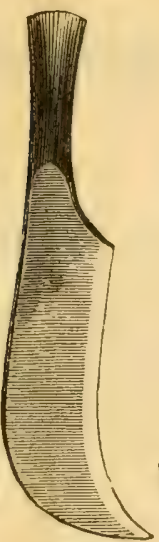

Fig. 815.

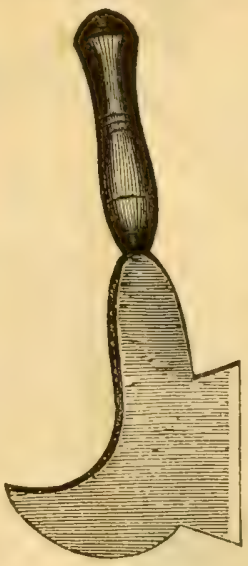

Fig. 316.

Fig. 314. The Bush or Bramble Hook has a long handle, and is a formidable implement for cutting long bushes, briers, etc.

Figs. 315 and 316. Bill Hooks are used for cutting small bushes, pruning, etc., and are used with one hand.

Of the bush hooks we have a variety of patterns.

Assorted Handles.
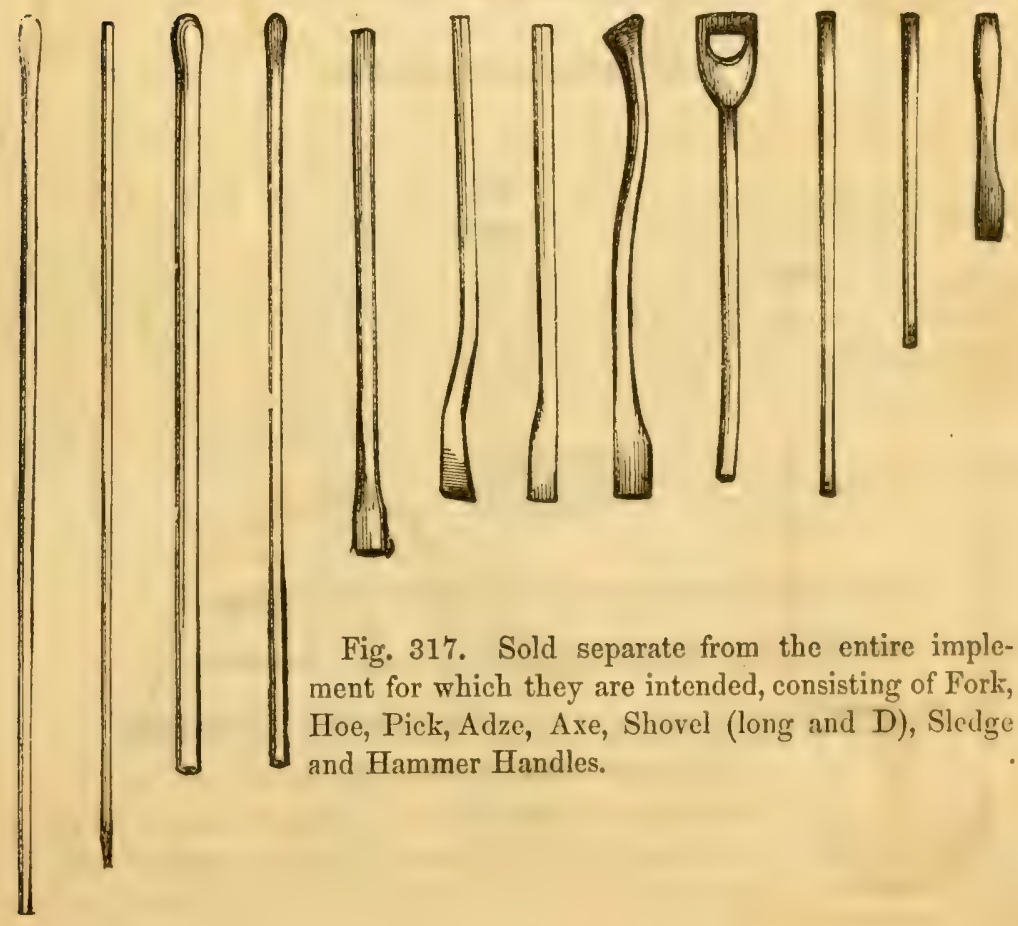

Fig. 317. Sold separate from the entire implement for which they are intended, consisting of Fork, Hoe, Pick, Adze, Axe, Shovel (long and D), Sledge and Hammer Handles. 
Fig. 318, with the various letters and figures for branding merchandise, farming tools, etc.

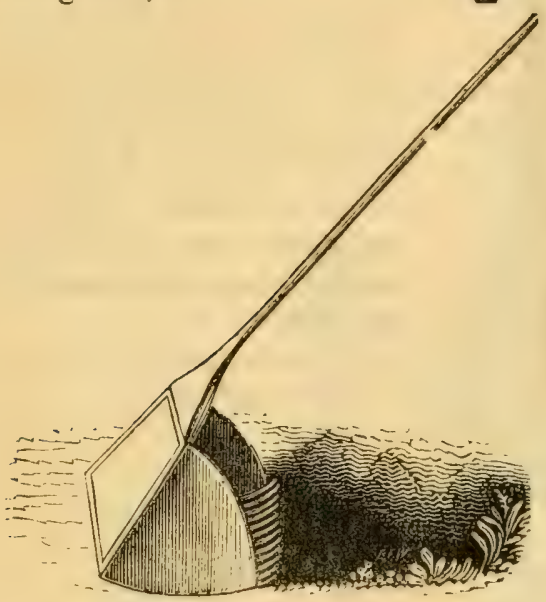

Fig. 318. Branding Ircns.

Fig. 319. Cranberry Rake.

\section{Fruit Gatherers.}

Fig. 320 represents two half-round cups of tin or other light metal, the size of a

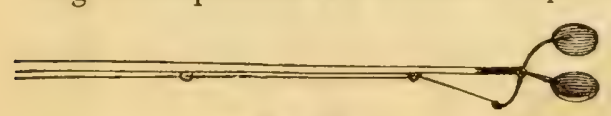

Fig. 320.

large apple, attached to iron arms confined to a light pole, along the side of which a strong string passes and is fastened to one arm. When this is drawn, it causes the cup to enclose the fruit, which is carried from the upper and outermost limbs with safety to the ground.

Fig. 321. This kind is made of tin or sheet iron, and placed on a handle;

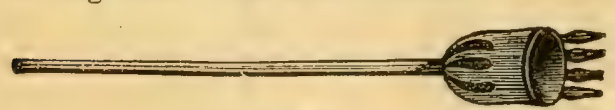
the stem of the fruit is passed be-

Fig. 321, tween the teeth and forced from the limb, and drops into the cup below. There are various other kinds.

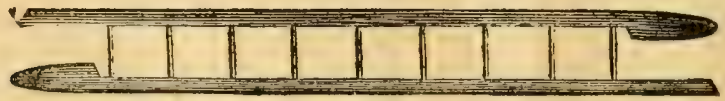

Fig. 322. Fruit or Folding Ladder.

Fig. 322 represents the Fruit or Folding Ladder, showing it both open and shut. It is a convenient article in orchards; it is made of various lengths; while shut, mav be set up among the branches of the fruit-tree with facility, and then opened 
for use. It is strong, yet very light and portable. They are of all lengths, from 6 to 18 feet.

These ladders are nseful in stores, libraries, etc.

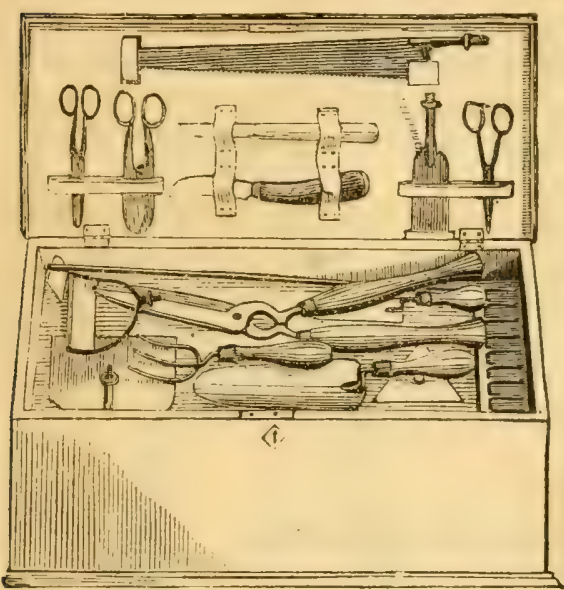

Fig. 323 Horticultural Tool Chest.

Fig. 323. A very useful collection of articles for the use of gentlemen or ladies, making up a complete set of Garden Tools, consisting of Pruning Saw, Pruning Chisel, Weeding Hoe, Garden Rake, Tree Scraper, and Scuftle Hoe, all of which are fitted to one handle, which may be screwed together or unscrewed as required, packed into the chest, and locked up. It also contains Twig Cutter, Vine Scissors, Flower Gatherers, Grafting Chisel, Grafting Hammer, Strawberry Fork, Flower Weeder, Transplanting Trowel, Weeding Trowel, Garden Reel and Line, Grass Shears, Sliding Pruning Shears, Pruning Knife and Budding Knives, or with more or less of these articles as wanted : and all so compact and light as to be easily carried about the nursery or garden with one band, by the handle on top. Chests are also fitted up, containing different assortments of tools, at different prices, to order.

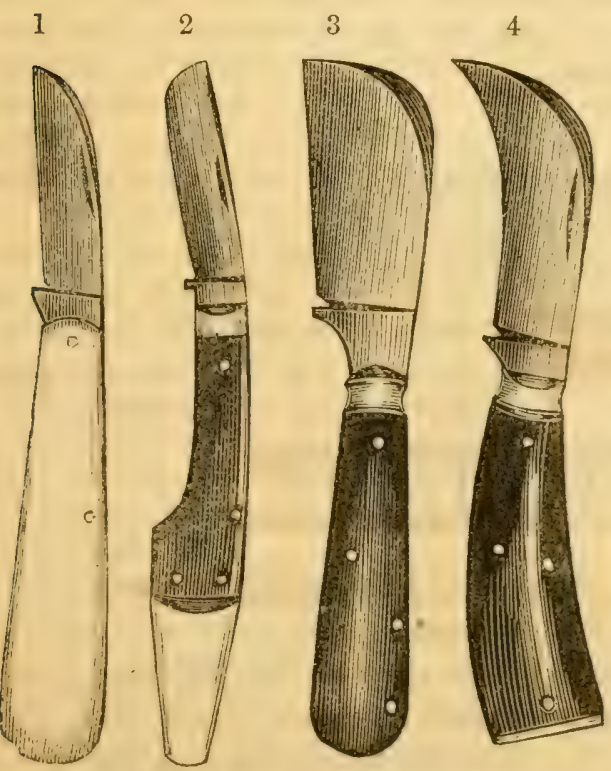

Fig. 324. Nos. 1, 3, and 4 are of convenient form for pruning young trees, and are made strong for that purpose.

No. 2 represents the most approved form for budding. Tha edge of the blade is rounded at the point, and will shut up as a pocket knife. At the other end is a thin flat ivory lifter, with which the baris is loosened and raised, after being cut to receive the bud-of these, we have a large assortment; also, leather rolls, containing a variety of blades saws, etc., etc., fitting one handle, forming a useful suite of pruning tools.

Fig. 324. Pruning and Budding Knives. 


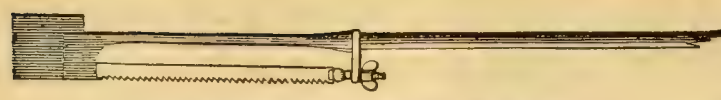

Fig. 325. The blade of the saw is about 12 inches long, attached to the blade of the

Fig. 325. Pruning Saw and Chisel. chisel at one end, and to the socket of the chisel handle at the other end. The chisel is 3 inches wide by 4 inches long, made thin and of the best cast steel. A wooden handle of convenient length is inserted in the socket handle, enabling a person to stand on the ground and trim his trees at convenience.

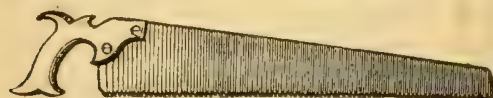

Fig. 326. Pruning Saw.

Fig. 326. This form is most commonly used, and is of various sizes, with fine teeth; it is usually from 12 to 18 inches long. We have another form of saw, which we prefer to No. 326 -it is wide on the edge, thin at the back, and the form of teeth is such as not to rag or separate the bark from the wood-the width is less than one inch, and of any required length.

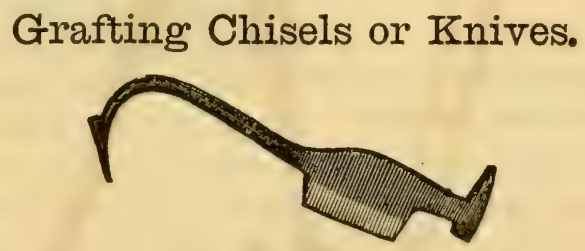

Fig. 327.

Fig. 327 represents a common Grafting Chisel. The wide edge is used for splitting the stock after being cut off with a pruning saw; the two pointed ends are used to open the same to receive the scions.

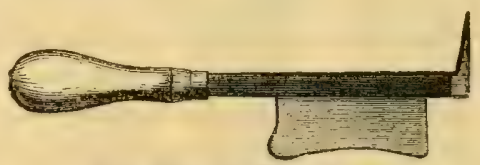

Fig. 328. Grafting Knife.

Fig. 328 is an improved Grafting Chisel or Knife, and is capable of being held more steadily when splitting the stock.

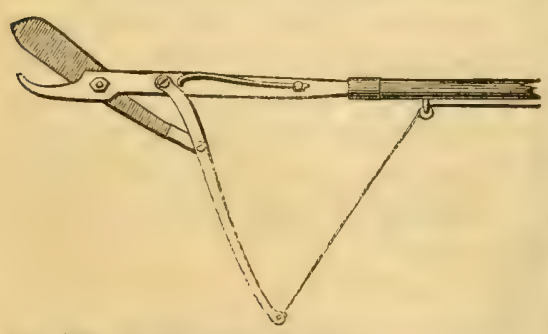

Fig. 329. Avarrancator, or Pole Pruning Shears.

Fig. 329. This article is attached to a pole, and operates by means of a lever moved by a cord and pulley; its use is to enable a person standing on the ground to prune trees, some of the branches of which could not, perhaps, be pruned by any other process. Branches of one inch in diameter may be easily cut off with this instrument. Avarrancators of small size are also very useful in cutting off from shade and fruit-trees small branches to which insects have attached themselves; 


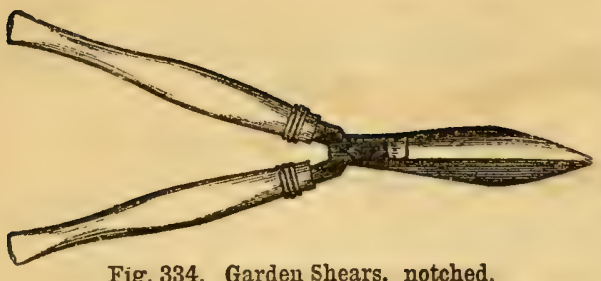

Fig. 334. Garden Shears, notched.
Fig. 334. These have the pruning notch, which is of considerable advantage when used for trimming hedges or shrubbery, as it enables the operator to cut much stronger twigs than would otherwise be cut by these shears.

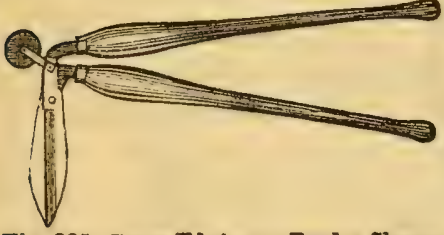

Fig. 335. These are chiefly used for trimming the sides of box and grass edgings, and are constructed so that the operator may stand upright while using them. They have a wheel attached, which is generally considered an advantage.

Fig. 335. Grass Edging or Border 8hears.

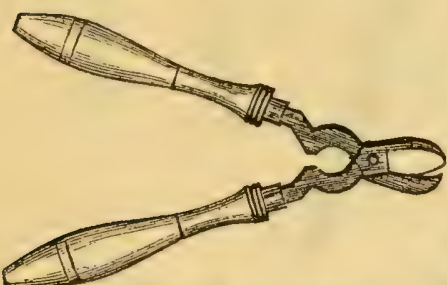

Fig. 336, with wood handles, are handsomely and lightly made; they are very useful in trimming shrubbery, etc., which is too large to be cut by the hand-shears.

Fig. 337. These are adapted to pruning flowers, etc., cutting small twigs and are a

Fig. 336. Ladies' Pruning Shears. very useful and cheap

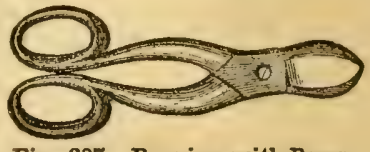

Fig. 337. Pruning with Bows. article for ladies' use. They are 5, 6, 7, 8, and 9 inches long.

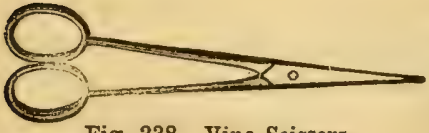

Fig. 338. Vine Scissors.

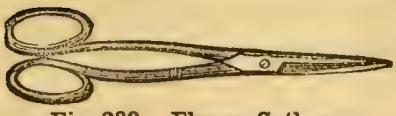

Fig. 339. Flower Gatherer.

Fig. 338. Used for thinning out grapes when they have grown too closely on the branch; also, for removing superfluous leaves, twigs, etc., from vines of any kind.

Fig. 339. A pair of scissors combining tweezers or pincers; they are of great advantage in gathering roses and other flowers which have thorny stems, as the flower cut by the scissors is held fast by that part which acts as pincers till deposited in a receptacle.

Fig. 340 represents the

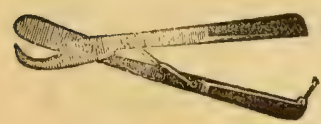
sliding shears, and Fig. 341 a French pattern which do not slide. Both are strong, light, and convenient.

Figs. 340.

Sliding Shears or Twig Cutter.

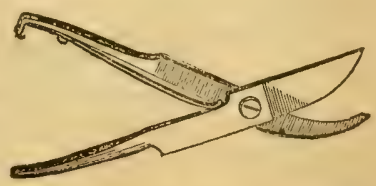

Fig. 341. 


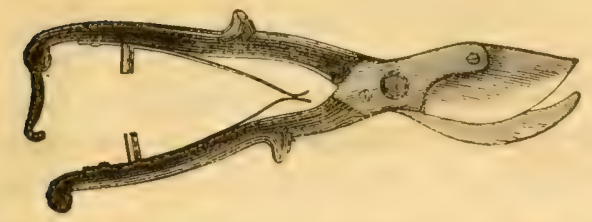

Fig. 342. Pruning Shears. New Pattern,-Cast Steel.

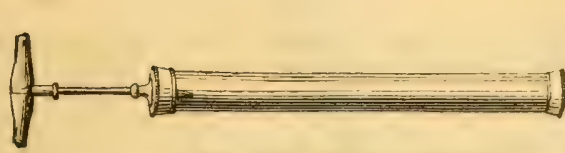

Fig. 343. Garden Syringe.

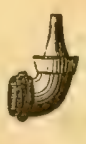

Fig. 343. Of various sizes and of various materials, as brass, Britannia, block tin, India-rubber, \&c. For watering the leaves and branches of trees, shrubs, and greenhouse plants, or destroying noxious insects by using various liquids, they are found to be very useful, and are extensively employed in flowergardens, nurseries and hot-houses, etc.

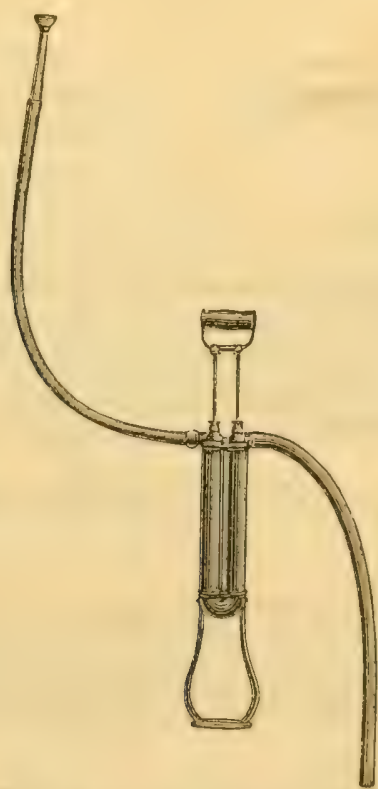

Fig. 344. Vose's Patent Hand Garden Engine.

Fig. 344 represents a new style of Garden Engine, to be worked by laand; the operator places his right foot in the stirup, and works the handle with the right hand; the short hose may be placed in a pail of water, and the long hose, held by 
the left hand and terminating in a nozzle, permits the exit of the water. This simple contrivance will throw 300 gallons or more of water per hour to a distance of 40 feet, and when furnished with a distributing-rose, is far superior to any other contrivance for watering plants. As a fire annihilator it is extremely useful, particularly in the country. It may be used for washing carriages, windows, etc. See description of the Aquarius, fig. 439, page 241.

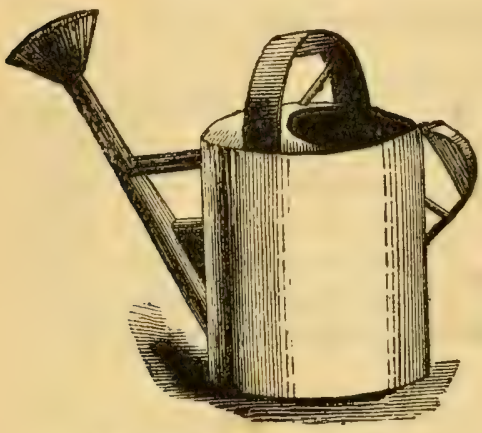

Fig. 345. Watering Pot.

Fig. 345 represents the ordinary Watering Pot. Of these we have a variety of kinds and sizes, with the several kinds of rose required for garden use, mushroom-beds, etc.

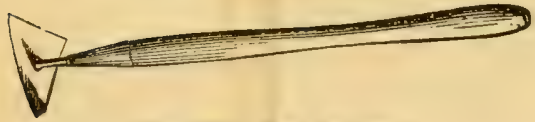

Fig. 346, Tree Scraper.
Fig. 346. A very convenient article for scraping and smoothing the bark of trees. It is simply a triangular plate of cast steel, each edge being four inches long, and attached to a short iron socket, through the centre, with a nut and screw, and a long or short wooden handle is fitted in the socket when used.

We have ship scrapers of a similar shape, for scraping floors, butchers' benches, etc.

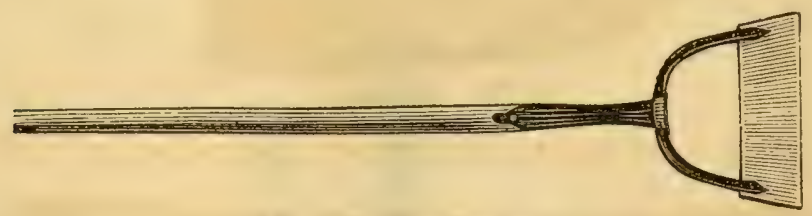

Fig, 347. Floor Scraper.

Fig 347. Used for cleaning the floors of groceries, markets, and other public places.

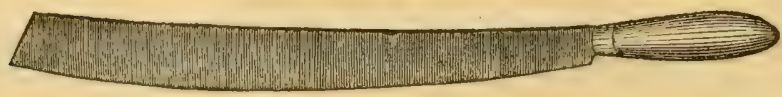

Fig. 348. Corn Knife.

Fig. 348 is a Corn Knife, used in the field for topping or cutting the stalks from their roots. 


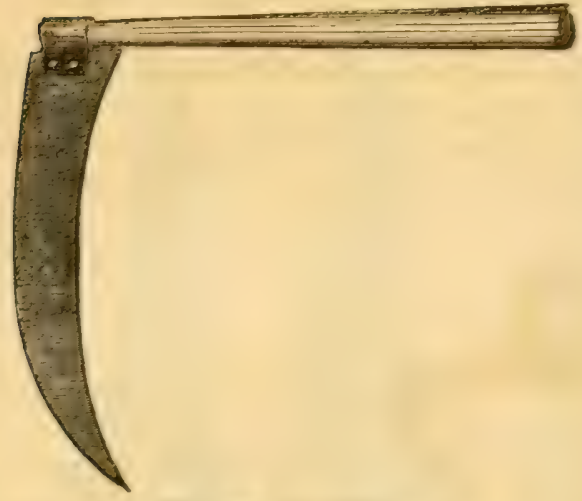

Tig. 349. Corn Cutter,

Fig. 349 is used for the same purpose as the above.

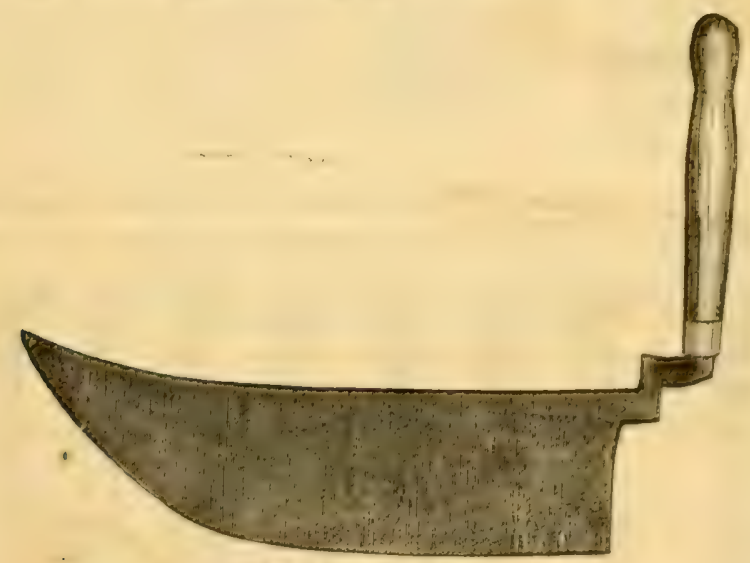

Fig. 350. Hay Knife.

Fig. 350. A Hay Knife, used for cutting down mows or stacks of Hay.

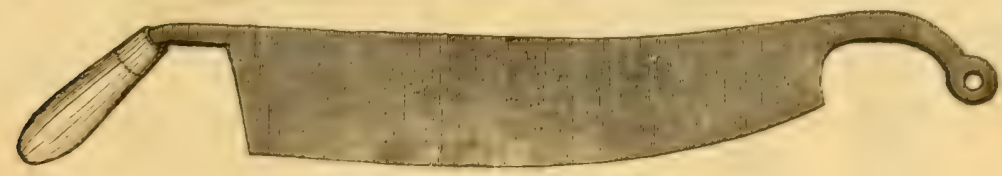

Fig. 351. Straw or Feed Knife.

Fig. 351. A kind of knife in greneral use for the plain or common cuttincr-box, and capable of being used with any analogous arrangement. 


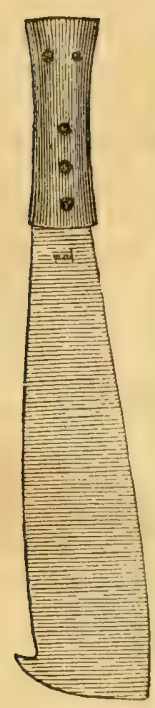

Figs. 352,

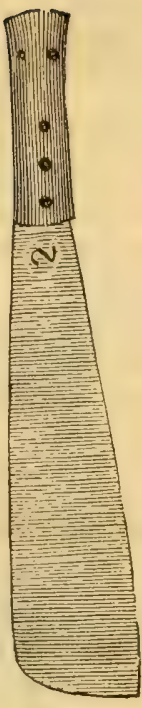

353 ,

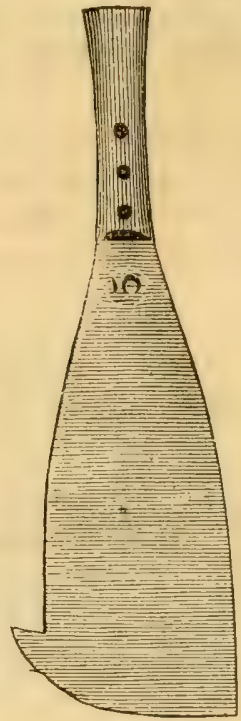

354 ,

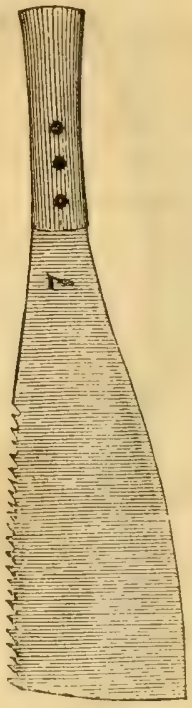

355 ,

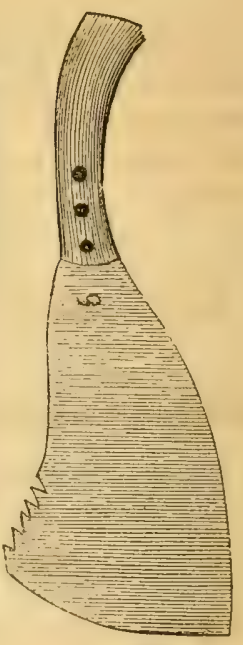

356.

These figures represent the Cane Kinives used in Cuba, South America, and else. where, and of which we have various other sizes and patterns.
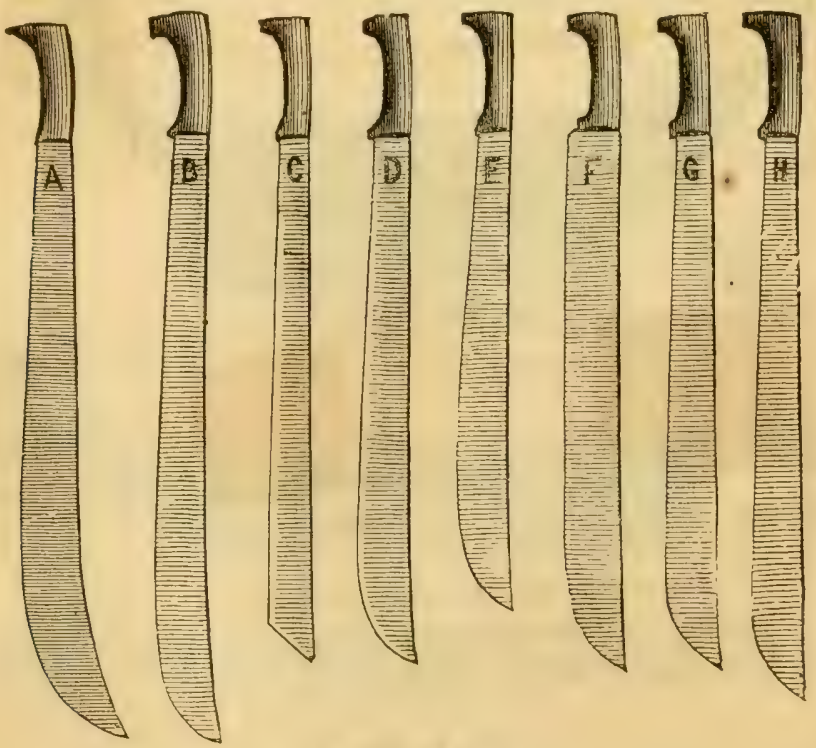

Fig. 357. Machetes.

Fig. 357 represents Machetes, or Cane Cutters, of eight different shapes and sizes. All the above are made of the best cast steel, and are highly finished. 


\section{Axes, Hatchets, and Hammers.}

Until within a few years these tools were all manufactured abroad, and the artisans who made them were prevented by law from leaving for the United States; but despite this ungenerous policy, American ingenuity has prevailed, and even the English colonies are now supplied with the best tools of these kinds from this country.

\section{AXES.}

Axes manufactured by Hunt, Collins, and others, of various patterns and sizes.

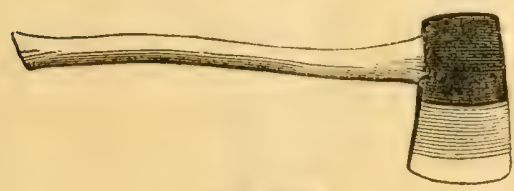

Fig, 358.

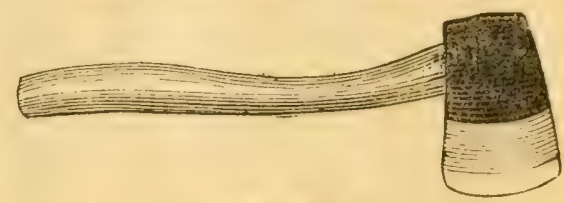

Fig, 359.

Fig. 358. Boys' Axe, handled.

" 359. Hand Axe or Hatchet.

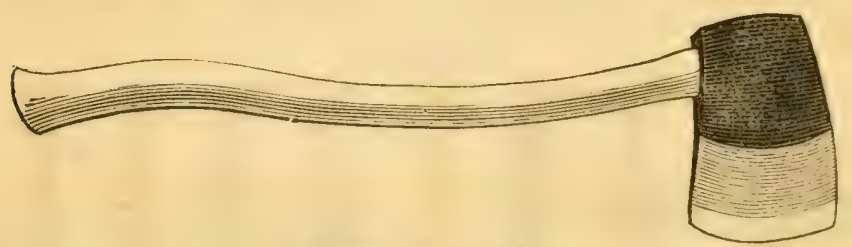

Fig. 360. Handled Are.

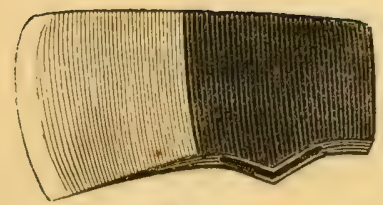

Figs. 361.

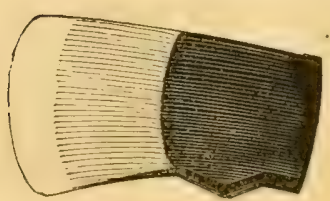

362.

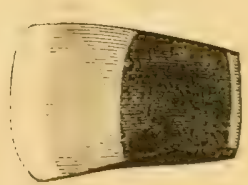

363.

Fig. 361. Spanish pattern of Axe.

" 362. Kentucky pattern of Axe.

" 363. New England pattern of Axe. 


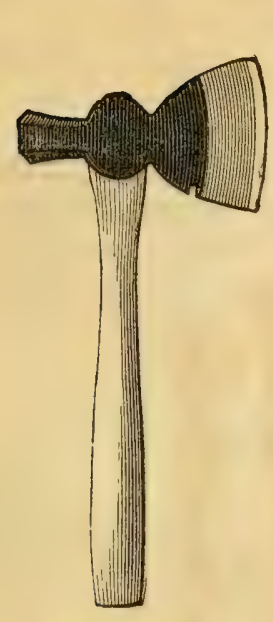

Figs. 364,
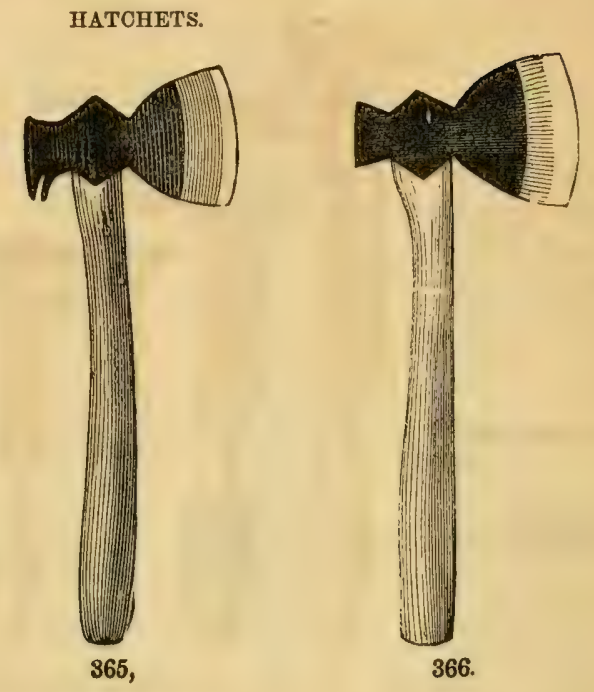

Fig. 364. Șhingling Hatchet.

" 365. Claw Hatchet.

"366. Broad Hatchet.

NAIL HAMMERS.

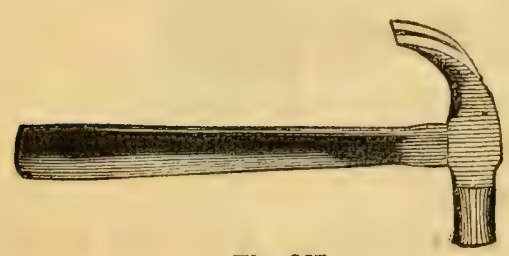

Fig, 367.

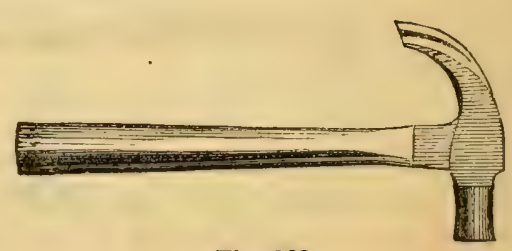

Fig. 368.

Fig. 367. Common nail, of solid cast steel or steel face.

"368. Adze-eye hammer, very strong.

Stone Hammers.-Of these we have every variety, which will be furnished to order.

Fig. 369 represents Coe's Patent Screw Wrenches. They are of various sizes and finish, as follows:

$6,8,10,12,15,18$ and 21 inches, Bright. 10, 12, 15, 18, and 21 inches, Black. By the arrangement and proportions of the parts, these wrenches are acknowledged to be the most convenient, efficient, and the strongest now made, and having been long in use and fully proved, are favorably known among our mechanics, manufacturers, and dealers.

The screw which moves the sliding jaw is expeditiously and easily operated by the thumb of the hand that grasps the handle, and the space between the jaws is adjusted to the size of the nut or screw to be turned, under any circumstances, 


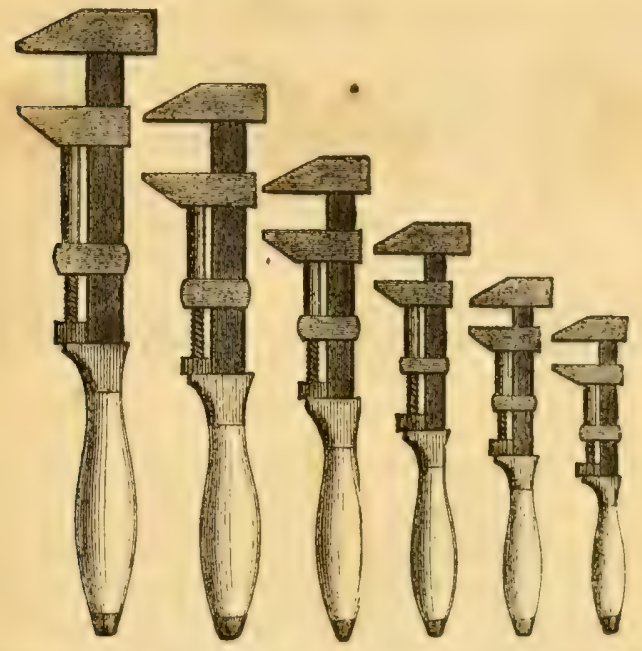

Fig. 369, Coe's Patent Screw Wrenches.

more easily without than with assistance of the other hand, which may be necessarily otherwise employed.

By placing the screw that moves the traversing jaw by the side of the shank, or main bar of the wrench, the full size and strength of the bar is attained.

\section{"The Universal" Wrench.}

PATENTED JANUARY 24TH, 1860.

Combining with the ordinary screw wrench, the power of gripping a round bar in a manner never before successfully attained.

"The Universal" Wrench is the invention of an engineer in the United States navy, who has long felt the necessity of having a tool like this, to supply a want experienced by all mechanics - of a wrench which, while perfectly applicable to all the purposes of the best screw wrenches, shall have the power of gripping firmly any cylindrical object, such as a bolt or worn nut, where the ordinary wrench is of no avail-and which can be sold at a low price. This combination has never before been attained, except in a tool too complicated and expensive ever to come into general use.

"The Universal" presents very nearly the same general appearance as the screw wrenches in most extensive use, but the jaws have a gripping motion toward each other, and being partly faced with a serrated steel plate, hold, with the greatest firmness, any cylindrical object placed between them, without the slightest attention on the part of the person using the wrench-the gripping motion being perfectly automatic. At all other times the wrench is precisely the same as the best description now in ordinary use. Combining as simply as this tool does, such important requisites at a low price, it is confidently offered to the attention of the 
trade and of mechanics generally. We are prepared to fill orders to any extent at manufacturers' prices.

8 in., \$12. 10 in., \$14. 12 in., \$16. 15 in., \$26.

For further description of. Wrenches, see page 224.

\section{UNDERDRAINING TOOLS, TILE MACHINES, \&.}

Underdraining may be viewed as the greatest of modern improvements. It secures the farm from drouth, enables larger crops to be raised with a less amount of fertilizing material, permits the soil to be worked with less expense, ameliorates its quality, presents all the necessary conditions for chemical change among its particles, gives a longer season to farming operations, and augments the profits of farming far beyond the cost of the improvement. For full instructions as to methods of underdraining and the advantages arising therefrom, see Working Farmer.

\section{Pratt's Ditching Machine.}

This machine is worked by a single team, and is capable of digging fifty rods or more per day, in soils of ordinary quality, and to a depth of three and a half feet. It removes the earth, placing it on each side of the ditch, and of any required width of cut.

\section{Mapes' Lifting Subsoil Plow.}

This implement is also used for cutting ditches. It acts like a horizontal pick, loosening the earth for a few inches, which may be repeated even to a depth of five feet.

For a full description and its use, see Working Farmer.

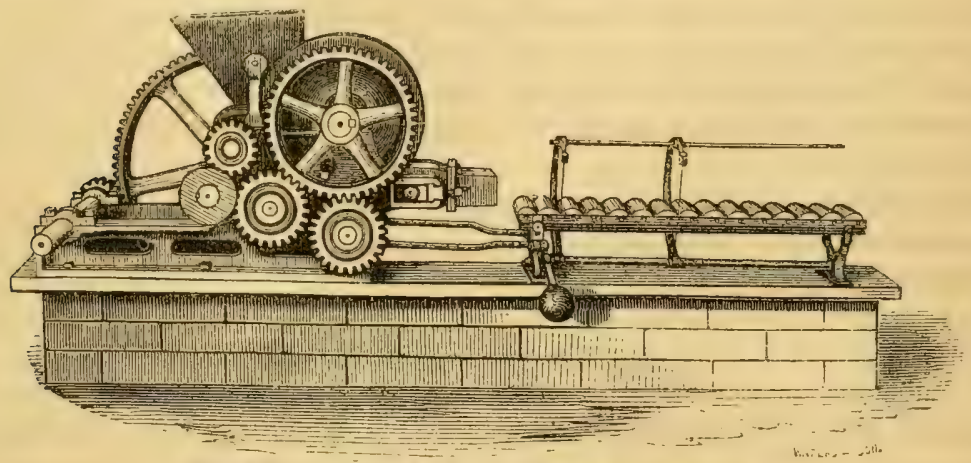

Fig. 372. Salisbury's Patent Tile-Making Machine, 


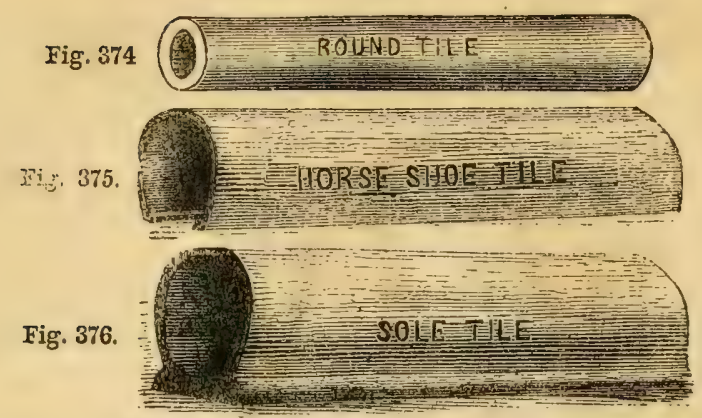

Figs. 374, 375, 376. Of these we have every variety of form and size, including collars when required, silt-basins, etc.

Fig. 377 represents the spades used in underdraining; in addition to those represented we have a variety of levelling tools, scoops, and others, for finishing last cut prior to depositing the tile in place; they include all the tools used by the English drainers, with a few improvements introduced in the Central Park, New York, and elsewhere.

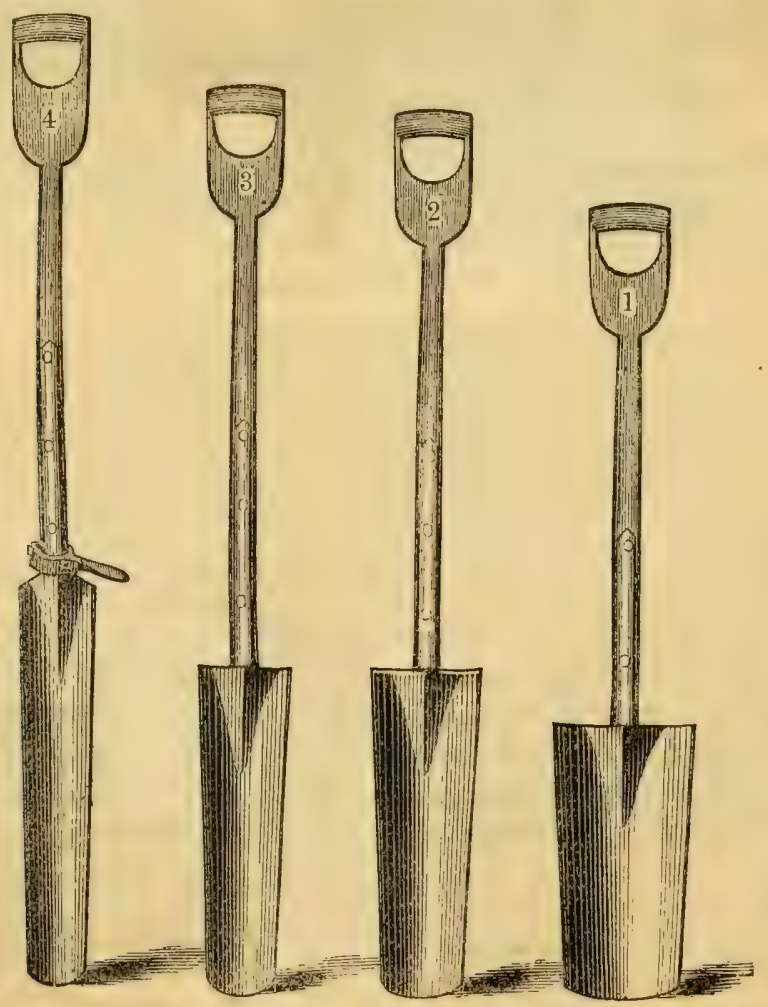

Fig, 377. Draining Tools. 


\section{GARDEN ENGINES, PUIIPS, ETC.}

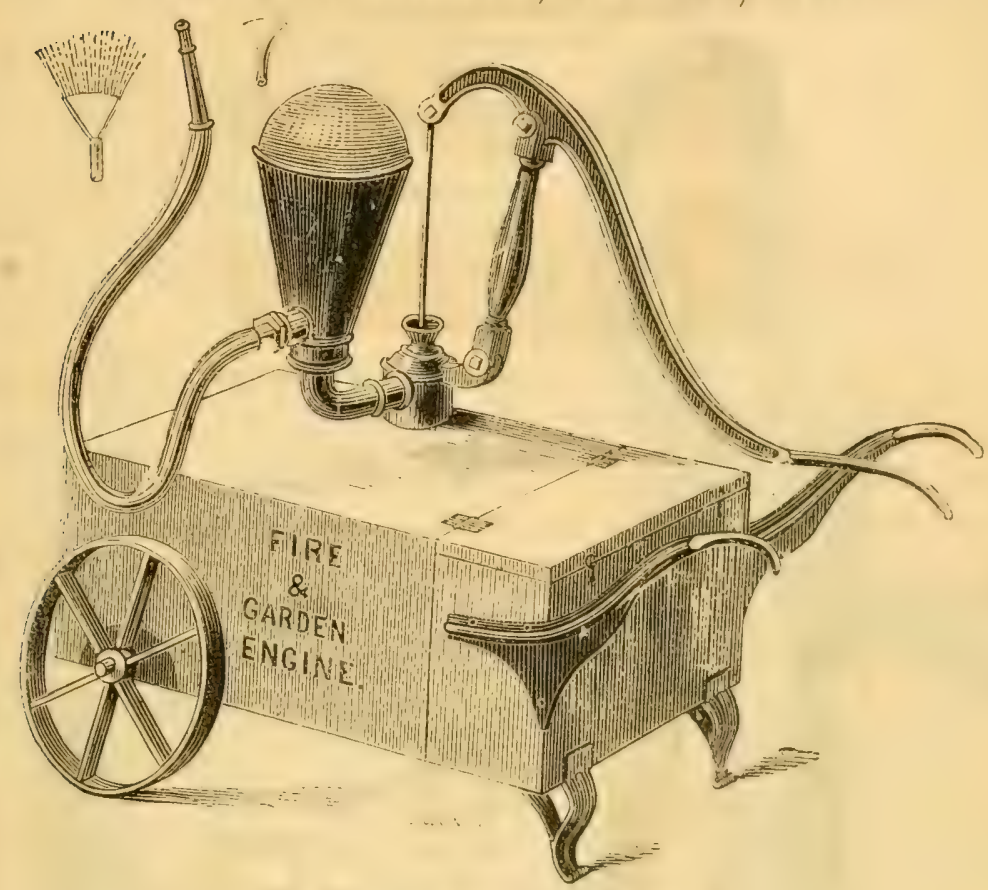

Fig. 378. Fire and Garden Engine.

Fig. 378 represents a Garden Engine arranged on wheels, so that it can be movec: by one man, even when filled with water. The force pump is supplied with an air chamber, so as to insure a steady stream without intermission, rendering it efficient for garden and nursery use, destruction of insects on trees, extinguishing fires, etr.. The box will contain 50 gallons, and the forec is sufficient for the wetting of ruols in case of firc.

Figg. 379. The box of this engine will hold 40 gallons; the engine has handle: and cast-iron wheels, so that one person can move it, and will throw water 70 feet horizontally, and 40 fect high, with one person to work it. It is well calculated for watering gardens, washing windows, destroying worms on trees or shrubbery, protecting buildings against fire from other buildings, etc. This engine is useful to horticulturists, and particularly serviceable in drought for watering gardens, nurscries, etc. It is extremcly simple in construction, and easily worked.

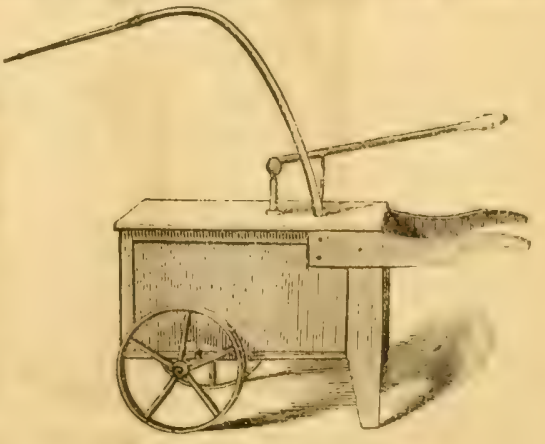

Fig. 379. Garden Eugine. 
Vose's Patent Garden Engine and Fire-Annihilator; for a description of this simple and cheap implement see Fig. 344 .

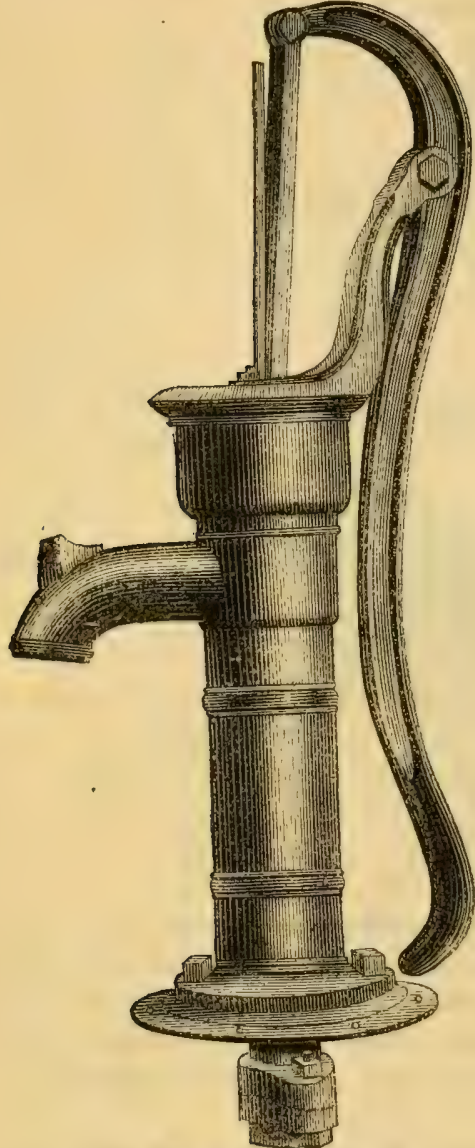

Fig. 380. Molasses or Hot-Water Pump.

Fig. 380 represents the molasses or hotwater pump. Of these we have several sizes, both of brass and iron, those of brass being particularly suited to fluids of acid tendencies, being less corrosive than iron,

No. 1 of $3 \frac{1}{2}$ inch bore, suitable for 2 inch pipes.

$\begin{array}{lllllll} & 2 & 4 & \text { " } & \text { " } & 2 \frac{1}{2} & \text { " } \\ \text { " } & 3 & 4 \frac{1}{2} & \text { " } & \text { " } & 3 & \text { " }\end{array}$

The top and brake or handle revolves round to any point most convenient for use.

Fig. 381. These pumps are of simple construction, and every part perfectly fitted. They are so made that they may be taken apart and access gained to all the valves without taking up the pipes or even detaching the platform to which the pump is fastened.

It will be seeh, from their simple and convenient construction, that the whole pump may be taken apart, examined, and repaired if needed, and replaced ready for operation in a few minutes, and that without the use of tools. The spout may be made to revolve simply by loosening the upper part of the stock, which will enable the spont to be placed in any desired position, which is a great convenience when the pump is to be placed in the corner of a room, and renders the same pump applicable for various locations. To avoid freezing, the water may be let out of the pump by 
raising the brake to its extreme height. These pumps will draw water as well horizontally as perpendicularly.

No. 1, 2 inch bore, 5 inch stroke.

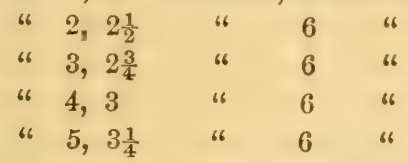

For Nos. 1 and 2 use $1 \frac{1}{4}$ inch pipe. For Nos. 3, 4, and 5 use $1 \frac{1}{2}$ inch pipe.

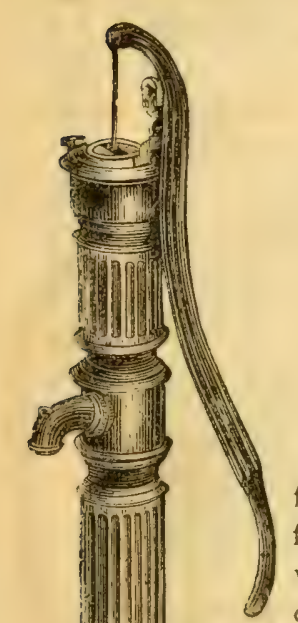

Fig. 382 represents a pump intended for wells of twenty-five feet depth and less; it is large and strong, and well calculated for an out-door pump. It is constructed so as to throw water with great ease and rapidity. The whole pump being made of iron, we can safely say that it is a durable and desirable pump for wells. The piston and valves are placed in the lower end of the pump, which is about three feet below the base. At the upper end of the cylinder we place a small hole, which allows the water to drain out of the pump, above the hole, when it is not in operation; this prevents the possiblity of its freezing in winter. We arrange this pump for wood, lead, zinc, or iron pipe, as may be desired.

For No. 1 of this kind use $1 \frac{1}{2}$ or $1 \frac{3}{4}$ inch pipe. For No. 2 use 2 inch pipe.

Fig. 382. Yard Pump. 
Fig. 383 is a simple force pump for elevating and forcing water into upper rooms, by the attacliment of pipe to the nozzle or upper tube. Of these we have several sizes.

\section{The American Pump.}

WITHOUT SUCTION-WITHOUT PACKING. PATENTED APRIL 5TH, 1859.
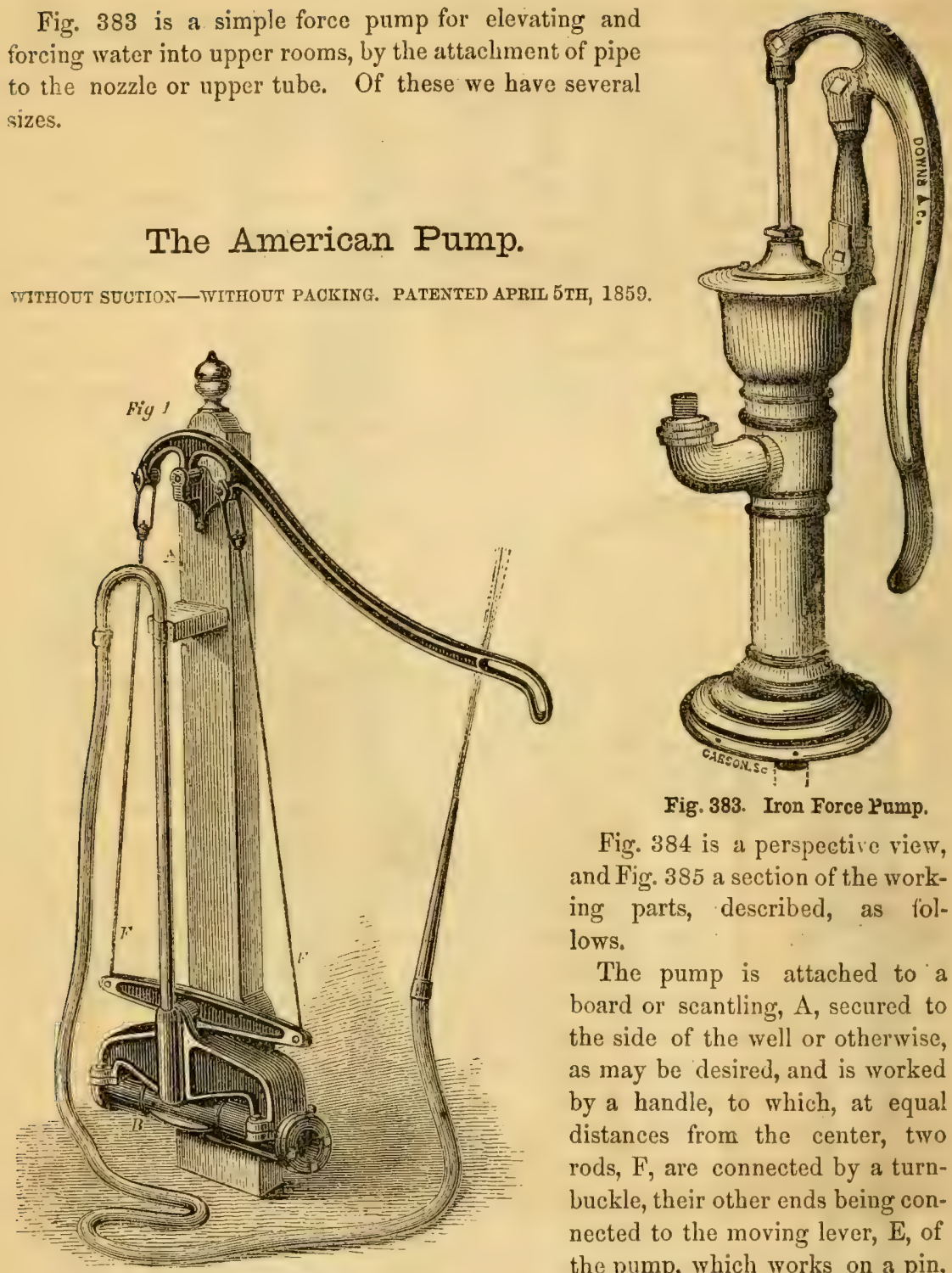

Fig. 383. Iron Force Yump.

Fig. 384 is a perspective view, and Fig. 385 a section of the working parts, described, as follows.

The pump is attached to a board or scantling, A, secured to the side of the well or otherwise, as may be desired, and is worked by a handle, to which, at equal distances from the center, two rods, F, are connected by a turnbuckle, their other ends being connected to the moving lever, $\mathbf{E}$, of the pump, which works on a pin, G. This lever, E, is T-shaped, and moves through a space, $I$, in the air-chamber, $H$, cast to receive it. The pumpbarrel, B, has closed ends, D, and the double piston, C, with its valves, J, works horizontally therein. $\mathrm{K} K$ are the valves of the air-chamber. The operation is as follows:

The pump is immersed in water, and the handle being given a recipro- 
cating motion, the T-piece, E, receises a similar one through the rods, $\mathrm{F}$. This gives the piston a horizontal back and forth motion, at each of which it takes

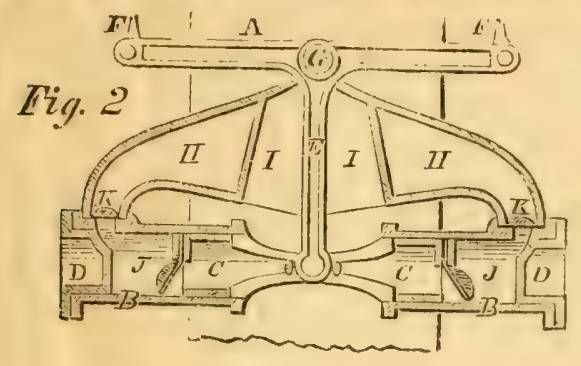

Fig. 385 . in a quantity of water and forces it into the air-chamber, and thence through the pipe upward to any height. 'To this pipe a hose is here attached to show how it throws water, etc.

One of these pumps may be seen working successfully in this city andelevating water 70 feet. We have 5 sizes. Circulars will be sent on application, giving full particulars of cut, etc.

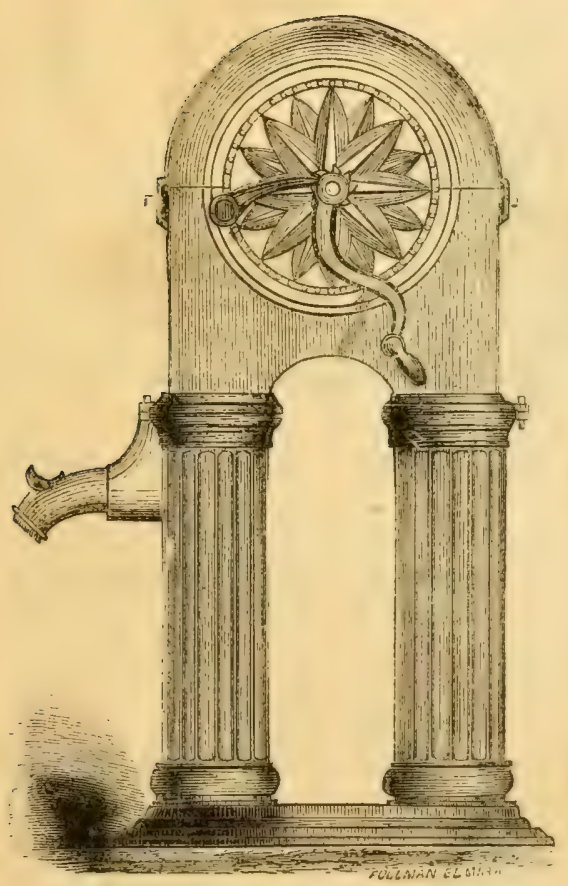

rig. 386.

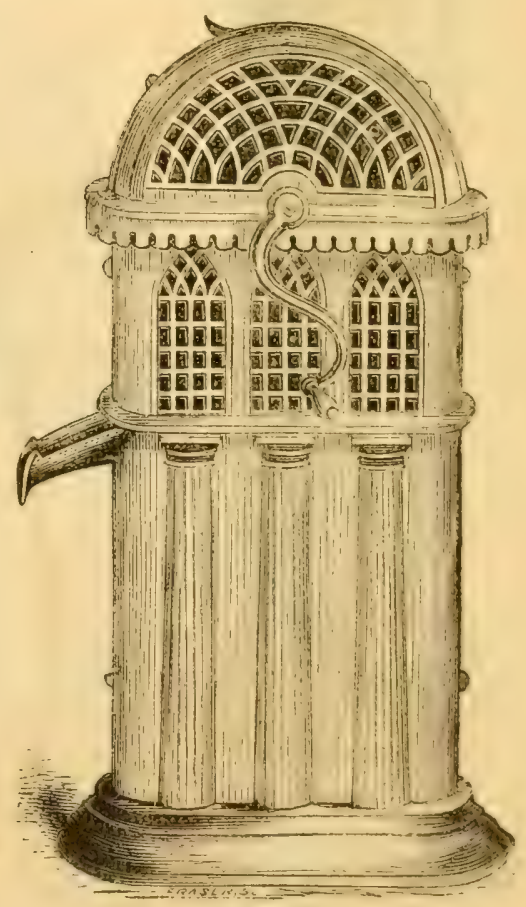

Fig. 387.

Figs. 386 and 387 are Iron Well Curbs, representing the forms u*Ially adopter for chain pumps. 


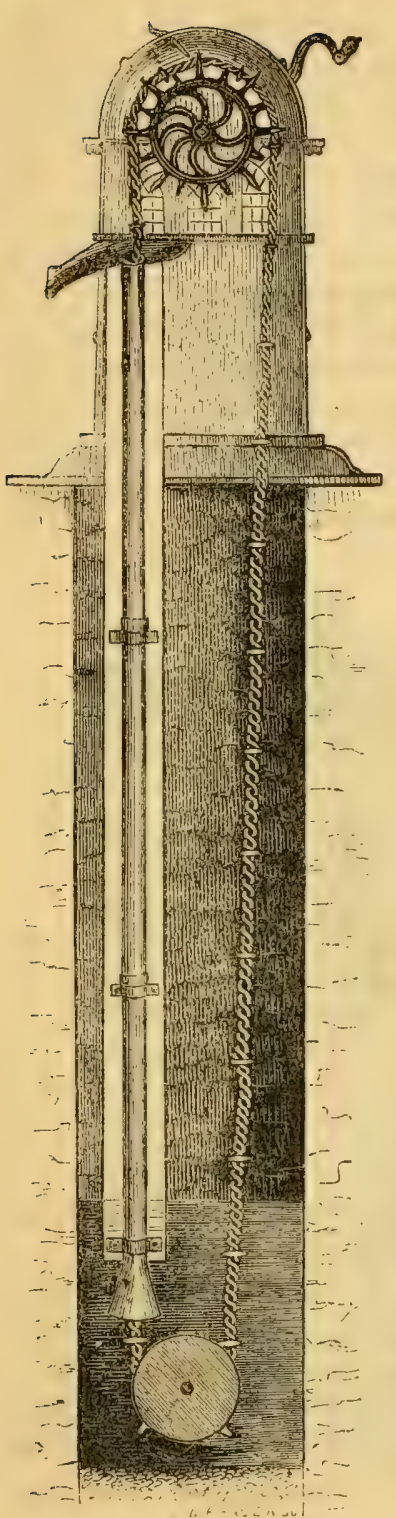

Fig. 388. Endless-Chain Pump.
Fig. 388 represents the Endless-Chain Pump, which is a very cheap and expeditious method of raising water perpendicularly from wells, cisterns, etc.

They are very much less liable to get out of order than other pumps, and cannot freeze in the most exposed locations.

As here represented, the pump has zinc tubing; but since the wooden tubing has been made from the solid stick it has been more generally used.

We can furnish these pumps of a varicty of sizes and patterns, some highly ornamented.

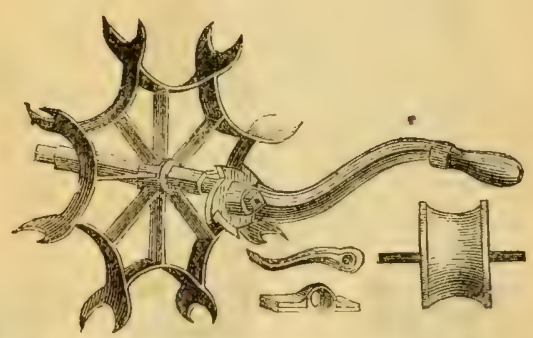

Fig. 389. Improved Wheels and Firtures for Chain Pumps.

Fig. 389 represents the improved wheels and fixtures for chain pumps. They are a very perfect and superior article, and most admirably adapted for the purpose required. The wheel which we are now making has eight more bearings or arms (on which the chain can rest in revolving) than shown in the cut, causing it to work more steadily and with less friction and wear on the tubing.

These can be furnished separately from the chain tubing, etc. 


\section{WATER RAMS.}

Fig. 390 represents the more recent form of Water Ram as now made, and of which we have 6 sizes.

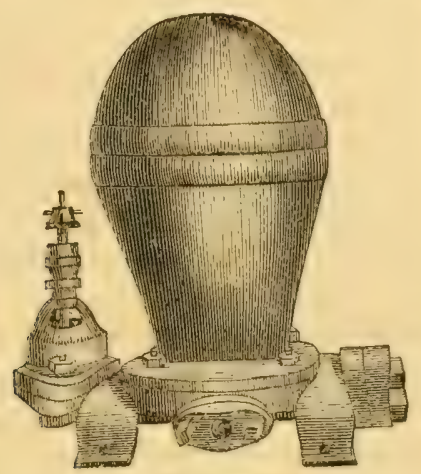

Fig. 390 .

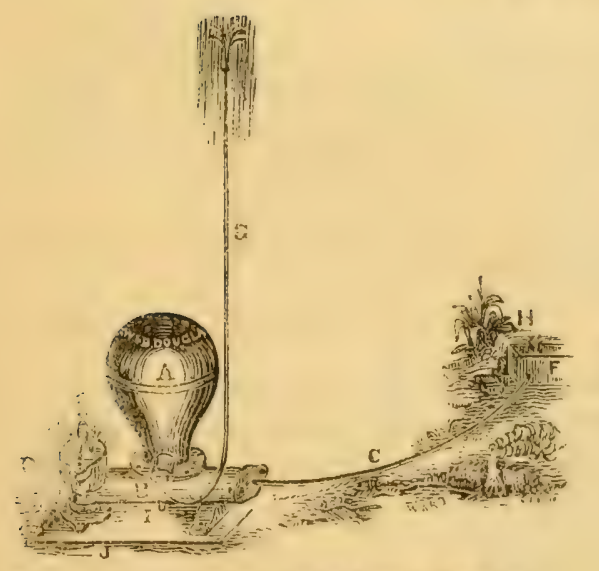

Fig. 391. Explanation.-H is the brook, spring, or fountain; $\mathrm{C}$, the supply or drive pipe; $G$, the pipe which conveys a part of the water from the drive pipe to the place where wanted; $A$, the air-chamber of the ram; E, top of the brass valve; $D$, water wasting through the valve, by which the power of the ram is secured.

Fig. 391. Water Ram, or Self-Acting Elevator. 


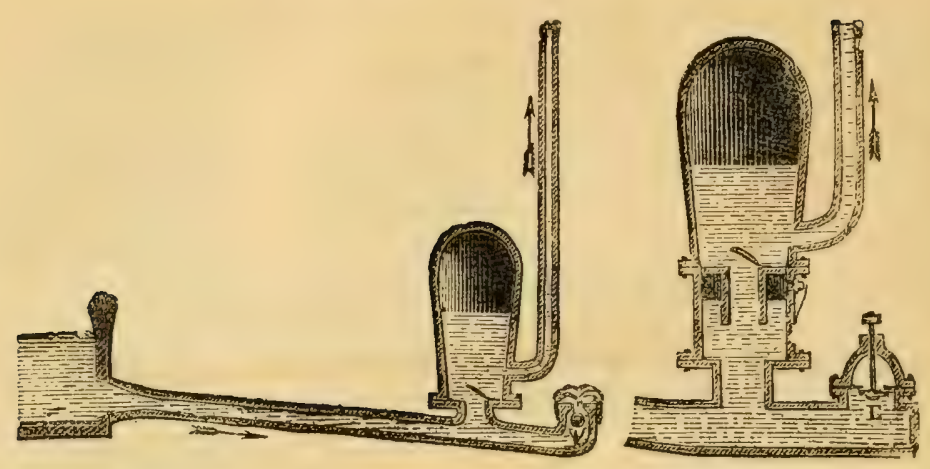

Fig. 392. Water Ram,--Sectional view.

The simplicity of the operation of this machine, together with its effectiveness and very apparent durability, render it decidedly an important and valuable apparatus for forcing a portion of a running stream of water to any distance and elevation proportioned to the fall obtained.

It is applicable where no more than 18 inches fall can be obtained, yet the greater the fall applied, the higher may the water be conveyed-the quantity raised varying in proportion to the height with a given fall.

Wherever a large spring, or a limited but constant stream, is at hand, by which a fall of four or five feet may be produced, by building a dam or otherwise, a considerable portion of the water of such stream may be raised to a perpendicular height of more than 100 feet by its own power. Thus, a stream in a deep valley, or a river, or brook, situated some distance below a point where it is desired to have a cistern or reservoir, may be made to raise itself by one of these machines. From such a cistern or reservoir the water may be conveyed to any part of the premises of a lower yard, and applied to the purposes of irrigation, the watering of stock, the supply of manufactories, or for domestic or ornamental use. By this means, lawns may be kept fresh and green through the driest weather, fields and gardens may be irrigated, fountains be kept playing, and public buildings, hospitals, hotels, private dwellings, and manufactories may be copiously supplied with water in their highest apartments.

The proprictors furnish these machines to order, of 6 sizes, and at a moderate cost. They will raise from 5 to 50 gallons per minute.

The plate, Fig. 393, represents the various tools used in securing the ice-crop. The tools used in this business are its own, peculiar and beautiful, of great variety, and some of them costly, but very effective. The ice-cutter alone has been estimated as of the annual value, to the ice-cutting business of the Northern United States, of twenty thousand dollars.

In the engraving, No. 1 is the marker, No. 2, the plow or cutter; No. 3, the hand cutter; No. 4, grappling tongs; No. 5, the grooving bar; No. 6, the ice-chisel ; 
C. V. mapes' iliustrated Catalogue.

Ice Tools.
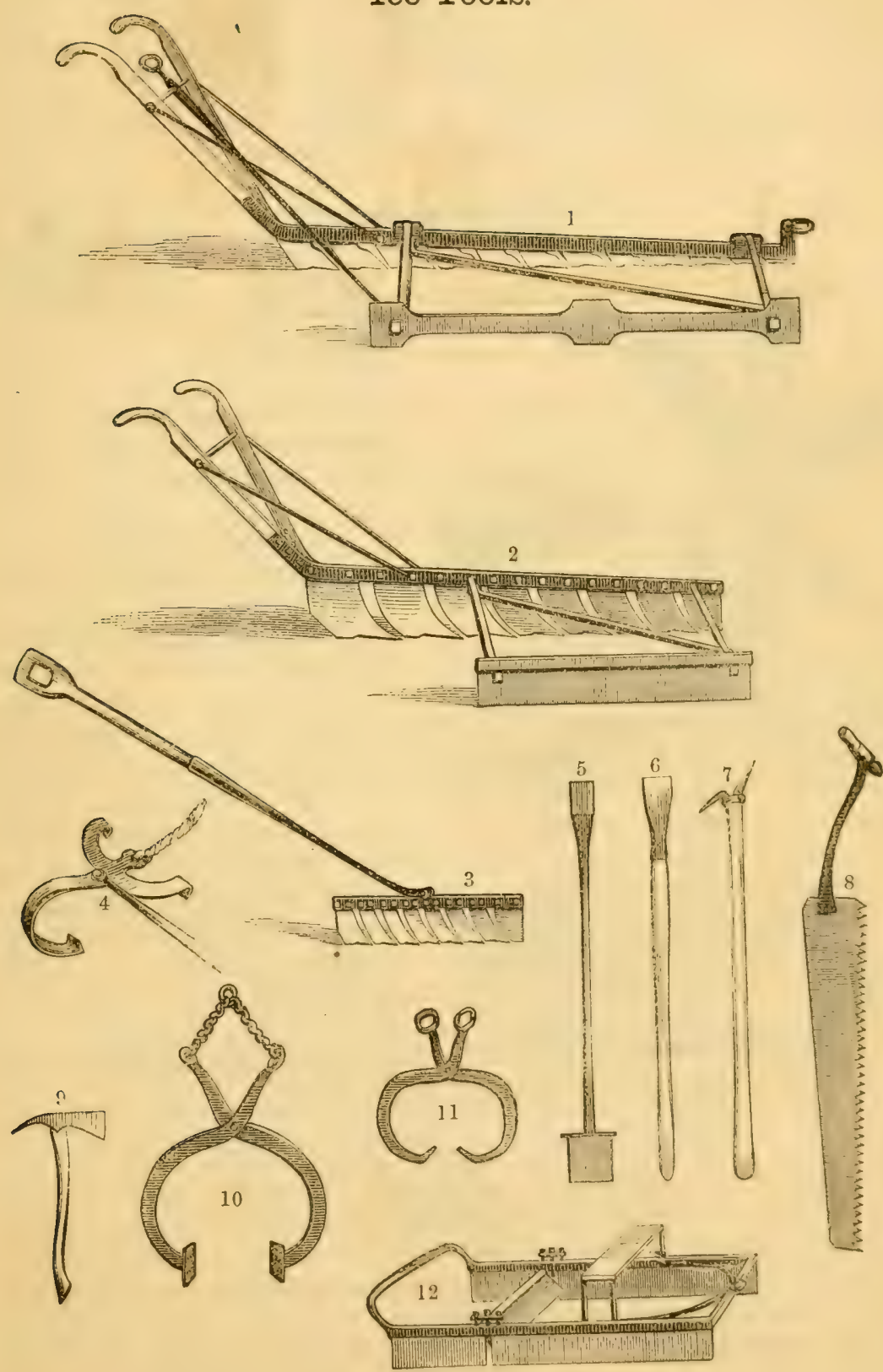

Fig 393. Ice Tools. 
No. 7, the ice-hook; No. 8, the hand-saw; No. 9, the axe; No. 10, the tongs for hoisting ice; No. 11, smaller hoisting tongs ; and No. 12, the ice-plane.

The ice business is peculiar to this country; the proprictors of the ice-houses of the northern and eastern states supply the British and other East Indies, the West Indies, South America, and indeed the whole southern world, with this luxury. This business may be viewed as the exponent of American ingenuity and enterprise, rendering the very latitudes a cause for enterprise.

\section{Wind Mills.}

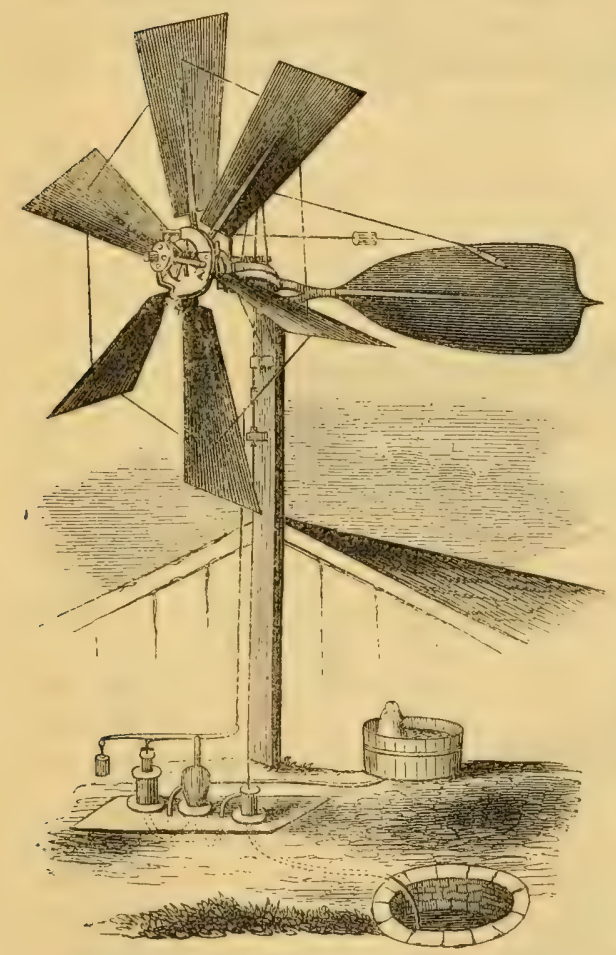

Fig. 394. Halladay's Patent Self-regulating Wind Engine.

Fig. 394. The attention of planters, superintendents of railroads, and scientific engineers generally, is called to Halladay's Patent Self-regulating Wind Engine, which is now in successful operation on some of the most noted railroads in this country. They are also in use in nearly every state in the Union, supplying public and private houses, fish-ponds, fountains, farmyards, stock-pastures, etc., with running water.

It is now six years since our first wind engines were put in operation, and not a single failure has ever come to the knowledge of the inventor. We believe there are but few wind engines ever offered to the public, which, in the variable velocities of the wind, are as fully under the control of a governor or an attendant, as is the steam engine. The wind-wheel as heretofore constructed, revolved with such velocity in high winds, that it soon destroyed itself, or greatly injured any kind of machinery attached, besides requiring the constant care of an attendant. Repeated experiments on railroads and farms in various parts of the country, had nearly discouraged the use of the wind as a motive power, until Halladay's Wind Engine was introduced.

The above-named difficulties are now entirely obviated, for, by a simple yet ingenious device, as the wind increases, the sails or wings gradually change from the angle at which they were set for a common breeze, presenting less and less surface or resistance to the wind, till finally, when the tempest is at its height, 
little is presented to its power except their thin edges; consequently, the steady, uniform motion produced, renders the mill and machinery moved by it, as safe and durable as that carried by a water-wheel. $\Lambda$ simple arrangement is made, whereby this wind engine stops itself when the cisterns are full, and starts itself again immediately when the water is drawn down a few inches.

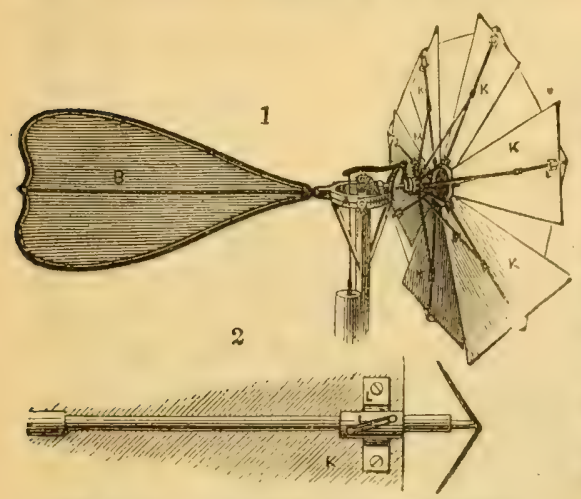

Fig. 395. Brown's Vermont Wind Mill.

Fig. 395. This Mill is ingenious, simple, and a perfect regulator of its own motion. It spreals a wide sail to a light breeze, and a small surface to a heavy one-the direct force of the wind, combined with the centrifugal force generated in the sails themselves, being made use of for governing the velocity of the mill.

Each of the arms or radii of the windwheel is furnished with a fan, or broad surface to receive the wind. The obliquity of the fans to the wind governs the velocity of the wind-wheel; and the velocity of the wind-wheel governs the obliquity or angle of the fans to the wind. Each fan or sail, with the attachments which secure it to the arm, may be regarded as a sliding weight, and as such performs the same functions as the weight upon the arm of the common steam-governor. Any increased velocity gives this weight an outward tendency, and while in the act of so doing, a helical slot slides against a strong steel pin made fast in the arm, and causes the weight or fan to become more oblique and expose less surface to the wind. When the velocity is sufficiently reduced, a coiled steel spring causes the fan to return to its former position.

The wind-wheel is therefore a governor whose revolving weights take the form of broad flat surfaces to receive the wind, thus making it in the simplest manner, and with the intervention of the least possible mechanism, both motor and governor.

The mill may be stopped, or put in position for starting, with ease and in a few seconds, and can be easily managed and kept in order-thus furnishing the means of using the almost unlimited power of the wind for pumping water, for irrigating or draining land, watering cattle, or for honse purposes; raising it from ponds, reservoirs, running streams or, deep wells; for grinding or threshing and cleaning all kinds of grain ; cutting fodder, sawing wood, or driving any ordinary machinery.

\section{Ericsson's Caloric Engine.}

It has been long an admitted adage among enginecrs that "when less than five horses' power is required, that steam cannot be used with profit;" and it has remained for the great mind of Captain Ericsson to supply a motor which may be used for any amount of power from that of one man to that necessary for the more extensive uses. 


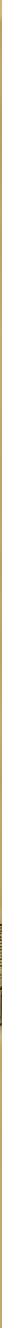

Fig. 396. Ericsson's Caloric Engine.

We are now prepared to supply the Caloric Engines of various sizes, from 12 inches diameter of cylinder to 42 two-inch twin cylinders. These engines cost more than steam engines of the same power, but the expense of running them is materially less; so that when the first cost and expense of running them are both taken into the account, they are much cheaper than steam engines. There being no boiler, no explosion can take place, and no engineer is required to work them; the parts affected by wear are casily renewed at small expense, and the cost of fucl docs not exceed one-tenth of that usually consumed by steam engines of similar power. Their use does not increase the rate of insurance as with steam engines. 


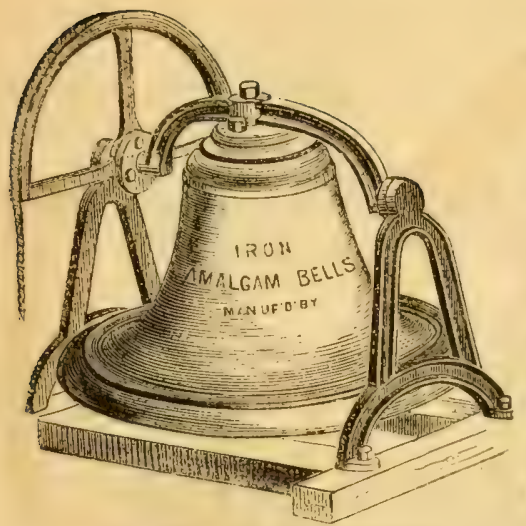

Fig. 397. Iron Amalgam Bell.

Steam Engines of all sizes and kinds made to order.

Fig. 397 represents this peculiarly cheap bell, which is rendered sonorous by a mixture of other metals with iron, and the mass is not only sufficiently homogeneous to give the necessary function-production of sound-but at a cost materially less than when made of the usual bell metal.

These as farm bells are efficient, and we have them of various sizes, from $\$ 8$ to $\$ 24$.

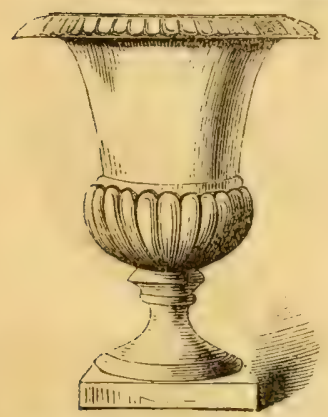

Garden Ornaments.

Fig. 399. Small Iron Vase.

Fig. 399 is an iron vase, bronzed, white, or of the material color of the metal.

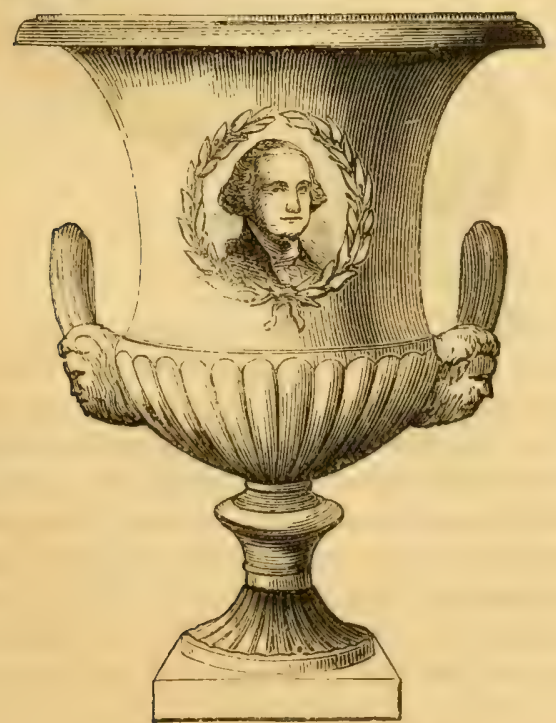

Fig. 400. Washington Vase.

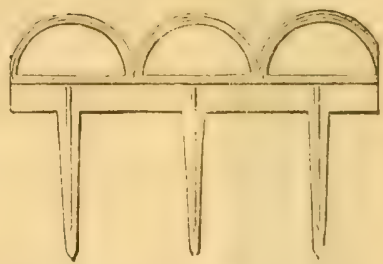

Fig. 401.

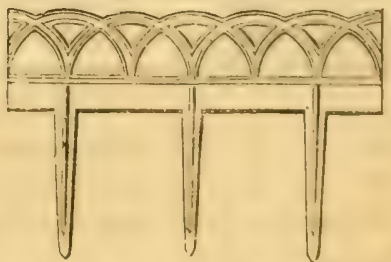

Figs 401, and 402. Garden Borders. 
Fig. 400 is known as the Washington Vase. We have a variety of patterns of vases, including the Warwick, Etrusean, etc.

Figs. 401 and 402 represent two patterns of Garden Borders. Price 16 to 20, cents per foot.

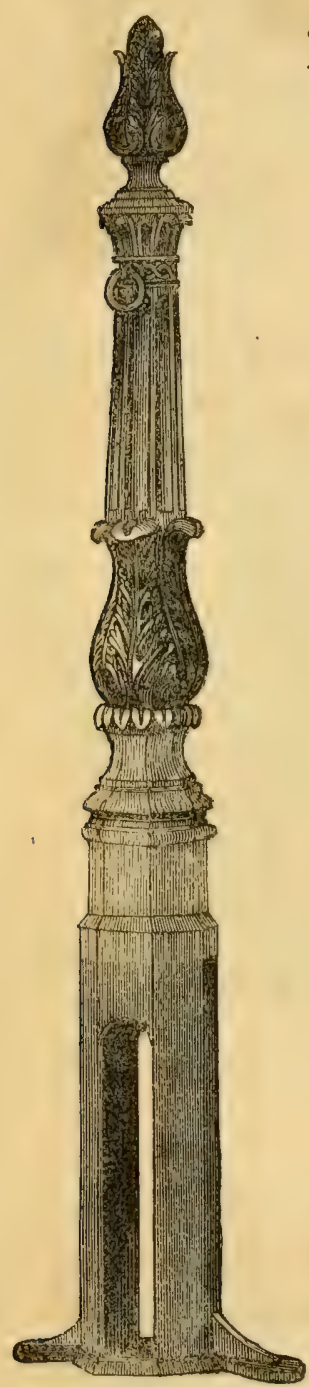

Fig. 403 is so arranged that a piece of locust, cedar, or other durable wood may be inserted in the lower end, so as to increase its length for insertion into the ground.

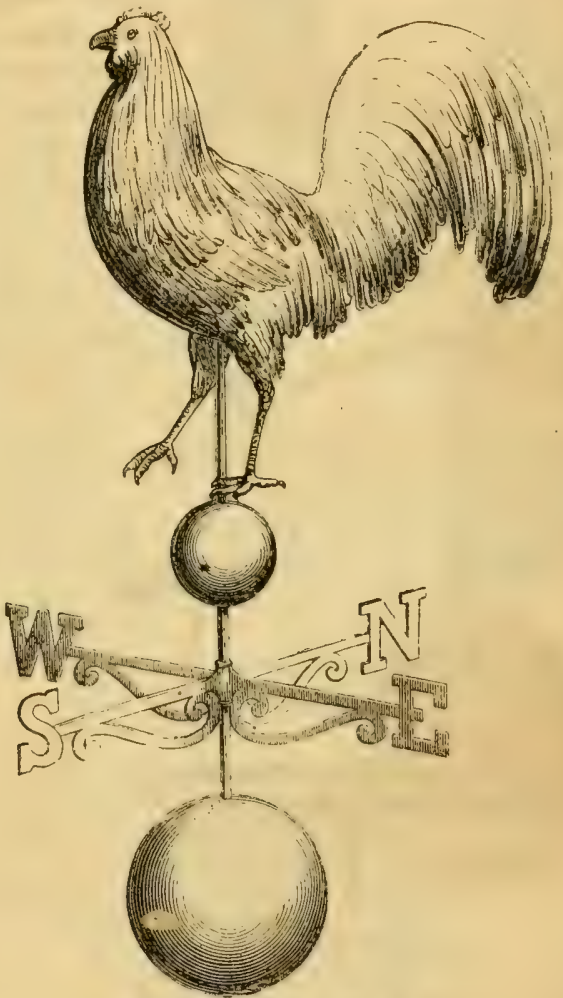

Fig. 404. Weather Vanes.

Fig. 404 represents a weather vane, of which we have a great variety, viz.: Darts, 3 sizes; Deer, 2 sizes; Fancy, 6 sizes; Horse, 3 sizes; Horse and Gig, Leaping Horse, Rearing Horse, Greyhounds, Peacocks, 2 sizes ; Rooster, 3 sizes; Cow, 2 sizes; Ox, 2 sizes; Plow, Locomotive, Church, 4 sizes, etc., all made of copper, representing the objects in double bas-relief, brazed together at the edges, and oilgilt so as not to tarnish by exposure.

Fig. 103. Iron Horse Post. 

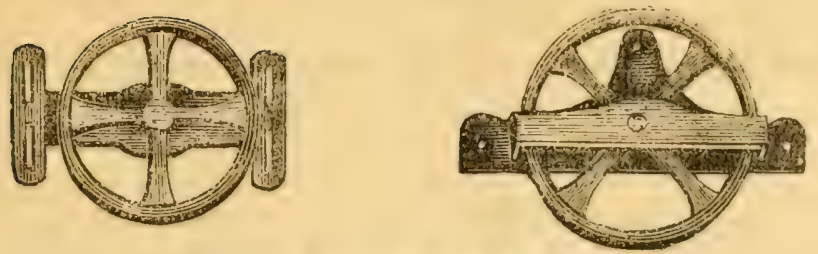

Fig, 405. Barn-door Roller and Hangers.

Fig. 405. Barn-door rollers and hangers of different sizes, varying from 2 to 15 inches in diameter; also, cast-iron track or way for rollers to run upon.

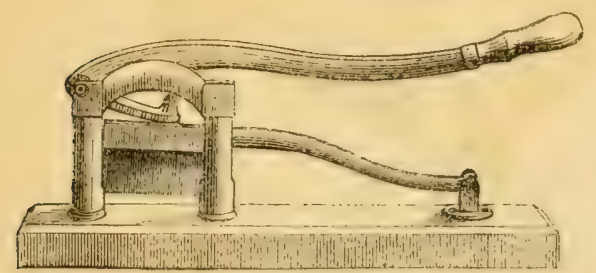

Fig. 406 is used for subdividing Cavendish tobacco for retailing purposes.

Fig. 406. Tobacco Cutter.

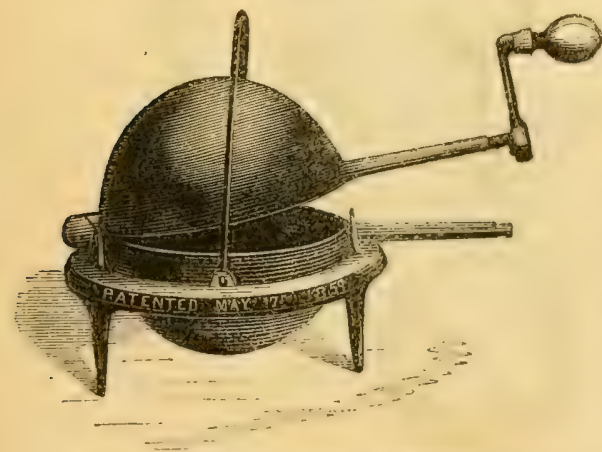

Fig. 407. Coffee Roaster. Of these we have two sizes, 7 and 9 inch: a convenient contrivance for roasting coffee; it may be placed over a fire, or over an opening in the kitchen range, and turned by hand. Price \$1 25 and $\$ 150$ each.

Fig. 407. Patent Globe Coffee Roaster.
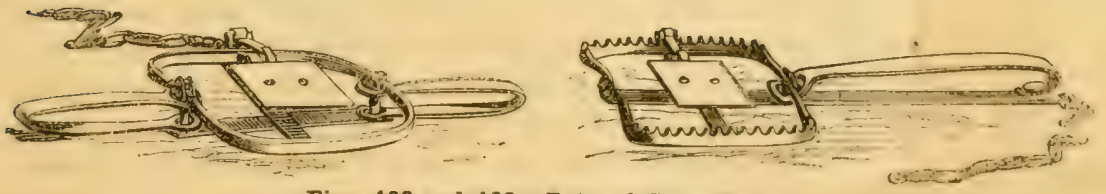

Figs. 408 and 409. Rat and Game Traps.

Figss. 408 and 409. Of these we have a large assortment, including for, woodchuck, musk-rat, common stecl rat-traps, ete. ; also, Colt's pistol traps, so arrangred that when the bait is attacked by animals, the pistols are fired, ensuring the death of the animal; suited for bears, wolves, etc. 


\section{Washing Machines.}

Among the labor-saving machines, those for washing are entitled to consideration, particularly in the country, where extra labor is both costly and difficult to procure.

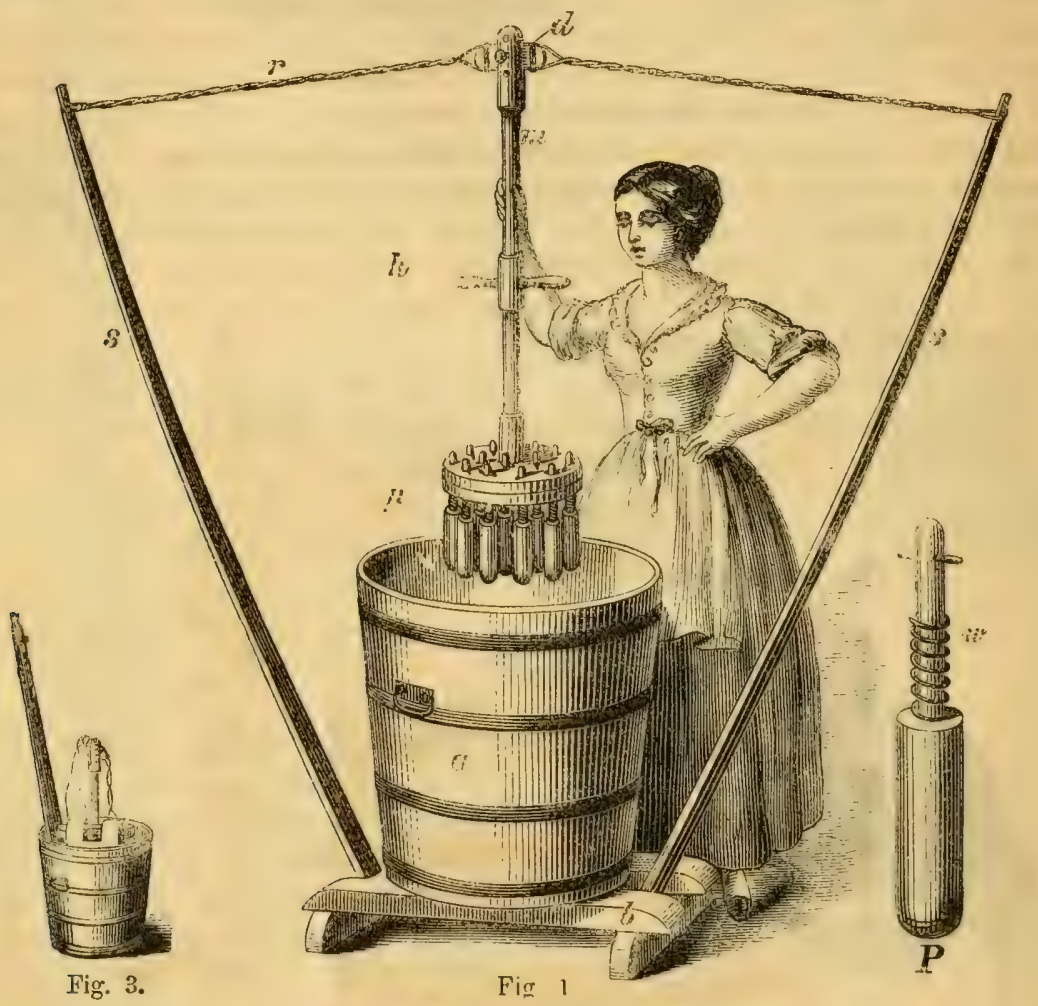

Fig. 410. Metropolitan Washing Machine.

Description. - Fig. 410 shows the implement set up and in operation. $a$ is the tub, 26 inches high, and 24 inches in diameter at the top, and 21 inches at the bottom. The tub stands upon the base-board, $b$. The pounder, $c$, is made up of a series of 16 smaller pounders or pestles, $p$. One of them is shown enlarged at $P$. These pass loosely through $c$, being held from dropping out by small brass pins. A strong spiral brass spring, $w$, keeps them down as far as the spring across the top will permit. It will readily be seen that when brought down forcibly upon clothing in the tub, the small pestles or pounders will yield, by compressing the springs, $w$. This effectually prevents tearing the fabrics washed, breaking buttons, etc. We tried letting the mass of pestles strike down upon the foot with considerable force, and it scarcely produced a painful sensation. We can say that there is certainly a great saving of buttons and in the wear of garments, when they are washed with a series of yielding spring pestles like those here shown. 
This separate arrangement of independent pestles divides the force, so that the inequalities upon a mass of clothing in the tub are fitted by the yielding springs. Again, the surface of the water is so broken up that there is none of that splashing which occurs when a broad single pestle is struck down. In several trials we found it next to impossible to splash the water over the sides of the tub.

The pestle, or combination of pestles, is hung at $d$ (fig. 1), on a double cord, $r$, which can be shortened by simply twisting it. This cord is stretched between the upper ends of two wooden springs, $s, s$. These springs are thin strips of tough wood set loosely into mortices in the base-board, $b$, so that they can be taken out when not in use. To show its construction, we have in the cut elevated the pounder above the surface of the tub, though in ordinary use it is not raised so high.

Fig. 3 shows the springs, base-board, and pestle packed into the tub, and the whole set aside. It occupies no more space than the width of the tub $\left(2 \frac{1}{4}\right.$ feet), and the height of the springs ( 6 feet).

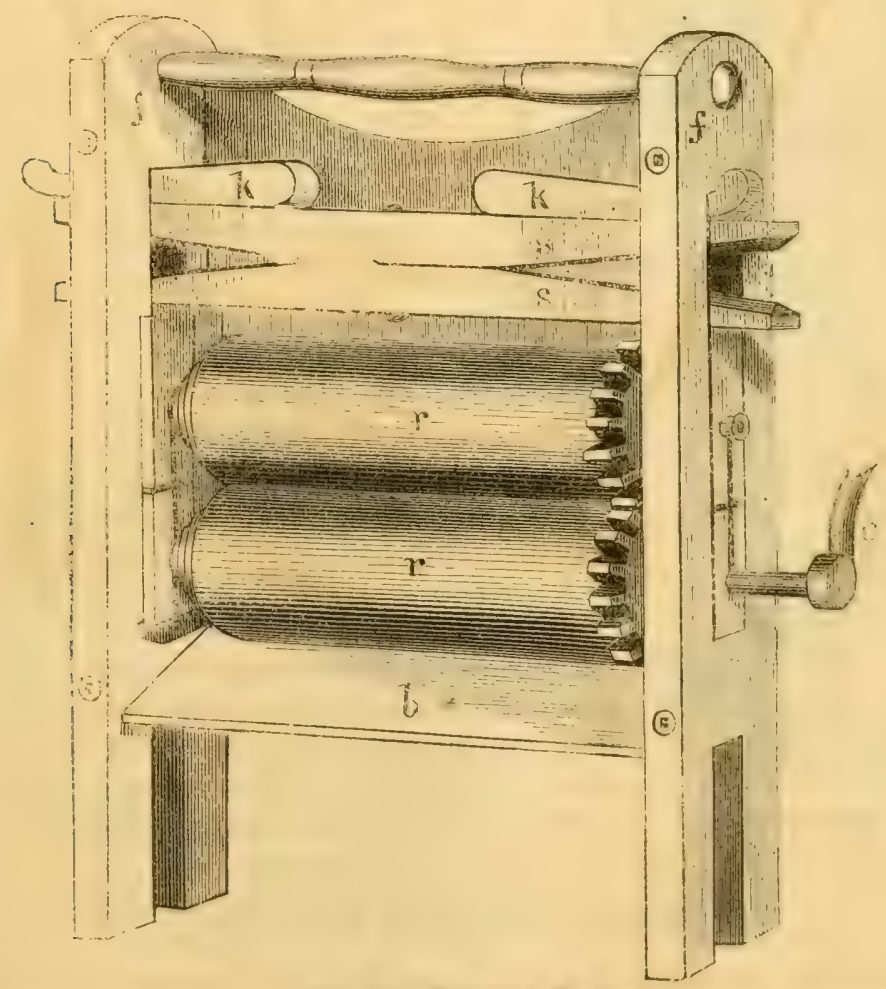

Fig. 411. Wringing Machine.

The whole operation is simple and effective. The batch for washing is 25 to 30 yards of cloth, or say eight or ten shirts, or their equivalent in other garments. Our first trial was upon a lot of bed-quilts being washed and put away for summer, and these at once brought out the capabilities of the machine for heary work. 
The springs throw up the pestle well, and it works so easily that a woman of only moderate strength is able to give it the requisite motion and forcible blow, and still stand in an erect position.

The Attachment, for removing water from the clothes, entirely dispenses with wringing, by passing the clothes between elastic rollers. It is done five times as fast as clothes can be wrung by hand, and removes the water so thoronghly that the clothes dry in one hour on the line. It is easily operated, and does not injure the cloth.

Fig. 411 represents the Wringing Machine referred to above, which fully explains itself.

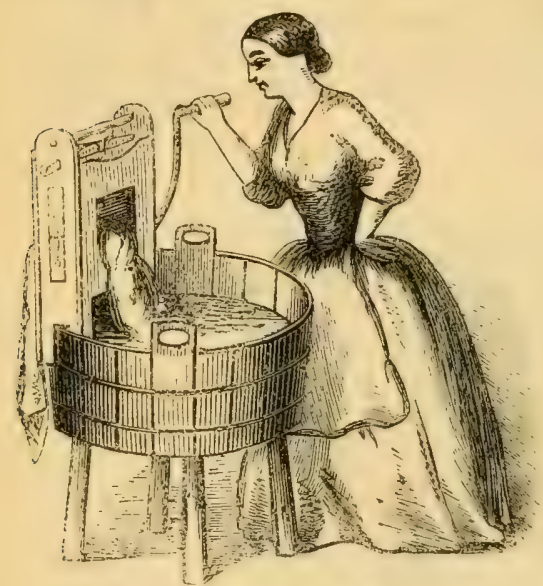

Fig. 412 represents the Wringing Machine attached to a common tubit may be placed on the Washing Machine if desired, and materially abates the labor of washing. The Washing Machine and Wringer are sold at $\$ 10$ each.

Fig. 412. Wringing Machine and Tub.

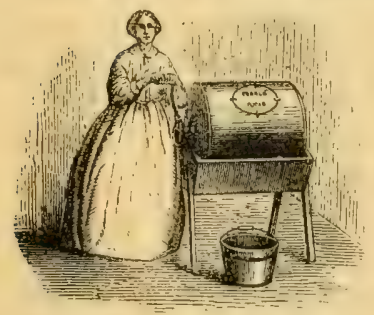

Fig. 413. Cataract Washing

Fig. 413 represents this new style of Washing Machine. It consists of a metal cylinder, with cleets on the inner surface, and an interior eylinder of wood with cleets. There is a space of from six to eight inches between the two cylinders. One crank turns both cylinders at the same time in opposite directions, rapidly creating suds, forcing the water through the clothes, and effectually removing the dirt.

These are of 3 sizes, at $\$ 12, \$ 14$, and $\$ 16$ each.

\section{Patent Portable Mangle.}

Fig. 414 is an admirable Mangle for mangling linen or cotton clothes, and the results are every way superior to the ordinary ironing process with heated irons. The rollers are operated upon by weights and levers contained in the lower or closed part of the case, and exercise a pressure, when in use, of many tons. For jroning bed and table linen, towels, etc., it is without an equal, and when closed, forms a sightly piece of furniture. Cost $\$ 40$. 


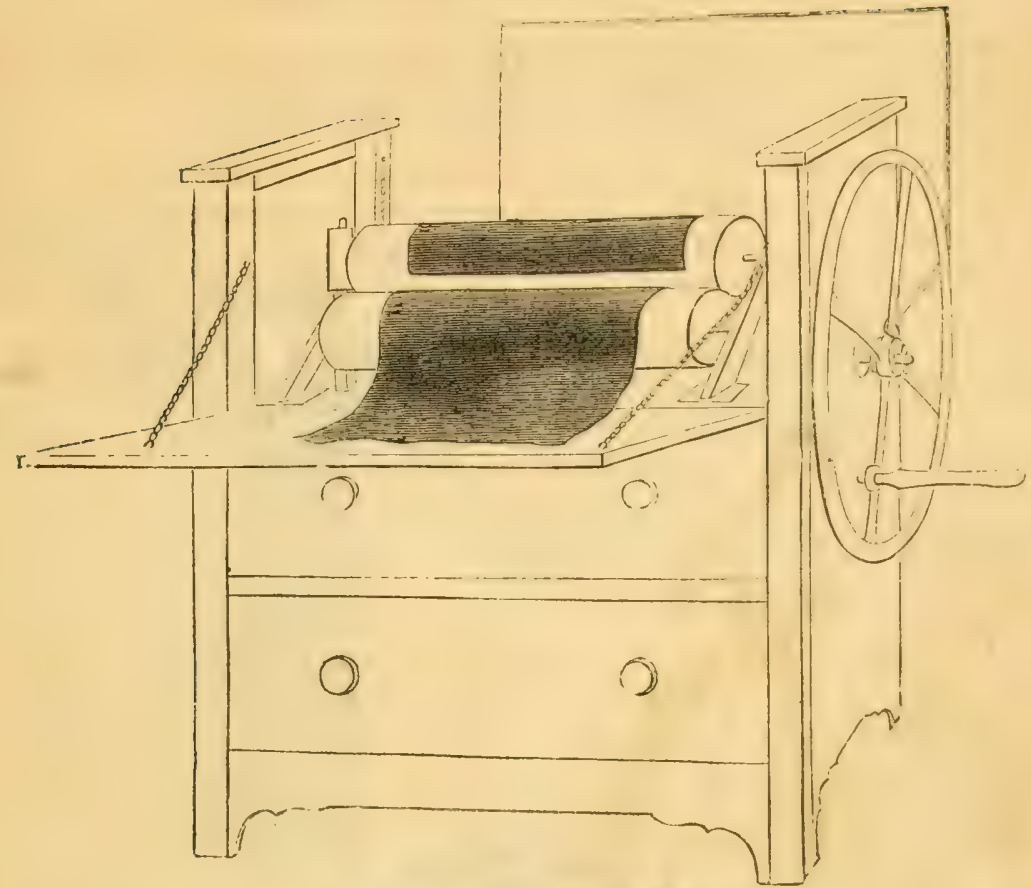

Fig. 414. Patent Portable Hangle.

\section{Bee-Hives,}

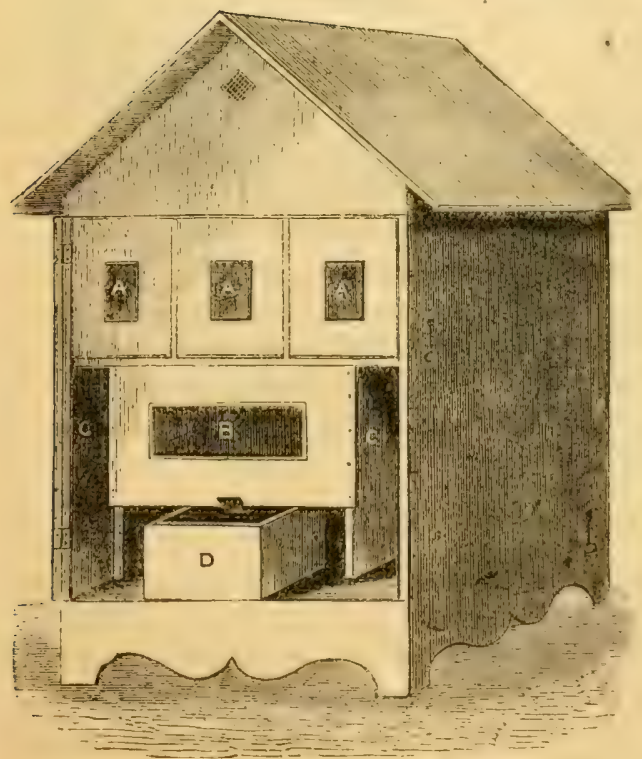

Fig. 415. Explanation of Cut A A A store boxes; B, brood hox; $\mathrm{C} \mathrm{C}$, air space around the brood box; $D$, feed box.

This hive has been constructed with reference to the greatest profit of the bee-kceper, and the protection of the bees from the moth and storms. The brood box, and also the store boxes, are all enclosed within a neat, well-made cottage house. The brood box, or hive, is placed upon the floor, some six inches from the foundation on which the cottage stands.

We have a large varicty of patent and improved bec-hives. Price $\$ 250$ to $\$ 500$.

Fig. 415. Freach's Bee Cottage. 


\section{Improved Boring Machine.}

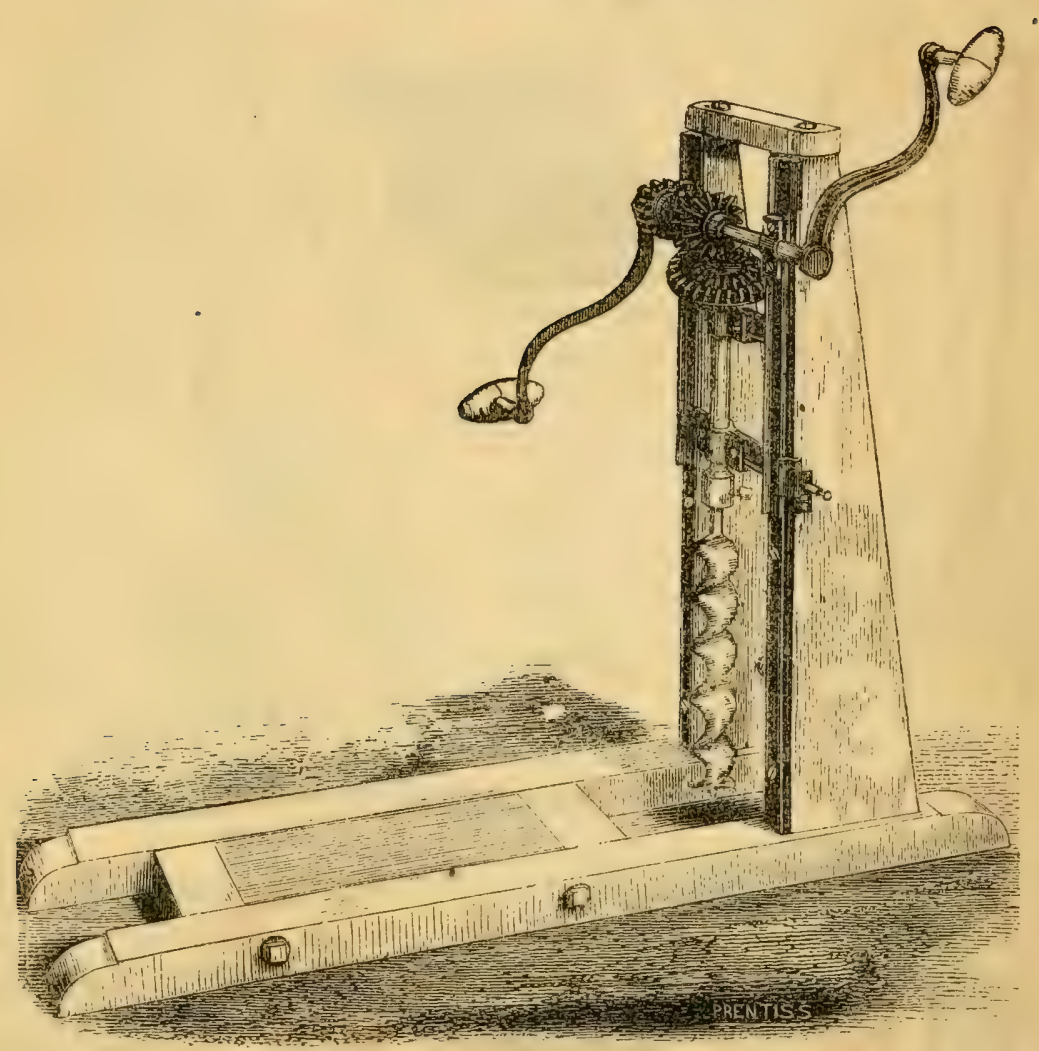

Fig. 416. Improved Boring Machine.

Fig. 416. Used for framing buildings, cars, bridges, etc. This machine is attached to the top of the timber that is to be bored, and the workman seats himself across it, operating the auger by turning the two cranks, one with each hand, and performs a much greater amount of work, more perfectly, and with more ease than can be done by the laborious operation of turning the common auger. By shipping a gear, and the same motion of the cranks, the auger is quickly drawn out, leaving the hole clear of chips. It is neatly finished, light, and portable, and but two feet three inches long, and two feet high.

A set of algers are fitted to each machine, comprising 1, 1 $\frac{1}{2}$, and 2 inches, 18 qrs. Extra augers, and other sizes, furnished to order.

Of these machines we have a variety, including those with iron frames capable of being set at any angle for boring. 
Fay's Portable Mortising Machine.

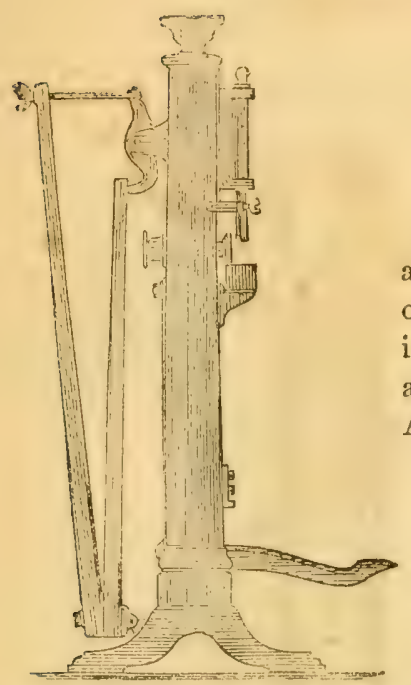

Fig. 417. This is a complete machine in itself, mor able from place to place in the shop or room, and is operated independently of any fixtures of the building. It is a convenient and valuable machine for all light work. Of these we have several patterns. Also, planing machines, tenanting machines, etc.

Fig. 417. Fay's Portable Mortising Machine

\section{Portable Forge and Bellows.}

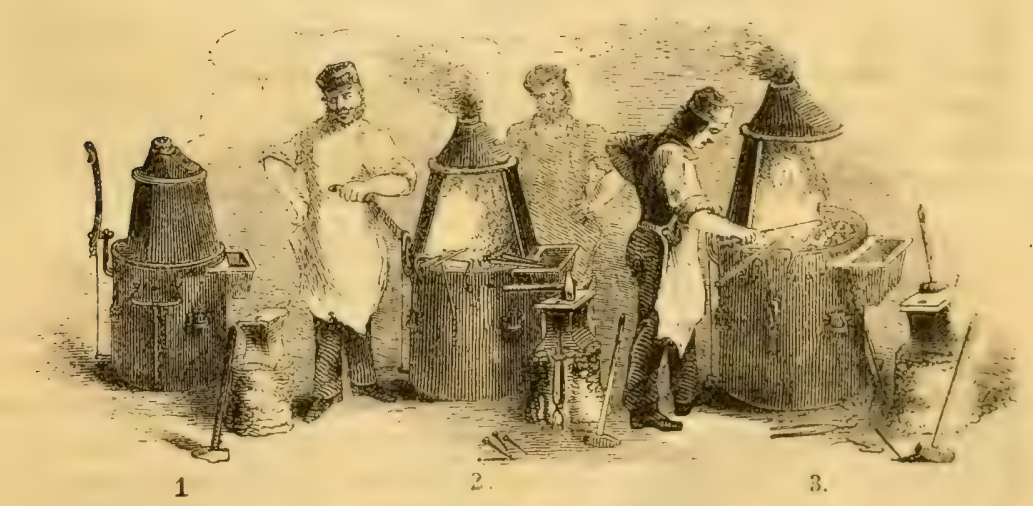

Fig. 418 .

These forges are circular, and capable of being entirely closed, so as to prevent danger from fire. The fumes and smoke are readily carrici, by a simple pipe, to a chimney; they have an opening at the apex of the cone, enabling them to be used out of doors. The bellows is situated bolow the hearth, and protected within the case; while the water, if used in excess, is carried off by a gutter connecting 
with the forge, directly under the twier, and carried off at the back. There are six sizes of Blacksmiths' Forges, and five sizes of Jewellers' Forges, represented by the engraving.

\section{The Patent Eccentric Wrench.}

PATENTED SEPT, 25, 1859. IMPROVED 1860.

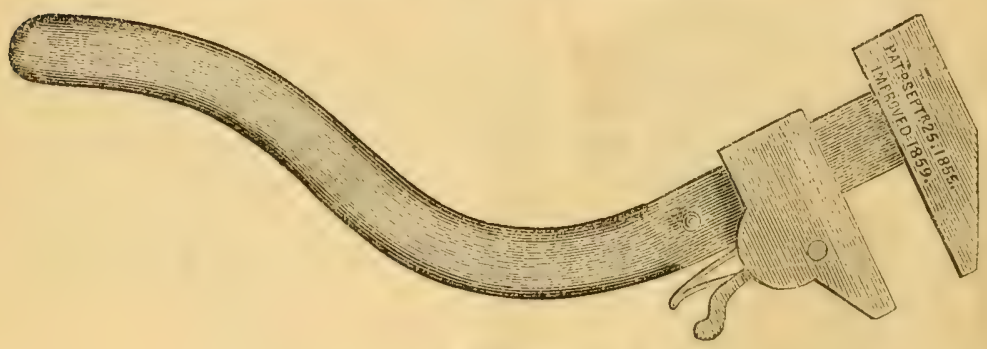

Fig. 419.

There is no wrench which can compare with this in ease and quickness of adjustment, since the motion required to change the position of the sliding jaw is performed instantaneously. The holding power of the movable jaw is derived from a steel cam or eccentric inserted within it, in contact with the bar, and increasing its stability by every increase of strain, until released by the pressure of the thumb upon a small projecting lever, when the jaw is free to move and adapt itself in an instant to a nut of any size. On releasing the lever, the jaw is firmly fixed. This is the only principle which can be successfully applied to the crooked or S wrench; and the eccentric S wrench is offered to the public as the first ever constructed with a movable jaw, and, from its ease of adjustment, is particularly recommended to machinists, carriage-builders, farmers, and all others who now use a separate sized $\mathrm{S}$ wrench for every size of nut. They are finished in the best manner, and combine, in a high degree, simplicity, strength, and durability.

\section{The Brush or Root-Puller.}

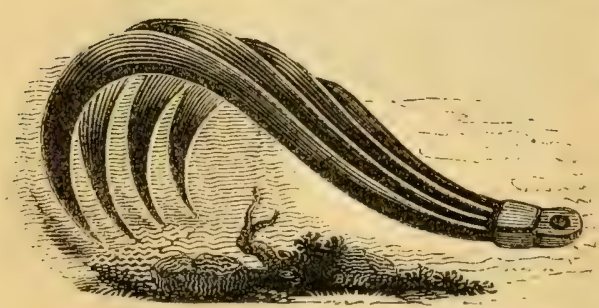

Fig. 420. The Bush or Root Puller.

Fig. 420. This is a very useful implement to attach to bushes, clumps of roots, and bogs, for the purpose of pulling them out of the ground. It is made with two, three, or four claws. These are hooked to the bush close to the ground, an ox-chain is then hooked into a hole at the other end of the puller, the cattle attached, when the bush or roots are easily hauled out. It is a great laborsaver in clearing new lands or bushy pastures. 


\section{Kenny's Patent Stump Extractor and Press.}

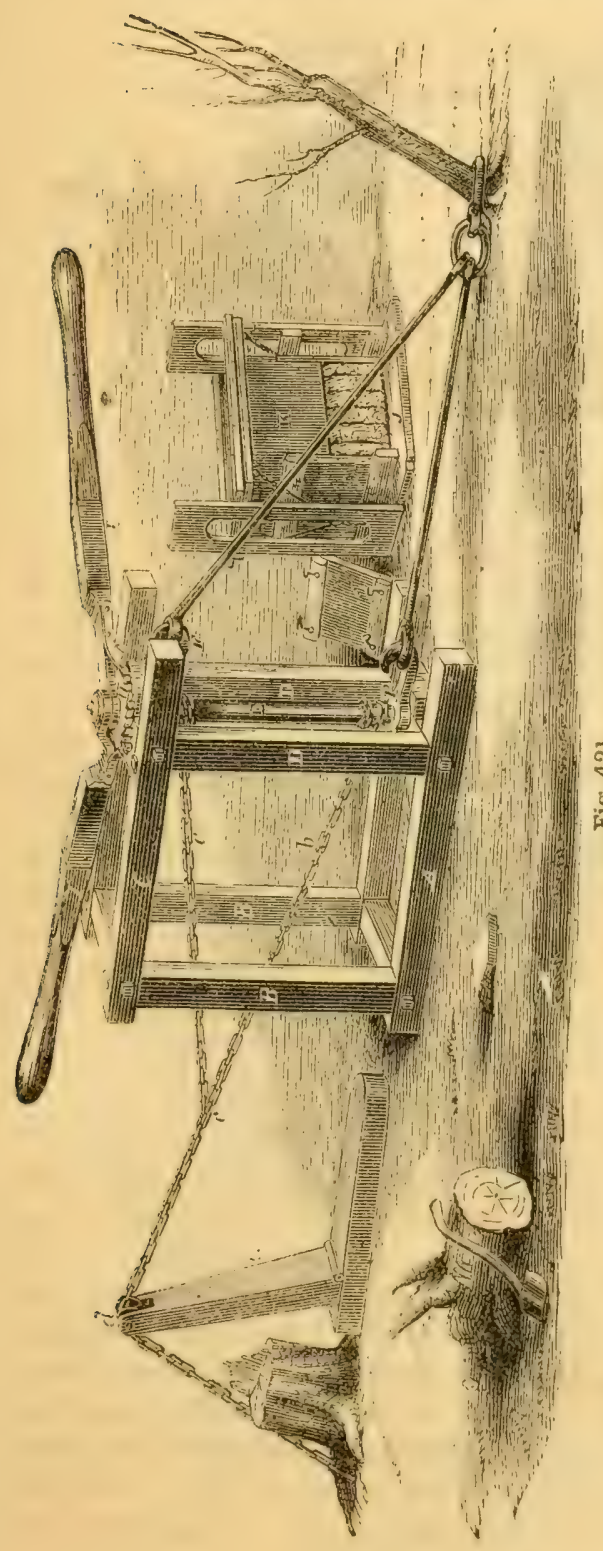

Fig. 421 is a good arrangement of lever chains, etc., as expressed in the engraving, for the pulling of stumps, removal of stones, moving buildings, pulling locomotives or สํ cars on the track when off, the pressing of cider, hops, hay, cloth, cotin ton, or almost any work where great lever power is wanted. It may be operated by hand or horse power, or by both combined; weighing 850 pounds. The price of No. I is $\$ 175$, No. 2, \$125. 


\section{Hall's Hand-power Patent Stump Machine.}

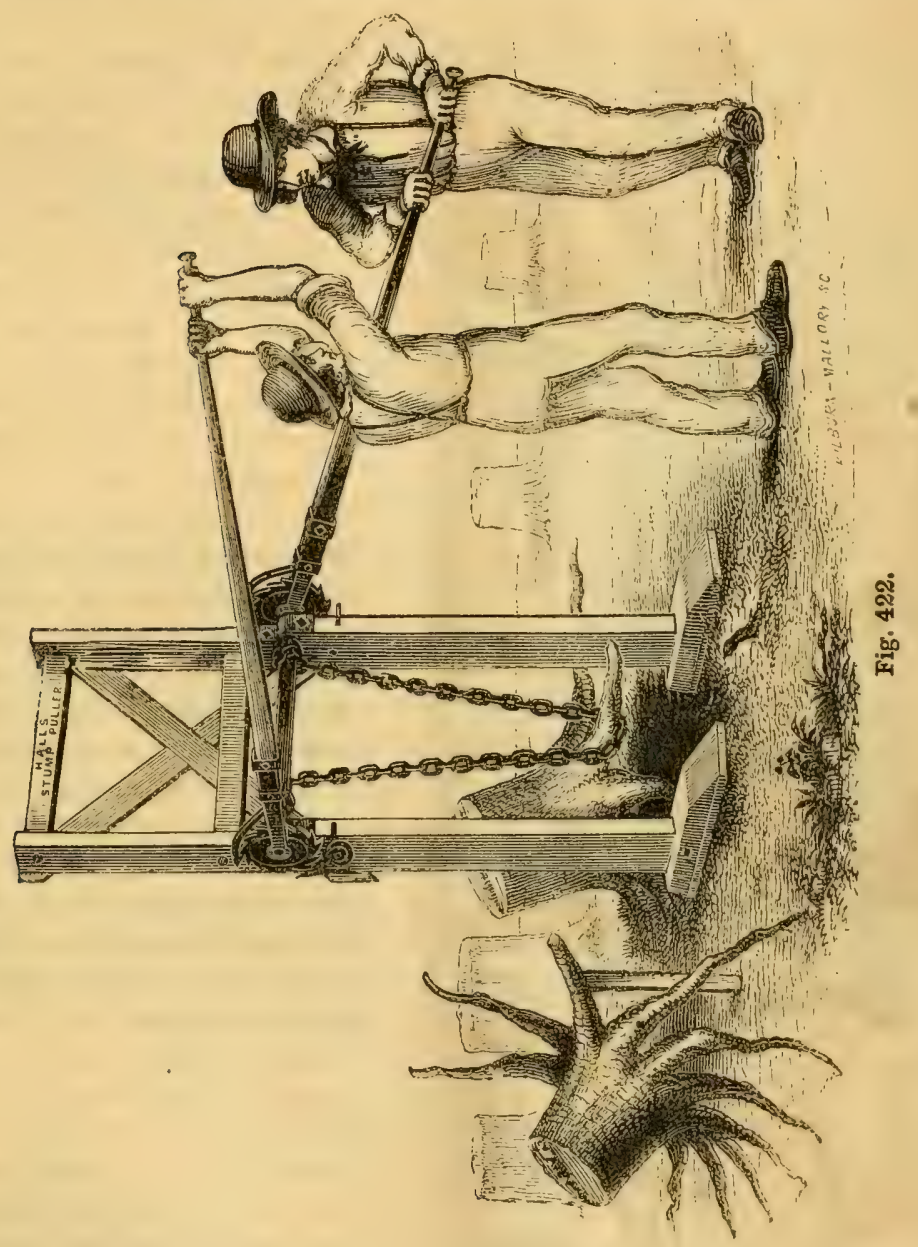

Fig. 422. This is a cheap machine, composed of an upright frame sustaining a shaft armed with a chain, and having a pawl and rachet on each end of the shaft, to which may be attached hand levers of any desired length; the chain being attached to the stump, may be worked like the handle of a pump, and all the power gained at each oscillation is retained by the pawl and rachet. It is extremely simple, and may readily be moved from place to place. 


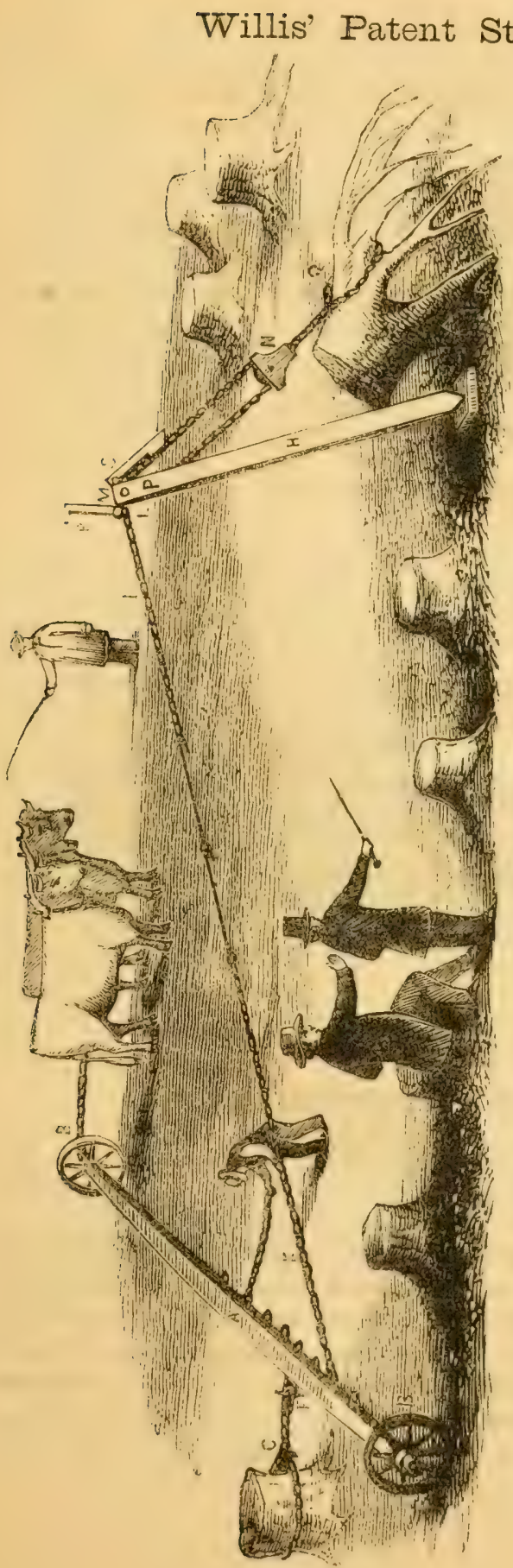

Fig. 423. The power of this machine is very great, and its action rapid. Secured to one anchor stump, in a central point, it may turn upon such anchor, without change of fastening, till perhaps an acre of ground is cleared of stumps, expeditiously, and with but slight expense of labor as compared with the work done. The machine is equally well adapted to clearing land of large stones, pulling them from their resting-place and lifting them high enough to place a cart or stone-boat under, and then depositing the stone on the vehicle for removal from the field. It is also advantagcously employed in the moving of buildings, and in the construction of roads, removing trees, stumps, stones, and other obstructions from the route.

\% This is a single-lever power, not \% in the least complicated, but havif ing chains so arranged in connection with it, that the resistance it is capable of overcoming is made to depend, not upon the strength of the team, but upon the time it works. Thus, a team that would overcome a resistance of ten tons in one minate, would overcome a resistance of a hundred tons in ten minutes. It was on this ground that the editor of the Springfield Republican, after seeing it work, has said, " With it a yoke of cattle will move any thing, lift any thing, dislodge any thing, so happily and advantageously is the lever power applied."

Hundreds of eyc-witnesses have reaflirmed the same thing, which is strictly true, and is so on the 
well-known mechanical principle, that as the resistance is increased the time is prolonged, two or three minutes being required to draw, with a yolie of oxen, a stump of one foot and a half diameter, five or six for one of three feet, and from ten to fifteen for the largest. Machines of different sizes, prices, and power have heretofore been in demand, but the impossibility of making the small machines adequate to the heaviest work, in connection with the ascertained fact that those who purchase them will put them to that work, has determined the manufacturer to offer hereafter none but the largest machines, adequate to all purposes; weight, almost 'wholly of the best wrought-iron, about one ton; cash price $\$ 225$; with exclusive right for a township, $\$ 250$; with ditto for a county, $\$ 350$ to $\$ 600$.

\section{Improved Carriage, Garden, and Farm Gates.}

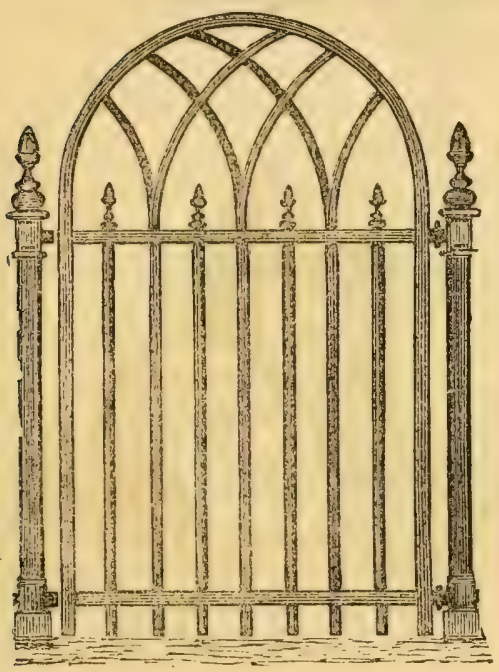

Fig. 424. This is a superior and durable article, being made of white oak, steamed and bent under end pressure, so as to preserve the solidity of the timber; they are light, strong, and durable, of many sizes and patterus. Those intended for main entrances are double or single as may be preferred. These gates vary in price, for gardens, from $\$ 2$ to $\$ 5$; and double gates for main entrances, from $\$ 8$ to $\$ 25$, according to style and size.

\section{Babbit's Premium Portable Fence.}

Fig. 425 represents, in perspective, the improved Farm, Plantation, and Railroad Fence. It was the design of the inventor to construct a cheap but durable fence, which conld be readily set up or taken down, and that when put up, should not be liable to any derangement by frost, exposure to winds, or unruly cattle. This fence can be used as a permanent or a temporary one. Forty rods of it can be taken down and put up in a day by one man. It is made of oak, Lemlock, or pine, and can be made ornamental by attaching caps to the posts. The fence cannot be blown down even in the most exposed places, as has been proved. It makes not only a cheap fence, but one in all respects equal to the best, and possesses decided advantages over all others, and is equally adapted for a cottage or a prairie fence. 


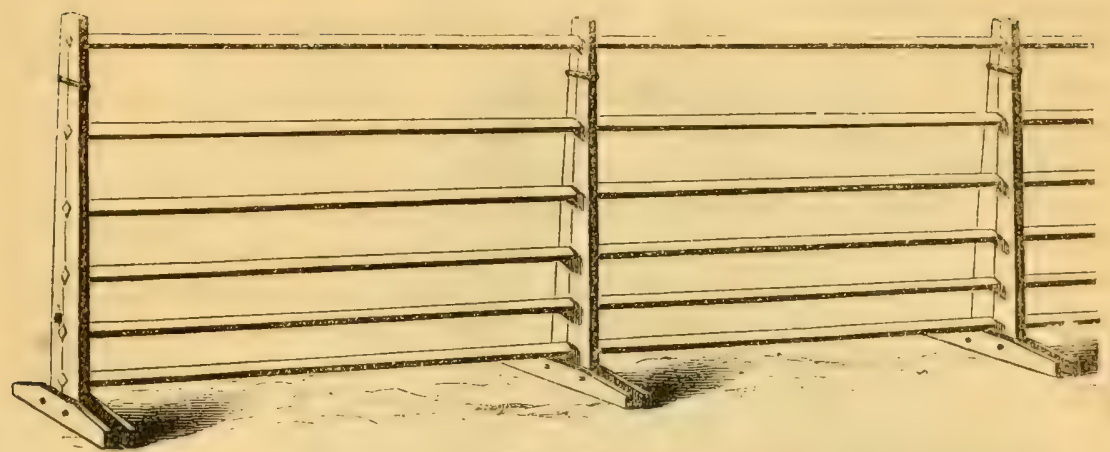

Fig. 425.

Picket, and other styles of fence, manufactured by machinery, are in preparation, and will be furnished at from $\$ 2$ to $\$ 4$ per rod.

\section{Scales.}

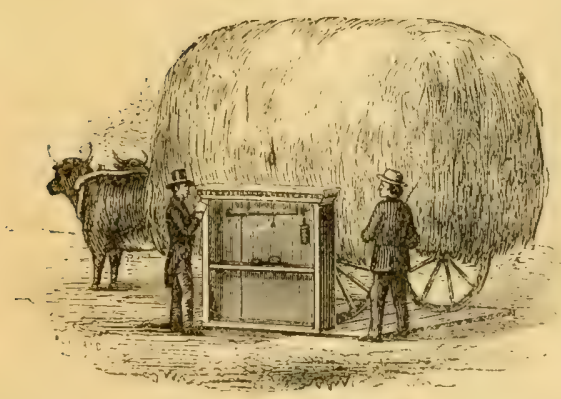

Fig. 426. Hay Scales,

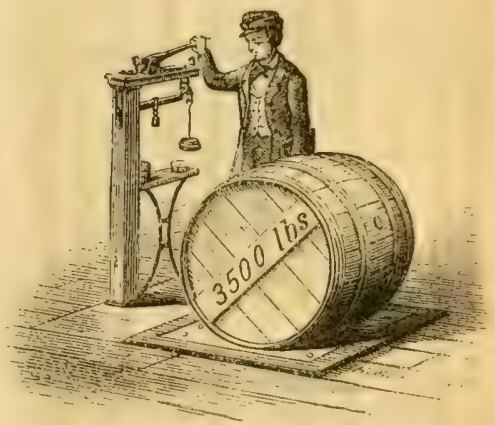

Fig. 427. Warehouse Scales.

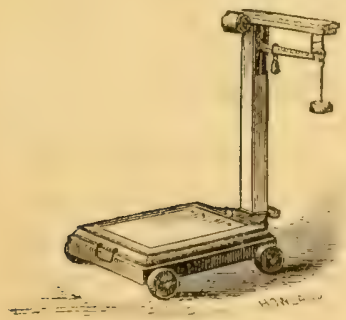

Railroad, canal, coal, hay, storc, and other platform scales, of every variety of size and pattern, at manu. facturers' prices.

Fig. 428. Platform Scales. 


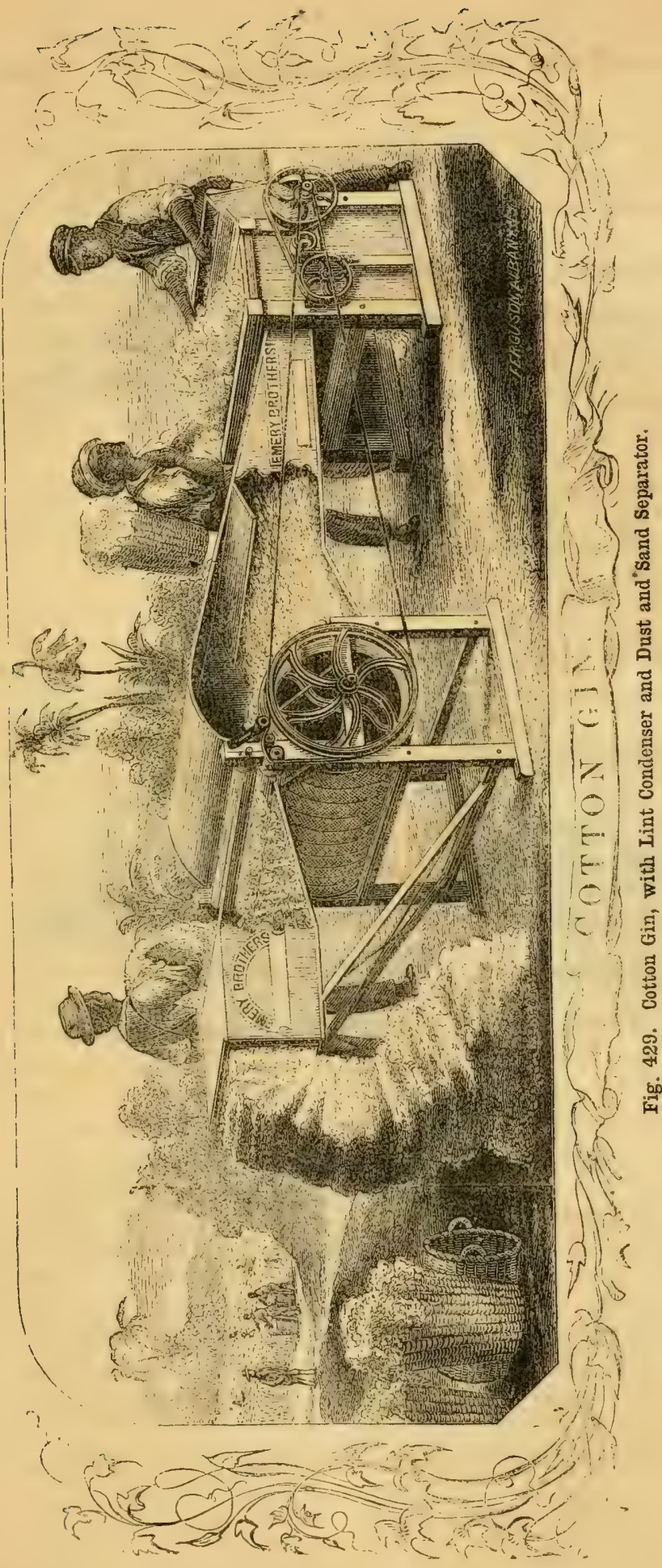

Fig. 429. Since the original invention of the cotton gin, by Eli Whitney, the improvements have been simply to increase the number of lags on the brush cylinder, with the view of subdividing the pellets from the saw-gin teeth into a finely-divided lint; but it has remained for the inventors of the above to add a condenser, , so as to deliver the lint in a continuous bat ready for packing in the bale, and thus doing away with the tedious process of stamping and compressing the sint. The engravbo ing so thoroughly represents the machine and its action as to render description unnecessary; the separation of sand, dirt, etc., is quite perfect. 


\section{Howell's Quartz Crusher and Universal Mill.}

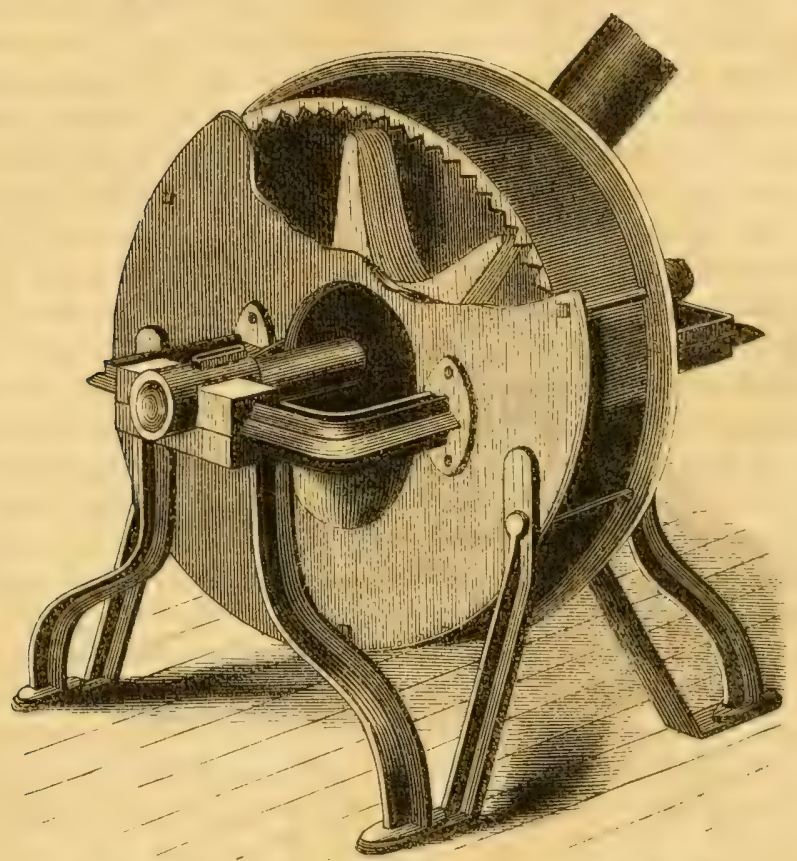

Fig. 430. Howell's Quartz Crusher and Universal Mill.

Fig. 430 represents this extraordinary mill which is capable of crushing a larger amount of material with a less expenditure of power than any other mill now in use. The engraving fully represents all the parts; and a portion of the side left off to exhibit the arms, shows its inside structure. The shell is three feet diameter and five inches wide; a steel shaft passes through the centre, armed with six projections or arms, reaching nearly to the periphery or rim, which is corrugated on its inner side.

The material to be crushed is thrown in alongside the shaft, and has its exit on the opposite side, through the pipe there represented. Each piece of ore or other material, as received, is stricken by the arms and immediately rendered dust fine, in which condition it is thrown out at the tube on the opposite side by the action as a centrifugal blower. The fineness of the product and the efficiency of the mill depend entirely upon the velocity with which it is moved, and the position of the pipe for the exit of the ground material. At low velocities it will be an excellent rice and coffee huller, and at high velocities the hardest gold quartz can be reduced to an impalpable powder.

The exit pipe should pass into a room of sufficient length to enable the different 
products, as in the grinding of wheat, to settle by their difference of gravity in various portions of the room, thus doing away with the necessity of bolting, bran dusting, etc.

It may be used for various purposes other than those enumerated, such as preparing facing for founderies; disintegration of short pieces of old rope, in place of picking oakum; shelling the various South American nuts; preparing linseed, prior to its being pressed; crushing of poppy and other oil-yielding seeds; preparing dye-woods after being sawed into blocks, previous to separating the extract; cleansing cocoa from its shells; crushing of bones ; grinding of corn, oats, etc., as horse feed; beating cut corn stalks into the loose fibre, after having been passed through the cutting box; grinding wheat without the flour being rubbed as in other mills, and cleanly separating, by difference of gravity, the bran, etc.; dividing bark for tanners' use into a fibre, instcad of compressed particles, so as the more readily to admit of the extraction of the tannic acid ; grinding of loaf sugar; preparation of zinc and other ores, previous to their use in furnaces; pulverization of Franklinite pig iron, Arkansite stone and other hard substances, before being mixed with gutta percha and cast into files, rasps, etc.; preparation of bone black for blacking makers, printing ink makers, etc.; the division of fur, preparatory to felting; grinding drugs; grinding, in the dry state, of white lead, arsenic, baryta, etc. ; grinding of old fire-brick in the manufacture of clay retorts; preparation of plumbago for black lead pots; preparation of clays, feldspar, etc., for the manufacture of porcelain; division of the coarser kinds of paper stock into fibre, such as beechwood shavings, cut straw, etc. ; grinding of Rosendale and other cement stones, either hot or cold ; grinding of many kinds of snuff; and for purposes of disintegration generally. Weight $1200 \mathrm{lbs}$; price, with pulley complete, in working order, $\$ 300$.

\section{ANALYSIS OF THE ACTION OF HOWELL'S QUARTZ CRUSHER.}

For a clear understanding of the action of this instrument, it will be necessary to analyze some of the natural laws which are brought into requisition during its lise.

The difference between absolute momentum and continued force is well unilerstood; but when the momentum is carried up to unusual speeds it is claimed that new actions and functions are developed, which are not to be found in the trip hammer or other usual methods of exercising momentum. Suppose a piece of gold quartz thrown into the atmosphere, and during its descent to be stricken by a sledge bammer, travelling at the rate of twenty thousand feet per minute, it is claimed that the action will not be merely to break the gold quartz into many pieces, but to surprise the cohesive power of the mass, and thus, for an instant of time, to do away with that property, rendering the mass representing smoke or the finest possible division of matter. And this claim, we think, can be rendered understandable by a clear illustration of what constitutes cohesion, and also by a development of a new function which may be thus expressed.

A body in motion is said, in common mechanical parlance, to have a power as a prujostile "equal to its weight multiplied by its velocity;" it may be said, with equal t: $:$ th, that the hardness of a body in motion is equal to its hardness multi- 
plied by its velocity. Thus it is known that a tallow candle may be thrown from a gun through an inch plank, while it is apparent that a candle is much softer than a board; it is also well known that a dise of soft iron rapidly revolved will cut in two a bar of steel, and, indeed, that any substance which from its surroundings and peculiar configuration can be passed with great velocity is increased in its relative hardness. Let us admit, then, that with Ilowell's machine the moving arms may be made to reach the velocity claimed as necessary to surprise coliesion. If we examine cohesion as a property in matter varying in different substances, and suppose it to arise from the attraction of particles for each other, rather than from a hook-like form of particles interlacing each other, we shall find no difficulty in comprehending the immense force necessary to sever it. Thus, a cubic inch of steel, or an inch area of steel would be more proper in this case, exercises tension at the rate of $90,000 \mathrm{lbs}$. when applied as continued force and not as a momentum. If we recollect the rule that attraction is inversely as the squares of the distances, and then admitting that, with an ordinary magnet, the attraction exercised upon the keep at the distance of one inch is $1 \mathrm{lb}$, then at a half an inch it will be $4 \mathrm{lbs}$. at a quarter of an inch $16 \mathrm{lbs}$, at the eighth of an inch $256 \mathrm{lbs}$, at the sixteenth of an inch $65,536 \mathrm{lbs}$, at the thirty-second of an inch, the square of that number, and so on at the same ratio, until at the point which is supposed to be actually in contact it is no longer curious that the inch area should sustain 90,000 llss, but, rather, that any amount of foree which could be practically applied wonld draw it asunder; and were it not for that film of resistance described by Newton it could not be separated. When a surface is attacked by absolute momentum this film of resistance may be pierced, and although in ordinary use two billiard balls do not really touch each other, and, therefore, the polish is not destroyed and the balls are not split, still, with an increased amount of momentum, both these effects will occur. As an illustration, suppose a polished anvil lave placed upon it a piece of gold leaf, and you should put upon this any amount of continued force, it would not cause any connection between the gold and the anvil, and after removing the impinging matter the gold leaf might be blown off; but if the gold leaf be strichen by a polished hammer, so as to develope momentum at the point of contact, that point alone will be found to be permanently gilt, and if we scrape off the surface to the depth of three times the thickness of the gold leaf we shall still find gold imbuing the metal. This is a well-known fact, and fairly illustrates that by absolute momentum the film of resistance may be pierced, and certain metals may be forced into each other.

Now, in the use of the arms of Mr. Howell's machine, we would claim that absolute momentum, and not continued force, is the form in which all the power is developed at the speed proposed by Mr. Howell; this momentum is sufficient not only to do away with the film of resistance at the point of contact, but to surprise the cohesion of the particles, so that instead of breaking the mass into many pieces it absolutely divides it into its ultimate particles; and there is a speed at which chalcedony and gold quartz may be crushed by this machine, so that the powder resulting is so fine that when rubbed between the fingers it is soft like velret, 
exbibiting no grit or other proof of crystalline or other structure; nor will the machine itself be abraded during this action, for so great is the speed of the arms giving the momentum, that their hardness, as before explained, is increased in the same ratio, and even the surface of these castings will not be abraded, while the substances they are impinged upon will be delivered from the machine in this finely-divided condition.

All former methods of crushing gold quartz have failed in exhibiting all the gold for the want of an entire mechanical division of the particles. This may be thus understood: a piece of pure gold drawn across the surface of a hone leaves a yellow mark, and in many kinds of gold ores this graphitic-like mark is to be found percolating the mass, and when dirided by washing, despite of all methods yet pursued, it passes off with the water. Indeed, this finely-divided gold will float a month on the surface of water without becoming wet on the upper side of the particles, or in other words without sinking, and it is therefore lost. Many specimens of gold quartz contain a much larger amount of gold than can be separated from them, after what is usually ealled thorongh grinding, by washing, and the same defects from the same causes occur during the attempted modes of amalgamation. When the quartz, however, is crushed by Howell's machine at its greatest velocity of action every graphitic indication of the gold is caused to appear upon the surface of the particles, and, therefore, it may be removed by ordinary amalgamation. We have seen ores crushed with this machine which would yield a larger percentage of gold beyond the amount obtained by the usual methods, than th" amount so obtained.

\section{Patent Agricultural Caldron and General Steamer.}

\section{Two Silver Medals have been awarded this Apparatus by the New York State Agricultural Society at Albany and Elmira; also the highest Premiums at several County Fairs.}

Fig. 431 represents Prindle's Patent Steamer, which takes the place of the open caldron-boiler, and at the same time is readily converted into an apparatus by which food of all kinds may be steamed, water heated, etc. The lower portion, as represented in the cut, is a furnace suited for either wood or coal, and readily changed from one to the other. In the top of this stove the apparatus is inserted, an hemispherical kettle, which may be used as an open kettle when required; on top, in a reversed position, is another hemisphere, forming the whole into a globe or sphere, half inserted within the furnace. These are connected together by the clamps $\mathbf{J} \mathrm{J}$, so as to make a steam-tight joint. Water may be introduced through the tunnel B. D is a steam pipe, with a flexible pipe, $\mathrm{L}$, attached, which may be passed into an ordinary hogshead or other convenient vessel containing water, for the exit of the steam, thus enabling vessels containing food to be steamed, water to be boiled, etc. $\mathrm{C}$ is both a safety and a vacuum valve, so that while it protects the vessel from accident, from the expansive force of the steam, it also prevents the vacuum 


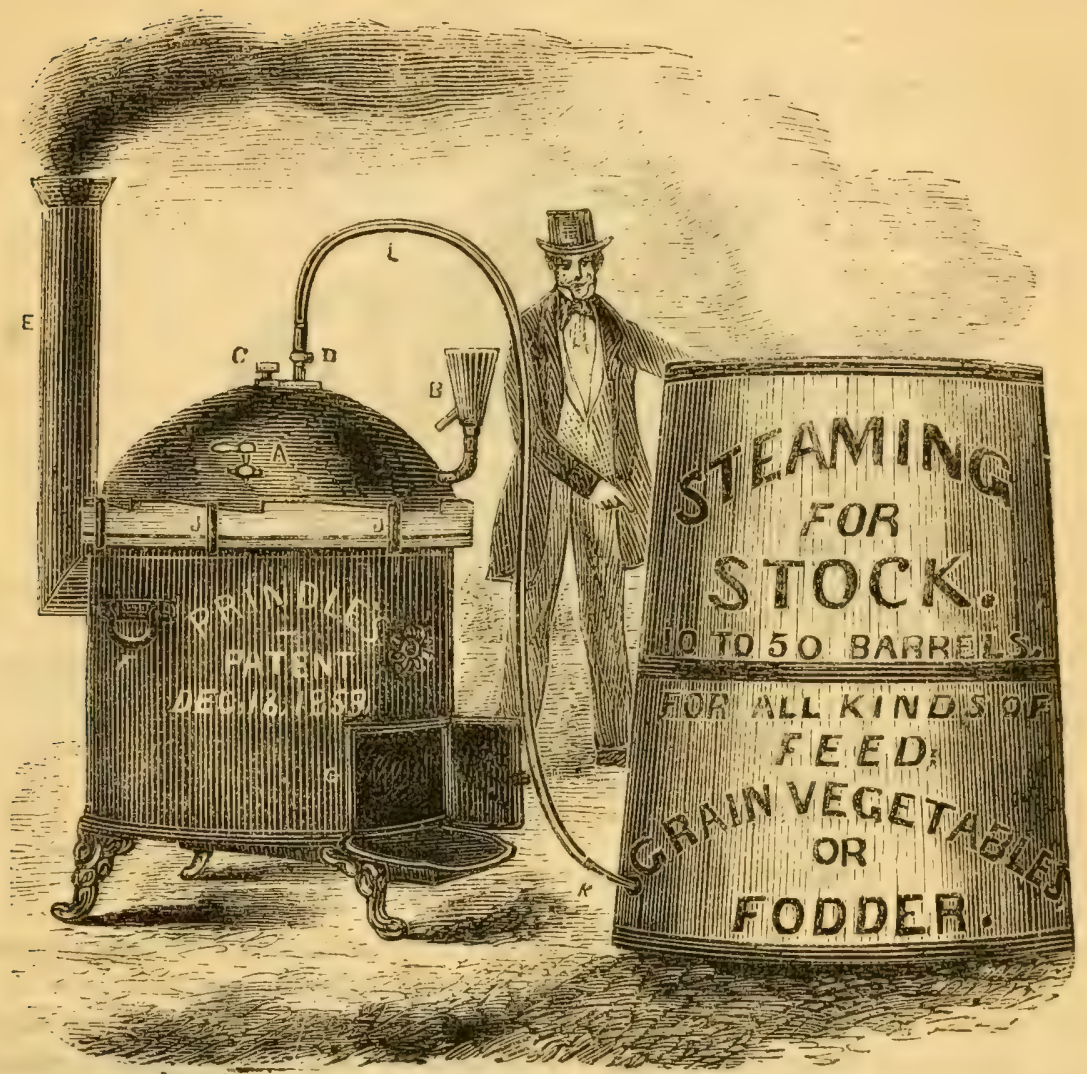

Fig. 431. Patent Agricultural Caldron and General Steamer.

which may be caused by negligence in permitting the hogshear to become empty of water, from drawing back fluids into the boiler, or from collapsing from outside pressure. When this flexible tube $\mathrm{L}$, connected with $\mathrm{D}$, is passed into wooden tubing placed beneath the ground, the steam may be conducted eighty or one hundred feet, and at the other end made to operate by another flexible tube on vessels containing water, etc.

The whole apparatus is simple, requiring no knowledge of mechanics to put it together or take it apart. The only joint to be made is $\mathrm{J} \mathrm{J}$, where clamps arranged on inclined planes may be driven until the joints are tight, thus connecting the upper and lower hemispheres; and a single cord or piece of twine placed between these two faces is compressed so as to make a perfect joint.

By reference to Working Farmer, for March, 1861, a full description may be lound of the advantages arising from the cooking of food for hous, cattle, etc. There are two sizes of these caldrons, prices $\$ 35$ to $\$ 40$. Circulars, with full descriptions and testimonials, furnished when required. 


\section{Patent Stone Digger and Wall Layer.}

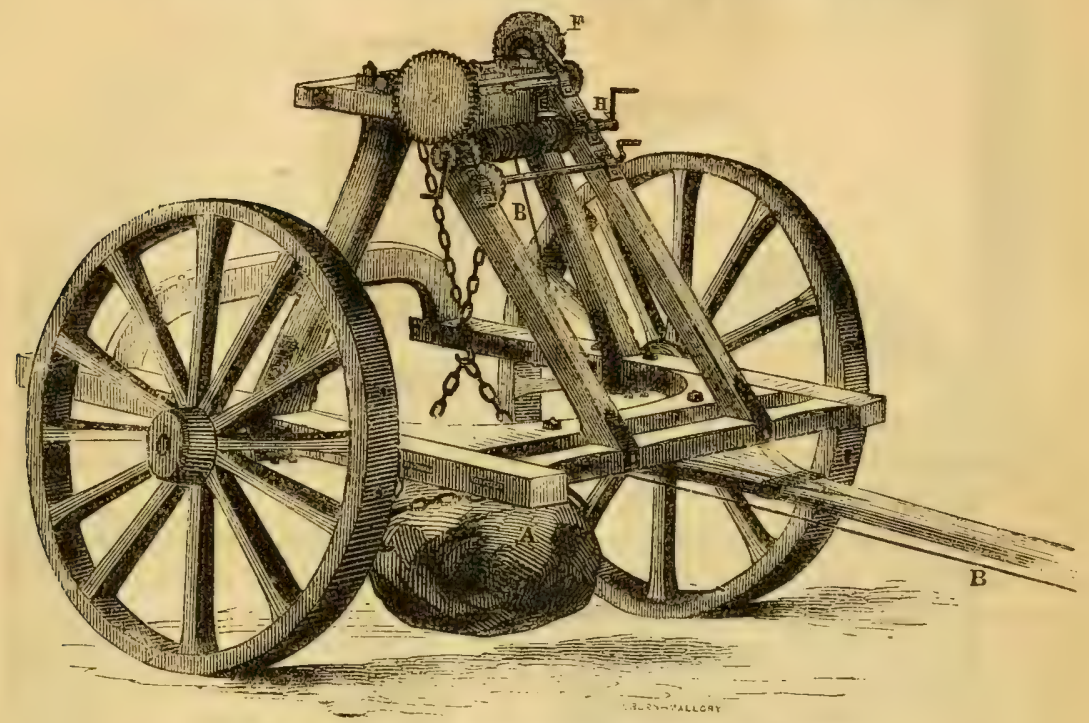

Fig. 432. Bolles' Patent Stone Digger and Wall Layer.

Fig. 432 represents this machine which has been found practically and economically useful, meeting with unqualified approbation from all who have seen it in operation. The mechanical appliances are of the best kind, enabling a single op rator to lift heavy stones from the earth, even of five tons' weight, without digging to relieve them. They can be drawn from the field without unloading, and placed into a wall five feet high.

Recommendations in relation to this machine are of the strongest kind. They are now in use in many parts of New York and New England.

\section{Patent Cow Milker.}

This machine is the invention of Mr. L. O. Colvin, and contains many theoretical advantages over all other machines previously proposed for the same purpose. It will be seen by the engraving, that it is a pan or pail with a portion of its top covered, and armed with an ingenious vacuum pump, so simple in construction as not to be liable to derangement; on this are four flexible teat cups, so arranged as to be capable, both as to size and distance apart, to fit any cow. The handles of this machine work the pump so as to alternate the action on the teats, which in all respects closely resembles the manipulations caused by the mouth of the calf while sucking. 


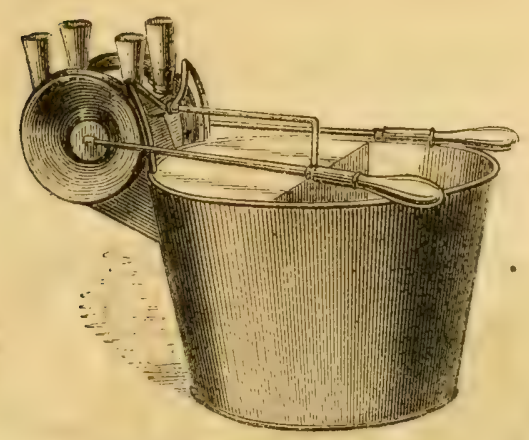

Fig. 433. Patent Cow Milker.

It is claimed that cows will stand more quietly to be milked by this machine than when milked by hand.

The pumps are readily taken apart for cleansing by hot water, and the diaphragms being made of part rubber are not injured, and are easily removed and replaced. The whole machine weighs but $6 \frac{1}{2} \mathrm{lbs}$; price $\$ 10$.

\section{Patent Knife and Fork Cleaner.}

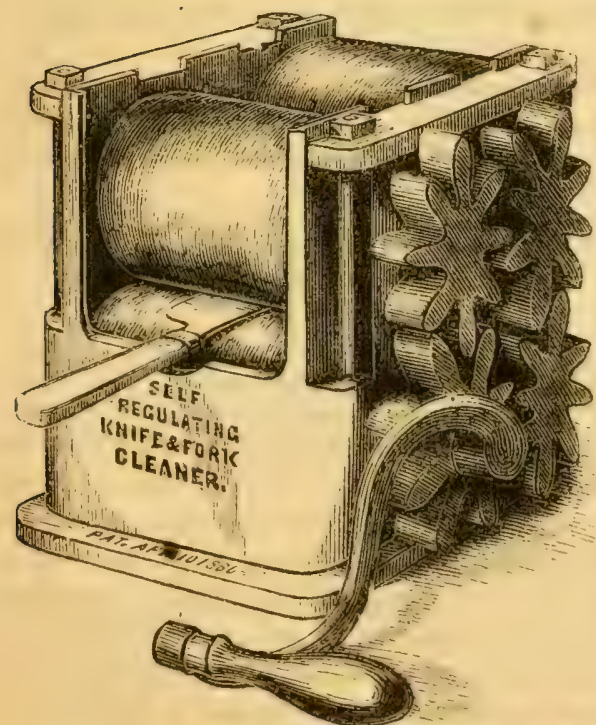

Fig. 434 is fully described in the engraving. It is composed of four rubber rollers serewed together, and the knife or fork is introduced between them. It is accompanied by a Polishing Powder, which while it removes the oxide from the surface of the utensil to be cleaned, does not materially abrarle the metal; giving to steel and iron a clean silvery finish, while silver forks may have their surfaces renewed very read. ily. Price of Cleaner, with package of Powder, \$2.

Fig, 434. Patent Knife and Fork Cleaner. 


\section{B. B. Hawse's Patent Clothes Dryer.}

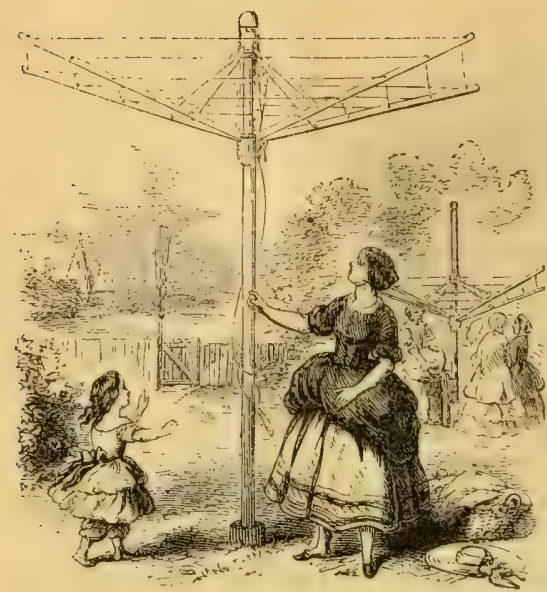

Fig. 435.

Fig. 435 is an improvement on all the Clothes Dryers which have preceded it. An upright is placed in the ground or floor of the drying room, and a folding frame is so arranged upon it, that it may either be closed so as to take up but little room, or suffered to expand as in the drying, so as to present a great length of clothes line for drying. It may be more or less elevated at the will of the operator so as to take advantage of light winds by high elevation, or be partially closed when necessary. There are two sizes, viz. : No. 1 has arms 7 feet long, and spreads 150 feet of clothes line; price \$6. No. 2 has arms 6 feet long, and spreads 120 feet of clothes line; price $\$ 5$.

\section{Gentleman's Tool Chest.}

Fig. 436. Gentleman's Tool Chest; size, 2 feet 4 inches long, 1 foot, 2 inches wide, and $10 \frac{1}{2}$ inches high ; made from best cherry, exterior French polished, with brass trimmings and lifting handles, partitions and drawers containing every article. Superior Tools ready for use, designed for mechanics, amateurs, planters and farmers.

LIST OF ARTICLES.

1 Jack Plane, double iron.

1 Smooth Plane, double iron.

1 Mill Saw File, handled.

1 pair 8 inch Carpenter's Nippers.

1 Claw Hammer.

1 Oil Can.

1 Chalk Line Reel, with Awl.

1 Rip Saw, 22 inch.

1 Cross Cut Saw, 20 inch.

2 Sewing Awls, handled.

2 Sadlers' Awls, handled.

2 Pegging Awls, handled.

1 Cold Chisel, extra heavy.

1 Nail Set.

1 Prick Punch.

1 Round Punch.

1 pair Compasses, 8 inch.

1 Try Square, 6 inch.

1 Ball Brace.

3 Spur Augur Bits, 7-8, 9-16, and 3-8 inch.
12 Brace Bits, assorted.

1 pair Plyers, $4 \frac{1}{2}$ inch.

1 Wood Gauge.

1 Cast Steel Drawing Knife.

1 No. 1 Hatchet.

12 inch Screw Driver.

16 inch Screw Driver.

1. Taper Saw File, handled.

2 Gouges, 5-8 and $\frac{3}{4}$ inch.

4 Firmer Chisels, $\frac{1}{4}, \frac{1}{2}, 1$, and $1 \frac{1}{2}$ inch, handled.

1 Oil Stone, in box, with cover.

1 Two Foot Rule.

1 Lead Pencil.

1 Square Lignumvitæ Mallet.

1 Appletree Brad Awl Set, containing 20 Tools and Wrench.

2 Gimlets.

1 Two Foot Iron Square.

1 Seratch Awl, handled. 

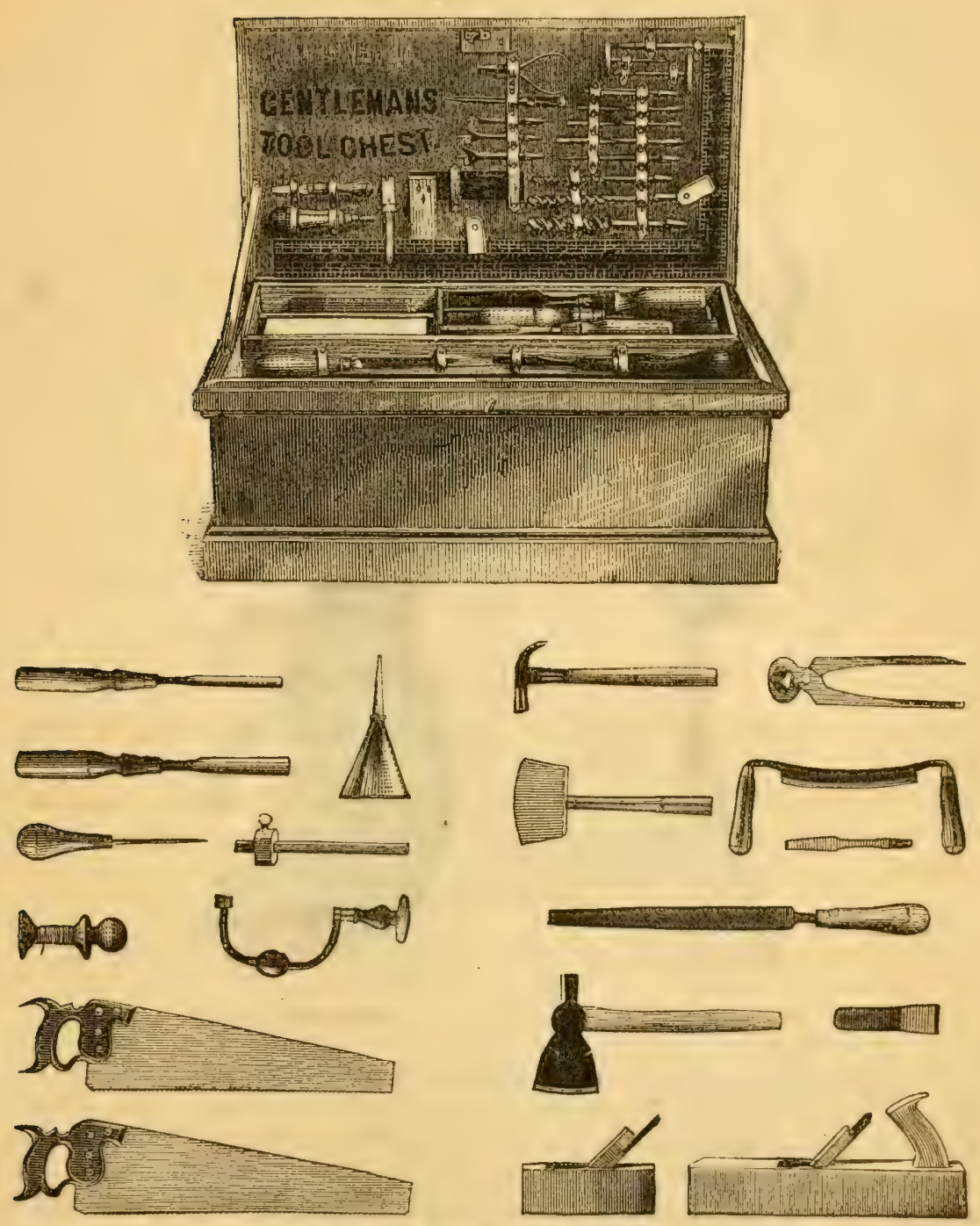

Fig. 436. Gentleman's Tool Chest.

Making in the aggregate eighty different Tools, besides the Chest, packed in cases ready for shipping. Price, each, $\$ 20$.

In addition to the above we have the Planter's Tool Chest, price $\$ 30$; Youth's Tool Chest, price \$13; Boy's Tool Chest, price \$8; Juvenile Tool Chest, price $\$ 250$. 


\section{Patent Animal Trap.}

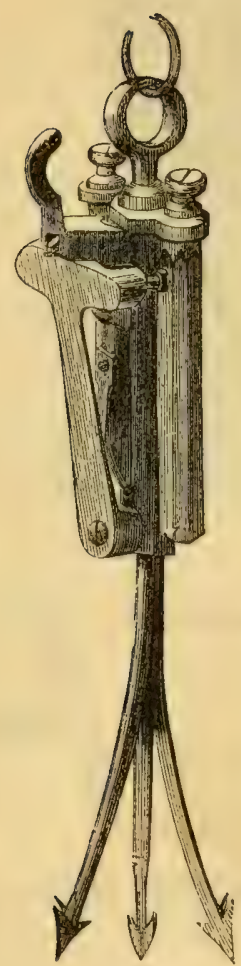

Fig. 437.

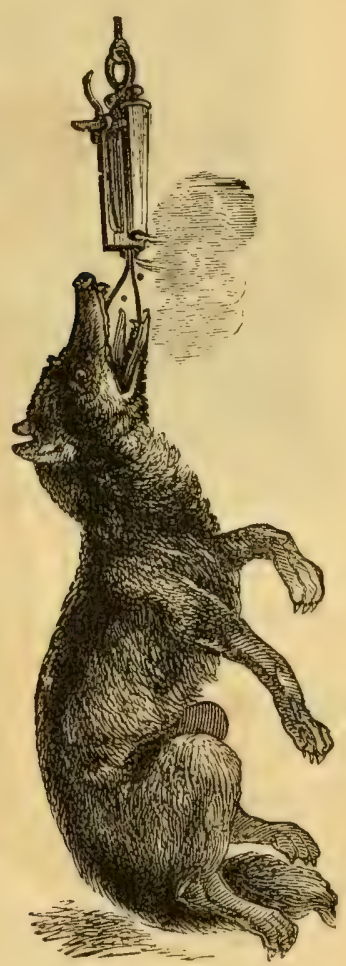

Fig. 438.

This ingenious contrivance is very effective in use. Wild animals of any size are readily caught by it. The upper part suspended to the loop, in Figs. 437 and 438 , is a pair of pistol barrels, to which is appended a spring and the necessary arrangement for percussion caps. Below extends a double barb, which when compressed together may be forced upward in a slot made to receive it. The bait is placed on this barb, and the pistol loaded in the usual manner, and the whole contrivance suspended from a tree or other convenient object. The animal seizes the bait, and instantly on touching it both barrels are discharged, throwing the balls immediately through his head, while the barbs expand themselves within his mouth rendering his retreat impossible. When desirable to catch the animal alive it may be done with the barb, leaving the barrels unloaded.

These traps will effectually operate on minks, wood-chucks, otters, wild cats, lynx, foxes, wolves, panthers, tigers, bears, buffaloes, alligators, etc., in fact, on all 
animals which repay hunting or are dangerous to the farmer. They are protected from the weather by a rubber casing. There are three sizes; price $\$ 3, \$ 5$, and $\$ 7$.

\section{The Aquarius.}

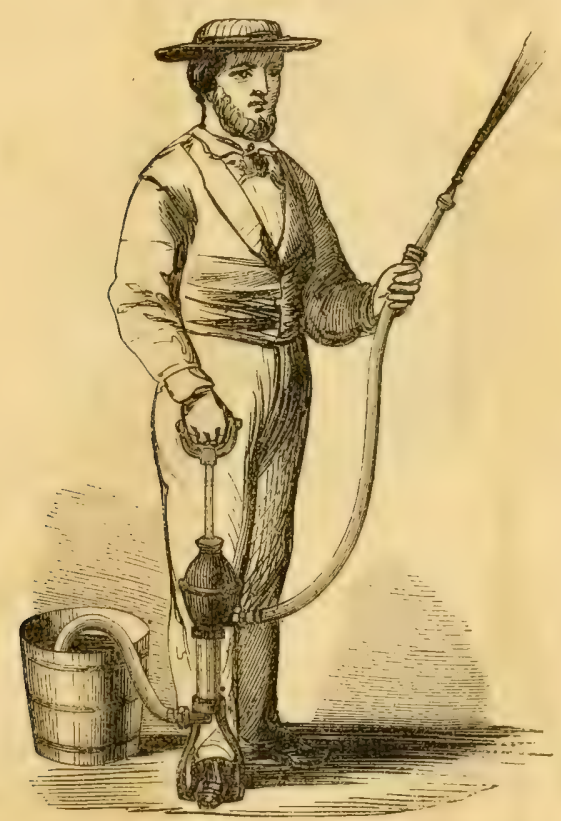

Fig. 439. The Aquarius.

Fig. 439 is a new and most invaluable article, being a complete and perfect hand apparatus for throwing water. It will throw about eight gallons per minute, fifty feet high, with the power of only one hand applied, and is suited for washing windows, carriages, watering gardens, sprinkling streets, throwing on liquid composition-such as whale oil, soap suds, tobacco water, etc., for destroying insects on trees, roses, and other plants-pumping water from the holds of vessels and small boats, cellars, etc., wetting sails, washing decks, starting aqueducts; it is most invaluable for extinguishing fires, and for wetting roofs near fires; it should be at hand in every barn, stable, work-shop or dwelling-house, as it may be put in operation by any one, is portable, and cannot readily get out of order. Its weight is but 8 lbs.

Price, complete, with $2 \frac{1}{2}$ fect of suction and 3 feet of discharge hose, with brass discharge pipe and sprinkler, $\$ 10$. 


\section{IMapes' Nitrogenized Super-Phosphate of Lime,}

For Corn, Cotton, Potatoes, Tobacco, Grain Crops, Vegetable Gardens, Lawns, etc. Composed of Dried Blood, Burnt Bones, Sulphuric Acid, Peruvian Guano, and Sulphate of Ammonia.

\section{PATENTED 1859.}

\section{LAREE SILVER MEDAL}

Awarded by the

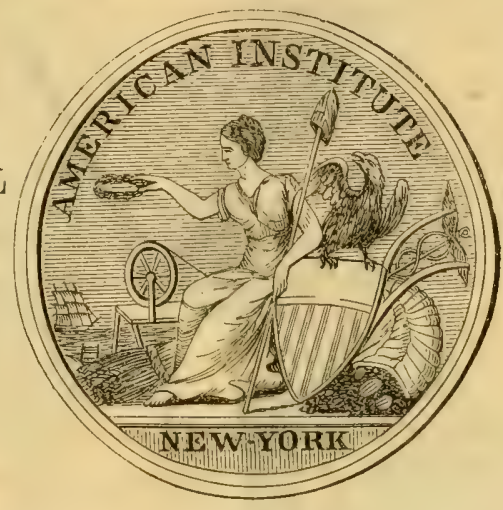

AMERICAN INSTITUTE OF NEW YORK.

1859.

Testimonials from hundreds of farmers of ligh standing, who have used it for several years.

Does not exhaust the land like guano, bat permanently improves it.

One hundred pounds of Nitrogenized Super-Phosphate of Lime will equal in effect and lasting power one hundred and eighty-five pounds of Peruvian Guano.

Prevents rust in cotton, bolls from shedding-ameliorates the effects of drought, etc.

Prior to the year 1847, Super-phosphate had been made in England, by treating burnt bones with sulphuric acid, and by the formation of sulphate of lime, thus abstracting one atom of lime from the bones, a soluble phosphate had been formed. In $184 \%$, J. J. Mapes made a series of experiments, thus: he found, analytically, that Peruvian guano contained the necessary elements for insuring the growth of plants, but not in the right relative proportions to each other. He instituted a series of experiments, practically, by which he proved that one hundred pounds of burnt bones, treated with fifty-six pounds of sulphuric acid, thirty-six pounds of Peruvian guano, and twenty pounds of sulphate of ammonia, formed a mixture every way superior to Peruvian guano, aud that it would not stimulate the soil, but would continually add to its fertility.

The market gardeners of Harsimus and elsewhere, who had tried this mixture, approved of its results, but complained that it was not quick enough in the early part of the season: as tomatoes and vegetables, when brought early to market, brought the same number of dollars that they produced shillings at twenty days' later date.

He had found that one barrel of blood, fresh from the animal, mixed with a cord 
of organic matter, would, by fermentation, produce a manure equal to a cord of well-rotted stable manure. He further found that seventeen barrels of blood, when dried, would make one barrel, and that blood could be procured at comparatively little cost, in certain sections; that it could be dried by cooking and pressing, so as to produce a dry powder.

The first mixture he had formed, before enumerated, he called Improved Super-phosphate of Lime, it being a better article than the English Super-phosphate; he mixed this with an equal bulk of drierl blood, and called it the Nitrogenized Super-phosplrate of Lime, since which, some fifty companies have imitated this article under various names, and with the view of rendering theirs popular, have traduced Professor Mapes and his article, claiming to make that of a superior quality. But during all this tirade, the demand for Mapes' Nitrogenized Super-phosphate of Lime has doubled.

Peruvian guano contains an excessive amount of ammonia, the only use of which is to render water capable of dissolving a larger amount of the inorganic constituents of the soil, or, in other words, to act as an excitant. The market gardeners of New Utrecht commeneed some years ago by using two hundred weight of guano to the acre; they are now compelled to use twelve hundred weight to produce the same effect, and their land is evidently impoverished by its use, while those who have used the Nitrogenized Super-phosphate of Lime have found their soils to be steadily improved, and instead of requiring more, they require less fertilizing material each year.

Among the advantages arising from the use of the Nitrogenized Super-phosphate are the following: It carries no weed-seed to the soil; it prevents rust, and insures the perfecting of plants; thus, when used on cotton, the bolls do not fall, and, as by the experience of Mr. Lomas, Colonel Davis, Colonel Godwin, Colonel Dowse, and others, it gives a greater weight of cotton per acre. For wheat, it has steadily proved itself superior to Peruvian guano: when in contact with seed, it does not destroy it as does the Peruvian guano; its application is less expensive than that of other manures. Uneven crops may be rendered even by applying phosphate to the less successful parts during their growth, and thus full crops may be attained. The wheat crop of New York has decreased from thirty-five bushels per acre to less than eleven; that of Ohio, from forty bushels to eleven and a half per acre; and this arises from the export of eighty pounds or more of phosphate of lime in the bones of every animal sent to the sea-board, and a relative quantity in every bushel of wheat exported. These and similar lands are at once restored by the use of Nitrogenized Super-phosphate. Its use dispenses with much labor in the care of the crop, as compared with the use of barn-yard manures, thereby increasing the profit of farming; it supplies the deficiency of phosphate of lime and other ingredients, produced by excessive reaping of grain and undue pasturage.

Every year presents néw imitators of this fertilizer, who manufacture an inferior article, using the mineral fhosphates as a basis, instead of the calcined bones of animals.

The Nitrogenized Super-phosphate of Lime is composed of the calcined bones of animals, treated with sulphuric acid, to the extent that it will be of use to render the phosphate soluble and acceptable to plant life, to which is adued thirty- 
six pounds of Peruvian guano, the carbonate of ammonia of which is immediately changed to the sulphate of ammonia by the sulphuric acid; to this is added twenty pounds of sulphate of ammonia, and to these an equal weight of dried bullocks' blood, thus forming a manure, one hundred pounds of which are equal in power and lasting effect to one hundred and eighty-five pounds of the best Peruvian guano.

The reports of committees of the American Institute, and other associations, who have visited the farm of Professor Mapes, prove that, although it is manured entirely with this fertilizer, no other manure has yet been used which produces an equal amount of profit.

The following are some of the Northern agents for this fertilizer:

Bamber \& Co., Fort Plain, N. X.

J. S. Cooley \& Co., Canandaigua, N. Y. Cyrus Chase, Croton Falls, N. Y.

Choat \& Bro., Auburn, N. Y. Wm. Walker, Rochester, N. Y.

S. II. Fullam, Fairport, N. Y.

J. A. Disbrow, Poughkeepsie, N. Y. Georgn Field, Geneva, N. Y.

J. D. Morgan, Penn Yann, N. Y.

Montanye \& Reynolds, Kingston, N. Y.

Hoviland, Clark \& Co., Hudson, N. Y.

J. Walker \& Co., Schenectady, N Y.

Webb, Walker \& Co., Utica, N. Y.

Nourse, Mason \& Co., Boston, Mass.

Hovey \& Co., Boston, Mass.

Draper \& Clark, Worcester, Mass.

Geo. A. Armes \& Co., Greenfield, Mass.

J. G. Dickinson, Hatfield, Mass.

Oscar Edwards, North Hampton, Mass.

Geo. Leonard, Taunton, Mass.

Crossett \& Co., Springfield, Mass.

Hall \& Trumbull, Palmer, Mass.

Stephen Mansur, Lowell, Mass.

Chas. R. Mason, Lawrence, Mass.

D. F. Woodwell \& Co., Newburyport, Mass.

J. S. Ires, Salem, Mass.

Fletcher \& Norton, Westfield, Mass.

R. B. Bradley \& Co., New Haven, Ct.

"Apothecaries' Hall," Waterbury, Ct.
O. J. Lamb \& Co., Norwich, Ct.

Harris, Williams \& Co., New London, Ct.

L. W. Crane, Stafford Springs, Ct.

Isaac Backus, Hartford, Ct.

J. N. Brown, Stonington, Ct.

T. Ransom \& Co., Bridgeport, Ct.

Barrett \& Son, Rutland, Vt.

Joseph Clark, Brattleboro', Vt.

Frost \& Goodhue. Brattlehoro', Vt.

Armes \& Wilson, Bellows Falls, Vt.

J. P. Dewey, Montpelier, Vt.

Jason Davenport, Middlebury, Vt.

D. C. Jenckes, Providence, R. I.

Jeremy Perkens, Dover, N. H.

A. H. Dunlap, Nashua, N. H.

J. F. Schores, jr., Portsmouth, N. H.

J. H. Chase, Concord, N. H.

W. Sparrow, Portland, Me.

"Cleves \& Kimball, Biddeford, Me.

D. Woodward, Augusta, Me.

Geo. C. Pickering, Bangor, Me.

Whitaker, James \& Darrah, Trenton, N. J.

Scott Berrian, Princeton, N. J.

T. N. Adams, Bordentown, N. J.

Thos. Milnor \& Son, Burlington, N. J.

Broadwell \& Corwin, Morristown, N. J.

A. R. Haines, Mount Holley, N. J.

Paschall, Morris \& Co., Philadelphia, $\mathrm{Pa}$.

Graham, Emlin \& Passmore, Philadelphia, Pa.

Among the principal Southern agents for this fertilizer are the following:

J. A. Quimby, Augusta, Ga.

W. J. Anderson \& Co., Fort Valley, Ga.

McNaught, Ormond \& Co., Atlanta, Ga.

E. W. Moise \& Co., Columbus, Ga.

Richardson \& Martin, Savannab, Ga.

Ayres, Wingfield \& Co., Macon, Ga.

W. P. Fambrough \& Co., Griffin, Ga。

Graveley \& Pringle, Charleston, S. C.

W. S. Woods, Columbia, S. C.

H. \& N. E. Solomon, Hamburg, S. C.
Stein \& Evans, Greenville, S. C.

B. T. Brockover, Norfolk, Va.

Irby \& Saunders, Lynchburg, Va.

Hugh Scott, Fredericksburg, Va.

Addison, Wallace \& Co., Alexandria, Va.

J. P. Bartholow, Washington, D. C.

Richardson, Small \& Co., Baltimore, Md.

Busey \& Barnard, Georgetown, D.C.

Pomeroy \& Marshall, Mobile, Ala.

R. M. Robertson, Demopolis, Ala. 
Certificates have been received from the following gentlemen, many of whom have used the phosphate for years :

L. Berckmans, Georgia.

* James Higgins, State Chemist, Baltimore, Md. James C. Choate, Portsmouth, Va.

Peter Jos. Clinton, Norfolk City. E. N. Fuller, Edisto Island, S. C.

* Prof. Chas. Upham Shepard, Charleston, S. C. W. H. Hite, New Glasgow, Amherst Co., Va. Sherman Mead, Macon, Ga.

* Prof. E. N. Hosford, Harvard University. H. Lomas, Columbia, S. C. Hon. E. A. Nesbit, Macon, Ga. E. M. Pendleton, M. D., Sparta, Ga. Editor "New York Day Book." Thomas Davis, Columbia, S. C. Charles W. Mixon, Edenton, N. C. Thomas A. Myers, Claymont, Del. Gideon Dowes, Georgia.

Carlisle. P. B. Martin, Macon, Ga. J. B. Eastinan, Baltimore, Ga. Solomon Mead, New Havey, Conn. T. S. Gold, West Cornwall, Conn. John C. Beardsley, Essex Co., N. J. Jonathan T. Comly, Comly's Mills, Ewing. Charles Denison, Westchester, N. Y.

* Dr Charles Enderlin, New York, N. Y.

* Dr. A. A. Hayes, Boston, Mass. Morris Ketchum, Westport, Conn. E. Hanford, Darien, Conn. Nathaniel Weed, Darien, Conn. John S. Beach, New Haven, Conn. Nathan Moore, jr., Stafford, Conn.

A. Bagley, New Haven, Conn.

L. P. Cummings, Mamaroneck, N. Y. Judge French, Exeter, N. H.

S. Sturtevant, Myanus, Conn. John Farnum, Philadelphia, Pa. James Gall, Paterson, N. J.

Enos Smedley, TVestchester, $\mathrm{Pa}$. C. V. Mundy, Metuchen, N. J. J. W. Arrowsmith, Somerset Co., N.J. Charles F. Stone, South Orange, N. J.
Thomas Shillingford, Essex Co, N. J.

Alonzo Dickerson, Chester, N. J.

William Green, East Woodstock. William P. Sherman, Trenton, N. J. Roswell L. Colt, Paterson, N. J. James P. Allaire, Monmouth Co., N. J. John Bucklin, American Phalanx, N. J. Robert Rennie, West Lodi, N. J. John O. Flood, Paterson, N. J. Hon. James Campbell, Weston, N. J. George Drayton, Delaware Co., Penn. Richard Bedford, Sullivan Co., Penn. William S. Lincoln, Worcester, Mass. Taertine Burt, Berkley, Mass.

H. D. Furbush, Portland, Maine. John S. Ives, Salem, Mass.

L. Bodman, jr., Pres't Conway Bank, Mass. D. D. Williams, Chester, Vt.

H. C.'Vail, Bellville, N. J. Joseph Lovell, Morristown, N. J. Amory Edwards, Shrewsbury, N. J.

B. Shattuck, "Farmer and Visitor."

C. I. Nichols, Fssex Co., N. J.

S. B. Haliday Providence, R. I.

Dexter Rowe, Sunderland, Franklin Co., Mass.

Scudder A. Terry, New Village, L. I.

William Hunt, Sunderland.

Prof. Teschemacher, Boston, Mass.

Mr. Belden, East Whately Mass.

John C. Robert, New Utrecht, I. I.

N. Macdonald, Brooklyn, L. I.

D. L. Cargill, Bloomingburg, N. Y.

J. Outwater, Tivoli, N. Y.

Reuben Fraser, Sullivan Co., N. Y.

Peter Voorhees, New Utrecht, I. I.

William Alfred Hull, Sing Sing, N. Y.

John Staats, Balston Spa, N. Y.

H. R. Ball, Staten Island, N. Y.

Solon Robinson, Westchester, N. Y. Samuel Wotherell, Bethlehem, Pa.

And many others.

\section{Seeds.}

A Descriptive Catalogue of Garden and Field Seeds for sale by Charles V. Mapes, at Mapes' Agricultural Implement and Seed Warehouse, 126 and 128 Nassau street, and 11 Beekman street, New York, will be furnished on application.

Nowk-Chose marked thus (*) are theoretical opinions founded on analysis or knowledge of its composition. 
Please Notice.-All of these Seeds are raised for me on the farm of Professor James J. Mapes, Editor of the Working Farmer, and other reliable growers, and purchasers may rely upon their purity.

Secls packed for Foreign Shipment in tin boxes, if so ordered. Parties ordering varieties not on the list, may rely upon a careful selection and prompt shipment.

Bulbous Flowering Roots inported direct from the First Nurseries in Europe.

Fruit and Ornamental Trees, of every description, and of every desirable age and size, securely packed and shipped at short notice.

Shrubs, Roses, Vines, Plants, etc., of every kind, embracing as full an assortment as can be procured at any establishment.

Boxes containing Twenty-five Varieties of Flower Seeds, of the most approved kinds, for One Dollar.

Boxes containing a full assortment of the Best Vegetable Seeds for a Family Garden, from One to Five Dollars each.

Papers, Five Cents each.

Seeds sent by Mail, Postage Six Cents per Ounce.

\section{The "Working Farmer."}

A Large Agricultural Monthly Journal-One Dollar per Annum-edited by Professor James J. Mapes, assisted by G. E. Waring, H. C. Vail, J. Payne Lowe, H. S. Alcott, and P. T. Quinn.

Volume XIII., of the present year, will contain series of articles on the following subjects: Vegetable Garden, alphabetically arranged. Manures, their Uses and Abuses. Fruits and Fruit Trees of America. Improved Implements and Machinery. New Processes of Cultivation, with a view to greater perfectness and economy. Culture of Cotton, Corn, Tobacco, and green crops as substitutes for grass crops in the South. Manipulation of Sugar; its Growth and Manufacture. Advantages of Deep Culture, including Under-draining and Subsoil Plowing. Full Reports of Grain and Produce Markets. Treatment and Care of Stock.

The Working Farmer contains more original matter than any Agricultural paper published in this country. All the Editors of this journal are practically engaged in conducting the several departments upon which they write.

The back volumes, bound in paper, from Volume II. to XII., will be furnished at One Dollar and Twenty-five Cents each, including postage-One Dollar each, without postage. Volume I. at Seventy-five Cents, including postage-Fifty Cents, without postage. These volumes will form a complete work on the progress of Agriculture since the year 1847 .

All subscriptions must be paid in advance. Remittances exceeding Ten Dollars should be in the form of drafts. Bills current in any State will be received at par value.

Address the Publisher, CHARLES V. MAPES,

126 and 128 Nassau and 11 Beekman streets, New York.

Specimen numbers sent free of expense. 


\section{N D E X.}

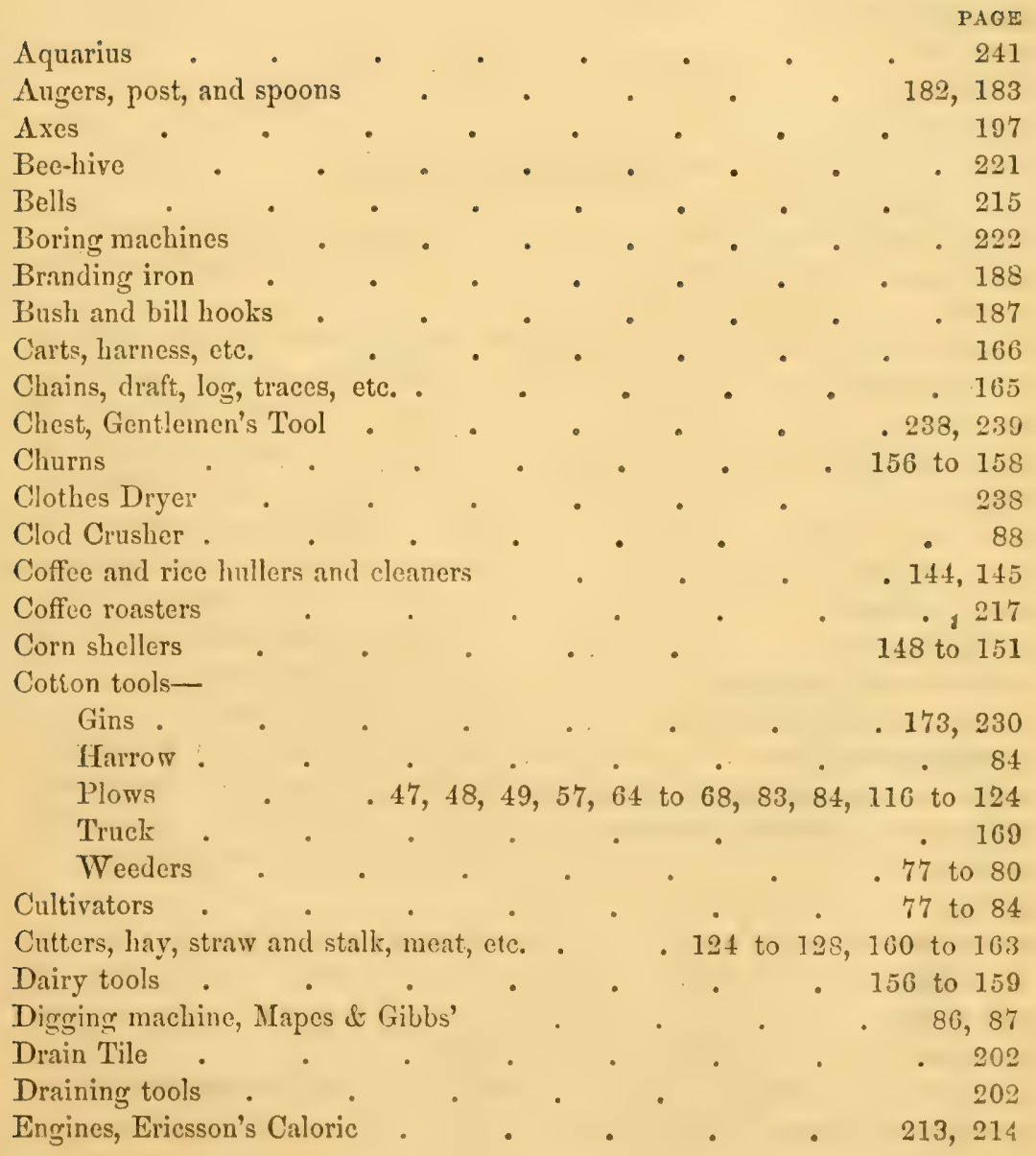


Fan mills .

Fence and gates . . . . . . .

Forge and bellows, portable

Forks-

Hay, manure, grain, and weeding

$99,101,115,183,185$

Fruit gatherer

.158

Furnaces, agricultural

152,153

Garden tools

Garden vases and borders

Grain cradles

Grindstones and fixtures

Handles, assorted

Hamess

Harrows .

Hatchets and hammers

Haymaker's

Hay and grain protectors

Hay, straw, and stalk cutters

Haying and harvesting tools

Hoes

Horse hoes .

184 to 194

- 215

100,101

101, 102

.187

166,167

- 73 to 76

198

- 114, 115

105

.124 to 128

98 to 115

.182 to 185

77 to 7 ?

.184 to 194

211,212

Ice tools

Jacks, wheel, and jack-screws

170,171

Knives-

Corn and hay

Pruning

Knife cleaners

Ladders, folding

Lawn mower, improved

Manger and hay rack, horse

Mangle, portable

Manures, super-phosphate of lime, etc.

Meat cutters and sausage stuffers

Milker, Cow

194 to 196

- 189,190

- 237

188

111 to 113

180

Mills -

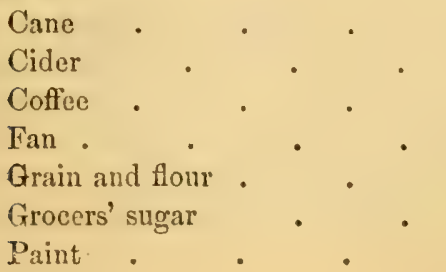

174,175

- 154,155

147

135 to 137

138 to 144,147

175, 176

176 to 178 
Mills-

Quartz and universal .

231 to 234

Saw

173

Wind

Mortising machines, etc.

Mowing and reaping machines

Ox yokes, bows, patent pins, etc.

106 to 113

- .10164

Pig troughs.

Plows-

Universal, cast-iron

Universal, stcel,

Eagle plows, new scries

Eagle plows, old series

Centro draft plows .

Subsoil plows

Sod and subsoil, or double, plows

Swivel or hill-side plow

Steel plows

Self-sharpening plows

Small plows, various patterns, southern, etc.

Double mou!d-board plows

Paring plow

Plow trimmings

Whitney's plowman

Lash's spring-beam plow

Shovel plow

Hand plow

$6,33,41$ to 43

38 to $41,-49,50$

54 to 57

45 to 47

46 to 49

- $48,49,52,53$

53,54

57 to 61

62,63

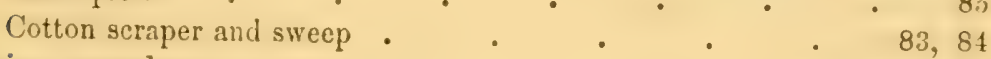

Plowing, remarks on

Plowman, Whitney's iron

Post augers and spoons

Potato diggers, etc.

Powers-

Horse powers

Dog and sheep

Caloric engines

Steam ongines

Wind mills

Prosses-

Cheese

Hay and cotton.

Wine and lard 
Price list

PAGE

Pruning tools

1 to 12

Pumps, water rams, etc.

.189 to 193

Quartz crushers

203 to 210

Rakes-

Cranberry .

Garden and lawn

Horse and hand hay

Rams, hydrauilic

Reaping machines

Rice and coffee hullers

146

Road scrapers .

Rollers, field and garden

Rollers and hanger for barn-doors

Root and vegetable cutters

Sausage fillers and cutters

160 to 163

Saw mills and saws, of various patterns . . . $\quad$. 172, 173, 190

Scales, hay, warehouse, etc.

. 229

Scrapers, floor, tree, road, etc.

$.167,194$

98, 99

Scythes, grass, grain, lawn, etc.

Seed sowers and drills

Seeds, garden, field, and flower

91 to 97

234,235

Shovels, spades, scoops, etc.

181,202

Smut machines

- 137

Steamer, agricultural

- 234,235

Stone digger .

- 236

Stump and root pullers

224 to 227

Threshing machines, cleaners, etc. . . . . 129, 133 to 137

Tile machines, etc.

200 to 202

Traps, animal.

Traps, rat and game

Trucks, store, cotton, warehouse, etc.

200 to 202

Underdraining tools, remarks, etc.

- 216

Vanes, weather

218 to 221

Washing machines, wringer, etc.

Weeders, for cotton and carrots

Well-buckets and wheels .

167,168

Wheelbarrows, garden, railioad, etc.

- 154,155

Wine presses, mills, etc.

200,224

Yolies, etc.

. 164, 165 



$0_{1}$
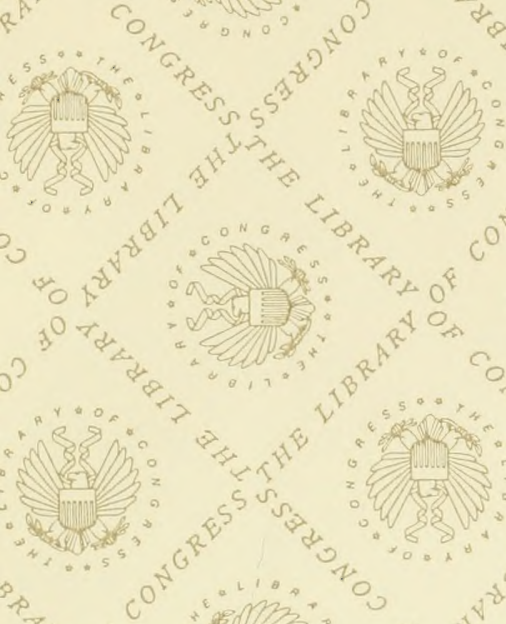

औ

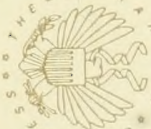

"थीजs:
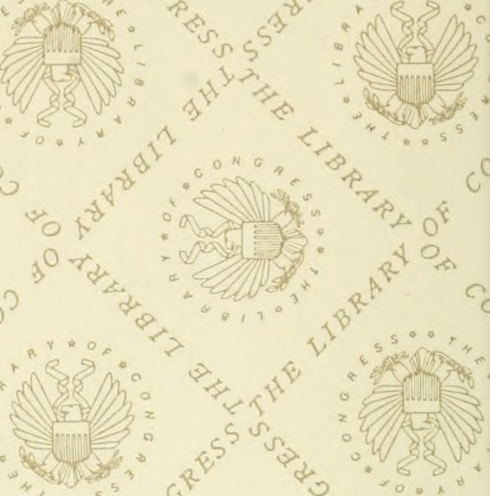

$A^{2}+0^{\circ}$ in in

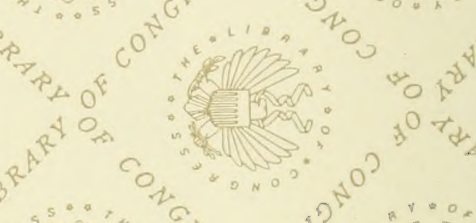

six

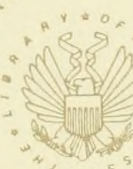

pro

abot से

政

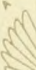

(s)

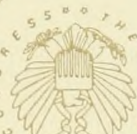

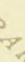

s 40 : : 40200

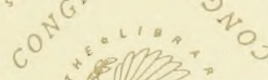

40

un

Antor.

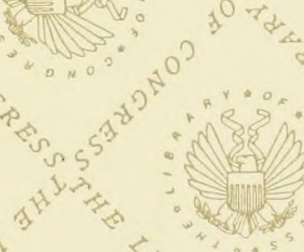

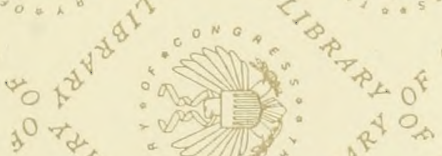

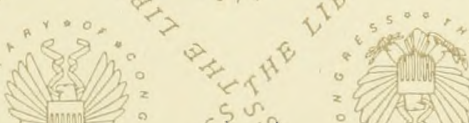

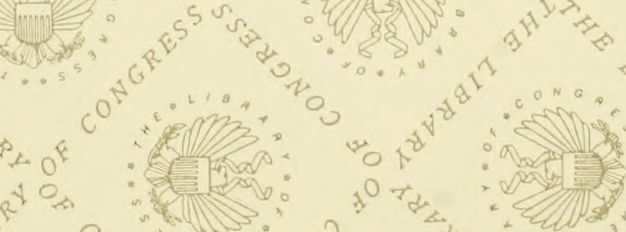

हn:

simpos

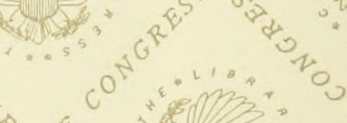




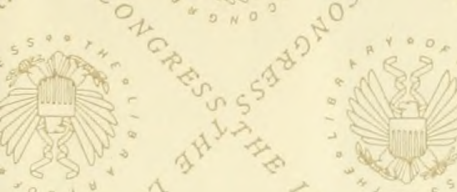

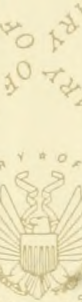

int

से

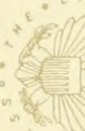

endin

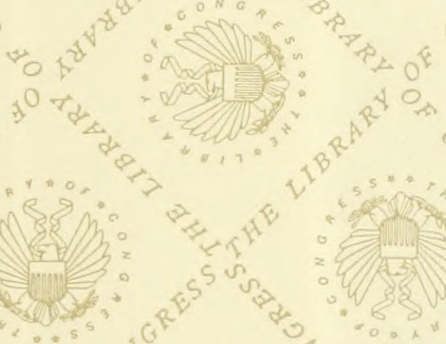

$p_{\perp 0}$

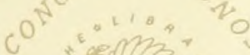
सt

\section{ant} ह s.

\section{की

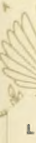

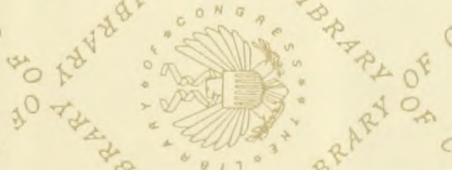

\section{$\therefore$ in}

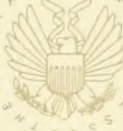

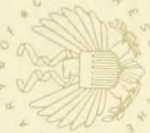
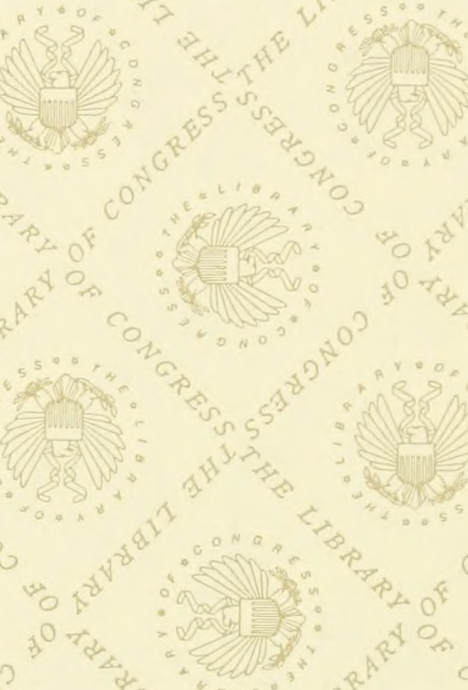
LIBRARY OF CONGRESS

|||||||||||||| |||||||||||||||||||||||||||

|||||||||||||||||||||||||||||||||||||||||||||||||

00009382501 